\title{
Metodología de las
}

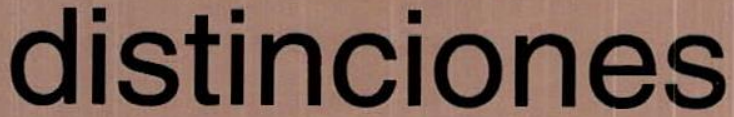

forma, complejidad, auto-referencia, observación, construcción de teorías integrando lo macro y lo micro en las Ciencias Sociales

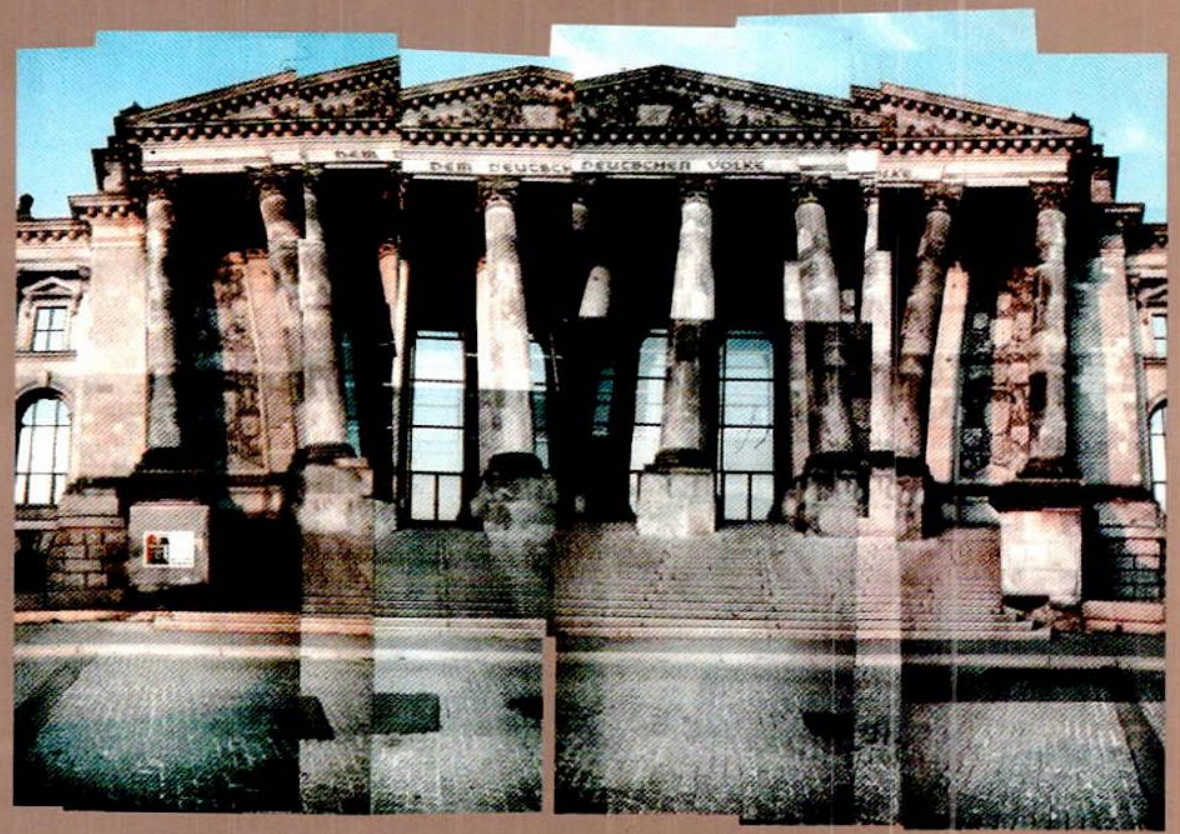

\section{Rodrigo Jokisch}

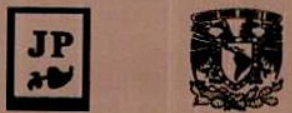




\section{Metodología delas distinciones}

forma,complejidad, autorreferencia, observación,construcción deteoria integrandolo macroy lo micro enlascienciassociales 


\section{Metodología
de las distinciones}

forma, complejidad, autorreferencia, observación, construcción de teorías integrandolomacroy lo micro en las ciencias sociales

\section{Rodrigo Jokisch}

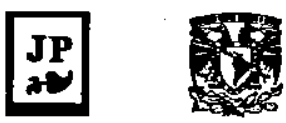

Ediciones casa juan pablos

Facultad de Ciencias políticas Y Sociales

Programa de apoyo a Proyectos institucionales

DE MEJORAMIENTO DE LA ENSEÑANZA

Universidad Nacional aUtónOMa de MÉxico

MExico, 2002 


\section{METODOLOGIA DE LAS DISTINCIONES}

FORMA, COMPLEJIDAD, AUTORREFERENCIA, OBSERVACIÓN, CONSTRUCCIÓN DE TEORÍAS INTEGRANDO LO MACRO

Y LO MICRO EN LAS CIENCIAS SOCIALES

de Rodrigo Jokisch

Primera edición en alemán: 1996

Primera edición en español: 2002

Titulo original en alemán: Logik der Distinktionen. Zur Proto-Logik einer Theorie der Gesellschaft

Traducción: Rainer Watschounek

(1) Rodrigo Jokisch, 2002

(1) Universidad Nacional Autónoma de México, 2002

Facultad de Ciencias Políticas y Sociales

Ciudad Universitaria, 04510, México, D.F.

(c) Casa Juan Pablos, S.A. de C.V., 2002

Malintzin 199, Col. del Carmen Coyoacán, 04100, México, D.F.

<casajuanpablos@terra.com.mx>

Diseño de portada: Imprenta de Juan Pablos, S.A.

<impre_juan@terra.com.mx>

Fotografía de portada: Rodrigo Jokisch

ISBN: 970-32-0205-5

Reservados los derechos

Impreso en México 
Prefacio

ADVERTENCIA TECNICA

LA CUESTIÓN GENERAL.

LA CUESTIONN ESPECIAL

1. ¿QUÉ ES FORMA?

Acerca de la forma de la forma . $\quad .51$

Diferenciaciones

El cóncepto de diferenciación de George Spencer Brown · . $\quad .74$

Objetos

El concepto de "objetos" de Ranulph Glanville _ . . . . . . 92

Relaciones

El concepto de tríada de Ph. G. Herbst : 100

Contextos

El concepto de policontextualidad de Gotthard Günther

Socialidad de lo lógico

Operación y forma

Predicación y forma 
- La lógica de las distinciones

Diferencia y diferenciación

Comunicación y acción

Complementaridad y distinción

II. ¿QUE ES COMPLEJIDAD?

Simple y complejo

Complejidad y ciencia

Temporalización de la circunstancia científica 263

¿Como es posible la complejidad?

268

* Valor-propio, primera vez y autopoiesis 281

Complejidad y "teoría sociológica" • 286

Elemento ültimo, ficcional y ontológico , ' . ' ' 290

Semántica de alto rendimiento $y$ de la cotidianidad

en el contexto del babla y de la escritura

III. ¿QUE ES AUTORREFERENCIA?

$\therefore$ La unidad como acontecimiento temporal

;. Operación, observación y auto-observación.

- Diferencia y doble contingencia

Diferencia doble, emengencia y autopiesis

- Semántica del "bombre" y emergencia de los tipos de sistemas del sentido

IV. ¿QUÉ ES OBSERVACIÓN?

Observaciones de observaciones.

Observamos al sistema global de la sociedad · 351

"El concepto de observación de la teoría de los

sistemas sociales (TSS)

Observación de acción y observación

de la observación

" Observación y operación, utilización y réalización

La auto-observación como diferenciación asimétrica 
V. ARQUITECTURAS DE TEORIAS $\quad \cdot 411$ Problema y forma $\quad \mathbf{4 1 1}$ La teoria del sistema general de la acción (TaH) 424 La teoria de la acción comunicativa (TkH) 479

$\begin{array}{ll}\text { PERSPECTIVAS } & 527\end{array}$

RESÚMENES DE LOS CAPITULOS I A V 531

$\begin{array}{ll}\text { BIBLIOGRAFIA } & 553\end{array}$

GlOSARIO 597 
Somos de la opinión de que la metodología de las distinciones aquí expuesta es una metodología que ya practicaba de manera $i m p l i c i-$ $t a^{1}$ el filósofo griego Platón, entre otros. Es más, todo trabajo académico e intelectual requiere la mencionada metodología. Por lo tanto, no estamos proponiendo algo completamente nuevo. Lo que realmente se ofrece en este trabajo es la práctica metodológica explicita de aquello que por lo general el académico e intelectual ejecuta de forma implícita.

Este trabajo metodológico ${ }^{2}$ es producto de muchos años de discusión de los proyectos metodológicos; en primer lugar, de los sociólogos Émile Durkheim, Jürgen Habermas, Niklas Luhmann, Talcott Parsons, Max Weber; del fisico y filosófo Carl Friedrich von Weizsäcker; de los filósofos y cibernéticos Heinz von Foerster, Gotthard Günther, Philip G. Herbst, Ranulph Glanville, y de los logico-filosofos George Spencer Brown y Charles Sanders Peirce. Los primeros puntos de partida concretos datan del año 1979 y se relacionan con las reflexiones concernientes al surgimiento de la biologia moderna. ${ }^{3}$ Transcurrio

${ }^{1}$ Prácticamente en todos los escritos de Platón se aplica dicha metodologia: Apología, Kriton, Protágoras, Ion, Hippias, Charmides, Lacbes, Eutbyphnon, Gongias, Menón, Menéesenos, Kratylos, Lysis, Symposion, Phaidon, Politeia, Phaidros, Parménides, Tbeaitetos, Sopbistes, Políticos, Pbilebos, $r$ maios, Krtitas, Nomot; pero su trabajo más importante en este contexto es el trabajo titulado Parménides.

${ }^{2}$ En su primera versión en español completamente revisada. La primera versión alemana se editó bajo el título Logik der Distinktionen. Zur ProtoLogik einer Theorie der Gesellscbaft, Opladen, Westdeutscher Verlag, 1996. Hacemos hincapié en que las diferentes versiones son hasta cierto punto similares, pero no idénticas.

${ }^{3}$ Jokisch, 1979. La literatura publicada acerca del complejo aquí tratado se ha integrado ahora al trabajo "Observaciones sociológicas desde el pun- 
muchio tempo hasta que pudimos reunir las notas dispersas y darles una forma discursiva. El motivo de decisión para comenzar, finalmente, con el presente escrito, fue la publicación en 1984, de los "Sistemas Sociales", de Niklas Luhmann, en la cual él expone su posición sociológica-constructivista-sistémica. Aunque nosotros veníamos trabajando en un campo similar, la diferencia consisitó en darle a nuestra posición una base metodológica y, en lo que respecta a la teoría, una base más plural. Por lo tanto, en este trabajo metodológico-teórico el concepto de sistema - que para propuestas teóricas como las de Parsons y Luhmann es central- desempeña un papel importante, más no dominante.

$\mathrm{El}$ aspecto metodológico es fundamental en este trabajo y se basa en los conceptos "forma", "complejidad", "auto-referencia" y "observación $n^{n}$. El tratamiento teórico representa el aspecto que complementa a la metodología y se basa en los conceptos "sistema", "acción", "decisión", "comunicación", "estructura", "función" y "evolución". Ambos aspectos -el metodológico y el teórico- parten y desembocan en los conceptos centrales y dominantes de este escrito: la "diferencia" (distinción simétrica) y la "diferenciación" (distinción asimétrica). Estos conceptos, por tanto, proporcionan a la metodología su coherencial lógica y su forma constructiva unitaria.

Un trabajo como el que aquí se presenta requiere cierta paz intelectual interior y libertad de movimiento. En dichos esfuerzos cualquier apoyo significa una ayuda valiosa. En este contexto agradezco a Rainer Mackensen su paciencia, tolerancia liberal y estímulo, así como las diferentes evaluaciones de Dirk Baecker, Ulrich Beck, Heinz von Foerster y Niklas Luhmann, que contribuyeron de manera relevante en la elaboración del presente trabajo. Este último consideró plausible nuestra idea de relacionar el concepto de operación con el concepto de acción. Además, aceptó integrar en su propuesta teórica nuestro tratamiento metodológico acerca de los conceptos "diferen-

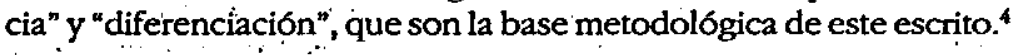

to de vista de la teoría de las distinciones" (1999), el cual se publica en la actualidad en alemán y en español.

:" Una primera aplicación de dichos conceptos los puede encontrar el lector en su trabajo La realidad de los medios masivos de comunicación, Niklas Luhmann, Die Realität der Massenmedien, Opladen, Westdeutscher Verlag. VÉase más adelante en este trabajo para corroborar nuestra afirmación. 
Respecto a la incorporación de la metodología de las distinciones en trabajos de algunos colegas europeos quisiera mencionar a Siegfried J. Schmidt, ${ }^{\text {s }}$ especialista en ciencias de las comunicaciones y literatura; Armin Scholl, ${ }^{6}$ sociólogo y especialista en ciencias del periodismo; Stefan Weber, ${ }^{7}$ especialista en ciencias de la comunicación y periodismo; Heiko Kleve, ${ }^{8}$ sociólogo y especialista en el campo de las ciencias del trabajo social. Les doy las gracias a todos ellos por su confianza y su interés al aplicar nuestra metodología como base y punto de partida en algunas de sus obras.

En relación con mis colegas mexicanos, la discusión respecto a esta propuesta metodológica apenas comienza. En este sentido, hemos tenido la posibilidad de discutir algunos de los puntos que se presentan en este trabajo, principalmente con nuestro colega Fernando Castañeda, a quien agradecemos además la invitación para incorporamos formalmente al Centro de Estudios Básicos en Teoría Social (CEBTS) de la Universidad Nacional Autónoma de México.

No podríamos, tampoco, dejar de mencionar que Amelia Coria, César Delgado, José Luis Hoyo, Javier Torres Nafarrate y Makoto Noda, además de los colegas del CEBTs de la Universidad Nacional Autónoma de México (UNAM), nos han estimulado favorablemente en nuestra labor docente y de investigación teórico-metodológica.

Por último, deseamos hacer patente que la edición de este libro ha sido posible gracias al Proyecto de Investigación "Cátedra Extraordinaria en Teoría Social", apoyado con recursos del Programa de Apoyo a Proyectos Institucionales para el Mejoramiento de la Enseñanza (PAPIME) y a cargo de Fernando Castañeda.

s Véase sus dos últimas obras, en las que Schmidt parte esencialmente de la Metodologia de las distinciones: Schmidt, Siegfried J., Die Zaebmung des Blicks. Konstruktivismus, Empirie, Wissenscbaft, Suhrkamp, Wissenschaft 1998, p. 180 y ss. y Schmidt, Siegfried J., Kalte Faszination. Medien; Kultur, Wissenschaft in der Mediengesellscbaft, Gebundene Ausgabe-Velbrueck Wissenschaft.

'Véase su trabajo: Scholl, Armin en Weischenberg, Siegfried, Joumalismus in Deutschland, Westdeutscher Verlag, 1998, p. 340 y ss.

7 Véase su trabajo: Stefan Weber: "Wie journalistische Wirklichkeiten entstehen", Schriftenreibe "Journalistik" des Kuratoriums für Joumalistenausbildung, 1999.

Heiko Kleve, Postmoderne Soztalarbeit. Ein systemtheoretisch-konstruktivistischer Beitrag zur Soztalarbettswissenscbaft, Wissenschafticher Verlag des IBS (Institut fuer Beratung und Supervisión), 1999. 
Naturalmente que la responsabilidad de las exposiciones teóricometodológicas que aquí se exponen son todas nuestras.

Este trabajo está dedicado, por razones obvias, a mi esposa Bárbara y a nuestra hija Alicia.

Cabe hacer hincapié que este trabajo es parte de una trilogía en teoria social que consiste en una metodología (el presente libro), en una teoría de la sociedad (ya terminada y en vías de publicarse en español) y en un estudio sobre la sociedad mexicana tomando como principio comparativo las sociedades alemana y salvadoreña.

México, agosto del año 2001 Rodrigo Jokisch 
Nos escondemos st no pensamos lo imaginable. Sin embargo, todos pasaremos aún por otras puertas. Tambiên la teoria es supuestamente sólo uno de los grandes niveles bistóricos. .

Carl Friedrich von Weizsäcker

1. Si se comprende la denominación de crisis como el señalamiento de una situación difícil, la crisis por la cual pása la sociología desde ya hace largo tiempo, continúa. Naturalmente, ninguna afirmación de crisis puede legitimar una renovación de la materia. Sin embargo, somos de la opinión de que es posible homogeneizar la materia sociológica - a nivel de teoria - en este sentido: observar lo sociológico de la sociología como "la unidad de lo social", el "átomo de

1 Weizsäcker, C. F. v., 1977, p. 597.

${ }^{2}$ Adelantando podemos decir que la unidad de lo social comprende los aspectos "activos" y "pasivos" de la sociedad. Los aspectos activos están representados por los conceptos "acción", "intención/decisión" y "comunicación"; los aspectos pasivos por los conceptos "estructura", "función" y "evolución social". La unidad de lo social es, por lo tanto, un complejo de distinciones que producen lo social. Lo sociat es, por consiguiente, no sólo acción (como piensan muchos sóciólogos), no sólo comunicación (como piensa Luhmann), ni sólo acción comunicativa (como piensa Habermas). Por otra parte, vale decir que, "estructura", "función" y "evolución social", como aspectos pasivos de la sociedad son resultado de los aspectos activos. Pero cuidado, realmente todo aspecto activo presuponé estructuras, funciones y evolución social, por lo tanto, todo aspecto activo se basa èn el aspecto pasivo de la sociedad. Por otro lado, todo aspecto pasivo dé la sociedad es producto de su aspecto activo. Esta mutua dependencia o complementaridad de los aspectos activos y pasivos de la sociedad es'importante considerarla. 
lo social" por así decirlo. Naturalmente, esta tarea viene a ser una labor teórica sumamente reconstructiva de aportes ya ofrecidos. Esta concepción optimista - de poder ofrecer lo que nosotros entendemos por "la unidad social" - es, en parte, resultado del conocimiento que poseemos actualmente del instrumental teórico para la realización de una tarea semejante. Por otra parte, el instrumental teórico no proviene exclusivamente de la tradición de la teoría sociológica. Es obvio que esto dificulta una manifestación crítica orientada genuinamente hacia lo sociológico.

2.' En lo que concieme a la sociología como teoría, partimos del hechó de que el área de la teoría sociológica se nos presenta actualmente én forma ya especializada y "sistémica". Lo característico de una forma de este tipo es, primero, un problema determinante de la unidad del área y, segundo, una diferenciación de roles, en el sentido de que no solamente existen los roles primarios, sino también roles complementarios como: político/elector, maestro/alumno o clérigos/laicos. El problema especifico de la materia existe, por lo menos, desde Georg Simmel. Se amplía por medio de Talcott Parsons, Jürgen Habermas y Nikląs Luhmann y se expresa en la pregunta “cómo es posible el orden social?" En lo que concieme a la diferenciación de roles, se débe constatar que existen dentro de la sociologia tanto "productores de teorias" como "receptores de teorías". La prueba empírica de este supuesto es la presencia de ún áréa específica llamada "teoria social". En este contexto hay que anotar que la complejidad del área mencionada ha aumentado de tal manera que actualmente sólo especialistas en teoría social pueden hacerle justicia.

3. Las técnicas metodológicas e investigaciones socioempíricas ciertamerite han enriquecido la disciplina con un conocimiento considerable, sin embargo, no háan óriginado ninguna consolidación de la

En este trabajo metodológico discutiremos en primer lugar los conceptos específicamente metodológicos sin ahondar en el aspecto teórico, el cual se refiere en especial a la teoría de la sociedad. Cuando hagamos referencia al aspecto teórico - teoría de la sociedad- usaremos los conceptos activos "COMUNICACION" Y "ACCION" asumiendo que representan una reducción bastante acentuada de lo que realmente implica el concepto de lo sOctal. 
unidad interna de la disciplina - lo que aquí llamamos aunidad de lo social ${ }^{n}$. Si se observa la producción de teorías de la disciplina, entonces uno tiene - de acuerdo con Niklas Luhmann-la impresión de que la misma se ocupa primordialmente de sus clásicos:

En sus aclaraciones teóricas la sociología se ocupa primordialmente de sus propios clásicos, es decir, con aquella literatura que fue concebida antes de la Primera Guerra Mundial. Sus conceptos (acción, interacción, símbolo, social, individuo, grupo, organización) utilizan de manera no analizada abstracciones y ocasionan controversias sin fin, mismas que se harían obsoletas en gran medida, si se pudiera alcanzar un profundo nivel de anślisis. Correspondientemente falta una capacidad de diálogo interdisciplinario. No se siguen (o solamente muy parcial e insuficientemente) y no se evalúan sociológicamente los aportes y desarrollos dentro de las teorías de sistema, de la evolución, de la lingüística, de la cibernética, de la biología. En vez de ello, se conforma con la repetición de viejas ideas de espanto, con el rechazo de las metáforas o analogías "mecanicistas" o "biologistas".

Se puede decir de manera complementaria que, también y sobre todo, los desarrollos en el ámbito de la física cuántica, como los que han sido presentados en primer lugar por Carl Friedrich von Weizsäcker, dan motivo al optimismo de la teoría aquí representada de, por lo menos, abordar "como tarea de reconstrucción teórica la unidad de lo sOctal".4

4. La unidad al interior de la materia sociológica se puede alcanzar -así lo creemos- exclusivamente por medio de las respectivas teorías, pero no vemos que se realicen dichos trabajos. En otras palabras, la situación no es muy alentadora para quien quiera emprender tal proyecto. Por otra parte, es enteramente comprensible que no se realicen esos trabajos, ya que el esfuerzo intelectual y el riesgo profesional ante el nivel de construcción y reconstrucción teórica son considerables. Consecuentemente, Niklas Luhmann, en conexión

${ }^{3}$ Luhmann, 1992a, p. 134.

'Somos de la opinión de que los aportes del físico y filósofo Carl Friedrich von Weizäcker son de suma importancia para las ciencias sociales, en gene$\mathrm{ral}$, y para la sociología en especial. Lamentablemente, la mayoría de nuestros colegas en el ámbito de la sociología visualizan trabajos netamente sociológicos, dejando de lado aportes provenientes de otras disciplinas tan importantes para el crecimiento y la consolidación de la sociología. 
con la teoría del sistema general de la acción de Talcott Parsons, escribe: "El esfuerzo de familiarización que debe realizar una adecuada crítica objetiva es grande, es desalentadoramente grande. ${ }^{n 5}$ Tampoco se debe pasar por alto que las condiciones para la investigación sociológica básica no son - dentro de la academia- favorables. Citamos nuevamente a Luhmann: "La nueva generación de científicos debe hacer carrera bajo condiciones frecuentemente desesperadas. Esto se logra solamente a través de publicaciones, mismas que de la manera más fácil se puedan elaborar mediante el análisis de cualquier recopilación de datos o por medio de la discusión crítica de las publicaciones de otros. ${ }^{n 6}$.

5. No obstante, en la actualidad existe una excepción notable entre las pocas teorías que aspiran a una unidad interna de la materia de lo social, y ésta se llama teoria de los sistema sociales (TSS). Consideramos este intento de Niklas Luhmann como el mejor que se haya ofrecido desde la teoria del sistema general de la acción (TaH) de Talcott Parsons dentro del área de la teoría social. Es notable en Luhmann el alto nivel de abstracción, la profundidad de campo del instrumental conceptual y la universalidad temática. Son realmente cualidades que le dificultan mantener el paso con otras empresas de carácter similar. En su laudatoria, con motivo del otorgamiento del premio Hegel a Niklas Luhmann, el filósofo alemán Robert Spaemann

${ }^{5}$ Luhmann, 1980b, p. 5. De manera similar, el sociólogo alemán Richard Münch escribe: "Los temores de House (desafortunadamente es tan largo y difícil el estilo; a muchos estudiantes americanos de sociología que obtendrían ganancias de él, se les quitan los ánimos de leerla; [se refiere a la teoría de Parsons (subrayado mío)] de que solamente poca gente tendria la disciplina de leer la Structure of Soctal Action, seguramente son acertados también para todas las obras posteriores. Sin embargo, esto no es solamente culpa del autor, sino también una culpa de la disciplina de la materia. La interpretación de todas las obras sociológicas de alto nivel requiere tiempo. No se puede comprender de paso a Marx, Weber, Durkheim o Parsons mediante la ingestión de bocadillos de su obra, dentro de un seminario, como lamentablemente es el caso en la carrera de sociología. No obstante, la sociología ha sido sometida, por medio de la demanda por parte de la práctica, también al ritmo del tiempo, y, por ello, tiene ahora una corta vida. Por la magnitud de la demanda aceptada abiertamente, no le queda tiempo nara la consolidación de un núcleo científico." (Münch, 1982a, pp. 19-20).

"Luhmann, 1992a, p. 235. 
opina: "La inexorabilidad de su reflexión, la precisión y profundidad de campo de su instrumental conceptual, son de tal calidad que muchos filósofos profesionales ni siquiera desean abordarlo. Y en lo que concierne a la universalidad de la temática y el grado de abstracción, lo mismo es válido en medida aún mayor. ${ }^{n 7}$ Consecuentemente, Spaemann considera la obra de Luhmann como la forma más reflexionada y moderna de la no-filosofia con la que tiene que enfrentarse la filosofia actual. ${ }^{8}$ Por lo arriba mencionado, debería quedar claro el hecho de que aquí no se avanza en la integración de determinadas tradiciones sociológicas y no sociológicas (por ejemplo, la "filosofia alemana clásica") sin un mínimo de argumentación filosófica. A pesar de ello, y precisamente debido a ello, hemos escogido la teoría de sistemas sociales (TsS) de Luhmann como un "hilo guía invisiblen , con el cual podemos medir nuestras propias propuestas, ya que somos de la opinión de que el terreno de teoría ganado por Luhmann no se debe perder imprudentemente. Asimismo, no es nuestro interés escribir una "crítica" de la teoría de sistemas sociales, dado que nuestra propia empresa teórica -la reconstrucción sociológica de una unidad social - representa una carga intelectual suficientemente completa. Para no dejar ninguna duda, estamos usando la proposición de Luhmann para consolidar la nuestra, no estamos haciendo un aporte "luhmanniano"; no somos partidarios incondicionales de su propuesta. Esto se refleja en el hecho de que para nosotros el concepto de sistema es un concepto importante, pero no imperativo, como lo es para la teoría de sistemas de Luhmann.

6. ¿De qué se trata para nosotros la reconstrucción de la unidad SOCIAL? A nivel metodológico se trata del proyecto de una teoria de las distinctones bajo el aspecto de su unidad; a nivel de teoría (teoría de la sociedad) ${ }^{9}$ se trata del proyecto de una teoría de la expectación, misma que relacionamos, en el contexto de este trabajo, con una teoría de los sistema de la sociedad (TgS). Esta connotación teórica

${ }^{7}$ Spaemann, 1990, p. 52.

8 Ibid., p. 73.

'Se debe hacer enfasis expresamente en el hecho de que la "teoria dé la sociedad" (o "teoría social") no se puede igualar con el nivel de abstracción "sociedad". La teoría de la sociedad resume formas semejantes de expectación como "socialidad", "personalidad", "afectividad", "corporalidad" o "per- 
del sistema fue escogida solamente porque consideramos que la reciente teoría de los sistemas es actualmente la mejor propuesta en el mercado de las "teorías sociológicas". No obstante, también es posible llevar a cabo nuestro proyecto teórico de la sociedad sin el concepto de sistema (una connotación de sistema se puede sustituir en gran medida, por ejemplo, a través de una connotación de expectación).

El proyecto aquí presentado clama universalidad respecto a todo aquello que desde Émile Durkheim se denomina "lo social", ${ }^{10}$ lo que, sin embargo, concebimos más ampliamente y designamos como "lo social". Al contrario de Durkheim ("hoy se nos concede de buena voluntad que las circunstancias de la vida individual y las de la vida colectiva son, en cierto sentido, heterogéneas [...." ${ }^{11}{ }^{11}$ incluimos en lo social no solamente las instituciones sociales ("lo social"), sino también la conciencia ("el pensamiento") como una forma especial de COMUNICACION, DECISION y ACCION, misma que genera, entre otras, los pensamientos ("lo espiritual"); incluimos también lo afectivo ("el alma"), lo fisico ("lo corporal"), y lo sensual ("la percepción") como formas especiales de la COMUNICACIÓN, DECISIÓN y ACCIÓN (= los aspectos activos de la teoría de la sociedad aquí ofrecida).

De manera similar a Luhamann con su TsS, nosotros tampoco compartimos la concepción de que, por medio de ello, podamos reflejar o agotar la realidad (social) completa de este objeto. También estamos muy lejos de clamar una verdad exclusiva respecto a otros proyectos de teoría. La universalidad de la pretensión está dada por

cepción" bajo el aspecto de la dimensión social del sentido, es decir, de manera doblemente distinta, y esto quiere decir sociológica (y no, por ejemplo, biológica, psicológica, neurológica, física, etcétera). Lo que, por ejemplo, en Luhmann se llama sociedad, podría mencionarse aquí bajo la denominación soctalidad. Con ello, la circunstancia ciertamente no se describe de manera suficientemente precisa; sin embargo, debemos dejar en suspenso el problema en este contexto. Sólo en el marco de una teoría de la sociedad orientada hacia la metodología de las distinciones, queremos someter esta circunstancia a una aclaración y ubicación. No obstante, si se correlaciona la SOCIAIIDAD con la sociedad (en el sentido de la TsS), entonces se podría decir, desde la perspectiva de la metodología de las distinciones, que la sociedad se podría delimitar frente a la personalidad, afectividad, corporalidad y percepción, representando socialidad, personalidad, afectividad, corporalidad y percepción aspectos diferentes de la socialidaD o de lo sOcial.

${ }^{10}$ Émile Durkheim, 1976, pp. 89 y ss.

!" Ibid., p. 92. 
el hecho de que el proyecto de teoría en cuestión se refiere a todo aquello que se puede designar como soctal. Bajo este concepto comprendemos unidades distintas (= diferentes) de COMUNICACION, DECISIÓN y ACCIÓN (- los aspectos activos de la teoría de la sociedad aquí ofrecida), mismas que constituyen distintos estilos de expectación. Visto de manera precisa, pero muy simple, lo social es la unidad de la distinción de los estilos accesibles de expectación.

7. ¿Qué comprendemos como ACCION, qué como COMUNICACIÓN? Aquí debemos distinguir minuciosamente entre una perspectiva distintiva y una operativa. Desde la perspectiva de la metodologia de las distinciones (a) comprendemos como Acción - dicho de forma abreviada - la operación de una determinación de selección; como COMUNICACIÓN comprendemos la oferta de una selección. Desde la perspectiva de la teoría de la operación (b); sin embargo, se trata de un contexto de los acontecimientos ACCION, DECISIÓN y COMUNICACIÓN, dado que las ACCIONES implican DECISIONES, y éstas, a su vez, requieren distinciones COMUNICATIVAS para poder realizarse. Con ello, la distinción ya clásica entre teoría (COMUNICACION) y práctica (ACCION) se impone nuevamente en forma modificada y mejor mediada (figura 1).

$\begin{array}{ll}\text { Teoria de las distinciones: } & {\left[\begin{array}{l}\text { ACCION: determinación de selección (práctica). } \\ \text { COMUNICACION: oferta de selección (teorfa). }\end{array}\right.} \\ \begin{array}{l}\text { Teoría de la operación: } \\ \text { (entrelace entre teoría } \\ \text { y práctica) }\end{array} & \begin{array}{l}\text { ACCION: posible solamente si... } \\ \text { DECISION: pOsible solamente si... } \\ \text { COMUNICACION: posible solamente si... }\end{array}\end{array}$

Relación entre teoría y práctica:

Desde la perspectiva de la metodología de las distinciones: teoria o practica Desde la perspectiva de la teoría de la operacion: teoría $y$ práctica

Ambas formas, comunicación y acción, se condicionan y necesitan mutuamente. Sobre la base de dicha combinación se puede alcanzar la formación de estructuras en la forma de expectativas y de 
experiencias, mismas que obtienen su estabilidad mediante las operaciones recursivas y, con ello, obtienen un carácter que Parsons o Luhmann denominarían sistémico. ${ }^{12}$

Los estilos de expectación más relevantes para nosotros, dentro de este contexto, son: el estilo de expectación sensual, el estilo de expectación corporal, el estilo de expectación afectivo, el estilo de expectación espiritual y el estilo de expectación social. La conexión de justificación formal pragmática de estos cinco (¿por qué solamente cinco?) estilos de expectación requiere, sin embargo, una teoría particular que debe ser capaz de demostrar la unidad de la distinción de los estilos de expectación. Formulado de otra manera, lo social está presente no solamente como comunicación verbal y/o escrita, sino que está condensado de manera igualmente esencial en forma no-verbal o no-escrita. No obstante, ¿cómo se reúnen COMUNCACioNES tan heterogéneas como, por ejemplo percepción corporal del sexo, posiciones afectivas de envidia, determinados actos espirituales de conciencia y las comunicaciones verbales/escritas específicamente sociales? Esto lo puede lograr sólo una teoría suficientemente general como para conectar entre sí, de manera sensata, una teoria de la percepción sensual, una teoria del comportamiento corporal de expresión, una teoría de la comunicación afectiva, una teoria de los actos de conciencia y una teoría de las instituciones sociales. Y esto, a su vez, sólo lo puede lograr una metodología basada en la teoría de las distinciones; una teoría que por lo pronto y sobre todo, convierte en objeto de su investigación a la función de las diferencias $y$ diferenciaciones. En este sentido, el presente intento representa una teoría general que debe formar el marco de una teoría de la sociedad y que, no obstante, puede ser bosquejada solamente de manera muy aproximativa.

Nuestro punto de partida no es "estructura", "función", "conflicto", "estratificación", "sentido", "autopoiesis", "paradoja" o "expectación"; tampoco la "edad moderna" o "edad posmoderna"; las posiciones como la teoría de la acción, la teoría de los sistemas, funcionalismo, teoría de la información, interaccionismo, teoría del conflicto, teoría de la comunicación, fenomenología o neomarxismo son sola-

${ }_{12}$ Con ello, esquivamos disposiciones de teorias sociol6gicas como, por ejemplo, las de Viktor Vanberg, 1975 y 1984 o Karl Dieter Opp, 1991 y 1972, que parten de concepciones dicótomas del tipo "sistema/acción" o "individualismo/colectivismo". 
mente de interés indirecto para nosotros. Partimos del hecho de que todos estos "síndromes de teoría" tienen un factor común: utilizan determinadas distinctions directrices para generar determinadas teorías sociales. ${ }^{13}$ De esta manera, por ejemplo, la teoria de los sistemas sociales (TsS, Niklas Luhmann) parte de la distinción sistema/ entorno (y recientemente de la distinción diferenciación/denominación); la teoria de la acción comunicativa (TkH, Jürgen Habermas) parte de la distinción sistema/mundo de vida; y la teoría del sistema general de la acción ( $\mathrm{TaH}$, Talcott Parsons) parte de la distinción sistemalacción. Con ello, están preprogramados — visto desde una teoría de la sociedad con base en una metodología de las distinciones-determinadas ganancias y pérdidas informativas, ya que una teoría social puede observar solamente aquello que su "distinction directrice" le permite observar: en este sentido, puede observar solamente aquello que puede ver. ${ }^{14}$ Esto es válido generalmente para cualquier teoría social, incluso para la teoría de la expectación o teoria de los sistemas de la sociedad (TgS), propuesta aquí por nosotros en bocetos rudimentarios.

El hecho de que se pueda representar una teoría semejante tanto en el marco de una "teoría de la expectación" como también en el contexto de una "teoría de los sistemas", la "libera", en cierta manera, de un planteamiento comprendido exclusivamente desde la perspectiva de la teoría de los sistemas, lo cual no significa que este planteamiento sea irrelevante. De este modo, el concepto de la "hermeticidad" — para dar solamente un ejemplo- es ciertamente más accesible para una explicación con la ayuda de una connotación teórica del sistema. Asimismo, se pueden generar, precisamente debido a ello, numerosos errores, ya que el instrumental conceptual de la teoría de los sistemas no es suficientemente preciso frente a las imprecisiones de los acontecimientos sociales ya que selecciona demasiado. ${ }^{15}$

${ }^{13}$ Véase el título del ensayo de Niklas Luhmann: "Distinction Directrices. ther Codierung von Semantiken und Systemen". (Luhmann, 1987c, pp. 1331).

${ }^{14}$ En el discurso de la TsS: "[...] un sistema puede ver solamente aquello que puede ver. No puede ver aquello que no puede ver". Sobre todo, y esto es especialmente relevante para la observación: "Tampoco puede ver que no puede ver aquello que no puede ver." (Luhmann, 1986a, p. 52).

is No tenemos ningún miedo de contacto en lo que concierne a la connotación teórica del sistema, como se puede observar en los autores que se 
Así, una teoría general de este tipo no puede ser una teoría de los sistemas, teoría de la comunicación o neofuncionalismo, sino solamente una metodología de las distinciones, misma que, por ello, analiza más detalladamente la función de las distinciones que producen, entre otras, también las corrientes sociológicas de teorías. De acuerdo con estos hechos presentamos aquí una metodología de las distinciones que denominaremos como "lógica de las distinciones" (figura 2).

Lógica de las distinciones basada en la metodología de las distinciones:

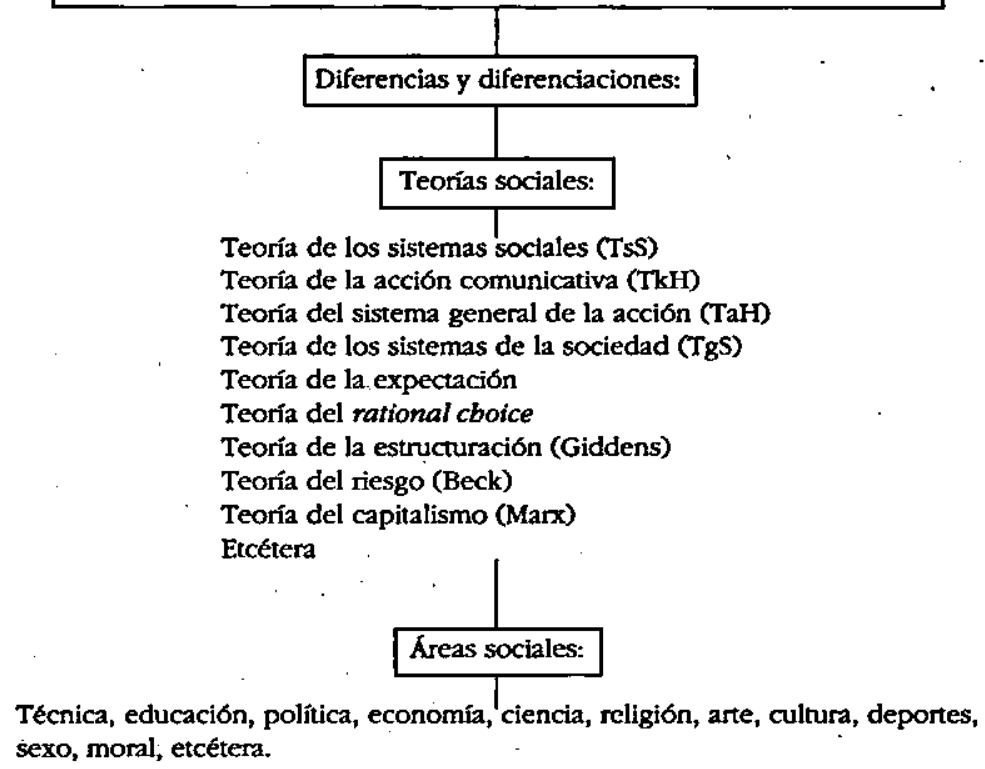

encuentran más o menos en las cercanías de la teoría de la acción comunicativa. Es sintomático por ejemplo, el artículo de Hans Joas "Die unglückliche Ehe von Hermeneutik und Funktionalismus. Über Jürgen Habermas Theorie des kommunikativen Handelns (Joas, 1986). La teoría de los sistemas no se debe subestimar, como lo hace Joas, y tampoco sobreestimar, como lo documentan numerosos trabajos de habla alemana en esta área. Repetimos: la insuficiencia de la teoría de los sistemas consiste precisamente en el hecho de que semánticamente selecciona con demasiada fuerza $\mathrm{y}$, con ello, deja poco espacio de distinción para las imprecisiones notorias de lo social. 
Por lo tanto, en el centro de este trabajo se encuentra una metodologia de las distinciones y no una determinada forma de la teoria de los sistemas, teoría de la información, funcionalismo, teoría de la comunicación o estructuralismo, aunque todos estos complejos de teoría pueden relacionarse directa o indirectamente con la metodología de las distinciones. Es importante realzar el hecho de que la metodología de las distinciones muestra un perfil propio, es decir, que se debe tratar y observar, en cierta manera, como proyecto de teoría autónomo, sin negar por ello la relación loose coupled con otras unidades de teoría. Formulado de manera drástica: si se derribara la metodología de las distinciones no sería necesario llegar al fondo de los complejos de teoría que se encuentran en una relación laxa con ella, como la teoría de la reflexión, el funcionalismo, la teoría de los sistemas, la teoría del sentido, la cibernética de segundo grado, la teoría de la percepción corporal o la teoría de la conciencia, para mencionar sólo algunos cordones de teoria acoplados de modo "laxo" con ella.

Los conceptos utilizados en este trabajo están dispuestos de manera "no-jerárquica": no existen conceptos "primeros" y/o "últimos", sino solamente conceptos que se explican mutuamente dentro del contexto de otros conceptos, de acuerdo con el supuesto teórico de que la información sólo es posible con base en una distinción que ocasiona otra distinción.

Partimos del hecho de que todos los fenómenos sociales "están afectados" por la forma principal del diferenciamiento del orden social. Esto significa que también los bienes culturales y espirituales están sujetos a una forma específica de diferenciación social. ${ }^{16}$ Por ello, se puede considerar como un fenomeno "normal" el hecho de que

${ }^{16}$ Pertenece a una sociedad ordenada de manera estratificada-jerárquica el hecho de que no solamente la posición de sus miembros muestra una forma estratificada, como se expresa de manera ejemplar en la obra del parisino Charles Loyseau en el año 1610:

Unos son llamados especialmente para el servicio a Dios, otros al mantenimiento del Estado por medio de las armas; aún otros para alimentarlo y conservarlo mediante las prácticas de paz. Estas son nuestras tres 6 rdenes o estamentos generales de Francia, el clero, la nobleza y el tercer estamento (Duby, 1986, p. 11). También su ámbito cultural se toca por un diferenciamiento semejante. Esto se expresa, por ejemplo, en los supuestos a priori o "naturales", mismos que, con ello, constituyen una jerarquía del conocimiento. 
los productos espirituales como las obras religiosas, filosóficas o de las ciencias naturales, vistos desde una perspectiva cultural, se dispongan con base en la diferenciación dominante de la sociedad -ya sea segmentaridad, estratificación, funcionalidad o reflexión social. Con la modificación de la forma dominante de diferenciación de la sociedad, de la estratificación en dirección hacia la funcionalidad -y recientemente hacia la reflexividad, un supuesto explícito en el marco de esta obra-, estos productos espirituales dispuestos jerárquicamente pierden paulatinamente su legitimidad. Sin embargo, ganan cada vez más reputación las estructuraciones conceptuales ordenadas de manera circular, como la cibernética, la hermenéutica, la autorreferencia, la complementaridad, la autopoiesis, la justificación última (de Apel) o la "marcha en círculo" de C.F.v. Weizsäcker. Éste formula: "La marcha en círculo no estaba pensada, de antemano, solamente como un medio literario de apoyo, sino como un principio filosófico metódico, como alternativa a cualquier planteamiento de una filosofia 'jerarquicista', misma que espera partir de un solo fundamento invariable, independientemente de que esto sea la experiencia o la autocerteza de la conciencia. ${ }^{n 17}$ El proyecto aquí presentado está ordenado también en el sentido de una "marcha en círculo" semejante, aunque no podemos recorrer todo el círculo correspondiente dentro de este trabajo.

Naturalmente, determinadas prioridades de conceptos del autor juegan un papel en el diseño de la estructuración conceptual, sin embargo, es sólo un papel pragmático: en algún momento se debe empezar en algún punto, en caso contrario, uno no empieza nunca. Por lo tanto, podriamos haber comenzado también con "complejidad" o con la "observación", en vez de empezar con la "forma", con lo cual tocamos el problema del comienzo de un "primer" inicio, mismo que seduce a la formación y constitución de jerarquías conceptuales. Los conceptos se colocan frecuentemente en la punta de una empresa intelectual y no se someten a ninguna explicación adicional, como el "ser", la "cosa en sî", la "existencia", la "conciencia", el "interés", la "naturaleza", la "validez", el "entorno", la "comunicación", la "acción", la "operación" o la "observación". Basados en una metodología "hermenéutica" o circular tratamos de evadir el problema de "jerarquía teórica". Por otra parte, debemos mencionar que le damos preferencia a ciertos conceptos, sin por eso construir una teo-

${ }^{17}$ Weizsäcker, C.F.v., 1992a, p. 594. 
ría "estratificada" o jerárquica. Los conceptos preferidos en esta obra son: realización, observación, denominación, diferencia, simpleza, decisión, DECISIÓN, experiencia, expectación, "algo", referencia ajena, forma, sociedad, SOCIEDAD, acción, ACCión, información, comunicación, COMUNICACIÓN, complejidad, operación, autorreferencia, sentido, sistema, diferenciación, utilización. ${ }^{18}$

El concepto de operación (que sería incomprensible sin un concepto de observación) desempeña un papel dominante en este trabajo. Para demostrar cómo un concepto de este tipo debe representar a otros y puede esquivar el fatal inicio de un comienzo, queremos observar cómo procede una operación en su operar, cómo opera una operación. ${ }^{19}$

Supongamos que establecemos una condición previa única y escogemos como punto de partida el concepto de la operación: "algo empieza/opera/tiene lugar o no empieza/no opera/no tiene lugar".

Si se parte del hecho de que el comienzo de "algo" se localiza en el tener lugar/no tener lugar de una operación (ya que el mencionado "algo" sucede con base en una operación específica), este supuesto suena, por lo pronto, trivial, dado que ¿cómo se debe comenzar sin comenzar simplemente? El lado no trivial de esta condición de partida consiste en el hecho de que se puede aclarar, mediante la reflexión de la actividad operativa, que el sentido de cualquier comienzo se constituye en el momento en que, de hecho, se comienza (con lo que sea). Transferimos ahora estas reflexiones al nivel operativo: (a) algo opera o no opera. Si tiene lugar, entonces se puede decir: lo que anteriormente no tenía lugar, tiene lugar ahora o tuvo lugar ahora. Con ello, se constituye la distinción de antes/después ( $=$ no había empezado/ahora ya empezó) que puede adquirir la forma de pasado/futuro, como distinción elaborada. Se nota que la "primera" operación constituye la dimensión del tiempo por medio de su "tener lugar por primera vez": algo no estaba, ahora sí está.

Aquí se afirma que la dimensión del tiempo no es algo que se preestablece, sino algo que se constituye operativamente. Se compren-

${ }^{18}$ En este contexto utilizamos en gran parte como sinónimos "término" y "concepto", aunque su distinción consiste en el hecho de que comprendemos como "concepto" la explicación reflexiva de un "término".

19 Regresaremos otra vez y más explícitamente a ello en los capítulos sobre forma y complejidad. 
de que no podemos demostrar semejante constitución operativa con todos los conceptos aquí utilizados. Sin embargo, se debe partir del hecho de que algo como COMUNICACION, ACCION, diferencia, diferenciación, sentido, identidad, información, sistema, entorno, organización, expectación, experiencia, individuo, conciencia, autoconciencia, etc., primero debe constituirse operativamente. Las identidades - de cualquier tipo- no son preestablecidas, sino que representan acontecimientos que se deben constituir, que se condensan en estructuras (= expectaciones) a través de la dimensión del tiempo. ${ }^{20}$

Por otro lado, ¿qué sucede cuando no sucede nada aunque nosotros esperamos que suceda algo? Podemos formular, sobre la base de una teoria del sentido, que dentro de un mundo del sentido, todo tiene un sentido, también el no tener lugar (algo que no tiene sentido es algo "sin sentido", algo que obedece al sentido de "no tener sentido). Si una operación esperada no ocurre, tiene lugar algo, es decir, su ausencia, la cual puede adquirir, dentro de la vida cotidiana, la versión del sentido de "ausencia", "olvido", "no aparecida", "aportación faltante", "no encontrada" o - en forma elaborada- de negación. Con ello está dicho que la operación se implica a sí misma en forma negativa (sólo y cuando es esperada naturalmente): si no ocurre, entonces tiene lugar precisamente como "ausencia de una operación esperada". Por lo tanto, para la constitución de la negación es crucial el concepto de la expectativa: $\sin$ la expectativa de que una operación tendrá lugar y la subsecuente frustración no es posible la negación. Ahora bien, se puede preguntar de manera sensata - obviamente desde la perspectiva de un observador-: ¿qué es lo que debería haber tenido lugar pero no lo tuvo?

El "enigma de la negación" consiste en el hecho de que dentro del mundo no (sic) existen las circunstancias negativas. El mundo es como es. La negación es un producto exclusivo de los aspectos activos de la sociedad, como son la comunicación, la acción - todos basados en la expectativa de "algo". Al parecer se da algo así como una protonegación que posee formas no-lingüísticas como son: el "engaño" a nivel de la "sensualidad", el "dolor" a nivel de la "corporalidad", el "miedo" a nivel de la "afectividad", etcétera.

${ }^{20}$ Tomaremos en cuenta especialmente esta circunstancia en otros capítulos. 
C.F.v. Weizsäcker formula de manera similar, en el contexto de una doctrina biológica del comportamiento: "Si tiene lugar la disolución [del comportamiento], entonces tiene lugar el desarrollo del comportamiento. Si la disolución no tiene lugar, entonces no sucede 'nada' y se requiere una consulta acerca del interés frustrado del observador respectivo, para enterarse de aquello que no tuvo lugar. ${ }^{21}$ La frustración de la expectativa es generada precisamente por medio del no tener lugar de una operación y, con ello, se pone en marcha el aprendizaje. ${ }^{22}$

Ahora tenemos la siguiente forma operativa: algo no estaba y no está tampoco ahora. Por ello, podemos decir que también la versión negativa de una operación (la espera de que tendría lugar, pero no tuvo lugar), constituye la distinción de antes/después y, con ello, una forma primitiva del tiempo. ${ }^{23}$

El resultado de una operación semejante se puede constatar naturalmente sólo con el apoyo del concepto de la observación: el observador observa (en otros, en sí mismo) que no tiene lugar una operación. Nótese que aquí también acoplamos la emergencia de la observación al concepto de la operación, en el sentido de una "ausencia de la operación $n^{n}$. Véase explícitamente el capítulo IV acerca de la observación.

En el nivel de abstracción de la teoría de las distinciones, definimos la observación como una operación que determina -como oferta de selección-, y con la ayuda de una diferenciación ya seleccionada (= distinción), a una diferencia (= distinción), con el objetivo de generar información. La observación ciertamente siempre está preñada de la distinción. Esto nos ha inducido - por razones de simplificación y comprensibilidad-A UTHIZAR observación y distinción. Si uno quisiera ser exacto debería formularse que cualquier

${ }^{21}$ Weizsäcker, C.F.v., 1977, p. 301.

${ }^{22}$ Cabe hacer hincapié que la constitución de la negación y lo que llamamos "aprendizaje" se encuentran intimamente ligados: aprender implica "frustrar" previas expectativas y, por lo tanto, negarlas. Si este proceso no se da, no se aprende.

${ }^{23}$ Se llama la atención sobre el hecho de que la operación de la negación está relacionada esencialmente con la operación de la expectación: es -en un "nivel primitivo", por así decir-el proceso de desilusión el que ocasiona aquello que nos hemos acostumbrado a denominar luego, en forma elaborada, como "negación". 
observación siempre consiste en dos distinciones, o sea en una diferencia simétrica y una diferenciación asimétrica. Por lo tanto, observación y distinción no poseen el mismo sentido. Abordaremos esta circunstancia más detalladamente en el capítulo IV acerca de la observación.

Mediante la secuencia de argumentación arriba desarrollada se aclara que solamente podemos esquivar la figura a priori o el jerarquismo conceptual si, primero, planteamos en un nivel lo suficientemente alto el potencial autorreflexivo del concepto en cuestión y, segundo, si logramos ubicar el concepto de manera sensata dentro de otros conceptos. En este contexto, tendríamos que recurrir a las teorias de la reflexión, de la observación, del tiempo y del sentido. Con ello, se hace evidente que los conceptos son utilizables como tales si se explican mutuamente. Esto es alcanzable, a su vez, solamente a través del camino de una mutua delimitación y limitación conceptual, misma que impide que el concepto adquiera una forma a priorista, una forma jerárquica.

De la perspectiva generadora del tiempo explicada arriba, misma que debe tematizar naturalmente también el operar de la operación, inferimos:

(1) El supuesto presentista de que todo lo que sucede, acontece de manera momentánea, inmediata, instantánea.

Sería equivocado suponer que el tiempo-lo que quiera que esto sea- existe antes de la operación. Sólo el acontecer operativo generador de sucesos, en conjunción con una mínima distinción objetiva (= el tener lugar/no tener lugar de la operación) puede constituir aquello que nos hemos acostumbrado a designar como "tiempo". Ia forma del sentido tiempo presupone la distinción de antes/después (o de pasado/futuro, en la forma elaborada). Se observa que sin distinción no existe ningún "tiempo", e incluso ninguna negación, ya que ésta es posible solamente si antes se puede distinguir entre algo que es y algo que no es. Abordaremos esta circunstancia más explícitamente en el capítulo I acerca de la forma. La negación es producto de la distinción, no su condición previa.

Algo puede operar, si es que opera del todo, solamente en el presente -en el momento inmediato-, y no en el pasado o en el futuro. Humberto R. Maturana formula, en un contexto similar: "Por ello, para mí se infería de este entramado peculiar de historia y presente: aunque tenemos que consultar a la historia, para explicar el cómo un sistema viviente singular se haya convertido en aquello 
que es ahora y aquí, no podemos utilizar la historia para explicar su operación como unidad, dado que su historia no forma parte de él, como componente [...]".24

Con la forma "distintiva" de "operar/no operar" inferimos:

(2) Una "primera objetividad primitiva", misma que se co-constituye en la forma de la distintividad en sí. Esto significa que comprendemos la dimensión objetiva de todo sentido como la emergencia de la distintividad. La distintividad se produce debido a una operación, la cual puede operar o no operar. En este sentido, esta "necesidad operativa" es la condición previa de la posibilidad de la emergencia de la distintividad. Debería ser plausible el hecho deque la negación solamente es posible si anteriormente tiene lugar una distinción, ya que sólo podemos negar lo que previamente hemos distinguido.

La distintividad arriba explicada justifica, por su parte, la pregunta: ¿si todo lo que sucede no sucede como una secuencia, sino como una simultaneidad del "esto y/o aquello", entonces, cómo es posible. algo como "algo" bajo estas circunstancias? Tiene lugar, por lo menos, la distinción de tener lugar/no tener lugar. Con ello, también está dicho que con el supuesto presentista se constituye simultáneamente (1) la dimension del tiempo y (2) la dimensión de la objetividad distintiva. Es una posición de partida extremadamente abstracta y al mismo tiempo muy rica respecto a sus consecuencias (figura 3 ).

\begin{tabular}{|c|c|}
\hline $\begin{array}{l}\text { El supuesto presentista } \\
\text { constituye al mismo } \\
\text { tiempo: }\end{array}$ & $\begin{array}{l}\text { La dimensión temporal del sentido } \\
\text { La dimensión objetiva del sentido }\end{array}$ \\
\hline
\end{tabular}

Con referencia a la sociología ¿cómo es posible la sOcIEDAD si la basamos sobre esta premisa operativa presentista?

Recordamos el hecho de que no comprendemos como SOCIEDAD solamente las así llamadas expectativas institucionales, șino también las expectativas subjetivas, afectivas, corporales y sensuales. En ello está arraigado un problema esencial de cualquier COMUNICACIÓN: es decir, generar "entendimiento" sobre la base de estos tipos de comu-

${ }^{24}$ Maturana, 1985, p. 17. 
NICACION, en parte muy heterogéneos. La operación del consenso es resultado de un previo entendimiento: es necesario haber comprendido explícita o implícitamente ("haber entendido" o "no haber entendido"), para poder efectuar una operación consensual (Habermas).

Con la ayuda de este supuesto presentista ( $=$ inmediatez) generador de la dimensión del tiempo y de la dimensión distintivo-objetiva, intentaremos demostrar a continuación, cómo se puede alcanzar la formación de "algo" (p. ej., objetos y "cosas" en el más amplio sentido de la palabra), pero también y sobre todo, cómo se puede generar la SOCIEDAD. En este sentido, las reflexiones de este trabajo no solamente se refieren a la SOCIEDAD, sino a algo como "algo" y son por ello genuinamente metodológicas. Así, la designación de la metodología que aquí se expone como "protológica" y "protosociología" adquiere su legitimación, ya que son reflexiones que se dan "antes de la lógica" y "antes de la sociología" ofreciendo, al mismo tiempo, la base constitutiva de dichas disciplinas.

En los años sesenta se manifestaron de manera central, en el curso de la discusión acerca del positivismo dentro de la sociología alemana, los referentes principales de antaño -Karl R. Popper y Theodor W. Adomo- acerca del tema de una "lógica de las ciencias sociales". Con ello, se evidenciaba que tanto Popper como Adomo efectúan una distinción entre una "lógica de las ciencias naturales", por un lado, y una "lógica de las ciencias del espíritu y sociales", por el otro. Para Popper, la diferencia más bien gradual consiste en el hecho de que las ciencias filosóficas y sociales deben tomar en consideración la llamada lógica de la situación. ${ }^{25}$ Adorno, por otro lado y si-

25 "La investigación lógica de los métodos de la economía política conduce hacia un resultado, el cual es aplicable a todas las ciencias sociales. Este resultado demuestra que existe un método puramente objetivo, dentro de las ciencias sociales, mismo que se puede designar seguramente con el método objetivo-comprensivo o con lógica de la situación. Se puede desarrollar una ciencia social objetivo-comprensiva, independientemente de todas las ideas subjetivas o psicológicas. Consiste en el análisis suficiente de la situación del hombre actor, para explicar la acción a partir de la situación, sin otra ayuda psicológica. La 'comprensión' objetiva consiste en el hecho de que vemos que la acción estaba objetivamente adecuada para la situación" (Popper, 1970, pp. 120-121). Al contrario de Popper, opinamos que, por ejemplo, los afectos comprendidos "subjetivamente" se pueden integrar del todo en el marco de una teoría social, sólo que la teoría se debe disponer de manera correspondientemente compleja. Desde la perspectiva social del sentido y 
guiendo una diferencia más bien sustancial, es de la opinión de que los objetos de las ciencias naturales representan "materiales humanamente no elaborados". Lo contrario sucede con las ciencias sociales y del espíritu: aquí la "elaboración humana" está siempre presente. ${ }^{26}$ Tambiến Jürgen Habermas parte de una distinción esencialmente ontológica entre las ciencias naturales y las ciencias filosóficas o sociales. Esta distinción se expresa, de acuerdo con su opinión, como la problemática específica de la comprensión de las ciencias del espíritu. ${ }^{27}$ Con ello, Habermas nos quiere decir que el "material de las ciencias sociales" ya esta preestructurado simbólicamente: el objeto de investigación de las ciencias sociales - o sea, el mundo de vida como experiencia cotidiana- permanece inaccesible para una "observación puramente objetiva" dado que el acto mismo de observación forma parte del mundo de vida. ${ }^{28}$

Opinamos que las tres posiciones arriba descritas no se pueden defender en la actualidad, sobre todo si se toma en consideración lo que sucede en el frente de la investigación de las ciencias naturales, de lo cual todavía se enteran supuestamente poco (por lo demás, ¡desde hace décadas!) las ciencias sociales y, en especial, la sociología. ${ }^{29}$ En particular en el área de influencia de la investigación física, sobre todo en el ámbito teórico de la física cuántica, se discute ac-

dentro del marco de una teoría social, consideramos, por lo tanto, a los afectos como una forma determinada de COMUNCACION, es decir, como COMUNICACIÓN a través de la cercania.

26 "Dentro de las ciencias naturales, se trata, en gran medida, de materiales no mediados, esto quiere decir ya humanamente preformados y, en este sentido, en gran parte no-calificados, de manera que la ciencia natural - si usted así lo desea- nos posibilita la selección de nuestro sistema categorial, de manera más libre que dentro de la sociología, cuyo objeto está determinado, ya dentro de sí mismo, de tal modo que nos obliga al aparato categorial." Th. W. Adorno, citado por Ralf Dahrendorf, 1970, p. 147.

${ }^{27}$ Esta problemática específica de la comprensión consiste en el hecho de que '[...] el científico social no puede 'utilizar' como un instrumento neutral este lenguaje 'encontrado' en el área del objeto. No puede 'entrar' a este lenguaje, sin recurrir al conocimiento pretérico del integrante de un mundo vivencial, es decir, del suyo propio, mismo que domina intuitivamente como laico, y que integra de manera no-analizada a cualquier proceso de comunicaciớn". (Habermas, 1981b, 1, pp. 163 y ss.).

${ }^{28}$ Ibid., p. 162.

${ }^{29}$ La teoría de los sistemas sociales (TsS) de Niklas Luhmann representa una excepción. 
tualmente de manera central la pregunta acerca del sujeto de la fisica. ${ }^{30}$ Precisamente aquí se muestra que una descripción natural como "física" depende del acto de observación, el cual procede de manera "fisica" y, en este sentido, se debe comprender como un aspecto parcial de una descripción semejante de la naturaleza. Formulando el problema de otra manera podemos decir que el físico (teórico cuántico) debe describir un mundo de vida físico, al cual él mismo pertenece como fisico. C.F.v. Weizsäcker lo formula de la siguiente manera: " $\mathrm{El}$ punto clave de la física cuántica consiste aparentemente en el hecho de que el tipo de nuestra descripción de la naturaleza depende del acto de observación. ${ }^{31}$ Por lo tanto, podemos formular que el acto de observación, tanto aquél motivado fisicamente como aquél motivado sociológicamente, forma parte, en si, del mundo material o social, mismo que estamos tratando de observar. Dicho de otra manera: sólo podemos observar el ámbito físico a partir de una observación física, sólo podemos observar el ámbito social a partir de una observación social, etcétera.

La siguiente metodología de las distinciónes fue proyectada explícitamente para poder indicar, en el área de la dimensión social del sentido (lo social), las coordinadas generales, las cuales determinan -de acuerdo con nuestra opinión-a este ámbito en su forma. Además, esta "lógica de las distinciones" contiene un margen de acción para las posibilidades, mismo que la hace utilizable también para la determinación de las coordinadas de otras áreas. Su instrumental consiste en las dos distinciones de "diferencia simétrica" y de "diferenciación asimétrica", las cuales se pueden definir solamente con base en una referencia recíproca. El cómo esto se deba desarrollar se explicará explícitamente más abajo. En el contexto actual es esencial el hecho de que la referencia de la diferencia simétrica con la diferenciación asimétrica posibilita exactitud y DECIDIBILIDAD a nivel teórico y práctico en el sentido amplio de la palabra. A continuación, demostraremos, sobre la base de ambos conceptos, cómo es posible la SOCIEDAD como referencia' de COMUNICACIÓN simétrica y ACCIÓN asimétrica. Las siguientes frases de C.F.v. Weizsäcker pue-

${ }^{30}$ Por eso, el título de un ensayo de Weizsäcker C.F.v. es: " $i$ Wer ist das Subjekt in der Physik?" (Weizsäcker, C.F.v., 1977, pp. 169-186). En este lugar, se tematiza explícitamente el papel del observador como el sujeto del conocimiento de la física.

${ }^{31}$ Weizsācker, C.F.v., 1992a, p. 836. 
den aclarar por qué suponemos que la lógica de la sociedad y la lógtca de la naturaleza poseen el mismo sentido y por qué se ha vuelto obsoleta la distinción entre las ciencias filosóficas, históricas, hermenéuticas y sociales; por un lado, y las ciencias de la naturaleza por el otro, todo esto a nivel de una metodologia general de las distinciones: "En la teoría cuántica puedo notar exactamente el hecho de que es una teoría, la cual se refiere al conocimiento humano. Necesito los pronósticos acerca del resultado de la decisión entre las alternativas finitas (Rodrigo Jokisch), éstos son los conceptos básicos, para inferir la teoría cuántica. ${ }^{n 2}$ También lo son, de manera similar, los conceptos que necesitamos para deducir una teoría general de la sociedad: con la ayuda de las distinciones "diferencia" (distinción simétrica) y "diferenciación" (distinción asimétrica) - a nivel de una teoria social: COMUNICACIÓN (distinción simétrica) y ACCIÓN (distinción asimétrica) - se demuestra la condición previa de posibilidad de la DECIDIBIIIDAD. Sólo con base en la DECIDIBILIDAD la COMUNICACIÓN social puede adquirir su capacidad de conexión y de sistema $\mathrm{y}$, con ello, formar estructuras sociales de expectación que, en consecuencia, conforman aquello que designamos como lo social, como SOCIEDAD. En pocas palabras: en un nivel muy abstracto podemos formular que no existe distinción alguna entre las ciencias sociales y las ciencias naturales, si tomamos como base la metodología de las distinciones.

Aquí no nos dedicamos a la física, sino a la sociología. A pesar de ello, nos importa llamar la atención sobre el hecho de que se ha agrietado considerablemente la validez de la distinción preñada de tradición entre las ciencias naturales y las ciencias sociales y filosóficas. Al nivel de una teoria general de las distinciones que integra al nivel abstracto la física cuántica podemos decir que se empieza a perfilar una lógica general de las ciencias. Por otra parte, sería un error suponer que, con ello, se pretende renovar el viejo programa reductivo de una ciencia unitaria como fue discutido en el Círculo de Viena (Carnap, Oppenheim, Popper, etc.). La distinción entre natu-

${ }^{32}$ Además, dice C.F.v. Weizsäcker a continuación, es imposible "[...] que dentro de ella no hablemos de cómo nos comportamos. Ésta es precisamente la inseparabilidad, la así llamada inseparabilidad de objeto y sujeto, dentro de la teoría cuántica. Los conceptos que utilizamos dentro de ella, no tienen ningún sentido, si no describen el comportamiento del hombre hacia sus objetos". (Weizsäcker, C.F.v., 1984a, pp. 311-312). 
raleza y sociedad ${ }^{33}$ conserva su validez venerable en un nivel más concreto. En todo caso, "la sociedad" y "la naturaleza" poseen, según nuestra opinión, un factor en común a nivel general de la metodología de las distinciones: ambas áreas se pueden comprender como constituidas y organizadas por medio de modalidades específicas de decisión, ${ }^{34}$ de altemativas finitas que implican una "lógica de las distinciones".

${ }^{33}$ Sin embargo, es necesaria la siguiente observación: La SOCIEDAD es posible solamente, si puede procesarse la distinción de comunicabilidad e incomunicabilidad. En este contexto, la semántica de "naturaleza" sirve como forma de la incomunicabilidad. I a "naturaleza" misma es obviamente una forma de comunicación, o sea, una incomunicabilidad comunicativa, misma que puede tener lugar solamente dentro de la SOCIEDAD. La pregunta que se debería formular, en este contexto, es: ccómo comunica la SOciEDAD su incomunicabilidad?

${ }^{34}$ Weizsäcker, C.F.v. define al comportamiento, que denominaremos como "comportamiento objetivizable de las ciencias naturales", de la siguiente manera: “[...] 'objetivizable' significa 'decidible', o sea, 'inequivoco' ". (Weizsäcker, C.F.v., 1992a, p. 1112). Por lo tanto, hemos introducido los conceptos de diferencia y diferenciación, para poder demostrar la posibilidad de la DECIDIBUIDAD. En este sentido, aquello que nosotros llamamos un "algo", tiene el mismo sentido que aquello que Weizsäcker designa como un "objeto". Véase capítulo I. 
En cuanto a los textos, las costumbres de la Edad Media que le permiten al libro mismo hablar como un autor, no ban sobrevivtdo a la imprenta. No sería completamente erróneo retomarlas, dado que solamente muypocas cosas provienen, porlo menos donde baya un comportamiento "científico", del autor mismo.

Niklas Luhmann ${ }^{1}$

En este trabajo permitimos hablar, en primera instancia, a la obra del autor, no al autor mismo. Es por ello que hemos escogido para esta presentación la primera forma del plural: somos "nosotros" - no un "yo"- los que exponen. Por lo tanto, escogemos una forma más neutral para la reproducción del texto en cuestión. Además, utilizamos constantemente las siguientes abreviaturas:

(TsS) Teoria de los sistemas sociales (N. Luhmann).

(TaH) Teoría del sistema general de la acción (T. Parsons).

(TkH) Teoría de la acción comunicativa (J. Habermas).

(TgS) Teoría de los sistemas de la sociedad (proyecto propuesto por nosotros que se designa también como Teoría de la expectación).

El texto original se extiende aproximadamente a cuatro veces más de lo presentado actualmente. El apartado de notas al pie refleja esta

'Luhmann, 1990, p. 11. 
circunstancia: se ubicaron numerosas informaciones relevantes o como inserciones en el texto principal, o se alojaron en la parte de las notas a pie. El glosario al final del trabajo pretende facilitarle al lector la familiarización con la terminología, parcialmente desarrollada aquí de forma específica. Sin embargo, se debe observar el hecho de que todos los términos empleados de manera central dentro de este proyecto están definidos desde la perspectiva de la metodología de las distinciones y no representan axiomas aislados. ${ }^{2}$ Un término tiene sentido solamente dentro del contexto de otros términos, con lo cual, el contexto conceptual de este trabajo se encarga de que cada término permanezca limitado en cuanto a su alcance semántico.

${ }^{2}$ El primer acceso teórico a la teoría de las distinciones puede ser tanto relacionado con la observación, como relacionado con la operación. Dependiendo del tipo de acceso se encuentran diferentes conceptos en el primer plano: si se elige un acceso relacionado con la observación, entonces las categorías simetría, diferencia, comunicación se encuentran en el primer plano; si se elige un acceso operativo, entonces las categorías como asimetría, diferenciación o acción se colocan en este mismo plano. 
Aprendi que vocablos idénticos $y$, con ello, planteamientos idénticos de pregunta, significan algo diferente, dentro de todas las filosofias serias. Comprendi que esto no puede ser de otra manera, ya que la filosofia intenta pensar el todo y, por ello, cada proyecto nuevo del todo modifica el sentido de cualquier término, de manera suave o expresa.

Carl Friedrich von Weizsäcker ${ }^{1}$

En el fondo, este trabajo pretende explicar solamente un pensamiento que, sin embargo, no es fácil de comprender: la unidad - de lo que sea- se debe comprender como la unión de la distinción de unidad $y$ diferencia. Para ello utiliza una terminologia propia que traduce el pensamiento mencionado a una forma más especifica y operacional: la de unidad como la unión de la distinción de difereñcia y diferenciación. Con ello, se presenta la diferencia como distinción simétrica y la diferenciación como distinción asimétrica² (figura 4).

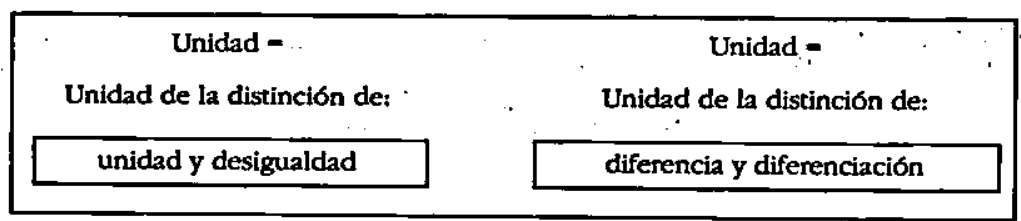

1 Weizsäcker, C.F.v., 1992a, p. 29.

${ }^{2}$ Anótese anticipadamente: son convertibles una en la otra, tanto una diferencia simétrica como una diferenciación asimétrica: dos diferenciaciones 
Este pensamiento básico es probado y corroborado con base en las categorias forma, complejidad, autorreferencia, observación y a partir de los proyectos sociológicos de las teorias de la sociedad de Niklas Luhmann, Jürgen Habermas y Talcott Parsons. Como base de comprobación nos sirve, en el caso de Luhmann, la distinción de sistema/entorno y de diferenciación/denominación; en el caso de Parsons la distinción de acción/sistema; y en el caso de Habermas la distinción de acción/mundo de vida. Con ello, el proyecto aquí presentado se distingue de otros que proceden desde la perspectiva de la teoría de la unidad, como es por lo general el caso de la tradición filosófica occidental; o exclusivamente desde la perspectiva de "lo distinto", como se expresa, sobre todo, en el proyecto de la teoría de los sistemas sociales de Luhmann. En realidad, se debería decir "desde la perspectiva de la teoría de la diferenciación como distinción asimétrica", ya que la propuesta de Luhmann se eleva sobre la base de una distinción exclusivamente asimétrica (sistema y entorno). Por lo tanto, es precisamente esta forma distintiva, exclusivamente asimétrica, la que criticamos en relación con la propuesta de Luhmann.

La pretensión de este trabajo es ofrecer la base metodológica para una teoría de la sociedad, misma que ya se encuentra - por lo menos un primer tomo- terminada. Lo que a nivel de una teoría de la sociedad queremos demostrar es cómo - a imitación del discurso y contenido semántico de la obra de Immanuel Kant- es posible la SOCIEDAD como experiencia social. Desde la perspectiva de la metodología de las distinciones, se puede comprender la unidad de algo como la "unidad de la distinción de diferencia y diferenciación" desde la perspectiva de la teoría de la sociedad, como la "unidad de la distinción de COMUNCACION y de ACCTON".

Este trabajo intenta avanzar hacia las puertas de una teoría de la sociedad, en el sentido de que explica las condiciones de la posibilidad de la estructura social como la "unidad de la distinción de expectación y experiencia". La teoría real de la sociedad debería comenzar aquí y demostrár cómo la sociedad global (= SOCTEDAD) constituye como "unidad de la distinción de expectación y experiencia", aquellas estructuras que conforman la pluralidad de la experiencia social. En este sentido, esto puede nombrarse como lo ver-

asimétricas pueden constituir una diferencia simétrica; una diferencia simétrica puede formar una diferenciación asimétrica. Véase especialmente acerca de ello La lógica de las distinciones. 
daderamente deseable del presente proyecto metodológico. El nivel teórico de abstracción que aquí se elige es el de una metodología general, misma que designamos por motivos de brevedad como metodología de las distinciones. Naturalmente, esto no significa que nos estemos ocupando exclusivamente de una metodología general por el mero hecho de hacer metodología: dentro de cada capítulo se adopta el nivel de la teoría social y, con ello, sí se ofrece una teoría de la sociedad. Sin embargo, una versión más detallada a nivel de una teoría de la sociedad le hubiera quitado a este proyecto metodológico su homogeneidad textual, la cual es indispensable para aclarar el punto de partida teorico de la metodología de las distinciones. Además, el trabajo hubiera alcanzado un volumen tal que habría resultado contraproducente, en cuanto a la comprensión de los contextos.

En un segundo volumen - ya terminado- ofreceremos una teoría de la sociedad basada en los postulados metodológicos de las distinciones y en un tercer volumen - también ya terminado- se ofrecerán aspectos máś concretos de la teoria de la sociedad como son las dimensiones del género, del amor, de la técnica, de la dimensión espacial-virtual, de la dimensión sensorial-fotográfica, etcétera. 


\section{LA CUESTIÓN ESPECIAI}

...teoria es... el arte de bacer conclustones de amplio alcance, a partir de trivialidades. Y la sociología podría expresar su distancia bacia la sociedad, posiblemente menos por medio de la crítica precipitada y más bien por medio de la forma del asombro acerca de las trivialidades de las otros.

Niklas Luhmann ${ }^{1}$

...en realidad, todos los proyectos estaban inconclusos, dentro de la bistoria de la filosofía efectuada basta la actualidad.

Carl Friedrich von Weizsäcker ${ }^{2}$

¿Cómo es posible la SOCIEDAD? ¿Cómo es posible la SOCIEDAD como unidad? ¿Se puede describir del todo como unidad? Quien pregunta de esta manera se coloca en el centro del planteamiento filosófico de preguntas. Y en el sentido de la última cita esto puede significar solamente que debe permanecer como inconcluso nuestro intento de proporcionar una respuesta a la pregunta acerca de la unidad. No obstante, tenemos la opinión de que es útil observar lo que se puede ver, cuando uno se pregunta acerca de la posibilidad de la unidad social.

La SOCIEDAD actual es sociedad global, sin embargo, ha aumentado enormemente el grado de diferenciación regional. ¿Se puede hablar

1 Luhmann, 1992a, p. 73.

2 Weizsäcker, C.F.v., 1992a, p. 17. 
aún de una unidad social, con estas condiciones de diferenciamiento? ¿O se tiene uno que adaptar exclusivamente a las distinciones, siguiendo las tendencias actuales del tiempo? Georg Friedrich Wilhelm Hegel, ciertamente uno de los primeros teóricos de la distinción, partía de las distinciones, sin embargo, terminaba finalmente en la unidad de un espíritu absoluto. ${ }^{3}$ ¿Se podía evitar esto? Una cosa es segura: la unidad no se puede comprender sin la distinción, no obstante, a la inversa, sin la distinción permanece en la oscuridad la operación de la unidad. Por lo tanto, unidad y desigualdad están ligadas una a la otra y, en este sentido, forman, en sí, una unidad. Si uno no quiere terminar en la red de lo "solamente unitario" o "solamente distinto" debe formular la pregunta, en un nivel más alto de abstracción, más o menos de la siguiente manera: icómo es posible la unidad de lo distinto a unidad y distintividad? Transferida a la soCIEDAD, la misma pregunta dice entonces: ¿cómo es posible la SOCIEDAD como la unidad de lo distinto de COMUNICACIÓN y ACCIÓN? En el nivel de la experiencia fenomenológica de la cotidianidad, presuponemos como un hecho que ya existe la SOCIEDAD (=unidad) con sus distintas formas (=distinción) diferenciadas. La teoria debe explicar ahora el cómo es posible una forma semejante. En este sentido, el problema que debemos resolver aquí tiene una naturaleza reconstructiva: ¿Cómo es posible, generalmente como tal, algo que de por sí sucede?

Una pregunta semejante rompe, de acuerdo con su naturaleza, el estrecho marco de la materia, mismo que la sociología como disciplina acostumbra delimitar. Se puede designar como una pregunta social filosófica, con lo cual se traspasan necesariamente los limites venerables de la materia. Con la pregunta “ ¿cómo es posible la unidad de [...]?", ya hemos pisado la tierra de la filosofía clásica y nos encontramos en medio del complejo de problemas del eleático Parménides y del diálogo del Parménides de Platón. ${ }^{4}$ Después de un cambio

${ }^{3}$ También se podrían designar como teóricos de la distincion, Charles Darwin, Karl Marx y Martin Heidegger. Y con referencia a la actualidad, tambiến se pueden mencionar Jacques Derrida, Jean-François Lyotard, Maurice Merlau-Ponty y Gerd Brand.

- No por casualidad, C.F.v. Weizsäcker se ocupa, dentro del marco de su programa de una "unidad de la naturaleza", del eleático Parménides. Véase sobre todo: "Parmenides und die Graugans" (Weizsäcker, C.F.v., 1984, 21, pp. 441-465) y "Parmenides und die Quantentheorie". (Ibid., 22, pp. 466491). 
del paradigma, la ciencia trata, de acuerdo con Thomas S. Kuhn, sus problemas con el instrumental conceptual "normal", mismo que el paradigma pone a su disposición. Si se presenta una crisis, entonces alcanzan una prioridad frente a las reflexiones específicas de la materia, las ajenas a la materia, sobre todo las filosóficas: se abandona el nivel normal centrado en la materia de la solución de enigmas, en favor de preguntas filosóficas más generales. El problema de la unidad de la distinción de la SOCIEDAD requiere, por ello, "[...] del arte escalador de cimas de la filosofía [... $]^{n} .^{5}$ El trabajo aquí presentado parte de la pregunta determinada filosóficamente acerca de cómo algo es posible como "algo", y luego relaciona el nivel alcanzado de la discusión con las prerreflexiones teóricas sociales.

Que no se nos malinterprete: en el contexto de este trabajo no se ofrece ninguna teoria de la sociedad. Se trata, por asi decir, de observaciones preparatorias acerca de una futura teoría de la sociedad.

La sociedad se basa, de cualquier manera, en la experiencia, es decir! en un cierto tipo de experiencia, mismo que es determinado mediante la dimensión social del sentido. ${ }^{6}$ En el discurso de Kant, preguntamos, dentro de este contexto, acerca de las condiciones de la posibilidad de la experiencia SOCIAL. Un enfoque semejante del planteamiento de la pregunta involucra también a la dimensión del sentido tiempo, ya que la experiencia es un acontecimiento que tiene lugar dentro del tiempo. El concepto del presente se puede considerar como la forma elaborada del concepto de lo instantáneo o del acontecimiento. La distinción asimétrica de la diferenciactón y la distinción "simétrica de la diferencia, se suman a una "lógica de las distinciones", cuya conceptualidad principal se apoya en el supuesto presentista de que todo lo que sucede, siempre sucede en el instante o en el presente. Luego podemos demostrar que lo inmediato (lo "instantáneo") es posible solamente como un entrelazamiento entre diferencia y diferenciación; como un entrelazamiento que, transferido al nivel de la teoría social, corresponde al de COMUNICACIÓN y ACCIÓN. ${ }^{7}$ Entonces, la condición de la posibilidad de la experiencia i

'Weizsäcker, C.F.v., 1985, p. 23. CIÓN.

${ }^{6}$ Sea dicho de manera preventiva que esto implica comunicactón y AC-

'Martin Heidegger opina acerca de lo inmediato: " El ser es lo más cercano que existe, lo más inmediato. Por ello, se le confunde constantemente" (Heidegger, 1976a, p. 332). Lo "inmediato" en el sentido del "a priori material", 
SOCIAL, se presenta como una selección específica, referida a la acción, de un determinado tipo de comunicación. Formulado de otra manera: lo social como dimensión del sentido, es el producto de una estilizactón binaria del mundo, con la cual el acontecimiento coMUNICATIVo es procesado simétricamente, mientras que el acontecimiento de la ACCIÓN es procesado asimétricamente. Lo inmediato se distingue como alternativas preñadas de comunicación que capacitan para la acción. El proceso de DECISIón perteneciente a la acción, a su vez, transforma los respectivos sucesos en alternativas preñadas de comunicación, lo que conduce a un proceso interminable de ACCIÓN Y COMUNICACION Y ACCIÓN Y ... Sin embargo, la experiencia SOCIAL real se genera cuando determinadas secuencias de COMUNICACIÓN y ACCIÓN se repiten de tal manera que este proceso ocasiona la formación de estructuras en la forma de una distinción de expectación y experiencia.

Visto con detenimiento, es suficiente una sola repetición de una "información primaria", para constituir la distinción de expectación y experiencia. Véase capítulo I acerca de la forma.

Dentro de la distinción de expectación y experiencia se esconde aquello que se podría designar como memoria social. Sin una memoria social semejante, COMUNCACION y ACCIÓN no podrían constituir ninguna SOCIEDAD. No obstante, dejamos fuera de consideración este conjunto de problemas.

La experiencia de SOCIEDAD se basa, de acuerdo con esto, en dos complejos de sucesos: primero, en la binarización de la COMUNICACIÓN, con la finalidad de la explotación de la ACCIÓN; y en su reintegración en la COMUNICACIÓN por medio de la ACCIÓN. Por lo tanto, vis-

del mundo vivencial, tiene un peso importante, dentro de la filosofía de proveniencia fenomenologica. Gerd Brand formula: "Husserl ha descubierto el a priori material. Desde entonces, la tarea principal de la filosofía es la interpretación del antecedente conocimiento a priori enigmático de todo lo existente, esto quiere decir, la interpretación del a priori material preestablecido, y que se debe comprender en su existencia, como el desdoblamiento del mundo vivencial. Esto es tema desde Heidegger, Sartre, Merleau-Ponty hasta Gadamer. También es válido para pensadores como, Foucault y Wittgenstein, los cuales no elevan explícitamente el tema del mundo vivencial a la conciencia" (Brand, 1971, p. 112). Sin embargo, se debe destacar que la figura imaginativa de lo inmediato, se puede interpretar como "Epifanía del presente eterno", como el tema central del eleata Parménides y que, en este sentido, representa una tradición venerable. Véase Picht, 1969a, 2, pp. 37-86. 
to estrictamente, una "binarización del mundo social" siempre debe ser incorrecta dado que, en última instancia, todo está relacionado con todo, y esto no solamente en el ámbito de la dimensión social del sentido.

Ésta es la razón más profunda de que estén programados "desarrollos negativos" dentro de todos los procesos sociales. No puede haber un "cielo en la tierra", mientras que el hombre se ve obligado a actuar. Lo malo es, por así decir, la condición de la posibilidad de la ACCión. Todas las demás consecuencias negativas son derivaciones de este comportamiento objetivo.

Cualquier ACción es basalmente errónea ya que debe "binarizar" al mundo social, debe disponerlo en forma de alternativas o "dañarlo", para poder constituirse en general. Para ello requiere la cOMUNICACION, misma que la puede orientar hacia las "binaridades". Es así que, podemos formular, en apego a Nietzsche: la Accrón es aquel error sin el cual un determinado tipo de seres vivos no puede vivir socialmente. ${ }^{8}$ El procesamiento binario del mundo en la forma de las COMUNICACIONES o el aislamiento de DECISIONES sociales, es la condición de la posibilidad de la AĆCIÓN. Se puede decir ciertamente: quien actúa, siempre actúa erróneamente; no obstante, ya que también la omisión de la acción es - visto socialmente- una acción, no podemos actuar de otra manera que de modo "erróneo".

En este sentido, cualquier acción singular siempre es básicamente "errónea". Sin embargo, solamente dentro del "espacio binario" se puede ACTUAR sensatamente, en este contexto no importa si es de

Weizsäcker, C.F.v. formula, de manera similar, acerca del ámbito de la realidad interpretada desde la teoría cuántica: "No existen objetos o alternativas aislables del resto del mundo como Torrentes. La versión específicamente teórica cuántica de este contexto global no-causal, está representada en un conocido 'experimento de pensamientos' de Einstein, Podolsky y Rosen [...]. Actualmente, esta circunstancia se designa frecuentemente como 'holismo' de la teoría cuántica [...] Sin embargo, la aislabilidad de las decisiones es una condición previa del pensamiento conceptual. Por ello, el holismo significa que la realidad, vista estrictamente, no se puede describir con conceptos. No obstante, la teoría cuántica está estructurada, de acuerdo con la intención, estrictamente en forma conceptual" (Weizsäcker, C.F.v., 1991, p. 134). "Visto estrictamente, no hay alternativas separables y, por lo tanto, tampoco objetos separables. Sin embargo, nuestro proceso conceptual comienza con la suposición de alternativas y objetos separables, mismos que luego se manifiestan, dentro de la teoría cuántica relativista, como partículas." (Weizsäcker, C.F.v., 1985, p. 410). 
manera atribuida o "realmente" existente. Segundo, la experiencia de la SOCIEDAD se basa en el proceso de repetición de este proceso, con la consecuente generación de la distinción de expectación y experiencia.

Nos permitimos señalar - mediante una cita de C.F.v. Weizsäckerla correspondencia sustancial (o sea, no solamente asociativa) que existe en cuanto a naturaleza y SOCIEDAD:

La experiencia tiene lugar dentro del tiempo. Por lo tanto, el primer objeto de nuestro estudio son las formas lógicas, con las cuales nos referimos a los procesos dentro del tiempo. De allí, pasamos al concepto de la probabilidad, mismo que comprendemos de manera pronóstica. Concebimos la teoría cuántica como una teoría general de pronósticos de probabilidad acerca de alternativas decidibles singularmente de manera empírica [RJ (subrayado mío)]. Pretendemos deducir la tridimensionalidad del espacio y la teoría de la relatividad, a partir de la teoría cuántica interpretada de este modo. Por lo tanto, la física sería tan generalmente válida como la separabilidad de las alternativas, $o$ sea, como la descomponibilidad de nuestro conocimiento en preguntas si/no. En esta razón de su éxito, en su "carácter de poder", se encontraría, a la vez, el límite de su [de la física $R . J$ ] verdad.?

Lo que para C.F.v. Weizsäcker significa, dentro del marco de su lógica de afirmaciones temporales, pasado, presente y futuro, corresponde, dentro del marco de una lógica de las distinciones, a la diferenciación asimétrica, al supuesto presentista como inmediatez y a la diferencia simétrica (figura 5).

Relaciones de correspondencia entre la "logica de las distinciones"

y la "logica de afimaciones temporales":

Lógica de lias afirmaciones temporales:

pasado / presente / futuro

Lógica de las distinciones:

diferenciación / inmediatez / diferencia

Ibid., p. 24. 
Con ello, la pregunta acerca de las condiciones de posibilidad de la experiencią de la SOCIEDAD resulta una estilización posterior, tardía, de las operaciones comunicativas con carácter de acción, mismas que se condensan en la forma de estructuras del tiempo ( $=$ expectativas y experiencias), a través de la dimensión del tiempo, constituyendo simultáneamente a ésta misma. 


\section{I. ¿QUEE ESFORMA?}

Toda forma siempre se encuentra ya envejecida. Dado que ya fue creada, ya ba perecido cuando se llega a mostrar.

Ludwig Hohl'

Todas las formas consisten en combinaciones de alternativas simples, "uiltimas".

Carl Friedrich von Weizsäcker ${ }^{2}$

\section{LA LOGICA DE LO SOCIAL}

Acerca de la forma de la forma

1. Comprendemos como forma el aspecto espacial-estructural de combinación de las distinciones básicas - diferencia asimétrica y diferencia simétrica. Forma, representa por lo tanto el "aspecto extemporal" de la combinación de dichas distinciones.

Visto más en profundidad se trata del aspecto fáctico-pasado de la realidad cognoscitiva, que depende del sentido temporal ya que cualquier hecho se puede caracterizar como perfectista y como ya pasado: todo "hecho" es algo "ya hecho", algo que ya pasó y que por

${ }^{1}$ Hohl, 1984, p. 254.

2 Weizsäcker, C.F.v., 1984,16, p. 362.

${ }^{3}$ C.F.v. Weizsäcker formula acerca de ello: "Un hecho es una circunstancia presente, misma que se concibe como consecuencia o como expresión de un proceso antecedente. 'Hecho' es ciertamente en su origen lingüístico un participium perfecti, designa lo hecho, efectuado, pasado: 'perfectum' es solamente el 'hecho' realizado". (Ibid., 1992a, p. 220). 
ello se nos presenta como una forma $\mathrm{x}$ que podemos señalar como

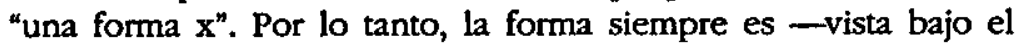
aspecto de la dimensión del tiempo- una forma "pasada" o "ya hecha", "ya formada", de otra manera no podría ser forma.

Si tratamos de observar el aspecto dinámico de toda forma como un "suceso a formarse", es decir observar algo que "está en vías de formarse, pero que todavía no se ha formado", entonces podemos hablar de autorreferencia. La dinámica autorreferencial es una dinámica futurista ya que representa aquella dinámica operacional que "engendrará forma" y, por lo tanto, está ligada al futuro desde el punto de vista de la dimensión del tiempo. Observar cualquier "formación" implica observar la dinámica de la autorreferencia, lo cual implica a su vez observar dinámicas que producen tautologías y paradojas. Pero en el sentido estricto de la palabra, las tautologías y las paradojas lo son solamente en el nivel de la dimensión espacialestructural que omite la dimensión temporal. Si a las tautologías y paradojas se les añade el aspecto temporal, entonces desaparecen. Un hecho es ciertamente paradójico cuando es - dentro de un espacio sin tiempo-idéntico a sí mismo. Si digo, por ejemplo, "miento", entonces la paradoja consiste en el hecho de que mi afirmación es idéntica a su contrario: si es cierto que miento, entonces no estoy mintiendo; sin embargo, si es falso que miento, entonces si estoy mintiendo... No obstante, esta operación requiere del tiempo, aunque sea un tiempo mínimo: "yo" ...y luego "miento". Tomando en cuenta la dimensión temporal se puede entender la contradicción porque "uno ve cómo la contradicción se forma temporalmente".

Luhmann (TsS) ${ }^{4}$ opina que toda forma es autorreferencia no pro-

${ }^{4}$ Recordamos nuevamente: TsS significa "teoría de los sistema sociales" (Niklas Luhmann), TkH significa "teoría de la acción comunicativa" (Jürgen Habermas), TaH significa "teoría del sistema general de la acción" (Talcott Parsons) y TgS significa la posición representada por nosotros de una "teoría de los sistemas de la sociedad". Estas abreviaturas tienen un valor pragmático: no se tiene que escribir el nombre completo de la teoría en cuestión. Además realzamos que no son los nombres los que tienen un papel importante, sino la teoría desarrollada por los autores y su diseño. Se trata más de la arquitectura de la teoria y menos de los autores que habían proyectado la teoría de este tipo. De esta manera, un autor se puede distanciar de su propia teoria y proponer una nueva, como lo muestra paradigmáticamente el ejemplo de Ludwig Wittgenstein. Con otras palabras: nos expresamos en favor de una distinción entre persona y obra, aunque es innegable que hay relaciones entre ambas. 
nunciada o autorreferencia "congelada". Tratemos de comprender esta circunstancia de manera más exacta: Forma es, vista estructuralmente y ubicada dentro de un espacio sin tiempo, simultáneamente autodistinción y autoidentidad; una afirmación que excluye el aspecto temporal de autorreferencia y que, por ello, ofrece un aspecto paradójico (y tautológico). ${ }^{6}$

Precisamente la expresión "simultáneamente" es una expresión que indica simetría, misma que representa a la dimensión espacial del sentido (como dimensión simétrica por excelencia). Podemos formular: las paradojas y tautología no son, por ello, otra cosa que operaciones dentro de la dimensión del tiempo que, trasladadas a la dimensión espacial del sentido, producen el aspecto paradójico o tautológico.

Por lo tanto es comprensible que Luhmann exprese que toda forma puede verse como "autorreferencia congelada" y, con ello, como algo "sin tiempo". Con Ludwig Hohl podemos repetir que toda forma siempre es forma "ya envejecida". Precisamente porque se puede

'La TsS (Luhmann, 1984e, p. 55) aplica en este contexto la distinción de forma/contexto, es una distinción que no nos parece suficientemente general y la cual indica también la cercanía al sistema del sentido arte. Se añade que nos importa no confundir forma con autorreferencia, lo que sugiere, por lo menos, la TsS.

6 "La comprensión de lo diferente como existencia simultánea constiuye al espacio", formula Josef Simon (1989, p. 98).Véase también, del mismo autor Spracbe und Raum. Pbilosopbische Untersucbungen zum Verbältnis zwiscben Wabrhett und Bestimtheit ion Satzen (1bid., 1969). Para prevenir una interpretación errónea: con el concepto del espacio utilizado por nosotros, no se trata de algo así como un concepto cuasi naturalista del espacio, sino de una distinción, la cual posibilita algo como "algo", en el sentido de que se pueden observar estos "algos" en el modo de la existencia simultánea diferente. El hecho de que se puede hablar, por ejemplo, de geometría no euclídica, implica ya la distinción del espacio como una distinción, misma que "presenta" lo diferente precisamente en la existencia simultánea.

7 C.F.v. Weizsäcker, aclara que la forma - como forma ya formada, pasada - no colisiona con el segundo teorema principal de la termodinámica: se puede demostrar "[...] que bajo condiciones apropiadas, los estados con más formas son también las más probables. Bajo estas condiciones, el crecimiento de la abundancia de formas no se opone a la irreversibilidad termodinámica, sino que es un caso particular de ella" (Weizsäcker, C.F.v. 1985, p. 174). El problema es ciertamente que se relaciona el aumento de la entropía con el desorden y, de esta manera, con la informidad: "La impresión de un conflicto entre el desarrollo de formas y el segundo teorema principal re- 
mostrar la forma -en caso contrario, no sería ciertamente ninguna forma-, está ya siempre creada, ha "pasado" de cierta manera, es decir, está formada. Las formas siempre ya están hechas, poseen un aspecto perfectista.

La relación problemática entre las dimensiones del sentido espacial y del sentido temporal se denota en el hecho de que "espacialidad" siempre expresa una simultaneidad o simetría, algo que se puede encontrar solamente dentro de un presente, dentro de un "ahora". Dicho de otra manera, la expresión temporal de la dimensión espacial parece ser el presente. Con ello, el presente es el lugar de transferencias o el "eje vial" para las distinciones adentro/afuera y antes/después, ya que el presente - como dimensión temporal-indica también la existencia presentista de la espacialidad (figura 6).

adentro/afuera $\leftarrow--\rightarrow$ presente $\leftarrow--\rightarrow$ antes/después $s^{8}$

2. La forma no es, por lo tanto, ni la Gestalt de una cosa o de un objeto ni la apariencia bonita o fea de algo o de alguien. La forma tampoco es la oposición entre materia y contenido ni entre ser y no-ser.

sulta [...] simplemente de una igualación generalmente no acertada, generalizada a partir de algunos ejemplos, de entropía con una cantidad de homogeneidad pobre en formas. La muerte por calor no sería, presuponiendo una temperatura lo suficientemente baja, una masa informe sino una reunión de esqueletos complicados." (Ibid., p. 178).

8 Weizsäcker, C.F.v. observa, no sin razón: "Utilizo la palabra 'presente' en el sentido de la presencia simultáneamente espacial y temporal [RJ]. (Weizsäcker, C.F.v., 1992a, p. 208, anotación). Se ha realzado el hecho de que aquello que Hegel llama "certeza sensual" o "conocimiento de lo inmediato", está estrechamente relacionado con el entramado mencionado de las dimensiones del sentido del espacio del tiempo: "El contenido concreto de la certeza sensual la hace aparecer inmediatamente como el conocimiento más rico e incluso como un conocimiento de riqueza infinita, para la cual no se puede encontrar ningún límite, tanto si nos salimos del espacio y del tiempo [RJ], dentro de los cuales se expande, como si tomamos un pedazo de esta abundancia y entramos mediante la división hacia dentro de los mismos" (Hegel, 1970, 3, p. 82). Heidegger opina, haciendo referencia al concepto de la "certeza sensual" de Hegel, que expresa "lo existente": "[...] expresa la presencia de lo existente [...]" (Heidegger, 1980, pp. 78-79), lo que significaría en la terminología de Hegel la "afirmación del ser". Se podría formular con Georg Picht: "La verdad del ser es la Epifanía del presente etemo." (Picht, 1969a, p. 2). 
Todo esto tiene que ver con la forma en el sentido mediato de la palabra, en el sentido en que la forma refleja la dimensión espacialestructural de la autorreferencia. Sin embargo, la materia que forma la forma está compuesta por distinciones, es decir por las distinciones básicas que son las diferenciassimétricasy las diferencias asimétricas, mismas que no ocupan ni una dimensión espacial, ni una dimensión temporal, ni una dimesión social: tienen un carácter objetivo-distintivo y representan, con ello, la dimensión objetiva de todo sentido. La formación de tales dimensiones como espacio, ${ }^{10}$ tiempo o socialidad, se genera dentro del contexto de las distinciones básicas operantes, o sea en el contexto de diferencia simétrica y diferencia asimétrica.

Dicho sea de paso: en el capítulo IV acerca de la observación, abordaremos el problema del surgimiento de las dimensiones del sentido,

' Como clásico acerca de ello, Gregory Bateson, quien describe la distinción del diferenciamiento: "¿Pero qué es una diferencia? La diferencia es un concepto muy especial y oscuro. Seguramente no es cosa ni suceso. Este pedazo de papel se distingue de la madera de este pupitre. Hay muchas diferencias entre ellos, en el color, la estructura, forma, etcétera. Sin embargo, si comenzamos a preguntar acerca de la localización [RJ] de esta diferencia, nos metemos en problemas. Aparentemente, la diferencia entre el papel y la madera no se encuentra en el papel; inequivocamente no se encuentra en la madera; seguramente no se encuentra en el espacio entre ellos y ciertamente no se encuentra en el tiempo entre ellos [...] Por lo tanto, una diferencia es algo abstracto." (Bateson, 1983, pp. 580-581). Y si las diferencias forman la base para la generación de información en el sentido de Bateson, entonces la información debe ser también algo muy abstracto. Se puede encontrar la diferencia como una forma determinada de distinción, es decir, como distinción asimétrica, solamente en el área de la dimensión objetiva del sentido. Se puede afirmar, en la medida en que cualquier forma cognoscitiva incluye objetividad en la forma de distinción, que ya la "vida simple" posee una dimensión objetiva del sentido.

${ }^{10}$ Por motivos hasta hoy inexplicables para nosotros, Luhmann deja fuera de consideración la dimensión espacial, a pesar de que su diferencia principal, es decir, la diferencia sistema/entomo, posee un carácter evidentemente espacial: no se puede comprender la diferencia entre sistema y entorno sin la diferencia adentro/afuera. No obstante, Luhmann "amalgama" la dimensión del sentido espacial con la dimesión objetiva, un procedimiento usual dentro de la tradición filos 6 fica europea.' Nuestra crítica: existe una diferencia fundamental entre algo "que es esto o aquello" (objetividad distintiva) o algo "que se encuentra aquí o aliá" (espacialidad). Por lo tanto, una confusión de la dimensión espacial con la dimensión objetiva no nos parece un procedimiento adecuado. 
o sea, también la constitución de la dimensión objetiva. Aquí debe ser suficiente la observación de que la puesta en práctica de operaciones pragmáticas desde la perspectiva de las distinciones, como las que se realizan en el contexto de este trabajo, requiere la dimensión objetiva de todo sentido como condición previa, ya que aquí se trata de bechos objetivas dentro del contexto de la ciencia. La justificación de la constitución de objetividad se ofrece en el contexto operativo: una operación -de cualquier tipo-debe tener lugar/no tener lugar. Precisamente debido a ello, se forma la distintividad ("esto y/o aquello"), la cual se puede considerar como la condición de la posibilidad de objetividad. Véase sobre todo el capítulo acèrca de operación y forma, más adelante.

Las diferencias simétrica y asimétrica -o sea las distinciones básicas - no se pueden localizar en un espacio (¿dónde está una diferencia?), ni determinar temporalmente (¿cuándo tiene lugar?), ni tampoco son decidibles socialmente (se les debe presuponer ciertamente, para tomar decisiones); se encuentran, por así decir, más allá del espacio, más allá del tiempo y más allá de lo decidible. Aun más, partimos de la suposición que sólo por medio de ellas se constituye algo así como el espacio (adentro/afuera), el tiempo (antes/después) y la socialidad (decidible/no decidible). La pregunta es naturalmente: ¿cómo?

La dimensión fenomenal del tiempo como suceso asimétrico siempre obliga a suponer un "primer comienzo", y la pregunta que resulta de ello regularmente, es entonces: ¿qué había antes del comienzo del mundo? La dimensión fenomenal del sentido del espacio como estado simétrico obliga, siempre por su parte, a suponer paralelismos o simultaneidades. La pregunta que surge a continuación es: ¿qué hay más allá del mundo? Ambas dimensiones se forman, sin embargo, mediante distinciones del tipo adentro/afuera o antes/después. Esto significa que una distinción es la base de una operación orientada espacial y/ otemporalmente, y noel "espacio" $y / o$ "el tiempo" mismo, independientemente de lo que esto significa. Para prevenir una interpretación errónea: no afirmamos que la dimensión del tiempo está formada en sí asimétricamente y la dimensión del espacio simétricamente. Solamente si se relacionan ambas dimensiones, es decir, si se combinan tiempo y espacio, resulta una relación entre simetría espacial y asimetría temporal, dado que en caso contrario no se podrian distinguir tiempo y espacio. Se debe suponer que cualquier dimensión del sentido en sí, 
se puede constituir solamente en la relación entre simetría y asimetria. Dejamos en suspenso este problema dificil.

3. No hay información si no hay distinción. ${ }^{11}$ No obstante, si no hay información, tampoco hay nada que se pueda observar, sobre lo que se pueda hablar o escribir, ni siquiera la negación. Si uno quiere negar, entonces se debe distinguir primero aquello que se quiere negar. Por ello, a cualquier operación de negación le antecede la operación de la distinción. ${ }^{12}$ Por lo tanto y resumiendo: las distinciones forman la materia primordial de la cual está compuesto nuestro mundo cog:noscitivo.

Partimos de la diferencia asimétrica entre un mundo cognoscitivo y un mundo real, o sea una realidad cognoscitiva y una realidad real. En este sentido y con referencia al sistema nervioso, el neurólogo alemán Gerhard Roth opina: "Debemos partir del hecho de que nuestra percepción es una percepción producida por el cerebro y de que el mundo en el cual vivimos es la realidad del cerebro y no la realidad del mundo 'objetivo', dentro del cual —así lo creemos- - existe el organismo de nuestro cerebro, y también de que no podemos tras-

"Como información comprendemos la "primera vez" como suceso de novedad o sorpresa. Sin embargo, "la primera vez" puede cobrar realidad solamente sobre la base de la confimación. Por medio de la confirmación se modifica la probabilidad de expectación para la misma información. Ya no es la misma que antes de la "primera información" (Weizsäcker, E.v., 1974, p. 89). La confirmación presupone, por su lado, estructura. Por ello, podemos decir con $E$. von Weizsäcker que apenas la "segunda vez de una primera vez" produce un valor informativo (Ibid., p. 95). El proceso de la repetición (una repetición singular ya deberia ser suficiente), mismo que constituye la estructura primeramente, es una operación que puede tener lugar sollo después de la formación de forma. Sólo el proceso de repetición dentro de una combinación de diferencia y diferenciación puede formar la estructura y, con ello, poner a disposición las condiciones previas para la producción de información como "primera vez" o novedad. Trataremos la información explicitamente dentro del marco de la distinción entre información y sentido. Aquí es suficiente decir que la información es una forma elaborada de la forma fundamental "diferencia/diferenciacion", y, con ello, la presupone.

${ }^{12}$ Por lo tanto, la TsS afirma con razón dentro de este contexto: "Con George Spencer Brown se puede demostrar que se posibilita la operación de la negación mediante la utilización de una diferenciación (y no a la inversa, como debería suponer un lógico!). Si uno quiere negar, se debe poder distinguir primero aquello que se quiere negar." (Luhmann, 1990a, p. 39). 
cender esta realidad con nuestra acción, ya que percibimos nuestra propia acción solamente dentro de esta realidad, como todo lo de-

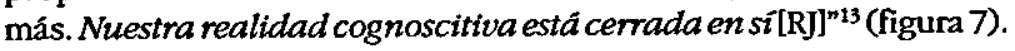

\section{Modalidad de lo real:}

Realidad:

Conocimiento: realidad cognoscitiva / realidad real reconocible /no reconocible

Por lo tanto, lo que realmente podemos conocer es lo que aquí denominamos la "realidad cognoscitiva". La "realidad real" es al parecer para nosotros algo a lo que no tenemos acceso directo, algo a lo que sólo tenemos acceso mediatizado por medio de la "realidad cognoscitiva". Y esta realidad cognoscitiva es reconocida por nosotros solamente por medio de distinciones, que son las que nos proporcionan la "materia prima" necesaria para conocerla: las informaciones. Resumiendo: entramos en contacto con la realidad real indirectamente por medio de la realidad cognoscitiva que se basa en distinciones básicas - diferencia simétrica y diferencia asimétrica. Estas distinciones son necesarias ya que sólo a partir de distinciones podemos obtener información. Sin distinción no hay información. Sin información no hay nada que podamos valorar. Es más, no existe ni la "nada", ya que para poder entender lo que es "nada" tenemos. que usar la distinción de "nada/algo", etcétera.

Ahora bién, ¿cuál podría ser el origen de las distinciones? En este lugar queremos intercalar una breve reflexión acerca del problema del origen de las distinciones y su integración a la COMUNICACION, una circunstancia que abordaremos nuevamente más adelante.

4. Se debe partir del hecho de que un "sistema de distinciones" posee una forma específica: consta de las dos distinciones básicas llamadas "diferencia simétrica" y "diferencia asimétrica". Un "sistema" de esta índole COMUNICA a través de sus "diferencias", las cuales se interconectan entre sí ya que cada diferencia consta de dos elementos.

${ }^{13}$ Roth, 1986, p. 172. 
Por lo tanto, todo "sistema de distinciones" consta de por lo menos cuatro elementos: dos por cada diferencia. La relación es entonces entre una distinción simétrica y una distinción asimétrica.

Ambas formas distintivas, la simétrica y la asimétrica, se designan aquí como distinciones. Esto tiene la ventaja pragmática de que uno se puede referir a ellas de manera general. Sin embargo, la unidad de una distinción consiste en un entrelazamiento entre diferencia simétrica y diferencia asimétrica. Por ello, la forma de toda distinción no está dada como simétrica ni como asimétrica. Con otras palabras, no es posible que una diferencia simétrica o una diferencia asimétrica se presenten solas por si mismas. Formulado de otra manera: la unidad de una distinción consiste en la distinción entre diferencia simétrica y diferencia asimétrica. Si ahora tratamos de observar la forma de todo "sistema de distinciones" entonces podemos decir que se compone de una distinción simétrica y de una distinción asimétrica observada desde el punto de vista de una diferencia simétrica, no desde el punto de vista de una diferencia asimétrica - lo cual implica a su vez una diferencia asimétrica. La asimetría de la observación reside en que observamos con ayuda de una distinción simétrica, no desde el punto de vista de una distinción asimétrica. Estas reflexiones no son tan fáciles de comprender. Sin embargo, esperamos que estas relaciones que constituyen la forma de toda distinción se perfilen más claramente, para el lector, con el avance del análisis (figura 8).

No: diferencia asimétrica $\rightarrow$ Si: diferencia simétrica entre: \begin{tabular}{l}
$\begin{array}{l}\text { diferencia simétrica } \\
y \text { (simetría) } \\
\text { diferencia asimétrica } \\
y \text { (asimetría) }\end{array}$ \\
\hline
\end{tabular}

Ahora bien, el "mundo" no representa ninguna distinción, el "mundo" no es ninguna información. ${ }^{14} \mathrm{El}$ concepto del mundo aquí empleado, es el otro lado de toda distinción, es decir, el mundo es nodistinción, algo que puede tener lugar solamente sobre la base de una distinción adicional, con base en la distinción entre distinción y

${ }^{14}$ Luhmann/Fuchs, 1989, p. 7. 
no-distinción. El concepto de mundo aquí empleado es una no-distinción. Si se quiere describir este estado, entonces se debe decir: el mundo es aquello que es; y al mismo tiempo no es aquello que no es. Las informaciones "entran" al mundo a través de las distinciones.

En palabras de Gregory Bateson: la información tiene por efecto una diferencia, misma que conforma entonces una diferencia. Por lo demás, debe tener lugar una diferencia doble, para que se genere una diferencia, es una circunstancia que intentamos registrar con la ayuda de dos distinciones, mismas que designamos como "diferencia asimétrica" y "diferencia simétrica". Tan sólo una diferencia, como un suceso absolutamente solo, es como "palmear con una mano": inconcebible, sin sentido, no localizable.

Ahora bien, si la distinción debe ser la primera operación, con la cual empieza todo, ¿por medio de qué se distingue esta primera distinción?, ¿cómo se genera una primera distinción? Seguramente mediante algo que no es distinción, dado que solamente de esta manera se puede observar la distinción como distinción. No obstante, ¿qué significa una "no-distinción"? Una "no-distinción" está dada cuando procesan máximo tres elementos/sucesos basales, de tal manera que no se puede formar ninguna diferencia simétrica ni tampoco ninguna diferencia asimétrica. ${ }^{15}$ Una distinción en el sentido aquí utilizado, se puede generar sólo sobre la base de una relación tetrádica de elementos que implica por lo menos dos diferencias: la simétrica y la asimétrica. Por ello, una "primera" distinción se puede distinguir solamente sobre la base de una no-distinción, misma que por su parte, se puede distinguir negativamente como una relación entre menos de tres elementos. Con ello, la "primera" distinción se distingue mediante la referencia con su versión negativa, lo que significa que tampoco una "primera" distinción puede escapar a la operación de la distinción (figura 9).

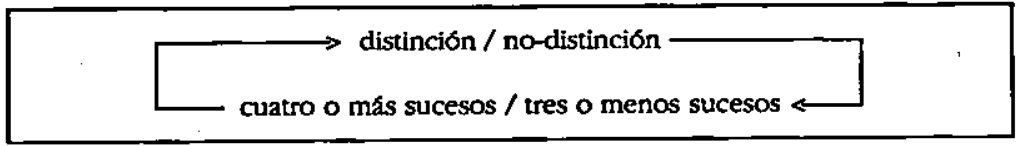

${ }^{15}$ La pregunta acerca de una "no-distinción" se puede contestar solamente a través de la exploración del pensamiento de que puede haber "algo" solamente sobre la base de, por lo menos, cuatro elementos/sucesos. No podemos saber, en última instancia, lo que realmente es una no-distinción, ya que podemos determinar la forma de una no-distinción solamente sobre la base de distinciones. 
5. Supongamos que disponemos solamente de tres sucesos de "algo", con lo cual queremos designar semánticamente este algo como espacio. Podemos representar este algo de la siguiente manera (figura 10).

adentro $\longleftrightarrow$ límite $\longleftrightarrow$ afuera

Es seguro que en este caso se requieren los tres elementos/sucesos ("adentro", "límite", "afuera"), para generar el algo (espacialidad) en cuestión: si se omitiera sólo uno de los tres elementos, se colapsaría el algo arriba mencionado. Sin embargo, ¿cómo sabemos que este algo procesa la espacialidad y no, por ejemplo, el tiempo (antes/después), sexo (hombre/mujer) u ontología (ser/nada)? Preguntado de otra manera: ¿quién o qué define al algo en cuestión como espacialidad? Esto puede tener lugar solamente a través de un segundo observador $o$, lo que es lo mismo, mediante una segunda distinción, misma que sea capaz de distinguir entre "algo" y "algo diferente". Se nota: una distinción sola no es suficiente, aunque conste de tres elementos/sucesos, como para poner en marcha un proceso de identificación cognoscitiva. Debe involucrarse un cuarto elemento/suceso, mismo que distingue la diferencia de otra diferencia y, con ello, la identifica como algo determinado. Con ello está dicho también que el proceso del distinguir es un acontecimiento comunicativo, ${ }^{16}$ dado que se requiere por lo menos, dos distinciones (simetría y asimetría lo que implica cuatro elementos/sucesos: dos por cada lado), para poner en marcha el proceso de distinguir.

6. Si en nuestra observación de una "unidad distintiva", de la "forma de toda distinción", dejamos fuera de consideración la dimensión del tiempo y, con ello, la historia de su relacionamiento tetrádico, entonces el resultado es una tautologia o una paradoja.

${ }^{16}$ Es algo que la que TsS pasa totalmente por alto, cuando efectúa el "primer comienzo" con la ayuda de una sola distinción, es decir, de una diferenciación, misma que puede procesar solamente de manera estrictamente asimétrica. Por lo tanto, opinamos que la TsS comienza, en contra de su propia intención, de manera monológica: es un comienzo de constitución realmente irrealista de SOCIEDAD como comunicación. 
Esto demuestra, por lo demás, que las tautologías y las paradojas se generan debido al hecho de que en el surgimiento de "algo" no se toma en consideración la dimensión del tiempo. Este problema también muestra la "imposibilidad" de transmitir el tiempo en forma discursiva. Cuando mucho, se puede decir: "Ahora, mi argumento se ve de esta manera, jhace diez minutos tenía en mente otro aspecto!" Dado que el tiempo está relacionado estrechamente con el movimiento, se podria hacer la pregunta aparentemente simple: ¿cómo se puede representar el movimiento en el nivel discursivo? ${ }^{7}$

17 Por lo demás, es un problema esencial de la comuncación que solamente puede evocar la dimensión del tiempo, sin embargo, no la puede representar realmente. En este contexto anota Konrad Lorenz: "Es más que probable que el pensamiento actual del hombre se ha originado por estas operaciones desprendidas de lo motriz, dentro del espacio 'imaginario' e incluso que también para nuestros más altos y complejos actos del pensamiento es indispensable esta funcion original. No logro encontrar ninguna forma del pensamiento que estuviera independiente del modelo central del espacio. El lenguaje nos confirma en la concepción de que todo pensamiento es espacial, en cuanto a su origen." (Jorenz, 1974b, p. 230). Véase también Bollnow, 1984. Esto significaría que hablar y escribir sobre fenómenos del tiempo, se puede lograr solamente por medio de metáforas espaciales. Sin embargo, se debe observar que precisamente este pensamiento posee una dimensión no-espacial y, con ello, es relativamente independiente del lenguaje verbal o escrito: no se puede localizar el pensamiento, más que en "el pensamiento mismo". Hannah Arendt observa: "Lo 'esencial' del pensar es '[...] lo en todas partes aplicable', y éste 'en todas partes', mismo que es responsable de la importancia particular del pensamiento, es, hablando espacialmente, un 'en ninguna parte'. Visto estrictamente, el yo pensante, mismo que se mueve con universales, con esencias invisibles, no está en ninguna parte; está desterrado en un sentido muy intencionado [...]". (Arendt, 1979, p. 195). Se debe observar que no queremos decir imaginar cuando hablamos de pensar, sino que nos referimos al proceso de la constitución de pensamientos. la imaginación está estrechamente relacionada con la percepción corporal: es la forma reflexiva de la percepción, mientras que se puede concebir la "idea" como la forma reflexiva de los pensamientos. Se debe aprender a ver el hecho de que aquí existe generalmente una distinción. Se podría hablar, a continuación de Immanuel Kant, de una concepción inmaterial y una material, aunque no consideramos como muy lograda esta versión conceptual: "Es muy distinta la idea que el alma del hombre tiene de sí misma como de un espíritu, por medio de una concepción inmaterial, observándose en su relación frente a seres de una naturaleza similar, dado que su conciencia se imagina a sí misma como un hombre, mediante una imagen, la cual tiene su origen en la impresión de los organos corporales y la cual no se concibe en una relación frente a otras cosas materiales." (Kant, 1977a 4, pp. 946-947 [A48/A49]). 
La observación de la forma como "unidad de una distinción" que incluye las distinciones básicas "diferencia simétrica" y "diferencia asimétrica" conduce al hecho de que estamos obligados a observar; o al haberse-generado (experiencia) o aún-no-haberse-generado (expectación-nunca se encuentra generándose, esta forma del tiempo no se puede representar discursivamente, sólo se puede evocar). Cuando está aún-no-generada o aún-no-formada, nos referimos, a pesar de ello, a ella, ya que hablamos sobre ella, aunque todavía no "está formada". Hablamos por lo tanto de una forma, misma que aún no "está formada", y afirmamos "que es una forma, porque será una forma", con lo cual producimos una paradoja. Afirmamos algo que "ya es" aunque obviamente tadavía "no ès".

Cuando la forma como "unidad de una distinción" se ha generado $y$, con ello, formado, entonces afirmamos que "ahora es una forma". Con esta afirmación sencilla repetimos solamente su estado actual, dado que nos pronunciamos en el sentido de que "ahora es una forma, porque ahora es una forma". Con ello, llegamos a una tautología.

Más adelante retomaremos el problema de la formación de unidad y de conversión de la mencionada unidad en una tautología y en paradoja. Aquí colocamos, por lo pronto, el problema arriba insinuado de una distinción primaria: una rejilla de calado grueso, para marcar provisionalmente el contexto dentro del cual tienen lugar las distinciones. Las tautologías y paradojas surgen, por lo tanto, primero debido al hecho de que se deja fuera de consideración la dimensión del tiempo y segundo, por medio del intento de querer comenzar de manera monólógica con el comienzo. No obstante, si uno está consciente de que cualquier proceso de identificación, cualquier "unidad de lo diverso", se basa en un relacionamiento tetrádico de elementos, entonces se puede iniciar sin tautologías y paradojas con el comienzo. Ciertamente, ni la sociedad ni la ciencia están libres de paradojas y tautologías debido al hecho de que el lenguaje ofrece la posibilidad de representar procesos de temporalización en una forma "sin tiempo". ${ }^{18}$ A ello se añade que la semántica del "comienzo"

${ }^{18}$ Ciertamente es bastante raro que utilicemos semánticamente conceptos temporales como "más tarde" o "antes" en una forma sin tiempo: solamente "decimos" "ayer" o "mañana". Por el otro lado, la comunICACIÓN verbal/escrita nos ofrece mediante su estructura secuencial la posibilidad de distinguir entre aquello que hemos dicho hace una hora y aquello que diremos posiblemente, después de una hora. Con ello, se puede invertir la dirección de la secuencia COMUNiCATIVA (de la COMUNICACIÓN yerbal o escrita): hemos dicho 
pone a disposición una semántica que reduce fuertemente la complejidad y que precisamente por ello es muy útil. Expresiones como "empezar de nuevo", "marcar un comienzo", "recién nacido", "el día primero del mes" cortan todo aquello que haya sucedido anteriormente $y$, con ello, crean un inmenso margen de acción COMUNCATIva. Aun dentro del sistema de la ciencia uno no se escapa, como se puede observar en el caso de Luhmann, a la fascinación del "comienzo de un comienzo", mismo que se pretende controlar, en última instancia, por medio del manejo de paradojas y tautologias.

El comenzar con un supuesto tetrâdico es menos excitante que el comenzar con el presupuesto de un comienzo primario. En cambio, el supuesto tetrádico es, de acuerdo con nuestra opinión, lógicamente más consistente y, sobre todo, más comunicatrvo que el comienzo primario, mismo que opera monológicamente y que no se puede inaugurar de otra manera que no sea monologica. Realzamos expresamente que no ha sido nuestra intención evitar las paradojas y tautologías. Este resultado se basa en el supuesto tetrádico de toda forma, supuesto que convierte en superfluas las operaciones de paradojizacion y tautologización. Cabe notar que ninguna sOCIEDAD puede arreglárselas sin supuestos primarios. Por ello las paradojas y las tautologías ya están preprogramadas de cierta manera y no se pueden evitar. Sin embargo, de acuerdo con nuestra opinión, se puede indicar la razón de su surgimiento: el inevitable comienzo de algo como "comienzo primario", mismo que se puede reconstruir mediante una observación de segundo grado (una operación reflexiva): el resultado de dicha reconstrucción es entonces un "comienzo primario tetrádico" libre de paradojas y tautologías. Pero vale hacer hincapié en que una observación de segundo grado, es por otra parte y a un nivel diferente de abstracción, también una observación "sencilla" y, con ello, también una observación de primer grado, con lo que el problema no puede encontrar "por su propia naturaleza" una solución definitiva.

7. Ahora regresamos a la temática más estrecha de la forma de la forma y preguntamos: ¿cómo sucede la forma? $\mathrm{El}$ hecho de que actualmente estemos un poco mejor informados acerca del procesa-

precisamente aquello que hemos dicho. Lo podemos revisar ciertamente, sin embargo, lo hemos dicho de la manera en que lo hemos dicho. Como operación es toda comunicación no-invertible, como modalidad de observación invertible. 
miento (lógico-temporal) de las diferenciaciones, se debe agradecer sobre todo a Georg Spencer Brown con su trabajo Laws of Form, mismo que fue publicado en el año 1969 bajo un nombre y por una editorial no localizable. ${ }^{19}$ Ya al inicio de sus explicaciones, Spencer Brown define toda diferencia asimétrica como forma: "We take [...] the form of distinction for the form.", ya que lo que él denomina "distinction" posee la forma de una "distinción asimétrica" ${ }^{20}{ }^{20}$ Este cálculo no estacionario, dado que incluye al tiempo, no es particularmente relevante para nosotros, ya que dentro de este contexto no queremos desarrollar ningún cálculo lógico. Por ello, no planeamos hacer un axioma lógico de los sistemas sociales, las áreas sociales como sistemas o áreas "lógicas probabilísticas". Nuestra opinión es que no se puede axiomatizar una teoría general como la teoría de las distinciones que presentamos aquí. Se puede intentar ciertamente colocar en la "punta" una serie de teoremas, de acuerdo con el modelo de la matemática deductiva, y deducir luego la teoría restante con ayuda de la matemática. Este método fue practicado ya por Euclides como geometria y tuvo una gran influencia sobre las ciencias naturales, especialmente sobre la física, durante milenios. Dejando fuera de consideración el descubrimiento de la geometría no-euclidiana, misma que cuestiona una aceptación de axiomas indudable y obviamente evidente, sabemos desde Kurt Gödel, “[...] que no existe ningún sistema de axiomas para la cantidad de afirmaciones de validez general, dentro de cualquier teoría matemática lo suficientemente capaz de expresión (es decir, dicho de manera abreviada, una teoría que comprenda por lo menos la aritmética) [...]". ${ }^{21}$ Esto significa: se pueden

19 "La obra de George Spencer Brown decisiva para estas preguntas Inos referimos a las bases logicas de la autorreferencia, mismas que interpretamos (-TgS) como entramado de las distinciones 'diferencia' y 'diferenciación' con Ia ayuda de la dimensión del tiempo RJ [...] ha permanecido casi desconocida. Una renombrada editorial alemana no se ha podido decidir a traducir su libro, debido a la ausencia de recomendaciones por parte de filósofos. En la biblioteca de las universidades se busca en vano su texto fundamental, aunque existe, dado que Spencer Brown evita escribir su nombre con un guión y, con ello, logra que su publicación se maneje de manera desacertada bajo el nombre muy común de Brown. La reseña más importante fue publicada en un catálogo del comercio por mayoreo de mercancías posiblemente invendibles." (Luhmann, 1988a, p. 47). Por lo demás, la reseña mencionada fue redactada por Heinz von Foerster.

${ }^{20}$ Spencer Brown, 1969, p. 1.

${ }^{21}$ Görnitz, 1992, p. 72. 
axiomatizar solamente teorjas parciales, pero una teoría con pretenciones universales como el proyecto metodologia de las distinciones aquí ofrecido, no es accesible a una axiomatización semejante.

La integración de la dimensión del tiempo en el cálculo de Spencer Brown no significa que el tiempo se represente en alguna forma "como tiempo", sino solamente que se debe aceptar que un comienzo lógico puede empezar de manera preñada de paradojas, porque en el transcurso del tiempo la paradoja inicial se puede resolver lógicamente en forma exitosa. Ya hemos realzado el hecho de que las paradojas y las tautologías se convierten en un problema de COMUNICACIÓN, en el momento en que se abstraen de la dimensión del tiempo y, por ello, una "identidad de algo" se comunica con su contrario (= paradoja) o consigo mismo ( - tautologia). La no-integración del proceso temporal conduce a algo que, por lo pronto, se transmite en una forma sin tiempo. Sin embargo, ¿se puede procesar la operación de la identidad de otra manera que en una forma atemporal? Existen dos respuestas posibles para ello: si toda identidad se concibe como distinción, entonces toda identidad adapta una forma "sin tiempo", una forma atemporal; si toda identidad, por otra parte, se concibe como operación, se puede demostrar que toda identidad implica también al tiempo y que incluso "consume" tiempo. Por lo tanto y de manera momentánea: Spencer Brown sólo integra a medias la dimensión del tiempo en su cálculo. Para aquel que se interesa solamente por su cálculo lógico probablemente esta "falta del tiempo" no es necesariamente relevante. Pero a nivel de las ciencias sociales, en especial a nivel de una teoría de la sociedad, es sumamente importante.

En lugar de ello, nos queremos ocupar de las "estructuras lógicas de la superficie", analógicamente a la lingüística y apoyándonos en Jon Elster, 22 para poder determinar con más consistencia y universalidad de lo normal las herramientas para una teoría de la sociedad.

Aquí pensamos sobre todo en el hecho de que se trata de la SOCIEDAD con, por lo menos, cinco tipos de sistemas del sentido y, con ello, de cuatro estilos de expectación y experiencia: el social, el personal, el afectivo/corporal y el de los sentidos sensoriales. Recordemos que Luhmann, por ejemplo, parte de solo dos tipos de sistemas: el sistema social y el sistema psíquico. Este concepto de sociedad nuestro implica

${ }^{23}$ Elster, 1981a, p. 27. 
un nivel de abstracción muy alto generalmente. Es más, las complicaciones para una teoría de la sociedad de esta índole son enormes ipero se puede manejar la circunstancia de manera más simple, por así decir, más ilustrativa o con más cercanía a la vida cotidiana? Creemos poder decir aquí decididamente que no, a no ser que se simplificara el hecho SOCIEDAD de manera indebida.

A largo plazo, perseguimos la meta de poder elaborar algo así como una unidad de la pluriformidad de la SOCIEDAD; es algo que podemos bosquejar aquí solamente en forma rudimentaria. ${ }^{23}$ El trabajo de Georg Spencer Brown ocupa un lugar especial dentro de este contexto.

8. Bajo el aspecto de una lógica de las distinciones consideramos eminente el trabajo de Spencer Brown para la empresa de una teoría social cuya tarea es presentar la SOcIEDAD como una relación de distinciones en la dimensión social del sentido.

Como sOciedaD comprendemos aquel sistema que procesa todos los tipos de comunicación: formas corporales, afectivas, sociales y personales de comunicación. Con ello, la socieDAD es el sistema comunicativo más amplio, en general. Por ello distinguimos la sociedad como una forma regional de comunicación: la sociedad inglesa, israelita, salvadoreña, argentina, etc. La SOCIEDAD tiene un carácter universalista, la SOCIEDAD tiene uno particularista, la sOcjEDAD es la sociedad global, mientras que la SOCIEDAD es una sociedad nacional.

De una "lógica de las distinciones" y, con ello, del procesamiento particular de distinciones semejantes, depende precisamente la teoría de los sistemas de Luhmann con su diferenciación principal entre

${ }^{23}$ Recordamos aquí el programa de C.F.v.Weizsäcker, quien persigue la meta de poder demostrar algo así como una "unidad de la naturaleza". Véase su obra programática Die Einbeit der Natur Studien (1984). También el trabajo "Die Einheit der Physik als konstruktive Aufgabe" (Weizsäcker, C.F.v, 1970, pp. 372-388). Creemos que se puede demostrar algo similar en el ámbito de la sociedad, con lo cual una meta esencial de nuestro trabajo es demostrar una posibilidad semejante. En este sentido, nuestro trabajo es una tarea esencialmente constructiva, si no es que reconstructiva, ya que construimos sobre lo ya realizado, con la intención de reunirlo en una unidad posible. 
sistema y entorno y su indicación de relacionar cualquier circunstancia con estas distinciones. Por ello, se puede comprender la teoría de los sistemas de Luhmann como una forma especial de la aplicación de una "lógica de las distinciones". La arquitectura de su teoría se basa en la distinción principal de sistema/entorno, o sea, en una forma "espacial" de distinción. Solamente dentro del contexto de una "logica de las distinciones", se puede preguntar acerca de qué tan grandes - visto desde la arquitectura de la teoría- pueden ser las pérdidas o beneficios de una teoría social, misma que se afirma bajo las condiciones de la teoría de los sistemas, es decir, aplicando categorías "espaciales" de distinción. Esta pregunta se puede generalizar naturalmente $y$, con ello, aplicar a cualquier teoría de la sociedad.

9. Desde la perspectiva de la teoría social; partimos del siguiente supuesto: si es cierto que cualquier teoría social se organiza alrededor de una distinción-guía que dispone a la sociEDAD de una manera cognoscitiva específica, entonces debería ser de interés particular averiguar cuál teoría social emplea cuál distinción (guia), para poder observar su objeto SOcIEDAD. En este sentido, se podría formular de forma personal, por ejemplo: "Dime qué distinción-guía utiliza tu teoría social y te diré a cuál sOCIEDAD observa tu teoría social."

10. Sobre la base de un supuesto de este tipo, se podría observar la teoría social como trabajo ordenador de la circunstancia SOCIEDAD. Con la selección de una determinada distinción-guía teórico-social - por ejemplo, aquélla de sistema/entorno (N. Luhmann), mundo vivencial/sistema (J. Habermas), sistema/acción (T. Parsons), socie$\mathrm{dad} /$ comunidad, solidaridad mecánica/orgánica, estatus/contrato, grupos formales/informales, relaciones primarias/secundarias, dominio racional/burocrático, gremios sacros/seculares, sociedad militar/industrial, estamento/clase, sociedad tradicional/moderna o era moderna/postmoderna- se dispondría de un instrumento de observación cognoscitivo que no se debe subestimar y con el cual se podrian ubicar tanto las posibilidades como los límites de cualquier teoría social. ${ }^{24}$

${ }^{24}$ Se retomaron algunas de estas formaciones de pares de conceptos de Habermas, 1969a, pp. 60-61. En este lugar, Habermas relativiza el catálogo 
11. Una primera pregunta que se podría plantear en relación con las distinctones-guía teórico-sociales tiene una estructura doble y dice: ¿qué tan indeterminada puede ser una distinción principal de este tipo, por un lado, como para ser aún capaz de discriminar?; ¿qué tan determinada debe ser, por el otro lado, como para poder reaccionar adecuadamente de manera sensible a los problemas del presente? Aquí se trata en primer lugar de la relación pragmática entre determinación e indeterminación. Una segunda pregunta posible se refiere a su consistencia lógico-semántica: ¿qué tan lógicamente consistente o inconsistentemente puede estar construida una distinción-guía de este tipo? De esta manera, una distinción-guía como aquélla de ser/no ser es lógicamente consistente, no obstante, está concebida demasiado indeterminadamente para las circunstancias actuales. La arbitrariedad es entonces el precio de una indeterminación demasiado grande. Por el otro lado, se pueden integrar numerosas áreas heterogéneas con una distinción-guía como la de mundo vivencial/sistema, no porque ésta estuviera concebida de manera suficientemente determinada, sino porque contiene una porción considerable de inconsistencia lógica. ${ }^{25}$ Suponemos, por ello, que la productividad de esta distinción-guía no proviene tanto de su determinación, sino de su inconsistencia lógica.

Como "consistencia lógica" comprendemos en primer lugar una utilización categorial lo más inequívoca posible de las distinciones, mismas que deberían permanecer sin contradicción entre ellas (teoría de la coherencia de la verdad). Esto no excluye naturalmente el hecho de que una utilización categorial inequívoca pueda consistir en dejar explícitamente sin modificación la ambiguledad de una distinción. Sin embargo, en este caso, se debe entonces pretender explícitamente esta ambigüedad. Segundo, a ello pertenece la "consistencia semántica" en el sentido de C.F.v. Weizsäcker: la teoría más nueva debe contener también la más antigua en los aspectos esenciales, en el sentido de que

de Parsons de las orientaciones de valores, con el argumento de que no agotan todas las decisiones sociales fundamentales, sino que están confeccionadas solamente con miras al análisis de un proceso histórico, es decir, con miras a la transición de la SOCIEDAD tradicional hacia la moderna.

${ }^{25}$ El "sistema" ciertamente no se puede concebir sin "entorno", sin embargo, el mundo vivencial no es equivalente con el "entomo". Véase, entre otros, acerca de la utilización problemática del concepto mundo vivencial por parte de la TkH, Matthiesen, 1985, pp. 32 y ss. y Kiss, 1987, pp. 63 y ss. 
demuestre que la anterior esté errónea y que, empero, sirve como caso límite o acercamiento local de la teoría más nueva. ${ }^{26}$

Una distinción-guía como la de sistema/entorno posee una consistencia lógica ejemplar, sin embargo, supuestamente está demasiado determinada debido a su forma orientada hacia la dimensión del espacio (distinción de adentro/afuera), como para poder comprender la circunstancia SOCIEDAD. Esto se expresa sobre todo con el hecho de que no puede tomar en consideración las diferentes formas autopoiéticas de la COMUNICACIÓN. ${ }^{27}$

La discusión entre Wil Martens (1992) y N. Luhmann (1992) acerca del problema de la emergencia, hace evidente que está presente un problema serio para la teoría de los sistemas y, sobre todo, para la TsS. Luhmann opina en relación con la distinción-guía de la teoría de los sistemas sistema/entorno:

Con todo esto, aún no está decidido qué y por qué se debe hablar sobre la emergencia, dentro del esquema de sistema y entomo. Aquí también parece estar ubicada la fuente de todas las irritaciones, dado que esto y solamente esto obliga a designar átomos como entorno de las moléculas y hombres como entomo de los sistemas sociales. La teoría de los sistemas no conoce otro lugar que: o sistema o entomo. Aquí babria posiblemente un margen de accion para disponer de otro diseño de la teoria [RJ]. No obstante, esto significaría renunciar a la teoría de los sistemas, y renunciar a mucho, ya que en el nivel de los "ordenes" emergentes (como deberíamos decir entonces) difícilmente se quería renunciar a las clasificaciones, entre las cuales la teoría de los sistemas tiene a disposición como teoría de la diferencia entre sistema y entomo. ${ }^{28}$

${ }^{26}$ Weizsäcker, C.F.v., 1985, pp. 253-260.

${ }^{27}$ Realzamos el hecho de que la TsS tiene dificultades, debido al carácter demasiado determinado de su distinción-guía sistemalentorno, no toma en consideración la cOMUNicıción en sus múltiples formas; mientras que la TkH es capaz, debido a la inconsistencia de su distinción-guía de mundo vivencialsistema, de presentar la variedad de la COMUNICACIÓN. Queremos demostrar con la propuesta de la distinción-guia diferencialdiferenciación, dentro del marco de una $\mathrm{TgS}$, que la consistencia lógica, una porción adecuada de determinación y un registro de COMUNICACIÓN más amplio, son pretensiones de la arquitectura de la teoría que se pueden satisfacer generalmente de manera conjunta.

${ }^{23}$ Luhmann, 1992, p. 142. 
Martens opina en el texto de réplica.

Visto de esta manera, la aplicación de la diferenciación entre sistema y entorno a la relación de emergencia de dos tipos de sistema; no solamente conduciria a insuficiencias en la determinación de la conexión de estos sistemas, sino a la catástrofe de la teoría de los sistemas como tal. ${ }^{29}$

En todo caso, por un lado la posición de Martens no es para nosotros aceptable dado que usa un concepto de autopiesis inconsistente. Por el otro lado, no es de esperarse que se pueda tratar adecuadamente la SOCIEDAD sobre la base de la distinción de sistema/ entorno, por lo menos, en la forma como la maneja Luhmann.

Con otras palabras, una diferencia-guía de teoría social, generadora de la SOCIEDAD, debe poseer una relación adecuada de dos distinciones entre sí: determinación/indeterminación (pragmática) y consistencia/inconsistencia (lógico-semántica). Sólo una relación equilibrada, un entrelazamiento equilibrado entre ambas distinciones, determina la relevancia de una teoría social actual (figura 11).

Determinación de relevancia de una distinción-guía:

determinación/indeterminación

consistencia/inconsistencia

12. Antes de dirigimos hacia algunas distinciones-guía de la teoría de la sociedad, para poder evaluar sus respectivos costos y resultados (capítulo $\mathrm{V}$ acerca de la arquitectura de la teoría), debemos discutir más exactamente la forma, la complejidad, là autorreferencia y la observación de las distinciones. Con ello, nuestra intención es reunir algo como una "unidad cognoscitiva", un "elemento cognoscitivo", que nos debe servir como componente de una teoría de la sociedad, la cual quisiéramos ofrecer aquí en formá nudimentaria.

Dentro del marco de este proyecto no se puede presentar ninguna teoría de la sociedad. Lo que podemos ofrecer es solamente una "lógica y metodología de las distinciones", misma que, sin embargo, es la con-

${ }^{29}$ Martens, 1992, p. 143. 
dición previa a la elaboración de una teoría de los sistemas de la sociedad (TgS), o sea, la elaboración de una teoría social.

No obstante, dicha "unidad cognoscitiva" debe fungir, a la vez, de medida para la evaluación de otras teorías sociales. La "unidad" buscada debe ser, por un lado, lo suficientemente flexible, como para - hablando metafóricamente- poder construir no solamente un tipo de casas, sino edificar diferentes estilos de casas. Estamos lo suficientemente optimistas como para afirmar que con una "unidad" semejante se pueden construir incluso puentes, carreteras y torres.

Aquí anotamos que no consideramos una unidad como una entidad compacta, sino solamente como el resultado de relaciones, como un relacionamiento de relaciones $o$, de manera mejor y más precisa, como una distinción de distinciones. Con ello, la unidad siempre es "unidad de la distinción de [...]". Dentro de la cosmológica de Whitehead, podemos decir que no suponemos que la unidad buscada se encuentra en el reino de la "materia" ni, como en el caso de Whitehead, en el reino de la "vida":

"[...] he tratado de bosquejar una doctrina cosmologica alternativa, misma que debe ser lo suficientemente amplia como para incluir todo aquello que es fundamental tanto para la ciencia como también para sus críticos. El concepto fundamental del material fue sustituido por aquél de la sintesis ongánica [RJ], dentro de este sistema alternativon. ${ }^{30}$

Suponemos que la unidad o la "materia constructiva" buscada se encuentra en el ámbito de la cognición, el cual integra, aparte de la cOMUNICACIÓN, tanto la "materia" como la "vida" y que, con ello, se concibe de manera más general. De modo similar argumenta C.F.v.Weizsäcker, quien parte del hecho de que la masa - vista de manera relativa- es equivalente a la energia, ${ }^{31}$ con lo cual se puede comprender, por consiguiente, la energía como información. ${ }^{32} \mathrm{La}$ información es para nosotros una figura clave de la cognición.

La "unidad" buscada será, esto lo queremos anticipar, la unidad de la distinción entre diferencia y diferenciación, en el ámbito de una "lógica de las distinciones" general; y la unidad de la distinción entre COMUNICACION y ACCION, en el ámbito de la teoría de la sociedad. En

${ }^{30}$ Whitehead, 1988, p. 184.

${ }^{31}$ Weizsäcker, C.F.v., 1984, 16, p. 345.

32 Ibid., pp. 352 y ss. 
ambos casos se trata de una relación que vincula dos distinciones. Una intención semejante requiere una determinación más exacta de aquello que se podría querer expresar semánticamente como diferencia y como diferenctación. Y la mejor manera de efectuarlo es ocuparse más de cerca de los supuestos fundamentales de las Laws of Form de Spencer Brown y su desarrollo posterior, por parte de von Foerster, Varela, Herbst, Glanville y Luhmann, entre otros. Es importante hacer hincapié que el concepto de diferencia' es equivalente al concepto de distinción simétrica y que el concepto de diferenciación equivale al concepto de distinción asimétrica.

13. El pensamiento básico que nos guía en la determinación de aquello que "existe generalmente", o sea, de un algo como "algo", es: para aumentar la capacidad de recombinación de un ámbito, aquí el de la "teoría sociológica", se deben "disolver" o descomponer analíticamente las "componentes" o las "unidades" de las cuales está compuesto el ámbito respectivo, de tal manera que se haga posible una estructuración nueva y, con ello, sea visible la figura vieja de la teoría, dentro de la estructura nueva. Esta "materia básica" -el relacionamiento entrelazado de la relación fundamental diferencia/diferenciación-se debe reducir a su especificidad solamente en la medida necesaria como para posibilitar una óptima aplicación universal. Se trata de la distinción entre ACCIÓN y COMUNICACION, en el ámbito de la teoría social. Con ello se valida que entre más alto sea el potencial funcional de una "unidad" semejante, más universal es su ámbito de aplicación. ${ }^{33}$ Para concretizar el problema tomaremos un ejemplo del área de la técnica: la máquina de vapor como "unidad" generadora de fuerza, se puede aplicar menos universalmente que el motor Otto, mismo que posee un radio de aplicación más grande que la máquina de vapor mencionada, debido a su modo de construcción y producción de energía (se podrian mencionar ejemplos similares con la tecnología de los "chips" o de los transistores). Creemos que podemos alcanzar, con la distinción entre diferencia y diferenciación, una relación óptima entre especificación y universalidad, misma que

${ }^{33}$ Acerca de la función de la función por una parte, y la afirmación de equivalencia de función y relación por otra parte, véase Watzlawick/Beavin/ Jackson, 1985, pp. 24-29. 
es necesaria para la construcción de una teoría de la sociedad, la cual tiene como objeto a la sociEDAD actual (figura 12).

\section{Unidades fundamentales:}

Nivel de la metodologia de las distinciones:

I. Unidad de la distinción entre diferencia y diferenciación.

Nivel de la teoría de la sociedad a):

II. Unidad de la distinción entre comunicación y ACCion.

Nivel de la teoría de la sociedad b):

III. Unidad de la distinción entre expectativa y experiencia.

Nivel de los sistemas particulares del sentido:

IV. Unidad de la distinción entre código y programa.

Se puede explicar el entramado de generalización y especificación también con la siguiente metáfora: quien nota todo, puede alcanzar una idea general solamente dentro del ámbito más estrecho. Puede obtener una idea general solamente aquel que nota mucho, pero no todo. ${ }^{34}$

\section{Diferenciaciones}

\section{- El concepto de diferenciación de George Spencer Brown}

14. Con la determinación de las distinciones de diferencia y diferenciación utilizadas dentro de este análisis, nos queremos adherir, primero, a las reflexiones acerca de una "lógica de las formas", misma que fue presentada por el matemático y lógico George Spencer Brown en el año 1969. Segundo, queremos adherimos, a la vez, a los trabajos que, continuando de igual manera la obra de Spencer Brown, han desarrollado de modo productivo sus reflexiones.

3* Véase acerca de ello Claessen, 1970, pp. 144-145, pero también Luhmann: "El hecho de que se hable de generalización y especificación [...] significa: no sólo importan simplemente los símbolos amplios, de gran alcance y cada vez más indeterminados, sino que se necesitarian las generalizaciones debido a su potencial de reespecificación y se escogerían con miras a esto." (Luhmann, 1978, pp. 74-75). Esto es naturalmente también un pensamiento básico de T. Parsons. 
Las aportaciones más importantes que se deben tomar en consideración, provienen de FranciscoJ. Varela, Humberto Maturana, Niklas Luhmann, Ph. G. Herbst, Heinz von Foerster y Ranulph Glanville. ${ }^{35}$

Observemos primero cómo procede el mismo Spencer Brown en esta tarea.

15. Spencer Brown inicia con un mundo aún no marcado, aún no dañado (unmarked state), para constituir un primer comienzo genético-formal.

Spencer Brown y, con él, naturalmente la TsS, presupone la logicidad del mundo o la logicidad de lo social. Demostraremos más adelante que está estructurada realmente de manera "lógica" la dimensión social de cualquier sentido. Por el otro lado, es notable que exista una socialidad de lo lógico. Ésta justifica presuponer la logicidad de lo social como lo hacen Spencer Brown y la TsS. Sin embargo, no hemos podido encontrar en Spencer Brown y los desarrollos posteriores de su planteamiento, ni dentro del marco de la TsS que se ocupa explícitamente de la dimensión social del sentido, una explicación del supuesto de una socialidad de lo lógico y/o de la logicidad de lo social. En este párrafo abordaremos primeramente la logicidad de lo social. Trataremos la socialidad de lo lógico en el párrafo siguiente.

Bien entendido, unmarked state no se refiere a vacío, deshabitado o una "nada", sino a un estado no-distinguido. Indica de manera inyuntivo-operativa: Draw a distinction y se atiene él mismo a las consecuencias de su indicación. Spencer Brown puede presentar una justificación consistente de lógica y álgebra incluyendo momentos autorreferenciales, con el apoyo de esta indicación y dos axiomas, mismos que llama the law of calling y the law of crossing y los cuales conducen respectivamente a la form of condensation y a la form of cancelation. No seguiremos su teoría en dirección hacia una justificación semejante, ya que aquí no nos importan los cálculos lógicos, sino la teoría de la sociedad. A pesar de ello, existe una relación estrecha entre nuestra intención de presentar una teoria del distinguir con motivos teórico-sociales y la empresa de Spencer Brown de una lógica de las formas.

${ }^{35}$ Para nuestro trabajo son centrales, sobre todo, las aportaciones de Herbst (1976), Glanville (1988), Varela (1975 y 1979) y Luhmann (1984, 1990 y 1990a). 
Aquí tomamos un camino parecido a aquel que toma la TsS:

No seguiremos a [...] esta teoría de las Laws of Form de Spencer Brown [R] en su propia dirección hacia una justificación de lógica y álgebra con la inclusión de momentos autorreferenciales, sino que nos desviaremos después de participar en los primeros pasos. Sin embargo, hacemos énfasis en la relación -aunque sea solamente para poder aprovecharla esporádicamente. ${ }^{36}$

Con el mismo espíritu que la TsS, acogemos también el estímulo central de las Laws of Form de Spencer Brown, para el proyecto aquí presentado. ${ }^{37}$

16. Spencer Brown presupone explícitamente la idea de la diferenciación (- distinción asimétrica) y la idea de la denominación.

No aceptamos esta condición previa, sino que integramos al proceso de constitución la idea de la diferenciación, la idea de la denominación y la idea de la diferencia; es algo que no efectúan Spencer Brown ni Luhmann. Se debe observar que nosotros introducimos ( $T g S)$ explícitamente el concepto de la diferencia (=distinción simétrica), en este lugar.

Sobre esta base, Spencer Brown define el concepto de la forma como la "designación de una diferenciación", misma que requiere una operación única, la cual está compuesta por dos momentos, es decir, por el distinguiry el designar..$^{38}$ Se debe suponer que Spencer Brown concibe ambos momentos como una operactón única, debido al hecho de que una diferenciación no sería posible sin designación: si hubiera comenzado con una operación, sin haber ofrecido un punto de conexión para operaciones adicionales, la operación iniciada ya hubiera llegado a su fin.

${ }^{36}$ Luhmann, 1986e, p. 181.

37 "We take as given [R]] the idea of distinction [RJ] and the idea of indication." (Spencer Brown, 1969, p. 1).

${ }_{30}$ " $[. .$.$] we cannot make an indication without drawing a distinction. We$ take, therefore, the form of distinction for the form." (Spencer Brown, 1969, p. 1). 
Demostraremos que ya en este nivel basal de la distinción, es necesaria una base comunicativa en el sentido de una diferencia mutua, misma que no presupone Spencer Brown ni tampoco el concepto de la TsS. Ya en este nivel se puede determinar que la TsS — pace Luhmannprocede monológicamente. Sin embargo, no notamos que la teoria de la acción comunicativa (- TkH) comenzara en este lugar con su critica de la TsS. Al contrario, nos parece simplemente mal ubicado el reclamo de la monología, el cual dirige la TkH hacia la dirección de la TsS, debido a otra comprensión de la comunicación.

No nos parece irrefutable la justificación de la TsS de que la "distinción" y la "denominación" se deben considerar como una operación ünica, dado que ambos momentos pretenden encontrarse en una relación complementaria. Sabemos ciertamente que "todo está relacionado con todo", o sea, que el mundo existe realmente como unidad. ${ }^{39} \mathrm{Sin}$ embargo, el mundo como mundo del sentido se hace relevante sólo cuando permite "cortes", es decir, causalidades o AccionEs o-de manera muy general-, cuando permite operaciones distintivas que siempre afectan precisamente a determinados segmentos del mundo. Por ello, el "contexto común" no es ninguna base de justificación para el supuesto de solamente una operación, como se supone ciertamente en el caso de las dos operaciones "diferenciación" y "designación". Es más, el hecho de pensar que las operaciones de la "diferenciación" y de la "designación", representan tan sólo una operación es debido a que lamentablemente no se tematiza aquella operación que posibilita ambas cosas, o sea, la diferencia. La TsS formula acerca de la relación entre designación y diferenciación: "Partimos de la suposición de que se introducen diferenciaciones para posibilitar designaciones, asimismo como las denominaciones resultan en aumentos de sentido capaces de conexión, solamente si se sabe dentro del marco de cuál diferenciación se designa a una cosa o a la otra. Por ello, se pueden considerar, siguiendo a Spencer Brown, la diferenciación y la denominación precisamente como una operación ünica [R]]. ${ }^{\text {"40 }}$ Nos oponemos a este supuesto.

Puesto que en el cálculo de Spencer Brown se trata de una operación única que, no obstante, conduce en el transcurso del desarrollo del cálculo a una forma más compleja, necesita para la estructuración de su lógica solamente un signo único:

37 C.F.v.Weizsäcker formula a este respecto: "Es obvio que podemos separar mentalmente de manera razonable los objetos de la totalidad del mundo. Esta separación siempre contiene ciertamente un error, ya que todo estŕ relacionado realmente con todo." (Weizsäcker, C.F.v., 1970, p. 383).

${ }^{40}$ Luhmann, 1987c, p. 16. 
Esto es asi porque Spencer Brown no presupone como dados los conceptos de diferencia, diferenciación y denominación y, con ello, los deja fuera de consideración ya al inicio, esto quiere decir que ya no los tematiza. Negamos que Spencer Brown pueda comenzar con sólo una distinción. Más adelante demostraremos que no lo hace realmente.

17. Para Spencer Brown, cualquier diferenciación está formada asimétricamente, por principio. No obstante, no pone suficiente énfasis en esta circunstancia. La diferenciación siempre está compuesta por dos lados: uno que distingue algo como "algo", y otro que separa este "algo" de "algo diferente". Por lo tanto, "se designa no éste, sino el otro lado", con la ayuda de una diferenciación. No obstante, a la vez se mantiene abierta la posibilidad de cambiar de un lado hacia el otro y de poder compensar así, de cierta manera, la asimetría surgida. ${ }^{41}$ A ello se añade que es necesario un crossing como posibilidad del cambio de un lado hacia el otro, ya que en caso contrario se perdería la diferenciación: sería diferenciación solamente por un momento breve ( $\sin$ embargo, iseria!).

Luhmann opina: "No obstante, esta asimetría se compensa por el hecho de que se mantiene abierta la posibilidad del cambio de posición (crossing), dado que en caso contrario desaparecería la diferenciación como diferenciación. ${ }^{* 12}$ Eso está realmente correcto, solo que Luhmann omite, con ello, abordar el proceso de constitución, mismo que comienza con una diferenciación "momentánea" de forma simétrica. Si se conserva o no la diferenciación, depende del hecho de si luego se llega a la condensation o a la cancelation de la diferenciación.

18. Ahora bien, si se designa una diferenciación (es decir, se marca) y se repite la designación, entonces no se forma, visto lógicamente, nada nuevo. Una repetición lógica es precisamente sólo una repetición lógica y, con ello, igual a la designación inicial: $\neg \neg=\neg$. Spencer Brown llama a este resultado de la repetición de designación la form

${ }^{1}$ Es precisamente un logro de la TsS, haber señalado una y otra vez este hecho. (Luhmann, 1986e, p. 181).

${ }^{42}$ Idem. 
of condensation. Si se designa una diferenciación, entonces surgen dos lados, el designado (o marcado) y el lado no designado (no marcado). Ahora bien, si se efectúa una segunda operación desde el lado designado hacia el no designado y nuevamente a la inversa, entonces se borra, visto lógicamente, el lado no designado: $ר$ = . Spencer Brown llama este cambio operativo de designación la form of cancelation.

19. Para poder convertir en fértiles estas reflexiones en torno a las de Spencer Brown y Luhmann para una arquitectura de teoría con intenciones teórico-sociales, las debemos relacionar con una teoría feriomenológica del sentido.

Con fenomenología nos referimos a aquel método de aceptar el mundo "asi como aparecen - -sin preguntar acerca de problemas ontologicos o metafísicos. Lo que aparece entonces, se debe interpretar como una selección, con la exclusión de otras posibilidades. ${ }^{43}$ Con las palabras de Edmund Husserl, el "principio fenomenológico de todos los principios" significa: "[...] que cualquier concepción originariamente generadora es una fuente jurídica del conocimiento", que "todo aquello" que se nos presenta "en la "intuición' de manera originaria" (por así decir, en su realidad corporal), se debe simplemente aceptar como aquello que aparenta ser; pero tampoco "solamente dentro de los limites en que se presenta", ninguna teoría imaginable nos puede confundir, ya que sabemos que cualquier teoría en sí podría basar su verdad también sólo en los hechos presentados como originarios.4 En la formulación de Heidegger, el fenómeno es precisamente aquello que, por lo pronto y en la mayoria de los casos, no se muestra en el momento, dado que permanece como oculto debido a la manera cotidiana de observar." $\mathrm{Y}$ el lema " $\mathrm{jDe}$ regreso a las cosas!" es, de acuerdo a Bemhard Waldenfels, no solamente el valor de utilizar la propia razón, "[...] sino también los propios ojos [...]"; tampoco se debe subestimar. ${ }^{46}$ Repetimos: es generalmente válido que no se pueda efectuar ninguna operación dentro de un "mundo del sentido", sin que se modifique nuevamente su sentido cada vez."7

43 Luhmann, 1985, p. 101.

${ }^{44}$ Husserl, 1950, p. 52.

45 Heidegger, 1979, pp. 34 y ss.

${ }^{46}$ Waldenfels, 1980 , p. 11.

47 Véase acerca de esto también Luhmann, 1986e, pp. 181-182. 
Una teoría semejante del sentido significa que cualquier operación (cualquier establecimiento de una designación, cualquier repetición o modificación desde uno de los lados hacia el otro, etcétera) siempre obtiene una "plusvalía sensata".48

Luego abordaremos más extensamente las particularidades de una reoría del sentido. Aquí se observa que está integrado también lo "irracional" dentro de una teoría fenomenológica del sentido, ya que produce sentido precisamente en la forma de la sinrazón: es precisamente un logro particular del sentido el hecho de que se procesa, dentro de la cotidianidad social, la "sinrázón" como ausencia del sentido.

Formulado de manera general: tiene sentido cualquier operación dentro de un mundo del sentido, dado que no hay nada dentro de este mundo que no tenga sentido.

Para el concepto de la operación, esto significa que se produce sentido con cualquier operación de cualquier tipo, dado que cualquier operación implica una dependencia de la observación. El problema que surge aquí consiste en el hecho de que se pretende designar con este concepto una realidad independiente del observador. Sin embargo, ¿quien dispone la distinción entre dependencia de la observación e independencla de la observación? Obviamente sólo un observador, el cual utiliza esta distinción. En este sentido dice también Luhmann: "Debemos aceptar que solamente un observador puede observar la independencia de la observación, ya que es también obviamente una diferenciación de un observador la diferenciación 'dependiente/independiente de la operación de la observación', y no algo que exista en el mundo externo mismo como una diferenciación de este tipo. ${ }^{n 99}$

Seguimos con más: aun la ausencia de operación produce sentido. Aquí, el observador puede plantear la pregunta: ¿qué es aquello que no pudo tener lugar?

Deducimos el concepto de la observación a partir de la ausencia primaria de operación. Esto obviamente lo podemos observar sólo desde la perspectiva del observador, lo que significa que no podemos observar la generación misma de la observación y de la operación. Ver más adelante.

48 Ibid., p. 181.

99 Luhmann, 1990, p. 271. 
20. El cálculo elegante de Spencer Brown que se construye mediante el cumplimiento obligatorio de la indicación: "iMarca una distinción!" fue frecuentemente criticado, pero también reinterpretado y desarrollado productivamente hacia distintas direcciones. Las reflexiones de Spencer Brown juegan un papel importante sobre todo en los trabajos de Francisco Varela (en menor medida también en el caso de Humberto Maturana), Heinz von Foerster, Ranulph Glanville, Ph. G. Herbst y Niklas Luhmann, para mencionar solamente algunos nombres.

Opinamos que la actual arquitectura de la teoría de Niklas Luhmann se basa ampliamente en las Laws of Form de Spencer Brown, lo que significa que también es aplicable a Luhmann la manifestación crítica realizada aquí en cuanto al trabajo de Spencer Brown.

- Lollamativo de la "teoría de las formas" parece basarse en el hecho de que se trata de una teoría elegante (isencilla y complicada!) y ampliamente consistente en cuanto a la lógica, la cual se puede aplicar, vista funcionalmente, a ámbitos muy heterogéneos.

Luhmann escribe acerca de ello: "Uno nota, cuando tiene el libro en la mano: la lógica de Spencer Brown es sencilla y complicada, elegante e intrincada de una manera encantadora $y$, con ello, accesible como un laberinto con solamente una entrada claramente marcada [R]]. ${ }^{n 50}$ Precisamente esta "única entrada claramente marcada" es la razón del proceder monológico de Spencer Brown. Esto se puede permitir dentro de la lógica, sin embargo, la monología bombardea lo social per se, en el ámbito de lo social. Luhmann comienza - Ésta es nuestra afirmación-de manera monológica, debido al hecho de que acepta en gran parte sin revisión las premisas de la lógica de Spencer Brown.

La dimensión del tiempo cumple un papel constitutivo en la "lógica de las formas", y esto realmente es inusual para una lógica.

Nos ocuparemos también un poco de la "Ígica de la afirmaciones temporales" de C. F.v. Weizsäcker, ${ }^{51}$ ya que se pueden observar aquí desarollos similares acerca del objeto, las cuales subrayan nuevamente la importancia del trabajo de Spencer Brown. Véase más adelante capitulo II.

${ }^{50}$ Luhmann, 1988a, p. 47.

51 Weizsäcker, C.F.v., 1986. 
Por lo resaltado arriba, Francisco Varela puede expresar con razón que el logro esencial de la lógica de Spencer Brown es precisamente la asociación de lógica y tiempo. ${ }^{52}$ Y Luhmann llama a la lógica de Spencer Brown una "lógica no estacionaria para el procesamiento de diferenciaciones". Con el concepto de la no estacionalidad quieré

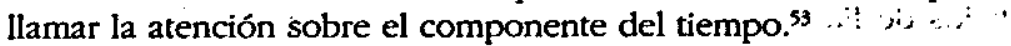
$\therefore$ nimitil.

Con esta lógica no estacionaria se trata del procesamiento dế diférenciaciones y denominaciones, no se trata en primera línea de una lógica de afirmaciones, sino de una lógica antes de la lógica, o sea, de una protológica. ${ }^{\text {st }}$

Interpretamos por lo tanto la lógica de Spencer Brown en dirección hacia una protológica operativo-distintiva, con lo cual intentamos deducir los conceptos necesarios para este trabajo a partir de la perspectiva operativo-distintiva.

21. La propuesta de Spencer Brown de convertir un mundo no designado en uno designado dice: Draw a distinction! Con ello presupone, como ya lo presentamos antes, the idea of distinction y the idea of indication como dadas y formulas: "[...] we cannot make an indication without drawing a distinction [... $]^{n} .{ }^{55}$ Esto es convincente, porque realmente no es posible la denominación sin haber distinguido anteriormente, ya que: ¿hacia dónde o en dirección a qué se debe designar? Una diferenciación ciertamente tiene sentido solamente cuando se designa, con lo cual una designación, por su parte, tiene sentido solamente sobre la base de una diferenciación. De esta manera, diferenciación y designación se presuponen mutuamente y parecen ser solamente dos momentos de una operación única.

Por ello, Luhmann opina también que la diferenciación requiere, a la vez, una designación, "[...] misma que tiene sentido, por su parte, solamente sobre la base de una diferenciación y que adoptaria otro sentido

52 "This interpretation is, in my opinion, one of his most outstanding contributions. He succeeds in linking time and description in a most natural fashion." (Varela, 1975, p. 20).

${ }^{53}$ Luhmann, 1988a, pp. 47 y ss.

54 Véase acerca de la misma circunstancia ibid., p. 48.

"ss Spencer Brown, 1969, p. 1. 
dentro del marco de otra diferenciación. Por lo tanto, diferenciación y denominación son básicamente sólo dos momentos de una operación única".56 Ya aquí se puede preguntar críticamente: ino reflejan estos "dos momentos" dos operaciones diferentes?

Visto temporalmente, es posible e incluso indispensable distinguir entre una diferenciación neutra en cuanto a los lados y su posterior (una realizada anteriormente) designación partidaria en cuanto a los lados. Una designación puede tener sentido sólo si puede designar entre "algo y algo". Sin embargo, esto implica la introducción de una distinción neutra en cuanto a los lados, misma que debe posibilitar precisamente una designación semejante. Queremos explicar más detalladamente este supuesto.

22. En la cotidianidad social se presenta frecuentemente el hecho de que nos encontramos dentro de una situación de diferenciación, misma que nos obliga a decidir (= designar) entre "algo" y "algo diferente ${ }^{n}$. No habría ninguna posibilidad de DECIsIón (= designación), sin el preestablecimiento de una diferenciación semejante neutra en cuanto a sus dos lados y, con ello, aün no distinguida.

\begin{abstract}
Aquí partimos, por motivos de simpleza, del hecho de que se trata del concepto de la decisión, tanto de formas de DEcisión explícitas como también implícitas. Con ello, el concepto de la DEcisıon se acerca al de la designación. Luego regresaremos explícitamente a la distinción de DECiSIÓN/decisión, sobre todo con miras al tipo de comunicación, el cual se realiza dentro de los sistemas sociales con la ayuda de "decisiones" o sea de designaciones explícitas.
\end{abstract}

Es decir, si las operaciones del designar y distinguir representaran solamente una unidad operativa, como Luhmann y sus partidarios presuponen, entonces deberían ser imposibles las operaciones cotidianas del DECIDIR.

Extrañamente, esta circunstancia casi nunca es objeto de reflexión, aunque es tan central que no tomándola en cuenta desaparece el fenomeno del DEcidir y con él una posible "lógica de la forma", con el su-

sto Luhmann, 1986e, p. 181. 
puesto de una fundición o una cuasi-identificación entre "diferencia-

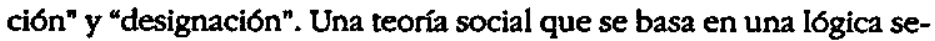
mejante sin decisiones, como es el caso de Luhmann, no dispone de espacio para ACCIONES - mismas que siempre deben presuponer DEC1SIONES, ya que no puede haber ninguna ACCION Sin DECISION. La misma circunstancia problemática se repite en las teorías de Varela, Glanville, von Foerster, Teubner, Wilke, Simon, Baecker. De acuerdo con nuestra opinión, Ph.G.Herbst es quien ha reflexionado más acerca de este problema. (Nos ocuparemos de su trabajo más adelante en este capítulo).

Es trivial la razón -operativa- de ello. Se debe poder DECIDIR (designar) entre "algo" y "algo diferente", para poder efectuar una acción. Si no se puede construir (o dicho con la semántica de la cotidianidad: no está dada) una situación semejante de DECISIÓN, la cual siempre debe estructurarse simétricamente, entonces la ACCIÓN pierde su base operativa, dado que en este caso no hay simple y sencillamente nada que DECIDIR.

Naturalmente no es así que se decide consciente (a nivel personal) o explicitamente (a nivel social) sin interrupción, dentro de la cotidianidad social. Esto sería una forma de decisión, la cual haría imposible la vida social. Dentro de este contexto, debemos observar primeramente aquella operación que indica generalmente la condición de la posibilidad para la ACCOON. Es otro problema el hecho de que entonces las ACCIONES se pueden canalizar, dentro de la vida social, de tal manera (palabra clave "codificación") que ya no están sujetas al esfuerzo de una DECISIÓN explícita. No obstante, podemos encontrar el problema de las "ACCIONES-ya-decididas" y observar las distinciones esencialmente en cuestión, precisamente por medio del supuesto formal pragmático de una situación de DECTSIÓN.

$\mathrm{Y}$ dado que la vida social consiste esencialmente en ACCIONES (aunque no solamente, ya que procedemos tanto desde la perspectiva de la teoría de la Acción como desde la perspectiva de la teoría de la COMUNICACION), se debería suponer a continuación de las condiciones previas antes establecidas en cuanto a la ausencia de distinciones simétricas, que no está dada realmente la dimensión social del mundo. Este es un supuesto verdaderamente fatal para la sociología, ya que perdería su objeto de investigación y se convertiría en innecesaria. Por lo tanto, se puede decir operativamente: no puede haber ninguna ACCIÓN Sin DECISIÓN (= designación). No obstante, una dife- 
renciación en el sentido de las Laws of Form de Spencer Brown y de Luhmann siempre es una forma de distinción ya asimetrizada, o sea, una diferenciación ya "decidida" que, por ello, no puede genemar ACCIONES de ningún tipo. De acuerdo con nuestra opinión, es capaz de DECISIÓN o designación solamente una forma de diferenciación que tiene un carácter simétrico. Queremos llamar a dicha forma de distinción neutra en cuanto a los lados, una diferencia. Por ello, distinguimos entre una diferencia neutra en cuanto a los lados (simétrica) y una diferenciación partidaria en cuanto a los lados (asimétrica) (figura 13).

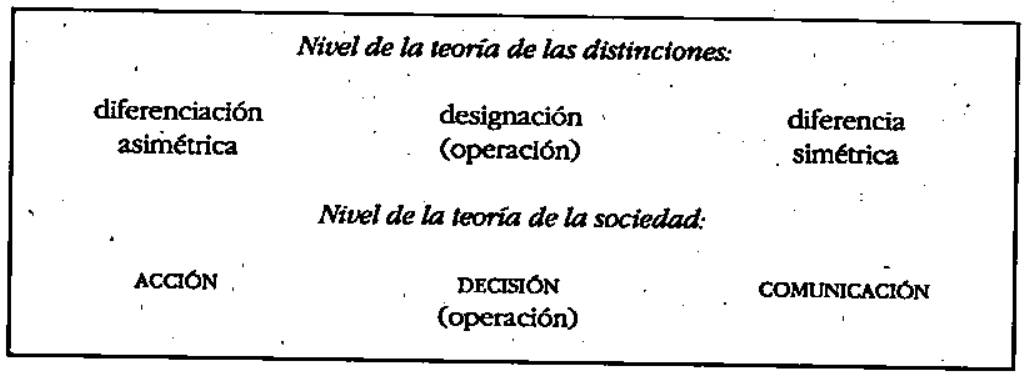

23. Extrañamente, Spencer Brown comienza con sus Laws of Form postulando una diferenciación que se caracteriza una "continencia absoluta": Distinction is perfect continence. ${ }^{57}$

Sin embargo, no aborda el problema de la "continencia absoluta", sino que formula inmediatamente después: "That is to say, a distinction is drawn by arranging a boundary with separate sides so that a point on one side cannot reach the other side without crossing the boundary. ${ }^{\text {"SB }}$ Con ello, se obstruye a sí mismo la posibilidad del conocimiento de procesar una "continencia absoluta" (-perfect continence), solamente una diferencia simétrica neutra en cuanto a los lados, la cual puede realizar.

Por ello, es el mismo Spencer Brown quien ofrece la indicación decisiva de que nada sucede sin la condición previa de una "diferenciación no decidida" (lo que equivale a una simetrización de la

77 Spencer Brown, 1969, p. 1.

${ }^{58}$ Idem. 
circunstancia) en la forma de una "continencia absoluta". Con base en esta circunstancia queremos desviarnos aquí del concepto propuesto por Spencer Brown y proponer las siguientes modificaciones: (1) queremos llamar diferenciación en el sentido verdadero de la palabra a una diferenciación ya decidida o designada; (2) además queremos designar como diferencia a una diferenciación aún no decidida, misma que se puede caracterizar en el sentido de Spencer Brown como "continencia perfecta"; y (3) finalmente queremos plantear la operación de la designación (= DECisIón o del referir) como una operación relativamente autónoma, lo que no es otra cosa que el simple resultado de la separación de diferencia y diferenciación. ${ }^{59}$ Y para aquel lector familiarizado con Luhmann: el concepto de acción aquí presentado esta íntimamente ligado al concepto de la operación.

Si transferimos estos supuestos metodológicos a una teoria de los sistemas de la sociedad ( $=\mathrm{TgS}$ ), entonces debemos partir, como ya lo mencionamos antes, del hecho de que se debe considerar diferencia como COMUNICACIÓN, designación como DECISIÓN y diferenciación como ACCIÓN, en un nivel más bajo de abstracción. Retomaremos nuevamente esta circunstancia.

Por ello, podemos decir que una diferencia consiste en el procesamiento operativo de una distinción neutra en cuanto a los lados, y que una diferenciación consiste en el procesamiento operativo de una distinción partidaria en cuanto a los lados. Decide, en última instancia, la denominación (=DECISION) sobre la selección entre diferencia y/o diferenciación. Esto es una operación relativamente autónoma que puede designar "éste, no el otro lado" de la diferencia y, con ello, convierte la diferencia en una diferenciación.

La denominación como operación relativamente autónoma es un supuesto, el cual también es efectuado por parte de la TsS, misma que,

7 Llamamos la atención sobre el hecho de que discutimos aquí el acceso operativo. Un acceso desde la perspectiva de la teoría de las distinciones significaría que definiríamos las distinciones o "diferenciación" y "diferencia" a través del modo de adjudicación. Con ello, es válido que una adjudicación de diferenciación determina como asimétrico al hecho en cuestión y como simétrica a una adjudicación de diferencia. Se podría formular algo similar en el nivel de la teoría social, con las distinciones ACCión y COMUNICACIÓN. 
sin embargo, no lo integra de manera consistente dentro de su arquitectura de la teoria: "Las diferenciaciones no se pueden diferenciar a sí mismas. ${ }^{60}$ En última distancia, la TsS parte de que las diferenciaciones sí se pueden diferenciar a sí mismas y, por ello, terminan en la paradoja "[... ] de un comienzo mediante el ya haber comenzado [...]".61 De hecho, consideramos el problema del comienzo como un problema serio, sin embargo, opinamos que se puede abordar solamente con la ayuda de un concepto dialógico o mutual. Podemos admitir tranquilamente que no se evita la paradoja del "comienzo de un comienzo". Sólo que el comienzo del comienzo está compuesto por un relacionamiento tetrádico de sucesos y estâ, con ello, estructurado dialógicamente, no monológicamente, desde el principio (y solamente un comienzo determinado monológicamente produce paradojas). No obstante, es una operación que se procesa continuamente dentro de la SOcieDAD, dado que la semántica del comienzo representa una semántica evidentemente importante, ya que reduce la complejidad de manera elegante y poco notoria: se comienza de nuevo, con lo cual se neutraliza la relevancia de todo lo sucedido anteriormente.

Ya que la operación de la designación (o DECISIÓN), solamente puede tener lugar sobre la base de dos distinciones, mismas que sólo son posibles debido al hecho de que ya fueron-designadas (diferenciaciones) o aún-no-han-sido-designadas (diferencias), la operación de la designación es (esencialmente) una operación comUNICATIVA. Puede tener lugar únicamente sobre la base de dos "complejos", de dos black boxes.

Solamente dos "algos" pueden producir una diferencia. Uno de ellos es "[...] una no-identidad, un no-ser. No distinguido de lo existente ni tampoco de lo no-existente. Algo no reconocido, una cosa en sí, el sonido de una mano palmeante*. ${ }^{62}$ Por lo demás, aquí nos adherimos a la conceptualidad de Gregory Bateson.

24. Es extraño que no se comprendan en todo su alcance las consecuencias de las distinciones entre diferencia, designación y diferenciación, hasta la actualidad.

${ }^{60}$ Luhmann, 1988a, p. 49.

${ }^{61}$ Ibid., p. 48.

${ }^{62}$ Bateson, 1984, pp. 87-88. 
Con las distinciones - de cualquier tipo- uno tiene el problema de que son, por un lado, distintas y, por ello, parte de una distinción; por el otro lado, forman por sí mismas una distinción. De este modo, aquí se trata, primero, de la distinción de diferencia/diferenciación, segun$d o$, esta distinción es una diferenciación asimétrica y, tercero, son distinciones relativamente autónomas, tanto la distinción de la diferencia como también aquélla de la diferenciación, mismas que procesan correspondientemente las formas "esto y/o aquello" y "esto, no aquello". Ya en este nivel se muestra qué tary compleja puede ser realmente una teoría de las distinciones en sus conclusiones.

Esto parece tener su razón en el hecho de que detrás de esta operación se esconde el problema del comienzo del comienzo. Spencer Brown evita, de hecho, - y expressis verbis - el problema situacional de una primera diferenciación y/o diferencia, comenzando con la indicación obligatoria: Drawa distinction!, dado que el problema del comienzo del comienzo conduce rápidamente a la paradoja, ya que la introducción de una diferenciación implica un lado exterior y uno interior, mismos que son, por su parte, diferenciaciones, las cuales se distinguen, por su parte..., etc. Por ello, cualquier comenzar debe comenzar con un ya-haber-comenzado, o sea, con una paradoja evidente, ${ }^{63}$ misma que, en vista de ello, Spencer Brown se ocupa de resolver en el estado avanzado de su trabajo donde su supuesto ya se ha hecho lo suficientemente complejo. Sin embargo, debido a esto ya no logra -y con él tampoco la TsS- dedicar la atención necesaria a la estructura del problema del "comienzo de un comien$\mathrm{zO}^{\prime}$, (la cual merece de acuerdo con nuestra opinión) y conduce a la conclusión de que cualquier comenzar procesa un relacionamiento tetrádico de suicesos. Obliga a observar paradojas y tautologías solamente la distinción asimétrica "diferenciación", misma que comienza monológicamente.

Para evitar interpretaciones erróneas queremos recordar que no negamosque las paradojasy tautologías acompañan (e irritan) continuamente a la semántica social. No obstante, consideramos esto como el resultado de la circunstancia de que se utilizan formas semánticas dentro de contextos COMUNCATIVOS, mismas que procesan "nuevos comienzos" o "inicialidades". Sólo las "monologías" que tienen lugar continua-

${ }^{63} \mathrm{Nos}$ adherimos en grandes rasgos a la formulación de la TsS. Véase sobre todo Luhmann, 1988a, p. 48 y 1990 d. 
mente dentro de la sociedaD producen "extraños nudos" (Hofstadter, 1985).

25. Hemos anotado antes que se puede evitar la paradoja del comienzo de un comienzo, generalmente, por medio del supuesto de un relacionamiento tetrádico de sucesos el cual determina a todo inicio. Sin embargo, debido a que Spencer Brown (y con él la TsS y aquellas teorias que cruzan en el sotavento de las Laws of Form y de la TsS) intenta oscurecer o desparadojizar lo más pronto posible el comienzo, se quita la posibilidad de poder distinguir expresamente entre diferencia, designación y diferenciación. Esta grieta puede parecer como no especialmente agravante para una "lógica de la for$\mathrm{ma}^{\text {n }}$ que no quiere ser ninguna sociologia. No obstante, una teoría social que no prevé el concepto de designación o DEciSIÓN como acontecimiento autónomo y que, por ello, no acepta la distinción entre diferencia/diferenciación, no puede explicar consistentemente el concepto de la ACción, central para ella, que implica el concepto no menos central de la COMUNICACIÓN.

Realzamos explícitamente que aquí no se trata de los conceptos en sí, sino de aquella circunstancia que expresan. Se debe elegir naturalmente la conceptualidad de tal manera que también pueda cumplir con los criterios fenomenológicos de la semántica. Asimismo, no estamos muy contentos con la selección de la distinción entre "diferencia" y "diferenciación", ya que puede ocasionar-debido a su similitud semánticainterpretaciones erróneas.

El no tomar en cuenta la distinción de diferencia/diferenciación es realmente un supuesto negativo para una teoría social exigente como la de Luhmann, dado que se quita a sí misma el fondo debajo de los pies.

Es característico de la manera de proceder de la TsS en el tratamiento del problema del comienzo del comienzo, el siguiente lugar representativo de muchos otros lugares:

"iMarca una diferenciación! ¿Quién manda aqui? ¿Un hombre? ¿Y qué pasa? La introducción de una diferenciación es, por lo pronto, la introducción de una forma. Una forma es la diferenciación entre un lado interior (de lo distinguido) y el lado exterior (de lo demás) [preguntamos: ¿Está la forma determinada solamente de forma espacial? Por lo 
tanto, la introducción de cualquier diferenciación es en sí ya una diferenciación. Y ¿quién distingue esta diferenciación? Todo comenzar comienza con ya-haber-comenzado, es decir, con una paradoja [...] No obstante, Spencer Brown demuestra que esto no impide el desarrollo de un cálculo y que puede'ser corregido luego, cuando el cálculo sea lo suficientemente complejo. ${ }^{64}$

La afirmación (o indicación obligatoria)

"jMarca una diferenciación!" sugiere, en el primer momento, capacidad de decisión, sin embargo, no puede tener lugar ninguna operación de DECISIÓN con una operación semejante, dado que está formada asimétricamente. Las diferenciaciones son distinciones siempre-ya-decididas y por lo tanto poseen una forma asimétrica.

26. En este contexto opinamos que es inconsecuente el procedimiento de la TsS, ya que, por un lado, no prevé ninguna posibilidad para la ubicación de la ACción dentro de su arquitectura de la teoría y que, por el otro lado, requiere de ella para poder firmar como "teoría sociológica". Tendremos que demostrar que la recepción de las distinciones del "distinguir" y del "designar" como modo de una operación ünica deben conducir, en última instancia, al hecho de constituir la teoría social sobre una base monológica. La indicación "iMarca una distinción!" señala la ruta, sin embargo, esta indicación solamente conduce hacia una distinción monovalente y puede comunicar en última instancia solamente consigo misma, con la consecuente producción de paradojas. Una distinción semejante solamente puede ser monovalente, ya que es esencialmente transitiva como diferenciación asimétrica, lo que se expresa por medio de la primacía de uno de los lados respecto al otro: no falso, sino cierto; no malo, sino bueno, etc. Con el supuesto de la autopoiesis se podría opinar que sólo se sigue consecuentemente con el pensamiento en relación con la comunicación consigo mismo. Sin embargo, autopoiesis no significa "ausencia del mundo" o "ausencia de cualquier dimensión social". Esto es el caso precisamente cuando se acepta sin revisión la conceptualidad de Spencer Brown para la "teoría sociológica". La circunstancia de que la TsS proceda monológicamente (supuestamente "involuntariamente") ya en sus estructuras fundamentales, no

64 Luhmann, 1988a, p. 48. 
debe conducir a cambiarla, por ello, contra una "teoría de la acción comunicativa" (TkH), misma que procede supuestamente de manera dialógica. Por más irónico que esto suene, precisamente la TsS, que realmente procede de manera monológica (por lo menos en lo que concierne a la "primera jugada" de la teoria), representa por otro lado un concepto consistente y realista de la comunicación; mientras que la TkH, la cual se esfuerza en proceder dialógicamente, trabaja con un concepto inconsistente y realmente irrealista de la comunicación. Dicho de otra manera: el concepto de comunicación de la TsS se concibe dialógicamente, sin embargo, ella misma procede monológicamente en cuanto a su intención; mientras que el concepto de comunicación de la TkH está diseñado monológicamente, lo cual, sin embargo, no le impide tener pretensiones dialógicas en su manera de proceder.

27. Ahora bien, aquí se anota que ni Spencer Brown ni Luhmann proceden, en última instancia, realmente de manera monológica, como lo deberian hacer consecuentemente. Se comienza ciertamente con la ayuda de la indicación de carácter obligatorio "iMarca una diferenciación!", sin embargo, en cuanto esto se haya realizado, nos encontramos dentro de un espacio delimitado por dos lados: por medio de un lado exterior y uno interior. Solamente sobre la base de esta diferenciación "bilateral", Spencer Brown es capaz de desarrollar su law of calling y su law of crossing y las formas de diferenciación deducidas a partir de ellas de condensation y cancelation, indispensables para su cálculo. Tenemos la opinión de que nada funciona sin una distinción bilateral semejante, misma que imita a dos black boxes en cuanto a la arquitectura de la teoría. La arquitectura de la teoría de la TsS presenta una contradicción similar entre intención de la teoria y realización de la teoria: comienza con una diferenciación concebida solamente como asimétrica y deduce de ella todo un mundo vivencial, a través de las paradojas, con lo cual, y con base en la operación paradojica conduce a la imitación de una situación con dos black boxes. ${ }^{65}$ No obstante, desarrollar un comienzo bivalente o incluso polivalente a partir de uno monovalente, sin justificar, en cuanto a la técnica de construcción de la teoria, la manera de cómo se convierte el "uno" en un "dos" o incluso un "múltiple", conduce .

${ }^{65}$ Véase Luhmann, 1986e, pp. 182-183. 
a una forma de emanación deductivista, misma que es también rechazada por el mismo Luhmann. ${ }^{66}$

\section{Objetos}

- El concepto de "objetos" de Ranulph Glanville

28. Ranulph Glanville, fotógrafo, arquitecto, cibernético y teórico del conocimiento ha escrito en el transcurso del tiempo un número de artículos que actualmente se ubicarían en el ámbito de la "cibernética de la cibernética" o cibernética de segundo grado. A nosotros nos interesa la obra de Glanville sobre todo debido a su discusión explícita de las Laws of Form de George Spencer Brown. Las aportaciones publicadas en 1988 por la editorial Merve, recomendadas a un público de habla alemana por parte de Niklas Luhmann y traducidas por Dirk Baecker, ofrecen una buena sinopsis de la creación teórica del autor. ${ }^{67}$ Nos ocuparemos sobre todo de aquellos trabajos que se refieren directamente a la obra de Spencer Brown.

29. En una discusión directa con Spencer Brown, Glanville realza tres insuficiencias del trabajo Laws of Form: primero, Spencer Brown parte, según Glanville, del hecho de que se producen "cosas", en el

66 "A partir de una unidad, surge una diferencia, dentro de la cual reaparece la unidad como el contrario de su contrario." La TsS menciona como ejemplos: a partir de la unidad familia, se desarrolla la diferencia familia/ corporación (Durkheim), a partir de lo sagrado surge lo sagrado y lo mundano, a partir del yo de Fichte surge la diferencia entre yo y no-yo, a partir de un pedazo de costilla de Adán surge Eva. Con ello, tiene preferencia aquel momento que mantiene la continuidad con el origen. Con Dumont (1983), la TsS considera este concepto de emanación como el resultado de una posición de pensamiento genuinamente jerárquica (Luhmann, 1988a, pp. 5152). Vemos presente en el concepto de una "designación diferenciadora", también un concepto de emanación: de la diferenciación emana ésta y la diferencia.

67 "Niklas Luhmann fue tan generoso al interesarse por mis trabajos, leerlos minuciosamente y proponer hacerlos accesibles para un público de habla alemana. Dirk Baecker se encargó de convencerme de que mi manera angloirlandesa se podía traducir al alemán y que él quería encargarse de este trabajo." (Glanville, 1988, p. 15). 
sentido amplio de la palabra, por medio de efectuar una distinción. Sin embargo, una actividad semejante presupone un agente, por así decir, un "distinguidor". Spencer Brown no da ninguna respuesta a la pregunta: ¿quién o qué distingue al distinguidor? Esto es el primer punto débil del trabajo. ${ }^{68}$ Segundo, Spencer Brown presupone un espacio dentro del cual se puedan realizar diferenciaciones, es un supuesto al cual no legitima. Esto lo considera Glanville como el segundo punto débil del trabajo. ${ }^{69}$ Tercero, con la designación de una diferenciación no solamente se marca uno de los lados de la diferenciación, sino que a la diferenciación también se le adjudica un valor (de diferenciación). Por lo tanto, la tercera insuficiencia es (de acuerdo con Glanville) la distinción omitida por parte de Spencer Brown entre una designación interna de la diferenciación, por un lado, y la diferenciación como tal en el sentido de una adjudicación de valor, por el otro. La circunstancia de esta tercera insuficiencia se puede formular también de la siguiente manera: Spencer Brown no distingue, en el caso de una diferenciación, entre su valor interno (p.ej., adentro/afuera) y el externo (p.ej. "espacio" [=adentro/afuera] del "tiempo"), entre su perspectiva de observación interna y la externa. ${ }^{70}$

30. Por lo tanto, Glanville reclama a Spencer Brown que presupone a priori, primero, al "observador" que realiza la diferenciación; segundo el "espacio" dentro del cual se efectúa esta diferenciación y, tercero, la distinción entre una observación interna y una externa de cualquier distinción. Glanville intenta integrar estos tres antecedentes, mismos que Spencer Brown, de hecho, presupone como dados, de tal manera que alcanzan la constitución sólo con la operación de la diferenciación y que, con ello, no deben ser implicados como dados a priori. Se trata entonces nuevamente del problema del comien-

${ }^{68}$ "Sin embargo, las diferenciaciones presuponen un agente, mismo que las efectúa. ¿Qué distingue entonces al agente (al distinguidor)? Ésta es la primera insuficiencia." (Glanville, 1988, p. 150).

69 "Las diferenciaciones presuponen un espacio, dentro del cual se efecnúan. ¿Qué distingue entonces al espacio? Esta es la segunda insuficiencia." (Idem).

${ }^{70} \mathrm{La}$ diferenciación es una marcación, "[...] la cual designa a un valor. ¿Qué distingue entonces entre marcación y valor, entre la diferenciación y aquello que está contenido en ella (su lado interior)? Ésta es la tercera insuficiencia."
(Idem). 
zo de un comienzo, un problema conocido desde hace tiempo, como hemos visto, el cual se trata de resolver tradicionalmente con la ayuda de un a priori, de un supuesto de la naturaleza o de una "norma". Ya hemos realzado el hecho de que Spencer Brown marca un comienzo monológico del desarrollo de su lógica, planteando las distinciones de la "diferenciación" y de la "designación" (= DECISIÓN) como dos momentos de una operación única. La TsS le sigue en este aspecto en el sentido de que acepta, en gran parte sin un análisis crítico, las premisas de las Laws of Form. Ahora bien, Glanville nota de manera suficientemente clara este problema del comienzo de un comienzo y también que no se puede comenzar simplemente, sin haber eliminado los a priori que se infiltran con ello. Sin embargo, su propuesta de solución sigue siendo, esto lo anticipamos, también un acto monológico. Observemos ahora cómo procede Glanville.

31. Glanville trata de resolver de la siguiente manera la primera insuficiencia del trabajo de Spencer Brown, o sea, el apriori de un observador que realiza las distinciones en cuestión: si el observador como distinguidor es aquel que marca una diferenciación, y la diferenciación es el comienzo verdadero de todo -el "acto originario"-, ¿quién o qué distingue entonces al distinguidor? Su respuesta: el distinguidor surge mediante su propia diferenciación y se distingue, por ello, a sí mismo. ${ }^{71}$

Aunque Glanville considera una solución dialógica (= mutual, "social"), sin embargo, no la persigue más: "¿Qué distingue entonces al agente? Una respuesta posible está contenida ya en el planteamiento de la pregunta. Se puede suponer otro agente externo [RJ] adicional, mismo que distingue a nuestro agente. No obstante, esta respuesta no es necesaria: dado que, ¿por qué no se debe distinguir el agente a sî mismo?" (Glanville, 1988, p. 152). Sin embargo, aquí se equivoca Glanville. Suponemos que no puede aceptar esta solución no porque es dialógica, sino porque para él se puede considerar una solución semejante solamente dentro del marco del concepto de la autorreferencia. Esto significa que cualquier solución de un problema semejante o similar debe tener lugar "internamente": vistas autorreferencialmente, todas las for-

"El problema del agente (= observador) desaparece si surge como su propia diferenciación; después puede marcar otras diferenciaciones." (Glanville, 1988 , p. 152). 
mas de distinciones se pueden explicar solamente a partir de la bermeticidad de la autorreferencialidad. Si se supone un observador posicionado externamente, para la operación de la "diferenciación de un observador", entonces este supuesto rompe con la premisa de la bermeticidad de la autorreferencia. Ahora bien, una respectiva hermeticidad depende del respectivo concepto de la autorreferencia. Glanville pasa por alto esta circunstancia. Si se plantea la autorreferencia desde el inicio solamente en el nivel de un actor, una black box, un observador que procesa exclusivamente sólo una distinción -es decir, si se procede monológicamente-, entonces uno se ve obligado a considerar cualquier distinción adicional como proceso de emanación de la primera "distinción originaria". El supuesto adicional de un segundo observador "externo", mismo que representa a la "segunda" distinción en este caso, bombardearía la autorreferencialidad del "primer" observador, que tiene a disposición solamente una distinción. El hecho de que Glanville intente resolver este problema con la ayuda del concepto de un "objeto" o "fundamental" el cual trasciende al observador, no modifica en nada el diseño de su teoría, misma que permanece igual: el supuesto de una autorreferencialidad concebida monológicamente. Partimos con cualquier forma de autorreferencialidad de su constitución doblemente contingente, dado que tratamos de evitar esta autorreferencialidad, diseñada de forma monológica. Esta observación significa que socialidad, personalidad, afectividad y corporalidad, o sea, SOCIEDAD, es posible solamente sobre la base de dos procesadores - los cuales planteamos en la forma de dos distinciones y que son aproximadamente equivalentes a los conceptos de las black broxes y del teorema egolalter.

De acuerdo con Glanville, la segunda insuficiencia, presuponer como a priori el espacio para posibilitar la operación de diferenciación, se resuelve por medio de una posible solución de la tercera insuficiencia: no distinguir entre una perspectiva interna y una externa de obsérvación de una distinción. ¿En qué consiste esta solución? Recordamos como observación previa que Glanville comprende la distinción "diferenciación" como una distinción asimétrica en el sentido de Spencer Brown. Es decir, si se hace, de acuerdo con Glanville, una diferenciación, entonces se distingue un lado interior, o sea, el contenido de la diferenciación, digamos "a", de una marcación, o sea " $\neg$ ". Con ello obtenemos la diferenciación "a $\neg$ ", misma que, por su parte, se distingue en " $a$ " $y$ " $\neg$ ". Ahora bien, "[...] si cualquier existencia depende de una diferenciación, misma que se marca, ¿qué distingue entonces la marcación de la cliferènciación y su valor? Se- 
guramente otra diferenciación adicional. ¿Y entre la marcación y el valor de esta diferenciación adicional? Seguramente otra diferenciación adicional. $Y$ así sigue en un regreso infinito de diferenciaciones que validan lo respectivamente anterior, y de las cuales, sin embargo, ninguna suministra la justificación del valor ${ }^{n} .{ }^{72} \mathrm{La}$ solución que propone Glanville (y con él Varela, dado que los renglones citados provienen de un trabajo redactado conjuntamente y, por ello, se puede suponer una posición coincidente de ambos autores) és equivalente a la solución ya ofrecida en cuanto a la primera insuficiencia: la diferenciación debe poder distinguirse a sí misma. ${ }^{73} \mathrm{Si}$ es posible una autodiferenciación semejante, entonces es posible también la solución del segundo problema, dado que entonces la diferenciación correspondiente no tendría que presuponer un espacio, sino que constituiría al espacio en el momento de la operación misma de diferenciación:

[...] nuestra exigencia [la de Glanville y Varela] acerca de una diferenciación unilateral, la cual se distingue a si misma [R]], resuelve no solamente el problema del regreso infinito de las diferenciaciones, mismas que se deben marcar dentro de diferenciaciones, sino que ya no se necesita un espacio antecedente, dado que la diferenciación ya no divide al espacio. ${ }^{74}$.

32. Ya habíamos anotado que Spencer Brown presupone como dadas a priori la "idea de la diferenciación" y la "idea de la designación" en el desarrollo de su lógica y que, por ello, es confrontado con el problema del comienzo de un comienzo, el cual resuelve monológicamente: su cálculo se basa en "[...] un acto primitivo único [...] Draw a distinction! ${ }^{\text {. }} .{ }^{75}$ Ahora bien, Glanville y Varela no parecen proceder de manera completamente diferente al mismo Spencer Brown, a pesar de su intento de someter a una revisión rigurosa las Laus of Form de Spencer Brown. Para llevar el problema del co-

72 Ibid., pp. 170-171. Contenido de un trabajo que redactó Ranulph Glanville en cooperación con Francisco J. Varela.

73 "Si lo hubiera, no habría ningún problema de contenido, dado que el contenido se encontraria dentro de la misma diferenciacion marcada." (Ibid., p. 153).

74 lbid., pp. 153-154.

Ibid., P. 170. 
mienzo de un comienzo hacia una solución, Glanville y Varela tratan de volver plausible adicionalmente, con la ayuda de los ejemplos figurativos de una cinta de Moebius y de una manguera de Klein, su propuesta de una "diferenciación unilateral" que no logramos comprender. ${ }^{76}$ No obstante, ofrecen la justificación real con el concepto del objeto (de Glanville), que consideran como una generalización del concepto de la autopoiesis. Es sobre todo Glanville quien tiene la intención de resolver, con el concepto del objeto, el problema del origen de aquello que circula generalmente como "autopoiesis". ${ }^{7}$ Ahora bien, los problemas del "surgimiento de la autopoiesis", del "comienzo de un comienzo" y de la "emergencia de la autorreferencia", son problemas funcionalmente equivalentes ${ }^{78}$ al problema principal . que formulamos en el capítulo II acerca de la complejidad, de la siguiente manera: ¿cómo es posible la unidad de lo diverso? o ¿cómo es posible algo como "algo"?

33. El concepto del objeto de Glanville corresponde, en cuanto a su pretensión, al concepto de la autopoiesis de Maturana, Varela y Uribe. ${ }^{79}$ Ahora bien, ¿qué es un objeto en el sentido de Glanville? Un objeto es un constructo menta ${ }^{80}$ capaz de observarse a si mismo: dispone de un medio de observación llamado "capacidad de modelo" y de dos roles, el rol auto-observador y el rol auto-observado, mismos que ${ }^{4}[. .$.$] no existen simultáneamente y, por ello, cambian dentro$ del tiempo [...]" ${ }^{n}{ }^{81}$ Estos dos roles complementarios están "forjados juntos" dentro de la unidad del "objeto" ${ }^{82}$ Un objeto semejante "[...] se

${ }^{76}$ Ibid., p. 153.

$\pi$ "[...] de todos los trabajos acerca de la autopoiesis, ninguno se ha ocupado de su origen como una explicación [...] En este artículo se relaciona el concepto de la autopoiesis con el concepto más general y más formal de un objeto [...]". (Ibid., p. 61).

${ }^{78}$ Acerca de la equivalencia de estos problemas diferentes, véase Teubner, 1987b. En este lugar, Günther Teubner aborda los diferentes planteamientos acerca de la explicación de la emengencia autopoiética o autorreferencial.

79 Véase en este contexto el trabajo clásico de Maturana/Varela/Uribe, 1985, pp. 157-169, contenido en Maturana, 1985.

Bo "Los objetos son constructos mentales y no se deberían confundir con algún tipo de substancia material, o buscarse dentro de la naturaleza." (ubid., p. 11).

${ }^{81}$ lbid., p. 62.

${ }^{82}$ Idem. 
autoestabiliza por sí mismo por medio de su autorreproducción. Es [RJ] autónomo y único, ya que es una unidad autopoiética, aunque sea tanto más abstracto también menos 'biológico' de lo que exige el concepto de la autopoiesis. ${ }^{n 33}$ Con ello, Glanville comienza con su concepto del objeto generalmente de manera dialógica, ya desde el principio con dos roles diferentes que operan autorreferencialmente.

No queda claro si se deben considerar como respectivamente autorreferenciales las formas observada y observante del objeto. En otro lugar Glanville formula: " $i c o$ mo puede estar seguro de sí mismo el conocedor [que ocupa entonces el rol observante], cómo puede distinguirse a sí mismo? Sabiendo de su propia existencia, refiriéndose a sí mismo [...] y a la inversa, debe adjudicar esta característica del autoconocimiento de la autorreferencia también a lo conocido [al rol observado], si quiere comprender lo conocido [...] como una interacción. Llamo objetos [...] a estas entidades." ${ }^{84}$ Aqui es evidente el hecho de que se hacen posibles la interacctón y, con ello, el mutualismo o el diálogo, solamente si el objeto se divide en dos roles auțorreferenciales.

No nos queremos ocupar más en profundidad de las sutilezas del concepto del objeto, dado que nos importan solamente las condiciones iniciales del concepto y, con ello, una posible solución del problema del comienzo de un comienzo.

34. Resumimos: se puede decir que Glanville trata de acercarse al problema del comienzo de un comienzo de manera monológica, presuponiendo el concepto de la "diferenciación unilateral"; sin embargo, no puede justificar plausiblemente este concepto, en última instancia.

Se puede considerar como una curiosidad el concepto de una "diferenciación unilateral", o sea, de una diferenciación autodistinguidora. Sin embargo, una construcción semejante tiene su lógica. Glanville quiere comenzar autorreferencialmente, y es evidente que la auto-

\author{
${ }^{83} \mathrm{Idem}$. \\ 84 Glanville, 1988, p. 11.
}


rreferencialidad siempre implica bermeticidad. Si comienza - de acuerdo con el modelo de las Laws of Form de Spencer Brown-con sólo una diferenciación, entonces está obligado a deducir "todo lo demás" a partir de esta diferenciación originaria, en la forma de una lógica de emanación, lo que debe tener lugar internamente de acuerdo con el supuesto de la autorreferencialidad. Puede provocar admiración la meticulosidad con la cual él y otros autopoietas intentan resolver este problema (del comienzo de un comienzo) con la ayuda de una distinción, sobre todo, asimétrica. No conduce, en mi opinión, a una solución plausible.

Glanville se ve obligado a este paso debido a que basa sus reflexiones en la lógica de Spencer Brown de marcar una (precisamente sólo una) diferenciación. Pero en última instancia, y esto es decisivo, justifica su inicio de manera dialógica. Introduce subrepticiamente dos "socios" (dos "complejos", dos black boxes o la distinción egalalter) dentro del concepto de un objeto (interpretado autopoiéticamente): un conocedor u observador y un conocido u observado. Glanville (y con él Varela) procede de manera monológica en cuanto a la intención, sin embargo, procede realmente de forma doblemente contingente, y esto quiere decir dialógica, aparentemente sin darse cuenta de ello. En todo caso, nosotros no hemos podido encontrar en la obra de Glanville un argumento consistente que se ocupe explícitamente del problema del supuesto de una "diferenciación unilateral".

35. Ya hemos tematizado brevemente nuestra solución del problema de la constitución de un objeto como algo que significa "algo" en el capítulo acerca de la forma de la forma. Es un problema que se debe considerar, dentro de este trabajo, como central, que reaparece una y otra vez como constitución de algo como "algo", como problema de la formación de la dimensión social del sentido (lo concerniente a la sociedad o lo SOCIAL), como emergencia de autopoiesis o como operación de una operación. Recordemos que comprendemos la constitución de algo como "algo" como un relacionamiento de sucesos de, por lo menos, cuatro sucesos/elementos (= tetradización), los cuales se presentan en la figura de un entrelazamiento específico de dos distinciones (incluyendo sus respectivos dos lados), es decir, diferencia y diferenciación. 


\section{Relaciones}

- El concepto de tríada de Ph. G. Herbst

36. Niklas Luhmann se refiere, en el contexto de la explicación de la función de los límites, a la forma de triadización de Herbst, con la intención de evitarla debido a su forma simétrica: "Con el concepto abstracto del límite, con el concepto de una mera diferencia entre sistema y entorno, uno no puede decidir si el límite pertenece al sistema o al entorno. ${ }^{855} \mathrm{Y}$ en el pie de página siguiente comenta: "Acerca de ello, véase a Herbst, en el lugar citado [página 88 y ss.], con la consecuencia de una triadización del planteamiento de conceptos fundamentales. Las reflexiones bosquejadas arriba en el texto sirven, desde la técnica de construcción de la teoría, para evitar la mencionada triadización. ${ }^{866} \mathrm{El}$ concepto de la tríada de Herbst está construido realmente de manera simétrica -como lo veremos-y, por ello, no es utilizable para la elaboración de una "lógica de las distinciones". Teniendo a la vista este problema, introducimos, por lo tanto, dos distinciones diferentes: una "diferencia" simétrica y una "diferenciación" asimétrica. Hemos visto que Spencer Brown y también Glanville (y naturalmente también Luhmann), intentan partir del supuesto de un "acto primitivo único", de una "diferenciación asimétrica", ya que utiliza el mismo concepto de una "diferenciación unilateral"), para explicar la "naturaleza del ser", "objetos", algo como "algo" u objetos sociales. Hemos demostrado que ambos se ven obligados - no obstante, sin legitimar un procedimiento semejante- a proceder mutual o dialógicamente: Spencer Brown, dividiendo la primera diferenciación desde el principio en dos lados y Glanville, postulando dos roles de observación dentro de su concepto del objeto y, con ello, comenzando también dialógicamente. Dentro del marco del proyecto de una teoría de las distinciones, mismo que aún debemos presen$\mathrm{tar}^{87}$ trataremos de demostrar que se puede proceder, de hecho, sólo de manera dialógica. Dentro de la dimensión del tiempo, ciertamente no es posible comenzar de otra manera que marcando un comienzo por medio de la realización de, por lo pronto, solamente una jugada. A este respecto, se debe dar la razón al procedimiento de las Laws

ss Luhmann, 1984, p. 53.

${ }^{86}$ Idem.

m Véase capítulo I acerca de la lógica de las distinciones. 
of Form de Spencer Brown, que comienzan con la indicación "iMarca la diferencia!”. ¿Cómo deberia comenzar - dentro del tiempo, bien entendido-, sino comenzar comenzando simplemente? Sin embargo, ni Spencer Brown ni Glanville aclaran este problema de la "marcación de una diferenciación $n^{n}$, lo que tiene como consecuencia que la "naturaleza" de aquello que designan como "diferenciacion" permanece en la oscuridad.

Por lo demás, vemos que conceptos como "diferenciación", "diferencia", "distinción", "separación" son utilizados por la mayoría de los autopoietas, unas veces como sinónimos, otras veces con significados diferentes. Esta praxis recuerda a la utilización del concepto différence por parte del filósofo parisino Jacques Derrida, mismo que trata de relacionar con éste los conceptos semánticos del "aplazamiento", de la "diferenciación", de la "discusión" y de la "espacialización". Por ello, Bernhard Waldenfels habla con razón de la différence de Derrida como de un "monstruo lingüístico" ${ }^{83}$ En el campamento de los autopoietas existen, sin embargo, también esfuerzos con fines de aclaraciones conceptuales. Aquí mencionamos, sobre todo, a Helmut Willke (1987d) y Gerhard Roth (1987b). Naturalmente no pasamos por alto la circunstancia (conocida) de que los conceptos pueden permanecer como conceptos solamente en su ambigüedad semántica, como lo formula Reinhard Koselleck: "Un concepto debe permanecer como ambiguo para poder ser concepto. El concepto está ligado ciertamente a la palabra, no obstante, es si multáneamente más que la palabra. Una palabra se convierte [...] en concepto cuando se integra en su totalidad a la palabra la riqueza del contexto político-social de significación, dentro del cual [...] es utilizada una palabra [...]. Los conceptos son [...] concentrados de muchos contenidos de significado. ${ }^{89}$ Ya Nietzsche tiene la concepción de que un concepto se escapa a una definición, la cual trata de abarcar a todo un proceso de manera semiótica. Definible sería solamente aquello que no tuviera ninguna historia (idem). Es así como un concepto debe hacerse cada vez más indeterminado, entre más circunstancias debe abarcar. Y la arquitectura de una teoría sociológica dispuesta universalmente, como la aqui presentada, ciertamente se ve obligada a trabajar con conceptos relativamente indeterminados, si quiere presentar lo general. No obstante, existe el peligro de que el concepto

Waldenfels, 1987, p. 543.

${ }^{89}$ Koselleck, 1972, pp. xxII-xxuII. 
pierda todo contomo y, con ello, su eficacia para la técnica de construcción de la teoría, si se sobrecarga con todas las condiciones de la posibilidad de una circunstancia. ${ }^{90}$

37. El científico social noruego Ph. G. Herbst presenta, ya en 1976, un proyecto que se ocupa en primera instancia de las condiciones de partida de las Laws of Form de Spencer Brown. ${ }^{91}$ Para nosotros, este trabajo es de interés porque describe con una cierta meticulosidad las exigencias minimas de la lógica de Spencer Brown. Para Luhmann, el trabajo de Ph. G. Herbst tiene un significado central. Luhmann formula con referencia a Herbst: "Se puede justificar de manera más abstracta la diferencia entre sistema y entorno, si uno regresa a la disyunción general, primaria, de una teoría de la for$\mathrm{ma}$, misma que define solamente con la ayuda de $u n$ concepto de diferencia: forma y diferente." ${ }^{\text {} 92}$ También nosotros queremos lograr precisamente esto, sin embargo, no solamente sobre la base del concepto de distinción, como lo efectúa Luhmann, sino sobre la base de una relación mutual, "dialógica", entre las distinciones "diferenciación" y "diferencia". Sobre este trabajo queremos formular, por nuestra parte, aquello que comprendemos como una "unidad mínima" "Social", misma que debe conformar, por así decir, el "material de construcción" de la SOCIEDAD. Sólo la exposición de una unidad fundamental semejante nos da la posibilidad de demostrar cómo procesan los distintos tipos de sistema del sentido en los diferentes niveles de la SOCIEDAD. Si se quiere explicar, por ejemplo, cómo comunica socialmente el sistema del sexo, mismo que está ubicado en el nivel de la forma corporal de comunicación, entonces no se pueden utilizar como unidad de explicación los "sentimientos" o "pensamientos", ya que estas formas de comunicación se refieren correspondientemente al nivel afectivo y al personal de sistemas del sentido, y no al nivel corporal de sistema del sentido. Por el otro lado, y esto representa la necesidad de una unidad fundamental de lo social, todos los tipos diferentes de sistemas del sentido deben reproducir SOCIABIIDAD. Sin embargo, esto se puede demostrar solamente si se pueden encontrar y describir unidades que: prime-

${ }^{90}$ Acerca de ello, también Luhmann, 1987e, p. 5.

${ }^{9}$ Herbst, 1976, pp. 67-106.

92 Luhmann, 1984, p. 35. 
ro sean más generales que las unidades comunicativas para la socialidad, personalidad, afectividad y oportunidad. Segundo, se puedan articular dentro del marco de la SOCIEDAD: deben poder reproducir la dimensión social de cualquier sentido de manera plausible. Esta circunstancia se puede describir con la ayuda de una metáfora de la siguiente manera: necesitamos material de construcción para la construcción de una casa. Ahora bien, la construcción de la casa, sobre todo la de sus habitaciones, tiene lugar naturalmente con la ayuda de un material semejante de construcción. ${ }^{93}$ Transferido a la teoría de los sistemas de la sociedad ( = TgS): la "unidad social" buscada es el material de construcción de lo SOCiAL, y los distintos tipos de sistemas del sentido como corporalidad, afectividad, individualidad y socialidad representan las diferentes habitaciones y sus instalaciones. Se puede formular esta circunstancia también de la siguiente manera: la descomposición de un sistema en elementos y sus relaciones conduce a una teoría de la complejidad del sistema y a la teoria de la unidad fundamental SOCAAL. La descomposición de un sistema en distinciones de sistema/entorno conduce hacia una teoría de la diferenciación del sistema y hacia una teoria de los tipos de sistema del sentido (o de los estilos de expectación). De manera similar piensa también Luhmann, ${ }^{94}$ sin embargo, con la diferencia de que nosotros (TgS) distinguimos entre, por un lado, complejidad del sistema y elementos fundamentales SOciales y, por el otro lado, diferenciamiento del sistema y tipos de sistemas del sentido (= estilo de expectación). Dentro del marco de la TsS no se prevén tipos de sistemas del sentido ( $=$ estilos de expectación) ni el elemento fundamental SOCIAL. Comprendemos como unidad fundamental ${ }^{95}$ de la SOCIEDAD la unidad de la distinción entre COMUNICACIÓN y ACCIÓN, una unidad, la cual corresponde a la unidad de la distinción entre diferencia y diferenciación, en el nivel de una teoria general de las distinciones. Dado que no procedemos sobre todo de manera teórica sistémica, sino de manera teórica en cuanto a la distinciones, resultan naturalmente entre ambas posiciones, tanto traslapes como también distinciones, mismos que no queremos aclarar más aquí (figura 14).

${ }_{93} \mathrm{La}$ TsS introduce la distinción de diferenciamiento del sistema/complejidad del sistemia con la ayuda de una metáfora similar. (Ibid., pp. 41 y ss.).

9t Ibid., p. 41.

95 Recordamos que una unidad siempre es, en este contexto, una unidad de la distinción [...] de lo que sea. 


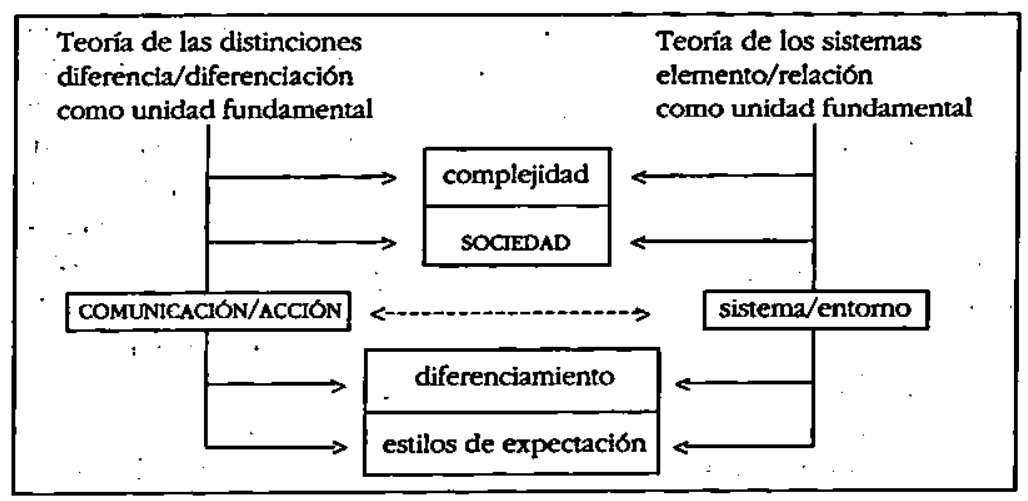

38. "[...] does the infant know in making its first intentional distinction between itself and its surroundings, that in this simple act he has generated in its consequences the whole field of logic?"96 En este planteamiento de Herbst se nota que su intención es la de establecer un fundamento lógico dentro del ámbito de la dimensión social. No por casualidad escoge para esta empresa la lógica de Spencer Brown, misma que opera con el tiempo, como punto de partida. Si se parte del supuesto de que el estado del mundo consiste en un vacío cognoscitivo, entonces surge la pregunta acerca de cómo se genera el hecho de que emergen, sobre la base de distinciones, "cortes" semejantes o "grietas causales" como finitud/infinidad, sujeto/objeto, sistema/entorno o ser/no ser. Aun más, la pregunta de Herbst es, en este contexto: "[...] what is the minimal requirement wich is sufficient for a world of this type to be generated?"97 Transferido a la TgS, podemos decir: ¿cuáles son los requerimientos mínimos para la generación de lo SOCIAL?

39. Herbst analiza three major theoretical approaches con referencia a lógica y matemática, mismos que han alcanzado, según su opinión, una cierta prominencia dentro de la tradición occidental del pensamiento y que se presentan una y otra vez en diferentes formas: "idealismo lógico-empírico", "empirismo" y una mezcla de los dos que designa como "planteamiento de Kant". Los tres plantea-

${ }^{96}$ Herbst, 1976, p. 84.

${ }^{7}$ Idem. 
mientos implican una distinción, es decir; aquélla de mundo trascendentaV/empírico. La tradición del idealismo (platónico) parte del supuesto de una concepción del mundo, la cual supone "objetos ideales" dentro de un mundo trascendental, mismos que se pueden realizar, transferidos a un mundo, solamente de manera aproximada. El empirismo (positivismo) parte del supuesto de que todos los "objetos" de la lógica y matemática se encuentran en este lado del mundo y, por ello, están dados empíricamente y son loćalizables. Finalmente se debe mencionar el planteamiento de Kant, mismo que parte . del hecho que las categorías lógicas fundamentales como espacio, tiempo o causalidad, poseen un carácter trascendental; en cambio los fenómenos, mismos que son coordinàdos por mencionadas categorías, son de origen empírico. De acuerdo con Herbst, se debe ver lo particular de la lógica de Spencer Brown en comparación con los planteamientos antes mencionados, en el hecho de que el planteamiento de las Laws of Form no implica ninguna distinción "concreta" en la construcción cognoscitiva del mundo, como trascendente/ inmanente o idealista/realista, sino que parte de la distinción como tal. ${ }^{98}$ Por ello, la circunstancia relevante es que Spencer Brown no utiliza una determinada distinción localizable fenomenologicamente como frio/caliente, bello/feo, ser/no ser o casualidad/necesidad para el desarrollo de su cálculo, sino la distinción misma (no obstante, como diferenciación asimétrica, por lo cual Spencer Brown se ve obligado a proceder monológicamente y, con ello, se debe confrontar con paradojas y tautologías, como lo mencionamos en varias ocasiones). Distinción es para él un acontecimiento operativo, mismo que a continuación genera o permite que emanen realmente todos los demás sucesos basados en distinciones menos "generales".

98 "It is in this context that a discovery by Spencer Brown (1969) tums out to be a remarkable step forward in the history of Western thought. He finds that the making of a primary distinction [R], wich is unexamined given in each of these theories [idealismo, empirismo, planteamiento de Kant RJ], is by itself sufficient to generate the structure of logic. If then the primary distinction, say into an internal and external world is made, and this by itself is sufficient to generate the structure of logic, then the structure in terms of wich phenomena are apprehended can be located neither in an internal or subjective world nor in an extemal or objective world, and in this case both idealist and materialist type theories can be rejected. The work of Spencer Brown has clearly ramifications in allmost all branches of human thought, and is likely in time to lead to basic reformulations of Western philosophies." (Herbst, 1976, pp. 85-86). 
40. Spencer Brown y con él también sus críticos parten, como ya lo hemos realzado, del supuesto de una operación primitiva única del diferenciar y no de una operación del "distinguir", misma que incluye, de acuerdo con nuestra ( $\mathrm{TgS}$ ) terminología, tanto a las diferenciaciones (asimétricas) como también a las diferencias (simétricas). Herbst tampoco acepta la premisa de Spencer Brown. Es decir que un análisis más exacto de aquello que resulta del cumplimiento de la indicación "iMarca una diferenciación!", muestra que están involucrados por lo menos tres momentos diferentes en la operación de diferenciación: si se marca una diferenciación dentro de un mundo aún no "dañado" cognoscitivamente, entonces uno tiene que vérselas con los dos lados de la diferenciación y con el límite que separa estos dos lados. Sin embargo, lo que se llama "mundo aún no dañado cognoscitivamente" y que se considera como equivalente a un "espacio vacío", representa un supuesto erróneo, según Herbst, ya que no se puede presuponer ni siquiera la "nada", si se parte de una prime$r a$ diferenciación semejante. Esta afirmación se puede plausibilizar con la ayuda de la siguiente diferenciación "más concreta": es decir, si se parte del supuesto de la diferenciación "interno [límite] externon", entonces uno tiene que vérselas con la diferenciación clásica, la cual genera "espacio". Ahora bien, ¿qué sucede si se omite uno de los elementos de diferenciación, o dos de ellos coinciden y, por ello, se hacen idénticos? Si desaparece uno de los elementos/sucesos, mismos que conforman la estructura de la diferenciación, entonces desaparece también aquella diferenciación que constituye al espacio. Por lo tanto, no existe ningún espacio, si perduran o solamente los sucesos "interno" y "LIMTTE", "externo" y "LfMITE" o "interno" y "externo" (obviamente sin LfMTTE). Segundo, la diferenciación desaparece también si se alcanza una identidad de dos elementos/sucesos. Se puede efectuar el mismo procedimiento con cualquier otra diferenciación (figura 15).

- Los tres elementos/sucesos de constitución de la semántica del espacio:

"interno"

- "[LfMrTE]"

"externo"

41. Con la distinción ${ }^{99}$ que constituye al espacio, o sea, con la distinción interno/externo se hace evidente que el espacio no "está pre-

'99 "Distinción" es nuestra terminología.. Herbst utiliza constantemente la semántica de la diferenciación. 
sente" antes de la mencionada distinción, por ejemplo, un espacio vacío, mismo que a continuación se separa mediante un límite. La dimensión espacial del sentido es constituida primeramente por la distinción espacial misma, la cual consta de los lados "interno" y "externo". Y el "vacuo" tiene sentido solamente, si la espacialidad ya fue constituida. ${ }^{100} \mathrm{Es}$, por lo menos, erróneo suponer que una distinción consiste solamente en un acto de "delimitación quebradiza": constituye simultáneamente también la semántica particular de la correspondiente distinción. Esto se puede aclarar con el apoyo de la distinción antes/después o pasado/futuro, misma que conduce a la constitución de la dimensión del sentido "tiempo". Precisamente el límite como "ahora". o como "presente" remite a la dimensión del sentido tiempo con su distinción de antes/después o de lo pasado y lo futuro. Por ello, el valor límite es aquel que se refiere a la especificidad de la respectiva distinción: no se trata de espacialidad (adentro/ afuera) o sexo (hombre/mujer) o pertenencia (nacional/extranjero), sino precisamente del "tiempo" (figura 16).

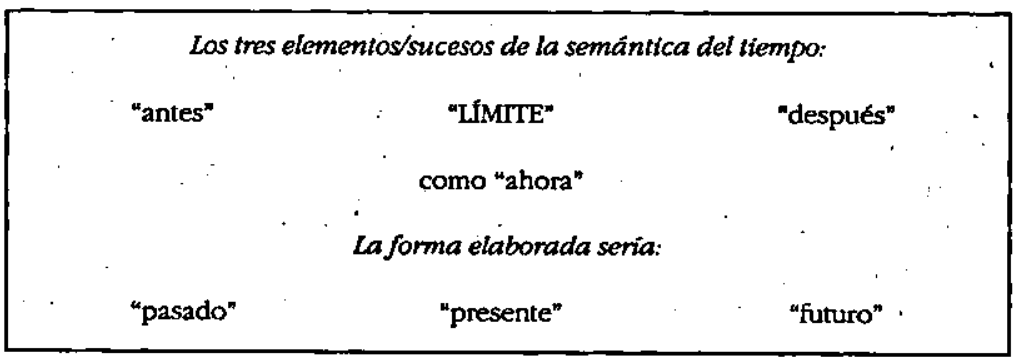

42. Hemos podido determinar con Herbst que todo aquello que se podría designar como una "unidad cognoscitiva", como un "algo", debe componerse de por lo menos tres elementos, los cuales se relacionan entre sí. Esto significa, expresado con la ayuda de una semántica espacial, que debe existir un lado interior, un límite y un lado exterior para que se procese "espacio". Por ello, se pueden designar como una triada aquellos minimal requirements que Herbst

${ }^{100}$ Aquí se debería trabajar con la distinción "vacio/plenitud", con lo cual se hace evidente que puede haber "plenitud" solamente con respecto a "vacío" y viceversa. 
presupone para la emergencia de algo como "algo". ${ }^{101}$ No obstante, una observación más exacta del concepto de la tríada demuestra que una "triadización" semejante no es suficiente como para causalizar cognoscitivamente o "dañar" al "mundo" con la ayuda de las distinciones, dado que ¿quién o qué distingue la supuesta distinción primaria? Preguntado de otra manera: ¿cómo se genera el hecho de que la distinción de interno/externo (o de sistema/entorno u hombre/mujer) no se observa como la verdadera y única distinción universal y enfáticamente exclusiva, misma que puede existir en general, sino como una forma especifica de distinción, es decir, como espacialidad (y no como sexo [hombre/mujer] o como economía [tener/no tener])? Y más: ¿quién nos dice que, por ejemplo, la distinción de ser/no ser o de frí/caliente o de blanco/negro no sea la, sino una entre muchas otras distinciones posibles? Los respectivos lados de una distinción representan al valor inmanente de una distinción semejante: "hombre" remite a "mujer", "frío" a "caliente", "cercano" a "lejano", etcétera. Pero "sexo" (hombre/mujer), "temperatu-

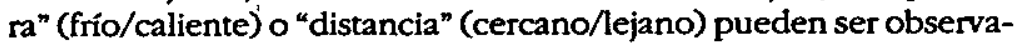
dos solamente como distinciones específicas cuando se observa una primera observación de distinción por medio de una segunda observación de distinción. Una distinción singular como tal es como el agua para el pez: no se puede percibir cognoscitivamente. Solamente debido al hecho de que se refieren la una a la otra (obviamente con sus respectivos lados y límites) se puede alcanzar una relativización de la distinción correspondiente y, precisamente debido a ello, se puede observar una constitución mutual. Por ello, las distinciones como "diferenciación" y "diferencia" llegan al mundo (cognoscitivo) por medio de la coevolución. Se requiere, por lo menos, dos distinciones o de cuatro elementos/sucesos, para poder constituir algo como "algo" a través de las distinciones. Ya que cualquier distinción consta de dos lados y se requiere, por lo menos, de dos distinciones, para poder constituir algo como "algo", en las cuales están involu-

101 "The point of departure is a world in wich nothing definable exists, and wich is thus void of any distinguishable characteristics. The characteristics of the primary distinction wich as we have seen leads to the simultaneous genesis [R] of three [R]] distinguishable components can be stated in the following axiom: The primary conceptual unit is given as a triad of distinguisbable undefined components, wicb are definiable in terms of one another." (Herbst, 1976, p. 90). 
crados por lo menos cuatro elementos/sucesos. Por lo tanto, no es suficiente una triadización como supone Herbst. La conclusión lógica de nuestra argumentación hace necesaria una tetradización. En relación con la espacialidad, la tétrada consiste en: el lado interior, el valor límite, el lado exterior y la referencia hacia otra distinción (figura 17).

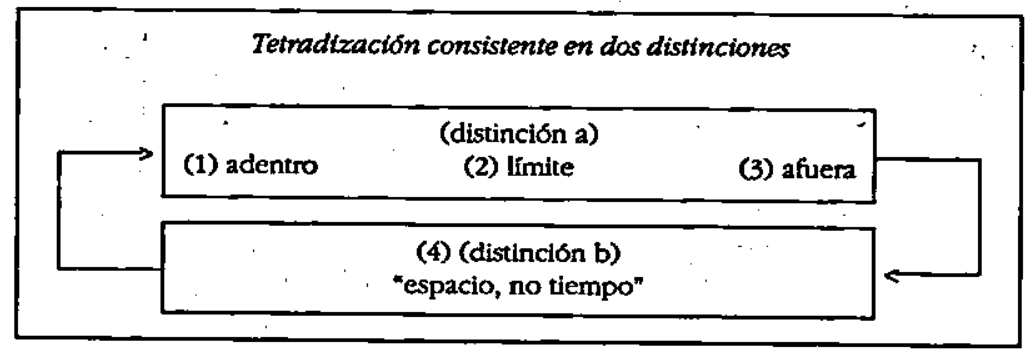

Se puede formular la circunstancia antes explicada también de la siguiente manera: cualquier distinción tiene una vista interior y una exterior, puede ser observada (jsic!) desde la perspectiva del participante y desde la perspectiva del observador, se puede explotar interna y externamente.

43. Si se pudiera observar una distinción en forma aislada (quién observa al observador, el cual observa a la distinción en cuestión, por su parte?), entonces Herbst tendría realmente razón con su triadización. No obstante, precisamente esto es un supuesto fenomenológicamente irrealista, ya que no tendríamos ninguna comparación para la distinción en caso y, por ello, ni siquiera sabriamos que se trata de una distinción. Como resultado de estas reflexiones suponemos una tetradización como la condición mínima para la constitución de algo como "algo". Con ello, los lados de la distinción correspondiente expresan su valor inmanente o interno: "adentro" remite a "afuera", "grande" a "pequeño", "poder" a "impotencia" y viceversa. Pero ¿cómo llegamos a "espacio" (adentro/afuera), "magnitud" (grande/pequeño) o "política" (poder/impotencia)? A través de una referencia hacia el valor límite de la distinción. Es decir que el limite, que une y simultáneamente separa los dos lados de una distinción, representa una de las distinciones que, sin embargo, solamente es observable como una, sobre la base de otra. Por ello, el límite hace aparecer el 
valor externo o "trascendental" de la distinción en caso (observación exterior).

Si transferimos las reflexiones anteriores al nivel de la teoría social, entonces podemos formular: con ello tenemos frente a nosotros las condiciones mínimas con que debe cumplir una unidad como elemento básico de lo socıal: debe consistir en, por lo menos, cuatro elementos o sucesos, o sea, en dos distinciones, las cuales, empero, no pueden existir aisladamente por sí solas, sino que forman una unidad en la distinción solamente como relación mutua.

Esto es un supuesto con consecuencias de amplio alcance, ya que con ello también está dicho que cualquier forma de identidad, de autonomía, debe ser una tétrada relacional. Además, queremos anotar que también la autorreferencia puede generarse sólo sobre la base de un relacionamiento de cuatro partes. Günther Teubner se acerca mucho a este fenómeno cuando anota: "La autorreferencia disuelve la unidad de una unidad y la sustituye por la tríada del referente, referidoy relación entre ambos. ${ }^{102}$ Por lo demás, Teubner se apoya aquí en Ranulph Glanville. ${ }^{103}$

Por lo tanto, una unidad es una relación entre cuatro, una "cuadriga", una relación tetrádica, en una palabra, una tetradización. En el nivel de la SOCIEDAD se trata de las distinciones COMUNICACIÓN y ACCIÓN, mismas que están compuestas respectivamente de los elementos información/comunicación y finalidad/medios (figura 18).

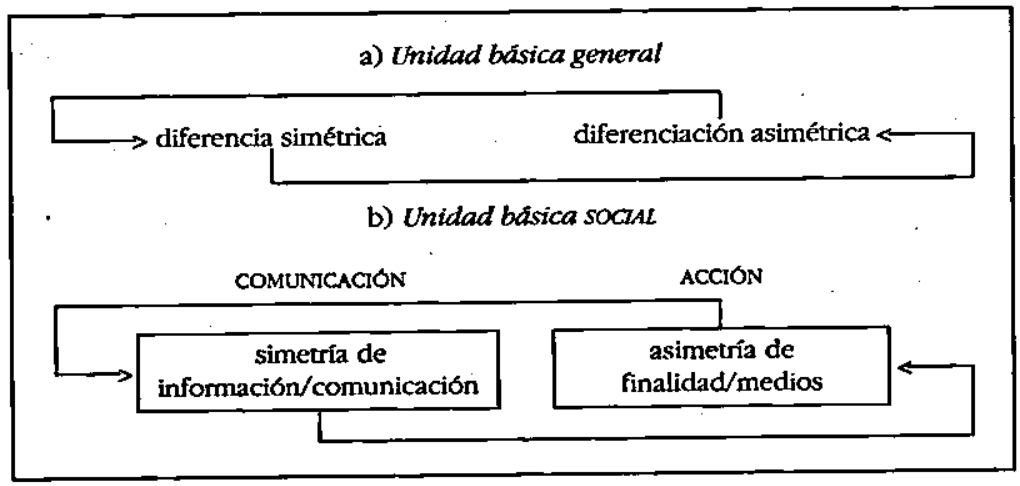

${ }^{102}$ Teubner, 1987b, p. 103.

${ }^{103}$ Glanville, 1988, pp. 61-78. 
44. Un segundo punto a criticar en el desarrollo de las Laws of Form por parte de Herbst (además de que no se trata de un relacionamiento tetrádico, sino de uno triádico en cuanto a la constitución del mundo y de la SOCIEDAD): la forma de relacionamiento de sus elementos/sucesos postulados posee un carácter exclusivamente simétrico, y esto no es precisamente un supuesto realista. ¿Por qué? Los acontecimiento con un desarrollo simétrico no muestran ninguna prioridad, ningún predominio, ninguna unilateralidad, ninguna jerarquía. Sin asimetrías, no obstante, no existe ninguna posibilidad de conexión y, con ello, ninguna posibilidad de Acción. Una ACCIÓN puede tener lugar (desde la perspectiva de la teoría de la operación, no desde aquélla de la teoría de las distinciones), solamente si una situación está estructurada de tal manera que existe la posibilidad de una DECISIÓN: o "esto" o "aquello", pero no ambas cosas a la vez, ni tampoco ninguna de las dos. ${ }^{104}$ Dentro del mundo de Herbst, solamente habría un "baile de sucesos comunicativos" que no encontrarían conexión en ninguna parte.

45. ¿Cómo debërían estar relacionados los sucesos tetrádicos para que se puedan constituir estructuras, para que se produzca un mundo cognoscitivo? Hacemos la propuesta de marcar el comienzo de un "daño al mundo" o el inicio de su causalización no con una distinción, como sucede normalmente entre los autopoietas, los cuales trabajan con la lógica de Spencer Brown, sino con un supuesto coevolutivo de dos distinciones diferentes: una diferencia simétrica y una diferenciación asimétrica. ${ }^{105}$ Con esta propuesta está ya asegurado el relacionamiento tetrádico, dado que se trata de dos distinciones con sus correspondientes lados. Con ello, la distinción diferenctación implica como distinción asimétrica un lado dominante, y esto quiere decir que puede aparecer solamente como distinción unila-

104 Ver acerca de ello los teoremas del tercero excluido y de la contradicción para las ACCIONES en C.F.v. Weizsäcker 1977, p. 302, mismos que comentaremos explícitamente más adelante y los cuales integraremos al concepto de la pragmática de las distinciones (distinción entre operación y distinción):

${ }^{105}$ Herbst asume una posición similar en relación con el fenómeno de la emergencia de las distinciones cuando formula, refiriéndose al relacionamiento de los elementos de partida: "The characteristics of the primary distinction which as we have seen lead to the simultaneous genesis [R]] of tbree [RJI distinguishable components [...]". (Herbst, 1976, p. 90). 
teral: cierto, no falso; bueno, no malo; bello, no feo, etcétera. Tiene la forma - visto desde la dimensión del tiempo- de un lado-ya-designado, o sea, una forma de pasado que llamamos experiencia. La distinción diferencia consiste por el contrario en dos lados orientados simétricamente, en dos lados aún-no-designados $\mathrm{y}$, con ello, aún-no-decididos: café y/o té; hoy y/o mañana; esto y/o aquello, etcétera. Su forma es - visto temporalmente- futura y la llamamos expectación. Con el supuesto coevolutivo de una distinción simétrica y una asimétrica, están decididas las vías para el comienzo del "daño cognoscitivo al mundo". Todo lo demás es entonces cuestión de tiempo (figura 19).

\begin{tabular}{|lll|}
\hline & \multicolumn{2}{l}{ Dimenstón objetiva de la teoria de las distinciones: } \\
Teoría de las distinciones: & $\begin{array}{l}\text { diferenciación } \\
\text { asimétrica }\end{array}$ & $\begin{array}{l}\text { diferencia } \\
\text { simétrica }\end{array}$ \\
& Dimensión del tiempo de la teoria social: \\
Teoría social: & experiencia & expectación \\
\hline
\end{tabular}

46. En resumidas cuentas, se puede decir que la unidad básica buscada de lo social consiste en un relacionamiento tetrádico que se genera a través de dos distinciones diferentes, una diferencia simétrica (es decir COMUNCACión) y una diferenciación asimétrica (o sea ACCION). Por ello, el comienzo del comienzo siempre es mutual, dialógico o conversacional: tiene lugar sólo sobre la base de una constitución múltiple, ${ }^{106}$ la cual genera aquello que luego se designa como "unidad". Por lo tanto, la constitución de una unidad es posible solamente sobre la base de dos distinciones. Con ello, los elementos (los lados) de ambas distinciones se relacionan de tal manera que de ello emerge la "unidad". Por ello, la unidad siempre es también distinción. ${ }^{107}$

${ }^{106}$ Utilizamos este concepto de la constitución mültiple o contingencia doble en una versión ligeramente distinta a la de la TsS. Sin embargo, ver Luhmann, 1984, pp. 65 y ss. Acerca de la versión del concepto dentro del marco de una teoría de las distinciones, ver el capítulo III acerca de la autorreferencia.

${ }^{10}$ Definimos la unidad - como siempre-como unidad de la distinción entre diferencia simétrica y diferenciación asimétrica. 


\section{Contextos}

- El concepto de policontextualidad de Gotthard Günther

47. El concepto de policontextualidad de Gotthard Günther es de interés para nosotros por dos razones: primero, existe la circunstancia de que Luhmann aparentemente estima mucho la obra de Günther. Esto se puede comprobar fácilmente con la ayuda de las numerosas citas con las cuales Luhmann intenta llamar la atención una y otra vez sobre el significado de los trabajos de Günther para la propia teoría. ${ }^{108} \mathrm{La}$ segunda circunstancia se debe ver en el hecho de que los trabajos de Günther alcanzan un significado especial dentro del marco de una pragmática de las diferencias (TsS), o como nos (TgS) gustaría decir, dentro del marco de una pragmática de las distinciones.

No consideramos como completamente justificada la afirmación algo dura de C.F.v.Weizsäcker sobre Gotthard Günther: "Gotthard Günther es un hombre muy original, sin embargo, es un soñador. Si se dice que existe la conciencia y que existe la materia y luego que existe la información como un tercero, entonces yo diria que las primeras dos no existen y, por ello, el tercero es superfluo. "109 Por un lado es correcto afirmar que Günther representa un tipo de "teoría de tres mundos" al estilo de Popper o Habermas, cuando parte del hecho de que existen "conciencia", "objetos" e "información". Por èl otro lado, Günther presenta una "teoría de la constitución del mundo", misma que se puede ubicar en las cercanías de C.F.v. Weizsäcker. En todo caso, queremos demostrar aquí que el concepto de información de Günther no tiene un sentido tan superficial como lo sugiere su supuesto de un "tercer mundo" como "mundo de información". El concepto de información de Günther se puede explicar de manera plausible, dentro del marco de la teoría de la información

${ }^{109} \mathrm{La}$ conexión entre los planteamientos de Günther y los de la TsS parece haber tenido lugar a través de la persona de Helmut Schelsky. Véase por ejemplo, "La historia aún ampliamente oculta de la sociologia alemana entre 1933 y 1945 debe haber dado los primeros impulsos a Schelsky. Sus contactos con Hans Freyer, Amold Gehlen, pero también Gotthard Günther datan de esta época." Luhmann, 1984g, p. 1.

109 Weizsäcker, C.F.v., 1984a, p. 301. 
del propio C. F v. Weizsäcker: la información existe solamente "[...] entre dos niveles semánticos [...]". ${ }^{110}$

Ahora bien, aquí no queremos honrar la obra completa de Günther, sino que queremos tratar solamente un aspecto importante $y$ —en relación con sus propios trabajos — central, el cual es de interés también para el planteamiento de una tétrada, representado por nosotros. Se trata del supuesto de una "policontextualidad del mundo", mismo que se expresa claramente, sobre todo en el pequeño trabajo "Life as Poly-contexturality"."11

48. Ia cita de Johann Wolfgang von Goethe que elige Günther como lema de su ensayo, ya ofrece una referencia importante al problema de una policontextualidad: "Ningún ser vivo es un uno, siempre es un muchos. ${ }^{n 112}$ El punto de partida de Günther es la epistemología aristotélica que divide, de acuerdo con Günther, todo lo que "es" en la distinción de "ser" y "no ser". ¿Qué se quiere decir con esto? Todo aquello que se puede designar como existente, se puede reducir en última instancia al sustrato "ser": "The realness of the objects is always the same at the bottom, although it appears in infinitely differentiated properties [...] Being is an undifferentiated all-pervading universality and the many things and appearances in this world are only the more or less particular manifestations of an underlying general substance or essence, which is the same in everything that exists in the world [...] Being-in-general shows no distinctions. ${ }^{113} \mathrm{El}$ "ser" está condicionado por medio de la ausencia de toda diferencia (visto internamente), por ello es simétrico, según Günther.

Günther considera la ausencia de distinciones como igual a la simetría, una práctica realmente común. Nosotros, en cambio, distinguimos ambos conceptos de tal manera que la simetría se puede distinguir generalmente en el sentido de un "esto y/o aquello", y que, sin embargo, precisamente debido a ello cumple la misma función que debe cumplir el concepto de la falta de distinciones: es decir, indecisión. Formulado de otra manera: para tomar (visto desde la teoría de la operación) una DECrSIón, la cual debe llevar a la ACCión,

110 Ibid., p. 303.

"II Günther, 1979, 2.

112 Ibid., 2, p. 283.

${ }^{113}$ Ibid., 2, pp. 283-285. 
se debe haber generado anteriormente una distinción, misma que forma precisamente la base para una DECISION semejante. Sin distinción no existe ninguna posibilidad de DEcisión y, con ello, tampoco de ACCión. Una distinción simétrica como la de "tomar café y/o tén genera primeramente el mismo problema de una indecisión como el hecho de la falta de diferencias. Ambas formas de distinción son equivalentes en lo que concierne a su función de ocasionar la "indecisión". Optamos por el concepto de una distinción simétrica. Luhmann se decide por el concepto de una "diferencia sin diferencias", con lo cual define luego el sentido como sigue: "El sentido es [...] una categoría sin diferencias."

La única distinción entre "ser" y algo más es aquélla frente a la "nada", con lo cual se arregla su relación entre sí sobre la base del principio del tercero excluido: algo solamente puede o "ser" o "no ser". Esta distinción de "el ser y la nada" se puede superar difícilmente en cuanto a su universalidad y, por ello, se puede aplicar a todo aquello que se puede designar como un "algo". Ahora bien, el principio de la monocontextualidad se puede formular sobre la base de esta distinción ontológica principal de la siguiente manera: todo aquello que es, pertenece al ámbito del "ser"; lo que no pertenece a él, es precisamente "nada". No hay ningún lugar para un observador, dentro de una contextualidad estrictamente monovalente de este tipo, dado que en caso contrario se diría: para que el observador participe en el "ser", o sea, para que "sea", debe ser observable. No obstante, si fuera observable, entonces no podría observar, a la vez, el "ser", dado que él mismo también tiene cualidad de ser (¿debe observar acaso la "nada"?). Sin embargo, si no puede observar el "ser" - como hemos dicho, él mismo forma parte del "ser" - ¿cómo puede saber entonces que el "ser" existe del todo? Ahora bien, dado que la "nada". es lo suficientemente indeterminada, puede servir como superficie de proyección para la ubicación del observador como "sujeto". Ésta es una práctica de proyección, misma que se practica consabidamente desde Dionysius Areopagita, por ejemplo, en la forma de una "teología negativa", dentro de la tradición del idealismo alemán, en la forma de un "yo trascendental" o, para mencionar un ejemplo de la actualidad, con Jean-Paul Sartre en la forma de una conciencia negativa.

${ }^{114}$ Luhmann, 1984, p. 96. 
Respecto al concepto de una conciencia negativa formula Sartre en un diálogo con Simone de Beauvoir lo siguiente:

J.-P.S.: He leído a Heidegger, cuando estuve en prisión. Por lo demás, lo comprendi mucho mejor a través de Husserl que por sí mismo. Además, ya lo había leído un poco en 1936 [...] S. de B.: ah sí, me acuerdo que me pidió traducir grandes partes de ello. Creo que hemos discutido sobre ello cuando aún estaba en Rouen. Pero simultáneamente $E l$ ser y la nada se integraba al descubrimiento que usted habia hecho en Lo imaginario. J.-P. S.: Sí, exactamente. El descubrimiento de la Conciencia como nada [R]]."15

49. Ahora bien, el idealismo alemán es, de acuerdo con Günther, la primera tradición filosófica que comienza a romper con este mundo monocontextual y monovolante. Es sobre todo Georg Friedrich Wilhelm Hegel quien impone las medidas de un nuevo comienzo. No queremos abordar más de cerca los problemas que surgen a partir de la circunstancia de una operación paradójica con el supuesto de la monocontextualidad, ni tampoco queremos perseguir más las diferencias entre la tradición alemana, como, por ejemplo, aquéllas entre Kant, Fichte, Schelling o Hegel. ${ }^{116}$ Es suficiente si generalizamos el problema: si es obvio que el mundo puede mostrar una heterogeneidad sin par y si, por el otro lado, parece ser plausible (p. ej., mediante un supuesto teórico-evolutivo o.mediante una teoría del diferenciamiento) que la heterogeneidad se haya diferenciado por medio de formas homogéneas, ¿cómo se pueden armonizar entonces ambas cosas, heterogeneidad y homogeneidad? ${ }^{117}$ Reducir todo aquello que "es" al "ser", significa que "todo" es homogéneo, en última instancia, las diferentes formas en el mundo son solamente apa-

115 Beauvoir, 1983, p. 229. Sobre la base de una teoría operativa de las distinciones, argumentamos que se genera un "lugar vacío" debido a la ausencia de operación, mismo que ocasiona la emergencia de la observación. En este sentido existe una cierta similitud con la teoría de la conciencia de Jean-Paul Sartre. Véase sobre todo el capítulo acerca de operación y forma.

116 Sin embargo, véase Günther, 1979, 2, pp. 288-289.

${ }^{117}$ Rupert Riedel formula: "Dios ciertamente juega a los dados, como sabemos, pero también sigue igualmente sus leyes. Surgen nuevas cualidades a partir del crecimiento cuantitativo de capas determinadas jerárquicamente." (Riedel, 1984a, p. 123). 
riencia. Günther define la contextualidad como un ámbito que se determina por el principio del tercero excluido y que no puede ser abandonado internamente. ${ }^{118}$ Ciertamente se puede avanzar desde el "ser" hacia la "nada" y regresar nuevamente, dentro de la ontología del ser; sin embargo, el hecho de cruzar la frontera no modifica el carácter esencial de la distinción: todo aquello que "es" se puede definir solamente con miras a todo aquello que "no es", y viceversa. A ello se añade que ningún acto de cruzar el límite lleva a ninguna parte, dado que existe o el "ser" o la "nada". Con otras palabras, bajo el dominio del conocimiento de esta venerable distinción ontológica, no existe ninguna sedimentación, ninguna condensación, ningtna formación nueva de ninguna cosa. Esto es de hecho un supuesto extremadamente irrealista. Ahora bien, ¿existe una posibilidad de escapar de esta distinción generadora exclusivamente de homogeneidad, con la observación del principio del tercero excluido?

50. La respuesta es: sí y su nombre es: policontextualidad. ¿Qué se debe entender bajo este concepto? Se trata del supuesto de que el mundo está compuesto por innumerables "monocontextualidades", o sea, de estructura bivalentes.

Günther formula: "We have insisted that a contextuality is a logic domain of a strictly two-valued [RJ] structure and its range is determined by using the TND [Tertium Non Datur RJ] as an operator such that the generality of the alternative wich the TND produces cannot be surpassed [...] if we consider the Universe as a compound-cotexture it must be composed of an innumerable number of two-valued regions [RJ] wich partly parallel each other or partly penetrate each other since [...] each observable entity in this Universe must be considered as intersection of an unlimited number of two-valued contextures. "119 Nosotros (TgS) tenemos básicamente la misma opiniơn, sin embargo, con la diferencia de que afirmamos: se deben relacionar por lo menos dos distinciones bivalentes para que se pueda formar algo como "algo".

118 “[...] we have defined a contexture, by reference to the TND [Tertium Non Datur RJ], as a domain the boundaries of which cannot be crossed by processes taking place within the range of the domain [...]". (Günther, 1979, 2, p. 290).

${ }^{119}$ Ibid., p. 291. 
Con ello, la forma surge debido al hecho de que "algo" se encuentra entre por lo menos dos contextualidades y, con ello, participa tanto del valor de la una como también del valor de la otra. ${ }^{120}$ Günther elabora ahora las condiciones lógicas mínimas, las cuales son necesarias para poder explicar, a partir de la homogeneidad de contextualidades bivalentes, la diversidad de las formas heterogéneas, misma que luego designa en su totalidad como "policontextualidad". Dado que en este contexto no tenemos interés en la elaboración de un cálculo, abandonamos las reflexiones de Günther en este lugar.

51. Si observamos los supuestos generales de Günther dentro del marco de una "lógica de las distinciones", entonces salta a la vista que el concepto de una policontextualidad consiste en el hecho de que algo puede ser comprendido como "algo" cuando se coloca entre por lo menos dos estructuras bivalentes, mismas que están determinadas, por su parte, por el principio del tercero excluido. Nuestro punto de partida pragmático de las distinciones es, como siempre: ¿qué sucede si todo aquello que sucede, sucede simultáneamente?; ¿qué sucede ahora, cuando algo sucede como "algo"? Primero, el punto de partida no se puede comprender de manera monista, ya que esto significaría: el "ser" ocasiona que todo lo que es, "sea", lo que también significaría consecuentemente que no hubiera ninguna posibilidad de distinción entre el "ser" y la "nada" (como una forma del no ser), con lo cual desaparecería el ser mismo por falta de una distinción determinante. Si entonces el "ser" no es constituido por ninguna distinción, entonces es irreconocible (de acuerdo con la teoría de información aquí representada, misma que afirma que la información puede surgir solamente sobre la base de dos niveles semánticos (V. Weizsäcker, Bateson]). Es como si el color azul fuera el único color existente, debido a lo cual ni siquiera podríamos obtener el concepto del color. Para nosotros los mortales, un "color azul" sería como el agua para el pez o como una escritura negra sobre un pizarrón negro, es decir, irreconocible cognoscitivamente, sería solamente medio.

120 "If we consider such a point of intersection as belonging to two contextures [...] the point will still only be able to be occupied by two values but they may now belong to two diferent contextures [...] one value may belong to one and the other value to the other contexture [...]". (Idem). 
Respecto al concepto del medio podemos formular que el medio no se puede comprender como medio -a diferencia de la forma-, puesto que su función consiste en posibilitar la forma. De esta manera, no podemos ver nuestra visibilidad ni oír nuestra auditividad. Lo que podemos ver u oír son formas determinadas como "el lago allá atrás" o "la música rock ruidosa". Para utilizar nuevamente la metáfora pez/agua: el pez no puede reconocer al agua, sola-mente puede moverse dentro del medio "agua" y, debido a ello, reconocer otros peces o alimento. También el lenguaje verbal representa un medio para la producción de comunicación (para no complicar las cosas demasiado, dejamos fuera de consideración el lenguaje escrito). Si nos concentráramos al hablar en la forma de nuestras expresiones, o sea, en su forma fonética y no en su forma informativa, entonces no seríamos capaces de comunicar. Solamente refiriéndonos a su forma comunicativa, somos capaces de comunicar contenidos semánticos o de utilizar el lenguaje como forma verbal-comunicativa.

Segundo, ¿cómo serían las cosas con una forma dualista? Una forma dualista sería aquélla de "ser"/"nada". Aquí tendríamos la distinción buscada, misma que suministraría la información necesaria para el "registro" cognoscitivo de la forma "ser". Sin embargo, ya hemos demostrado que una distinción se hace reconocible como tal, solamente si se le puede distinguir, por su parte, de otras distinciones. De este modo, podemos registrar cognoscitivamente como "espacio". la distinción adentro/afuera, solamente si la colocamos frente a una distinción de antes/después como "tiempo". No obstante, si una distinción única es todo aquello que existe, entonces representa una distinción universal en el sentido exclusivo: todo puede o ser "ser" o ser "nada", no hay otra cosa. Günther designa precisamente esta forma como monocontextualidad: esta actividad cognoscitiva conoce o "ser" o "nada". No permite otra cosa, porque no puede permitirla.

En este contexto, Luhmann argumenta con razón: "La conciencia o comunicación nunca han podido generar de manera monocontextual el mundo como correlación de sus operaciones. Solamente las descripciones del mundo han presupuesto esto. Actualmente, las descripciones de este tipo se han hecho desesperadamente inadecuadas $[. . .]^{n} .{ }^{121}$.

131 Luhmann, 1990a, p. 24. 
Añadimos que una forma de distinción semejante no puede ser reconocible - visto estrictamente-, dado que con ello se procesa. solamente una distinción única, misma que no se encuentra en ninguna relación de distinción con ninguna otra distinción. Sin embargo, ya que esto no sucede fácticamente, Günther puede registrar cognoscitivamente el "ser" y distinguirlo de la "nada", no obstante, sin justificar cómo esto puede ser posible en general. Si no nos ayuda a avanzar una dualización universal en el sentido excluyente, entonces podemos intentar, tercero, comenzar con una triadización; es la operación preferida de, por ejemplo, Charles Sanders Peirce.

Peirce anota: "Tres conceptos aparecen continuamente en cualquier lugar de cualquier teoría de la logica y en los sistemas muy redondeados se presentan en forma relacionada uno con el otro. Se trata de conceptos, los cuales son tan amplios y, consecuentemente, indeterminados, que son difíciles de comprender, y es fácil pasarlos por alto. Los llamo los conceptos de lo primero, lo segundo y lo tercero. Lo primero es el concepto de aquello que es o existe independientemente de algo diferente. Lo segundo es el concepto de aquello que existe en forma relativa hacia otra cosa distinta, o el concepto de la reacción. Lo tercero es el concepto de la mediación, por medio del cual se relacionan mutuamente un primero y un segundo". ${ }^{122}$

Aquí no podemos abordar explícitamente el significado central, el cual ocupa "lo tercero" en los escritos de Peirce. Nótese que procedemos de manera similar a Peirce en el capítulo acerca de la acción de observación y la observación de observación. Allí se comentan las modalidades de la acción de observación, con lo cual la acción fáctica, posible o alternativa de observación corresponde a aquello que Peirce quiere expresar como lo "primero", lo "segundo" y lo "tercero".

Si cualquier información se genera sobre la base de dos niveles semánticos, entonces una distinción, que siempre está compuesta por dos lados, aún no produce ninguna información, ya que presenta solamente un nivel semántico. Se requiere de un segundo nivel semántico para producir una unidad de información. Éste puede ser suministrado solamente por parte de otra distinción, misma que está compuesta, por su parte, por dos lados.

${ }^{122}$ Peirce, 1970, p. 246. 
52. En el contexto de la discusión acerca del concepto de la tríada de Ph.G.Herbst ya hemos demostrado que la información no puede emerger sobre la base única de tres sucesos. Aquí podemos repetir el argumento ahí utilizado, en forma un poco variada con la ayuda de la distinción de forma y medio. Si queremos observar algo, por ejemplo, "sexo" en la forma de una distinción de "hombres y/o mujeres", entonces procesamos ya con esta actividad posible dos distinciones diferentes: por un lado, queremos "observar", no "actuar"; por el otro lado, la finalidad de nuestra observación es "sexo" como la observación de la distinción de "hombres y/o mujeres". Procesamos la forma "hombres y/o mujeres" con la ayuda del medio "observación" . ${ }^{223}$ Sin embargo, entonces ya tenemos dos distinciones, es decir, observar/actuary hombres/mujeres, con lo cual hemos terminado en una forma tetrádica, o sea, en una forma que está compuesta por dos distinciones. Opinamos que es especialmente interesante la utilización de la distinción de medio/forma, debido al hecho de que el medio debe permanecer normalmente como latente para que se constituya la forma. De esta manera, la percepción auditiva como forma (en lugar de una percepción visual) se puede procesar como onda sonora, solamente dentro del medio "aire" (o sea, no dentro del medio "luz" como ondas de luz), la comunicación verbal como forma (es decir, no la comunicación escrita) es posible solamente dentro del medio de "sonidos" (es decir, no por medio de la escritura), etcétera.

53. Hemos mencionado el concepto de policontextualidad de Günther debido al hecho de que se puede ver un paralelismo entre su supuesto de dos distinciones bivalentes y nuestro concepto de una "lógica de las distinciones". Günther supone como condición mí-

${ }^{123}$ Véase acerca de un concepto similar de medio y forma, Luhmann, 1987c, pp. 202-203, y 1987a, pp. 81 y ss,; también véase Heider, 1926. La experimentación mental con esta distinción es especialmente interesante, porque también las formas se pueden conventir en medios. De esta manera se constituyen formas perceptibles a través del medio de la percepción visual, mismas que pueden servir; a su vez - y orientadas específicamente- como medio para la formación de obras de arte dentro del sistema del arte. Las últimas, por su parte, pueden tener un papel como medios para la especulación monetaria dentro del sistema de la economía, etcétera. 
nima para la constitución de algo como "algo", dos distinciones bivalentes, mismas que alcanzan su bivalencia a través del principio lógico del tercero excluido. Nuestra "lógica de las distinciones" se basa en el relacionamiento de dos distinciones, o sea, de una "diferenciación" asimétrica y una "diferencia" simétrica. Sin embargo, en el caso de Günther extrañamos una caracterización más exacta acerca de cómo se deben relacionar mutuamente las estructuras bivalentes para que se pueda constituir algo como "algo". Tampoco su cálculo desarrollado dentro de este contexto resuelve este problema. En todo caso, queremos anotar que se pueden armonizar la homogeneidad y la heterogeneidad, con referencia a la constitución del mundo, sobre la base de una "lógica de las distinciones". El mundo es homogéneo en la medida en que está compuesto por distinciones (cognoscitivas), y ciertamente sólo por distinciones. Aquí nos desviamos del concepto de Günther en el sentido de que determinamos la constitución de algo como "algo", como un entrelazamiento (dicho de manera más exacta, como una complementaridad) de dos distinciones, es decir, como un entramado de una "diferenciación" asimétrica y una "diferencia" simétrica. De esta manera se gene- ra la heterogeneidad del mundo, ya que puede haber innumerables entrelazamientos de este tipo, mismos que constituyen respectivamente "algos" determinados. Estos "algos" entrelazados representan sucesos, es decir, formas del tiempo, las cuales ya con su surgimiento desaparecen nuevamente. Ias estructuras surgen sólo cuando un "algo" semejante se condensa o confirma en el proceso de la repetición, con lo cual se forma la expectación. Esto no es otra cosa que la condición de la posibilidad de identidad, con lo cual nos encontramos nuevamente ante la puerta de emergencia del sentido. Una teoría social debería comenzar en este lugar: de acuerdo con nuestra comprensión, la diversificación social es el resultado de la emergencia de tipos y estilos de expectación. De esta manera, las formas comunicativas de corporalidad, afectividad, individualidad y socialidad representan tipos de expectación. Los estilos de expectación surgen sólo sobre la base de tipos de expectación: en el contexto de la socialidad, "religión", "poder", "educación", "técnica" o "economia" representan estilizaciones de expectación; en el contexto de la corporalidad, "sexo", "pertenencia" o "edad" representan estilizaciones de expectación. Dentro del marco de este trabajo no presentamos, sin embargo, ninguna teoria social, sino solamente una metodología de las distinciones con intenciones teórico-sociales. 
1. Aquí se tratará el problema general de una correspondencia entre la lógica y otros ámbitos cognoscitivos, en primera línea el ámbito cognoscitivo de la SOCIEDAD. Con ello no se trata únicamente (aunque sí también) del problema de una correspondencia de afirmaciones lógicas con afirmaciones de otros campos científicos. Se trata en primer lugar de si es posible encontrar las características del sistema lógico también en otros sistemas, los cuales no tienen que ver primariamente con la lógica en el sentido estricto de la palabra. Ya habíamos partido de la presunción, en el capítulo sobre las Laws of Form de George Spencer Brown, de que prácticamente no tiené lugar una "transferencia" de afirmaciones lógicas hacia sistemas nológicos.

Cuando se hace la siguiente observación: "Aquí a la tzquierda se encuentran estacionados dos autos, allá a la derecha, tres. En total son cinco autos estacionados." Sabemos que la suma de $2+3$ es 5 . ¿Por qué la "realidad" se deja "calcular" en esta forma? Nuestra respuesta será: tanto la lógica (y la matemática) como también la sOcıeDAD constituyen sus acontecimientos con distinciones. Suponemos que en un alto nivel de abstracción teórica las condiciones de la posibilidad de la experiencia de la naturaleza y la sociedad son equivalentes. Apoyándonos en Carl Friedrich von Weizsäcker, ${ }^{124}$ opinamos que el programa de la "Unidad de la distinción de naturaleza y sociedad como tarea constructiva" tiene enteramente oportunidades de ser realizado.

Pero aún no hemos hablado de la verdadera fundamentación. ¿Qué podría justificar una suposición de transferencia de este tipo? No se ha dicho que la estructura de las afirmaciones lógicas fuera transferible a hechos sociológicos. Una suposición de este tipo solamente podría ser justificada cuando fuera demostrable que, por ejemplo, la estructura de los hechos teóricos "se adecúa"125 a la estructura de los hechos prácticos en el sentido de que la teoría tiene que ver con problemas que se encuentran a su vez en la "praxis". Los "problemas de la praxis" teóricos y prácticos tendrían con ello una relación "uno por uno" de pattern matching. Por lo tanto, el camino que quere-

124 Weizäcker, C. F., v., 1970.

${ }^{125}$ Para el concepto de "adecuarse" o del pattern matching véase más adelante y a Campbell, 1966. 
mos proponer para evidenciar un pattern matching de esta clase, consistirá en hacer plausible que la lógica y la SOCIEDAD son diversas expresiones de sucesos de la misma "protológica de las distinciones" (protol6gica debe ser entendida aquí en el sentido de una "lógica" de la lógica) (figura 19).

\begin{tabular}{|l|l|}
\hline Protológica de las distinciones: & $\begin{array}{l}\text { La lógica como } \\
\text { sistema de distinciones } \\
\text { La socitedió como } \\
\text { sistema de distinciones }\end{array}$ \\
\hline
\end{tabular}

Hacer plausible la suposición de una correspondencia semejante dependerá, naturalmente, de lo que entendemos como "lógica" y como "SOCIEDAD" y del sentido que representan éstas según nuestra opinión. En cierta forma, se trata aquí de la distinción proveniente de la vieja Europa entre teoría ( = lógica) y práctica (= SOCIEDAD), solamente que nosotros elegimos una base de partida pragmática de distinciones la cual cimentamos a continuación en la teoría de información y de sistemas. No se trata pues, y esto hay que ponerlo de relieve, del problema de una aplicación directa de afirmaciones lógicas a hechos empíricos, es decir, de una práctica que en el marco de un proceso estadístico pertenece absolutamente a la investigación social empírica cotidiana. Lo que nosotros tenemos enfrente como problema pertenece, antes bien, a la tradición clásico-filosófica y será explicado, por regla general, en el contexto de las figuras argumentativas social-filosóficas. Se trata de la cuestión de si lo "lógico" se puede comprender también como lo "social" y, en caso afirmativo, ¿en qué sentido? Se trata con ello del problema de la socialidad de lo lógico.

En este lugar se debe echar un vistazo al Tractatus Logico-Pbilosopbicus de Ludwig Wittgenstein. Uno de los problemas fundamentales se encuentra en la tesis de una similitud estructural entre las afirmaciones y los hechos aseverados. Se podría formular esta tesis con Bertrand Russell de la siguiente manera: entre mapa y región domina una cierta similitud estructural. ${ }^{126} \mathrm{El}$ hecho se representa para Wittgenstein de la siguiente forma:

${ }^{126}$ Russell, 1988, p. 115. 
El disco del gramófono, el pensamiento musical, la escritura musical, las ondas sonoras, se encuentran todas en aquella relación interna reflectiva que existe entre el idioma y el mundo. A todos ellos les es común su estructura lógica. (Como en el cuento de los dos jóvenes, sus dos caballos y sus lirios. Todos ellos son, en cierto sentido, uno). ${ }^{127}$

Estamos de acuerdo con Wittgenstein en la opinión de que en los hechos la COMUNICACIÓN (como tal no sólo entendemos la forma verbal/escrita, sino también la forma pensante, la afectiva y la perceptiva) tiene una "forma lógica", la cual se puede describir con la ayuda de las distinciones "diferencia" y "diferenciación". No existe, sin embargo, ninguna correspondencia representativa entre las diversas formas de COMUNICACIÓN. ¿Es pues, representable la forma lógica de la COMUNICACIÓN? De acuerdo con Wittgenstein esto no es posible lingüisticamente:

La frase puede, entonces, representar la realidad en su conjunto, pero no puede representar aquello que debe tener en común con la realidad para poderla representar. Para poder representar la forma lógica, nos deberíamos poder situar afuera de la lógica con la frase, esto significa, afuera del mundo. ${ }^{128}$

Situarse afuera de la lógica no impliça que deba uno situarse fuera del mundo o del mundo vivencial como parece suponer Wittgenstein. Esto sería en los hechos una audacia imposible. Tomamos posición fuera de la lógica con la ayuda de una protólógica y estamos con ello en la situación de poder observar a la lógica todavía dentro del mundo. Realizaremos esto ayudados por un desarrollo ulterior de la protológica de, Spencer Brown, la cual es una "lógica de la lógica". Y al contrario de Wittgenstein opinamos que una forma protológica de tal tipo se puede explicar completamente como una pragmática de la distinción. En este contexto señala con razón Russell:

"Para Wittgenstein [...] esto era un punto fundamental [la similitud de las estructuras del tdioma y del mundo $R J$, desde el cual llegó a una variante lógica realmente curiosa de la mistica. Es decir: él afirma que la forma que comparte una afirmación con el correspondiente hecho, es algo que se muestra en la afirmación correspondiente o se refleja en ella, pero no algo sobre lo que se podría hablar [.... $]^{n} .129$.

${ }^{377}$ Wittgenstein, 1966, p. 34, 4.014.

${ }^{128}$ Ibid., p. 4.12.

129 Russell, 1988, p. 116. 
2. Se debe realzar que las contribuciones que fueron entregadas en el transcurso de siglos para el campo de tensión entre una logicidad de lo social (la suposición de que lo social se encuentra estructurado "logicamente" en cierta forma), y una socialidad de lo lógico (la suposición de que lo lógico se encuentra estructurado en una cierta forma "socialmente"), configuran un tema central de la tradición sociofilosófica y filosófica europea. Más aun, se puede afirmar con todo derecho que esta temática y sobre todo el problema que plantea -es decir: ¿por qué funciona la lógica en sentido amplio, así como funciona? $\mathrm{o}$, expresado más simplemente (y malinterpretablemente): ¿cómo es posible que "sean" $2+2=4 \mathrm{y}$, por consiguiente, una afirmación verdadera?-, pertenece a uno de los más importantes "catalizadores" del espíritu europeo. Ya Parménides había evidenciado claramente el problema con su aparentemente simple afirmación de que el ser "es" y el no-ser "no es".

Una manera de pensar "libre de propósito", es decir, reflexionar sobre el ser "en sí", no es de ninguna manera un sobreentendido. Esta manera de pensar se encuentra ya personificada en la geometría de Tales: en los teoremas de la geometría de Tales, de acuerdo con Jürgen Mittelstrass:

"L...] se debe prescindir completamente de las tareas y posibilidades de aplicación especiales [R]]; estos teoremas no están formulados para poder construir éste o aquel triángulo, sino para comunicar algo que precede a la construcción de todos los triángulos posibles [...] El formular 'teoremas sobre las relaciones en el círculo' o 'teoremas sobre los ángulos' y ver en ello una actividad sensata, representa 'un descubrimiento' que no era necesario ni simplemente obvio y el haberlo hecho es mérito de un pensamiento que admiramos generalmente como pensamiento griego". ${ }^{130}$

$\mathrm{Y}$ no es ninguna casualidad que filósofos como Georg Wilhelm Friedrich Hegel y Martin Heidegger marquen con Parménides ${ }^{131}$ los comienzos de la filosofía (occidental).

Georg Friedrich Wilhelm Hegel escribe en sus "Cátedras sobre la historia de la filosofia": "Con Parménides ha comenzado el verdadero filosofar: en ello se puede ver la elevación al reino de lo ideal. Un hombre

${ }^{130}$ Mittelstrass, 1974, p. 33.

${ }^{131}$ Así M. Heidegger en su Einfübrung in die Metapbysik, 1976, p. 119. 
se libera de todas las concepciones y opiniones, les niega toda verdad y dice: solamente la necesidad, el ser, es lo verdadero. ${ }^{n 132}$ Se puede decir que Parménides descubrió la "posibilidad del ser" y con ello la autorreferencia del ser a través del hecho de que el ser hace referencia a sí mismo ("es ser"), se estabiliza poco a poco de tal manera que se constituye una dimensión del sentido como "esfera del ser", la cual se caracteriza probablemente de manera imprecisa con el concepto "filosofia". Dicho sea de paso, ya Parménides había pronunciado con toda claridad la tesis presentista ("Todo lo que acontece, acontece en el presente, por ello, todo acontece simultíneamente"), la cual hemos escogido como guía de este trabajo. Así dice en el legado fragmentario del Simplicius: "Pero la verdad solamente es el es. Éste no fue generado y es imperecedero, completo de un sexo sin movimiento y sin fin. No fue, ni sera, sino que ahora es todo simultáneamente [RJ] un contexto."133

El problema ocupa tanto a pensadores griegos clásicos como Platón y Aristóteles, como también a toda la tradición fiolosófica medieval. Asimismo, pensadores posteriores como René Descartes, Blaise Pascal, Baruch Spinoza, Gottfried Wilhelm Leibnitz y David Hume se han dedicado, en mayor o en menor medida, a aspectos del problema de una logicidad de lo social en el sentido de una distinción de concepto y experiencia y sus expresiones equivalentes. Pero sobre todo Immanuel Kant y posteriormente Johann Gottlieb Fichte, Friedrich Wilhelm Joseph Schelling y Georg Wilhelm Friedrich Hegel tenian un vivo interés en la solución del problema mencionado.

Richard Rorty se refiere a la tradición filos6fica "terapeuticamente" (su libro no es, como los escritos de mis filosofos favoritos [Wittgenstein, Heidegger y Dewey, RJ], constructivo, sino terapéutico) ${ }^{134}$ opinando que la concepción de que la distinción entre concepto y experiencia (o razón y sensualidad) es en el fondo solamente un juego social, sin problemas del idioma, y carga sobre Kant la responsabilidad de la problematización "absurda" de algo así: "Antes de que [...] Kant sea dejado atrás, se debe hacer la pregunta de cómo logró hacer de la diferenciación de concepción y concepto un asunto plausible y sorprendentemente problemático [...] ${ }^{n} .{ }^{135}$ Ahora, no tiene que ser exactamente esta dis-

${ }^{332}$ Hegel, 1974, Bd. 18, p. 290.

${ }^{133}$ Hegel, 1970, Bd. 18, p. 288.

134 Rorty, 1984, p. 17.

${ }^{135}$ Rorty, 1971. 
tinción, pero el problema mâs profundo, el cual no es visto aparentemente por Rorty, consiste en esto: nada puede ser observado cognoscitivamente, sino cuando están en juego por lo menos cuatro acontecimientos, los cuales generalmente adoptan la forma de un entrelazamiento entre "diferencia" simétrica y "diferenciación" asimétrica. Esto se da también en el caso de la distinción concepto/experiencia, como una relación de generalidad simétrica y particularidad asimétrica Se puede debatir con Rorty si hoy en día una distinción de este tipo es aún semánticamente actual. Pero persiste el problema de que la "unidad" (del tipo que sea) no es posible sin tal entrelazamiento. Junto con Karl-Otto Apel somos de la opinión de que los representantes de un cambio critico-lingüístico y hermenéutico dentro de una filosofía como la de Rorty (o Jaques Derrida y Jean-François Lyotard), reducen la filosofia a una autoterapia, y con ello introducen "[...] una autodestrucción del discurso filos $\delta$ fico ${ }^{n 136}$ por más meritorias que, en un momento dado, puedan ser sus aportaciones.

En cuanto al presente, sólo tenemos que señalar las polémicas acerca de complejos de problemas tales como "logocentrismo", "fonocentrismo", "logica polivalente", "autorreferencia", "autopoiesis" o "paradojas". Deseamos mostrarle nuestra reverencia en vista de una tradición de pensamiento social tan agobiante alrededor del mencionado problema, pero opinamos que el problema se puede evaluar nuevamente desde una perspectiva actual, pudiendo así sacar a la luz del día nuevos conocimientos al respecto. Queremos expresar con esto que aunque el problema de la socialidad de lo lógico nos parece que puede resolverse en ciertos aspectos, se le debe considerar como fundamentalmente irresoluble bajo otros puntos de vista más bien "metafísicos".

Con ello queremos decir que los problemas de tal alcance, independientemente de si lo social está estructurado lógicamente y/o si lo lógico está determinado socialmente, siempre producen soluciones que se pueden considerar como funcionalmente equivalentes entre sí y que, de este modo, generan una historia del problema correspondiente, pero que el problema como tal no encuentra una solución definitiva. Más bien es así que puede permanecer sin consideración por un tiempo corto o largo, para más tarde atraer nuevamente la atención sobre si. 
3. El ya tratado complejo de preguntas acerca de una logicidad de lo social había dado por resultado que se puede generar, sobre la base de las distinciones, diferencia y diferenciación y con el apoyo de las Laws of Form de Spencer Brown; un concepto teórico general y a la vez universal, con el cual entonces se puede formular plausiblemente aquéllo a lo que habíamos llamado unidad de "algo".

El concepto es general en el sentido de que está formado de la manera más simple posible y de que es a la vez suficientemente manejable como para poder integrar lo heterógeno. Y entre más capaz de explicar lo heterógeno sea una teoria, sin volverse con ello insignificante o "vacia" en cuanto a contenido, más general es. Generalidad significa un aumento de abstracción, y el aumento de abstracción eleva la cuota de indeterminabilidad que necesariamente debe estar adherida a una teoría de este tipo. Considerando esto, el arte de la generación de teorias consiste en no forzar la indeterminabilidad hasta convertirla en insignificancia. Sin embargo, la simplicidad del concepto no debería ocultar la complejidad que se puede deducir de sus consecuiencias. Con universalidad queremos expresar que el concepto de la pragmática de las distinciones debe ser aplicable a sí mismo, como lo mostramos antes. Niklas Luhmann opina acerca de las circunstancias de las teorías universalistas: "Pertenece a las características de las teorias universalistas el que ellas mismas aparezcan otra vez en su área de objetos - aunque sólo sea como un hecho entre muchos otros. El que los físicos hagan fissica (incluyendo las condiciones y límites de los cuales depende ésta), es también un proceso físico. "137 Así también, la teoría de las distinciones, la cual percibimos como una secuencia de distinciones operativas, las cuales a la vez, producen distinciones [...] etcétera.

Este concepto dice que cada "algo" consiste en un relacionamiento de elementos tetrádico o en un entrelazamiento de las distinciones "diferencia" y. "diferenciación", lo cual, trasladado al nivel social, se puede formular como unidad de las distinciones de COMUNCACIÓN (simétrica) y Acción (asimétrica). Por lo tanto, dentro de un mundo cognoscitivo, el comienzo del comienzo siempre es puesto dialógica o mutualmente, dado que se requieren por lo menos dos distinciones para este comienzo reflexivo, lo que indica que diferencia y diferenciación (y por lo tanto COMUNICACION y ACCION) son "del mismo origen". Si un "algo" ofrece menos de cuatro elementos, entonces simplemente no existe, no es concebible cognoscitivamente.

is7 Luhmann, 1984, p. 650. 
Tal vez no se entienda por sí mismo que el concepto de la teoría de las distinciones se comprenda no tan sólo respecto a la "teoría socio"lógica". Más adelante relacionaremos explícitamente el concepto con la teoría social. Con ello queremos decir que la metodología aquí presentada posee un vasto campo de aplicaciones.

En nuestra argumentación, hasta aquí hemos supuesto la logicidad de lo social, una suposición que encuentra su expresión en la aplicación natural de conceptos lógicos, tales como los de las Laus of Form de Spencer Brown a la SOCIEDAD, y la cual queremos ahora tematizar en la forma de una socialidad de lo logico. Preguntamos: ¿está justificado un supuesto tal? Luhmann y aquellas teorias que se refieren a las Laws of Form parten, en todo caso, del supuesto de que una transferencia de esta clase de lo lógico hacia lo social es "normal" y que por regla general no merece ninguna reflexión. La práctica como tal no se legitimará más. De los trabajos de Karl R. Popper y Konrad Lorenz, entre otros, sabemos ahora que tal operación se denomina como principio de transferencia: lo que tiene validez en la esfera lógica, tiene validez también en el ámbito del comportamiento cotidiano.

Popper dice: "[...] lo que vale en la lógica, también vale en la psicología [...]. Admito que eso es una suposición atrevida en el campo de la psicología del pensamiento y del conocimiento [...]". ${ }^{138} \mathrm{Y}$ más adelante, relacionado con decisiones personales llenas de consecuencias: "Así llegué a la conclusión de que la teoría del surgimiento de una creencia de Hume 'por razones logicas' no puede ser correcta en absoluto. Eso me llevo a reconocer que las reflexiones lógicas pueden ser transferidas a las psicológicas; además me llevó a la suposición heurística de que, en general, algo que vale en la logica, vale, con una transferencia adecuada, en la psicología. (A esto lo llamo yo el 'principio de transferencia'). Creo que fue principalmente este resultado el que me alej6 de la psicología y me llevó a la lógica de la investigación [.... ${ }^{.139} \mathrm{Konrad}$ Lorenz retoma el principio de la transferibilidad de Popper (Principle of Transference), lo interpreta como transference entre lo subjetivo y lo objetivo, y opina que equivale a aquello que habia dicho sobre la identidad de todos los procesos experienciales con los procesos psicológicos. Esto significaría entonces el considerar a los procesos psico-

138 Popper, 1973, p. 18.

139 Ibid., p. 36. 
lógicos como la "lógica" de los procesos experienciales. Lorenz formula: "Pertenece a los principios metódicos de Popper el transferir toda terminología subjetiva hacia una objetiva, siempre y cuando se encuentren involucrados problemas lógicos. El afirma simplemente: 'Lo que es cierto en la lógica, es cierto en la psicologia' (What is true in logic, is true in psicology). Este principio de la transferibilidad entre lo subjetivo y lo objetivo corresponde a nuestra convicción acerca de la identidad por principio de todos los procesos del conocimiento con los procesos psicológicos ya expresados en el prolegómeno [... $]^{n} .{ }^{140} \mathrm{Sin}$ embargo, desde nuestra posición no podemos aceptar la distinción de subjetivo/objetivo así como la entienden Lorenz (y Popper). La pasamos inadvertidamente con la distinción del observador/observado. Véase para ello el capítulo acerca de la observación.

No obstante, Popper limita su afirmación al opinar que el principio podría tener validez solamente con una "transferencia adecuada". Pero no especifica con más precisión qué se podría comprender como "transferencia adecuada".

4. Nuestra meta será mostrar que, en un sentido elemental, la lógica se puede fundamentar con teorías de acción y de comunicación.

Dicho de manera simple, ninguna ACCIÓN se lleva a cabo sin COMUNICACIÓN. Sólo con la ayuda de un proceso comunicativo, en el cual se puede diferenciar entre "algo" y "algo diferente", se puede realizar operativamente una acción. Las acciones requieren comunicaciones para poder realizarse. Por ello, una "teoría sociológica", la cual esté basada solamente en la teoría de la acción, no puede explicar concluyentemente cómo se lleva a cabo el proceso de la acción, sino solamente que se está actuando fácticamente.

Con ello entendemos por ACCiON una ejecución del sentido de la atribución del sistema: con una ACCIÓN se logra una identificación del sistema, la cual tiene lugar procesalmente si, con la pretensión de una finalidad y con la integración de determinados medios, se aceptan ciertos acontecimientos comunicativos específicos y otros, por el contrario, se rechazan. Con COMUNICACIÓN se alude a la ejecución del sentido de una oferta de selección: se comunica una información de una forma determinada. Éste es el punto de conexión para el establecimiento de relaciones con los cuatro tipos de sistemas de

${ }^{140}$ Lorenz, 1973, p. 136. 
sentido: la forma de la comunicación que debe ser entendida, puede ser social, personal, afectiva o corporal. La comunicación informativa, podría formularse así, que puede ser entendida o mal entendida, se transmite por medio de determinados "canales" comunicatrvos. En ese contexto también hablamos del surgimiento de tipos de expectación como formas sociales, personales, afectivas y corporales de comunicar informaciones (figura 20).

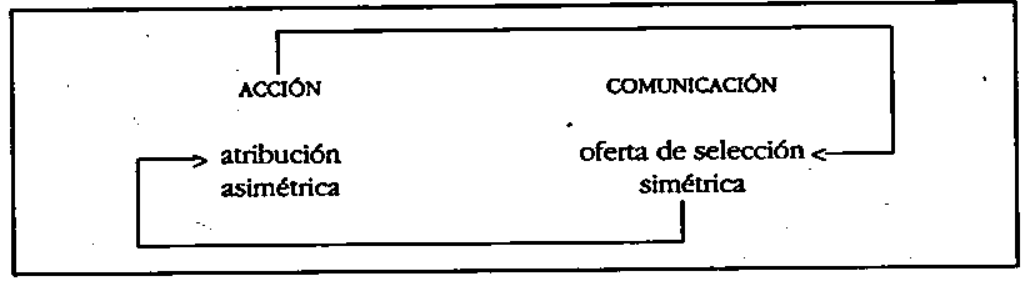

Y sólo cuando procesamos COMUNCACIÓN Y ACCIÓN como unidad de la distinción de COMUNICACION y ACCION, tienen la oferta de selección y la atribución de sistema un sentido SOCLAL. Una oscilante oferta de selección COMUNICATIVA es una oferta sólo en lo concemiente a un sistema identificable por medio de la ACCIÓN: la oferta de información tiene sentido sólo cuando puede ser utilizada como oferta elegible. Por el otro lado, el acto de una ACCion, y eso significa el de una atribución de sistema, es realizable sólo si se puede tomar una DECISIÓN entre "algo" y "algo distinto", o sea que esté presente una oferta de selección COMUNICATIVA. La unidad social consiste, según la teoría aquí representada ( $\mathrm{TgS}$ ), en un entrelazamiento entre COMUNCACIÓN y la ACCIÓN, lo que significa en el contexto de una "lógica de las distinciones": en un entrelazamiento de la diferencia simétrica (COMUNICACIÓN) y la diferenciación asimétrica (ACCIÓN) (figura 21).

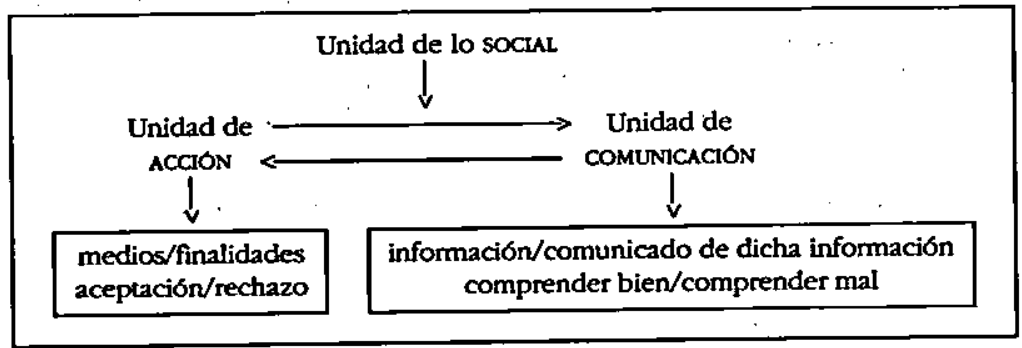


Si ahora la lógica se constituye también de una combinación específica de las distinciones "diferencia" y "diferenciación", entonces se podría demostrar la socialidad de lo lógico, dado que tanto la lógica como la SOCIEDAD tendrian con las distinciones principales "diferencia" y "diferenciación" una plataforma común.

5. Las teorías de la comunicación y de la acción se basan en la "lógica de las distinciones" en el sentido aquí representado: interpretamos COMUNICACIÓN comio una forma específica de diferencia (simétrica) y ACCION como una determinada manifestación de diferenciación (asimétrica). En este sentido hemos buscado un acceso a la teoría sociológica por medio de una revisión de las Laus of Form de Spencer Brown y su desarrollo posterior, y hemos presentado rudimentariamente el concepto de una "lógica de las distinciones". Con ello está dada la logicidad de lo social, en la medida en que la forma de la lógica de las distinciones, es decir "diferencia" y "diferenciación $n^{n}$, corresponde fundamentalmente con la forma de la SOCIEDAD, es decir con COMUNICACION y ACCIÓN. Con ello se trata de la suposición de que una intención de $A C C I O N$ asimétrica se puedè constituir solamente respecto a una situación de COMUNICACIÓN simétrica, con lo cual se condicionan mutuamente la oferta de selección comuNICATTVA y la atribución del sistema relacionada con la Acción. Si esta suposición fuera correcta, èntonces también deberíamos imos por el camino inverso y demostrar la socialidad de lo lógico. Si una comprobación de esta clase es suficientemente consistente, entonces estaría legitimizado el mencionado "principio de transferencia", el cual aplican explícitamente Karl R. Popper y Konrad Lorenz, e implícitamente Niklas Luhmann a sus propios supuestos. Para encontrar un primer acceso a este complejo de problemas de una socialidad de lo lógico escogemos, por un lado, el planteamiento que Carl Friedrich von Weizsäcker ha presentado en el marco de sus "Biologische Präliminarien zur Logik ${ }^{n}{ }^{141}$ y por otra parte el planteamiento de Ernst Tugendhat para la comprensión de la estructura predicativa de la frase afirmativa, presentado en sus "Vorlesungen zur Einführung in die sprachanalytische Philosophie”. ${ }^{142}$ Además, someteremos ambas teo-

${ }^{141}$ Weizsäcker, C.F.v., 1976b, pp. 281-331; 1977, pp. 294-314; 1985, pp. 207-215 y 1986.

${ }^{142}$ Tugendhat, 1979 y 1967. 
rías a una nueva interpretación con la ayuda de la "lógica de las distinciones".

6. La dirección a seguir es la siguiente: si lográsemos atribuir, de manera plausible, tanto lógica como SOcreDAD a las distinciones fundamentales "diferencia" y "diferenciación", entonces habríamos demostrado que ambas áreas, aunque su relación es heterógena, se encuentran entre sí en una relación homóloga respecto a la pragmática de las distinciones. Esto obedecería al hecho de que muestran un origen "lógico" idéntico. La evidencia (enigmática) de la lógica, no sería entonces otra cosa que su "relación adecuada" con la soCIEDAD en el sentido de una adecuación entre llave y cerradura. ${ }^{113}$ Por el otro lado sería comprensible el por qué una pragmática formal - como por ejemplo en la teoría de la acción comunicativa (TkH), pero también en la teoría de los sistemas sociales (TsS) por medio de la incorporación de las "Leyes de la Forma" (Laws of Form) de Spencer Brown en el sentido de una "pragmática de las diferencias" - puede ser tan exitosa a pesar de que un procedimiento formal de tal naturaleza no expresa, por el momento, mucho sobre los fenómenos “concretos". Se puede tomar "la teoría del sistema de la acción general" (TaHD) de Talcott Parsons, como el quizá más vistoso ejemplo de un proceder pragmático-formal dentro de la "teoría sociológica", con lo cual no se puede afirmar realmente que el intento de Parsons haya fracasado, aunque algunas veces se haya tenido que exponer

${ }^{143}$ Para el concepto de "adecuación" o de patterm-matching véase el trabajo clásico de Donald Campbell (1966), pero tambiên Konrad Lorenz, quien hace notar el problema de una transferencia del concepto patterm-matcbing al alemán: pattern significa, además del significado de muestra, también disposición, configuración, pero nunca muestra en el sentido de por ejemplo, colección de muestras. Muestra en este sentido, se dice sample en inglés. De manera similar es dificil traducir el verbo matching. Significa una puesta frente a frente comparativa, hasta una calculadora confrontación con el claro significado secundario de que esta comparación sirve a la determinación y puesta en relieve de las diferencias, así como es el caso en cada competencia, en el match de dos equipos de fútbol o de dos boxeadores. La expresión pattern matching es una denominación completamente no-artificial, tomada del idioma cotidiano y completamente acertada para el proceso del conocimiento en cuestión, aunque lamentablemente sea intraducible. (Lorenz, 1973, pp. 38-40). 
a severas críticas. ${ }^{144} \mathrm{Si}$ se reflexiona acerca de que tales "obras de la vida" como las de Richard Münch, Wolfgang Schluchter, Jeffrey Alexander, Jürgen Habermas o Niklas Luhmann, serian apenas imaginables sin la influencia de Parsons, solamente entonces se puede juzgar correctamente el alcance de su proyecto pragmático-formal, con lo cual atribuimos la fertilidad dé su teoría a su "utilización inteligen$t^{n}$ de los supuestos pragmático-formales. Para caracterizar aquí conceptualmente la posición de salida de una "transferencia de correspondencia" de la lógica a la SOCIEDAD, queremos hablar en lo futuro de una pragmática de distinciones, la cual expresa en lo esencial el proceso de un entrelazamiento entre las distinciones basales de "diferencia" y "diferenciación".

\section{Operación y forma}

7. Antes de ocuparnos de las teorias de Ernst Tugendhat y C.F.v. Weizsäcker en lo particular, queremos observar al sistema de la lógica desde la perspectiva de una pragmática de las distinciones. Para ello recurrimos a la perspectiva operativa de la pragmática de las distinciones, la cual.se refiere al procesamiento actual de la reproducción del sistema.

Dependiendo del contexto de la situación y de la problematización de una relación de hechos, se puede escoger un acceso operativo o uno del tipo observador. Aquí escogemos el acceso operativo. ${ }^{\text {its }}$ Cabe senalar que, por un lado, las operaciones son observables, y que por el otro lado, las observaciones reproducen una determinada forma de operación.

Nos adherimos aquí también a Luhmann: "By operation I mean the actual [R] processing of the reproduction of the system. ${ }^{n 166} \mathrm{El}$ concepto de la operación aqui empleado implica que una operación siempre y solamente tiene lugar en el presente inmediato. Y Humberto $\mathrm{H}$. Maturana formula: "[...] que los sistemas vivientes operan exclusivamente $[R]$ en el presente $[. . .]^{3.147}$ Nosotros añadimos que los sistemas proce-

${ }^{144}$ Así por ejemplo, a través de Alwin Gouldner o Ralf Dahrendorf, ver el capítulo V sobre arquitecturas de teorías.

${ }^{145}$ Similar en el asunto: Luhmann, 1985, pp. 100-101.

146 Ibid., p. 100.

${ }^{147}$ Maturana, 1985, p. 17. 
sadores del sentido también realizan operaciones del sentido solamente en el presente. Véase acerca de esto la introducción a este trabajo.

De la circunstancia de que el modus general de cualquier operación siempre es el "presente inmediato" deducimos la suposición, rica en consecuencias, de que todo aquello que sucede acontece simultáneamente (figura 22).

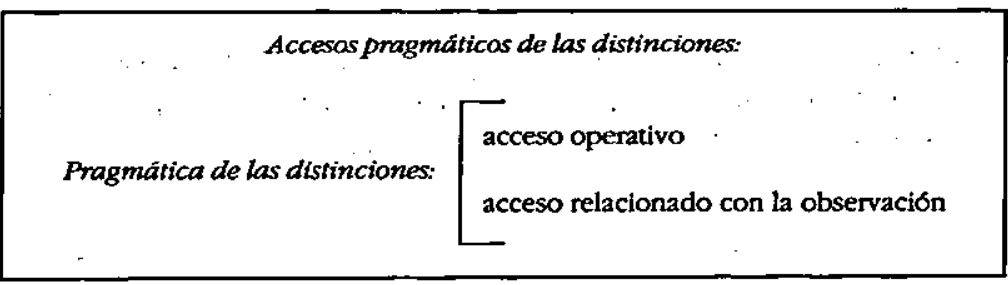

Con ello hacemos uso de la suposición de que los sistemas siempre y solamente pueden realizar sus operaciones - su actividad reproductiva- en el presente.

Aquí nos apoyamos especialmente en Humberto R. Maturana, quien se expresa, refiriéndose a los sistemas vivientes: "[...] a pesar de que tengamos que consultar a la historia para explicar cómo un sistema vivo particular ha llegado a ser lo que es aquí y ahora, no podemos utilizar la historia para explicar su operar como unidad, dado que su historia no le pertenece como componente [...] la historia juega su papel en el sentido de que muestra cómo ha surgido la estructura actualmente realizada de un organismo, pero no explica cómo funciona de momento a momento este organismo concretamente. Este conocimiento fue para mí, de un significado decisivo [....". 148 $^{\text {L }}$ Lo que entra en juego aquí es la importante distinción entre la unidad de operación y utilización por un lado, y la unidad de observación por el otro lado. Precisamente porque cada sistema en el sentido aquí concebido funciona de momento a momento (Maturana), partimos de la tesis de que . todo aquello que sucede, acontece simultáneamente. Ésta es una tesis que no está concebida por sí misma, sino en relación con el sistema. Es esta tesis de la simultaneidad -deducida de la tesis de la inmediatez- la que nos permite enfocar el funcionamiento de algo como "algo". En este contexto observamos que la TsS, la cual postula algo

148 Idem. 
similar, omite fundamentar más precisamente cómo se llega, propiamente dicho, a la tesis de la simultaneidad. Nosotros fundamentamos la tesis de la simultaneidad con el concepto de inmediatez.

¿Qué llega uno a ver entonces, si observa el sistema o la estructura de expectación de la lógica bajo este supuesto? La respuesta es: operaciones lógicas. Primero y ante todo se debe decir que a este nivel del presente no se puede tratar de ciertos contenidos de afirmaciones lógicas y tampoco de funciones variables o relaciones, de los cuales se sabe que, vistos lógicamente, están "vacíos de contenido". ¿Pero qué se puede observar entonces desde esta perspectiva? Simplemente esto: una operación lógica, la cual cuando opera, opera en el presente y entonces o tiene lugar o no tiene lugar. Con ello, no puede ser realizada y omitida al mismo tiempo, ni tampoco se pueden excluir simultáneamente ambas cosas. Si a la vez tiene lugar/no tiene lugar, entonces la operación contraviene la tesis de la contradicción (para operaciones); ${ }^{149}$ si no tiene lugar ninguna de las dos cosas, entonces contraviene la tesis del tercero excluido (para operaciones). ${ }^{150}$ Esto significa que cualquier sistema -incluyendo el de la lógica - a causa de las necesidades autoconservadoras operativas debe poder manejar la alternativa basal operar/no operar, para adaptarse exitosamente. Si no opera, entonces se disuelve (figura 23).

Operactón y lógica

A la vez, tiene lugar y $\longrightarrow$ Tesis de la contradicción no tiene lugar (para operaciones)

A la vez no tiene lugar ni tampoco no tiene lugar

Tiene tesis del tercero excluido (para operaciones)

${ }^{149}$ También cońocido como "Principio de contradicción". Aristóteles formula: "[...] hemos partido del supuesto de que algo sea y, simultáneamente, no sea". (Aristoteles, 1966, p. 74, 1006a). O en forma abreviada: A no es no-A.

${ }^{150} \mathrm{La}$ formulación de Aristóteles dice: "Decir que lo existente no es y que lo no existente es, es falso, y decir que lo existente es y que lo no existente no es, es cierto. Quien, entonces, predica un ser y un no ser, debe pronunciar lo cierto y lo falso. Pero no se dice de lo existente que es o que no es, y tampoco de lo no existente:" (Ibid., p. 88, 1011b). 
De manera clara, estas exposiciones dicen que se pueden deducir tan sólo del comportamiento de "algo", de las condiciones de la posibilidad de operación de un "sistema", de una forma, de un objeto o de un "algo", el principio de la contradicción y el principio del tercero excluido de la lógica clásica aristotélica. Ahora, bajo la premisa de que el sistema debe operar, y precisamente siempre en el presente, para mantenerse a sí mismo, ${ }^{151}$ surge entonces la pregunta: ¿cómo opera, cuándo opera? Preguntado de otra manera: ¿cómo es posible la operación? Para llevar a cabo una actividad operativa, el sistema debe decidir, esto quiere decir, debe poder realizar una reacción de elección, para lo cual con DECISIÓN no necesariamente nos referimos a una DECISIÓN expresa.

Partimos de un concepto de decisión, el cual permanece aplicable también a procesos debajo del umbral de la conciencia, y por lo tanto incluimos también el comportamiento rutinario. ${ }^{152}$ Queremos llamar a las DECISIONES expresas, explícitas o conscientes, "decisiones". (figura 24).

\section{Modalidades de decisión}

DECISIONES = operaciones latentes y/o manifiestas

Decisiones $=$ operaciones manifiestas de sistemas sociales

151 No se debe olvidar, condicionado por la aparentemente trivial afirmación de que cada "sistema" cuando opera, opera en el presente, lo central de esta suposición en última instancia: si el "sistema" no opera, entonces deja de existir.

${ }_{152}$ Utilizamos el concepto de DECISIÓN, pará aclarar y también para no permitir que se olvide que las DECISIONES implican distinciones, ya que solamente se puede "decidir" realmente bajo una condición de este tipo. En forma alternativa a ello ofrecemos el concepto de una "reacción de elección", el cual encuentra aplicación en el área de la neurobiología cognoscitiva, como con Emst Pöppel (1985; pp. 36 y ss.). Se debería evidenciar que las reacciones de elección o DECISIONES son ya efectivas desde el nivel psicológico más "bajo": "Ciertamente, la discontinuidad [RJ] de la identificación y de la decisión se escapan a nuestra conciencia, pero los indicios experimentales son inequívocamente que -con un periodo de oscilaciones del cerebro de 0.03 hasta 0.04 segundos- en un segundo solamente tenemos aproximadamente 30 posibilidades de identificación y puntos de decisión. No nos debe molestar que no estemos concientes de ello. (Ibid., p. 42). 
8. Una operación puede realizarse solamente cuando se puede referir a una distinción, para lo cual su distinción primaria, "primitiva" - realización de la operación/omisión de la operación-implica la condición de su propia posibilidad. Ella puede fijar su actividad basal solamente con la ayuda de la distinción operar/no operar, lo cual implica su autoconstitución (figura 25).

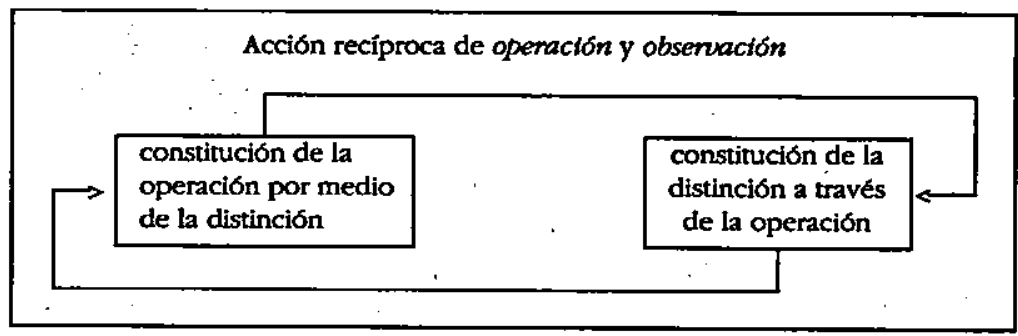

Obsérvese que en este caso la operación y la observación (= observación de la distinción) están relacionadas una con la otra: la realización de la operación/omisión de la operación es, por un lado, la condición operativa de la posibilidad de la existencia de un "sistema", por el otro lado, el sistema debe dominar por lo menos esta distinctón de operar/no operar, si quiere seguir existiendo como "sistema", objeto o "älgo". Dado que en el presente inmediato es procesada, por lo menos, esta distinción, se puede proponer la tesis de la simultaneidad, con las consecuencias problemáticas para el sistema, de que no puede operar y simultáneamente no operar, ni tampoco puede omitir ambas cosas (= principios de contradicción y exclusión del tercero, la base de la lógica aristotélica).

Si se debe llegar a un sistema, entonces se debe ampliar el catálogo de las distinciones más allá de la primera, primitiva operación de distinción. Solamente así se puede llegar a la formación de una unidad más compleja y duradera, a un "sistema": la actividad de continuacióni operativa implica la constitución de más distinciones.

Recordemos: algo se constituye como "algo" solamente después de haber ocurrido dos veces. Ver capítulo I:

Repetimos algo ya dicho: "el sistema debe formar distinciones, para tomar DECISIONES".

Esto no es precisamente un conocimiento nuevo. Así, por ejemplo, se expresa acerca de ello Carl Friedrich von Weizsäcker de la siguiente 
manera: "La bivalencia, la divisibilidad de la realidad en alternativas no es una característica que el mundo nos muestra sin nuestra participación; es la manera de cómo accesamos la realidad —exitosamente." ${ }^{m 53}$ Y Dieter Claessens opina: "Sin esta guía por parte de la 'naturaleza' [por medio de los instintos, RJ] el hombre parece un ser 'sin medida', el cual apenas debe crearse sus medidas. Dado que las decisiones se pueden tomar sensatamente sólo después de las diferenciaciones (Gehlen), este ser obligado a la decisión continúa sin un trasfondo de instintos, esto quiere decir, sin estar equipado con una dirección, depende de manera especial de la capacidad para la diferenciación. Ya que debe evaluar al mundo, en cuanto a las características de diferenciación, no está equipado con órganos de recepción que trabajen profunda e intensivamente, sino más bien con órganos de recepción que se complementan ampliamente en forma mutua, a cuya disposición se encuentran órganos de ejecución muy variadamente aplicables, especialmente a través de las manos, las cuales a su vez están relacionados por medio un cerebro capaz de alto rendimiento con los órganos de recepcion. ${ }^{154}$

Transferido a la "lógica de las distinciones" esto quiere decir: una operación requiere, para su propia autoconstitución, una forma con la cual puede ser capaz de DECIDIR entre "algo" y "algo diferente ${ }^{n}$. Una forma de este tipo sólo puede ser una distinción simétrica, con dos lados aún-no-decididos, para que a fin de cuentas pueda tener lugar el proceso del DECIDIR o la reacción de elección. Llamamos una forma distinta de este tipo con dos lados aún-no-decididos una "diferencia". Pero ¿quién o qué refiere, denomina, opera, DECIDE? Seguro que no la diferencia misma porque no puede observarse a sí misma y para ello emplearse a sí misma, simultáneamente. ¿Una segunda diferencia? Entonces tendríamos dos formas simétricas que se encontrarian frente a frente y solamente serían capaces de procesar indeterminación. Por lo tanto no se podría llegar a un comportamiento de conexión. Lo que necesitamos aquí es una forma asimétrica, la cual pueda emular una "responsabilidad", una "dirección" debido a su unilateralidad en cuanto a valor, la cual, en relación con la diferencia simétrica, puede decidir entre "algo" y "algo diferente", puede operar. A esta forma la llamamos una "diferenciación". Su forma es

153 Weizsäcker, C.F.v, 1977, p. 303.

ist Claessens, 1980, pp. 51-52. 
la de una distinción ya-decidida, la cual se da a conocer en cuanto a valor como unilateral: "o aquí, sino allä". A su vez, la forma de una diferencia simétrica es la de una distinción aún-no-decidida, la cual se da a conocer, en cuanto al valor, como bivalente: "aquí y/o allă".

9. Aquí anotamos que los componentes conceptuales de una lógica de afirmaciones temporales - facticidad, presente y posibilidad-, como ha sido presentada por Carl friedrich von Weizsäcker, ${ }^{155} \mathrm{CO}$ rresponden a los conceptos de una lógica de las distinciones: diferenciación, posición de salida presentista o inmediatez, diferencia. Weizsäcker explica, en relación con el concepto del azar: "Aquí [en la comprensión del proceso del azar RJ] me ayudó mi análisis del segundo postulado de la termodinámica. Llamamos azar a aquellos. procesos que cumplen con las leyes del cálculo de probabilidades. Estas leyes definen posibilidades, y precisamente porque son posibilidades, permanece indeterminado cuál de ellas acontece. Pude hacer plausible el que la misma estructura del tiempo tiene como consecuencia el crecimiento de la entropía y el reciente diferenciamiento de las figuras. En conexión con una formulación tardía de Picbt puedo decir: lo pasado no desaparece, con ello crece la cantidad de hechos; el presente del futuro es su posibilidad fundada en los hechos; con ello crece la cantidad de posibilidades." ${ }^{n 56}$ Relacionado con la lógica de las distinciones: las diferenciaciones emulan hechos, las diferencias posibilidades, con lo cual —como se mostrará más adelante- dos diferenciaciones se pueden convertir en una diferencia, una diferencia en una diferenciación. Con ello también está dada una continuidad en la producción de diferencias y diferenciaciones (figura 26).

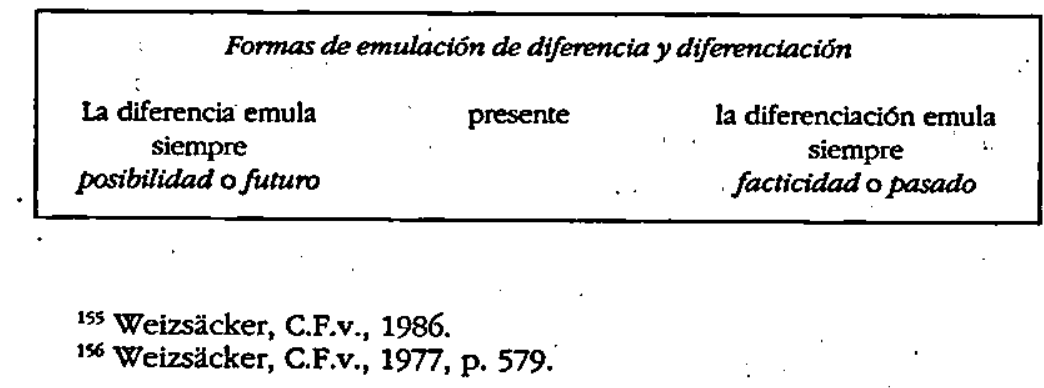


10. Sólo cuando se relacionan entre sí estas dos distinciones, resulta la posibilidad de la operación. Con ello se hace evidente que no consideramos a la "operación" como un proceso continuo, sino esencialmente como un proceso discontinuo y esto quiere decir "despedazado". Ésta es una suposición que nosotros consideramos confirmada a través de investigaciones empíricas. En relación con procesos de tiempos neurobiológicos, Emst Pöppel se expresa como sigue: “ ¿Es el tiempo, pues, continuo o se encuentra 'cuanteado'? En nuestra concepción acostumbrada el tiempo es aparentemente [...] continuo. Pero, ¿qué dicen las observaciones aquí discutidas? Si sola . mente pudiéramos reaccionar o actuar en tiempos determinados, entonces la continuidad del tiempo es una ilusión [...] podemos [...] suponer [...] que el desarrollo de nuestra experiencia y de nuestro comportamiento están desmenuzados [RJ] en cuántos de tiempo." 15 El proceso esencialmente discontinuo de la unidad básica social coMUNICACION/ACCION se traslapa por lo demás, de una manera no-trivial con la interpretación teórico-cuántica de la naturaleza: tanto la naturaleza como la sOcIEDAD están —al nivel de abstracción de una mecánica cuántica o de una lógica de las distinciones- "despedazadas", "cuanteadas", "desmenuzadas". También creemos poder demostrar de manera argumental y sustancialmente consistente -apoyándonos en una lógica de afirmaciones temporales, como la presentada por C.F.v. Weizsäcker-, ${ }^{158}$ que la naturaleza y la socIEDAD están constituidas de una manera asombrosamente similar. La legitimación más exacta de este presupuesto, sin embargo, rompería el marco de este trabajo. Por esta razón, en este lugar sólo mencionamos: si este presupuesto se evidenciara de hecho como cierto, entonces se podría demostrar que no sólo la "unidad de la naturaleza", ${ }^{159}$ sino también la "unidad de la SOCIEDAD" se encuentra dentro del ámbito de una realización teórica. Si entonces tanto la unidad de la naturaleza como la unidad de la SOCIEDAD implican idénticos presupuestos básicos filosófico-físicos o filos 6 fico-sociales, entonces nos encontrariamos frente a la posibilidad de una unidad, la cual sobresaldría sobre la naturaleza y la sOCIEDAD. Eso es realmente un supuesto improbable y excitante.

157 Pöppel, 1985, pp. 41-42.

158 Weizsäcker, C.F.v., 1986.

159 Weizsäcker, C.F.v., 1984. 
11. ¿Qué sucede cuando una diferenciación se refiere operativamente con una diferencia? Se indica que el caso es "no esto, sino aquello". La diferencia se convierte en una diferenciación, es reducida a la forma de una diferenciación asimétrica y por lo tanto parcializada. Todo esto implica tiempo (figura 27).

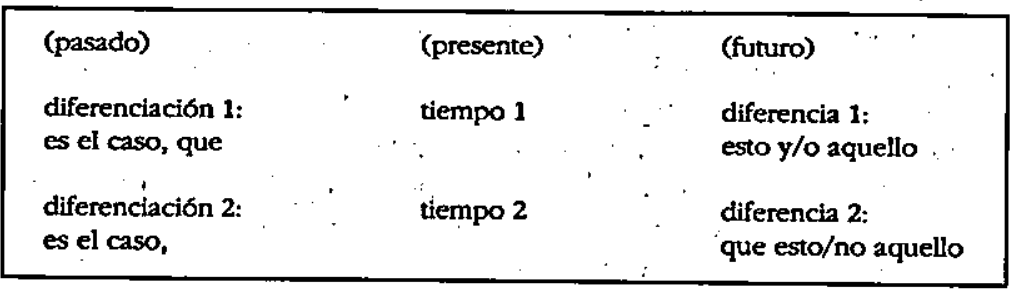

Para poder persistir como "sistema", este tipo de entrelazamiento relacional de dos distinciones debe encargarse de que continuamente se produzcan siempre nuevas diferencias simétricas, para que pueda continuar el proceso del operar incluyendo un comportamiento reactivo de elección. Entonces, precisamente por medio del relacionamiento de una diferenciación con una diferencia se disuelve (o se inactiva) la simetría original de la diferencia y la diferencia se convierte en diferenciación. Pero, por el otro lado, puede darse un "acoplamiento" de dos diferenciaciones asimétricas, de las cuales, por su lado, emerge una diferencia simétrica. De las diferenciaciones "no leer, sino escribir" y "no ver televisión, sino ir al cine" se puede formar la diferencia "escribir y/o ir al cine" (figura 28).

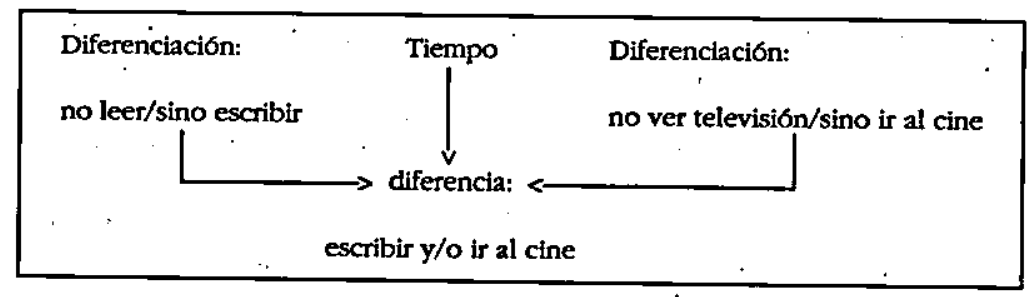

Si partimos del hecho de que un sistema básico consiste en el entrelazamiento de la diferencia y la diferenciación, entonces un sistema básico de este tipo es capaz de conservarse a sí mismo por medio de las transformaciones operativas de diferenciaciones y diferencias. Por lo tanto, se puede establecer en forma permanente, 
con el tiempo, una determinada distinción en la forma de una expectación de una estructura - por ejemplo, en forma de la distinción sistema/entorno.

12. Resumimos lo dicho hasta aquí. Primero: tenemos el hecho de que tan sólo por el requerimiento operativo de un "sistema" (lógico o de cualquier otra índole), se procesa una distinción fundamental, la cual consiste en un principio-de-todo-o-nada, que integra plausiblemente el principio de la contradicción lógica (para operaciones) y del tercero excluido (para operaciones): la operación relacionada con el presente no puede tener lugar y simultáneamente no tener lugar, tampoco puede, simultáneamente, no hacer ninguna de ambas cosas. Segundo: el cómo este tipo de operación representa un comportamiento reactivo de elección el cual requiere distinciones, ya que una elección tiene como condición previa necesaria una selección. Solamente así se puede realizar la operación de manera discontinua. Tercero: se puede demostrar que, con las distinciones fundamentales "diferencia" y "diferenciación" se hace posible la formación de algo así como un sistema momentáneo básico. Cuarto: se puede demostrar igualmente, que por el hecho de que las distinciones diferencia y diferenciación se constituyen mutuamente, un sistema puede - como entrelazamiento de ambas distinciones- constituirse a sí mismo: esto no significa otra cosa sino que procesa de una manera autopoiética o autorreferencial. ${ }^{160}$ Quinto: una adaptación del sistema que a través de ello hace posible "su historia", debe presuponer por regla general que no contraviene los principios de la contradicción y del tercero excluido para operaciones: por lo tanto, para el sistema es "cierto" todo aquéllo, lo cual debido a su actividad operativa lleva hacia una adaptación a su entorno: esto se deduce a partir de una teoría de la verdad interpretada pragmáticamente que califica "algo" como cierto, cuando este "algo" (sistémico) se relaciona con su capacidad de adaptación a las circunstancias correspondientes. Se entiende que estas reflexiones no se refieren exclusivamente a la lógica, aunque el sistema de la lógica es aquel que pone

160 "A sí mismo". significa que, debido al procesamiento de ambas distinciones se puede sedimentar sentido en forma de una estructura de expectación, con la consecuencia de una formación permanente de sistema de sentido. 
de manifiesto los "mecanismos". y los prepara para el discurso (figura 29).

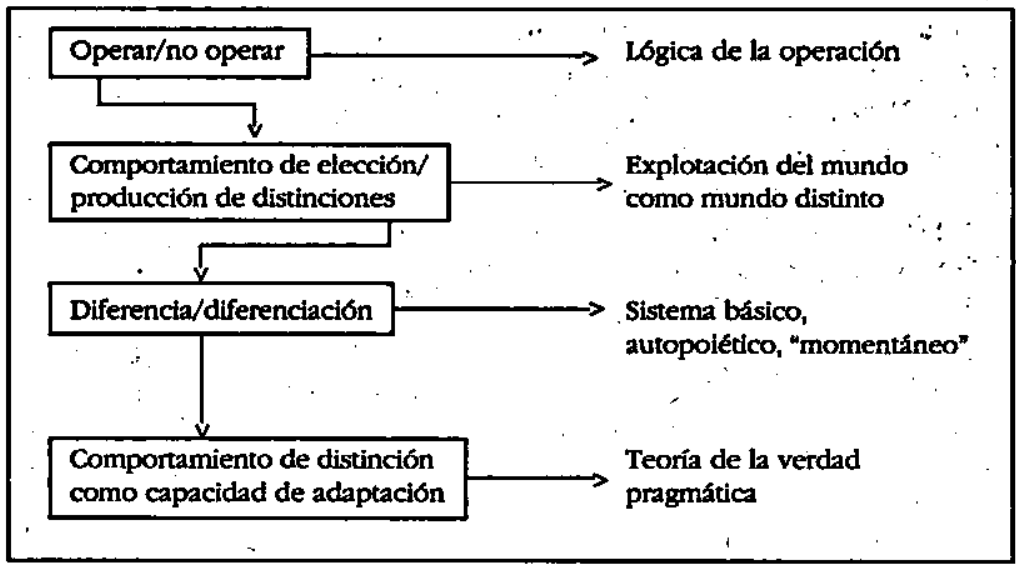

13. Si ahora se puede demostrar que algo que solamente puede operar y por ello, debe adaptarse para no dejar de existir, ya en su estructura fundamental implica la bivalencia, laproducctón de distinciones y la capacidad para la verdad (pragmática). Este conocimiento tiene así importantes consecuencias para las formas COMUNCATTVAS que no hacen uso explícito del idioma y mucho menos de la escritura, como por ejemplo, las formas de comunicación corporales o afectivas.

Considerado estrictamente, la operación lleva a través de la repetición a la formación de sistemas. Pero dado que no existe una operación "en sí, sino solamente operaciones específicas, el procesamiento de operaciones específicas lleva a la formación de sistemas específicos. Esto también es la razón de nuestro supuesto, de que ya las operaciones de la percepción corporal satisfacen una "logica de las distinciones". Por lo demás, se debe tomar en cuenta que una operación no es tan "primitiva" como frecuentemente se piensa cuando, a partir de sus fundamentos, se puede explicar (ededucir?) consistentemente la lógica aristotélica completa.

Aun más, posiblemente también las percepciones poseen un contenido predicativo, como opina Viktor von Weizsäcker: [...] el logro esencial de la percepción no se agota en la omisión o la comple- 
mentación, sino que ella depende de la donación predicativa de una relación $[R J]$; no de una parte del campo hacia la otra, sino en una determinación particular de aquello que se determina lcolor de la fruta, casa en el jardín, número de los puntos, velocidad del movimiento, etc.]. ${ }^{161}$ Carl Friedrich von Weizsäcker opina acerca de la estructura predicativa de la frase afirmativa, que en la frase afirmativa elemental se predice algo de un sujeto; por medio de ello, algo se le atribuye o no se le atribuye, se le niega o se le adjudica. Desde Aristóteles esto se enseña en conexión con la "unidad de la intención de la frasen y de la bivalencia de la lógica. Y Platón, ya desde el Sofistes, fundamenta esta estructura predicativa de la frase. ${ }^{162}$

Entonces se puede partir de que ya en el nivel más bajo de la soCIEDAD, es decir en su nivel de la percepción, se erigen construcciones capaces de bivalencia, distinción y verdad. Con ello estaría dicho que, primero, no puede haber una percepción libre de teoría.

Gerhard Roth ha calculado que en el sistema nervioso de un hombre, un "suceso externo" se encuentra en relación con por lo menos 100 mil "sucesos internos" autoproducidos: "Mientras que con los así llamados vertebrados 'inferiores' la proporción de neuronas sensoriales, periféricas, neuronas de procesamiento en el cerebro y neuronas motoras se encuentra entre 1: 1 : 1 y 1:10: 1 ; la proporción en el cerebro humano se encuentra entre 1:100.000: 1 y 1:1.000.000: 1 . Esto significa que aquello que llega al cerebro a través de los órganos sensoriales como excitación es, en el caso del hombre, casi nulo frente a aquello que tiene lugar como modalidades de procesamiento, en el cerebro. Y esto significa además, [...] que aquello que experimentamos como percepción consciente, no son las excitaciones primarias de los sentidos, sino los resultados de la interpretación de estas excitaciones primarias de los sentidos. ${ }^{n 163}$ En este nivel ubicamos aquello que entendemos como "comunicación corporal". El que por medio de ello no seamos capaces de percibir la "realidad" tal como es, no debería sorprendernos especialmente.

El que entonces alguien pudiera opinar que "percibe hechos reales", se puede señalar como una forma especialmente ingeniosa de una "teoría de los hechos".

161 Weizsäcker, V.v ., 1973, p. 140.

162 Weizsäcker, V.v., 1977, p. 306.

${ }^{163}$ Roth, 1987a, p. 413. 
Segundo, que las percepciones son capaces de bivalencia, distinción y verdad.

La capacidad para la verdad de la percepción sensorial se puede explicar por medio de la distinción de percepción/ilusión, la cual, en un nivel "primitivo", ya emula la distinción de positividad y negatividad: la ilusión (o apariencia), en este sentido, es la forma de negación del . sistema corporeo..$^{164}$

Esto significaría que ya la percepción corporal y con ello la forma corporal de comunicación es estructurada "lógicamente" y distintamente. Un presupuesto realmente rico en sus consecuencias.

Aquí ponemos entre comillas el predicado "lógico" porque partimos de que lo lógico - si es que se dejara legitimar desde una teoría de la acción y la comunicación - sería antepredicatioo en el sentido lingüistico, aun cuando el sistema de la lógica se explica generalmente con la ayuda de la frase predicativa y este conocimiento se representa solamente con la ayuda de frases que contienen afirmaciones predicativas.

Ya que generalmente partimos de que la sOCIEDAD consiste en cuatro tipos de COMUNICACIÓN, es decir de la socialidad, personalidad, afectividad y corporalidad, nos importa mucho cubrir en el aspecto lógico la pragmática de las distinciones ya en el "más bajo" nivel de comunicación de la SOCIEDAD, es decir, en su corporalidad. Por lo tanto, esto puede ocurrir solamente, si se puede demostrar que la lógica "funciona" ya en este nivel, lo que es el caso, como pudimos demostrar.

14. A partir de las circunstancias observables del requerimiento operativo de un sistema en el presente, hemos podido deducir los principios lógicos de la contradicción y del tercero excluido, la necesidad de la constitución de las distinciones y la posibilidad de la formación de sistemas básicos, autopoiéticos (momentáneos), sin comprometernos explícitamente con la lógica. También hemos podido deducir de las formas capaces de adaptación de un sistema aquello

${ }^{164}$ Véase también Hintikka, 1975, pp. 73 y ss. 
a lo que se llama "verdad", por medio de una interpretación pragmática de la verdad. Un sistema siempre opera solamente en el presente: ésta es nuestra posición de salida. Si ahora partimos del supuesto extremadamente improbable de que un sistema o hace algo o no hace nada en absoluto - sin considerar los niveles intermedios de comportamiento que son normales sobre todo en los primates más altos y el hombre, ya que éstos poseen un esquema de comportamiento complicado, en el cual están integradas numerosas secuencias de decisiones-, entonces podemos observar lo siguiente: si tiene lugar el desencadenamiento de una operación, entonces la operación simplemente tiene lugar; si no tiene lugar un desencadenamiento operativo, entonces no tiene lugar "nada". Podemos formular con C.F.v. Weizsäcker que el observador "decepcionado", el cual puede ser también un auto-observador, puede formular la pregunta acerca de qué era entonces aquello que no ba tenido lugar. ${ }^{165}$ Ya aquí se presenta la negactón en forma "primitiva", ${ }^{166}$ al menos en un mundo comunicativo, lleno de sentido, donde todo lo que sucede, sucede primero en la forma de la distinción de tener lugar/no tener lugar, y en el cual tiene significado "todo", por lo tanto también "nada". Ahora bien, si un sistema del sentido opera dentro de un mundo preñado de sentido, entonces se puede observar además lo siguiente: si tiene lugar una COMUNICACión, entonces tiene lugar; si ella no tiene lugar, entonces, a pesar de ello, tiene lugar algo, es decir "nada". Se podría formular que en un mundo significativo, la negación consiste por lo pronto en la ausencia de una actividad operativa. Pero ¿cómo se combina esta ausencia de la operación con el ya formulado hecho de que un sistema puede existir solamente cuando realiza operativamente un comportamiento de conexión y por lo tanto una comunicación de conexión?

Bien entendido, no hemos afirmado que la sobrevivencia de un sistema del sentido consista en la circunstancia de una actividad operativa ininterrumptda, éste sería probablemente un supuesto no realista. Aquí, la actividad operativa como tal no es central, sino el comportamiento de conexión - a través de la operación-en el sentido de la posibilitación de la conexión [...] con lo que sea.

16s Weizsäcker, C.F.v., 1977, pp. 300-301.

${ }^{166}$ Ibid., p. 303. 
La respuesta de lo expuesto arriba es: la ausencia de una operación (de una acción, una manifestación de la voluntad, una percepción, etc.) es en si, dentro de un mundo del sentido, una operación (la omisión de unà acción es, en sí, una acción, como lo sabemos desde Max Weber) que genera alguna forma de negación (p. ej. que alguien no venga, o que falte algo o que esté presente un engaño), la cual entonces se encarga del comportamiento de conexión necesario. Por lo tanto, un sistema del sentido opera siempre, aun cuando con ello no se presentan operaciones, ya que también a esta ausencia se le adjudica un sentido. ${ }^{167} \mathrm{La}$ negación, dentro de un mundo preñado de sentido, es por lo tanto la consecuencia del comportamiento operativo de "nada" como "algo". Luhmann expresa: "Las negaciones se utilizan siempre solamente en un sentido positivo de la capacidad de conexión, y se les encuentra siempre condicionadas por un antecedente en el mismo sistema"168 (figura 30 ).

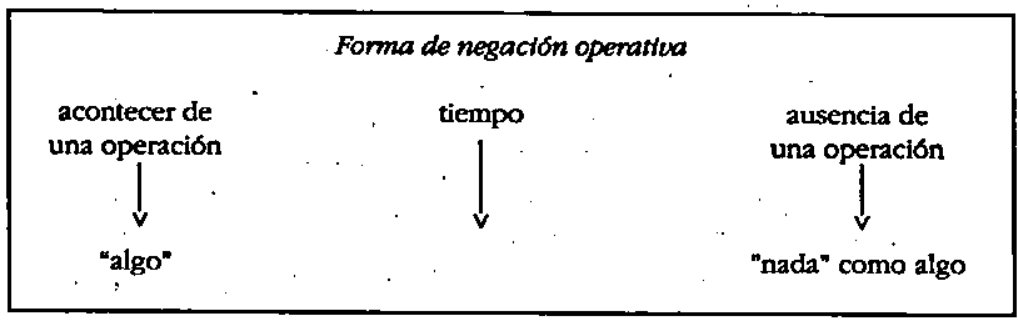

15. Con esta forma de negación "primitiva" está colocada la primera piedra para un distanciamiento basal reflexivo de un sistema de su entorno: puede distinguir entre operaciones operativas y no operativas como error, ilusión, ausencia o simplemente como "nada", y por lo tanto puede encontrarse a sí mismo en su actividad operativa (operativamente) como algo que hace algo, pero que también puede dejar de hacerlo sin perder por ello la capacidad de conexión.

Si fuese de otra manera, si, al cesar la actividad operativa se perdiera también el comportamiento de conexión, probablemente no se lle-

${ }^{167}$ Gregory Bateson formula algo equívocamente (porque es aparentemente limitante de la conciencia): "En el mundo del espíritu, nada -lo que no es- puede ser una causa [...] la carta que no se escribe, puede disparar su respuesta iracunda [...." (Bateson, 1983, p. 581).

${ }^{168}$ Luhmann, 1990, p. 517. 
gatía a un desarrollo mínimo de la capacidad de observación en el sentido de la "ausencia de operación". Por lo tanto, se debe suponer que, por lo menos en el nivel de sistemas SOcIaIEs, la operación y la observación van de la mano, aunque en forma complementaria: una unidad de operación tiene solamente un valor de utilización, mientras que una unidad de observación también posee un valor de distinción. Esto significa, entre otras cosas, que en el momento de la utilización de una observación, ésta no se puede aplicar simultáneamente a sí misma, para observarse a sí misma. Una auto-observación es posible solamente por medio de relaciones de tiempo: la observación referida al presente de un algo en sí mismo solamente puede observar la observación perteneciente al pasado del mismo algo en sí mismo. Pero no se puede observar a sí misma en la consumación operativa de una simultaneidad de la observación y de la constitución operativa de la misma observación. Carl Friedrich von Weizsäcker formula el mismo hecho para sistemas personales como sigue: "La conciencia es un acto inconsciente. ${ }^{169}$ En este sentido también se podría formular: la observación es -en el momento de su constitución- una operación no observable.

La observación puede por lo tanto observarse a sí misma en un sentido negativo, con lo cual emerge la observación como ausencia de la operación y se constituye sólo a través de ello. Así, la observación es una operación "no operativa", que surge a través de su ausencia y que, por su parte, es posible observar. Con ello tenemos el siguiente desarrollo: por la ausencia temporal de las operaciones surgen formas de negación como "lugares vacios" que, sin embargo, adoptan ellas mismas el significado de "operaciones negativas".

Se señala por precaución que aquí nos ocupamos de sistemas del sentido dentro de un mundo preñado de sentido, en el cual todo lo que sucede tiene sentido o significado. Esto implica que también el "no suceder" produce sentido. Sobre esta base legitimamos la aparición de la observactón como la ausencia de la operación. Dado que las operaciones, por su parte, consisten en acontecimientos discretos -en "vacíos" por así decirlo-, es muy probable él surgimiento de la observación sobre la base de acontecimientos operativos discretos.

Por medio de una forma de negación de este tipo se forma la distinción central entre observación y operación. Ahora el sistema puede implicar (operativamente) tanto a otros sistemas como también al

${ }^{169}$ Weizsäcker, C.F..v, 1983a, p. 411. 
tiempo; posteriormente se puede observar a sí mismo, dado que la observación puede ser manejada reflexivamente, o sea, como la observación de una observación, lo que no es posible con una operación (una acción, p. ej.). Una operación (acción) solamente tiene valor de conexión, ningún valor de reflexión: el actuar del actuar no produce ningún sentido-de-observación.

Una operación no puede observar, como operación, a otra operación; solamente puede hacer conexión con la siguiente operación. Una observación puede observar tanto a otra observación como también a una operación, con lo cual, desde luego, una observación es también una operación. O: todas las observaciones son también operaciones, pero no todas las operaciones son también observaciones.

A través de la auto-observación el sistema puede observar, cómo opera (actúa) y no opera (observa) y por lo tanto, controlarse a sí mismo reflexivamente (figura 31 ).

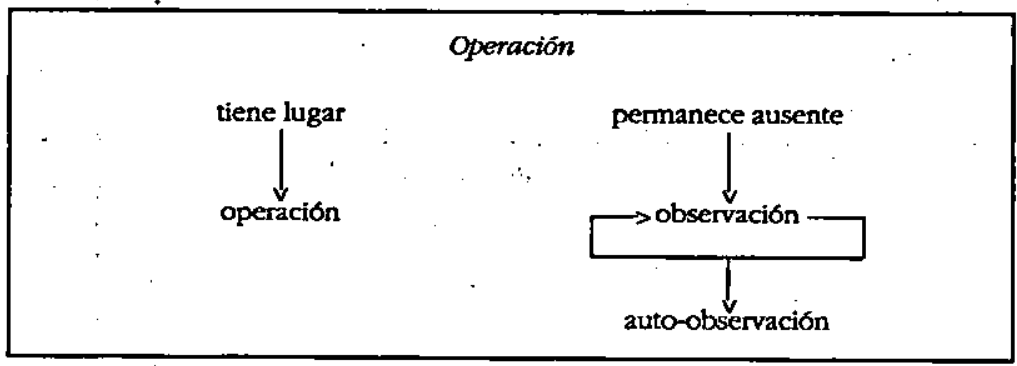

16. ¿Cómo se llega ahora a la forma de auto-observación?; ¿cómo es posible la auto-observación? La ausencia temporal de la operación tiene como efecto la observación, algo que sucede obligatoriamente, ya que una operación sólo puede ser operación cuando tiene lugar en unidades discretas, cuando es posible como acontecimiento, lo que presupone un comportamiento de conexión: ella tiene lugar en el presente solamente como consecuencia de otra anteriormente acontecida y de otra, también diferente, a efectuarse en el futuro. Esto significa que una operación nunca es posible como un evento singular, sino que "es evento" siempre en conjunto con otros eventos del mismo tipo. Por lo tanto, las operaciones representan sucesos, los. cuales son "ciegos" en cuanto a la observación, pero deben ser dis- 
tintos (desde la perspectiva de la observación) como unidades de utilizactón de un sistema: solamente de esta manera está garantizado su valor de conexión, algo que en primer lugar los constituye como sucesos. Precisamente esta circunstancia de que una operación reproduce un evento singular, el cual comienza, tiene lugar y desaparece, origina que las operaciones estén sujetas a un ritmo de tener lugar/ no tener lugar. Si una operación tiene lugar como suceso, entonces debe desaparecer pronto y cederle el espacio a otra operación. Pero entre el acontecer de la "primera" operación y el acontecer de la "segunda" operación hay una así llamada "pausa operativa", un "vacío operativo" o "nada", es decir, algo que se cristaliza como la "observación" dentro de un mundo del sentido. Si se réaliza una segunda vez una secuencia de este tipo y con ello una segunda vez "na$\mathrm{da}^{n}$, entonces tendremos con ello un proceso de repetición de la observación (es decir, un segundo "vacio de operación"), lo cual no significa otra cosa que una observación de una observación, una observación de segundo grado. Más adelante abordaremos este proceso de repetición, el cual constituye la condición de la posibilidad de la identidad (figura 32).

\section{Observactón de una observación (auto-observación)}

tiene lugar la operactón 1

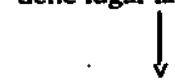

pausa operativa 1

tiene lugar la operación 2

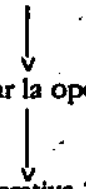

pausa operativa 2

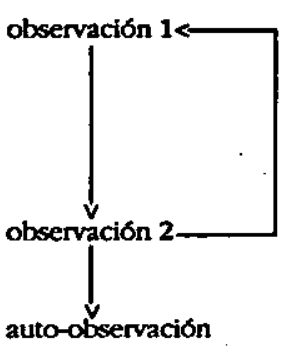

Con ello el sistema está provisto de la capacidad para la auto-observación, ya que la "segunda" observación puede observar a la "primera" y además a la operación. Un sistema basal tal; es capaz ahora 
de poder observar a la distinción de operación y observación, una distinción que por ejemplo puede llevar a desarrollarse a la distinción fundamental de la teoría de sistemas, es decir sistema (operación o "algo en sî") y ambiente (observación o "nada") (figura 33).

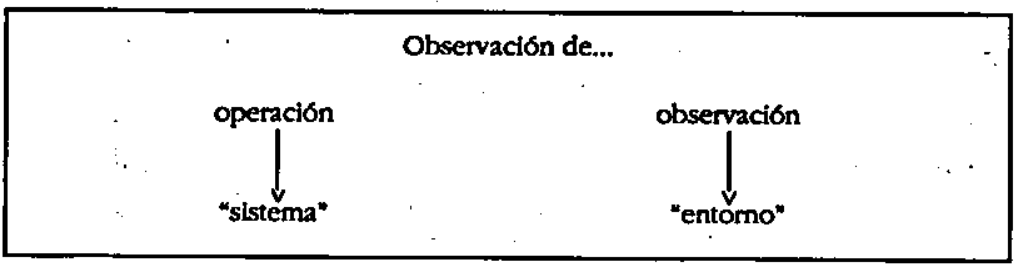

Spencer Brown y la TsS hablan en este contexto de un re-entry de una distinción en la esfera de operación del sistema, el cual se constituye precisamente debido a esta distinción. Sea dicho explícitamente que la operación y la observación reproducen hechos que se condicionan entre sí y que por lo tanto se constituyen mutuamente. Por un lado, una operación sólo se puede realizar a través de distinciones, dado que solamente se puede desarrollar operativamente como un suceso entre otros sucesos: surge, tiene lugar y desaparece, encontrándose disponible ya la siguiente operación [...] la realizada ha desaparecido [...] por lo tanto, los sucesos deben poder ser identificados como sucesos distintos. Las distinciones a su vez son distintas únicamente sobre la base de las observaciones. Por otra parte, una observación sólo se da por la ausencia de las operaciones, lo que indica que las operaciones - aun en sentido negativo- son la condición previa para la constitución de las observaciones (figura 34).

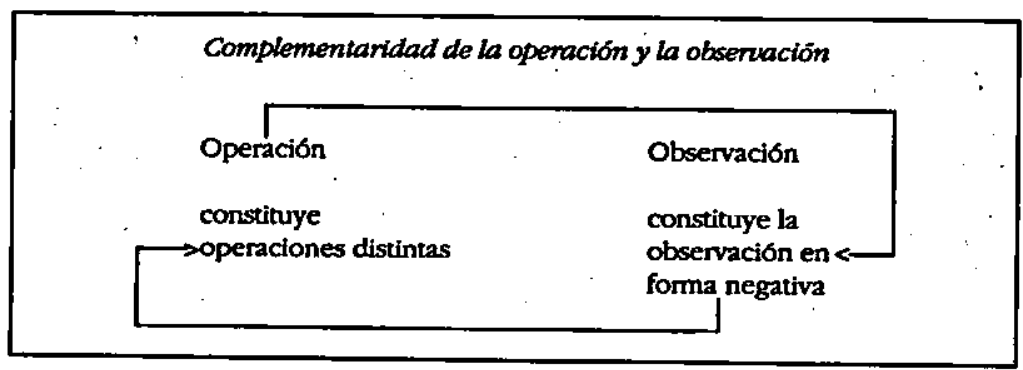


17. Transferido lo anterior a la SOCIEDAD, proponemos la siguiente interpretación: considerar a la cOMUNICACión como una forma de la observación ${ }^{170}$ y a la ACCiÓN como una forma de operación. Si no tiene lugar una ACCIÓN entonces se puede -por medio de la ausencia de la acción-llegar a la COMUNCACIÓN. Luhmann comprende a la ACCIÓn como la forma de auto-observación de un sistema del sentido (de un sistema social). Esto es una connotación semántica la cual consideramos equívoca. Seguramente una acción como suceso operativo de un sistema del sentido es una forma de reducción particularmente extrema del sistema en cuestión, pero sobre todo es una forma de acontecimiento, la cual "señala" al sistema respectivo, lo presenta, lo atribuye o "se dirige a él" como sistema. Pero ¿es por ello un suceso de esta naturaleza una forma de auto-observación? Dado que no compartimos la opinión de Luhmann, tampoco queremos relacionar la forma reflexiva de la auto-observación con la ACCIÓN, sino precisamente sólo la observación de una observación (figura 35).

\begin{tabular}{|l|}
\hline \multicolumn{2}{|c|}{ Sistema socul basal } \\
Comunicacion:
\end{tabular}

18. Ya desde la perspectiva operativa de una pragmática de las distinciones hemos visto cómo se puede hacer plausible que de una operación (lógica o de cualquier otra índole) que tenga lugar en el presente, se puede deducir, en el sentido de un procedimiento protológico, el principio de la contradicción y el principio del tercero excluido, sin abordar la lógica en cuanto a su "contenido". Pero el verdadero fundamento de una lógica depende enteramente del prin-

17 En realidad se trata en primer lugar de una distinción. La forma de observación se da, cuando ya haya tenido lugar una operación primaria. Para simplificar las cosas dejemos sin considerar a la importante, pero en este contexto, sutil, distinción de la distinción y a la observación. 
cipio de la identidad, el cual, como se sabe, afirma: $A=A$ o, expresado en palabras: "algo es idéntico consigo mismo". ¿Se puede ahora dibujar un principio de autoidentidad sobre el nivel operativo aquí seguido? Recordemos que nuestro punto de salida es: una operación siempre tiene lugar en el presente, sólo y cuando realmente tiene lugar. Solamente tiene la alternativa de tener lugar o de no tener lugar. Si tiene lugar solamente una vez, y esto quiere decir como suceso sin comportamiento de conexión, entonces desaparece y con ella también aquello que se podría haber formado.

Recordemos aquí que una operación lógica tiene un significado dentro del sistema de la lógica, el cual excluye el significado cotidiano. Se podría formular también: su sentido consiste precisamente en prescindir de este sentido cotidiano. En todo caso intentamos aquí combinar la fenomenología de la vida cotidiana y la lógica de "manera razonable".

Si tiene lugar, independientemente de las razones, una segunda vez, entonces se realizan - hablando como Spencer Brown y la TsS- ${ }^{171}$ simultáneamente una confirmación y una condensación.

Spencer Brown define: (condensation) condensación y (confirmation) confirmación. ${ }^{172}$

La primera operación como "suceso primario" se convierte por medio de la segunda operación en un "suceso secundario", a través de lo cual está dada una confirmación. A la vez, el "suceso primario" se junta con el "suceso secundario", con lo cual amplía a éste y lleva a la sedimentación o a la condensación (figura 36).

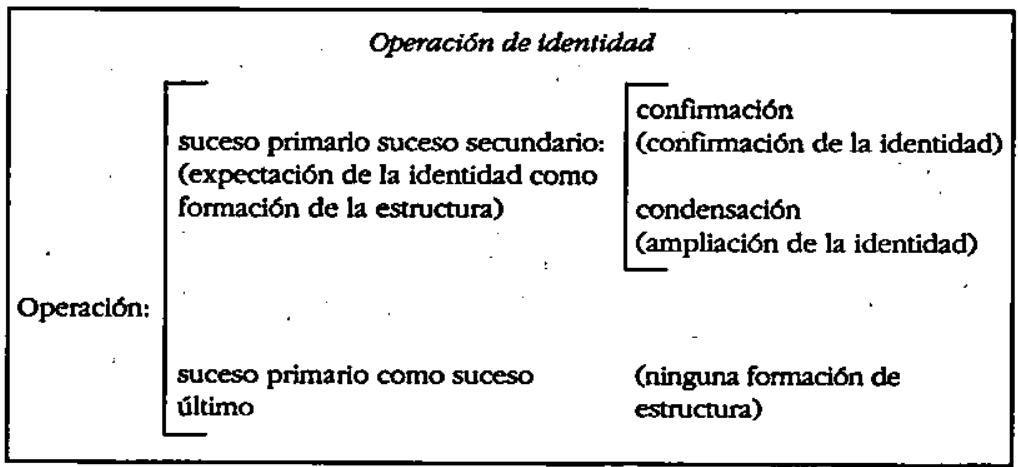

171 Luhmann, 1990a, p. 22.

172 Spencer Brown, 1969, pp. 9-10. 
La identidad tiene lugar de forma doble, dependiendo de la dirección de la lectura, como lo formula la TsS. Se condensan dos operaciones (actos, acciones, percepciones, etc.) en una: la identidad se forma "[...] como condensado de una multitud de operaciones". ${ }^{173} \mathrm{Al}$ guien llama. La hija no oye. Se llama otra vez. Se confirma la primera operación por medio de la segunda, con lo cual la identidad aparece, en este caso, como resultado de una confirmación que implica dos operaciones diferentes: "Se forma una identidad la cual, sin embargo, es compatible con situaciones diferentes, que indica entonces un cierto margen de acción para las posibilidades. ${ }^{n 174} \mathrm{La}$ segunda llamada no es la primera, pero tampoco es una llamada totalmente diferente: es precisamente una primera y una segunda llamada.

19. Hemos llegado hasta aqui $\rightarrow$ sin preestablecer una identidadpudiendo demostrar cómo la identidad es posible únicamente sobre la base del concepto de operación. Con ello llegamos ante las puertas de una teoría genética de la constitución del sentido, la cual no depende de representar fenomenológicamente todo lo existente, para después "destilar" identidad. Con la ayuda de la distinción de una operación que tiene lugar/no tiene lugar, la cual, cuando se presenta .una segunda vez, emula la distinción adicional de idéntico/no idéntico, estamos en condiciones de demostrar la formación de la identidad "constructivistamente" (figura 37).

\section{Génesis del sentido sobre base operativa}

1) Una operación puede tener lugar/no tener lugar; si tiene lugar, entonces

2) se observa como idéntica/no idéntica; ${ }^{175}$ si se observa como

3) idéntica, entonces se llega a la distinción de condensación y confirmación. Por medio de ello se puede activar una unidad del sentido actual-fáctica en conexión con un cambio del horizonte hacia otras posibilidades, la cual entonces logra aquello que la TsS describe como la distinción constituyente del médium sentido, es decir el

4) procesamiento de la actualidad fáctica dentro de un horizonte de posibilidades.

${ }^{173}$ Luhmann, 1990a, p. 22.

174 Idem.

is La TsS señala dentro de este contexto, que la observación del rendimiento operativo "[...] depende de la diferenciación idéntico/no idéntico". 
Naturalmente no tiene lugar una reflexión de este tipo dentro de un mundo del sentido fáctico. En este mundo la comunicación se lleva a cabo bajo condiciones económico-comunicativas, sin que los participantes tengan que reflexionar sobre esta ejecución reflexiva del sentido. En la ejecución del sentido inmediato, sea pensando o comunicando, no es necesario incluir el pensar o comunicar, ya que esto es una condensación o una confirmación. ${ }^{176}$

Al contrario, una hiperreflexión semejante probablemente perturbaría el proceso de comunicación en tal grado que debería intenumpirse.

\section{Predicación y forma}

20. ¿Cómo están relacionados la forma de la operactón con el sistema de la lógica, en el cual se trata de realizar "afirmaciones verdaderas" operativamente? Con la ayuda de una frase de predicado se afirma o se predica lo verdadero. La verdad no representa ninguna característica de la gramática. Si éste fuera el caso, entonces se podría delegar el problema de la verdad a la lingüística. Además, no podríamos entender en absoluto el éxito evolutivo de numerosas formas nogramaticales sobre la tierra. Se admite totalmente que podemos aclarar todo esto solamente sobre la base y con la ayuda nuevamente de afirmaciones predicativas. Lo que "no se puede decir" no significa que por esta razón no se pueda expresar en forma gramatical.

Dentro del sistema de la logica se formulan las condiciones que se deben exigir a las formas de las manifestaciones lingüísticas, para que éstas puedan ser capaces de verdad. Esto significa que una teoria de la lógica tiene como condición previa una teoría de la verdad, puesto que se trata de la capacidad para la verdad de sus afirmaciones. Y entonces la pregunta que surge en este contexto es ésta: ¿qué se puede entender como verdad? Carl Friedrich von Weizsäcker -ya arriba nos hemos referido explícitamente a sus indagacionespropone en este contexto una teoría de la verdad pragmática, la cual dice: las verdaderas operaciones del conocimiento son operaciones cognoscitivas adaptadas a las respectivas circunstancias. Una teoría semejante de la verdad pragmática se basa en última instancia en una teoría de la evolución sociocultural, dado que solamente desde esta perspectiva pueden volverse inteligibles los productos de adap-

${ }^{176}$ Luhmann, 1990a, pp. 22-23. 
tación consumidores de tiempo de las operaciones del conocimiento. La evolución sociocultural y la teoría de la verdad pragmática están por ello estrechamente relacionadas. Pero, para no complicar innecesariamente las circunstancias, nos quedamos primero con esta observación. Naturalmente no está explicado el "ser intrínseco de la verdad $^{n}$ con el planteamiento de una teoría pragmática de la verdad, sino que solamente está realzado uno de sus aspectos. Pero - y esto lo queremos explicar en detalle más adelante- en última instancia una pragmática así de la verdad acaba en la corrección del comportamiento, lo cual significa que el comportamiento de un sistema se adapta a las respectivas circunstancias, una adaptación que el respectivo sistema registra, percibe o juzga entonces como "correcto".

Las exposiciones de Carl Friedrich von Weizsäcker, relevantes en este contexto, dicen: "Como definición pragmática de la verdad, señalo en lo siguiente su definición como adaptación de las acciones del conocimiento a las circunstancias. Esta definición no clama ilustrar acerca del ser de la verdad. Ella realza un aspecto de la verdad. Ella comprende a la lógica (R]) como una teoría de los actos del hablar [R] y los actos del hablar como un tipo especial de acciones [R]]. En la aplicación que se hace de ella en este capítulo, observa en las acciones humanas esencialmente aquellos rasgos que tienen en común con el comportamiento animal. La verdad así definida se reduce entonces a la corrección de comportamiento." ${ }^{13}$

21. Si una teoría de la lógica implica una teoría de la verdad, ésta a su vez se puede explicar, siguiendo la tradición, en forma de una frase predicativa, ${ }^{178}$ entonces el siguiente paso consiste en una explicación de la forma de una frase predicativa. Para esto, analizamos algo más de cerca la forma predicativa de una frase que suponemos que expresa lo verídico: En la frase de la forma "R es $Q$ " $O$ "El libro es de papel" se predica algo de un sujeto " $R$ " o "Libro", es decir la " $Q$ " o "de papel". También en las afirmaciones "El hombre es bueno" o "El tiempo está mal" o "Julia es una mujer" siempre se trata de que el sujeto (libro, hombre, tiempo, Julia) se relaciona con su predicado

17 Weizsäcker, C.F.v., 1977, p. 298.

178 Véase entre otros Erst Tugendhat, Vorlesungen zur Einfübrung in die spracbanalytiscbe Filosofie, 1979. 
(de papel, ser bueno, ser malo, ser mujer) en la proporción del individuo (sujeto) con lo general (predicado).

Sea puesto aquí de relieve que el predicado es en realidad un término gramático-sintáctico y que no corresponde exactamente al concepto semántico de lo general o común. Ernst Tugendhat añade en ese contexto: "En là oración 'el caballo está cansado' están solamente presentes un predicado (está cansado), pero dos términos generales (caballo y cansado). Muchos filósofos analíticos (p. ej.; Strawson) hablan también de predicados cuando se refieren a términos generales. ${ }^{179}$ Nosotros seguimos en este uso del idioma a Strawson. Ahora, el hecho de que el sujeto de la frase se relacione con su frase del predicado, naturalmente no significa que el sujeto (en si), visto semánticamente, fuera siempre algo concreto y que el predicado (en sî) fuera siempre algo general. Aquí se trata de la relación entre el sujeto y el predicado, y en cuanto a esta relación se puede afirmar que la frase predicativa (o categorial) de la forma " $R$ " es " $Q$ " produce sentido sólo cuando se conserva la relación asimétrica entre un término singular y uno general.

Tugendhat habla en ese contexto del "problema de la asimetria [RJ] entre el término singular y el predicado $[. . .]^{n}:{ }^{180}$ Según Tugendhat debemos ya haber especificado el objeto, con la pregunta de si con la frase predicativa " $\mathrm{Fa}$ " el predicado corresponde al objeto [...] para poder, en fin, formular la pregunta de si el predicado le corresponde. ${ }^{181}$ Somos de la opinión que esta suposición necesita otra radicalización más: la especificación y la generalización están presentes simultáneamente en la frase predicativa y no una después de la otra, como bien parece suponer Tugendhat. Por lo demás, con la ayuda de la distinción entre diferencia y diferenciación se puede comprender la relación entre los términos singulares y los generales, de sujeto y predicado, como un contexto de constitución de la simultaneidad de sujeto y predicación. Más adelante regresaremos a ello.

La calificación o la caracterización de un sujeto de la frase en cuestión por medio de una predicación de la forma " $\mathrm{R}^{n}$ es " $\mathrm{Q}$ " sólo puede tener lugar de tal manera ${ }^{182}$ que el sujeto de la frase sea so-

379 Ibid., p. 52.

${ }^{180}$ Ibid., p. 487.

${ }^{181}$ Idem.

${ }^{182}$ Tugendhat ve la función del predicado en la caracterización de un término singular. Por ello, el entender un predicado como predicado sig」 
metido a una caracterización o determinación. Sin embargo, la circunstancia de ser caracterizada o determinada no se puede encontrar en un más alto nivel de abstracción -exclusivamente en relación a la caracterización o determinación a ser realizada- y por ello ser más general y más indeterminada que la misma operación con la caracterización o determinación. En caso contrario no sería realizable la caracterización o la determinación. Dicho de otra manera: lo que dentro de una frase categorial lleva a cabo la determinación, esto es, el predicado, debe permanecer más indeterminado y más general que aquello que dentro de la misma frase será determinado, es decir el sujeto. Si lo determinante (predicado) fuera más determinante que aquello que debe determinar (sujeto), entonces se invertiría simplemente la relación entre sujeto y predicado: el predicado se convertiría en sujeto y viceversa, con lo cual terminariamos en la misma relación de asimetría.

De lo contrario lo determinante no podría determinar a lo determinado como determinado: lo determinante (predicado) debe permanecer más indeterminado que aquello que lo determina (sujeto).

Para excluir malentendidos: no opinamos que el predicado "determina" y el sujeto "se deja determinar". Más bien se trata de un acto de determinación mutua. Sólo con el fin de una mejor comunicación hemos escogido aquí la distinción de determinante/determinado, de actividad y pasividad. Se podría formular también así: el sujeto le ofrece a la predicación la oportunidad de caracterizarlo...

La generalidad del predicado es, por lo tanto, la expresión de su forma más indeterminada frente de un sujeto correspondiente. Se puede decir inversamente, que lo inequívoco del sujeto es la expresión de una ambigüedad del predicado en la frase correspondiente.

22. En la frase predicativa' "Fa" se establece la relación entre determinado (inequívoco) e indeterminado (ambiguo). En la frase "el león ruge", se introduce por un lado, la determinación "león rugiente". Por el otro lado, a través del verbo "rugir" se abre un área de indeterminación o de posibilidades en el sentido de un "león

nifica “[...] entender su función de caracterización”. (Tugendhat, 1979, pp. 178-179). 
rugiente/no rugiente": precisamente la determinación del sujèto por medio del predicado rugir hace patente que el león también puede dormir, tragar o generalmente no-rugir. C.F.v. Weizsäcker habla en este contexto de un lado explícito y de un lado no-explicito del predicado (bien entendido, solamente del predicado) de una expresión: 'Si la afirmación es expresada sencillamente [RJ], entonces tiene [...] la prevalencia de lo positivo; se comprende 'como cierta': de la afirmación sencilla se ramifica hacia ambos lados en un espectro de comportamiento posible [R]. Hacia el lado de la tivexpresabilidad [RJ] se encuentran maneras de la orientación que ni siquiera adoptan una forma lingüística. Hacia el lado de la expresabilidad [RJ] se encuentran, desde la duda ligera o decidida, hasta la forma de la frase reflectada." ${ }^{n 183}$ Esta distinción de explícito/no explícito de la predicación es dificil de comprender, precisamente porque el nivel de posibilidad del predicado permanece no-explícito; mientras que se procesa explícitamente el nivel de lo actual. $Y$ es precisamente con la ayuda de esta distinción del predicado, que la frase afirmativa procesa el sentido como distinción de actualidad y posibilidad.

El lado determinado de una frase afirmativa (el sujeto), y el lado determinante de la misma frase (el predicado), se constituyen simultáneamente y esto quiere decir mutuamente, con lo cual la determi'nación del sujeto condiciona la indeterminación del predicado y viceversa: precisamente el sujeto determinado hace evidente que el predicado no es nada más una caracterización posible entre otras caracterizaciones.

Sea observado ad cautelam que con una frase predicativa se puede hablar de dos lados de la frase, los cuales son: sujeto y predicado. Pero también el predicado consta de dos lados: de un lado explícto y uno no explícito, de un lado "actual" y de uno "posible". Asimismo, el sujeto se da a conocer por su forma asimétrica precisamente como aquel sujeto determinado que lo separa de otros sujetos generalmente no mencionados o del todo inexpresables.

Lo importante es la relación sujeto/predicado y no el sujeto "en sî" o el predicado "en sî". En la frase "el león ruge", el verbo predicado "rugir" es más general (naturalmente en relación con rugir) que el sujeto "leon". Pero, en la frase "el rugir es ruidoso" esta vez es más general el predicado "ruidoso" (en relación con volumen) que

${ }^{183}$ Weizsäcker, C.F.v., 1985, p. 214. 
el sujeto "el rugir". Podría imaginarse también un rugir ronco o sordo o uno que dure largo tiempo.

23. ¿Es entonces el "rugir" más abstracto que el "ser ruidoso"? Se puede construir una escala de abstracción progresiva con los predicados como los términos generales de una frase predicativa, como lo enfatiza Ernst Tugendhat: por ejemplo, la secuencia de los predicados "palatino", "alemán", "hombre", "ser vivo", "objeto del tiempo-espacio", representaría una abstracción progresiva. ${ }^{184} \mathrm{Cada}$ vez, el predicado próximo correspondiente es más general que el anterior, porque se puede aplicar a todos los hechos a los cuales se pudo aplicar el anterior, lo cual, sin embargo, no es válido en dirección opuesta. Ahora, visto exactamente, con una argumentación semejante se esquiva el problema de la diferencia de la abstracción entre el sujeto y el predicado de una determinada frase categorial, ya que en el caso arriba discutido se observa el predicado solamente en sí.

Uno se deja seducir fácilmente por una posición de esta naturaleza debido al hecho de que se enfocan sujeto y predicado lingüisticamente y se olvida que la relación de sujeto singular y predicado general es válida solamente dentro de una determinada frase predicativa. En el trasfondo de esta argumentación se encuentra nuestra suposición presentista, de que todo lo que sucede, sucede en el presente, sucede inmediatamente. Si se deja sin consideración la suposición de la inmediatez, entonces se pierde el sentido para la contextualidad de cualquier acontecer, de cualquier operación.

Sólo cuando se comprende la función determinante del predicado dentro de una frase, se comprende también que ningún predicado dentro de una frase afirmativa puede ser más concreto, determinado o inequívoco, que el sujeto predicado dentro de la misma frase, el cual precisamente se predica o caracteriza por el predicado. Y solamente dentro de una determinada frase, el predicado es siempre más general que el sujeto, porque por medio de la operación predicativa se introduce determinación a la frase. Repetimos: el predicado és más general que el sujeto solamente en cuanto a la predicación correspondiente a ser realizada.

${ }^{184}$ Tugendhat, 1979, p. 40. 
24. En la frase afirmativa está réalizada entonces una relación entre juicio singular y general, y con razón se puede hacer la pregunta: en resumidas cuentas ipor qué existen frases que conectan nombres propios (juicios singulares) con conceptos (juicios generales)? Preguntado aun más fundamentalmente: ¿por qué existen las frases en general?

En esta forma fundamental pregunta también C.F.v.Weizsäcker: " ${ }^{\text {PPor }}$ qué existe, en general, la forma de la frase predicativa? ¿Qué constituye su significado fundamental lógico? ¿Por qué hay frases, conceptos, nombres propios?"?

Entonces, la pregunta acerca de la relación entre lo particular y el concepto es una pregunta que introduce el "sentido de la lógica", ya que la lógica formula las condiciones que se deben exigir de la forma de las manifestaciones lingüísticas, para que éstas puedan ser capaces de verdad. ${ }^{186} \mathrm{Y}$ es con la ayuda de la forma de la frase predicativa que se intenta expresar lo verídico.

Tugendhat formula el contexto de verdad y predicación de la siguiente forma: "Naturalmente la palabra 'cierto' no es definible. Será una de nuestras tareas, después de la comprobación del fracaso del planteamiento y en cuanto a la teoria de los objetos, el aclarar cómo se puede preguntar filosoficamente por el significado de las expresiones y clases semánticas de expresiones, y entonces resultará que la explicación de la palabra 'cierto' coincide con la explicación de la forma de la frase acertiva y, en última instancia, con la forma de la frase predicativa." ${ }^{187}$ Por lo tanto, Tugendhat establece una relación estrecha entre la operación de la predicación y la operación de la verdad.

La cuestión de la relación entre términos particulares y generales se ha hecho conocida dentro de la tradición filosófica europea como "la lucha entre el nominalismo y el realismo"188 o como "lucha de universalias". Y esta lucha que ha durado hasta hoy ${ }^{189}$ gira esencial-

${ }^{185}$ Weizsäcker, C.F.v., 1977, p. 295.

${ }^{106}$ La pregunta acerca de la relación entre lo particular y el concepto [...] es una pregunta parcial de la pregunta acerca del sentido de la lógica. (Idem).

187 Tugendhat, 1979, p. 135.

188 Löwe, 1876.

189 El aquí mencionado trabajo de Ernst Tugendhat es en sí una comprobación de este supuesto. 
mente alrededor de la cuestión de la prioridad de la "cosa particular" (empirismo) y del concepto (idealismo). Este trasfondo históricofilosófico indica también que el problema que se esconde detrás de la lucha de universalias es un problema muy explosivo que siempre evoca nuevas soluciones.

De hecho se pueden interpretar los trabajos de Tugendhat como un esfuerzo de reflexionar nuevamente con la ayuda de teorias del análisis lingüístico sobre el "problema de las universalias" y llevarlo, en un cierto sentido, hacia una solución nueva por medio del análisis lingüístico.

25. Queremos recaptitular brevemente lo hasta aquí dicho con la ayuda de la pragmática de las distinciones. Es indiscutible que la frase afirmativa refleja una forma de la distinctón, que ahora podemos determinar más detalladamente. En primer lugar, está dada la distinción evidente de sujeto y predicado, de lo particular y lo común, de lo singular y lo general. Preguntamos con referencia a la pragmática de las distinciones: ¿representa la forma de la frase afirmativa una diferencia simétrica o una diferenciación asimétrica? En el primer instante podría pensarse que se trata de una diferenciación asimétrica, pero ya con C.F.v.Weizsäcker hemos establecido que el lado del predicado de la frase consiste en una forma explicita y una forma no explicita (figura 38).

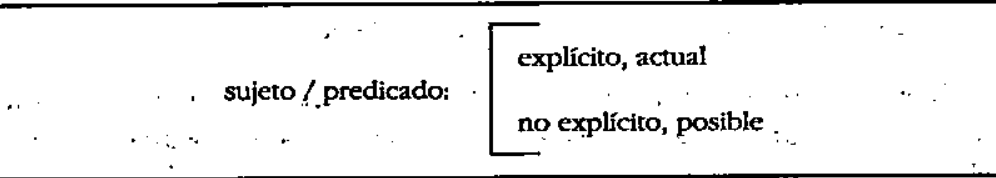

Esto significa que el lado predicativo de la frase afirmativa oscila entre explícito y no explícito, entre actualidad y posibilidad. Con la afirmación: "el león ruge" no se hace inmediatamente claro que el sujeto "el león fuera intercambiable. Antes bien, se llegaría a percibir que el león no ronca, no come o dormita, sino que precisamente ruge. El predicado "rugir" parece por lo tanto, moverse en el campo de tensión de la actualidad (del rugir) y la posibilidad (de algo diferente, de otra actividad). Precisamente esta tensión caracteriza su ser 
común, su generalidad: se percibe también (por medio de una mirada oblicua) ${ }^{190}$ que el león podría ser caracterizado también de otra manera. Se podría decir asimismo, que en la frase afirmativa se indica o se expresa también la functón de caracterización del predicado. En relación con la forma de la distinción vemos como dada, en la predicación, una diferencia potencialmente simétrica en la forma de una distinción de actualidad y la posibilidad, la cual, sin embargo, es astmetrizada a través del otro lado de la frase afirmativa, es decir, a través de su sujeto: èl león podría dórmir, correr o estar parado, pero la frase nos indica que "el león ruge".

26. ¿Qué hay ahora con el statuis de este otro lado de la frase afirmativa, con su lado de sujeto? En este caso se procesa lo inequívoco, el "ser dirigido a" o la "responsabilidad": se trata de un león, nada más, ninguna desviación, ninguna oscilación: Por eso se puede caracterizar el lado del sujeto de la frase afirmativa como ocupado por los términos singulares, los cuales significan la "singularidad". ¿Qué distinción reproduce entonces este lado de la frase afirmativa que significa "singularidad"? distinción con dos lados? Las frases, al menos las frases afirmativas, nunca existen solas, sino únicamente dentro de un juego de lenguaje o de frases. Por lo tanto, se puede partir, dentro del universo de juegos de frases, de que además de la frase "el león nugen ; debe haber por lo menos una segunda frase afirmativa, la cual se encuentra en relación con la primera. Si hubiera solamente una frase afirmativa, entonces ni siquiera sabriamos lo que es una frase afirmativa.

Similarmente lo expresa Ludwig Wittgenstein, solamente que refiriéndose al contexto de la palabra y la frase: "Se puede decir: con la denominación de una cosa aún no está hecho nada. Tampoco tiene ningún nombre, con excepción del juego [lingúistico R】. Esto también era

${ }^{190}$ C.P.v. Weiszäcker habla en este contexto del fenómeno de la "percepción-conjunta": "[...] que en el caso particular percibimos lo general". (Weizsäcker, C.F.v., 1977, p. 312).

191 Para recordar: cada distinción consta de dos lados. En este sentido se debe decir: la frase afirmativa consiste en dos lados (sujeto/predicado) los cuales a su vez constan cada uno de dos lados: punto ciego/lo determinado y actualidad/posibilidad. 
aquello que Frege expresaba de la siguiente manera: 'una palabra tiene significado solamente en el contexto de la frase'. ${ }^{192}$

En ese sentido, las frases presuponen una estructura mutual o dialógica, porque además de la primera frase siempre hay una segunda, la cual la completa, rechaza, afirma, etc., y de esta manera sólo la constituye a ella y a sí misma. Nosotros sostenemos ahora que el sujeto de la afirmación posee una forma de distinción, a la cual llamamos diferenciación asimétrica, una distinción que procesa la unilateralidad. En el caso de la afirmación "el león ruge", "león" es el sujeto de la frase, pero podemos comprender semánticamente el hecho de que se trata de un león, sólo porque "león" se debe distinguir, a un nivel de la teoría de la información, de algo diferente: de "leona", "hombre", "elefante" o de lo que sea.

La información solamente es posible, cumo ya lo hemos formulado anteriormente, sobre la base de una distinción que origina una distinción. Entonces la información es el resultado siempre de la confrontación de por lo menos dos distinciones. Según el conocido Dicrum de Gregory Bateson: "El terminus tecnicus 'información' puede ser definido provisionalmente como alguna diferencia, misma que constituirá una diferencia en un acontecimiento posterior. ${ }^{793}$

En el contexto de la diferenciación asimétrica no tiene lugar ninguna oscilación entre un lado y otro. Al contrario, su función consiste precisamente en comunicar lo inequivoco, con lo cual el otro lado que no aparece de la diferenciación, forma el "punto ciego" de la frase afirmativa. Ahora bien, podemos resumir los hechos de esta manera: dentro de un juego de la frase se juntan dos distinciones de la frase en la forma de una diferenciación asimétrica y de una diferencia simétrica. La asimetría de la diferenciación es el sujeto del acontecimiento de la frase, y la simetría de la diferencia se procesa modalmente en forma predicativa como "así, pero también de otra manera". El resultado es entonces un suceso como suceso de la frase, dentro de un juego de la frase en la forma de un relacionamiento de la diferenciación asimétrica (sujeto) y la diferencia simétrica (predicado); de tal manera, que la diferenciación se refiere al lado actual

${ }^{192}$ Wittgenstein, 1982, p. 46, núm. 49, véase también B. Lee WhorfWhorf, 1963, p. 9.

193 Bateson, 1983, p. 488. 
de la diferencia, sin "borrar" o suspender completamente el lado de la posibilidad. En especial es la distinción de actualidad/posibilidad, la que le da sentido a cualquier frase.

Aquí nos adherimos al concepto del sentido de la TsS: ' $\mathrm{El}$ procesamiento del sentido es [...] una reformación continua de la diferencia constitutiva del sentido de actualidad y posibilidad. El sentido es la actualización corriente de las posibilidades. Dado que el sentido [...] puede ser sentido solamente como diferencia de lo actualmente actual y del horizonte de las posibilidades, cada actualización lleva siempre también hacia una virtualización de las posibilidades conectables en consecuencia. ${ }^{n 94} \mathrm{El}$ significado de una frase estaría entonces en la actualización del predicado del sujeto, lo que no significa otra cosa que en su caracterización en el sentido de Tugendhat: "Una frase como 'el candado es rojo' no se [...] explica en forma que el predicado represente una característica [lo rojo] que se lleva hacia la síntesis con el objeto, sino de manera que se caracteriza el objeto -el candado- por medio del predicado "es rojo" de manera determinada [R]]. ${ }^{\text {ngs }}$

Con ello aparece una estructura tetrádica de la frase afirmativa (figura 39).

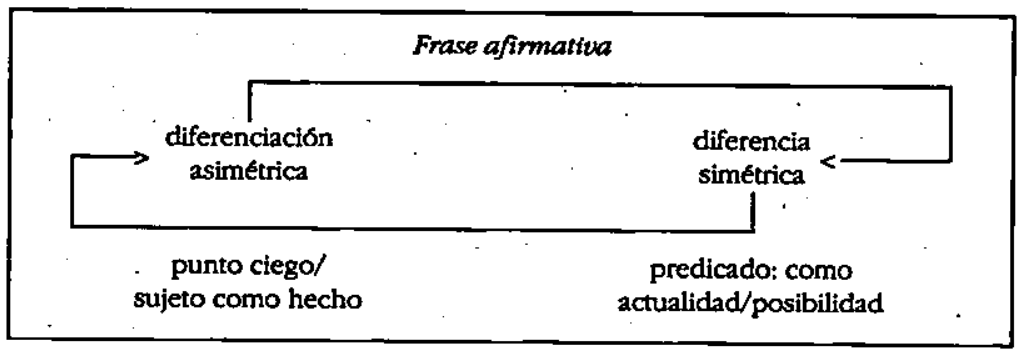

27. La instancia que se considera competente para la contestación de las preguntas del tipo "¿por qué existen frases con conceptos y nombres propios?" o "¿en qué consiste el significado fundamental de la forma de la frase predicativa?" es la lógica en el sentido amplio de la palabra. Lo problemático de esta instancia es, sin embargo, que

194 Luhmann, 1984, pp. 100-101.

195 Tugendhat, 1979, pp. 178-179. 
la lógica se considera como "evidente", "razonable" y por lo tanto como cierta a priori: ${ }^{16}$ si se pregunta por las bases de su certeza, entonces se responde con la "experiencia de la evidencia", con lo cual. uno se mueve en círculo.

La tradición consideraba a la lógica como evidente, como cierta a priort. Si esto es así, entonces la instancia para nuestras preguntas seria precisamente esta evidencia, el discernimiento al cual debemos la certeza de la lógica. La demanda de información aclaratoria con una experiencia de la evidencia, sin embargo, no lleva normalmente más lejos que a una repetición precisa de la afirmación, un aseguramiento de que realmente así es. ${ }^{197}$

Dentro de la lógica más moderna se determina la analítica de una frase cierta por medio de su mera forma. Esta forma, a la vez, debe estar relacionada con las reglas de la lógica, las cuales se consideran como "evidentes". Ahora bien, lo interesante es precisamente la respuesta de la pregunta según la evidencia de las afirmaciones lógicas, una pregunta que hasta hoy no ha sido abordada con el cuidado necesario. Por ello C.F.v. Weizsäcker opina en este contexto que las bases de la lógica han permanecido sin resolverse filosóficamente hasta hoy día:

- "Tal vez sirva esta breve especulación (acerca de la circunstancia problemática de la "evidencia" de las afirmactones lógicas [RJD, para hacer comprensible la afirmación, la cual estaría dispuesto à defender en un tratamiento amplio, de que las bases de la lógica están sin resolver filosoficamente". ${ }^{198}$

${ }^{196}$ Aquí donde se trata del problema lógico de la certeza a priort podemos recordar a Imanuel Kant, quien introduce la distinción entre juicio sintético y analítico. Con ello Kant intenta aclarar esta diferenciación con la forma de la frase predicativa. Un juicio analítico es un juicio cuyo predicado solamente . expresa lo que ya está contenido en el concepto del sujeto de la frase. Un juicio sintético, por su parte, añade predicativamente algo al concepto del sujeto. Por ello los juicios analíticos son certeros, pero los juicios a posteriort son sintéticos. Ahora bien, el problema real que surge para Kant en lo sucesivo es: ¿cómo son posibles los juicios sintéticos a priori? Esto se recuerda brevemente aquí para aclarar la prominencia del problema a tratar. Véase Weizsäcker, C.F.v., 1977, Pp. 295-296.

${ }^{197}$ Ibid., p. 295.

${ }^{198}$ Ibid., p. 296. 
Ya habiamos determinado que la verdad de una frase afirmativa no depende de su gramática, lo cual implica que una teoría de la lógica debe presuponer una teoría de la verdad. Ahora bien, la teoría de la verdad más conocida es la teoría de la correspondencia, una teoría que se puede encontrar ya en la filosofía de Aristóteles: decir de algo que es, que no es; o decir de algo que no es, que es, es falso. 'Al contrario, decir de algo que es, que es; o de algo que no es, que niges, es cierto.

"Decir que lo existente no es o que lo no-existente es, es falso, decir, por el contrario, que lo existente es y que lo no-existente no es, es cierto. Entonces, quien predica un ser o un no-ser, debe pronunciar lo cierto o lo falso. Pero no se dice de lo existente que es o que no es, y tampoco de lo no existente. ${ }^{n 199}$ En ello se puede observar claramente que Aristóteles no "aclara" lo que es la lógica, sino que solamente explica su utlización. Pero ¿se puede definir a la lógica (y a la matemática) de otra manera que explicando cómo se debe utilizar?

Alfred Tarski traduce más tarde la concepción de la verdad aristotélica de la siguiente manera: "La verdad de una afirmación consiste en su concordancia (o correspondencia) con la realidad."

Si nos queremos adaptar a la moderna terminología filosofica, podemos expresar quizás esta concepción por medio de la conocida formulación: "la verdad de una afirmación consiste en su concordancia (o correspondencia) con la realidad", y formulado más parcamente: "una afirmación es cierta cuando designa una cincunstancia extstente" ${ }^{200}$

Ahora bien, se puede, y tomamos esta interesante propuesta de C.F.v. Weizsäcker, "traducir" pragmáticamente la teoría de la correspondencia de la verdad, sin abandonar el aspecto de la correspondencia: no se trata de la correspondencia de una afirmación con la realidad, sino de la adaptación de un logro cognoscitivo (p. ej. de un sistema) a las circunstancias (p. ej. a su medio ambiente). ${ }^{201}$ Con ello la adaptación está expresada en el sentido de un "ser adecuado" o de un pattern-matcbing, de una llave con su cerradura. Se puede

${ }^{199}$ Aristóteles, Metafísica, p. 1011 b.

${ }^{200}$ Tarski, 1972, p. 57.

${ }^{20 t}$ "Como definición pragmática de la verdad [R] designo yo en lo siguiente su definición como la adaptación de la acción del conocimiento a las circunstancias." (Weizsäcker, C.F.v., 1977, p. 298). 
decir ahora - con las reservas semánticas necesarias- que la llave se encuentra en una "posición de correspondencia" con la cerradura que puede abrir.

Una teoria pragmática de la verdad, eso ya lo habíamos anotado, implica una teoría de la evolución sociocultural, dado que solamente en el marco de una teoría semejante se puede explicar plausiblemente el hecho de una adaptación cognoscitiva a las circunstancias con la ayuda de la dimensión tiempo (figura 40).

\section{Teorias de la verdad}

Correspondencia: la afirmación concuerda con la realidad

Pragmática: el rendimiento cognoscitivo se adapta a las circunstancias

28. Una concepción pragmática de la verdad no requiere una identidad en el sentido de una suposición de similitud entre el sistema que se adapta y su entorno, como se debe presuponer dentro de la teoria de la correspondencia de la verdad. Expresado metafóricamente: "cerradura" y "llave" son diferentes por definición, pero si "se combinan" cumplen a través de este camino con el requerimiento de la identidad, sin tener que ser idénticos como objetos. Y es precisamente debido a que la concepción pragmática implica esta forma de "verdad no idéntica", que tiene un rendimiento especial, ya que es mucho más universalizable que la teoría de la correspondencia, la cual puede - conceptuar a la verdad solamente en la forma de una relación de similitud entre "teoria" y "realidad", entre "concepto" y "cosa particular".

Es de sospecharse que la teoría de la correspondencia de la verdad obtiene su plausibilidad por medio de una supuesta identidad entre Ia afirmación y los hechos. En realidad, esta identidad es una operación de identidad que se apega fuertemente a la percepción fisiológica. Desde ahí, la teoría de la correspondencia es, si se quiere así, más "original" que la concepción de la verdad pragmática. En ese sentido (perceptible), Karl R. Popper ofrece el ya clásico ejemplo de una correspondencia entre afirmación y circunstancia: " $\mathrm{La}$ afirmación inglesa The moon is made of green cheese corresponde a los hechos o a la circunstancia real precisamente cuando la luna está hecha de queso verde. ${ }^{202}$

${ }^{202}$ Popper, 1973, p. 58. 
29. La verdad, determinada pragmáticamente, señala la adaptación de la acción del conocimiento a las circunstancias. Con ello se comprende la lógica como una teoria a través de actos de babla y los actos de habla como un tipo especial de acciones. En este sentido las afirmaciones veraces son afirmaciones "correctas": expresan que lo que sostienen implica una adaptación a las circunstancias, lo cual legitima su pretenstón de corrección: la "llave" cabe en la "cerradura". Esta pretensión, sin embargo, es, desde la perspectiva de un observador, una tautología, puesto que un sistema puede realizar su adaptación a las circunstancias solamente en cuanto a sí mismo. En ese sentido, la dirección de corrección de la adaptación siempre es ella misma, una dirección hacia el sistema que se adapta a sí mismo. Y las acciones del conocimiento exitosas lo son, porque son exitosas precisamente para el sistema "cerrado". La verdad pragmática se puede definir como la corrección del comportamiento de un sistema.

C.F.v. Weizsäcker formula así esa circunstancia: "La verdad [pragmática R】 definida de esta manera se reduce, entonces, a la corrección del comportamiento. ${ }^{n 203}$ Que este hecho aplica también a las teorías, lo hacen evidente las siguientes afirmaciones de la TsS relacionadas con la autoreferencia: "La corrección de una teoría sociologica se encuentra en su dirección, y la única dirección sostenible es la dirección hacia sí misma." ${ }^{2 N}$ Esto está pensado consecuentemente en cuanto a la teoría de la evolución.

30. La frase afirmativa está caracterizada por el hecho de que - como unidad-solamente puede adoptar $u n$ valor de la verdad: o es cierto o es falso. ¿Pero cómo se llega a esta unidad, a la unidad de la intenctón de la frase? La teoría de la concordancia o de la correspondencia de la verdad diría: la unidad de la intención de la frase es precisamente la unidad de la "circunstancia intencionada". Pero ¿qué puede imaginarse uno como una "circunstancia intencionada"? ¿Por medio de qué es intencionada? Aquí parecen presentarse dificultades de principios, las cuales P.P. Strawson, por ejemplo, trata de esquivar invirtiendo la dirección de la explicación y opinando que un hecho es aquello que puede ser expresado en una frase. ${ }^{205}$ Pero los hechos

${ }^{203}$ Weizsăcker, C.F.v., 1977, p. 298.

${ }^{204}$ Luhmann, 1987h, p. 39.

${ }^{205}$ Véase el tratamiento detallado de Strawson hecho por Tugenhat (1979, pp. 380-407). 
de una frase, como es sabido, se convierten uno en el otro continuamente. ¿Qué efectos tiene entonces su selección dentro de un continuum semántico de este tipo? C.F.v.Weizsäcker opina que la intención de la frase inteligible, pero nunca completamente articulada, es la que escoge, del continuum de los hechos de una frase (del juego de las frases en el sentido de Wittgenstein), un hecho difusamente delimitado como el "hecho intencionado". Con ello, von Weizsäcker describe solamente que se forma una unidad, pero no cómo se . genera esa unidad, en qué consiste pues el mecanismo del surgimiento de una formación de unidad de tal naturaleza. ${ }^{206}$.

31.Queda la impresión de que Weizsäcker, en última instancia, no pone en relieve suficientemente claro aquello que él llama la "unidad de la intención de la frase ${ }^{n}$. Por otra parte hace referencia, en el contexto de este problema, al fenómeno de la percepción-conjunta. Queremos abordar este fenómeno para una aclaración más exacta de la unidad de la intención de la frase. ¿Qué se quiere decir con una percepción-conjunta? El fenómeno de la percepción-conjunta consiste, en cuanto a la percepción de "algo", en que con su percepción se debe percibir también (percibir-conjuntamente) la unidad en la cual está integrado el "algo" como tal. No se puede percibir la unidad como tal directamente, ya que sólo puede existir como unidad percibida-conjuntamente. Algo se percibe como "algo" solamente en referencia con "algo diferente", no por y en sí. La unidad que surge de ello es la unidad que existe por ejemplo en la percepción de lo actualmente dado en cuanto a sus posibilidades. Una percepción directa de la unidad destruiría la relacionalidad de la actualidad y la posibilidad, y con ello menos que nunca enfocaría alguna unidad. Dado que una unidad es perceptible sólo como unidad relacional de un "algo" respecto a "algo diferente", no puede existir naturalmente una percepción directa de la unidad, ${ }^{207}$ sino solamente una percep-

${ }^{206}$ Weizsäcker, C.F.v.; expone el siguiente ejemplo: "Rlueve" ¿dónde? "aquí": O sea, en el entomo del locutor (Weizsäcker, C.F.v., 1977, p. 299).

${ }^{207}$ Acerca de ello dice C.F.v.Weizsäcker: "En cada concepto hay una percepción-conjunta de la unidad, pero la unidad misma no se puede describir directamente por medio de los conceptos, dado que esto la haría depender de la multiplicidad; pero quizás el cómo es descrita por los conceptos descansa en la unidad acompañante." (Jbid., p. 185). 
ción-conjunta de la relación de un "algo" en referencia con "algo diferente", una relación que con ello constituye la unidad.

Sea recordado que definimos a la unidad, en cuanto a la pragmática de las distinciones, como unidad de la distinción de diferencia y diferenciación.

Se puede hacer plausible el problema de la percepción de la unidad también con la diferenciación de la figura y del trasfondo. La figura como unidad se puede perçibir como figura solamente frente a un trasfondo, y no es posible percibir una figura sin trasfondo. Por lo tanto, cualquier unidad (como p. ej. sistema) no es perceptible como tal, sino solamente frente a un trasfondo generador de unidad (p. ej. el medio ambiente). La percepción-conjunta sería entonces una percepción que oscila entre un sistema y su entorno, y que no solamente percibe al sistema, sino también su entomo o su integración al trasfondo. Por lo tanto, la unidad no es è sistema o su entomo, sino la distinción misma, que siempre es relacional. La "unidad" es siempre una operación relacional, una operación de la percepción-conjunta, la unidad de la distinción. El significado sobresaliente del fenómeno de la percepción-conjunta consiste, según C.F.v. Weizsäcker, en que parece iluminar uno de los problemas probablemente más fundamentales de la filosofía, al menos de la platónica:

"Aquí está arraigado el significado fundamental para la comprensión de la filosofia, por lo menos, de la platónica, a la cual quiero llamar la percepción-conjunta. ${ }^{n 208}$ Hablar en este contexto de un problema fundamental de la filosofía es legítimo, en el sentido de que se trata de la aclaración de la relación entre la generalidad y la particularidad, el concepto y el caso particular, la diferencia y la diferenciación. En la Edad Media, esta discusión toma la forma de una disputa entre los nominalistas y los realistas. Nuestra propuesta de solución es interpretar particularidad/cosa particular en el sentido de una diferenciación asimétrica y generalidad/concepto è el sentido de una diferencta simétrica. Se trata de una solución pósible, pero opinamos que es una solución muy general y, por lo tanto, "poderosa" en sentido cognoscitivo.

Sin embargo, la condición de una percepción-conjunta es la separación por principio de aquello que por un lado, se percibe y, aquello que, por el otro lado, se percibe-conjuntamente, y que von

${ }^{203}$ Ibid., p. 312. 
Weizsäcker entiende como la divergencia del concepto y el caso particular. Nosotros interpretamos esto - transferido a la sociologíacomo la distinción de COMUNICACIÓN y ACCIÓN O, aun más fundamentalmente y en el marco de la "lógica de las distinciones", como la distinción de diferencia y diferenciación

Heinz von Foerster menciona en este contexto la pareja de conceptos fisiológica sensorium y motorium, ${ }^{209}$, Viktor von Weizsäcker habla del movimiento y la percepción, ${ }^{210}$ una semántica que utiliza también C.F.v. Weizsäcker. ${ }^{211}$ Además interpreta las parejas de conceptos concepto/ cosa particular y concepto/información en el mismo sentido representido arriba. Niklas Luhmann habla en este contexto, con referencia a la sociología, de la comunicación y de la acción, lo cual nosotros - también visto sociológicamente- generalizamos e interpretamos como COMUNICACión y ACCIÓN. Y con referencia a la "lógica de las distinciones", se trata de la distinción de diferencia y diferenciación.

Sólo en este nivel se puede volver comprensible el fenómeno de la percepción-conjunta (figura 41).

\section{Modalidades de la realidad}

Percepcion:

Escritura:

Teoría de la sociedad:

Pragmática de las distinciones: percepción/percepción-conjunta

sujeto/predicado

ACCION/COMUNICACION

diferenciación/diferencia

32. Hemos visto: una percepción-conjunta es la percepción de "algo" con la integración de "algo diferente". En el lenguaje de la "lógica de las distinciones" se trata de la distinción de "diferencia" y "diferenciación". En el ejemplo "ahí vuela la pelota" pregunta Von Weizsäcker: " $\mathrm{H}$ He percibido aquella cosa particular que se asocia con el concepto pelota o he percibido el eidos (el concepto) pelota en una de sus realizaciones?" La respuesta es que la pregunta está mal formulada, dado

${ }^{209}$ Foerster, H.von, 1985, p. 66.

210 Weizsäcker, V.v., 1973.

211 Weizsäcker, C.F.v., 1977, pp. 206 y ss. 
que "he [RJ] [...] percibido ésto como pelota".$^{212} \mathrm{Si}$ transferimos esta afirmación a la pragmática de las distinciones, entonces podemos formular: aquí se procesa (predica) una "diferenciación" asimétrica, es decir la pelota (como sujeto inequívoco), en cuanto a su "diferencia" simétrica como volar y/o no volar. Según Von Weizsäcker, el fenómeno de la percepción-conjunta consiste en la percepción de la distinción de eidos y la cosa sensorial, del caso particular y lo general: esta pelota volando. Nosotros interpretamos el fenómeno de la percepción-conjunta como la unidad de la distinción de diferenciación (pelota) y diferencia (volar/no volar).

Para apreciar la importancia que le da C.F.v.Weizsäcker al fenómeno de la percepción-conjunta, se señala la siguiente secuencia de su trabajo "Biologische Präliminarien zur Logik": "En una estilización ligeramente juguetona se deja explicar la tarea de la filosofia en la siguiente escala de niveles: si en la percepción reflectiva se hace la diferencia entre el caso particular y el concepto, entonces esto significa que en el caso particular de esta percepción se percibe conjuntamente la diferencia entre el concepto del caso particular y el concepto del concepto. El eidos es, descrito desde el caso particular, la regularidad que percibimos conjuntamente con el concepto, en la posibilidad de la manera constitutiva del comportamiento del concepto correspondiente. La percepción-conjunta del eidos con el objeto sensorial es la apariencia del eidos, así como la filosofía griega comprende el concepto apariencia [...]. La percepción conjunta de la diferencia del eidos y la cosa sensorial es la apariencia de esta diferenciación. Desde Platón, la filosofia es el intento de percibir directamente esta diferenciación, así percibida-conjuntamente; ella es una meditación de esta diferenciación. Por ello la filosofia es la doctrina de la apariencia: ella es la apariencia de la apariencia." ${ }^{\text {213 }}$

Por lo tanto, la unidad de la intención del sentido de la frase es la condición previa para la monovalencia de la frase en el sentido del tercero excluido: o la frase es cierta o es falsa. Aun más: la unidad de la frase consiste en su monovalencia. Pero aún no se ha contestado la pregunta de cómo se da el hecho de que la frase predicativa consista en un relacionamiento asimétrico del sujeto con el predica-

${ }^{212}$ Ibid., p. 312.

213 Ibid., pp. 312-313. 
do. Basándose en Platón, Aristóteles y Chomsky, Von Weizsäcker indica como unidad una justificación temporal de la estructura sujetopredicado de la frase. Ésta dice: "Quien quiera describir el cambio, debe designar algo que permanece igual (si nada permaneciese inmutable, entonces es de suponer que una descripción conceptual sería imposible) y algo que cambia. ${ }^{\text {214 }}$ Con la ayuda del conocido ejemplo de una estatua de bronce de Aristóteles se demuestra cómo lo cambiante y lo constante se apoyan mutuamente. Aristóteles llama a lo constante, en relación con la estatua de bronce, "materia", a lo cambiante "forma". El bronce es materia en relación con una no-modificación, y forma en relación con sus componentes cambiables cobre y estaño. En la frase afirmativa se debe afirmar también algo que permanece igual y algo que cambia. Lo que permanece igual es el sujeto y lo que cambia es el predicado. ${ }^{215}$

33. Hemos visto que todo lo que es, siempre se presenta en forma tetrádica, la cual consiste en el entrelazamiento de una diferencia simétrica y una diferenciación asimétrica. Así hemos definido también la operación de la observación. En el caso de la distinción de sujeto y predicado se sugiere partir de la dimensión social de dos locutores y, en ese contexto, hacer la pregunta: ¿cómo es posible la forma de la frase predicativa?, ¿cómo es posible la unidad de la intención de la frase en este contexto? Partimos de una situación doblemente contingente y suponemos que ambos locutores se encuentran semánticamente en una relación simétrica, ¿cómo se vería la forma de análisis de una situación semejante? Entendida correctamente, la simetría debe ser válida en toda la frase, es decir, para el sujeto y para el predicado. Una forma posible sería la siguiente: éste y/o ésta es esto y/o aquello. La simetría se puede expresar también así: solamente la dimensión sintáctica de los signos es válida.

"Denominamos [...] a esta dimensión de los signos, en la cual ciertamente dan a entender que son signos, pero no qué es aquello que representan, la dimensión sintáctica de los signos. ${ }^{\text {216 }}$

214 Ibid., p. 307.

215 Idem.

216 Seiffert, 1972 a, p. 90. 
Una conciliación lingüística no sería posible bajo la condición de una forma simétrica de las afirmaciones de ambos locutores, porque de esta forma solamente se puede comunicar la indeterminación. Sólo cuando la frase adopta la forma: éste, no ésta, es esto, no aquello, o sea al asimetrizarla es que existe una conexión posible. Pero irealmente es así que la frase afirmativa muestra una forma inequívocamente asimétrica? ¿A qué sẹe refiere la asimetría: al sujeto, al predicado o a la relación entre ambos? La función de la asimetría consiste en constituir lo inequívoco. En ese sentido el sujeto de una frase afirmativa siempre es asimétrico, ya que a través del sujeto se introduce lo inequívoco o la unilateralidad a la frase. Aquí se trata de la dis-. tinción de la "diferenciación", la cual se presenta dentro de la frase: en forma cortada: el otro lado de la diferenciación asimétrica es el. "punto ciego" de una frase, el lado que generalmente no se dice o que no puede o no debe ser dicho. Y ¿qué pasa con el otro lado de la frase afirmativa, con el predicado? El predicado es procesado en la forma: de una simetría incompleta: cualquier caracterización de un sujeto tiene lugar en la forma de una distinción de la actualidad y la posibilidad, de explicidad y no-explicidad (C.F.v. Weizsäcker). En este caso se trata de la distinción de la "diferencia", la cual indica sólo in-. completamente su forma simétrica. Por otro lado, la asimetria "ligera" que se puede detectar entre el sujeto y el predicado es la referencia del sujeto al aspecto actual o explícito del predicado, $y$ por lo tanto ninguna asimetria real. Podemos generalizar ahora y decir: para que los locutores puedan hablar de manera sensata uno con el otro, sus frases afirmativas deben mostrar una mezcla bien dosificada de determinación/asimetría e indeterminación/simetría.

Esto se lleva a cabo con la ayuda de la distinción del sujeto y del predicado, con lo cual el sujeto comunica lo inequívoco y el "punto ciego", el predicado comunica la actualidad y la posibilidad. Cada frase afirmativa reproduce, por lo tanto, una relación tetrádica de acontecimientos que consiste en dos distinciones: en una asimetría (sujeto) que adjudica determinación con su "punto ciego", y en una simetría incompleta (predicado) que adjudica indeterminación. La unidad buscada de la frase afirmativa es, por lo tanto, la unidad de la distinción de la determinación y la indeterminación. El mecanismo de la producción y reproducción de un idioma verbal o escrito encuentra su origen en esta relación. A través de su función de determinación, el lenguaje se fija semánticamente y provoca por ello la contradic-. ción o la protesta (cuando lo hace). Esta clase de contradicción es po- 
sible solamente porque, por el otro lado, deja abierto si ès que sigue con el predicado actual o lo cambia. Por lo tanto, podemos decir que hay una correlación entre la determinación de una frase afirmativa y su indeterminación: lo inequívoco provocativo del sujeto se amortigua por la ambigüedad del predicado. Más aun, en el marco de una situación conversacional doblemente contingente, la determinación del sujeto constituye la indeterminación predicativa y viceversa (figura 42).

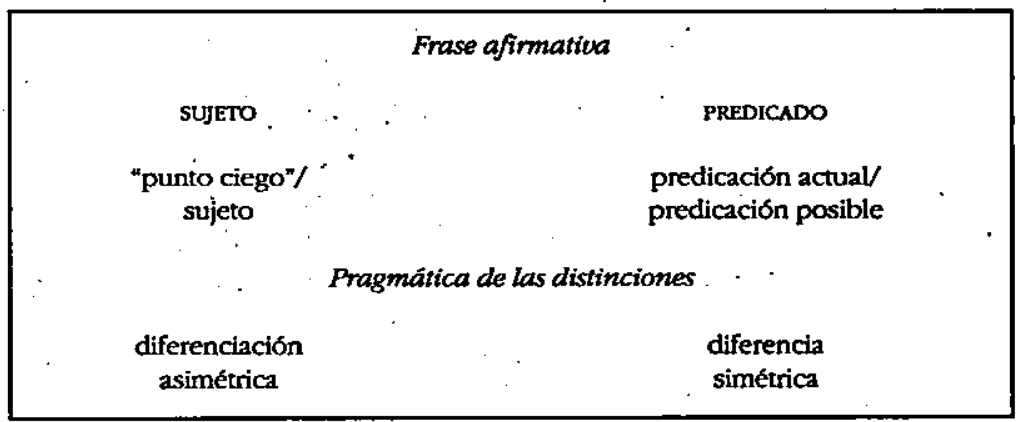

34. Al principio hicimos la pregunta de cómo se vería la conexión entre la forma de una operación como operación y la forma de la lógica como "afirmacion cierta". Ahora podemos responder: si uno se apoya en la pragmática de las distinciones como medio analítico, entonces se puede demostrar que tanto la operación como la verdad de la frase predicativa -entendida pragmáticamente- son accesibles a nivel de la teoría de las distinciones. Con esto no se afirma una reducción de la operación y/o de la afirmación. Ciertamente, el escalpelo de una pragmática de las distinciones hace patente las conexiones en este contexto, pero de ninguna manera reduce la operación a la lógica de afirmaciones o viceversa. Precisamente porque parte de las unidades de sentido autopoiéticas, cerradas, la pragmática de las distinciones puede constatar las equivalencias entre formas por lo demás heterogéneas entre sí, tales como la operación, la frase afirmativa, el objeto, la SOCIEDAD. En este sentido, precisamente la consideración y el respeto hacia el nivel de abstracción de la unidad correspondiente representan la llave, con la cual la pragmática de las distinciones puede abrir las más diversas cerraduras. 


\section{LA LÓGICA DE LAS DISTINCIONES}

\section{Diferencia y diferenciación}

1. Para poder desarrollar una lógica de las distinciones debemos observar más detalladamente de qué manera procesan los componentes de esta clase de (proto)lógica, es decir, diferencia, diferenciación y denominación (o decisión).

Para la comprensión del concepto "decisión" se anticipa la siguiente anotación: como "decisión" no entendemos el proceso que uno relaciona conjuntamente con el acto de la conciencia. No se trata de una "decisión consciente", sino de una determinación en el sentido general de la palabra. Una "decisión consciente" implica siempre una determinación, pero una determinación no siempre implica una "decisión consciente". En la cotidianeidad uno se determina continuamente sin implicar con ello a la conciencia. No queremos prescindir del concepto de la decisión, pero lo queremos aplicar no solamente a los sistemas de la conciencia, sino también a sistemas afectivos, corporales y sociales. Por ello está claro que esta utilización arbitraria puede llevar a malentendidos. En el área de los sistemas sociales, las decisiones juegan un papel especialmente prominente. Para poder, por ello, distinguir la semántica general de la decisión de su semántica específica, hablamos de DECISIÓN cuando se trata de la versión general, y de decisión cuando se trata de la versión específica, la cual juega un papel importante en los sistemas sociales. Lo mismo vale, por lo demás, para otros conceptos aquí empleados, tales como Acción/acción, coMUNICACIÓN/comunicación o SOCIEDAD/sociedad. Haremos notar esto en el lugar oportuno.

Por lo pronto, comencemos entonces y no sin intención, con la observación de una diferencia. Una diferencia refleja una distinción que posee carácter simétrico (en este lugar se recuerda nuevamente que definimos la distinción como concepto superior de la diferencia y de la diferenciación). Con ello, lo diferente es diferente y no indiferente. La diferencia está expresada aquí en el sentido de Spencer Brown como perfect continence. La diferencia se delimita frente a la falta de diferencia, no frente a la indiferencia. La indiferencia ${ }^{217}$

217 Véase recientemente Georg Lohmann, quien utiliza la indiferencia como "validez idéntica" y como "indeterminación". (Lohmann; 1991, p. 21). Dado que consideramos la función de la diferencia como una distinción si- 
reproduce una distinción reflexiva, con la cual se anula parcialmente de nuevo una diferencia o una diferenciación observada (o a ser observada potencialmente), para dejarla sin efectos a pesar de su "presencia". En este sentido, la indiferencia implica una formación previa de diferencia o diferenciación: a algo previamente considerado (o a ser cońsiderado) nó se le toma en consideración de manerá sistemática, se le superpone indiferencia y con ello se neutraliza. Este efecto de neutralización se designa con la ayuda de la semántica de la indiferencia.

2. La diferencia distingue entre "algo" y "algo diferente". Ella representa una distinción de dös làdos, la cual no pone prioridades entre "algo" $\dot{y}$ "algo diferente". Ella va y viene de un lado para otro, oscila entre las distintas posibilidades y no se puede. "decidir", no se puede, por así decirlo, determinar a cuál de los dos lados debería de dar preferencia. Una diferencia expresa la simultaneidad de sus dos lados y es, por lo tanto, neutral. Queremos ahora llamar observación a aquella operación que denomina la unidad de lo diferente, para generar información a través de ello. Así, nos distanciamos de la TsS, la cual parte de la observación vista como una diferenciación: "Queremos llamar una observación a la operación que distingue algo para denominarlo. ${ }^{\text {218 }}$ En ese sentido queremos definir la observación como el manejo de una distinción que fija lo diferente - por disparatàdo que sea- en la unidad de la diferencia: "algo" es observado respecto a"su integración en "algo diferente". La observación como la unidad de una diferencia consiste en su efecto como unidad, mientras que la diferencia como unidad de una diferencia tiene su origen en su efecto como diferencia. La observación significa percepción-conjunta en el sentido de C.F.v.Weizsäcker: ${ }^{219}$ una afirma-

métrica en la emulación de la indeterminación y con ello de las posibilidades de selección, llegamos con esta maniobra semántica a la cercanía de aquello que Lohmann expresa como "validez idéntica".

${ }^{218}$ Ya desde aquí se podría uno preguntar el cómo una operaciốn de esta naturaleza llega a procesar una diferenciación. Si la observación es definida de esta manera, entonces desaparece precisamente debido a ello la base de la diferenciación, o sea, distinction como perfect continence en el sentido de Spencer Brown o la diferencia en el sentido aquí representado de una distinción neutral de los lados. (Luhmann; 1990d, p. 11).

' 219 Weizsäcker, C.F.v., 1977, p. 312. 
ción en relación con la composición dentro de la cual está hecha: un minuto respecto a una determinada hora, el dia respecto a una semana, una acción respecto a sus consecuencias. Se ve algo diferente, cuando la unidad de la diferencia tiene efectos como diferencia: se ven un pantalón rojo y uno azul y uno no se puede decidir entre el rojo y el'azul.

* Esta es una operación que genera la duda en un nivel menos general

$\because$ (como "ambigüedad"), como el "ver dos posibilidades".220 Para decirlo

- otra vez: esta operación de apertura de posibilidades de selección o del "dudar" solamente se hace posible cuando una diferencia se presenta a la vista. Pero la TsS deja sin considerar precisamente esta forma, cuando entreteje el "diferenciar" y el "denominar" de tal manera:que esta distinción ya no es visible porque de ello hace una operación

- $\quad$ ünica. Aun más, debido a que hace esto, se le escapa la base real de

1. La diferenciación, es decir la diferencia, la cual en Spencer Brawn se considera como perfect continence. Sin embargo, Spencer Brown no deduce de ello ninguna otra conclusión adicional más explícita.

"Sólo cuando se denomina un lado y no el otro de la diferencia, lo culal significa una forma de la Acción, es entonces que la diferencia se convierte en una diferenciación.

- Con ACCión queremos denominar el aspecto general de aquello que, por lo demás, en la literatura sociológica se denomina acción: como la indicación de una dirección, de un centro de acción. Por ló tanto, la ACCIÓN cubre también algo que en la doctrina del comportamiento se llama "comportamiento". Con ello queremos distanciamos de un concepto de la acción que se acople estrechamente con la conciencia. El concepto "acción" nos lo reservamos para la forma de comunicación de sistemas sociales.

La diferencia experimentá una reducción de ella misma porque se unilateraliza y se vuelve así capaz de diferenciación: uno se decide por ejemplo por el pantalón azul claro y por ello contra la tendencia hacia los colores fuertes.

Naturalmente se puede uno decidir por ámbos colores, pero en última instancia con ello se separan todos los demás colores y por lo tanto también se realiza una reducción de la diferenciación: jsolamente los

230 ibid., p. 303. 
colores rojos y azules, todos los demás colores no se consideran! Por - lo demás se necesita - visto modalmente- para "todo lo que pudiera - venir al caso" solamente una diferencia, la cual sin embargo puede va. riar fuertemente en cuanto al contenido: pantalón rojo y/o azul, este mundo y/u otro mundo, lo existente y/o lo posible, la posibilidad de selección y/o la imposibilidad de elegir. Se comete frecuentemente el error de creer que el área de lo posible consiste en una posibilidad de ordenamiento, en lo posible, infinitamente clasificable. Se puede ir aun más lejos y afirmar que cualquier clasificación se reduce a una distinción neutra de los lados, o sea, a una diferencia, lo cual significa que las diferencias son "más poderosas" que las clasificaciones. Aquí no trataremos más esta circunstancia.

Visto desde una teoría de la sociedad, las diferencias son las condiciones de la posibilidad de la COMUNICACIÓN, mientras que las diferenciaciones son las condiciones de la posibilidad de la ACCIÓN. Y sólo el entrelazamiento de diferencia y diferenciación lleva a la observación, así que la diferencia y la diferenciación son las condiciones de la posibilidad de la observación. Por lo tanto, la observación es una operación rica en condiciones previas, la cual, no obstante, puede ser observada ya en el "nivel social primitivo" (como por ejemplo en el nivel de la percepción general).

Partimos del hecho de que la sociedad surge sollo cuando se puede observar que se está observando. En este sentido existe la sociEDAD ya en el nivel de la comunicación corporal, dado que aquí "se percibe continuamente que se está percibiendo", con lo cual, en este contexto entendemos la percepción como una forma de la observación.

Dado que la observación es el procesamiento de una diferencia con la ayuda de una diferenciación, con la observación de un observador cualquiera se puede tratar solamente de observar el cómo el observador realiza esta operación con la ayuda de qué diferencia y de qué diferenciación.

3. Hemos escogido como objeto de investigación una forma reflexiva de la observación, una observación autológica, una observación de segundo grado o una reflexión: observamos la observación de un observador cualquiera. Sin embargo, no observamos una observación determinada como "el libro sobre el escritorio". Más bien tra- 
tamos de observar cómo una observación observa algo: “CCómo observa el observador que hace la observación "el libro sobre el escritorio?" Por lo tanto, se trata de una observación de la observación. Con ello debemos nosotros mismos efectuar una observación de tercer grado, dado que tratamos de observar cómo se realiza la observación de una observación que observa algo (lo que produce una observación de cuarto grado..., etc.). No obstante, para no complicar demasiado las circunstancias queremos, por lo prönto, dejar sin consideración la observación de tercer (y cuarto) grado. Aun llegaremos a tratar explícitamente de las consecuencias que surgen porque podemos observar a la observación solamente sobre la base de una observación, y por consiguiente sólo sobre la base de una "cibernética de segundo orden" o reflexión. Sin embargo, aquí ya podemos decir que con el concepto de una observación de segundo grado o una reflexión nós encontramos en el contexto genuinamente comunicativo, ${ }^{221}$ ya que con ello una unidad-de-diferencia observa'a otra unidad-de-diferencia, la cual, por su parte, puede observar. Esto es entonces un modus de operación que sólo puede tener lugar (en el sentido a explicar más detalladamente) comunicativamente.

Por supuestó compartimos la opinión de Niklas Luhmann dè que la coMUNICACION se hace posible solamente cuando se construyen cognoscitivamente dos "unidades de efecto o de comportamiento", dos "actores" o dos black boxes.

4. No puede haber ninguna información sin observación, dado que la información șe constituye solamente cuando están en juego las distinciones, las cuales son llevadas a la unidad de distinción por medio de la operación de la observación. Esto significa que sin la observación no hay nada, ni siquiera la nada. Sin embargo, con ello ya presuponemos lo que queremos analizar: ciertamente queremos observar cómo opera una observación cuyas bases son las distinciones "diferencia" y "diferenciación". Pero esto lo podemos llevar a cabo solamente cuando nosotros mismos utilizamos la operación de la

$221 \mathrm{Y}$ esto tan solo porque "[...] no hay ningún observador independiente en absoluto." (Luhmann, 1990d, p. 13).

${ }^{222}$ Luhmann, 1990, p. 28. 
observación, es decir cuando observamos la observación. De estè modo, nos movemos en círculo.

- Aquí se trata de una figura ${ }^{223}$ conocida (también) como "círculo hermenéutico". Menos conocido es, por lo demás, el surgimiento paralelo de los conceptos sistema y bermenétutica, un surgimiento que, visto desde la perspectiva de los hechos, puede reclamar para sí una fuerte plausibilidad y no se puede ver como una "casualidad histórica". Precisamente en el supuesto de que la comprensión (hermenéutica) de lo particular se guía por el todo (p. ej. Las Sagradas Escrituras), este "todo" implica una idea, por lo menos vaga, del "sistema": "El surgimiento del concepto del sistema se encuentra evidentemente fundamentada en la misma situación teológica que el de la hermenéutica." ${ }^{n 4}$

- En todo caso, al final de la investigación debería quedar claro que aquello que vale para el objeto de la investigación "observación", también es aplicable para la propia actividad de observación, la cual por fuerza debemos presuponer continuamente. De esta manera somos observadores que observan la operación de la observación y que, en este sentido, deben efectuar la misma operación que quieren observar. El que nos enredemos aquí en una autorreferencia, en un círculo hermenéutico, puede ser molesto para algunos observadores, pero para nosotros una autorreferencia de este tipo es inevitable.

No obstante, es necésario aclarar el status paradófico (y tautológico) que resulta forzosamente del círculo. En última instancia se trata aquí del sentido social de las paradojas y tautologías, es decir de algo a lo que se ha prestado poca atención dentro de la tradición hermenéutica.

- Ahora bien, la pregunta que debemos hacernos en este contexto es si podemos sacar provecho cognoscitivo de este "enredo autorreferencial ${ }_{p}^{p}$ Si bien no podemos evitar las tautologías y paradojas encerradas en esta observación circular, sí las podemos "desdoblar" exitosamente. El que esto sea posible y que se practique exitosamente, lo sabemos por trabajos que deben manejar un planteamiento del problema dispuesto similarmente. Se trata de los trabajos ya mencionados de Maturana, Varela, Luhmann, Spencer Brown; Glanville, von Foerster, Baecker, Willke, Teubner y otros.

${ }^{233}$ Véase acerca de ello, clásicamente, Martin Heidegger, 1979, pp. 311 y ss., y Hans Georg Gadamer, 1960, pp. 250 y ss.

224 Gadamer, 1960, p. 164. 
25. Con esto, una parte del próblema de la autorreferencia o del "comienzö de un comienzo" tiene su causa en el hecho de que un cómienzo o inicio exṕlícito provoca inmediatamente la pregunta por un comienzo del comienzo, por el inicio del inicio. Debería ser evidente que la jugada de un comienzo del comiènzo del comienzo... no es practicable porque en esta forma resulta infructuosa. Por ello comenzamos con el comienzo comenzando simplemente, y esto en correspondencia exacta (pero no en el mismo nivel monológico) con la instrucción de George Spencer Brown: Draw a distinction! Por lo tanto vale, con la correspondencia exacta: "Observa al observador (haciendo su observación). "Bien entendido, no "hacemos ninguna diferenciación", sino que "observamos una diferencia" y nos preguntamos cómo es posible una diferencia de esta riaturaleza, ya que hemos definido a la observación como el manejo de una diferencia frente al trasfondo de una diferenciación para generar información. Pờ lo tanto, no procedemos monológicamente como Spencer Brown y, entre otras, la TsS, sino dialógicamente. Empezamos con el comienzo no en forma de ACCION, sino COMUNICATIVAMENTE. Dicho de otra manera, el "hacer una diferenciación" representa una operación monológica, condicionada por la acción; la "observación de una observación" puede ser sólo comunicativa, dialógica o mutual. Por éllo, cualquier comienzo, en el sentido aquí presentado, presupone como mínimo dos ùnidades de diferencia, es decir dos observadores (figura 43).

\section{Comienzo del comienzo...:}

Monológicamente: "¡Haz una diferenclación!"

Dialogicamente: " "Observa al observador, el cual observa esto o aquello"

Viéndolo así, cada comienzo que tenga lugar, está determinado siempre dialógica, nunca monológicamente. Con ello, se contradice -en el nivel de abstracción del concepto de la observación-el comienzo como comienzo mismo: insinúa como el inicio, un origen monológico que sólo puede producirse dialógicamente.

En este contexto no se debería hablar del "comienzo", sino de "los comienzos".

Con otras palabras, el comienzo es posible solamente en la forma de los comienzos. 
6. Ahora bien ¿cómo es posible una observación en el contexto arriba definido?, ¿cómo se llega a la unidad de una diferencia neutra de los lados? Si ambos lados de una "diferencia" no reclaman la prioridad para sí, o sea, si están dispuestos simétricamente, entonces la diferencia no puede alcanzar su unidad a través de sus mismos lados dispuestos simétricamente, ya que un lado vale tanto y/o tan poco como el otro lado respectivo, con lo cual cada lado remite al otro y viceversa. Un pantalón azul es un pantalón rojo...es un pantalón azul... es un pantalón rojo... y continúa siempre así. Entre rojo y azul no existe ninguna diferencia de valor (interna).

Y esto ya según la definición. Se debe observar que, por un lado, puede haber una diferencia de valor interna, por ejemplo la que existe entre ambos lados (café y/o té). Pero también hay una diferencia de valor externa que se trata de la diferencia de la observación frente a otra observación: ¿frío y/o caliente? Aquí se trata de la distinción entre operación de la observación interna y externa o-en la dicción de la $\mathrm{TkH}$ - de la distinción entre la perspectiva del observador y del participante.

Esta paradoja de que el pantalón azul es el rojo... el azul... el rojo, es a la vez una taütología, dado que la observación de la diferencia observa a la mismidad de una diferencia. Pero esta tautología es por su parte una paradoja disfrazada, ya que la observación señala a la diferencia de rojo y azul simultáneamente como la identidad de rojo y azul.

7. Nosotros preguntamos: ¿cómo es posible la diferencia como distinción neutra de los lados? En este caso se enfoca (en la unidad de lo distinto) a la diferencta y no a la unidad, se observa la unidad de la diferencia como diferencia: lo diferente. Se observa una simultaneidad del "esto y/o aquello" y no del "esto/no aquello". Pero ¿de dónde sabemos que la diferencia está sostenida por una unidad la cual nos da la posibilidad de partir de una diferencia determinada?

Una obsenvación es una distinción operativa bajo el aspecto de su unidad, una diferencia es una distinción operativa bajo el aspecto de su distinción. Esta sutileza es de especial importancia, dado que "separa mundos", cuando no se observa. Con "diferencia determinada" 
queremos decir la forma aquí presentada de una diferencia general, la cual posee su determinación precisamente debido a su generalidad: no nos referimos a ésta (café y/o té) o aquella diferencia (televisión y/o cine), sino precisamente a la diferencia que señala lo diferente en su generalidad. De la misma manera en que hay especialistas para lo general (filósofos, sociólogos, teólogos, etc.), también existe la distinción, misma que presenta a su forma general como algo específico.

Se observa precisamente esta diferencia general y ninguna otra; se hace la observación de una determinada diferencia en su generalidad. Con esto, la determinación de la diferencia puede consistir tanto en su carácter concreto como en su generalidad, no obstante, se le observa como a una determinada diferencia escogida. Pero, ¿cómo se llega a la determinación de "ésta" y no "aquella" diferencia observable? Quién escoge una diferencia de este tipo?

Se podría pensar que ya hablando de la diferencia se asegura su unidad. Ahora bien, si hablamos de la diferencia, entonces ya la hemos convertido, en cuanto a la afirmación, en el sujeto (dirigida o actorizada), un proceso que está estrechamente relacionado con la frase afirmativa y el cual trataremos de aclarar más en el capínulo correspondiente. Repetimos algo ya mencionado: la estructura básica de la frase afirmativa que consiste en su estructura de sujeto/predicado, implica a las operaciones de la diferencia (-predicación) y de la diferenciación (zpuesta del sujeto o actorización).

8. Para observar más detalladamente el aspecto arriba mencionado de una diferencia observada, queremos distinguir la posibilidad de observación entre una perspectiva interna y una externa. Esto nos da la posibilidad de dirigir la observación de una diferencia tanto hacia adentro como hacia afuera. Internamente la diferencia observada se muestra en su neutralidad de los lados, la cual, visto más detalladamente, parece paradójica, dado que un lado remite al otro y éste, a su vez, al primero, etc. Observada externamente la diferencia es precisamente "la" diferencia que se observa y no cualquier otra diferencia, es decir no cualquier otra distinción que es observada. Uno se quiere comprar un pantalón y no se puede decidir entre los colores, así que vacila entre uno y otro color. Esta indecisión o este oscilamiento corre por cuenta de la diferencia observable entre pantalón rojo y/o azul. Pero ¿de dónde el pantalón? El pantalón es una dis- 
tinción determinada que se ha formadò ya anteriormente: no śe trata de camisas o calcetines o cinturones, sino de pantalones. Con base en la referencia al pantalón, rojo y azul obtienen su colorido específico. Ciertamente se podría hablar en lugar de los pantalones rojos o azules más generalmente de los colores como juicios del gusto: "Me gusta más lo rojo que lo azul". Entonces el gusto específico ("me gusta") o la "estética artística" sería la distinción unificadora de la diferencia entre rojo y azul. Por lo tanto, la diferencia observable rojo/ azul obtiene su unidad a causa de una distinción anteriormente formada, es decir una diferencia que ha sido unilateralizada.

- La unilateralización o reducción de una diferencia constituye una distinción: el acoplamiento de dos diferenciaciones constituye, a su vez, una diferencia... Más adelante regresaremos a este proceso de la constitución mutua de las distinciones. Aqui se observa que el proceso de constitución no tiene lugar simétricamente: una diferencia se puede reducir a una diferenciación, pero no viceversa. Una diferenciación, por su parte, requiere otra diferenciación, para constituir, a su vez; una diferencia (figura 44).

a) Constitución de una diferencia:

Diferencia

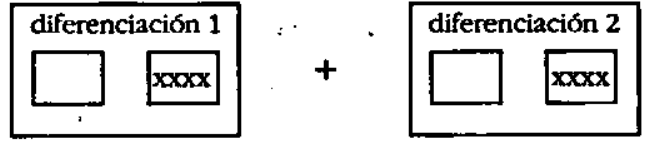

b) Constitución de una diferenciación:

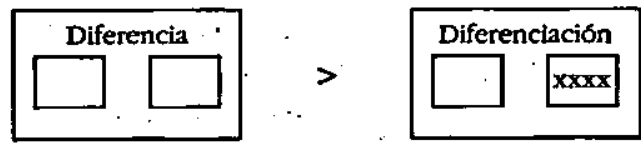

Queremos llamar a esta distinción una diferenciactón. Aseguremos por lo pronto que la unidad de la bifurcación entre "rojo y/o azul" se da por medio del "pantalón". Con ello -y esto es aquí de importancia decisiva- la diferencia neutra de los lados "rojo y/o azul" se somete a una "presión de ambivalencia" por medio de la diferenciación "pantalón": un pantalón rojo o uno azul. Esto ocurre generalmente con el mismo origen (figura 45). 


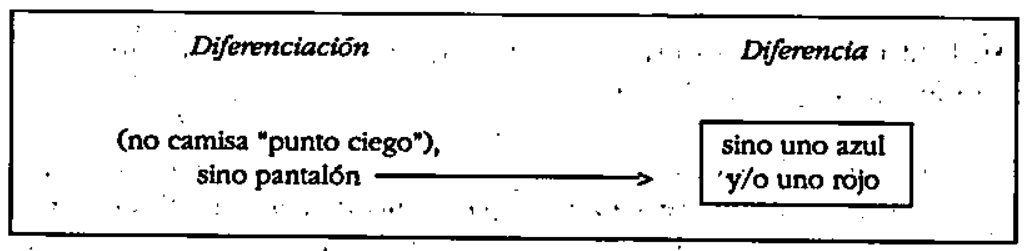

9. Ahora bien ¿es la distinción de, por ejemplo, "camisa o pantalón" a su vez una diferencia? Si y no. Todo depende de la perspectiva (de observación) que se tome. Si se observa la distinción desde adentro, es decir interna o inmanentemente a la observación, entonces se tratárá de hecho de la diferencia de pantalón y camisa, pero no sabemos quée hacer con una diferencia neutrá de los lados del tipo pantalón/camisa. El que un pantalón se distingue de una camisa, nos lo dice el sentido común, pero eso no puede valer como garantía de la unidad de una diferencia de esta naturaleza. Un "pantalón" se puede distinguir de una "mesa", la "camisa", de "Peter". Pero visto así, se podría hacer la pregunta acerca de icuál sentido deben tener tales distinciones?, ¿porqué precisamente "camisa/pantalón" y no por ejemplo "lámpara/libro" o "comida/carro"? Lo que falta aquí es la unidad de utilización, o sea de una operación unificadora que le ponga límites a la arbitrariedad (contingencia) de una diferencia de esta índole. Sólo una unidad de utilización de este tipo constituye a la diferencia de la unidad buscada por nosotros. Cualquier unidad de utilización siempre es una diferencia unilateralizada y, por lo tanto, una diferenctactón: la unidad de la diferencia se elabora con la ayuda de una diferenciación. $Y$ al entrelazamiento de ambas distinciones, o sea a la unidad de la diferencia entre diferencia y diferenciación, lo lla-. mamos una observactón (figura 46).

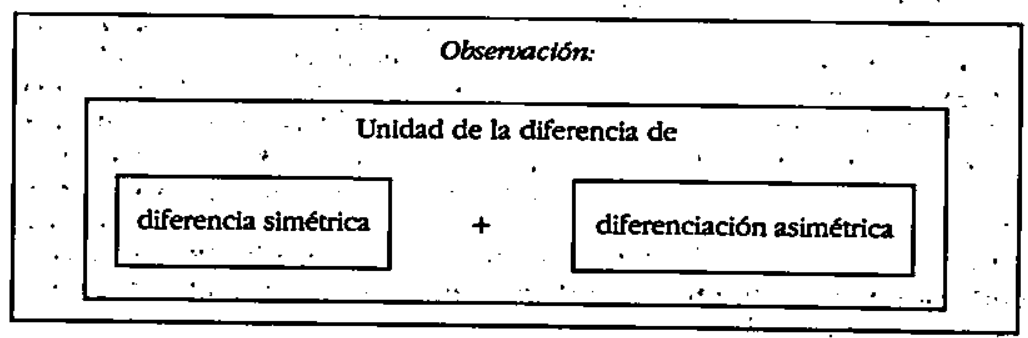


10. Una diferencia es en sí una forma de distinción que divide el mundo en "esto y/o aquello".

¿Existen diferencias sociales no homogéneas? Estas diferencias no cohesivas existen en el sentido de que se puede distinguir perfectamente entre la luna y la lámpara, el carro y el césped, el cine y la pared. Sin embargo, surge inmediatamente la pregunta "para qué sirve todo eso", dado que con una diferencia no-cohesiva de esta naturaleza no parece estar presente ninguna unidad de utilización, ningún "interes", ningứ "motivo", ninguna "meta", o sea, ninguna posibilidad de ACCIÓN. Por lo tanto dice Spencer Brown consecuentemente: "There can be no distinction without motive $[. . .]^{n} .255$ El que aquí podamos detectar diferencias a pesar de ello, las cuales no son cohesivas, tiene su razón precisamente en esta no cohesividad como unidad de utilización (o "interés pragmático"). Formulado de otra manera: aun la detección de una diferencia no homogénea requiere una operación unificadora, la cual consiste en este caso en la diferenciación de "no cohesivo, sino no-cohesivo".

Con ello no está dada ninguna contingencia absoluta, sino solamente una contingencia relativa, ya que de todos modos con la distinción "esto y/o aquello", se presenta una posibilidad cognoscitiva de delimitación por medio de dos lados neutros de valor, "no interesados". Pero aun con una "última diferencia", es decir, con la observación de una diferenciación de la diferencia - no de la ausencia de diferencia, con la cual un lado de la diferenciación, o sea la "ausencia de diferencia" señala aquel lado ${ }^{226}$ que está carente de cualquier diferencia - no está dada ninguna contingencia absoluta. Esto tampoco puedé ser el caso, ya que la combinación de las distinciones permanece siempre relacional, nunca está dada ontologicamente: pode-

225 Spencer Brown, 1969, p. 1.

${ }^{226}$ Con una diferenciación ("esto no aquello"), se designa cotidianamente solamente un lado, el otro se puede observar solamente cuando es reflectado hacia la diferenciación. Si digo "yo", entonces me refiero a mí en el sentido de: "no lo otros, sino yo". Si se quiere efectuar explícitamente una diferenciación, entonces se debe observar-conjuntamente el lado no considerado de la distinción. Es, sin embargo, un asunto muy laborioso, el cual pronto paralizaría cualquier ACCION, dado que la particularidad de la ACCIÓN Consiste precisamente en procesar diferenciaciones $y$, con ello, distinciones unilaterales, las cuales dejan sin consideración una observación continua de esta naturaleza de la distinción completa "diferenciación". 
mos introducir por ello una "última diferencia" solamente porque la podemos observar con la ayuda de la diferenciación "de la diferen-

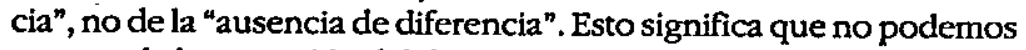
escapar de la operación del distinguir, sin procesar con ello otra operación de distinción. $Y$ aun en la cotidianidad, donde las operaciones reflexivas como operaciones explícitas son raras, vale lo mismo. Así estaria dado un relacionamiento existencial, "último", si "ya no supiéramios, dónde estamos" o "ya no supiéramos qué hacer". En las situaciones de este tipo estamos "desesperados". ${ }^{227}$ Pero podemos decir, escribir y pensar esto solamente porque el otro lado de la diferenciación aún permanece accesible para nosotros. Expresado en el lenguaje de la cotidianidad: "Si todas las cuerdas se rompen, sabemos al menos que se rompieron". En la cotidianidad podemos escapar de la capacidad de relacionamiento de las distinciones solamente bajo condiciones extraordinarias, como por ejemplo por medio de determinadas formas de meditación o por medio del miedo de lo que sea, las cuales podrían llevar entonces a un "horror vacur".228 Pero todo esto son acontecimientos que dejan sin consideración tan sólo temporalmente la rejilla de protección del relacionamiento de las distinciones y de esta manera lo hacen invisible, pero no lo "aniquilan": siempre hay una última posibilidad de relacionamiento, la cual es solamente la penúltima.

11. Advertimos nuevamente que también la última (o primera) diferenciación aún posible entre la diferencia ỳ la ausencia de diferencia permanece dependiendo de una denominación de aquel lado que marca la "diferencia", no la "ausencia de diferencia". Esta operación asimétrica de diferencia y falta de diferencia solamente puede ser realizada precisamente por una diferenciación, la cual designa un lado de la diferencia y no el otro lado. Por lo tanto se puede decir que aun una forma última o primera de la observación de la diferencia como "diferencia y falta de diferencia" puede ser observada como unidad solamente cuando se relaciona operacionalmente una dife-

${ }^{227}$ Aquí se refiere a la duda en el sentido de dudar, como el ver de dos posibilidades, o sea, doblez. Véase acerca de ello Weizsäcker, C.F.v, 1977, p. 303.

${ }^{228}$ VEase por ejemplo, la pérdida transitorià del idioma de Peter Handke. (1987, pp. 33 y ss.). 
renciación (como "motivo", "interés", “acción", "voluntad") como unidad de utilización con la diferencia correspondiente.

12. Las diferencias "azul y/o rojo" y "pantalón y/o camisa". son en sí neutras de los lados y por eso indeterminadas. Se podrían ensamblar igualmente de otra manera. Una determinación participa sólo cuando se relacionan estas diferencias entre sí: ¿camisa azul y/o roja?, ¿pantalón azul y/o rojo? Y ¿por qué no un "azul camisoso y/o pantalonoso"?, o un ¿"rojo pantalonoso y/o camisoso"? Porque la pragmáttca de las distinciones que introduce la determinación a la diferencia no sugiere esto en el mundo vivencial. La evolución sociocultural selecciona en el transcurso de la evolución social determinadas distinciones que han resultado útiles. ${ }^{229}$ Otras diferencias permanecen inutilizadas e inobservadas. Así la semántica de la diferencia de "frío y/o escribir" tiene menos sentido pragmático que la de la diferencia de "frío y/o caliente"; la semántica de la diferencia de "escribir y/o ir" tiene menos sentido que la diferencia de "escribir y/o hablar". En ese contexto juegan un papel especial aquellas particularidades de un contexto semántico-histórico que refuerzan la formación de determinadas diferencias y diferenciaciones, y que no observan otras menos "razonables" o no las dejan surgir.

13. La jugada de la indeterminación se abre con la "diferencia" y se termina con aquella "diferenciación" que introduce la determinación al juego. Por lo pronto, al comprar un pantalón no me puedo decidir entre los colores azul y rojo. Finalmente me decido por un pantalón de color rojo. La jugada de la indeterminación, la cual se expresa a través de la diferencia de "rojo y/o azul", se termina a través de la jugada de la determinación, la cual se introduce con la diferenciación "pantalón". El resultado es entonces la compra de un "pantalón rojo". En realidad se deben diferenciar los siguientes aspectos de la combinación de ambas distinciones: primero, una diferenciación siempre es producto de una diferencia en el sentido de una reducción de la diferencia a "este lado, no el otro". No se dice: "vengo

${ }^{2 a}$ Aquí se encuentra el punto de conexión para una teoría de la verdad interpretada pragmáticamente. Véase acerca de ello capítulo I. 
mañana y/o hoy", sino "vengo hoy, no mañana". Por lo tanto, una diferenciación es producto de una diferencia seleccionada (o sea denominada) anteriormente. Segundo, precisamente la diferenciación vuelve seleccionable a la diferencia habilitándola para la unidad de utilización, y a través de ello la hace parecer razonable. "Hoy y/ o mañana" son en sí "inconducentes", o sea no seleccionables. ${ }^{230}$ Solamente la circunstancia de que por ejemplo el "venir de mi persona" se relaciona con la diferencia hoy/mañana produce una unidad de diferencia razonable. Tercero, la diferenciación siempre es potencialmente el lado posible de otra diferencia cualquiera. El hecho de venir se puede referir a "mí y/o a ti": "¿Quién debe venir, tú o yo?" $Y$ en lo que concierne a la compra de un pantalón, se puede tratar de la diferencia de la compra de "pantalón y/o camisa". Resumiendo se puede decir entonces que las diferencias y las diferenciaciones se presuponen mutuamente en un sentido no trivial $y$, por lo tanto, se posibilitan mutuamente.

14. Si se observa la operación de una diferencia, entonces se puede nuevamente hacer evidente con otras palabras el entrelazamiento de diferencia y diferenciación arriba mencionado. Una diferencia consta - en relación con su perspectiva interna- de dos lados, y es neutra en su relación de lados, pero esto lo puede observar el observador solamente, porque mira la diferencia desde una perspectiva exterior: se apoya, por así decirlo, en la relación externa de la diferencia observada, esto quiere decir en una diferenciación, para llevar la atención a su relación interna. Dado que alguien se ha decidido por la compra de un pantalón y no de una camisa, y con ello ya ha efectuado una diferenciación (la cual proviene de la diferencia anterior "camisa y/o pantalón"), ahora se puede dirigir a la diferencia neutra de lados de "azul y/o rojo", para hacer una selección. El observador mantiene al pantalón en el trasfondo de su atención como una diferenciación ya hecha. Se mantiene latente y es aquella diferenciación que le otorga su unidad a la diferencia de "rojo y/o azul". Si el observador la expulsara de este trasfondo - por ejemplo por medio del olvido a causa de la extensa oferta de mercancías-, entonces

${ }^{230}$ Aqui se recuerda nuevamente que, en un mundo del sentido, la sinrazón también tiene sentido, en tanto que la misma ausencia del sentido representa, a su vez, un sentido determinado. 
habría extinguido también a la diferencia neutra de lados, la cual lo tenia vacilando entre "rojo y/o azul", dado que ahora ya no tiene una unidad de utilización. Michael Polanyi hablaría en ese contexto del conocimiento praximal y distal, con lo cual se puede obtener el conocimiento distal-explícito solamente cuando se presupone un conocimiento proximal-implícito.

Citando a Austin Farrar, Polanyi dice que quitamos nuestra atención de determinadas cosas (disattending from), para dirigirla a otras (attending to). Con un acto del conocimiento implícito, la relación funcional se ve entonces cuando nosotros "[...] desviamos nuestra atención de algo hacia otra cosa [.... $]^{n}{ }^{231}$ Precisamente la integración de las características individuales a una entidad coherente es posible solamente por medio de una operación semejante del "de [...] hacia". 232 Transferido a los conceptos de la diferencia y la diferenciación, esto significa que primerola unidad de la diferencia no es producible sin la diferenciación; y segundo, en el rasfondo de la percepción permanece la diferenciación, cuando se trata de una diferencia, o la diferencia, cuando se trata de una diferenciación.

La misma circunstancia se puede explicar con la ayuda de la diferencia entre latente y manifiesto: una diferencia manifiesta se puede observar solamente sobre la base de una diferenciación latente.

15. ¿Puede una diferenciación asimétrica ser también una diferencia simétrica? En el ejemplo de la diferenciación "pantalón, no camisa" y de la diferencia "rojo y/o azul" poseemos un punto esencial de interés, una perspectiva de observación, desde donde podemos escoger entre "algo" y "algo diferente": ¿debe ser un pantalón rojo o uno azul? Se trata del pantalón, no de la camisa. De todos maneras podemos anotar que cualquier diferencia se unilateraliza en el proceso de la selección y, por lo tanto, se asimetriza hacia una diferenciación. Por otra parte, una selección puede tener lugar solamente cuando hay algo que elegir, lo que sólo es posible precisamente en la forma de una diferencia simétrica: "¿rojo y/o azul?" La relación de condicionamiento mutuo de diferenciación y diferencia se puede observar de mejor manera cuando se parte de un mundo aún no marcado, de un mundo aún no "dañado".

231 Polanyi, 1985, p. 19.

232 Ibid., p. 25. 
Spencer Brown formula en este contexto: "Call the state not marked with the mark the unmarked stated. ${ }^{n 233}$

En un mundo de esta naturaleza, en el cual aún no existen las distinciones, no puede ni siquiera haber "nada", esto es algo que sólo es posible precisamente cuando hay "algo". Dado que las distinciones son la condición de la posibilidad de la información, un mundo de este tipo, sin distinciones, es inaccesible para cualquier forma de COMUNICACIÓN social. La información llega al mundo sólo por medio del proceso de introducción de distinciönes. Ahora bien, hemos podido formular la afirmación recién hecha sobre un mundo sin información porque disponemos de la distinción de un "mundo distinto/sin distinción". Por lo tanto podemos trazar al mundo con una "prime-

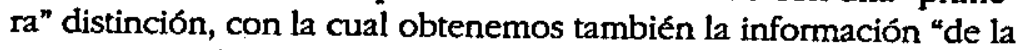
primera vez" de que el mundo consiste en un lado informativo y uno sin información (figura 47).

\begin{tabular}{|c|c|}
\hline & "Primera" distinción: \\
& mundo distinto $/$ mundo sin distinciones \\
$\therefore \quad($ informativo) & $($ sin información)
\end{tabular}

16. Esta "primera" distinción del preñado de distinciones/sin distinciones es una distinción que presenta la elección entre un mundo informativo y uno sin información, y esto significa que solo puede ser una diferencia simétrica con dos lados. Ahora bien, hemos podido hacer esta afurmación informativa sobre la distinción de información/ ser $\sin$ información solamente porque ya nos encontramos dentro del lado informativo: en el momento del trazamiento de un mundo distinto/sin distinciones nos hemos "decidido" por el lado distinto de una "primera" distinción posible. Si hubiéramos elegido el lado sin distinciones, entonces deberíamos callar ahora, ni siquiera podriamos empezar con la anotación de estas afirmaciones.

Numerosas técnicas meditativas representan el intento de cambiar de un mundo distinto hacia uno sin distinciones. Nosotros dudamos seriamente de la posibilidad de realizar una intención de esta índole, dado

${ }^{233}$ Spencer Brown, 1969, p. 5. 
que ya la COMUNICACIÓN corporal se procesa a través de las distinciones (claro/oscuro, móvil/inmóvil, ruidoso/callado, etc.). No se niega que, de hecho, se pueden alcanzar ciertos "niveles sin distinciones". relativos. ${ }^{234}$

Pero seguimos escribiendo y por lo tanto seguimos produciendo información. Esto significa que hemos reducido y limitado la simetría de "distinto y/o sin distinciones" a la asimetría "distinto/no sin distinciones".

17. Si todo lo que sucede simultáneamente, y nosotros tenemos presente la distinción objetiva de "distinto y/o sin distinciones" como una diferencia simétrica en la forma de una oferta para la selección, entonces no podemos utilizar simultáneamente ambos lados de esta . "primera" distinción. La simultaneidad actual de ambos lados nos obliga - si queremos utilizar la distinción- a darles una forma de no simultaneidad actual: solamente a través del hecho de que convertimos la simultaneidad de "distinto y/o sin distinciones" en la no simultaneidad "mundo no sin distinciones, sino preñado de distinciones", podemos comportarnos informativamente en el mundo; algo que ciertamente ya estamos haciendo (figura 48 ).

\begin{tabular}{|cc|}
\hline Diferencia & Diferenciación \\
distinto y/o sin & distinto, \\
distinción & no sin distinción \\
\hline
\end{tabular}

Solamente si nos "decidimos" por un mundo preñado de distinciones, podemos procesar la información, una afirmación que implica "selectibilidad" y, por lo tanto, una diferencia simétrica entre "mundo distinto y/o sin distinciones". Pero simultáneamente procesamos información, lo que indica que ya nos hemos "decidido" por un mundo distinto y contra un mundo sin distinciones: la diferencia simétrica se ha convertido en una diferenciación asimétrica. Por lo tanto, las condiciones de salida para el procesamiento dentro de un

234 Para un vistazo a tales técnicas, desde la perspectiva de la teoría de los sistemas, ver Luhmann/Fuchs, 1989. Acerca de los peligros que pueden presentarse al alcanzar un "nivel sin distinciones" de este tipo, véase Weizsåcker, C.F.v., 1988, pp. 9-50. 
mundo informativo son dos distinciones diferentes, las cuales operan en la forma de un relacionamiento tetrádico. Con ello están dados simultáneamente el "mundo distinto/no sin distinciones" y la "diferencia y/o diferenciación" con el "punto ciego" dentro de un lado de la diferenciación asimétrica como el "mundo sin distinciones" (figura 49).

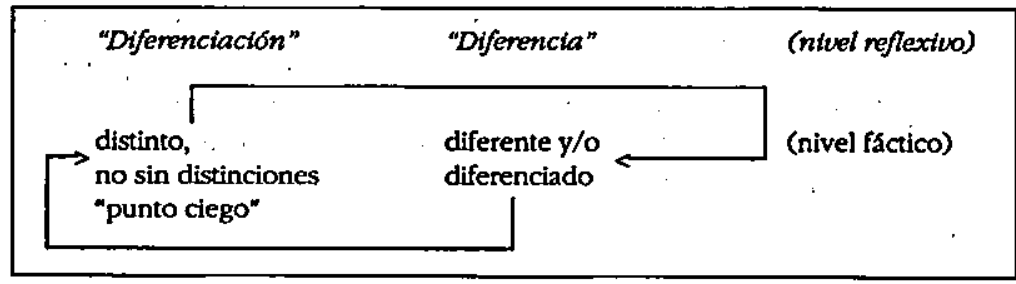

$\checkmark$

Por lo tanto, la información llega al mundo cuando las distinciones "diferencia" y "diferenciación". se entrelazan de tal manera que una diferenciación se refiere a una diferencia seleccionable, con lo cual un lado de esta diferenciación siempre forma el "punto ciego" que es inherente a cualquier información. En ese sentido, la información siempre es unilateral, siempre selectiva, siempre información "seleccionada". También podemos formular los hechos diciendo: la observación de una diferencia es la observación de una diferencia manifiesta con la ayuda de una diferenciación conservada en forma latente; $o$, la observación de una diferenciación es la observación manifiesta de una diferenciación con la ayuda de una diferencia conservada en forma latente. Si se hace patente una forma de distincion, la otra debe permanecer latente. Precisamente este fenómeno lo denomina C.F.v.Weizsäcker como percepción conjunta. ${ }^{235}$ Nosotros lo hemos definido como la operación de la observación. ${ }^{236}$

18. Esté tipo de procedimiento fundamental, operativo-tetrádico, hace posible la constitución de las principales modalidades sociales del sentido, o sea: dejar emerger la dimensión del tiempo, el espacio, el objeto y lo social, con base en un entrelazamiento de la diferencia y la diferenciación en su forma "primitiva". Con esto interpretamos,

${ }^{235}$ Weizsäcker, C.F.v., 1977, pp. 312 y ss.

236. Véase capítulo IV acerca de la observación. 
en relación con la pragmática de las distinciones, al sentido en su forma general como entrelazamiento de la facticidad (=diferenciación) y de la posibilidad (=diferencia): lo fáctico es fáctico sólo en cuanto a lo posible; lo posible, por su parte, constituye su margen de posibilidades sobre la base de hechos ya no posibles. Respecto a las dimensiones del sentido podemos formular pragmáticamente en cuanto a las distinciones: la dimensión del sentido social del tiempo surge porque una diferencia siempre es una distinción aún-no-designada, pero una diferenciación siempre es una distinción ya designada; con lo cual están preestablecidos potencialmente el antes y el después. La dimensión del sentido espacial se da porque una diferencia siempre es una distinción "completa", dispuesta simétricamente, a través de la cual mantiene presente 237 "todo lo que es" y lo incluye en esta forma presente (lo internaliza, le da espacio). Por el otro lado, contrariamente, la diferenciación siempre reproduce una forma de distinción "incompleta", asimétrica, la cual en relación con la "inclusión completa" siempre debe permanecer "afuera" ella misma, y por lo tanto, produce "externalidad". A la dimensión del sentido objetiva se llega porque cualquier diferencia siempre permanece indetermina$\mathrm{da}$, pero la diferenciación siempre insta a la determinación, lo que lleva al "esto, no aquello". Finalmente se hace posible la dimensión del sentido social porque, por un lado, cada diferencia siempre abre la selectibilidad (es decir posibilidades de acción y de direccionamiento), ya que siempre es una distinción aún-no-seleccionada; pero por el otro lado, cada diferenciación siempre excluye la selección, ya que siempre representa una diferencia ya-escogida, o sea una diferenciación. Por ello surge la posibilidad de postular un actor en el entrelazamiento de la selectibilidad/no selectibilidad o de interpretar al entrelazamiento mismo como una forma de actor (jel actor "es" el entrelazamiento!).

Aquí no se trata de "un hombre" como actor, sino de la operación de la atribución, la cual se puede extender a las COMUNICAciones corporales, afectivas, intelectuales y sociales, y a la cual designamos como ACCIÓN.

Se pone de relieve que la caracterización de las distinciones en antes/después, interno/externo, determinado/indeterminado y capaz

${ }^{237}$ Acerca del concepto de Heidegger de la "presencia", véase Heidegger, 1980, pp. 78-79 y naturalmente, O. F. Bollnow, 1984. 
de selección/incapaz de selección solamente es caracterizable así en su entrelazamiento, solamente en su complementaridad. Esto señala que se deben observar la diferencia y la diferenciación siempre solamente en su entrelazamiento. Esto significa que se debe observar a la diferencia y a la diferenciación sólo en su entrelazamiento mutuo. Lo que es la "diferencia en sî" o la "diferenciación en sî" está fuera de nuestro conocimiento (figura 50).

\begin{tabular}{|c|c|c|}
\hline . & MODALIDADES DEL SE & \\
\hline Dimensión & Diferencia & Diferenciación \\
\hline Sentido & - Posibilidad & Facticidad \\
\hline \multicolumn{3}{|c|}{ Dimensiones del sentido } \\
\hline Tiempo & lado aún-no-designado & lado ya-designado \\
\hline Espacio & lado completo & lado incompleto \\
\hline Objetividad & lado indeterminado & lado determinado \\
\hline Soctalidad & lado seleccionable & lado no seleccionable \\
\hline
\end{tabular}

La modalidad de entrelazamiento se ve entonces diferente para cada dimensión del sentido: para la dimensión del tiempo dice antes/ después; para la dimensión del espacio, adentro/afuera; para la dimensión objetiva determinado/indeterminado; y para la dimensión social capaz de selección/incapaz de selección.

19. Ahora bien, ninguna dimensión del sentido en particular puede procesar sola a través del proceso de la pragmática de las distinciones, sino solamente en la forma de un relacionamiento tetrádico. Así, la distinción de adentro/afuera es observable como dimensión del sentido espacial solamente cuando otra distinción como dimensión del sentido - por ejemplo la distinción de antes/después como dimensión del sentido temporal- se distingue de ella (figura 51).

Adentro/afuera (espacialidad)

Antes/después (temporalidad) 
Solamente así es posible referir adentro/afuera como "espacio" y antes/después como "tiempo". Si operara sólo una dimensión (de dos lados), entonces no se sabría ni siquiera que se trata de una dimensión del sentido, y mucho menos de cuál.

Para ello el ejemplo clásico del color azul de Benjamín Lee Whorf: "Supongamos, por ejemplo, que hubiera una especie humana la cual pudiera ver, a causa de un defecto fisiologico, solamente el color azul. Los hombres de esta especie no serian capaces de reconocer la regla y de formular que solamente ven azul. El término 'azul', no tendría sentido para ellos, su idioma ni siquiera incluiría algún término para los colores. Y las palabras con las cuales ellos designasen sus diferentes sensaciones de azul corresponderian a nuestras palabras 'claro, oscuro, blanco, negro', etc., pero no a nuestra palabra 'azul'. Para poder captar la regla o norma 'solamente vemos azul', tendrían que tener, de vez en cuando y excepcionalmente, también momentos en los cuales pudieran ver colores."238

Sin embargo, una dimensión del sentido podría procesar como la dimensión del sentido dominante, sin, por ello, poner en duda el conjunto de relacionamiento tetrádico. ${ }^{239}$ Hasta aquí, ego/alter, yo/tú (social), esto/aquello (objetivo), antes/después (temporal) y adentro/afuera (espacial) dependen uno del otro, y precisamente por eso son distintos uno del otro. En esta forma presentista las dimensiones del sentido "éste", "ahora", "tú" y "aquî" se utilizan operativamente como diversidad objetiva, secuencia temporal, perspectividad social y ubicación espacial. No obstante, éstas son formas del sentido fuertemente esquematizadas que por un lado, en formas cortas de este tipo (abreviaturas), facilitan el procesamiento comUNICATIVo de la SOCIEDAD, dado que las conexiones para la COMUNICACIÓN se hacen mucho más "manejables": una esquematización de esta naturaleza abrevia y simplifica en forma bruta, "[...] para posibilitar conexiones". ${ }^{240}$ Por otra parte, estas esquematizaciones obligan "[...] a opciones no realistas, y con ello estructuran [...] la autosimplificación continua del sistema", ${ }^{241}$ con lo cual vuelven preñadas de conflictos

238 Whorf, 1963, p. 9.

239 Acerca de las diferentes formas de adquisición del dominio de una dimensión del sentido, véase Luhmann, 1984, pp. 108-109.

240 Ibid., p. 126.

${ }^{241}$ Idem. 
a la COMUNICACIÓN, ya que por ello son de esperar casi seguramente los malentendidos. Así, el tiempo o el margen de acción de un sistèma no son el tiempo y el margen de acción de otro sistema. El tiempo que toma el sistema de la ciencia para su búsqueda de la verdad, se encuentra frecuentemente en contradicción con el tiempo de, por ejemplo, el sistema de la economía, para el cual significa "tiempo=dinero". El espacio de acción del sistema moral, en cambio, está trazado estrechamente en comparación con el espacio de acción de la economía por medio de la distinción preñada de conflictos de bien/mal; mientras que la economía con su distinción de solvente/ insolvente procesa "amoralmente ${ }^{n}{ }^{242}$ lo que hace comprensible su espacio de acción global. Con esto queremos expresar que las cuatro dimensiones del sentido o del mundo, que tienen su origen en las distinciones básicas de "diferencia" y "diferenciación", permanecen en dependencia mutua, y con ello se agravan y alivian mutuamente dependiendo de la constelación del tipo de comunicación (socialidad, personalidad, afectividad o corporalidad) y de la tipificación del sistema (economia, educación, política, sexo, etc.). De todos modos, se debe partir del hecho de que en cada COMUNICACIÓN están representadas las cuatro dimensiones del sentido, aunque la una o la otra se puede volver dominante en el momento del intento de comunicación.

\begin{abstract}
Algo igual formula la TsS cuando escribe: "La dimensión objetiva, la dimensión del tiempo y la dimensión social no pueden aparecer aisladamente. Se encuentran con una obligación de combinación. Se les puede analizar por separado, pero aparecen en cada sentido intencionado realmente como autotercero. ${ }^{\text {n243 }}$ Hasta hoy no es completamente explicable por qué la TsS ni siquiera menciona a la dimensión del espacio, aunque la teoría de sistemas actual con su distinción principal de adentro/afuera debe procesar en lo esencial espacialmente, y con ello expresa un carácter espacial. ¿Es esto quizás el "punto ciego" de la teoría de sistemas?
\end{abstract}

20. La diferencia como una forma de distinción neutra-de-dos-lados puede conducir en forma elaborada y transferir los diferentes niveles

${ }^{242}$ Acerca de la tendencia de desmoralización de la economía desde el siglo XVII, véanse las observaciones en Luhmann, 1986a, pp. 92 y ss.

${ }^{213}$ Luhmann, 1984, p. 127. 
de las dimensiones del sentido, a la sincronicidad, simultaneidad, presencia, percepción, observación, existencia, homogeneidad, igualdad, consenso, funcionalidad, analogización, simplicidad, etc. La diferenciación, en cambio, como una distinción unilateral-partidaria, también en la forma elaborada, puede dar ocasión, por su parte, a la asincronicidad, no simultaneidad, heterogeneidad, disensión, contradicción, ausencia, causalidad, digitalización, pluralidad, acción, voluntad, motivo, interés, etc. Su transferencia general al concepto de la $\mathrm{TgS}$ señala que la diferencia lleva a la comunicación y la diferenciación a la ACCIÓN. Es una de las tareas esenciales de una teoría de los sistemas sociales (TgS) el relacionar la COMUNICACIÓN y la ACCIÓN con los diferentes tipos de sistemas del sentido como la socialidad, la personalidad, la afectividad y la corporalidad en su entrelazamiento, y con ello proveerlas en cada nivel del sentido de suficiente plausibilidad.

21. La denominación es aquella operación que produce y/o relaciona una diferencia (a través de la homogeneización sobre la base de una diferenciación) o una diferenciación (por medio de la unilateralización sobre la base de una diferencia), con lo cual ella misma no es una ni la otra. La denominación es una forma primaria de la selección, la cual requiere del tiempo y hasta ella misma representa al tiempo.

Aquí nos adherimos a la TsS, la cual opina que la selección "[...] misma es un concepto del tiempo: ella es inminente, es necesaria, entonces se efectúa y entonces habrá pasado". ${ }^{244}$

Su función, en relación con ambas distinciones de "diferencia" y "diferenciación", consiste en combinar ambas selectivamente, en entrelazarlas en una forma determinada. Queremos aclarar esta circunstancia algo más detalladamente, con lo cual tenemos entre ceja y ceja sobre todo tres posibilidades de una combinación selectiva de ambas distinciones: primero "diferencia" y "diferencia", segundo "diferencia" $^{\text {y }}$ "diferenciación" y tercero "diferenciación" y "diferenciación". Primero: al chocar como evento, una contra la otra, dos diferencias, cada una con dos lados aún no determinados, aparece el problema

${ }^{244}$ Ibid., p. 70. 
de la contingencia de lados dobles: ${ }^{245}$ si ninguna de las dos distinciones pone en marcha un comportamiento selectivo, entonces no habrá ninguna conexión entre ambas diferencias: Si tiene lugar una denominación selectiva y con ello un comportamiento de conexión, entonces pueden surgir por ejemeplo de las diferencias "camisa y/ o pantalon" y "azul y/o rojo", diferentes diferenciaciones completas como "(no un pantalón rojo, sino...) uno azul", "(no una camisa azul, sino...) una roja", "(no un pantalón azul, sino...) uno rojo" o "(no una camisa roja, sino...) una azul”.

En la cotidianidad fenomenológica se presenta por lo general solamente el lado asimétrico de la diferenciación bilateral. En esto consiste precisamente su función como distinción asimétrica: en la facilitación de la conexión por medio de un subrayado semántico, unilateral.

Una diferenciación como "(no un rojo camisoso, sino...) un rojo pantalonoso" o "(no un azul pantalonoso, sino...) un azul camisoso" ciertamente no está prevista en la evolución social en cuanto a la pragmática de las distinciones, pero, en principio, sí sería posible. Segundo: al chocar como evento una con la otra una diferencia y una diferenciación, se da el problema de la contingencia simple (unilateral): de la diferenciación incompleta "pantalón". (se podría tratar de uno, muchos, largos pantalones, de uno de cuero, etc.) y de la diferencia rojo/azul pueden surgir, con una correspondiente denominación selectiva, un "pantalón azul" o un "pantalón rojo" como diferenciación asimétrica. Con ello, la denominación selectiva de la diferencia por medio de una diferenciación asimétrica anteriormente seleccionada ya no es tan verbosa, dado que ahora se trata de su indeterminación. Una determinación más fuerte de esta naturaleza en la relación de dos distinciones entre sí requiere una predeterminación del medio ambiente selectiva, correspondientementè más fuerte, como por ejemplo, "adolescentes masculinos que quieren comprar pantalones". Tercero: existe el caso del choque como acontecimiento de dos diferenciaciones asimétricas, o sea de dos diferencias ya seleccionadas o denominadas. Si una diferenciación es el "pantalón" y la segunda también, entonces hay solamente una conexión o no hay ninguna, pero en este caso ya no tiene caso una reducción selectiva de una diferencia a una diferenciación. Si solamen-

${ }^{245}$ Trataremos esta posibilidad en el capítulo III. 
te se permite "pantalón" como única diferenciación, entonces se puede llegar a una conexión entre las dos diferenciaciones sólo cuando se haya seleccionada anteriormente la comunicación de tal manera que se puede actuar solamente sobre la base de una sola forma de diferenciación. Esto podría ser el caso en el marco de una fábrica que produce pantalones, o en el marco de una "feria del pantalón": aquí, la conexión es posible solamente cuando se utiliza la diferenciación "pantalón". como diferenciación principal (figura 52).

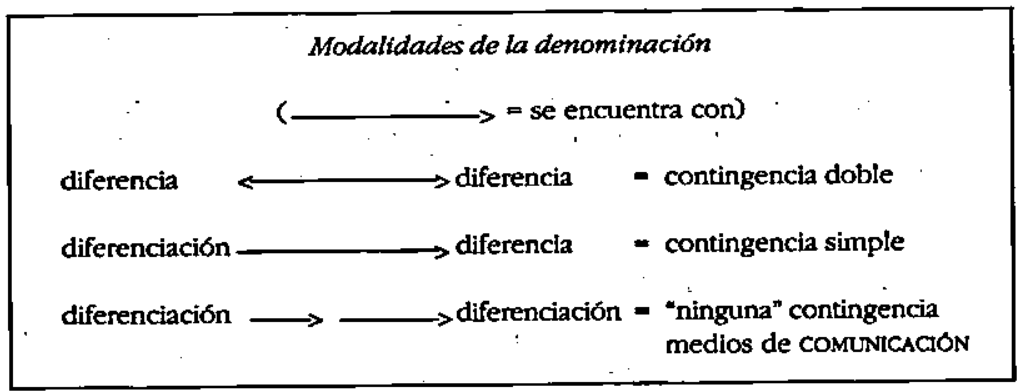

22. El proceso de la denominación está dado solamente en una distinción de conexión/no conexión. A esta forma de la denominación se refiere el proceso de conexión autopoiético de los sistemas del sentido, los cuales han elaborado los medios de comunicación: una acción del derecho, del dinero, del poder, encuentra una conexión o no la encuentra. Günther Teubner formula esta circunstancia así: "De esta manera, la invención del acto jurídico posibilita el cerramiento autorreferencial del sistema jurídico, el cual se reproduce por medio de conexiones continuas de las acciones jurídicas. La constitución del acto de pagar adopta la misma función en el sistema económico. ${ }^{246}$ Las distinciones importantes, por ejemplo, del sistema económico, del sistema jurídico o del sistema político, es decir "cierto, no falso", "derecho, no injusticia" y "poder, no impotencia", ya son diferenciaciones asimétricas y como tales tienen efecto sólo asimétricamente en los medios de comunicación "verdad", "derecho" y "poder". Esto significa que en los sistemas autopoiéticos completamente formados se procesan distinciones ya decididas, o sea diferenciaciones asimétricas. Asimismo, sólo asî se puede entender el por

246 Teubner, $1987 \mathrm{~b}$, p. 90. 
qué dentro de estos sistemas ya no es actual el problema de la decisión, de si es que se deberían formar del todo el derecho, el poder o la verdad; sino que se debe resolver el problema de la conexión, de si una comunicación correspondiente hace conexión/no hace conexión con el sistema. En un nivel menos general, pero aún altamente abstracto, partimos del hecho de que tienen lugar cadenas de COMUNICACIÓN sobre la base de un entrelazamiento tetrádico de la "diferencia" y la "diferenciación" en la forma de información/comunicación y entender/malentender; mientras que se realizan las cadenas de ACción sobre la base de una referencia unilateral de las "diferenciaciones" en la forma de una acción con carácter de suceso, a la siguiente acción con carácter de suceso (una diferenciación "cortada" se conecta con la siguiente, ésta por su parte..., etcétera).

\begin{abstract}
Comprendemos una COMUNICACION como el relacionamiento tetrádico de dos distinciones, es decir de información/comunicación y entender/ malentender. La ACCIÓN, por su parte, consiste en el relacionamiento de aceptacion/rechazo y fin/medios. Los sistemas de sentido procesan de tal manera que relacionan a la COMUNICACión con la información, con el intercambio y con la comprensión, y con ello dejan sin considerar los malentendidos, lo manejan como "punto ciego". Con la Acción, el proceso de reducción es aun más craso: sólo se procesa el acontecimiento finalidad, los demás sucesos se dejan sin consideración o se reducen considerablemente. No es necesario realzar que por medio de ello se puede errar en la "comprensión" (con COMUNiCACIONEs) o en la "finalidad" (con ACCIONES) y que se errará frecuentemente.
\end{abstract}

23. Nosotros compartimos - no operacionalmente pero si en cuanto a la teoría de las distinciones-en gran medida la propuesta de la TsS de comprender la comunicación como una selección de la información, del intercambio y la comprensión: "Si se comprende la comunicación como la síntesis de tres selecciones, como unidad de la información, el intercambio y la comprensión, entonces la comunicación está realizada, cuando y en la medida en que se logra la comprensión. Todo lo demás sucede 'afuera' de la unidad de una comunicación elemental y la presupone. ${ }^{n 247}$ Sin embargo, se debe hacer la siguiente corrección: realmente son cuatro acontecimientos selec-

${ }^{247}$ Luhmann, 1984, p. 203. 
tivos (tetrádico) en la forma de dos distinciones, o sea información/ intercambio (=diferencia) y entender/malentender (=diferenciación) los que hacen posible el proceso comunicativo. El suceso comunicativo "malentender" (o "no entender") es el "punto ciego" de la comunicación: ciertamente se debe partir del hecho de que en el proceso comunicativo predomina el componente de la comprensión, y en ese sentido existe una asimetría de entender/malentender con el punto de peso "entender". Por otra parte, es casi seguro que tenga lugar el suceso del "malentender" ( 0 "no entender"), dado que el proceso informativo consiste en una distinción, y es por ello relacional, pero se procesa ontológicamente, y tampoco es posible de otra manera. Con esto se quiere decir que para los fines de la comunicación no se comunica la información que se genera con ello en su calidad relacional, sino que se procesa en la forma de suposiciones compactas de forma atemporal. Hay sociólogos como Norbert Elias que tienen la noción de que esta "ontologización de la COMUNICACión" se podria evitar: "La tendencia obligatoria de nuestros idiomas de hacernos hablar y pensar como si todos los objetos de nuestra reflexión, los hombres incluidos, fueran primero objetos, no solamente sin movimiento, sino también sin relación, es para la comprensión del entrelazamiento humano, el cual forma el objeto de la sociología, extremadamente obstaculizante. ${ }^{\text {248 }}$ Para Elias no parece ser claro que no puede ser de otra manera: la COMUNICACIÓn que se puede observar de la forma más evidente como COMUNICACIÓN verbal y por escrito, tiene lugar en una "forma no relacional, despedazada". Aun para la forma de COMUNICACión de la percepción corporal, y hasta referido a la percepción del tiempo, vale: "Podemos suponer que el proceso de nuestra experiencia y nuestro comportamiento está desmenuzado en cuantos de tiempo [RJ]. No 'siempre' podemos reaccionar. ${ }^{n 249}$ Seguramente se le debe dar la razón a Elias en cuanto a que no se practica suficientemente el "pensar relacionalmente" dentro de una ciencia como la sociología. Pero aun cuando se piensa relacionalmente, no se puede escapar a la obligación de tener que "ontologizar" u "objetivar". Se debe poder decir o escribir: "Esto es así, lo otro es diferente." Una determinación reductiva de esta índole es, en última instancia, responsable del procesamiento continuo de

${ }^{248}$ Elias, 1978, p. 120.

249 Pöppel, 1985, p. 42. 
"malentendidos". Pero si uno no se determina COMUNICATIVAMENTE, si uno no reduce sus relaciones a unas cuantas, entonces no se llega a la comprensión y, en última instancia, tampoco a la ACCIÓN. En el contexto de la pragmática de las distinciones aquí representada, la distinción asimétrica es "diferenciación", la cual tiene por efecto a la "ontologización" u "objetivación" de la comuncación: "no hoy, sino mañana", "no aquí, sino allă", etcétera.

\section{Comunicación y acción}

24. Adoptamos la propuesta de la TsS de no separar la COMUNICACiÓN y la ACCION, pero sí distinguirlas: "Yo veo el problema en la circunstancia de que la comunicación y la acción de hecho no se pueden separar (pero'sí distinguir) y que forman una relación que se debe comprender como la reducción de una complejidad. ${ }^{\text {250 }}$ Con ello entendemos (TgS) cualquier forma de comunicación (o sea coMUNICACION) como una distinción de carácter simétrico, como una "diferencia". Por el otro lado, entendemos a cualquier forma de acción (o sea ACCIÓN) como una distinción de carácter asimétrico, es decir como una "diferenciación". De ahí que la COMÚNICACión posee la forma de "esto y/o aquello", mientras que la ACCION tiene la forma "esto; no aquello". Entonces es relativamente fácil describir —en cuanto a la teoría de las distinciones, no en cuanto a la teoría de las operaciones- el proceso de la COMUNICACIÓn y el de la ACCIón: una oferta de comunicación de cualquier tipo de procesamiento, una oferta de selección en la forma de una diferencia simétrica, como "ir con el carro y/o ferrocarril" choca con una acción correspondiente como determinación de la selección en la forma de una diferenciación asimétrica, como "no quedarse en casa, sino salir de vacaciones", con lo cual se denomina el uno o' el otro lado de la diferencia.

Lamamos la atención sobre el hecho de que la ACCION no coincide con la DECISIÓN: una ACCION indica determinación de la selección, mientras que una DECISIÓN se refiere al proceso de la denominación o selección, el cual tiene lugar entre una determinación de la selección y una oferta de selección, o sea una COMUNICACION.

250 Luhmann, 1984, p. 193. 
Al final del proceso de carácter del evento puede resultar que alguien "se va de vacaciones con el ferrocarril". Es importante realzar el hecho de que la diferencia simétrica "ir con el carro y/o el ferrocarril" se unilateraliza a través del proceso de decisión, y con ello se reduce a una diferenciación de la forma: "no ir con el carro, sino con el ferrocarril". Un sistema de este tipo con esta forma no tiene, de acuerdo con su naturaleza, una larga duración (figura 53).

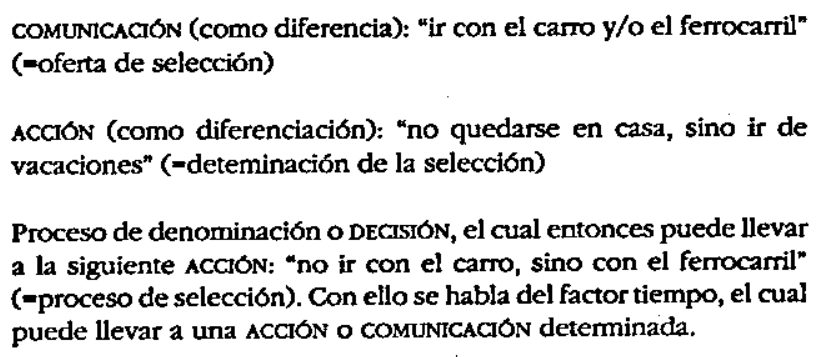

COMUNicación (como diferencia): "ir con el carro y/o el ferrocarril" (=oferta de selección)

ACCION (como diferenciación): "no quedarse en casa, sino ir de vacaciones" (-deteminación de la selección)

Proceso de denominación o DECISION, el cual entonces puede llevar a la siguiente $A C \mathrm{C}$ ON: "no ir con el carro, sino con el ferrocarril" (-proceso de selección). Con ello se habla del factor tiempo, el cual puede llevar a una ACCIÓN o COMUNICACIÓN determinada.

25. Con COMUNICACION se quiere decir -en cuanto a la teoría de las distinciones- la ejecución del sentido de una "oferta de selección": una información determinada se comunica de una forma determinada (-tipos de sistemas del sentido), la cual puede ser "entendida" o "malentendida". Con Acción se quiere decir - también en relación con la teoría de las distinciones- la ejecución del sentido de una determinación del sistema o "atribución del sistema": una identificación del sistema se da porque, con la prefijación de una finalidad y con la integración de los medios disponibles, se aceptan sucesos comunicativos específicos, mientras que otros se rechazan. Y sólo cuando la COMUNICACIÓN y la ACCIÓN procesan comola unidad de una distinción por medio del proceso de DECISIÓN, la oferta de selección y la atribución del sistema tienen un sentido soctal. Ciertamente se puede formular con la TsS: "La comunicación se asimetriza sólo por la integractón de una comprensión de la acción al acontecer comunicativo, sólo a través de esto obtiene una dirección del comunicador hacia el receptor de la comunicación [...]. ${ }^{n 251}$ Pero con esto se debe observar que la reducción de un acontecer comunicativo de este tipo a una forma de acción (forma manejable), implica el relacio-

${ }^{251}$ Ibid., p. 227. 
namiemto de las distinciones información/comunicación, entendimiento/malentendimiento, aceptacio $\mathrm{n} / \mathrm{rechazo}$ y finalidad $/ \mathrm{medios}$, con lo cual está dicho que con la reducción de la COMUNICACIÓN a la ACCIÓN se reducen conjuntamente las distinciones arriba mencionadas (figura 54).

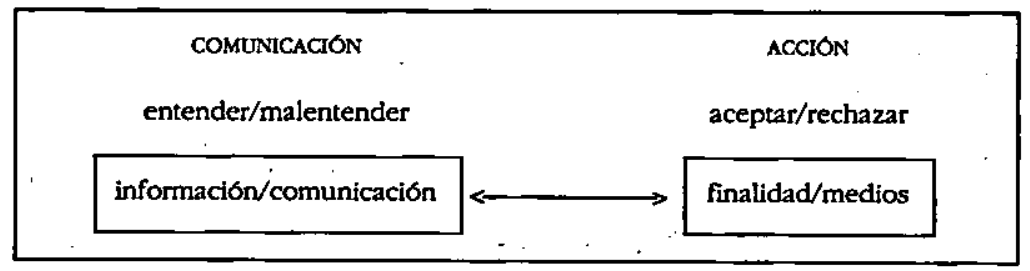

En este contexto se debe observar que aun en el nivel basal de la pragmática de las distinciones, la distinción de "diferencia/diferenciación" está entrelazada de tal manera que una separación puede parecer poco sensata. Pero en un mundo del sentido siempre es posible exponer lo supuestamente no separable a una distinción, la cual entonces puede tener efecto sensatamente como distinción.

Dado que una distinción puede tener efecto sensatamente, denominamos la posición que decribe el cómo tiene efecto la información que tiene efecto sensatamente, como pragmática de las distinciones. En relación con el carácter informativo de cualquier distinción se puede formular también que en el mundo todo está conectado con todo, y que cada separación incluye el germen de lo incierto. De esa manera, la información como separación distinta es posible solamente bajo la condición previa de que informa y desinforma simultáneamente. Carl Friedrich von Weizsäcker, refiriéndose al cuestionamiento de la ontología de sujeto/objeto por medio de la teoría cuántica formula: "Confrontemos la cibernética con la teoría cuántica! El darwinismo, la investigación del comportamiento y la cibernética, tratan al sujeto como una cosa que aparece en el espacio y en el tiempo. Ellos ofrecen un modelo físico del sujeto empírico. Nunca se tematiza el hecho de a quién se le aparece esta cosa, ni tampoco que el ser en el tiempo y el espacio es una manera de la apariencia. La teoría cuántica destruye, pues, a la ontología aquí presupuesta. Resulta ser de lo más evidente en la composición de los objetos, misma que se manifiesta en la 'paradoja' de Einstein, Rosen y Podolsky: si un objeto total es divisible entre objetos parciales, entonces esto no significa de ninguna manera que los objetos parciales existan también aunque el objeto total no esté fác- 
ticamente desmenuzado en estas partes. Ahora bien, cada objeto se debe comprender como parte de objetos más grandes. Los objetos designan facticidad, pero los hechos son hechos solamente gracias a las posibilidades dispuestas en ellos. Cuando mucho, el universo podría ser el único objeto total irreductible, pero precisamente éste no es ningún objeto, dado que ¿para quién sería objeto?"252

Con esto enfatizamos otra vez la relación de correspondencia entre las distinciones ACCION/COMUNICACIÓN y diferenciación/diferencia, con lo cual obviamente, los tipos de distinción están localizados en diferentes niveles del sentido: la ACCIÓN y la COMUNICACIÓN en el ámbito de la teoría de la sociedad; la diferenciación y la diferencia en el ámbito de la teoria de las distinciones (figura 55).

\author{
Teoría de la sociedad: \\ unidad de la distinción de COMUNICACION y ACCIÓN \\ Teoría de las distinciones: \\ unidad de la distinción de diferencia y diferenclación
}

26. La posibilidad de un sistema del sentido depende en última instancia de si una COMUNCACIÓN social logra transformar la distinción basal de diferencia/diferenciación en el nivel de la SOCIEDAD y por ello en el nivel de abstracción de la distinción de COMUNICACión y ACCION, y con esto concretarla.

La durabilidad (o sea no la posibilidad) de un sistema del sentido, contrariamente, depende de la distinción de expectativa/experiencia, la cual condensa las informaciones y con ello las concretiza en maneras y tipos de sistemas de sentido. La verdadera teoria de la sociedad comienza con esta distinción, pero en el marco de este trabajo solamente podemos insinuarla, dado que aquí no presentamos una teoría de la sociedad, sino una teoria general de las distinciones.

¿Qué significa eso? Sabemos que las distinciones "diferencia" $\mathrm{y}$ "diferenciación ${ }^{n},{ }^{253}$ las cuales forman en su entrelazamiento el elemento

252 Weizsäcker, C.F.v., 1977, p. 581.

33 Para prevenir malentendidos se ha dicho: por una parte hablamos en singular de la distinción "diferenciación/diferencia", por la otra, hablamos en plural de las distinciones "diferencia" y "diferenciación". 
basal de carácter de suceso, pueden presentarse solamente en forma relacional.

Si la denominación "elemento originario" no diera ocasión para malentendidos, la utilizariamos en este contexto. Con esto tenemos en mente aproximadamente - no asociativamente, sino en la cosa misma, es decir "sustancialmente" - la "hipótesis originaria" de C.F.v. Weizsäcker, un supuesto "[...] curya total trivialidad no hemos podido demostrar: o sea que todas las altemativas reales, incluyendo la dinámica perteneciente a ellas pueden ser construidas a partir de las alternativas-originarias binarias ('hipótesis-originaria')."254

En el nivel de la SOCIEDAD, se trata de la unidad básica social, es decir de la unidad de la distinción de COMUNICACIÓN y ACCIÓN. Ahora bien, en este nivel de abstracción aún no se puede formar ningún sistema del sentido, ya que las distinciones que tienen lugar en este nivel son todavía demasiado poco determinadas, y por eso aún no "funcionan" socialmente. También en el nivel de la COMUncación de tipos de intercambio que llevan a la constitución de tipos de sistemas del sentido como la corporalidad, afectividad, subjetividad (conciencia) y socialidad (instituciones), los acontecimientos COMUNICATIVOS permanecen demasiado generales, como para que ofrecieran ocasión para la formación de sistemas del sentido concretos. Sólo abajo de este nivel de tipos de comunicación se puede suponer que la distinción básica social de COMUNICACIÓN y ACCIÓN se vuelva capaz de conexión. Aquí adoptamos una propuesta de la TsS y formulamos: sólo cuando la distinción en cuestión de COMUNICACIÓN/ACCIÓN se relaciona, por medio de las distinciones información 'e intercambio, con aquélla de codificación/programación, se trata de sistemas del sentido concretos (figura 56).

\section{Capas de abstracción de una pragmática de las \\ distinciones generadora de sistemas del sentido.}

Diferencia/difenenciación: nivel del sistema de distinciones

COMUNICACION/ACCIÓN: nivel del sistema SOCIAL

Información/comunicación: nivel de los tipos de sistemas del sentido

Codificación/programación: nivel del sistema del sentido individual

${ }^{254}$ Weizsäcker, C.F.v., 1985, p. 37. 
Podemos representar las capas de abstracción de la pragmática de las distinciones que se refieren a la teoría de la sociedad también de la siguiente manera (figura 57):

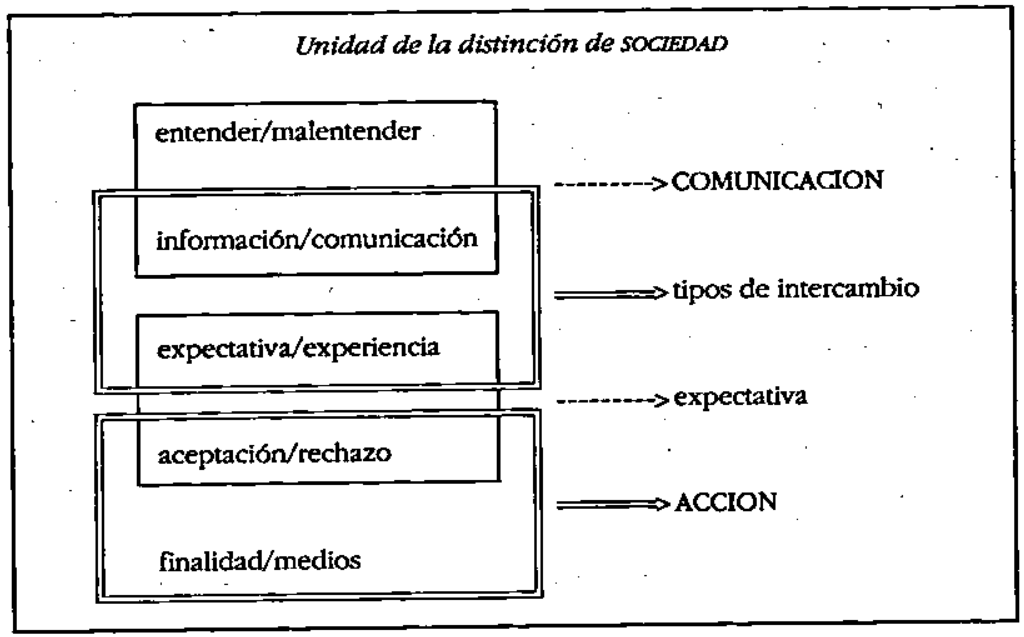

27. Se puede describir el nivel de abstracción de los sistemas del sentido particulares, con la ayuda de la distinción de código y programa. Por ello se debe preguntar: ¿qué es un código? Una respuesta conocida a esta pregunta es la siguiente: un código reproduce una regla de duplicación que hace posible que se le ponga a cada ítem de un valor un ítem correlativo a éste. El concepto del código encuentra resonancia a través del descubrimiento del "código genético" por James D. Watson, Francis H.C. Crick y Maurice H.F. Wilkins, con ayuda de la hipótesis que explica la operación de duplicación de los genes de la siguiente manera: "La duplicación de un gen presupone el surgimiento de una imagen (negativa) complementaria cuya forma se encuentra en la misma proporción respecto a la superficie (positiva) originaria, de la misma manera que se encuentra el hoyo de la cerradura en relación con la llave. Esta imagen negativa complementaria [desempeña RJ] pues, el papel de una forma hueca para la construcción de una figura positiva nueva. ${ }^{\text {2255 }}$ Se puede denominar, por ejemplo, al idioma como un código, ya que "[...] posibilita

2ss Watson, 1973, p. 104. 
comunicar todo lo que se comunica en la versión sí y en la versión no, aunque se sabe que no hay en absoluto nada negativo fuera de la comunicación" ${ }^{256}$ En el contexto de una teoría sociológicade los sistemas, los códigos valen como medios de comunicación específicos -como el poder, sexo, amor, inconfundibilidad, dinero o la verdad-, "[...] los cuales posibilitan que comunicaciones más bien improbables tengan, a pesar de ello, éxito". "Que tengan éxito" significa con ello: aumentar la disposición de aceptación para las comunicaciones de tal manera que se puede arriesgar la comunicación; y no se omite sin esperanza desde el principio. ${ }^{257} \mathrm{La}$ COMUNICACIÓN se canaliza en formas espécíficas, las cuales entonces tienen efectos sistémicos: en estos casos no se requiere la COMUNCACIÓN en general, sino el poder comunicativo, amor comunicativo o sexualidad comunicativa, etc. Pero al contrario de la TsS, partimos del hecho de que los códigos se procesan como diferenciaciones asimétricas. La justificación de esto es simple: los sistemas del sentido prefieren el valor positivo de la distinción, la cual, a través de una "evaluación unilateral" de esta naturaleza, se convierte en una diferenciación. Así, el sistema de la ciencia prefiere lo cierto, no lo falso; el sistema jurídico prefiere lo justo, no lo injusto; el sistema político, poder, no impotencia; el sistema del amor, amor, no odio, etc. Se debe realzar que la TsS tiene sus dificultades cuando se trata de una determinación más detallada de la forma de un código, presuntamente porque la arquitectura de su teoría prevee solamente una distinción, es decir una diferenciación asimétrica. Así interpreta, por un lado, al código como una distinción simétrica: en el nivel del código no hay ninguna "preferencia preestablecida por el valor positivo y contra el valor negativo [...]. Una regla de preferencia de esta indole sabotearía al sentido y a la función de la codificación ${ }^{n}{ }^{258}$ Por otra parte, poco después se anula la misma afirmacion: "El valor negativo [de un código RJ] que solamente sirve para la regla de duplicación y la obtención de contingencia, no puede alcanzar una equivalencia completa, aunque esté asegurada la reversibilidad lógica. Permanece como un contravalor, un aditivo asimétrico que no puede alcanzar ningún significado autónomo $[. .]^{n} .259$

${ }^{256}$ Luhmann, 1987c, p. 13.

${ }^{257}$ Luhmann, 1982b, p. 21.

${ }^{258}$ Luhmann, 1987c, p. 15.

${ }^{259}$ Ibid., p. 18. 
Una maniobra conceptual evidentemente inconsistente e inconsecuente. Esto también es el precio de que la TsS, como ya lo hemos visto, proceda monológicamente: empieza con la puesta de una diferenciación asimétrica, la cual es simultáneamente una denominación. Esto es un acto social evolutivo irrealista.

En este lugar nos desviamos en lo que concieme a la concepción de la distinción código/programa de los supuestos de la TsS: interpretamos a los códigos exclusivamente como diferenciaciones asimétricas y a los programas exclusivamente como diferencias simétricas (figura 58).

\section{Nivel del sistema del sentido particular \\ Código como diferenciación asimétrica \\ Programa como diferencia simétrica}

28. Fieles a nuestro supuesto de que cada "algo" estă formado tetrâdicamente, partimos del hecho de que también los sistemas del sentido de más duración surgen sólo cuando el proceso comuNicatrvo conduce a la formación de la codificación y de la programación, en el sentido de un relacionamiento tetrádico entre dos distinciones. ¿Qué se quiere decir con esto? Comprendemos los códigos como diferenciaciones asimétricas que señalan o atribuyen al sistema correspondiente del sentido "justicia, no injusticia", "amor, no odio", "propiedad, no carencia de propiedad", "cierto, no falso". En este nivel está cerrado completamente el sistema del sentido: "En el nivel de la codificación se diferencia un sistema por medio de un esquematismo binario. En este nivel, un sistema se establece simultáneamente como un sistema cerrado [RJ]."260

En el nivel del programa se llega a la apertura del sistema frente a su entorno, con lo cual los programas "[...] son condiciones preestablecidas para la corrección de la selección de las operaciones [.... $]^{n} .^{261}$ del sistema: "Por un lado posibilitan una cierta 'concretización' (u operacionalidad) de los requerimientos que se exigen a un sistema de funciones, y por el otro lado, deben permanecer modificables en

${ }^{260}$ Luhmann, $1986 \mathrm{a}$, pp. 90-91.

sil Ibid., p. 91. 
cierta medida, precisamente por esto. ${ }^{\text {262 }}$ Así, el sistema jurídico está cerrado frente a su entorno a través de la asimetría del código "derecho, no injusticia", pero está abierto a través de la simetría del programa "normativo/cognoscitivo". El sistema económico está cerrado sistémicamente a través de la asimetría "propiedad, no carencia de propiedad" y abierto para el entorno por medio de la simetría del programa "caro/barato" (o sea sobre los precios). El sistema de la ciencia es, en referencia al código asimétrico, "cierto, no falso" un sistema cerrado, pero respecto a la simetría "sintético/analítico" es capaz de resonancia a los requerimientos del medio ambiente. El sistema político es a través de la asimetría de "poder, no impotencia" un sistema cerrado, pero abierto a las resonancias del entorno por medio de la simetría de "gobierno/oposición" (figura 59).

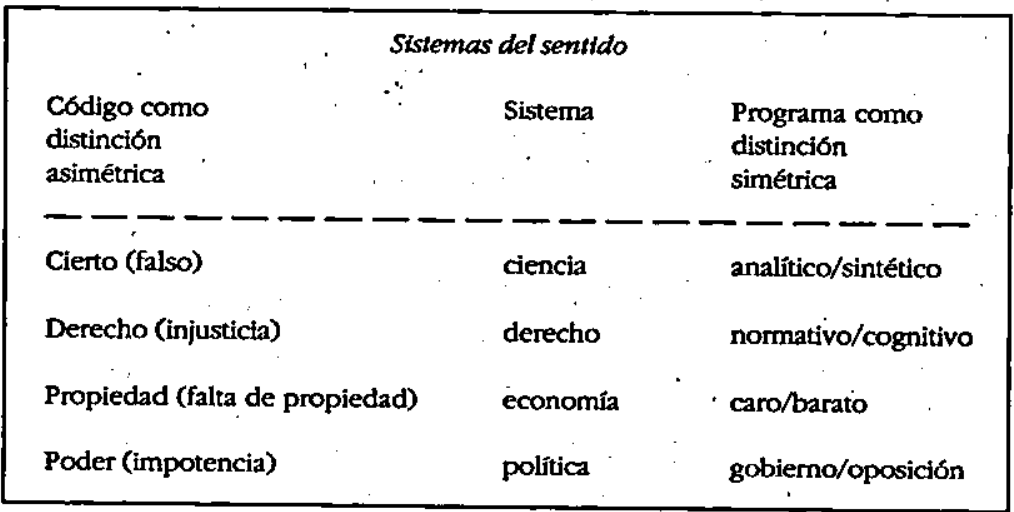

29. Para no complicar innecesariamente la circunstancia que encuentra su expresión en la distinción de COMUNICACIÓN/ACCION, la hemos analizado solamente desde la perspectiva de la teoria de las distinciones. Naturalmente, también la perspectiva desde la teoria de las operaciones juega un papel relevante, lo que dentro del marco de la teoría de la sociedad será, en el contexto de la distinción mencionada, el tema central. No obstante ya aquí queremos observar lo siguiente: el acceso operativo a la distinción de COMUNICACIÓN y ACcIón permite demostrar sobre todo en relación con la teoría de fun-

${ }^{262} \mathrm{Idem}$. 
damentación, el por qué esta distinción muestra una necesidad interna. ¿Cómo debe uno imaginarse una justificación de esta índole desde la teoría de las operaciones? Procedamos en orden. Por lo pronto: empezamos fácticamente, con lo cual "hacemos algo": ACTUAMOS. Hagamos una breve pausa y reflexionemos sobre esta operación. Preguntamos: ¿cómo es posible una operación de este tipo?, ¿cómo es posible el ACTUAR? Evidentemente necesitamos la operación de la DECISION, si queremos ACTUAR. Pues, ¿cómo queremos ACTUAR, si no tenemos que DECIDIR nada? Reflexionemos ahora sobre la operación de la DECISIÓN y preguntemos: ¿cómo es posible una DECISION? Evidentemente, solamente porque tenemos que DECIDIR algo. Para esto se requiere alguna forma de distinción. Y la distinción mínima sería una operación del ACTUAR mismo, es decir si queremos realmente ACTUAR o no. Con otras palabras: las ACCIONES implican DECISIONES, éstas implican por su parte, distinciones. Ahora bien, hemos interpretado las distinciones desde una perspectiva de la teoría de la sociedad como COMUNICACIONES, o sea como ofertas de selección. Si esto fuera más o menos cierto, entonces podemos decir ahora: las ACCIONES implican DECISIONES, las cuales, por su parte, implican COMUNICACIONES. Desde la perspectiva de la teoria de las operaciones podemos afirmar por ello: ninguna ACCIÓN es posible sin COMUNICACION, ya que existe una necesidad interna entre ACCION y COMUNICACIÓN, la cual se facilita a través de la operación de la DECISIÓN.

\section{Complementariedad y distinción}

30. Regresemos a la operación de la denominación (o DECISION). Ella es precisamente aquella operación que siempre opera en el presente, y que dirige y fija el valor no-visible del entrelazamiento de la diferencia y la diferenciación. Ella misma es una diferencia del trasfondo o una diferenciación del trasfondo, pero nunca se presenta como tal, ni puede presentarse como tal. Una operación que produce una distinción determinada por medio de la denominación, no se puede denominar simultáneamente a sí misma en este proceso de la producción. La operación del distinguir con la ayuda de la denominación siempre tiene lugar en el presente, no puede tener-lugar-aún ni ya-haber-tenido-lugar. Es el "ahora", el cual en el momento actual no se vuelve tampoco tangible, porque ya ha ocurrido [...] ahora otra vez ha ocurrido ya [...] etc. El medio de la operación como el dis- 
tinguir de algo actual (=la denominación) es el ojo que puede ver solamente cuando no se ve a sí mismo. $Y$ cuando el ojo es obligado a verse a sí mismo porque le da "glaucoma", ya no es capaz de ver "todo lo demás". En este sentido, las operaciones de la diferencia y la diferenciación son posibles sólo sobre la base de un "punto ciego". La ceguera es, por lo tanto, la condición de la posibilidad del ver en un sentido elemental. Si se transfiere esta metáfora a las distinciones "diferencia" y "diferenciación", entonces se puede decir que, por un lado, la diferencia es la condición de la posibilidad de la diferenciación, y que, por el otro lado, la diferenciación es la condición de la posibilidad de la diferencia, dado que siempre se puede denominar desde la perspectiva de una determinada distinción (figura 60 ).

\section{Denominación y distinción}

Lo denominado $\rightarrow$ Diferenciación como facticidad

Lo que se debe denominar $\rightarrow$ Diferencia como posibilidad

La denominación $\rightarrow$ Presente como supuesto presentista

31. La denominación se efectúa con la ayuda de una diferenciación o con la ayuda de una diferencia. Pero ambas distinciones-diferencia y diferenciación- no pueden hacerse visibles simultáneamente durante el proceso de denominación, ya que la denominación no puede denominar simultáneamente "algo" (en este caso una diferenciación o una diferencia) y a sí misma. Para ello, la denominación necesita otra denominación, la cual, sin embargo, entonces ya no es la denominación denominadora o la denominación actual: iprecisamente necesita tiempo! En ese sentido, una denominación nunca puede alcanzarse a sî misma, siempre se queda "detrás de sí misma" (expresado metafóricamente: ella es típicamente más rápida que ella misma), y con ello siempre invisible.

Ha sido este problema el que nos ha motivado a introducir la $\mathrm{ACC} O \mathrm{ON}$ como una forma de distinción asimétrica, o sea como una diferenciación: Naturalmente, la pragmática de las distinciones -referida al nivel de la teoría de la sociedad-se puede interpretar también desde la perspectiva de la teoría de la acción: una Acción posible sería una diferencia, una ACCIÓN efectuada sería una diferenciación y la ACCIÓN que se está desarrollando seria la operación de la denóminación entre dife- 
renciación y diferencia. Pero consideramos equívoca una limitación desde la perspectiva de la teoría de la acción de este tipo de la teoría de las distinciones, dado que a través de ello el concepto de la ACCIÓN se vuelve ambiguo y con ello inutilizable. Además, se agrega que se requieren sucesos COMUNiCATTVOS para la realización general de la ACCIÓN.

Lo único que se puede decir es que utiliza una diferencia o una diferenciación como base de sus operaciones. Pero lo que haya usado realmente sólo se puede averiguar con posteridad (con la ayuda de otra denominación, con la cual deberíamos proceder de la misma manera que con la primera), es decir pues, cuando ya haya desaparecido, cuando la operación (sobre la base de una denominación nueva) ya esté realizada.

No es completamente correcto decir "lo que realmente era", dado que cada distinción nueva puede anular otra vez a la que haya tenido lugar, y siempre es posible que al observador se le ofrezca (a el mismo o a otros) con una distinción nueva una interpretación nueva de la distinción "efectuada en aquel entonces".

Una denominación opera en el presente o no tiene lugar. Una denominación "reconocida" es, entonces, siempre una denominación ya realizada.

32. Queremos hablár siempre de una operación de la distinción basal, cuando ésta se efectúa como una operación de carácter momentáneo "infectado de ceguera", para que, primero, no se genere ninguna confusión entre las diferentes formas de distinción y segundo, para que quede claro el significado fundamental de una no-esquivabilidad del "punto ciego" de cualquier tipo de operación de distinción. Un observador que observa con la ayuda de una diferencia y/o diferenciación, puede observar posiblemente el "punto ciego" de otro observador, sin embargo, lo puede hacer solamente sobre la base de su propio "punto ciego". Aquí tampoco la autoobservación ayuda más, ya que también puede efectuarse solamente sobre la base de una operación de la distinción, la cual está arraigada radicalmente en el presente y por lo tanto implica una "ceguera" operativamente condicionada. Y si se realizara una observación de la observación de la observación..., o sea una observación del tercer 
o cuarto o décimo grado, aun entonces la operación de la distinción basal debe operar en el presente, en el momento, lo que hace imposible escapársele alguna vez al "punto ciego".

33. Ahora bien, ¿cuál operación se efectúa primero, la operación de la "diferencia" o la operación de la "diferenciación"? Hemos visto que una diferenciación es una diferencia partidaria unilateral, y una diferencia una diferenciación neutra bilateral. Una diferenciación asimetrizante es una distinción ya seleccionada, una diferencia simetrizante es una distinción que aún se debe seleccionar. Dado que la diferencia presenta su bilateralidad en la forma de la simultaneidad, se puede escoger entre uno y el otro lado, se puede convertir la diferencia en diferenciación, unilateralizarla o reducirla. Dado que la diferenciación presenta su bilateralidad en la forma de la no simultaneidad (como unilateralidad), ya no es seleccionable como forma de distinción. Cierto, se puede revertir la unilateralización otra vez, y de esta manera regresar la diferenciación a su diferencia "original". No obstante, esto sería entonces una operación nueva y ya no sería una diferenciación, sino una diferencia (naturalmente una diferencia igual, pero no la misma). Dado que yo quiero comprar un pantalón, puedo vacilar entre un pantalón rojo y un pantalón azul. ¿Qué viene primero aquí, el pantalón como forma de la diferenciación o rojo/ azul como forma de la diferencia? Cierto, para dar a la diferencia rojo/azul una unidad de utilización sensata, se debe referir una diferenciación a ella: un pantalón rojo y/o uno azul. De acuerdo con el aspecto temporal debería estar presente entonces primero la decisión (=denominación) por la compra de un pantalón, sólo entonces se hace posible el romperse la cabeza entre un pantalón rojo y/o uno azul. Esto confirma el hecho ya mencionado de que las diferenciaciones siempre son formas de distinción ya-seleccionadas, las diferencias son formas de distinción aún-a-seleccionar. Naturalmente, esto es también el sentido de las diferencias, o sea la exploración de las posibilidades de selección para producir un comportamiento de conexión. La posibilidad de elegir se regula por medio de las diferencias, el comportamiento de conexión a través de las diferenciaciones. Cuando una posibilidad de selección se hace visible solamente sobre la base de una conexión potencial, la cual se puede efectuar solamente bajo el preestablecimiento de una selección, entonces ambas distinciones pueden presentarse solamente en forma entrelazada (figura 61). 


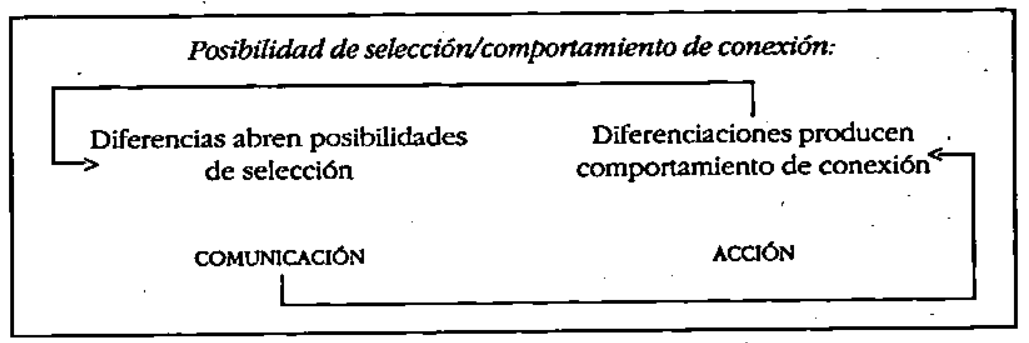

34. Intentemos, en la forma de un experimento de ideas, colocamos en un estado de un "comienzo originario" $y$ hagamos otra vez la pregunta por la prioridad de las distinciones diferencia y diferenciación. ¿Qué viene primero, la diferencia o la diferenciación? Dado que la información presupone la operación de las distinciones, las distinciones son la condición de la posibilidad de la información. Sin distinción no ocurre nada. El que algo sea "algo" ya es un logro de una distinción particular, altamente compleja. Nuestra pregunta en el contexto de un "primer comienzo" es entonces: ¿qué viene primero, la diferenciación originaria o la diferencia originaria? (o, expresado popularmente: ¿el huevo o la gallina?). Ahora hemos hecho uso - ya al formular la pregunta - de una diferencia neutra de los dos lados: “Qué viene primero, la diferencia y/o la diferenciación original? Por su parte, el hecho de que nos dejamos guiar por una diferencia preoriginaria indeterminada al hacer la pregunta signifca (viendo là observación desde afuera) que hemos escogido precisamente esta diferencia preoriginaria y para nada la diferenciación preoriginaria. Pero exactamente esta selección implica por su parte una diferencia pre-preoriginaria, o sea entre diferencia preoriginaria y diferenciación preoriginaria. Si hiciésemos otra vez la pregunta acerca del origen del origen en el sentido de una diferencia originaria o de una diferenciación originaria, entonces llegariamos siempre al resultado ya obtenido, es decir, que una diferencia siempre implica... una diferenciación... una diferencia... una diferenciación.

35. En este contexto hemos llegado ahora al punto de poder ocuparnos más detalladamente del teorema de la complementariedad. En el marco de la física teórica vale, según C.F.v.Weizsäcker, él con- 
cepto de la complementariedad como el concepto clave "[...] para la mejor comprensión posible hoy en día de la teoría cuántica". ${ }^{263}$

La frase completa dice: "Por esto se puede designar al concepto de la complementariedad como la clave para la mejor comprensión posible hoy en día de la teoría cuántica."

También juega un papel central en la "lógica de las distinciones" aquí presentada. El término de la complementariedad fue introducido a la física por Niels Bohr en 1927, para conducir hacia una mejor aclaración de la relación de indeterminación de Heisenberg.

Se sabe que Niels Bohr introdujo a la física el concepto de la complementariedad en la presentación que hizo en 1927 en el congreso Volta, en Como, con el título: "Das Quantenpostulat und die neuere Entwicklung der Atomistik. ${ }^{\text {261 }}$

Aquí nos interesa ante todo la posible ganancia de explicación de la semántica sociológica que podríamos alcanzar con un concepto de este tipo.

36. ¿Qué es entonces el núcleo de una relación semántica complementaria? Primero, se trata con ello siempre de dos circunstancias que se refieren la una a la otra. Segundo, con ello son complementarias cuando son coexistentes: para entender de qué se trata en la primera circunstancia, se debe consultar la segunda circunstancia, pero para entender también esta segunda circunstancia, se debe consultar nuevamente la primera circunstancia. Con otras palabras, se deben relacionar ambas circunstancias entre sí, y permitir que se expliquen mutuamente. Tercero, las circunstancias se excluyen en el sentido que dos algos que pertenecen juntos, no se pueden presentar juntos. Por lo tanto, no se puede decidir o disponer de ambas circunstancias simultáneamente.

Complementariedad significa por lo tanto: "Dos afirmaciones se llaman complementarias cuando no pueden ser decididas simultáneamente. ${ }^{265}$ Aqquí seguimos a C.F.v. Weizsäcker.

${ }^{263}$ Weizsäcker, C.F.v., 1976b, p. 281. tación 1.

264 Véase acerca de este supuesto Weizsäcker, C.F.v., 1976n, p. 281, ano-

${ }^{265}$ Weizsäcker, C.F.v., 1976b, p. 311. 
Una característica importante de los hechos complementarios está dada en la circunstancia de su ceguera inberente: una perspectiva determinada impide a otra perspectiva (determinada) que está dispuesta complementariamente, mirar simultáneamente también en esta otra dirección. Ahora bien, este impedimento no es ninguna ceguera casual, sino que está fundamentada en el asunto mismo, entonces pues, es una ceguera inmanente.

Con el término de la complementariedad se designan situaciones "[...] en donde una determinada perspectiva nos impide mirar hacia otra determinada dirección visual simultáneamente, ciertamente no debido al azar, sino por el ser intrínseco de la cuestión. [...] bajo este aspecto, el nombre de la complementariedad sí resultaria apropiado para una categoría extensiva". ${ }^{266}$ Exactamente eso intentamos también, relacionando el concepto de la complementariedad con el concepto de la teoría de las distinciones de manera sustancial en cuanto al objeto.

La ceguera es una ceguera necesaria y por ello condición de la constitución de la relación complementaria entre ambos hechos coexistentes.

37. Con referencia a las distinciones "diferencia" y "diferenciación" resulta la complementariedad en el siguiente sentido: primero, la constitución de una "diferencia" es posible solamente sobre la base de una "diferenciación" asimétrica, la cual ya ha seleccionado ope-

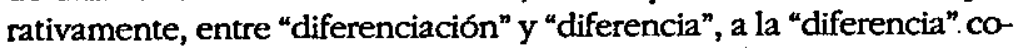
mo el lado a elegir. Segundo, la constitución de la "diferenciación" es posible solamente sobre la base de una "diferencia" simétrica, la cual aún no ha escogido entre el lado "diferencia" y el lado "diferenciación". La "diferencia" simétrica es por ello la condición de la posibilidad de constitución de la "diferencia" simétrica, y la "diferenciación" ${ }^{n}$ asimétrica es la condición de la posibilidad de constitución de la "diferencia" simétrica. Con esto se cumple la primera condición de la complementariedad: ambos hechos son coexistentes entre sí y esto significa que se hacen posibles muiuamente y sólo mutuamente.

${ }^{266}$ Ibid., p. 331. 
38. Una diferencia simétrica es una distinción neutra de dos lados aúnno-seleccionada, pero una diferenciación es una distinción partidaria unilateral ya-seleccionada Una de las distinciones posee una forma seleccionable, la otra distinción es una forma no-seleccionable. En el aspecto de la dimensión social, ambas distinciones son, por así decirlo, su parte contraria correspondiente y se excluyen una a la otra. Con ello está dada ahora la segunda condición de la complementariedad: porque se excluyen mutuamente, no pueden presentarse simultáneamente, o sea conjuntamente, no se puede decidir o disponer de ellas simultáneamente. No obstante, se presuponen mutuamente. El hacerse manifiesto de una distinción presupone el hacerse latente de la otra y viceversa.

39. Dado que por un lado, ambas distinciones no pueden presentarse simultáneamente, que por el otro lado se condicionan mutuamente y con ello se presuponen mutuamente, surge una ceguera inherente que se puede justificar con su constitución. Con ello está cumplida la tercera condición de la complementariedad. Resumiendo, se puede decir que el contexto de constitución mutua y de exclusión mutua forma el núcleo de un hecho complementario. Ahora bien, precisamente esta relación de condición constitutiva mutua y exclusión mutua es también la caracteristica central del entrelazamiento

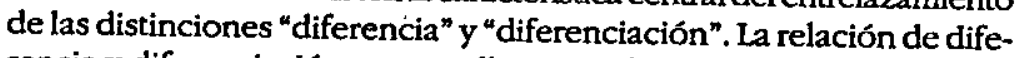
rencia y diferenciación es, por ello, una relación complementaria en el sentido clásico.

40. Si transferimos este resultado al nivel de la teoría de la sociedad, e interpretamos a la diferencia como COMUNCACIÓN en el sentido de una oferta de selección, y a la diferenciación como ACción en el sentido de una determinación de la selección, entonces se puede formular: primero, la COMUNICACION y la ACCION se constituryen mutuamente, posibilitándose mutuamente (no. 37); segundo, la ACCrón y la COMUNICACIÓN como determinación de la selección y oferta de selección se excluyen mutuamente (no. 38); tercero, la ACCION y la coMUNICACION no pueden presentarse simultáneamente; sobre ambas formas no se puede al mismo tiempo: a) decidir distintivamente, y b) disponer de ellas como operaciones (no. 39). Resultado: o se actúa o se comunica. 


\section{I. ¿QUE ES COMPLEJIDAD?}

La cantidad de simbolos en la secuencia que denominamos gen, rara vez sobrepasa la magnitud de mil. Tan sólo con una longitud del gen de mil símbolos - a cada una de las posiclones está adjudicado uno de los cuatro simbolos $A, T, G y$ $C$ - existen cuatro elevado a 1000 disposiciones alternativas de la misma longitud. Este número es inimaginable. Nada en ello cambia tampococuando lo traducimas al sistema decimal en donde es aproximadamente diez elevado a 600 . Simplemente no poseemos ninguna capacidad de imaginación para nümeros tan grandes... En comparación con la fisica: los fisicos boy en dia son capaces de calcular el contenido total de materia del universo. Este seria el equivalente a diez elevado a 74 de tales genes. La edad del universo ni siquiera suma diez elevadó a 18 segundos.

Manfred Eigen'

\section{SIMPLE Y COMPLEJO}

1. Es de suponer que complejidad no es ningún concepto específicamente nuevo, ${ }^{2}$ aunque se debe constatar que su semántica de

'Eigen, 1989, pp. 153-154.

2 "El concepto de la complejidad no ha sido inventado en tiempos recientes. No es ningún concepto específicamente moderno." (Luhmann, 1990a, pp. 59 y ss). 
trasfondo ${ }^{3}$ ha cambiado esencialmente, y esto quiere decir que su significado semántico especial sí es, en ese aspecto, de origen relativamente moderno. Se puede leer cuantitativamente la modernidad de la semántica de la complejidad en el hecho de que el concepto está en auge actualmente, ${ }^{4}$ lo que significa que goza de una amplia utilización dentro de diferentes disciplinas científicas. Sobre todo en el sistema de la ciencia es utilizado tan extensamente que se podría opinar que sirve como indicador para el proceso integrativo de las más diversas tradiciones y disciplinas científicas. De hecho, la tradicional controversia entre una tradición ideográfica de las ciencias filosóficas y una tradición mnomotética (W. Windelband) de las ciencias naturales ya no parece apropiada, por lo menos no con la severidad actual, frente al trasfondo del concepto de la complejidad. Si el problema más afamado del sistema de las ciencias, es decir, el problema de la complejidad, es comprendido como "obligación a la selección", entonces se puede decir que: la categoría "materia" sirve para la solución dèl inextricable problema de la complejidad en el ámbito de las ciencias orientadas hacia la física, la categoría "vida" logra algo igual en el ámbito de las materias orientadas hacia las ciencias biológicas, y la categoría "sentido" (no del sentido corporal) logra lo equivalente dentro de las disciplinas orientadas hacia las ciencias sociales y filosóficas. Valdría la pena reflexionar si la categoría "ser humano" tiene que tratar con el mismo problema de la

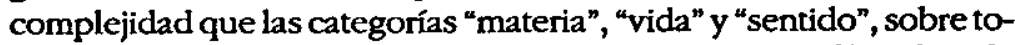
do con referencia a las disciplinas orientadas hacia la filosofia y la antropologia. Niklas Luhmann expresa pensamientos similares cuando opina que "The core problem of the hard sciences is the complexity of the complexity and that of the soft sciences is the meaning of the meaning. ${ }^{n 5}$ El problema de la complejidad de la complejidad y el del sentido del sentido están naturalmente relacionados en forma estrecha. Sentido se refiere a la categoría de la observación, complejidad a la categoría de la operación. Regresaremos a esto.

3 Con "semántica de trasfondo de la complejidad" nos referimos al campo conceptual histórico de la complejidad.

4 Como representativa de esta afirmación, servirá la indicación de la colección de ensayos: Tbe Science and Praxis of Complexity. Contributions to the Symposium Held at Mont Pellier, Francia, 9-11, mayo, 1984, también citado como The Science and Praxis..., 1985.

'Luhmann, 1985i, p. 99. 
2. Actualmente no se puede mencionar casi ninguna disciplina que no haga uso de la complejidad del concepto de complejidad, ${ }^{6}$ con lo cual ya se empieza a hablar de una new science of complexity. ${ }^{7}$ Se está abriendo paso una transferencia del interés científico y con ello una mutation of knowledge del determinismo hacia el indeterminismo, de la estructura hacia el proceso, de lo simple hacia lo complejo, de la ontología hacia la reflexión, del ser al llegar a ser, ${ }^{8}$ de la identidad hacia la diferencia.

En este contexto se puede hablar de un "silencioso" cambio de paradigma dentro del sistema de las ciencias, lo cual, sin embargo, no significa que no ocurra "revolucionariamente" en el sentido de Kuhn. El "nuevo" vocabulario de las ciencias es ahora: inestabilidad, oportunidad, posibilidad, novedad, creatividad, espontaneidad, paradoja, improbabilidad; pero también: repetición, regularidad, redundancia. Ilya Prigogine habla en este contexto de una new scientific rationality y de opening up a new theoretical space.?

En este contexto habrá que aclarar, entonces, en qué consiste realmente la modernidad del moderno movimiento de las ciencias. EI supuesto de la teoría de los sistemas sociales (TsS) dice:

"Su pensamiento básico [de la modernidad de la ciencia RJ] es el de una conexion entre el diferenciamiento funcional del sistema social y la autocomprensión constructivista de la ciencia. ${ }^{10}$ Estamos de acuerdo plenamente con la autocomprensión constructivista de la ciencia, pero no con la suposición de un diferenciamiento funcional, dado que hoy vemos el problema de que la "supervivencia" de los sistemas de sentido que procesan funcionalmente, depende en gran medida de si desarrollan una forma de reflextón que haga referencia a las consecuencias de su estatus autónomo-funcional. Este hacerse reflexivo de los

6. Así, por ejemplo Edward W. Ploman: "Complexity itself is a somewhat dauting, admittedly exciting and complex subject" $y$ "The subject of complexity is itself a prime example of complexity which inevitably, it seems, involves epistemological issues, both complicated and complex", en: Ploman, 1985, pp. 7 y 11 y Prigogine, 1985, pp. 107-118.

${ }^{7}$ Mbid., 1985, p. 7.

Así, el título alemán de la conocida obra de Ilya Prigogine cuyo subtítulo "Tiempo y complejidad en las ciencias naturales" hace clara la moderna tendencia del sistema de la ciencia hacia una temporalización y temporización de su circunstancia.

9 Ambas en Ploman, 1985, p. 8.

${ }^{10}$ Luhmann, 1990, p. 704 . 
sistemas de sentido funcionales se puede observar ante todo en los sistemas ciencia, política y economía. Sea dicho de paso" que detrás de ello se esconde el clásico problema sociológico de los efectos no intencionales del actuar humano. Sea dicho también que el análisis funcional de Niklas Luhmann está relacionado esencialmente con aquello que en cierto modo integra el problema de las consecuencias del actuar no intencional, y que a la vez lo extingue, o vive de este extinguimiento: "El análisis mismo se concentra en la exploración de las causas posibles bajo el punto de vista directriz de un efecto, o en la exploración de los efectos bajo el punto de vista de una causa. Realizar ambas cosas simultáneamente es imposible, ya que cada análisis funcionalista presupone un punto de vista referencial seleccionado, el cual no puede ser modificado sin que los resultados se desfasen. Entre causa y efecto existe, en este sentido, una relación de indeterminación. ${ }^{n 12} \mathrm{Y}$ luego: "Con ello, la apertura de una posibilidad de comparación descansa en el hecho de que en el área de los efectos es escogido uno particular como punto de referencia y es abstraído... No se excluyen los rasgos característicos individuales de la parte individual sino los efectos secundarios [R]]. Si se quisieran considerar, asimismo, todos los efectos secundarios, entonces ya no existiría ninguna elección entre las causas; se entregarian a la observacion completamente individualizadas y, por ello, serían incomparables. Porque las causas particulares frecuentemente tienen un efecto en común, pero nunca todos los efectos... En otras palabras: un efecto obtiene aquella ambigüedad que es esencial para un punto de vista de referencia funcional, cuando se prescinde de los efectos secundarios de sus causas. Debido a ello aparecen varias posibilidades del efecto llas cuales se distinguirían solamente por sus efectos secundarios] como funcionalmente equivalentes. ${ }^{n 13}$ En este aspecto se puede considerar al análisis funcional como una forma clásica de reducción de la complejidad, la cual puede ver su objeto de investigación solamente bajo la condición previa de una reducción de este tipo. En este sentido, un análisis funcional de esta indole vive de la invisibilización del problema de los efectos secundarios. Aquí, la teoría del actuar comunicativo (TkH) trata, por asi decirlo, de conectar ambas líneas estructurando el problema del orden social -interpretado como el problema de la coordinación de las acciones- en dos subproblemas: por un lado se trata de problemas de dirección que son resueltos por los así llamados medios, es decir, se trata del subproblema de la integración del sistema. Por otra parte, se trata de los problemas de comunicación que pueden ser

"Jokisch, 1981.

${ }^{12}$ Luhmann, 1974a, p. 17.

13 Idem. 
llevados hacia una solución sólo en el contexto de la intersubjetividad producida linguísticamente, es decir, del subproblema de la integración social. En el contexto del tratamiento de un concepto de la crisis, la TkH formula: "Un concepto de crisis científicamente adecuado debe abarcar, asimismo, el contexto dè la integración social y del sistema. Ambas expresiones 'integración social' e 'integración de sistema' provienen de diversas tradiciones teóricas. Hablamos de integración social en relación con los sistemas institucionales, en los cuales se encuentran socializados sujetos parlantes y actuantes; los sistemas sociales aparecen aquí bajo el aspecto de un mundo vivencial que se encuentra estructurado simbólicamente. Hablamos de integración de sistema en relación con la producción específica de control de un sistema autorregulado; aquí los sistemas sociales aparecen bajo el aspecto de la capacidad de conservar sus limites y su existencia por medio del dominio de la complejidad de un entorno inestable. Ambos paradigmas, mundo vivencial y sistema, tienen un derecho; un problema representa su conexion. Bajo el aspecto de mundo vivencial tematizamos en una sociedad las estructuras normativas [valores e instituciones]... Bajo el aspecto sistema, tematizamos en una sociedad los mecanismos del control y la ampliación del espacio de acción de la contingencia..."."14 Aquí se encuentra también el punto de conexión para el tratamiento del problema del orden social desde la perspectiva de la TkH, la cual considera este problema como el "problema de la coordinación de las acciones". La distinción de integración del sistema e integración social es particularmente relevante, con lo cual la TkH introduce en este contexto la distinción de sistema y mundo vivencial (figura 62).

\begin{tabular}{|l|l|}
\hline Integración del sistema $\longrightarrow$ sistema \\
Integración social $\longrightarrow$ mundo vivencial
\end{tabular}

Nosotros suponemos que la modernidad de las ciencias modernas no se revela solamente en una transición del diferenciamiento del sistema estratificatorio hacia uno funcional, lo que también implica el diferenciamiento de diversas formas de cogniciones; sino que se manifiesta más radical y profundamente como transición de un diferenciamiento del sistema funcional hacia uno reflexivo. Este desarrollo está soldado esencialmente con la forma de diferenciamiento domi-

${ }^{14}$ Habermas, 1979, pp. 13 y ss.

15 Ver más detalladamente capítulo $\mathrm{V}$ referente a arquitectura de teorías. 
nante de las sociedades modernas, con lo cual todos los indicios señalan que hoy en día se trata de una transición de la función hacia la reflexión (figura 63).

Formas de diferenciación de la sociedad en su conjunto:

Segmentaridad

Estratificación (o jerarquización)

Funcionalidad

Reflexividad

Sea puesto de relieve que no es posible la formulación de una teoría de la evolución sociocultural sin el preestablecimiento de una teoría del diferenciamiento de la sociedad. Se necesitan diferentes tipos sociales de diferenciamiento para poder indicar una "dirección evolutiva".

3. Pero regresemos al concepto de la complejidad. Pensamos que la teoría del diferenciamiento que se menciona en este contexto, no debe observar solamente la segmentaridad, estratificación y funcionalidad como formas del diferenciamiento social tal como lo suponen normalmente la TaH (Parsons), la TsS (Luhmann) y la TkH (Habermas). En este contexto es importante la observación de la reflexividad como forma de diferenciamiento. Somos de la opinión de que no solamente el derecho como sistema diferenciado desarrolla funcionalmente reflexividad, como opinan Helmut Willke y Günther Teubner, ${ }^{16}$ sino también sistemas parciales tales como la economía, ciencia, educación, cultura, tecnología, etc. El problema central es de hecho el "... comportamiento contraintuitivo de los sistemas complejos" ${ }^{\prime 1}{ }^{17}$ Reflexión sistémica significa en este contexto: a... la capacidad de los sistemas parciales de institucionalizar mecanismos por medio de los cuales pueden tematizar su propia identidad y ajustarla de tal manera que en su entorno relevante actúen otros sistemas parciales en relaciones de interdependencia; o sea que cada sistema parcial de un sistema en red debe representar, para los

${ }^{16}$ Teubner/Wilke, 1984, p. 5.

${ }^{17}$ Idem. 
otros sistemas parciales correspondientes, un entorno utilizable".18 Somos de la opinión de que no se trata solamente, como con Willke y Teubner plantean, de "derecho reflexivo", sino también de "ciencia reflexiva", "economía reflexiva" o "política reflexiva". En este contexto se perfila una forma de diferenciamiento de la sociedad en su conjunto que se puede denominar como diferenciamiento reflexivo.

4. Los inicios del moderno concepto de complejidad dentro del sistema de la ciencia se pueden encontrar en el artículo "Science and Complexity" de Warren Weaver que se publica en 1947 en el American Scientist; en la teoría de la información de Claude Shannon que se presenta un año después; y por último en la "Einführung in die Kybernetik" de Norbert Wiener, que se publica también en 1948. ${ }^{19}$ A principios de los años cincuenta se reúnen en los seminarios Macy de Norbert Wiener, entre otros, el matemático John von Neumann, el neurofisiólogo Warren Mc Culloch, los antropólogos Gregory Bateson y Margaret Mead y por último Heinz von Foerster, quien está considerado comó uno de los pioneros en el ámbito de la cibernética, de la teoría de la información y de la teoría de la auto-organización.

Warren McCulloch se puede considerar como uno de los pioneros genealógicos del concepto de la autopoiesis. Junto con J.Y. Lettwin, H.R. Maturana y W.H. Pitts analizaron los procesos que ocurren en el ojo de la rana con su percepción visual (What the frog's eye tells the frog's brain), y comprobaron que no existe en absoluto el principio de una reproducción punto por punto de la imagen que se proyecta en la retina. El ojo de la rana posee cinco clases de avisos, y la rana puede "ver" solamente dentro de un nivel de abstracción de este tipo: "The operations thus have much more the flavor of perception than of sensation if that distinction has any meaning now. That is to say that the language in which they are best decribed is the language of complex abstractions from the visual image." ${ }^{20}$

Acerca de H. von Foerster escribe Wolfram K. Köck:

El legendario Biological Computer Laboratory (BCL) de la University of Illinois en Urbana perduró hasta el año de 1976. Heinz von Foerster,

${ }^{38}$ Ibid., p. 6.

19 Véase Ploman, 1985, pp. 13-14.

${ }^{20}$ Lettwin, Maturana, McCulloch, Pitts, 1959, p. 1959. 
mago, investigador, técnico y bomme du monde fue director durante dos décadas, el infatigable spiritus rector de un equipo internacional -que en retrospectiva parece fantástico- de vanguardistas artísticos y cientificos de los cuales se mencionan aqui solamente a $\mathrm{W}$. Ross Ashby, Gotthard Günther, Lars Löfgren, Herbert Brün, Gordon Pask y Humberto R. Maturana. ${ }^{21}$

Sobre todo su principio Order from noise se convierte en una característica marcada de la auto-organización. ${ }^{22}$ De estos diferentes esfuerzos surgen teorías sintéticas tales como las tesis de la teoría de los sistemas de Ludwig von Bertalanffy y Kenneth Boulding, ${ }^{23}$ pero también la teoría de los sistemas dinámicos de Jay Forrester, a quien se presta atención internacionalmente por su actividad en el Club of Rome. ${ }^{24}$ Estos esfuerzos científicos fecundan de manera notoria sobre todo a las ciencias computacionales (computer science) y a su aplicación; esto, por una parte, especialmente en el área de modelado de sistemas complejos y, por la otra, en el área del análisis de los fenómenos con estructura de auto-organización. En el área del sistema de expertos (Knowledge-based Systems) de la teoría del aprendizaje y generalmente en las ciencias de la cognición ${ }^{25}$ se logran progresos notables y profundos, ante todo sobre la base del concepto de la auto-organización. La revolución antes descrita probablemente no hubiera sido posible en la forma actual, sin la teoría de la información de Shannon; ${ }^{26}$ quizá porque es más accesible para casi cualquiera, en la telecomunicación y los nuevos medios electrónicos.

5. El concepto de la complejidad juega un papel eminentemente importante, si no es que central, en algunas disciplinas del sistema

${ }^{21}$ Foerster, H.v., 1985, p. X.

${ }^{23}$ Aquí se trata de la idea central de Foerster acerca de un orden "a partir del caos", un "orden a partir de la perturbación" u order from noise. Véase por ejemplo, Foerster, H.v., 1985, pp. 125 y ss. Von Foerster explica su idea con el pequeño escrito de Erwing Schrödinger “QQué es la vida?", del año 1947. (lbid., p. 124).

${ }^{23}$ Por ejemplo Bertalanffy, 1968 y Boulding, 1985.

${ }^{24}$ Acerca de ello, las explicaciones en Ploman, 1985, p. 14.

2s Como una introducción informativa a esta temática, véase Francisco J. Varela, Kognitionswissenschft-Kognitionstechnik. Eine Skizze aktueller Perspektiven, 1990, y también Klir, 1985 y Atland, 1985.

${ }^{26}$ Ploman, 1985, pp. 14-15. 
de la ciencia. Sin embargo, la influencia de un concepto de esta naturaleza ya casi no se puede demostrar con los medios de denominación de las disciplinas tradicionales. Aquí, uno se ve obligado a referirse a determinados clusters de disciplinas, a "haces" de disciplinas.

Como "haces" de disciplinas denominamos aquello que Siegfried J. Schmidt formula acerca de las ciencias de la cognición, de la siguiente manera:

\begin{abstract}
A pesar de su productividad teórica y eficiencia práctica... las ciencias de la cognición y las técnicas de la cognición no son, hasta hoy en día, ninguna ciencia natural madura establecida con una comunidad homogénea de investigadores, sino más bien un campo de investigación multidisciplinario dinámico, en el cual se traslapan y se afectan mutuamente las teorías disciplinarias. ${ }^{77}$ La pregunta es, si estos "haces" de disciplinas se pueden integrar del todo a un grupo homogéneo. En caso negativo, se trataria entonces de un desarrollo completamente nuevo de la disciplina, en el cual el "modo de conexión flojo" entre las disciplinas establecidas sería su base emergente.
\end{abstract}

El cluster orientado biológicamente que reune en si disciplinas y áreas parciales de disciplinas como la biología, microbiología, teoría de la evolución biológica, análisis de la auto-organización biológica, neurofisiología y medicina, muestra la utilización central del concepto de la complejidad. Habría que mencionar, en este contexto, a científicos tales como Ilya Prigogine, Humberto H. Maturana, Francisco J. Varela, François Jacob, Henri Atlan, Henri Laborit, Karl H. Pribran, Konrad Lorenz y Jean Dausset. El cluster referido a la cognictón (ciencias de la cognición) junta, entre otros, a la neurobiología, investigación del cerebro, lingüística y psicología. Fundamental para ello es la obra de Jean Piaget, la cual se continúa desarrollando sobre todo en los trabajos de Ernst von Glasersfeld en relación con el tema de la complejidad. ${ }^{28}$ Pero también habría que mencionar a Noam Chomsky, Daniel C. Dennet, Douglas R. Hofstadter, John R. Searle, Terry Winograd y Fernando Flores. En el cluster de la ecología y del medio ambiente se encuentran disciplinas tales como la geografia moderna (time geography approach) junto con planeamiento sistémico regional y urbano, arquitectura y diseño. Habria que mencio-

27 Varela, 1990, p. 7.

${ }^{28}$ Más literatura en este contexto en Varela, 1990. 
nar a científicos como Torsten Hägerstrand, Tommy Carlstein, Peter Gould y Graham P. Chapman. ${ }^{29}$ En cuanto al cluster de las ciencias sociales y epistemológicas, hay que mencionar a disciplinas tales como la sociología, psicología, antropología, ciencias culturales ( $c u l$ tural studies), economía, filosofia, teoría de la ciencia y sociología del conocimiento, las cuales lo llenan en cuanto a la categoría de la complejidad. A estas ciencias se vinculan nombres como Gregory Bateson, Margaret Mead, Edgar Morin, Cornelius Castoriadis, Jean Pierre Dupuy, Michel Crozier, Magoroh Maruyana, Yves Barel, Herbert Simon, Orio Giarini, Rene Passet, Fritz Machlup, Michel Serres y Niklas Luhmann. ${ }^{30}$ El cluster físico comprende áreas como la de la teoría de la relatividad, la física cuántica, la termodinámica, la entropía, pero también determinadas rúbricas de la cosmología y la astronomía. Los nombres de David Bohm, Costa de Beauregard, Fred Hoyle, Jayant Naarikar, Freeman Dyson, Rolan Aktins, Carl Friederich von Weizsäcker y Stephen W. Hawking, representan la asociación de las disciplinas orientadas hacia la fisica. ${ }^{31}$

6. Las exposiciones hechas antes, nombran disciplinas y clusters de disciplinas conjuntamente con algunos representantes de las áreas correspondientes, dentro de las cuales el concepto de la complejidad juega un papel desde fundamental hasta determinante. No por el mero hecho de mencionar a tres o cuatro premios Nobel que han logrado aportaciones decisivas en el concepto de la complejidad (y que en parte han recibido el premio en estrecha relación con su seguimiento), tales como Manfred Eigen, Ilya Prigogine o Herbert Simon, se ha distinguido algo acerca del concepto en cuanto al contenido. Sobre todo, debería haberse aclarado qué posición privilegiada le corresponde al concepto de la complejidad dentro de determinados clusters de disciplinas, especialmente porque su papel generalmente es subestimado por los sociólogos dentro y fuera de las ciencias so-

${ }^{29}$ Véase las aportaciones de Chapman, 1985 y Hägerstrand, 1985.

${ }^{30}$ Véase Ploman, 1985 y la síntesis instructiva en Varela, 1990, p. 119.

${ }^{32}$ Este desarrollo se documenta generalmente con la síntesis en Ploman, 1985, p. 16, pero también con las aportaciones del tomo de la colección The Science and Praxis of Complexity, sobre todo las aportaciones de Boulding, 1985; Klir, 1985; Luhmann, 1985; Prigogine, 1985; Dupuy, 1985; Atlan, 1985 y Zeleny, 1985. 
ciales. ${ }^{32}$ A pesar de esta relativa difusión del concepto de la complejidad, Edgar Morin, por ejemplo, es de la opinión de que el problema de la complejidad dentro del sistema de las ciencias aún no ha sido considerado con la debida atención que merece. Así, debates epistemológicos de amplia resonancia, tales como el que tuvo lugar recientemente entre Karl R. Popper, Thomas S. Kuhn, Imre Lakatos, Paul K. Feyerabend, John Watkins, Norwood R. Hanson y Gerald Holton acerca del problema de la racionalidad dentro del sistema de las ciencias, de hecho ni siquiera mencionan el concepto de la complejidad. ${ }^{33}$

7. ¿Qué es pues, tan relevante en el concepto de la complejidad, que merece un tratamiento tan detallado? En la "teoria de los sistemas sociales" (TgS) representamos la concepción de que sin la integración del concepto de la complejidad al área de la "teoria sociologica", no puede surgir comprensión suficiente para los problemas que habría que tratar dentro del marco de una teoria de la sociedad. Sin duda, para ello es necesario perfilar más claramente aquello que se pudiera entender como complejidad. Para penetrar más profundamente, debemos observar detalladamente, qué es lo que sucede cuando utilizamos la semántica de la complejidad. Para este fin, introducimos el concepto de la observación: si queremos generar información sensata en este contexto por medio de la operación de la observación, entonces estamos obligados a realizar una distinción. La información -es posible según un conocido dictum de Gregory Bateson- solamente sobre la base de una distinción que genere, por su parte, una distinción (obsérvese: sólo la segunda distinción genera información). La teoría de la información aquí representada -apoyándonos en Bateson- dice: no puede haber ninguna información sin una distinción generadora de distinciones. Dado que ca-

${ }^{32}$ Además de las obras de Niklas Luhmann, no conocemos en qué otra parte, dentro del área de la "teoría sociologica", ocuparía el concepto de la complejidad una posición tan central.

${ }^{33}$ The "problem of complexity is still considered to be of marginal importance in scientific and epistemological thought as well as in philosophical thought: When you examine the major discussions on epistemology by Popper, Kuhn, Lakatos, Feyerabend, Hanson, Holton, etc. there is talk of rationality, of scientificity, of non-scientificity, but no mention of complexity". (Morin, 1985, p. 62). 
da distinción tiene dos lados, esta clase de distinción tiene efecto solamente, y esto quiere decir informativamente, cuando se denomina el uno o el otro lado, pero no ninguno de los dos y menos ambos a la vez.

Lo cual es enteramente posible con la consecuencia de que se arruina el concepto, ya que por medio de ello no puede tener lugar ninguna operación de conexión. El concepto se vuelve "no informativo". Se debe poner aquí de relieve, que una denominación (o una referencia, o una "decisión") sigue como operación, en el marco de una diferenciación, (y/o diferencia) a una "lógica de la acción", la cual simultáneamente se puede considerar como la justificación de la bivalencia de la lógica: "La manera de actuar tiene un principio de todo o nada: puede efectuarse en una situación dada o no efectuarse, pero no ambas cosas simultáneamente [el teorema de la contradicción para acciones], ni tampoco ninguna de los dos [teorema del tercero excluido para acciones]. ${ }^{31}$ Naturalemente, la bivalencia de las frases afirmativas $y$ de las acciones es un conocimiento de la reflexión. En la afirmación "simple" o acción simplemente "decimos" o "hacemos" algo. La observación significativa de la circunstancia de que existe una correspondencia plausible entre una "lógica de lo social" (acciones) y una "socialidad de lo logico" (conocimientos), la hemos tratado más de cerca en el capítulo I sobre la forma.

8. Con la selección de una distinción comienza todo, aun más, solamente puede comenzar así.

Esto está dicho cum grano salis. Aquí nos adherimos a George Spencer Brown quien opina:

... A universe comes into being when space is severed or taken apart... By tracing the way we represent such a severance, we can begin to reconstruct, with an accuracy and coverage that appear almost uncanny, the basic forms underlying linguistic, mathematical, physical, and biological science, and can begin to see how familiar laws of our own experience follow inexorably from the original act of severance..$^{35}$

Y es el lógico y matemático George Spencer Brown, quien, debido a la operación generadora de la información de diferenciación y denominación exige consecuentemente: Draw a distinction!

34 Weizsäcker, C.F.v., 1977, p. 302.

${ }^{35}$ Spencer Brown, 1969, p. V. 
We take as given the idea of distinction and the idea of indication, and that we cannot make an indication without drawing a distinction. We take therfore, the form of distinction for the form. ${ }^{36}$ Detrás de estas pocas frases se esconde todo un universo de posibilidades. Con ello queda claro que la forma es algo que tiene que ver con las diferencias y las diferenciaciones. Recordemos que Spencer Brown (y con él la TsS), presuponen como dado el concepto de la diferenciacion (idea of distinction) y el de la denominación (idea of indication), conceptos que nosotros desenvolvemos explícitamente en el capítulo I.

Toda información depende, en última instancia, de cuál distinción es seleccionada. Con ello se puede decir: "dime qué distinción escoges, $\mathrm{y}$ te diré qué información obtienes a cambio". Es un hecho que las diferenciaciones y las diferencias son necesarias para generar información. Pero, ¿quién hace cuáles diferenciaciones? ¿Quién es aquí el que se refiere, el que denomina, el que decide? Esto se puede averiguar solamente a través de una observación de la praxis en el ámbito de la pragmática de las distinciones.

Con ello, una parte del problema del comienzo de un comienzo está, por así decirlo, "resuelto"; dado que cualquier comienzo empieza, dentro de este contexto, con la observación de una observación; con lo cual el comienzo consiste en observar cómo otro observador procesa con su actividad de observación. Con referencia a las diferenciaciones la TsS formula: "Las diferenciaciones se hacen arbitrariamente. Pero esto no significa otra cosa sino que ellas no están dadas en forma independiente de la observación. No resultan del hecho mismo [...] ellas son construcciones de una realidad que se podria construir también de otra manera partiendo de diferenciaciones completamente distintas. Esto no excluye el que su utilización [como lo puede ver un observador] esté motivada y sea justificable....". ${ }^{37}$

Recordamos la definición del concepto de observación como el manejo de una diferencia ante el trasfondo de una diferenciactón (de un "interés", de un "motivo"), para generar información.

Niklas Luhmann define a la observación sobre la base de las Laus of Form de George Spencer Brown, comoel manejo de una diferenciaciónya-denominada, con lo cual comprende a la denominación y a la dife-

${ }^{36}$ Ibid., p. 1.

${ }^{37}$ Luhmann, 1988a, p. 49. 
renciación solamente como dos momentos de una operación única. Consideramos una construcción semejante como problemática, ya que por medio de ello no está dada en absoluto una posibilidad para la verdadera denominación, para la referencia o la "decisión" como operación relativamente autónoma. Pero si no se posee ninguna semántica de decisión (interpretada operativamente o adjudicada), entonces no se puede explicar plausiblemente cómo se llega a las acciones (construidas semánticamente de cualquier manera). Una problemática de consecuencias realmente fuertes para la teoría de la sociedad, que ha ubicado a la categoría de la acción como una categoría esencial dentro de su arquitectura teórica (figura 64).

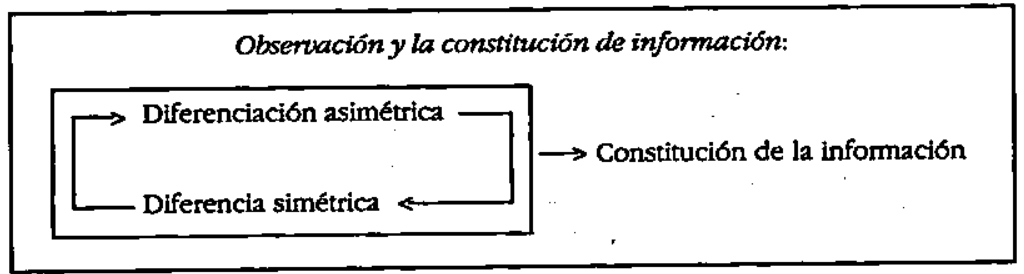

Por lo tanto, nuestra indicación en este contexto no es: "haz una diferenciación", como lo propone Spencer Brown sino: "observa al observador, que utiliza la distinción en cuestión" (este observador puede, dependiendo del interés, ser "una acción", "otra observación", "un concepto", "una teoria": o "toda una tradición de la teoria"). Transferido al problema de la complejidad esto significa: una observación para la utilización del concepto de la complejidad como distinción se trata esencialmente de la utlización de la distinción de lo complejo y lo simple, aunque el contraconcepto "simple" no aparezca en el primer plano, lo que se comprende puesto que se trata de la circunstancia de la "complejidad". Pero tanto la historia del concepto de la complejidad (ver más adelante), como también la teoría de la información aquí representada (la información se genera solamente por medio de la utilización de las distinciones), nos obligan a la suposición de una distinción entre "simple" y "complejo", lo que atañe a la diferenciación básica de la circunstancia "complejidad" ${ }^{38}$ Nosotros

${ }^{36}$ Niklas Luhmann rechaza esta distinción, lo cual sentimos y consideramos como una evaluación errónea del modo de operación de la distinción complejo/simple. Aun más, el concepto de la autopoiesis es únicamente canjeable si el sistema en cuestión trata sus "elementos últimos" como "simples elementos", como "fundamentales" (Glanville). (Luhmann, 1990a, p. 59). 
opinamos entonces que la distinción de complejo (variado) y simple (elemental, rudimentario), ofrece una buena posibilidad de partida para una determinación más exacta de la complejidad; ya que con ella se puede distinguir lo complejo en una forma primeramente simple (sic) y manejable, de acuerdo con una larga tradición semántica.

De esta manera, aplicámos el concepto de la complejidad a sí mismo para hacerlo accesible a la investigación. Pero para ello se debe observar lo siguiente: por un lado, simplificamos el concepto de la complejidad para hacerlo accesible operativamente, sin embargo, por el otro lado, aumentamos su complejidad (sic) a través de la introducción de un contraconcepto. Esto significa que reducimos y aumentamos simultáneamente complejidad al concepto para fines de investigación.

Ahora queremos ver qué tan lejos conduce esta distinción específica y qué podemos producir con ello en cuanto a información al observarla en su utilización, pero también -y precisamente por medio de ello- qué información queda fuera de consideración.

La operación de una diferencia diferenciadora representa la condición de la posibilidad de información, pero simultáneamente, y precisamente a través de ello, la condición de su imposibilidad; dado que debe cerrar, por medio de la explotación de un universo determinado, a los otros universos posibles. Quien explota al mundo con la ayuda de la distinción de hombre/mujer, puede ver mucho a ese respecto. Pero simultáneamente debe colocar atrás, dejar sin consideración, otros accesos posibles al mundo tales como viejo/joven, bello/feo o afectación/indiferencia, como distinciones principales. El proceso de la explotación vía las distinciones, está ligado estrechamente a aquél del cerrar: lo uno es solamente posible a través de lo otro y viceversa (figura 65).

\section{Observación de la complefidad:}

como distinción de lo simple y lo complejo

9. Sólo a mediados de la nueva era se comprendió aristotélicamente a lo simple como "elemental", "fundamental", como la "unidad de algo" más pequeño, indivisible. Con ello la elementaridad de lo simple o rudimentario consiste en su no-divisibilidad, su condición de com- 
pacto, impenetrable y sin transparencia. Lo simple nunca puede convertirse en lo diverso, por lo tanto tampoco volverse transparente. Si fuera transparente, entonces tendría una envoltura, o sea partes, lo cual —observado semánticamente- no puede ser. Precisamente es simple. Solamente así puede formar un componente básico inmanente de algo.

Aristóteles dice:

(2a) de ello se transfiere el nombre elemento también al caso de que algo como pequeño y único sea útil para mucho. Por ello, lo pequeño, simple e indivisible se llama elemento. (b). De ahí resulto entonces, que las cosas más generales se consideren como elementos, dado que cada una de ellas como simple y única, se encuentra en muchos o en la mayoría: por lo cual, según la opinión de algunos, también el uno y el punto son principios. ${ }^{39}$

Desde el punto de vista histórico, la semántica de lo "simple" cambia radicalmente dentro el área de la filosofia, y más tarde dentro de las ciencias naturales modernas. Lo simple, rudimentario o elemental se transforma en lo complejo, variado y polimorfo. La consecuencia es una difuminación de la distinción entre simple/complejo, dado que lo simple ahora también puede ser complejo. Aun veremos cómo la transformación de la semántica de lo simple se convierte en uno de los componentes nucleares de la ciencia moderna. La complejización de lo simple - preferentemente por medio de su temporalización-conduce a un enorme aumento de la diversidad dentro del sistema de las ciencias, con la consecuencia de que se deben introducir técnicas para el procesamiento de la complejidad por medio de la dimensión del tiempo, para manejar esta "marea de información". El dimensionamiento dominante espacial como forma de la limitacionalidad ${ }^{40}$ que los constructos teóricos mostraron antaño (pero en parte aún hoy en día) no puede ya coordinar razonablemente la cantidad de datos que aumenta y se extiende. Las limitaciona-

${ }^{3}$ Aristóteles, Metapbysik, 1014b, p. 5.

${ }^{40}$ Limitacionalidad comprendida en el sentido de una forma por lo menos mínima de la limitación y no arbitrariedad en el área de las afirmaciones, para poder producir un mínimo de información. Consabidamente la "limitación" aparece como una de las doce categorías básicas dentro de la facultad "razón" en la Crítica de la razón pura de Kant. Al lado de la "realidad" y la "negación" pertenece al tipo de categoría "calidad". 
lidades jerấrquicas ${ }^{41}$ determinadas espacialmente, que se encuentran naturalmente en una relación "adecuada" ${ }^{\text {42 }}$ con la forma de diferenciación de SOCIEDAD, pierden significado paulatinamente, lo que tiene efectos sobre la arquitectura de las teorías concebidas universalistamente. ${ }^{13}$

10. Se pone de relieve que, obviamente, las cuatro dimensiones del sentido de la SOCIEDAD, o sea la dimensión espacial, la temporal, la objetiva y la social, tienen efecto siempre y en todas partes. Si partimos del hecho de que la dimensión espacial ha determinado la limitacionalidad de la ciencia en el área de la teoría, entonces queremos expresar que esta dimensión se debe considerar como la dimensión dominante anteriormente y no que solamente se procesa el sentido espacial. Dado que el espacio es concebible únicamente como limitado (pero como absoluto infinito, tal como lo enseña la fisica reciente en el área de la teoría de la relatividad), el tiempo no puede ser infinito en una época en la cual la espacialidad predomina como dimensión dominante. Por lo tanto, el tiempo es determinado en la Edad Media a través de la teleología: la sociédad de la vieja Europa limita la dimensión del tiempo por medio de la teleología "[...] contra la posibilidad de pensar como un todo la infinidad temporal del mundo". "Sea permitida la indicación de que Hegel, en su Fenomenologia del espiritu, comienza con cuatro dimensiones del sentido en el tratamiento de la "certeza sensual": "aquí" (espacial), "ahora" (temporal), "esto" (objetivo) y "yo" (social). ${ }^{45}$ Se añade que el punto

"Existe fundamentalmente la pregunta acerca de si las jerarquías deben ser siempre espaciales o si pueden existir jerarquías temporalizadas. Preguntado de otra manera: ise pueden pensar la espacialización y jerarquización semánticamente s6́lo en forma conjunta?

${ }^{42}$ Como la llave con el candado. Acerca del concepto de "adecuado" o pattern matching véase Campbell, 1966 y Lorenz, 1973, pp. 38-40.

${ }^{43} \mathrm{La}$ TsS opina acerca del concepto de limitacionalidad y de lo "adecuado" de SOCIEDAD y la ciencia respecto a la limitacionalidad: "Con ello [con limitacionalidad RJl se quiere decir, que se deben colocar límites [horizontes] a aquello que es posible pensar, para que las operaciones se puedan volver productivas y no terminen en el vacio de un eterno etcétera. Las formas en las cuales las limitaciones de este tipo pueden convencer, están relacionadas con las formas de diferenciación [R]] del sistema social y logran su plausibilidad por medio de esta conexión." (Luhmann, 1980a, p. 40).

*Idem.

${ }^{45}$ Hegel, 1970, 3, pp. 82 y ss. 
de partida de su fenomenología, o sea la "certeza sensual" señala en la forma de un "esto", "ahora", "aquí" o "yo" el problema del cual nos hemos apropiado como problema de salida de esta investigación: ¿cómo es posible algo como "algo" (sOcirdad o "espíritu" en el sentido de Hegel), si todo lo que sucede, sucede inmediatamente y con ello, simultáneamente?

11. Ya para Immmanuel Kant no se puede encontrar lo simple en el mundo de las apariencias, puesto que siempre se puede proseguir con la actividad de la divisibilidad. Aún más, "[...] imaginarse a un objeto como simple, es un concepto meramente negativo [...]" el cual, sin embargo "[...] es inevitable para la razón, dado que sólo él contiene lo incondicional ensamblado en el todo [... $]^{n} .{ }^{46}$ Es interesante observar en este contexto que Kant llama la atención sobre la inevitabilidad (sin embargo, "razonable") del postulado de la simpleza. Él enfatiza explícitamente: "sólo digo que pienso algo simplemente porque realmente no sé decir nada más que algo es" ${ }^{\text {. }}{ }^{7}$ En este sentido la TsS realza que ya en la filosofía trascendental se hace reconocible cómo el concepto de lo simple se convierte en un concepto meramente negativo. ${ }^{48}$ No obstante, permanece el problema de que, por una parte, lo simple se debe comprender ahora como complejo pero, por la otra parte, se debe comprender como simple.

12. Más adelante nos ocuparemos detalladamente de la distinción entre complejo/simple y del problema de la "necesidad de pensar" de lo simple. Pero ya desde aquí se observa que la suposición de lo simple es autopoiéticamente necesaria en un cierto sentido aún por aclarar. Sin una autorreferencia basal, y esto quiere decir, sin la suposición de un "elemento último" para el sistema, o sea, de lo "simple"

- ${ }^{46} \mathrm{Kant}, 1977$, p. 323. La cita completa dice: "Imaginarse un concepto como simple es un concepto negativo inevitable para la razón, dado que sólo él contiene lo incondicional ensamblado en un todo (como una cosa, no de la forma pura), cuya posibilidad está condicionada en todo momento."

${ }^{47}$ Ibid., 1969, p. 108.

48 "En la filosofia trascendental se hace reconocible que estas condiciones previas del pensar se han disuelto en complejidades naturales. El concepto de lo simple se convierte en un concepto puramente negativo, aunque necesario para la razón." (Luhmann, 1990a, p. 60). 
para el sistema, no es posible la formación de un sistema que se realiza a través de la autorreferencia basal. Los sucesos basales deben ser "simples" para el sistema correspondiente. Solamente de esta manera se genera una formación de estructura sistémica. Precisamente en la cotidianeidad social se muestran como necesarios para la formación de expectativas los acontecimientos basales "simples", tales como las diferentes formas de ACCIONEs como voluntad, motivo, decisión o necesidad. Ia "teoría del sistema general de acción" de Talcott Parsons (TaH), muestra que aquí se esconde un serio problema para la sociología. Precisamente porque su concepto de la acción no se concibe como un suceso simple para el sistema correspondiente, se puede afirmar que sus sistemas no pueden actuar. Su concepto de la acción está diseñado tan complejamente (desde la perspectiva del sistema que debe emplear esta acción compleja), que se arruina como concepto de acción. Una posible salida de este dilema podría haber consistido en admitir que una acción -en cuanto a la teoría de la distinción- es de hecho un constructo altamente complejo, pero que el sistema del sentido correspondiente debe reducir - con respecto a la teoría de la operación- a un suceso "simple", para poder actuar. Tomamos precisamente este camino y creemos haber resuelto por medio de ello un problema central de la concepción de acción de la teoría del sistema general de la acción (esta solución se hizo posible porque procedemos en el marco de la pragmática de las distinciones, tanto de manera teórico-operacional como respecto a las distinciones. Acerca de T. Parsons ver capítulo V):

13. Mientras que lo simple se imagina como elemental, indestructible y sin transparencia, lo complejo debe aparecer "solamente" como un compendio de, precisamente, estos elementos indestructibles o simplicidades. Con una versión de la distinción de este tipo de complejo/ simple, están dados dos límites insuperables, uno hacia arriba (o en dirección hacia el "todo", lo complejo) y otro hacia abajo (o en la dirección hacia las partes del todo, o sea las simplicidades de las cuales se compone lo complejo). Lo complejo, entendido como aquello que es ensamblado por lo simple, se puede extender sólo cuantitativamente, pero no se puede modificar cualitativamente. Algo es complejo cuando consiste en una colección de simplicidades, así por ejemplo, la sOciEDAD de los hombres, la naturaleza de los átomos, la 
ciencia de las frases básicas. ${ }^{49}$ Esto es seguramente también la razón de la circunstancia de que, empezando con las sociedades simples hasta llegar a las estratificadas al comienzo de la nueva era, no se puede sobrepasar un límite que es, en última instancia, dual en cuanto a la estructura de la semántica de la sOcIEDAD. ${ }^{50}$

Un límite dual significa que "el todo" (como lo complejo) es el resultado "de las partes" (como los elementos simples) y que, con ello, se han colocado marcas límite hacia arriba (el todo) y hacia abajo (las partes simples) que no pueden ser sobrepasadas. En este sentido, una jerarquía o estratificación consta de solamente dos niveles, en lo cual no es importante si estos niveles se llaman arriba/abajo, centro/periferia o complejo/simple.

Ciertamente, la figura de la jerarquia como paradigma de una forma de orden con límite dual, la cual determina tanto a la semántica como a la estructura de las sociedades medievales, representa capas intermedias, pero primero estas capas intermedias discurren solamente de arriba hacia abajo (una jerarquía es transitiva en el sentido relacional, como cualquier asimetría); no hay ningún acceso desde abajo hacia arriba.

Ésta es la característica típica de las burocracias y de las organizaciones: con referencia a la COMUNICACIÓN, representan vías unidireccionales, dado que la COMUNICACIón formal discurre en las instituciones de esta indole, desde arriba hacia abajo. El que cualquier jerarquía o forma estratificada pueda peligrar por COMUNICACión informal, ya que toma el camino opuesto desde abajo hacia arriba, es conocido suficientemente a partir de los estudios sociológicos de la organización.

En este sentido, las jerarquías poseen el carácter de vías unidireccionales. Segundo, la jerarquía es limitada tanto desde arriba (por medio de una "punta privilegiada, compleja"), así como también

${ }^{4}$ Un supuesto que llega hasta la mitad del siglo Xx. Sobre todo los representantes del positivismo lógico como Rudolf Camap y Otto Neurath con su supuesto de frases protocolarias, parten del hecho de que la ciencia posee una base objetiva (-lo simple, lo elemental), la cual descansa sobre afirmaciones acerca de experiencias (fundamentales). (Popper, 1969, pp. 60 y ss.).

${ }^{\text {so }}$ Véase por ejemplo, Durkheim/Mauss, 1963; Neetham (ed.), 1973; Leach, 1982. Aquí se trata de la estructura de orden jerárquica o estratificada: la punta de la jerarquía o el centro de la estratificación representan lo complejo, lo cual consiste en partes simples de la base de la jerarquía o de la periferia. 
desde abajo (por medio de unidades elementales, simples, basales), a través de límites intransigibles. Tercero, la punta o el centro determinan finalmente el carácter del orden total.

La TsS dice:

Toda jerarqufa estable presupone por lo menos, tres niveles. El carácter de tres niveles hace insensible a la relación de arriba y abajo contra la transformación o el rompimiento de uno de los niveles. ${ }^{51}$ Esta observación no es razonable dado que cualquier jerarquía se refiere, en última instancia, a la distinción de arriba/abajo, de centro/periferia o de punta/base. No no compartimos en este contexto la opinión de la TsS de que el concepto de clases del trabajo y del capital se correlaciona positivamente con la forma de diferenciación estratificatoria de la soCIEDAD. 52

Desde la perspectiva actual, las formas de ordenamiento de jerarquía y de estratificación sociales ciertamente resultan poderosas y eficientes, siendo con ello, muestras típicas de burocracias, ejércitos - sociedades nacionales regidas dictatorialmente. Pero, a medida que las sociedades se vuelven más complejas, se pueden ordenar con la ayuda de un esquema de ordenamiento jerárquico, el cual es típicamente monovalente (la monovalencia se impone por la fuerza por medio de la calidad de la punta correspondiente o del centro correspondiente generalmente por medio de la religión y/o política), solamente a costa de grandes pérdidas de complejidad y diversidad, y esto únicamente debido a la pérdida de información relevante. Ia jerarquía como orden dominante -desde la perspectiva de observación de una forma de diferenciamiento reflexiva o funcional- restringe demasiado.

Desde un punto de vista realista, simplemente no es cierto que los sistemas sociales se conforman siempre en la forma de jerarquías, este principio los tensaría aparentemente demasiado, los centralizaría demasiado, los simplificaria demasiado. ${ }^{53}$ Si se observa desde la perspectiva actual la descomposición de los países de cuño comunista, entonces se podría mencionar como una de las razones principales de esta descomposición la organización jerárquica correspondiente de estas sociedades, no solamente su política, sino también su educación,

${ }^{31}$ Luhmann, 1985a, p. 124.

52 Ibid., 1988, pp. 151-176.

${ }^{33}$ Ibid., 1984, p. 405 
economía, arte, religión, moral, etc.: la organización social global nacional de estos Estados estaba completamente burocratizada y con ello había sido, en cierto aspecto, privada nuevamente de su ya alcanzada alta complejidad (reiteradamente a fines de 1800/principios de 1900). La "potencia social" de las sociedades capitalistas consiste en permitir políticamente que - visto global-socialmente- sea tolerada una forma de "control sin conductor".

Con ello se puede decir que la distinción entre "simplicidades indestructibles" y su compleja recopilación, expresa semánticamente a la estratificación, y que, en ese sentido, la complejidad se puede comprender como "complejidad jerárquica". Esta cercanía del concepto de la complejidad con el concepto de la jerarquía se puede observar paradigmáticamente en el trabajo de Herbert A. Simon. ${ }^{.44}$.

\section{COMPLEJIDAD Y CIENCIA}

14. En el sistema de las ciencias se modifica la relación entre complejo y simple sólo por medio de la inclusión de la dimensión del tiempo, mediante el dominio de las categorías temporales, las cuales conducen entonces hacia una historización y temporalización de la circunstancia correspondiente de la disciplina. La adquisición de esquemas de pensamiento históricos los ubica Michel Foucault entre 1775 y 1825.55 Wolf Lepenies opina que al final del siglo XVIII se perfila una nueva comprensión de la ciencia por medio de la penetración de la dimensión temporal en las disciplinas particulares. Él encuentra la razón para este cambio en la circunstancia de que la presión de la experiencia social general dentro de las disciplinas individuales - designada como presión empirizante- conduce a que el orden espacial tradicional del material de conocimiento sea completado, es decir, superpuesto, con una dimensión temporal: " $\mathrm{La}$ espacialización [...] representa una técnica premoderna; en la transición del siglo xviII al xIX, la temporalización de existencias de informa-

s4 " $[. .$.$] my central theme is that complexity frequently takes the form of$ hierarchy and that hierarchic systems have some common properties that are independent of their specific content. Hierarchy, I shall argue, is one of the central structural schemes that the architect of complexity uses." (Simon, 1969 , p. 87).

s5 Foucault, 1974 y 1981. 
ción complejas ocupa su lugar. Se abandonan los viejos sistemas de clasificación concebidos espacialmente, provenientes de la historia natural ${ }^{56}$ Foucault habla en este contexto del límite de la representación espacial, la cual "[...] se cambia completamente a partir del siglo XIX. La teoría de la representación, como base general de todos los posibles ordenes, desaparece [...] Una profunda historicidad penetra al corazón de las cosas, las aísla y las define en su propia coherencia, les superpone formas de orden obligatorias, las cuales están implicadas a través de la continuidad del tiempo". ${ }^{57}$ Una teoría de la representación funciona solamente cuandó representa, de manera jerárquica, la punta o centro del esquema a ser ordenado. Por lo tanto, una forma de teoria de esta naturaleza, es efectiva solamente como parte de un orden de jerarquía de circunstancias científicas.

Obsérvese que solamente una arquitectura de teorias capaz de integrar como parte de sí misma a sus propios principios fundamentales, su posición de salida, sus primeros rasgos, y que no presenta a la "naturaleza", a Dios, a la moral o al "interés de conocimiento" como a prioris, puede evitar el fatal "comienzo del comienzo". Esto lo pueden lograr solamente las teorias concebidas autorreferencialmente, las cuales son en este sentido, no jerárquicas. El que las jerarquías puedan asumir funciones centrales dentro de esta clase de teorías (por ejemplo, como forma de asimetrización, o sea, como diferenciación) no se afecta por el supuesto antes mencionado.

Pero en lo que la jerarquía desaparece como esquema dominante, creador del orden del diferenciamiento social, ya no queda ninguna posibilidad de asumir un nivel de representación que "ordene el todo", "represente el todo". Ahora bien, a partir de que la forma de diferenciamiento estratificatorio de la SOcIEDAD perdió su papel dominante, las formas de representación (jerárquicas) de la SOCIEDAD, entre ellas el sistema de la ciencia, tuvieron que aceptar pérdidas de credibilidad. Así, hoy en día ni la religión, ni la política, ni la economía, ni el sexo, ni la milicia, ni la educación, ni el arte, por mencionar tan sólo algunos sistemas del sentido, pueden representar jerárquicamente a la SOCIEDAD en su conjunto. En el área de la técnica de las teorias, sobre todo los a prioris, géneros o supuestos acerca de la "naturaleza de las cosas", han tenido la función de una representación

${ }^{56}$ Lepenies, 1976, p. 18.

"Foucault, 1974, p. 26. 
cotal de las circunstancias científicas. Las condiciones sociales para semejantes a prioris han desaparecido desde que el modo de diferenciamiento de la SOCIEDAD fue cambiado de la estratificación hacia la funcionalidad y recientemente se insinúa un cambio de la funcionalidad hacia la reflexividad.

15. Sobre la base de una dimensión del sentido exclusivamente espacial, los objetos de investigación científica pueden ocupar - vistos semánticamente- solamente un lugar limitado, dado que el marco de la investigación se determina precisamente de forma espacial.

Esta afirmación está expresada principalmente en el sentido de que aun la teoría de la correspondencia de la verdad aristotélica, se encuentra erigida sobre la base de la similitud (primeramente sensual): algo es cierto solamente cuando coincide con el hecho percibido, con lo cual, la operación de la concordancia se orienta por la representación de los hechos. Seguramente no es posible distanciarse de cualquier supuesto de similitud, si es que se quiere identificar algo. Pero el concepto de la similitud como un funcionalismo de equivalencias (similitud respecto a una solución equivalente de un problema, por ejemplo), o de una teoría pragmática de la verdad (similitud respecto a la "adecuación" de llave y candado, por ejemplo), es mucho más abstracto y con ello más variable que aquél de la teoría de la correspondencia de la verdad. Se puede añadir también: la capacidad de rendimiento de una teoría aumenta en la medida en que logra procesar lo disimil como similar consistentemente. Y entre más se pueda comprender lo disímil como símil consistentemente en cuanto a la teoría, "más poderosa" resulta la teoría correspondiente respecto a la logica. Debido a ello, resulta también la tendencia de cualquier teoría "buena", de primero encontrar las unidades fundamentales "basales" para homogeneizar los diferentes fenómenos en cuestión; segundo, de explicar cómo se construye lo heterogéneo a partir de las unidades homogéneas; $y$, tercero, mostrar la forma relacional de esta clase de unidades básicas, para escapar a la trampa de la ontologización.

En todo el nivel espacial, el marco de la investigación permanece, necesariamente, monovalente.

Vemos, en la dimensión del sentido espacial, la fijación de la simultaneidad fundamental que, por así decirlo, es inherente a toda dimensión del espacio. Formulamos esta circunstancia con la ayuda de la 
distinción "diferencia" como una distinción simétrica que constituye operativamente a la simultaneidad y la hace, así, observable. Refiriendose a la teoría cuántica, C.F. v. Weizsäcker formula: "La teoría cuántica como teoría general de las prognosis de la probabilidad indeterninista para alternativas decidibles, aún es una versión supuestamente provisional de las únicas leyes que tienen validez del todo. Todas las leyes especiales deben ser aplicaciones de estas leyes a los casos especiales cuya posibilidad misma es consecuencia de la teoría general. En este sentido el espacto mismo es la forma de la simultaneidad determinada por medio de la teoria cuántica de la alternativa [R]]. "58 Para prevenir malentendidos: la semántica del espacio representa solamente una posibilidad de procesar simetria. Dejando de lado el hecho de que existen diferentes conceptos del espacio, tales como el matemátco; el físico, el fenomenologico o el empírico, también hay diferentes posibilidades de procesar la simultaneidad. Así por ejemplo, a través de la "igualdad" o "equivalencia". Lo que queremos decir es que en cuanto a la semántica del espacio aquí utilizada, no se trata exclusivamente de un espacio supuesto empíricamente.

La disposición dentro de un área espacial ofrece solamente una posibilidad de valor que conforma el "marco" del espacio semántico utilizado científicamente. ¿Pero qué hacer "[...] cuando en la zoología de alrededor de 1740 se conocían aproximadamente 600 especies, mientras que, escasamente 100 años después, tan sólo las mangostas (icneumón) se cuentan en cuatro veces más[...]?" ${ }^{\text {n59 }}$ Dentro de la botánica, la química, la historia del derecho, la astronomia, por mencionar solamente algunas de las disciplinas en voga de aquel entonces, sucede algo estructuralmente similar. En las ciencias, la categoría de la similitud ${ }^{60}$ es (según Foucault), aquella que se debe hacer responsable, en última instancia, del orden y la coordinación de los hechos científicos. Esta forma de los epistemos con sus subformas derivadas de la convenentia, de la aemulatio, de la analogía y de la simpatia, ${ }^{61}$ junta o "cohesiona" a todos los hechos científicos.

"Convenientia, aemulatio, analogía y simpatía nos señalan cómo el mundo debe cerrarse, reduplicarse, reflejarse o encadenarse para que

so Weizsäcker, C.F.v., 1977, p. 585.

${ }^{39}$ Lepenies, 1976, p. 17.

${ }^{60}$ Véanse las observaciones acerca de la teoría aristotélica de la correspondencia de la verdad, la teoría pragmática de la verdad y el funcionalismo de equivalencias.

${ }^{61}$ Foucault, 1974, pp. 46-56. 
las cosas puedan parecerse. Nos dicen cómo van los caminos de la similitud. No nos đicen dónde está la similitud, ó cómo se ve, ni tampoco en qué característica es reconocible. ${ }^{\text {"62 }}$ Sólo una SOCIEDAD que se determina por medio de la forma de diferenciamiento funcional, puede hacer posible comparaciones dentro del sistema ciencia, las cuales no deben estar cubiertas por su similitud fenomenal. Así se puede abarcar el problema de la complejidad por medio de posibilidades de solución diferentes, pero funcionalmente equivalentes: a través de la jerarquización/estratificación, por medio de la funcionalidad y a través de la reflexividad.

Ahora bien, la operación de la similitud que - visto semánticamente- puede ser comprendida sólo espacialmente, puede efectuarse exclusivamente a través del camino de lo visible, de la representación visual. Pero, zcómo puede tener lugar esta operación sin contradicciones, si se debe constatar simultáneamente, que muchas cosas están escondidas y por ello permanecerán invisibles? Esto no representa - según la solución de aquel entonces- ningún problema, ya que los hechos (cosas) y su denominación (palabras) se comprenden como indivisibles, aun más, porque para el sabio de aquella época aún no existia esta distinción.

El hecho de que aquí se encuentre presente una distinción no significa que ambas cosas fueran completamente diferentes. Partimos del hecho de que las circunstancias se reducen por medio de (sus) denominaciones, o sea que se encuentran en la relación entre COMUNICACIÓN y ACCION o entre diferencia y diferenciación. Ias circunstancias son direccionables y con ello identificables (nombrables) solamente a través de este proceso de reducción unilateralizante.

Con otras palabras: no "[...] hay ninguna similitud sin forma. El mundo de lo similar puede ser solamente un mundo designado". ${ }^{63}$ En este contexto, es también particularmente interesante una observación de Theophrastus Paracelsus, quien opina: "Dan alles was got ershaffen hat dem menschen zu gutem und als sein eigentumb in seine hent geben, wil er nit das es verborgen bleib. und ob ers gleich verborgen, so hat ers doch nicht unbezeichnet gelassen mit auswendigen sichtlichen zeichen, das dan ein sondere praedestination ge-

${ }^{62}$ Ibid., p. 56.

${ }^{63}$ Ibid., p. 57. 
wesen. zu gleicher weist als einer, der ein schaz eingrebt, in auch nicht unbezeichnet laBt mit auswendigen zeichen, damit er in selbs wider finden könne. ${ }^{n 64}$

16. Lo que Lepenies y Foucault denominan en el área de la producción de conocimiento de alto rendimiento, correspondientemente, como "cambio de las mentalidades" y "cambio de los epistemas epocales", se puede interpretar, por un lado, como la expresión de las posibilidades cognoscitivas, pero por el otro lado, como la expresión de los límites cognoscitivos de una determinada época de formación social. Sabemos que la SOCIEDAD no puede observar lo que no puede observar.

En el capitulo IV acerca de la observación, tratamos la ceguera inherente a cualquier observación aquí mencionada. Queremos observar que la "sociología" es la forma de observación de la SOCIEDAD por excelencia: es la forma de autorreflexión del sistema global sOcIEDAD, el cual implica los tipos de expectación de la corporalidad, afectividad, subjetividad y socialidad.

En este sentido, existe una relación de pattern matching entre el cambio de la ciencia y el cambio social de la mentalidad, de tal manera que los desarrollos científicos pueden afectar, por ejemplo, en la forma de descubrimientos (máquina de vapor, fusión nuclear) ciertamente, a las estructuras psiquicas y sociales, "[....] pero, contrariamente, determinadas situaciones de conciencia y sentimientos, forman límites más allá de los cuales tampoco los conocimientos científicos pueden volverse efectivos" ${ }^{65}$ Con ello parece existir, dentro del periodo de diferenciamiento social, un límite no transgredible, más allá del cual ningún descubrimiento, por más atrevido que sea, puede desdoblar su efecto.

Paradigmáticamente acerca de esto, el descubrimiento "precoz" del mecanismo de producción de energía por medio del vapor (máquina de vapor), por el griego Herón de Alejandría. En última instancia, este

${ }^{66}$ Theophrastus Paracelsus, los nueve libros de la Natura Rerum, en: el mismo, Sämtliche Werke, Karl Sudhoff (ed.), München, Berlín 1923/33, t. 11, p. 393.

${ }^{65}$ Lepenies, 1976, p. 203. 
logro técnico está ligado estrechamente con el proceso industrial en la Europa de la nueva era. Pero, para la sociedad griega, esta innovación no tenía ningún significado técnico y/o económico digno de mención (jaunque sí uno religioso!). ${ }^{66}$

El aumento del conocimiento, que se acelera en el siglo XvmI cada vez más en el nivel del sentido espacial —en forma de una presión experiencial y de una obligación empirizante en el área de las ciencias- conduce, en última instancia, a una aceptación de formas de pensamiento temporales y a la detonación de la dimensión del sentido semántico-espacial como dimensión del conocimiento dominante para la coordinación: en el cambio hacia la modernidad, la necesidad de "[...] procesar la complejidad por medio de las técnicas de la temporalización" conduce "[...] a una generalización de la idea del tiempo, la cual se puede aceptar también como la premisa de una teoría general de la evolución" ${ }^{67}$ Resulta siempre plausible el por qué la "temporalización" puede valer como una excelente técnica para el dominio de un crecimiento del conocimiento cada vez más acelerado, o sea de la complejidad en el sistema de la ciencia.

La TsS resume este desarrollo como la "temporalización de la complejidad" $\mathrm{y}$ ve en este desarrollo la condición para la posibilidad de la formación de sistemas del sentido autopoiéticos altamente complejos: "La temporalización de la complejidad se genera, como ya se ha dicho, por medio de la temporalización de los elementos del sistema. El sistema está conformado por elementos inestables, los cuales tienen solamente una corta duración de tiempo o incluso no tienen ninguna duración propia, sino que desaparecen nuevamente al nacer, como por ejemplo las acciones. Visto cronológicamente, cada elemento requiere naturalmente de un determinado tiempo de reloj; pero la duración del tiempo por la cual es tratado como unidad ya no posible, se determina por el sistema mismo; tiene un carácter otorgado, no propio. Correspondientemente, un sistema suficientemente estable consiste en elementos inestables: agradece su estabilidad a sí mismo, no a sus elementos; se construye sobre una base que ni 'existe' y es, precisamente en este sentido, un sistema autopoiético. ${ }^{n 68}$ Aquí surge el problema central de que el sistema debe, por un lado, temporalizar los elementos para reproducirse a sí mismo; por el otro lado, debe tratar a estos ele-

${ }^{66}$ Véase, por ejemplo Geitel, 1911, pp. 12 y ss.

${ }^{67}$ Lepenies, 1976, p. 19.

${ }^{68}$ Luhmann, 1984, pp. 77-78. 
mentos como a unidades "últimas", como "fundamentales" que no son capaces de otra reducción, para poder efectuar la operación de la $A C C I O N$.

Un procedimiento de ordenamiento espacial es posible solamente como procedimiento de simultaneidad: todo debe desarrollarse al mismo tiempo espacialmente. Un orden que tiene lugar con la ayuda de las dimensiones temporales puede encontrar lugar "ayer para esto, hoy para aquello y mañana para algo completamente diferente". El mantenimiento de un despacho médico o jurídico -instituciones que son demasiado obvias para nosotros actualmente- sólo sería imaginable con base en un orden temporal. Un orden "espacial" significaría que todos los clientes/pacientes deberian ser atendidos al mismo tiempo, por ejemplo, en habitaciones diferentes, lo cual debería limitar drásticamente, como es fácilmente reconocible, la complejidad de una institución de este tipo.

17. Aquí se entrelaza la suposición general de este trabajo con la ayuda de la semántica del espacio. La semántica de la espacialidad produce simetría: se podría formular que espacialmente todo existe a la vez y que, por ello, el mundo está dado en su totalidad presentistamente. Una "presencia" mundana o "inmediatez" es, por consiguiente, la posición de salida de la Fenomenología del espiritu de Hegel: " $\mathrm{El}$ conocimiento, el cual es primero o inmediatamente nuestro objeto, no puede ser otro que aquel que es en sí un conocimiento inmediato de lo mediato o de lo existente. ${ }^{\text {} 69}$ Esta descripción de la pragmática formal de la "certeza sensual" de Hegel, la interpreta Martin Heidegger como "presencia pura" o "ser puro" "[...] solamente es, porque es. Es lo presente respectivamente y nada más".$^{70}$ Las semánticas de la "inmediatez", "presencia espacial" y "simultaneidad", tienen siempre una forma simétrica y son, con referencia a los sistemas, siempre un problema de la sobrecanga del sistema: es la expresión del hecho de que el ambiente siempre le ofrece más al sistema, le presenta más de lo que él mismo es capaz de procesar (simultáneamente), capaz de asimilar. En este concepto presentista, encuentra su expresión uno de los conceptos básicos de la teoría

${ }^{69}$ Hegel, 1970, 3, p. 82.

${ }^{70}$ Heidegger, 1980, p. 79. 
de sistemas, a saber: que el ambiente del sistema debe ser siempre más complejo que el sistema mismo. Y precisamente este declive de la complejidad entre sistema y ambiente la "razón" de la constitución del sistema: si el sistema y el ambiente fueran igualmente complejos, entonces no se podría establecer ninguna distinción entre ambos, ambas cosas serían uno y el mismo ambiente (o uno y el mismo sistema). Hegel ha descubierto este problema con su suposición originaria de una "certeza sensual" como "inmediatez pura" y se ha atrevido, en conexión con ello, a una constitución del mundo (conciencia, autoconciencia, razón, espíritu, religión y conocimiento absoluto), la cual puede valer como sin par hasta hoy dia. Seguramente no se tomará otra vez este camino en esta forma, dado que los conceptos de la filosofía de la conciencia y de la metodología de la dialéctica empleados en ello, son supuestos problemáticos que han perdido reputación científica debido a sus debilidades inmanentes en cuanto a la técnica de construcción de las teorías. Pero el aspecto "presentista" de la fenomenología de Hegel se puede defender aún hoy enteramente con la suposición "de que todo lo que sucede, sucede simultáneamenten. Y preguntamos en vista de esta suposición: ¿qué ocurre si todo lo que ocurre, sucede simultáneamente? Una tesis seguramente trivial, pero también excitante. ${ }^{71}$

Se entiende (¿quizá no por sí mismo?) que el supuesto de la simultaneidad tiene sentido solamente bajo el supuesto de una no simultaneidad. Esta circunstancia se puede expresar operativamente de la siguiente manera: algo es observable simultáneamente pero utilizable solamente no-simultáneamente. Con referencia a la dimensión del sentido se correlacionan la simultancidad temporal, la simetría espacial, la indeterminación objetiva y la no-decidibilidad social, por un lado; la no-simultaneidad temporal, asimetría espacial, determinación objetiva y decidibilidad social por el otro lado. El supuesto de la TsS: "Hablar de [...] simultaneidad, tiene sentido naturalmente, sólo bajo la condición de la diversidad objetiva de aquello que sucede. El prescindir de una diferenciación de tiempo requiere una diferenciación objetiva; si no, no podría designarse nada determinado. Reformulado en cuanto a la teoría de los sistemas, esto significa que la simultaneidad es un aspecto del diferenciamiento de sistema y ambiente, y que surge con éste. ${ }^{n / 2}$ Esto reproduce solamente la mitad de la verdad, dado que

${ }^{71}$ La TsS, en Luhmann, 1990a, pp. 95 y ss.

72 Idem. 
la TsS intenta correlacionar la renuncia con una distinción temporal con el supuesto de la distinción objetiva. Para la justificación de la distinción como dimensión objetiva del sentido se ha dicho que, por lo pronto, es necesario el supuesto de la inmediatez operativa: algo opera o no opera, algo tiene lugar o no tiene lugar. Precisamente en esa necesidad de "operación inmediata" (- lo que no opera se atrofia), resulta inmediatamente notorio que solo es posible si construye a la vez la distinción objetiva de operación/no operación (ver acerca de ello la introducción y el capítulo I sobre operación y forma). Esto significa que: con la necesidad indispensable de tener que operar, los sistemas del sentido constituyen (presuntamente también los sistemas vivos), simultáneamente, una dimensión objetiva. Referido a la observación antes citada de la TsS, se debe decir que: primero, no se comprende por qué la distinción de sistema/ambiente refleja una distinción objetiva y no como nosotros pensamos, una distinción espacial. Segundo, cada dimensión del sentido consiste en dos distinciones diferentes: una diferencia y una diferenciación. Y este entrelazamiento entre diferencia y diferenciación es precisamente aquel que conduce a la constitución de la dimensión del sentido (naturalmente no negamos que las diferentes dimensiones del sentido se condicionan mutuamente, como lo explicamos en el capítulo IV acerca de la observación). Una cosa parece quedar clara de cualquier manera: la distinción entre diferencia y diferenciación expresa la conexión constitutiva que realmente se pretende con las distinciones ("concretas"), simetria/asimetria (espacialidad), simultaneidad/no-simultaneidad (temporalidad), indeterminación/determinación (objetividad) y no decidibilidad/decidibilidad (socialidad).

El supuesto de que "todo lo que sucede, sucede simultánea e inmediatamente", se encuentra en el centro de este trabajo.

En el marco de una "lógica de las afirmaciones temporales", tal como ha sido presentada por C.F.v.Weizsäcker, se hablaría en este contexto de una afirmación presentista. Se llama la atención sobre la muy estrecha conexión entre los conceptos de esta clase de lógica de afirmaciones temporales, y la "lógica de las distinciones" aquí presentada: el concepto de diferenciación asimétrica corresponde a la afirmación perfectista; el concepto de diferencia simétrica corresponde a la afirmactón futurista; y el concepto del supuesto presentista o de la inmediatez corresponde a la afirmación presentista. ${ }^{73}$ No obstante, somos de la opinión de que no solamente las afirmaciones muestran

${ }^{73}$ Weizsäcker, C.F.v., 1992a, pp. 192-235. 
una forma de esta naturaleza. Es de suponerse que, ya en el nivel de la percepción, se debe contar con formas de esta indole. En todo caso, ésta es nuestra posición de salida, una posición que podemos explicar solamente en una forma insuficiente, en el marco de este trabajo, por razones de espacio. Se señalan los trabajos de V.v. Weizsäcker, sobre todo, "el círculo de figuras" en relación con esta problemática. ${ }^{74}$

El supuesto presentista también es suficientemente problemático y de sentido profundo, como para llamar sobre sí la atención de un Hegel. Por lo demás, esta tesis se encuentra en concordancia con el hecho de la complejidad como "ob̈ligación de selección ${ }^{n},{ }^{75}$ aun más, sólo a través de ello, la complejidad como problema, se hace manejable y comprensible, dado que su problema está arraigadò precisamente en el hecho de que todo lo que sucede, sucede precisamente en forma simultánea, y con ello, la obligación de selección se encuentra preprogramada.

Opinamos que se puede detectar, con la distinción de espacialización y temporalización, en referencia con el problema de la complejidad, una tendencia esencial de la ciencia moderna: la renuncia al concepto de la simpleza o elementaridad como unidad científica basal. Mostramos este desarrollo sirviéndonos de un aspecto del desarrollo de la ciencia. Además, hay que realzar que el supuesto presentista, de que todo lo que sucede, sucede inmediatamente y precisamente por ello, también simultáneamente, forma la línea conductora de este trabajo y que no se refiere exclusivamente a lo específico de una determinada época de la evolución de la ciencia. Sin embargo, el supuesto presentista está conectado con un deslizamiento del acento modificado desde las dimensiones del sentido hacia la dimensión del tiempo: los fenómenos de temporalización de la SOCIEDAD son insoslayables. En este sentido, la tesis de la simultaneidad aquí representada como tesis del presente, es producto de la evolución sociocultural. ${ }^{76}$

74 Weizsäcker, V.v., 1973.

75 "Complejidad significa obligación de selección, obligación de selección significa contingencia y contingencia significa riesgo." (Luhmann, 1984, p. 47).

${ }^{76}$ Acerca del trasfondo histórico del supuesto del presente o de la inmediatez, véase, sobre sodo, Georg Picht, Die Voraussetzungen der Wissenschaft, 1969a, p. 1; Die Epiphanie der ewigen Gegenwart, Wabrbeit, Sein und Erscbeinung bei Parmenides, 1969a, p. 2; y El dios de los filósofos, 1966, p. 1. También véase C.F.v. Weizsäcker, "Georg Picht als Philosoph" y "Notizen zur Religionsphilosophie von Georg Picht", en Weizsäcker, C.F.v., 1992a, pp. 1126-1141. 
18. $\mathrm{Si}$ Wolf Lepenies escoge una dimensión del espacio del sentido para describir cómo cambia la calidad de la técnica de procesamiento del conocimiento científico en el siglo xvIn. [ ${ }^{\text {"Con }}$ mayor fuerza que nunca anteriormente, las ciencias son sometidas a una presión experiencial [...." y "[...] las técnicas de procesamiento de información convencionales, las cuales -en estrecho apego a los métodos de la historia natural clásica- descansan sobre todo en una disposición espacial de las existencias del conocimiento, [estân (R]), agotadas ahora en su capacidad...." ${ }^{n}$ " entonces describe un modo de procesamiento del conócimiento "[...] de la disposición espacial ad-

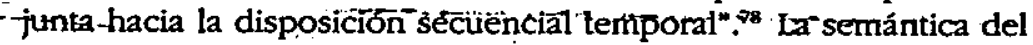
espacio le sirve así como "generador de simultaneidad": debido a que el aumento del conocimiento crece, pero las ciencias solamente poseen "técnicas de simultaneidad" para su procesamiento (dentro de la historia natural, por ejemplo, el supuesto de una inmodificabilidad de las especies), éstas se encuentran sobrecargadas. La salida es: la temporalización; la disposición conjunta o adjunta espacial se traduce en una secuencia temporal. En última instancia, esta clase de "temporalización del conocimiento" conduce a la formación del pensamiento histórico, a una teoría de la evolución, etc.: "En el cambio hacia la nueva era se imponen maneras de observación históricas en muchas disciplinas [...], con ello la dimensión del tiempo obtiene más significado frente a la del espacio. En el tiempo surge más y más espacio para posibilidades [... $]^{n}{ }^{79}$ Con la ayjuda de la categoría del espacio, Lepenies describe una determinada fase del desarrollo del conocimiento de alto rendimiento, que se podría designar quizá de la mejor manera como "tendencias de temporalización en la ciencia". Nos interesa de esta semántica del espacio sobre todó su aspecto teórico, mismo que vemos en el hecho del procesamiento de la simetria o de la simultaneidad. Si es postulado un espacio matemático (geometría, espacio Gilbert), uno físico (el espacio absoluto de la mecánica clásica, la diversidad tiempo-espacio de la electrodinámica clásica, el concepto de campo de la teoría general de la relatividad), uno filosófico (los lugares naturales de Aristóteles, el espacio a priori de Kant) o uno fenomenológico (el espacio hodológico de Sartre), depende seguramente del tipo de circunstancia espacial en

7 Lepenies, 1976, pp. 16-17.

${ }^{78}$ Ibid., p. 26.

${ }^{7}$ Ibid., p. 106. 
cuestión..$^{80}$ Partimos del hecho de que la función de la semántica del espacio está relacionada esencialmente con la constitución de la simultaneidad, de la simetría. Si se busca cómo se podría constituir "la simultaneidad", generalmente en cuanto a la teoría de la información, esto quiere decir por medio de la formación de las distinciones, entonces la distinción de la "diferencia simétrica" que procesa dos lados de igual valor, nos parece ser una solución posible. Por ello podemos afirmar que la "semántica de la diferencia" y la "semántica del espacio" son funcionalmente equivalentes, con lo cual tenemos una distinción en la diferencia simétrica, que es más general que la distinción adentro/afuera, misma que constituye la espacialidad real.

19. Retomamos nuestro hilo de argumentación después de esta pequeña excursión sobre la conexión entre "diferencia" y "espacio". La característica de la mentalidad pretemporal se puede ver seguramente en sủ forma estratificatorio-jerárquica. Ya Voltaire expresa que, en el área de la historia natural, la noción de una "cadena de los seres

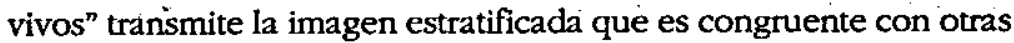
áreas de una sociedad estructurada jerárquicamente.$^{81}$ El reino de las plantas y de los animales se compara con los estamentos de la sociedad, con lo cual se suponen naturalmente niveles intermedios, los cuales, sin embargo, como también en la sociedad estratificada, no permiten reconocer transiciones de una posición hacia la otra (no de abajo hacia arriba, siempre de arriba hacia abajo, dado que cualquier jerarquía discurre como vía unidireccional) ${ }^{82}$ Linneo construye un orden de los estamentos del mundo de las plantas según la forma en que, los musgos "[...] conforman a los más pobres, los pastos deben ser considerados como los campesinos, las hierbas como la nobleza, los árboles como los príncipes". ${ }^{83}$ Qué tan importante es aun para Linneo la jerarquía como el método que reduce la complejidad del

- 3 Janich/Mittelstrass, 1973.

81 "Esta jerarquía le gusta mucho a la gente, quienes crèen ver al Papa y sus cardenales, a los que le siguen, por su parte, los arzobispos y obispos; luego vienen los clérigos, los vicarios, los simples sacerdotes, los diáconos y los subdiáconos; finalmente aparecen los monjes y los capuchinos cierran la procesi6n." Voltaire, citado por Wolf Lepenies, 1976; p. 47.

82 Lepenies, 1976, p. 47.

${ }^{83}$ Ibid., pp. 47-48. 
mundo de las plantas y crea el orden, lo muestran sus manifestaciones en relación con Cäsalpin: "Si a las plantas no se les mete en determinados órdenes y se les distribuye en sus clases, como un ejército, entonces todo conocimiento debe ser necesariamente incierto. ${ }^{884}$ Los límites de las especies se hacen más permeables y, con ello, se facilitan las transiciones intermedias sólo cuando el objeto del conocimiento es temporalizado o relacionado con el tiempo. El proceso de merma con el cual se reblandecen los esquemas rígidos de clasificación de la historia natural, lo relaciona Ernst Jünger con un "aceleramiento y una dinamización de la vida" ${ }^{85}$ En el área de las disciplinas de la astronomía y cosmología, Alexandre Koyré describe muy minuciosa e ilustrativamente este proceso de desjerarquización y temporalización en su trabajo trascendental Del mundo cerrado bacia el universo infinito. Con ello, su investigación, no por casualidad, empieza con Nikolaus von Kues, dado que quizás el más interesante aspecto histórico de la cosmología de Kues consiste precisamente en que rechaza la estructura jerárquica del universo. ${ }^{86}$.

20. Si resumimos lo hasta aquí dicho, entonces resulta que el proceso de temporalización dentro de las ciencias ya es claramente observable desde el siglo xvin, pero que ese proceso aun hoy en día está en marcha y en absoluto está terminado.

Es así que, primero, a nivel mundial, en la mayoría de las sociedades nacionales, aún predomina la jerarquía como forma principal de diferenciamiento. Segundo, se puede observar que los estilos de comunicación en un grupo de sociedades nacionales, aún son procesados de manera estratificada, mientras que en otras sociedades nacionales ya son manejados funcionalmente. Sobre todo la comunicación de los sexos con su distinción hombre/mujer sería de mencionar aquí como un ejemplo particularmente notorio. Pero también los estilos de comunicación polticos, económicos o religiosos señalan, de acuerdo con las

${ }^{84}$ Linneo, en Lepenies, 1976, p. 48.

${ }^{85}$ Ernst Jünger, citado por Wolf Lepenies, 1976, p. 48.

86 "Rechaza la noción de la estructura jerárquica del universo; en especial niega que la Tierra ocupe esta posición extremadamente baja y despreciable -aunque sea central-, que le fue adjudicada por la cosmología tradicional." (Koyré, 1969, pp. 28 y ss.). 
formas de la identidad nacional social, diversas formas de estilos de diferenciamiento. Tercero, se puede observar adicionalmente que se comienza a perfilar una nueva forma principal de diferenciamiento, la cual se encuentra por sustiruir a la forma de diferenciamiento funcional: la forma de diferenciamiento reflexiva.

La transición de las ciencias, de una forma de cognición jerárquica hacia una funcional, de un ordenamiento del conocimiento monocéntrico hacia uno policéntrico, ${ }^{87}$ parece ser un fatigoso y largo proceso, con el cual la "despedida de lo principal", y esto quiere decir de los a prioris, de la moral, de los presupuestos de la naturaleza y de las "constantes profundamente arraigadas antropológicamente", no resulta tan fácil.

El modus de una forma de cognición no jerárquica, es aquél acunàio por medio de la autorreferencia. Esto significa que cualquier arquitectura de la teoría que procede autorreferencialmente - la teoría cuántica dentro de la física, la teoría de sistemas dentro de la sociología, la cibernética de segundo grado dentro de la teoría de la informaciónproduce un carácter no jerárquico.

Se solicita, en el ámbito de una epistemología de caracter espacial, la ayuda de ontologías tales como "naturaleza", "norma", "valor", "materia", "consenso", "contrato", "moral" o un a priori de cualquier tipo, como punto de partida sobre el cual ya no se reflexiona, y que permite entonces la emanación del cuerpo total del orden de la teoria.

Se debería "[...] reflexionar acerca de si no se encuentra ya implicado en los nuevos desarrollos de las teorías, el que en gran medida la historia y el tiempo ocupan exactamente aquel lugar teórico, en donde anteriormente fungian la naturaleza, las normas o los valores como expendedores de seguridad ${ }^{n} .99$ Solamente entonces se debe poder explicar plausiblemente el cómo algo tan volátil como el "tiempo" puede producir, a pesar de ello, estructuras de alguna duración; cómo pue-

87 Polanyi, 1951, pp. 111 y ss.

${ }^{8}$ Marquard, 1981.

Q Luhmann, 1984, p. 175. 
den mudarse, entonces, elementos temporalizados hacia sistemas con una buena porción de estabilidad dinámica.

Sólo una teoría capaz de reflexionar acerca de su propio punto de partida y que no sólo sabe plantear la pregunta acerca del "punto de partida", sino que sabe conducirla hacia una solución, puede escapar a la poderosa tradición jerárquica de conocimiento.

Naturalmente no se escapa a la jerarquía. Ella solamente será integrada en el marco de un modelo no-jerárquico, lo cual significa que su capacidad de ordenamiento puede ser aplicada puntualmente, sin que domine todo el modelo de ordenamiento en cuestión. Las burocracias y los ejércitos son solamente posibles en el sentido de una estructura de ordenamiento jerárquica. Un ejército no jerárquico sería por ello una contradictio in adjecto. No queremos rechazar generalizadamente a la jerarquía como forma productora del orden de la sociEDAD y de la ciencia, porque sería un burdo error.

Esta clase de logro teórico puede producirse, según nuestra opinión, solamente en el marco de las operaciones autorreferenciales, porque solamente de esta manera puede utilizarse el propio punto de vista como punto de partida y simultáneamente ser alcanzado como punto final. Solamente las teorias construidas autorreferencialmente, o sea teorías que proceden en forma universal, "superteorias" 90 grand theories tienen, desde el punto de vista de la

${ }^{90} \mathrm{La}$ capacidad de complejidad y ordenamiento de una superteoría se mide según qué tanto o qué tan poco es capaz de limitar, en cuanto a la arquitectura de la teoría. Si admite cualquier explicación, es vacía, si limita demasiado, entonces disminuye su posibilidad de aplicación universal. Por ello, también la TsS dice, que la limitabilidad está dada cuando "[...] las negaciones no transcurren en balde, sino cuando la afirmación, de que algo sea non-A, ayude para la determinación de A". (Luhmann, 1978, p. 14). Importantes procesos de limitacionalidad son por ejemplo la utilización de especies y géneros, de dialéctica (Hegel), de tipologías (Parsons, Münch, Schluchter), de falsificación o eliminación de juicios no ciertos (Popper, Albert) y de complejidad en el sentido de un declive que genera problemas entre el sistema y el entorno; según la suposición de una teoría general de sistemas, el

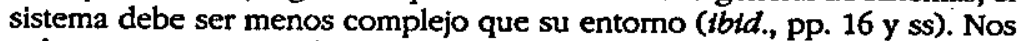
colocamos en un nivel más bajo y divisamos en la tesis presentista de la simultaneidad el verdaderamente moderno proceso de la limitacionalidad, dado que la simultaneidad sólo actualiza a la complejidad como problema. 
arquitectura de las teorías, la posibilidad de anteponer algo diferente, sobre todo a la jerarquización del conocimiento cognoscitivo.

Carl Friedrich von Weizsäcker formula: "De la insostenibilidad de las filosofías jerárquicas que se nos ofrecen hoy en día, ya me había convencido cuando era un físico joven. Las doctrinas aprioristas, neokantianas, habían fracasado a causa de la teoría de la relatividad o de la teoría cuántica; pero el neopositivismo empírico ni siquiera entendió - eso lo vi pronto- la inevitabilidad de la pregunta de Kant acerca del sentido y de las condiciones de la posibilidad de la experiencia. La experiencia de esta insuficiencia de los jerarquismos ofrecidos era primero, sin embargo, una apnría [para von Weizsäcker R].. ${ }^{n 1}$

Con ello se quiere decir que las teorías con un planteamiento universal, como la teoría de las distinciones aquí representada, o la reciente teoría de los sistemas, son teorías que se deben reencontrar como parte de su objeto del conocimiento, si piensan mantener la universalidad de su exigencia. Dado que, si todo lo que tratan como su objeto, lo tratan como sistema o como distinción, este supuesto implica que se deben tratar a sí mismos también como sistema o como distinción. Si se parte, por ejemplo, de una sociología orientada hacia la teoría de los sistemas, entonces se puede describir el objeto y la ubicación de una sociología de este tipo de la siguiente manera: La sociología orientada hacia la teoría de los sistemas es parte del subsistema "teoría sociológica", el cual por su parte tiene una función reflexiva dentro del sistema de la sociología. La sociología es, por su parte, un subsistema del sistema de la ciencia, el cual a su vez es subsistema del sistema global de la sociEDAD. Con ello, la sociología cumple la función reflexiva en el sistema global de la SOcIEDAD. Se ve que: la generalización universal y la especificación perspectivista están estrechamente relacionadas. Solamente en este sentido, una sociología orientada hacia la teoría de los sistemas puede tener exigencias de universalidad, es una "superteoría", (figura 66).

Por el otro lado, la tesis de la inmediatez de una operación es condición para la simultaneidad. La inmediatez emula así al mismo tiempo a la simultaneidad y a la no-simultaneidad, algo que a la vez es posible observar a través de la operación de la observación..., etc. Este estilo de argumentación posee una forma no-jerárquica, comr. se puede observar.

${ }^{91}$ Weizsācker, C.F.v., 1992a, p. 594. 


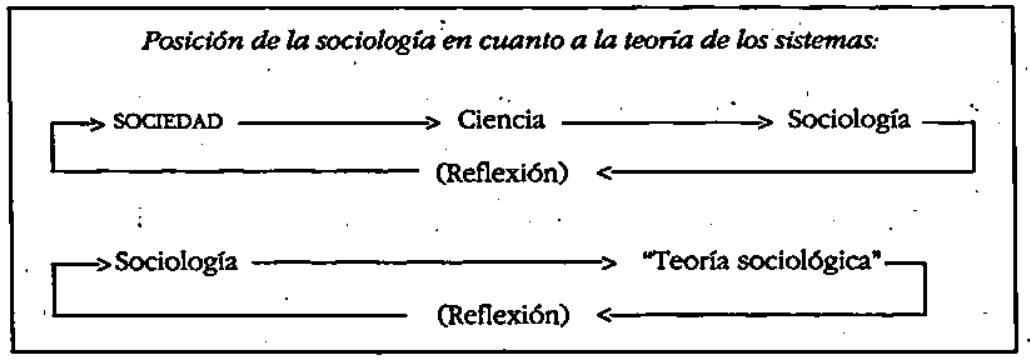

TEMPORALUZACIÓN DE LA CIRCUNSTANCIA CIENTIFICA

21. La cada vez más radical temporalización del objeto científico de la investigación, supuesto como simple, conduce, por una parte, al hecho de que éste se extienda hacia la "infinidad" de las áreas macro y micro, o sea, que pierda sus límites y con ello su identidad. Segundo, se hace claro que cualquier simplicidad observada a otro nivel, es una formación altamente compleja. Gastón Bachelard, refiriéndose a la microfísica, expresa el problema de la volatilización del elemento simple físico "cosa", que se genera a través de la temporalización de la partícula elemental, y así se desnuda de su espacialidad cotidiana, de la siguiente manera: "[...] una vez asociado el concepto de la cosa con las características de la partícula elemental, ya se deben pensar los hechos experimentales de tal manera que se retenga aquella plasticidad exagerada que se encuentra encerrada en esta inofensiva palabra cosa. En especial, se le deben quitar a la cosa sus características espaciales. Pero, con ello, se define a la partícula como una cosa que es una no-cosa".92 No se puede expresar más claramente la pérdida de identidad (a través de la paradojización: como una cosa, la cual no es ninguna cosa) de un objeto de investigación cientifica. Pero dado que no es imaginable una actividad científica sin la identificación de un hecho científico básico, se presenta en este contexto el problema de la inclusión y, con ello, el de la identificación de lo simple como la forma basal del hecho científico. ¿Cómo es aún posible, bajo esas condiciones de volatilización de la simplicidad basal, la ciencia? ¿Bajo cuáles condiciones se puede aún hablar de una circunstancia basal-homogénea dentro del sistema de la ciencia?

${ }^{92}$ Bachelard, 1974, pp. $64-65$. 
22. El problema de una posible pérdida de identidad del hecho científico se formula, por lo pronto, en la forma del problema de su "evidencia": ¿cómo se verían, por ejemplo, los átomos (o las unidades aun más "pequeñas", como los neutrinos), si se les pudiera hacer un billón de veces más grandes de lo que realmente son? "Respuesta: no se verian de ninguna manera; entonces tampoco habria nada que ver; los átomos son no-evidentes en el sentido de la palabra." ${ }^{.93}$ Las estructuras del conocimiento que hacen colapsar nuestra facultad intuitiva en el área de la física moderna, representan en primera línea estructuras que están relacionadas con las dimensiones del objeto, o sea, con su distinción grande/pequeño. Las estructuras biológicas - esto debe realzarse especialmente- y sobre todo las estructuras sociales, o sea las expectativas y estilos de expectación, conducen también hacia el colapso de la facultad intuitiva normal, ${ }^{94}$ pero no debido a la proporción numérica o a las magnitudes de los "componentes" que la constituyen, sino debido a una intrincada diversidad de los efectos recíprocos de los componentes sociales; esto quiere decir, debido al rerracionamiento sobreproporcionalmente observable de los elementos que constituyen el "objeto".

Con "componentes" de lo social nos referimos a la unidad de distinción entre COMUNICACIÓN y ACCION, la cual se puede comprender, en el marco de una teoría de las distinciones, más ampliamente como la unidad de la distinción de diferencia (simétrica) y diferenciación (asimétrica). Las estructuras y los estilos de estructuras (percepción, corporalidad, afectividad, personalidad y socialidad) de la sOcIEDAD son apenas una consecuencia de la condensación de la unidad entre distinción de expectación y experiencia.

${ }^{93}$ Vollmer, 1986, p. 125. Acerca de ello también P. Frank: "La idea de que con una mayor agudeza de los sentidos se podrían ver los átomos así como ahora se ve el sol es una ilusión." (Idem). La ciencia natural de Goethe es seguramente ilustrativa, en ella se trata de la percepción del fenómeno original, pero el programa de la fisica nuclear es, desde el principio, desesperadamente no-ilustrativo. Algo similar se aplica al programa de una sociología orientada hacia una teoría de los sistemas o hacia una teoría de las distinciones, y ciertamente, a toda la empresa "sociológica".

"Con "facultad intuitiva normal" se expresa aquí el ámbito del mesocosmos: al área del mundo que vivimos y experimentamos ingenuamente (precientíficamente) la llamamos el "mesocosmos". Es "[...] un mundo de las dimensiones medias". (Vollmer, 1986, p. 103). Acerca de ello también A. Schack, J.K. Feibelman y LV. Bertalanffy. (lbid., anotación 3, p. 132). 
Por ello, Jaques Monod opina que la causa de las dificultades de entendimiento en el área de la física, sea la escala de magnitudes del fenómeno observado, la cual ya no puede ser comprendida con las categorías de nuestra experiencia de la contemplación inmediata. Esta deficiencia podría compensarse ciertamente con la ayuda de una determinada operación de abstracción, que, sin embargo, no la puede reparar fundamentalmente. Con la biología - y añadimos con cualquier tipo de "fenómeno" social - la dificultad seria de otra manera.

En este contexto, son clásicos los trabajos de Norbert Elias, quien siempre intenta demostrar que con las estructuras sociales no se trata y no se puede tratar de estructuras visibles o perceptibles. Las sociedades no tienen ninguna forma ilustrativa, "[...] no poseen estructuras que se puedan ver, oír o tocar inmediatamente en el espacio. Son, contempladas en su totalidad, siempre más o menos no-cerradas: permanecen en la esfera del tiempo, abiertas, es decir, hacia el futuro o el pasado, independientemente de dónde se comienza con la observación. A los padres, hijos de padres, les siguen los hijos; a las madres les siguen hijas. Ahí existe, de hecho, un fluir continuo, un cambio rápido o lento de las formas de vida y estilos; sólo dificilmente el ojo encuentra un punto en donde fijar la vista". 95 Podemos añadir adicionalmente que las estructuras sociales son esencialmente estructuras del tiempo (unidad de la distinción de expectaciones y experiencias), las cuales carecen, precisamente debido a ello, decualquier espacialidad. Esta caracteristica las hace difícilmente concebibles. $Y$ en lo que concieme a la ACCIÓN como forma central de lo sOCAal, está expresada en los más raros casos como una operación corporal y con ello perceptiblemente. Aquí se hace notorio el problema de una comunicación verbal y escrita cuya forma semántica es, en gran medida, espacial. Este problema es descrito muy ilustrativamente por Otto Friedrich Bollnow. 96

Los efectos recíprocos elementales que sirven de base a todo, son relativamente fáciles de comprender, debido a su carácter mecánico. La monstruosa complejidad de los sistemas vivos se escapa a cualquier imaginación intuitiva vasta. ${ }^{97}$ Aquí puede ayudar solamente una

${ }^{95}$ Elias, 1998, p. 29.

${ }^{96}$ Bollnow, 1984.

"Monod, 1975. 
determinada forma de operación de la abstracción, que utiliza de manera adecuada la distinción de lo abstracto y lo concreto.

La distinción presupuesta en ese contexto de abstracto/concreto significa - lo que no parece ser tan obvio- que la inclusión de lo concreto ya implica una gran capacidad de abstracción, o sea que sólo es posible como algo abstracto. ${ }^{\$}$

Partimos del hecho de que se debe reconstruir la identidad del hecho científico en el área de la sociología por medio de la semántica del tiempo, y que se debe considerar como el contexto de las distinciones COMUNICACIÓN/ACCIÓN y expectación/experiencia. Con ello se debe partir del hecho de que un suceso de larga duración asume una función de estructura frente a un suceso de menor duración.

Queremos expresar con ello que, con los fenómenos sociales se trata de relaciones entre los relacionamientos de sucesos temporalizados, con lo cual se forman las estructuras (o sea las expectativas y experiencias), debido al hecho de que los sucesos que duran más que otros, asumen una función de estructura frente a éstos más volátiles. Esta relación de formación de sucesos momentáneos/duraderos dentro de la sociedad, se procesa paradigmáticamente con ayuda de la distinción COMUNICACION Y ACCION, de la cual entonces emanan las estructuras correspondientes (expectación y experiencia).

El acontecimiento corto (una ACción, por ejemplo) es la condición previa indispensable para el sostenimiento de los sucesos de más larga duración (una expectación, por ejemplo), y viceversa.

Con esta afirmación expresamos la posición de este trabajo: todo lo que "es", "es" solamente debido a una relación en el tiempo; "es" solamente sobre la base de relaciones temporalizadas de sucesos. De ahí viene también la temporalización del problema de la complejidad en la forma "[...] de que todo lo que sucede, sucede simultäneamente".99 No obstante, la tesis de la simultaneidad implica el supuesto de una

*Claessens, 1980 , pp. 235 y ss.

${ }^{99}$ Luhmann, 1990a, pp. 98 y ss. 
tesis de la inmediatez, como ya lo hemos demostrado antes. La TsS parece no ver esto.

23. La temporalización y la conexión con el factor tiempo de io simple, conducen a la comprensión de su estructura compleja. Pero con ello, la distinción de complejo y simple pierde - por lo menos aparentemente- su función regulativa indicadora de distinciones. Dado que por medio de la temporalización del objeto de la indagación, los limites ilustrativos pierden ahora su validez, tanto en el área macro como en la micro, se llega al problema de la determinación de los límites del objeto de la indagación científica. En este contexto, siempre se han ofrecido dos procedimientos de reducción ${ }^{100} \mathrm{pa-}$ ra solucionar este problema: primero, la reducción de las unidades complejas hacia otras menos complejas, y con ello la reducción de lo complejo hacia lo simple, con lo cual, en la discusión, se trata frecuentemente de un "reduccionismo ontológico", que trata de reducir, por ejemplo, lo orgánico a lo inorgánico. Segundo, la "reducción" de lo simple a lo complejo en el sentido de que el todo es más que la suma de sus partes. Esta segunda estrategia, conocida como el "holismo ontológico", es también un reduccionismo (disfrazado), ya que parte del hecho de que, por ejemplo, la realidad física "no sea otra cosa que un tipo de simplificación ejemplar de la realidad [...] organísmica", como lo expresa el biólogo A. Mayer-Abich. ${ }^{101}$ Ahora bien, en la ciencia uno seguramente no llega lejos sin un "reduccionismo" orientado pragmáticamente. Con esto se quiere decir que se puede escoger de la abundancia de fenómenos solamente uno u otro fenómeno, para poder analizarlo y procesarlo todo, dentro de un determinado lapso. ${ }^{102}$ Ciertamente no es suficiente formular con Franz $\mathrm{M}$. Wuketis, ${ }^{103}$ que la reducción y el holismo (composición) representan dos alternativas de direcciones opuestas entre sí, las cuales, no obstante, son aspectos complementarios de la inclusión del mismo objeto de investigación, pero sí señalan hacia la dirección correcta. Es decir que adicionalmente se debe mostrar operativamente cómo funciona realmente una complementariedad de esta índole.

${ }^{100}$ Véase acerca de ello el ensayo informativo de Gerhard Roth, 1981.

${ }^{101}$ Franz Wuketits, 1983, p. 128.

${ }^{102}$ Esto es un problema demasiado conocido de la investigación. Véase, con referencia a los modelos de estructuras de la historiografía acerca de la industrialización en Europa, Rapp, Jokisch, Lindner, 1980.

${ }^{103}$ Franz Wuketits, 1983, pp. 129 y ss. 
24. Si lo simple fuera verdaderamente lo complejo, entonces el holismo reproduciría una forma de reduccionismo (o sea la "reducción de lo simple a lo complejo"), y la operación de la reducción como operación metodológico-pragmática representaría una conditio sinequa non de la práctica de la investigación científica, ¿cómo se pueden conciliar estos supuestos? La volatilización de lo simple por medio de su temporalización y complejización condicionada por ello, conducen a una "inconsistencia" de lo que ahora solamente es complejo, dado que todo lo anteriormente simple es complejo en el presente. Esta "inconsistencia" se genera debido al hecho de que lo complejo ya no es ontologizable, por un lado, en lo simple e indestructible y, por otra parte, en lo complejo, y esto quiere decir, lo ensamblado. ${ }^{104}$ Lo complejo que se ha vuelto insostenible, puede encontrar un "sustento" solamente cuando se organiza a si mismo en una forma tal que lo envista de sustento, a pesar de su "insostenibilidad". Dado que un "sustento ajeno" ya no es posible por medio de lo ontológicamente elemental o sin transparencia o fundamental, solamente queda un "autosustento". Pero ¿cómo debe lo complejo consumar esta misma operación? ${ }^{105}$ No debemos olvidar que también lo simple ahora es complejo y que con ello lo complejo ya no puede constituir su identidad por medio de lo simple. ¿Cómo es aún posible lo complejo bajo estas condiciones?

\section{¿COMO ES POSIBLE LA COMPLEJIDAD?}

25. El problema clásico de la complejidad consiste en la aclaración de la unidad de lo diverso. E. Leeuwenberg lo expresa asi: "Complexity is only of importance if in a certain respect there is a high degree of complexity and in another respect there is unity. ${ }^{106}$ El hecho complejo se presenta por ello simultáneamente (esto quiere decir a la vez) como la uniformidad y como la diversidad. ${ }^{107}$ Con ello se puede decir

${ }^{104}$ Acerca del contexto de historia de la teoría simple-indestructible-no desarticulado por un lado, y complejo-destructible-desarticulado por el otro, véase Luhmann, 1984, p. 50.

${ }^{105}$ Dado que procedemos autorreferencialmente, también debemos demostrar cómo algo (lo complejo, la comunicación, la acción, la expectación, etc.) se constituye operativamente a sí mismo como "algo".

${ }^{106}$ Luhmann, 1975a, p. 204.

307 "Un concepto uniforme es sensato solamente cuando la diversidad puede ser tratada bajo algún aspecto como unidad. Por ello, el concepto de 
que el problema de la complejidad es equivalente a la pregunta: ¿cómo es posible la unidad de la diversidad? Si todo lo que sucede sucede simultâneamente, entonces la "unidad de lo que acontece simultáneamente" debe implicar una forma capaz de operación como el problema de la complejidad, precisamente para poder constituir una unidad en lo diverso. Si esto no ocurre, entonces tiene validez el dicho de que todo está relacionado con todo, una afirmación ciertamente inteligente, pero poco informativa. Una posibilidad de operacionalizar el problema de la diversidad simultáneamente dada, consiste en traducirla en la distinción de los elementos y sus relaciones. ${ }^{108}$.

Observamos que la constitución de las distinciones responde al problema de la simultaneidad. Pero con ello se alimenta más al problema, porque después existen aün más elementos que pueden estar presentes a la vez.

Con ello, la complejidad se considera como el problema del relacionamiento de sus elementos constitutivos. La unidad de la diversidad se puede traducir entonces como el relacionamiento (=unidad) de los elementos en forma determinada (=diversidad). Aquí tenemos ante nosotros una distinción, a la cual observamos como la simultaneidad de los elementos y sus relaciones, pero a la que podemos manejar operativamente sólo cuando nos dirigimos hacia el uno o (en el sentido excluyente, solamente en la forma de la no simultaneidad) el otro lado de la distinción. Para poder acercamos al problema de la complejidad, necesitamos, en ese sentido, de dos distinciones: por un lado. los elementos y sus relacionamientos, por el otro, las observaciones y operacionalizaciones (figura 67).

\begin{tabular}{lc}
\hline Pragmática de las distinciones: & Problema de la complejidad: \\
Observación $\rightarrow$ (simultaneidad de:) & elementos y sus \\
$\downarrow$ & relacionamientos \\
\hline
\end{tabular}

complejidad formula por lo pronto la intención de ver lo diverso bajo el aspecto de su unidad. El objeto complejo debe ser simultáneamente lo diverso y la unidad." (Ibid., pp. 204-205).

${ }^{108}$ Luhmann, 1984, p. 45. 
Ya con el intento de captar el problema de la complejidad, estamos obligados a hacer uso de dos distinciones diferentes: una diferenciación asimétrica de observación/operación y una diferencia simétrica de elementos/relaciones. Dado que cada distinción consiste en dos lados respectivamente, resulta una forma tetrádica. La asimetría de observación/operación se genera debido al hecho de que no es posible efectuar ambas operaciones simultáneamente: 0 se observa a la distinción en cuestión, o se utiliza una distinción correspondiente (quizás para observar a otra distinción). Pero no se puede utilizar y observar a la misma distinción simultáneamente. Por el otro lado, la distinción de elementos/relaciones está dada, desde la perspectiva de la observación, simultäneamente en sus dos lados y esto quiere decir, actualmente, pero desde la perspectiva operativa es designable solamente en secuencia, y esto quiere decir que es operativamente accesible solamente con el consumo del tiempo (formulado modalmente: posible).

Con referencia a una diferenciación asimétrica, la TsS formula la circunstancia de manera análoga: "Toda observación requiere un diferenciamiento y una denominación de un lado (y no el otro) de la diferenciación, o sea, una cosa y no la otra. Con ello, ambos lados de la diferenciación deben ser separados por un límite y estar simultáneamente dados por él. Por otra parte, la transición de un lado hacia el otro requiere del cruzamiento del límite, una operación, o sea tiempo. Los dos lados de la diferenciación están dados simultáneamente, pero no son utilizables simultáneamente [R], ya que esto anularía la diferenciación y con ella la observabilidad. Ambos lados están dados simultáneamente y'en una relación de antes/después. ${ }^{109}$ ¿Cierto! Por ello partimos del hecho de que la "operación" como forma de la inmediatez constituye simultâneamente las distinciones "diferencia simétrica" (-simultaneidad) y "diferenciación asimétrica" (=no simultaneidad). Cada comienzo es - visto desde la teoría de las distinciones-siempre tetrádico: genera dos distinciones diferentes, cada una con dos lados. No nos queda claro por qué la TsS no pone este supuesto al principio de su arquitectura de la teoría.

26. Queremos recordar otra vez que la forma nueva del problema de la complejidad se obtiene obligadamente por la circunstancia de que ahora también lo simple se considera como complejo; un cono-

${ }^{109}$ Luhmann, 1990a, p. 100. 
cimiento del cual ya Karl Marx está conciente explícitamente: "Lo concreto es concreto porque es el resumen de muchas determinaciones, o sea la unidad de la diversidad. ${ }^{110}$ Con referencia a la observación de la distinción de los elementos y sus relaciones, vale por principio, que ni existen los elementos sin vinculación relacional, ni tampoco las relaciones sin los elementos. Dado que ambas cosas se condicionan mutuamente, ya desde aquí se trata de una unidad, la cual, no obstante, tiene efecto como distinción de los elementos y sus maneras de relacionarse

Desde el punto de vista científico constituimos a la unidad mostrando, en el nivel operativo, que la "unidad" solamente es posible como distinción, con lo cual lo particular de una distinción de este tipo descansa en el hecho de que es complementaria: los lados de la distinción (por ejemplo elemento/relación) se constituyen mutuamente, pero simultáneamente se excluyen uno al otro. Para detalles, ver el capítulo I sobre la forma. En lo que concierne al contexto de constitución de la circunstancia científica y del fenómeno, nos apoyamos en Humberto R. Maturana, quien formula: "Con ello me pareció o quedó claro que cualquier intento de explicar cientificamente un fenómeno, de hecho debe consistir en desarrollar un mecanismoqueproduciria el fenómeno por explicar [R]."11!

La "unidad de la diversidad" sería en este caso - visto formalmente- la unidad y la distinción. Y precisamente así hemos definido también a la observación: como el manejo de una diferencia simétrica (=una operación que causa una distinción) frente al trasfondo de una diferenciación asimétrica (=la operación que causa unidad) con la medida de generar información.

Sea dicho preventivamente que: primero, aquí se puede observar la distinción de diferenciación y diferencia; segundo, tanto la diferencia como la diferenciación consisten en distinciones diferentes: la diferencia, en una distinción simétrica, la diferenciación, en una distinción asimétrica. Tercero, la distinción entre diferencia y diferenciación es, a su vez, una distinción de forma asimétrica, o sea una diferenciación... etcétera.

${ }^{110} \mathrm{Karl}$ Marx, en Marx/Engels, tomo 13, 1969, p. 632. Hemos encontrado la referencia en Luhmann, 1975a, p. 216.

"11 Maturana, 1985, p. 16. 
Ahora se pueden contar los elementos y calcular las relaciones entre ellos. Pero una operación de esta naturaleza, de conteo y cálculo de los elementos, produce en última instancia solamente lo cuantitativo, nada cualitativo. Si ahora se debe partir del hecho de que - visto en general- la constitución del mundo tiene lugar sobre la base de la complejidad, y de que el mundo consiste de hecho en una diversidad de cualidades, pero que los elementos y sus relaciones sólo permiten una expresión cuantitativa, ¿cómo llega al mundo la cualidad? Con otras palabras: ¿cómo produce la cantidad a la cualidad, la homogeneidad a la heterogeneidad?

Presuponer que el mundo o la SOCIEDAD estén determinados cualitativamente desde el principio, sería un supuesto irreal, el cual chocaría además con los conceptos actuales de la teoría de la evolución.

27. La pregunta acerca de la calificación de las cantidades conduce a la operacionalización del problema de la complejidad en la forma de una relación de los elementos y sus relaciones. ${ }^{112}$ Esta operacionalización dice que un aumento del número de elementos conduce a un aumento de las relaciones posibles entre ellos. Con ello existe en algún momento "[...] un umbral, desde el cual ya no es posible relacionar cada elemento con todos los demás". ${ }^{113}$ En ese contexto, "algo" es complejo cuando, debido a las limitaciones inmanentes a la capacidad de relacionamiento entre los elementos, ya no se puede asociar en cualquier momento cada elemento con cada uno de los otros. Ya desde ahora se ve que la complejidad no es posible sin la referencia del sistema, dado que siempre se debe presuponer un "algo", o sea un enfoque, una "multitud relacionada" de elementos como referencia del sistema, para poder observarla y describirla.

1 Por ello también la afirmación -efectuada consecuentemente- de la TsS es esencial: "Con el aumento del número de elementos, los cuales deben ser mantenidos juntos dentro de un sistema o como entorno para un sistema, se llega rápidamente a un umbral [...]". ${ }^{134}$ La condición previa de un sistema está dada aquí claramente en la TsS, respecto al problema de la complejidad. Esta observación es importante porque en otro lugar, aún por mostrar, la TsS niega esta condición previa del

${ }^{112} \mathrm{La}$ TsS ve en este problema el problema principal de la complejidad. 113 Luhmann, 1984, p. 46.

114 Idem. 
sistema y trata de introducir a la complejidad sin ninguna referencia de sistema. Una maniobra arriesgada, como veremos.

Lo "interconectado" (cualquier cosa que esto sea) expresa, en este caso, la autorreferencia: simplemente está conectado con "algo". En ese sentido, la complejidad, comprendida como la distinción de los elementos y sus relacionamientos, es concebible solamente en cuanto a una autorreferencia, y con ello, solamente en referencia con la distinción de sistema y entorno, dado que los elementos sólo pueden ser elementos (precisamente de este sistema) respecto a un sistema (o "algo", para mantener el nivel de abstracción seleccionado).

No hay elementos "en sî", pero los elementos pueden ser sistemas en otro nivel de abstracción, y con ello limitar y generarse mutuamente los "elementos" y los "sistemas".

Por ello, la complejidad siempre es posible solamente como complejidad organizada o - lo que significa lo mismo- como complejidad de sistema. Con ello, sin embargo, no se ha divisado nada sobre el surgimiento de un sistema de esta índole, el cual pueda ser comprendido como la "unidad de lo diverso", y que forme simultáneamente al problema de la complejidad. Debemos deducir entonces que el problema de la complejidad siempre es el problema de la complejidad de un sistema, el cual se constituye como la "unidad de lo diverso". En ese sentido, el problema general de la constitución de un sistema es idéntico al problema general de la complejidad, lo cual señala que se puede describir a cada formación de un sistema como el intento de resolver el problema de la "unidad de lo diverso" bajo las respectivas condiciones específicas. Cada formación de sistema es, por lo tanto, una solución lograda (provisionalmente) del problema de la complejidad. ${ }^{115}$ Si se vuelve a hacer la pregunta acerca de cómo sería posible la complejidad, entonces, en ese contexto, se puede responder provisionalmente: por medio de la formación de un sistema, realizada de cualquier manera.

28. Ia TsS introduce el concepto de la complejidad también como un concepto problemático, y lo define sobre la base de los concep-

${ }^{115}$ Es un supuesto del todo trivial y obvio en su consecuencia argumental, pero como constitución argumental de esta consecuencia es una tesis excitante. 
tos elemento y relación. La justificación es: "Esto tiene la ventaja de que el concepto es aplicable también a los no-sistemas (mundo, medio ambiente), y que puede enriquecer con aspectos adicionales el análisis teorico de sistemas, ya que está definido sin la utilización del concepto delsistema [R]]. ${ }^{116}$ No obstante, hemos visto que los elementos sólo pueden ser elementos de un sistema, y que en ese sentido, la conexión de sistema y elemento es imprescindible. Si se utiliza el concepto de elemento sin el concepto de sistema, entonces uno tendră que tratar consecuentemente con una ontologización del concepto elemento, dado que se abandona el carácter relacional del concepto elemento.

Seguramente, el entorno no es ningún sistema porque sistema no es, precisamente, ningún entorno. Ahora bien, si el concepto elemento debe ser aplicable a no-sistemas como el entorno, entonces este supuesto implica la existencia del entorno. Pero sin la existencia del sistema nó es concebible una existencia del entorno (por lo menos según la teoría de sistemas, la cual se presupone aquí como obvia). Entonces, ila referencia de un elemento hacia el entorno, como una forma de nosistema es, no obstante, "sistémica" en el sentido de que no puede haber ningún entorno sin sistema? Esto sería de todas formas una interpretación posible de la secuencia de argumentación, la cual nos parece inconsistente, y es presentada por la TsS en referencia al concepto de elemento.

Lo notable en este contexto es que la TsS continúa, inmediatamente después de los citados renglones, con el establecimiento de que los elementos pueden ser elementos solamente dentro de un sistema: "Pero conservamos la unión con la teoría de los sistemas por medio de la tesis [...] de que lo que funge como elemento respectivo, no puede ser determinado independientemente del sistema. ${ }^{117} \mathrm{Con}$ sideramos una argumentación de esta naturaleza como extremadamente inconsistente, aunque queremos conceder que una maniobra de esta índole siempre es posible (y aunque sea solo precisamente porque es posible proceder de esta manera; sin embargo, con ello habrá que aceptar inconsistencias lógicas).

${ }^{116}$ Luhmann, 1984, p. 45.

${ }^{117}$ Ibid.; pp. 45-46. 
Una grand theory bien llevada puede permitirse ciertamente ubicar las inconsistencias lógicas en determinados lugares seleccionados para ello. Esto provee a la teoría de más flexibilidad y elasticidad y la puede prevenir de un posible "callejón sin salida". Sería seguramente atractivo referirse a la función de la inconsistencta lógica dentro del discurso científico. Por el momento, solamente llegaremos hasta aquí.

29. La imposibilidad de poder asociar, a partir de cierto número de elementos (dentro de un sistema o para un sistema), a cada elemento con los demás, conduce a un relacionamiento selectivo de la cantidad de elementos del sistema. Esta "limitación inminente" (o saturación del relacionamiento) del elemento que remite "[...] a la complejidad interna de los elementos, la cual no está disponible para el sistema[...]", ${ }^{118}$ es la razón de la tránsformación productiva de la cantidad a la calidad. Con ello, la calificación de la cantidad tiene lugar a través del hecho de que el relacionamiento de los elementos de un sistema específico, pueden efectuarse solamente de manera especifica. De esto surge una forma de unidad especifica cualitativa de los elementos calificados, por lo demás, cuantitativamente. Por ello, es la selección especial del tejido de relaciones, la que califica al sistema. Debido a que solamente puede tener lugar un relacionamiento determinado entre los elementos, aun cuando serían posibles otros relacionamientos, esta operación selectiva produce la contingencia. ${ }^{119}$ Con ello también se ha dicho que la calificación de la cantidad representa, debido a la limitación inmanente de la capacidad de relacionamiento de los elementos, un problema de tiempo. Si los elementos (como sucesos, como ACCIONES) "tuvieran tiempo infinitamente", entonces podrian realizar todos sus relacionamientos posibles. Pero los elementos mismos son - como sucesos- formas del tiempo con una duración limitada, y por ello tienen una forma volátil de identidad. Por esto se puede formular también que es particularmente el carácter temporal de los elementos como sucesos, el responsable de la limitación inmanente de su capacidad de relacionamiento. Por el otro lado, precisamente por ello, es posible una calificación de la cantidad, una heterogeneización del mundo o de la SOCIEDAD, sobre la base de elementos volátiles homogéneos. Ahora bien, si se

118 Ibid., p. 46.

119 Así también formula la TsS: "denominamos a este 'poder ser de otra manera' con el término, rico en tradición, de contingencia ${ }^{n}$. (bbid., p. 47). 
condiciona un relacionamiento selectivo, entonces se puede explicar, " $[. .$.$] que se pueden formar de una capa inferior de características$ muy similares [por ejemplo, a partir de unos pocos tipos de átomos, organismos humanos muy similares] sistemas muy variados" ${ }^{n}{ }^{120} \mathrm{En}$ tonces, la calificación de lo cuantitativo, y la diversidad del mundo (de su complejidad), no es otra cosa que el producto de la limitación selectiva de la capacidad de relacionamiento de los elementos de un sistema; lo cual, por su parte, no es otra cosa que el intento de un sistema por conducir su problema de complejidad hacia una solución (especifica para este sistema). La heterogeneidad surge de la' homogeneidad; la diversidad de la simplicidad; la calidad de la cantidad. Por lo tanto, los sistemas no son otra cosa que las soluciones específicas provisionales del problema de la complejidad. Cada sistema debe encontrar una solución especial para la operacionalización de su unidad de lo diverso, por medio de lo cual se vuelve, precisamente, "simétrico".

El que nunca se llegue a una solución definitiva del problema de la complejidad está garantizado por la doble contingencia (nosotros [TgS] hablamos en este contexto de la doble diferencia, ver capítulo III): con el intento de hacer transparentes las black boxes, por principio no-transparentes, el problema de la complejidad regresa una y otra vez, siempre es actual y siempre da ocasión a la formación de sistemas.

Únicamente así es posible explicar, transferido a la SOCIEDAD, el cómo puede surgir de las unidades COMUNICACTTVAs homogéneas simples, una diversidad de COMUNICACIONES en la forma de expectativas y estilos de expectativas, la cual conformará entonces la diversidad y la poliformidad de la SOCIEDAD.

Aquí también se encuentra el punto de conexión para la fundamentación de los estilos de COMUNICACIÓN. Regresaremos a ello.

30. Los elementos no pueden ser observados sin la referencia del sistema, dado que los elementos, como ya lo hemos visto, son elementos del sistema correspondiente. Si ahora se quiere comprender la complejidad en el marco de la pragmática de las distinciones, entonces se deben presuponer dos distinciones que se encuentran en po-

${ }^{120}$ Idem. 
sición ortogonal entre ellas: sistema/entomo y elemento/relación. Habiamos dicho que la observación consiste en el manejo de una diferencia simétrica frente al trasfondo de una diferenciación asimétrica con el propósito de generar información. Transferido al hecho de la complejidad, esto significa entonces que la complejidad se constituye por medio del entrelazamiento de dos distinciones, o sea de la diferenciación asimétrica de sistema y entorno, y de la diferencia simétrica de los elementos y relaciones. Así, la complejidad es un ensamble de relacionamientos tetrádico, consistente en cuatro relaciones de sucesos: sistema, entomo, elemento y relación (figura 68).

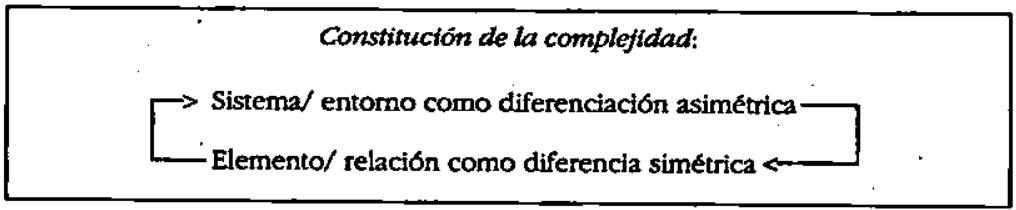

Se recuerda que hemos procedido ya con el planteamiento de la pragmática de las distinciones, para poder observar el fenómeno de la "complejidad", tetrádicamente, y esto quiere decir que nos pudimos acercar al hecho de la "complejidad" solamente sobre la base de dos distinciones, o sea aquélla de la observación/operación y la de elemento/relación. Lo complejo, por su parte, se constituye por el relacionamiento de las distinciones elemento/relación y siste$\mathrm{ma} /$ entomo. Ahora bien, la formación de "algo" - por ejemplo de un sistema- es posible solamente por medio de su bermeticidad frente a "algo diferente", con lo cual esta hermeticidad se genera con la ayuda de los limites.

Partimos generalmente del supuesto de la existencia de los sistemas del sentido cerrados - autorreferenciales-y adoptamos a ese respecto el supuesto básico de la teoría de los sistemas autopoiéticos, tal como se encuentra expuesta en el marco de la teoría de los sistemas sociales (TsS): "Las siguientes reflexiones parten del hecho de que existen sistemas." (Luhman, 1984, p. 30). La cuestión de la validez será tematizada aquí solamente en forma rudimientaria por razones de unidad y espacio. Esta hubiera tenido, por lo demás, la siguiente forma: debería ser mostrado reflexivamente que el proceso operativo en cuestion únicamente era posible con posterioridad, de la manera en que fue realizado. Ésta clase de demostración debería indicar que es ge- 
neral y necesario. En otro lugar - la forma de la sOcIEDAD (Jokisch, 1995) - intentamos demostrar que para la solución del problema de la validez se debe acoplar la figura de la autopoiesis con la figura de la autorreflexión. En este contexto, son de significado particular, sobre todo, los trabajos de Karl-Otto Apel (1976a, 1976b, 1990); Wolfgang Kuhlmann (1985); Dietrich Böhler (1985) y Vittorio Hösle (1988 y 1992). Se comprende que aquí, sobre todo, la filosofia trascendental juega un papel relevante. En otras palabras, a través de las categorías "operación", "distinción" y "observación", intentamos hacer concordar. aspectos de la arquitectura de la teoría de la filosofia trascendental, comprendida como la reflexión acerca de las exigencias propias en cuanto a la validez (Kant, Fichte, Hegel) con la pragmática trascendental (Apel, Kuhlmann, Böhler, Hösle), con la pragmática universal (Habermas), con la teoría de sistemas (Luhmann) y de la biología (Maturana, Varela).

No pueden existir en absoluto, dos "algos" que no muestren ninguna distinción entre sí, pues serían entonces una "primera vez" no identificable, tal como el "aplaudir con una mano". Si "algo" se debe distinguir de "algo diferente", entonces uno de los "algos" debe ser menos complejo que el "otro algo", debe surgir un declive de complejidad entre ambos "algos", respecto al diferenciamiento de los elementos y sus relacionamientos.

- Ésta también es la razón para que la información de cualquier tipo, - siempre constituya un entrelazamiento entre la diferenciación asimétrica (por ejemplo, sistema/entorno) y' la diferencia simétrica (por ejemplo, elemento/relación).

De esta manera, es exactamente la forma de la calidad de los elementos presupuestos cuantitativamente y de sus relacionamientos, la que determina el nivel de diferenciación entre el sistema y su entorno. Teniendo esto en mente, se puede decir que el sistema siempre debe ser menos complejo que su ambiente.

Al revertir esté hecho, o sea con la afirmación de que el sistema fuese más complejo que su entorno, se llegaría al mismo resultado, porque entonces el "entorno" sería el sistema y el "sistema" sería el entorno.

¿Pero por medio de qué se alcanza un declive de complejidad de esta naturaleza? Por medio del cierre del sistema frente a un entorno sobrecomplejo. El cierre del sistema separa al sistema de su entorno y lo constituye a la vez preçisamente a través de él. Por esto, el 
cierre con la consecuencia de un declive de complejidad entre sistema y entorno (o entre "algo" y "algo diferente") es la condición para la posibilidad de la formación (de "algo" o) de un sistema de cualquier tipo. Si el sistema permaneciera abierto frente a su entorno (en forma general), entonces ni siquiera se podría constituir, ya que no podría generarse ninguna diferencia de niveles entre el sistemä y el entorno: el sistema y el entorno serían congruentes en cuanto a la complejidad y, de esta manera, no serían ni sistema ni entomo, sino solamente caos, o sea "primeras veces". Con referencia a la distinción de sistema/entomo, se puede formular que cualquier "algo" y con ello, cualquier sistema es posible únicamente sobre la base de una asimetría de complejo/menos complejo, es decir, sólo sobre la base de un declive de complejidad.

31. No obstante, ningún sistema puede existir como sistema absolutamente cerrado.

Esto es un reproche que aparece una y otra vez respecto a una teoría de los sistemas cerrados autorreferencialmente, el cual se produce presuntivamente por medio de la semántica - del cuño de la teoría de sistemas- de la "hermeticidad", sin que el crítico se tome el trabajo de analizar más exactamente cómo el sistema (o sea, también él mismo) logra combinar la hermeticidad con la apertura. Somos de la opinión de que la connotación teórica del sistema, en relación con la SOCIEDAD, selecciona demasiado fuertemente. A través de ello los malentendidos son preprogramados desde el principio. Nosotros vemos una posible solución para este problema al complementar una connotación teórica de sistemas con una connotación teórica de expectativas, un propósito que en este trabajo solamente intentamos hacer visible a grandes rasgos.

Alguna forma debe poder abrirse frente a su entorno. Sin embargo, el problema es que una apertura "absoluta" conduciría hacia la nivelación del declive de la complejidad, con lo cual desaparecería el sistema. Aparentemente, la única alternativa plausible consiste en el hecho de que el sistema logra ambas cosas: un cierre y una apertura "relativa" simultáneos. ${ }^{121}$ ¿Pero, cómo se genera una operación paradójica de esta índole?

${ }^{121}$ La TsS opina que el concepto de la hermeticidad autorreferencial de un sistema, no se encuentra en contradicción con su apertura hacia el entor- 
Recordemos otra vez que las paradojas y tautologias se generan porque se deja sin consideración la dimensión del sentido del tiempo. La presentación de la identidad por ejemplo, no es posible de otra manera que dejando fuera al factor tiempo: como una simultaneidad de igualdad y diversidad. Si se incluyese al factor tiempo, entonces desaparecería aquello a lo que se podría llamar, desde la perspectiva de una lógica de la identidad, "lo invariable" (cualquier cosa que esto sea). La identidad es, desde esa perspectiva, una ilusión necesaria (para la vida cotidiana) dado que solamente de esa manera puede emularse aquello que se conserva idéntico a sí mismo.

La complejidad, así lo habíamos dicho, es posible solamente como complejidad del sistema, dado que de otra manera, los elementos no son observables como elementos (y relaciones): siempre son únicamente los elementos de un sistema. Lo complejo como unidad de lo diverso se cierra por medio de la diferenciación asimétrica de sistema y entorno (y se constituye precisamente por medio de ello) y se abre a la vez, internamente a través de la diferencia simétrica de los elementos y sus relacionamientos (y se constituye también, precisamente debido a ello), dado que los relacionamientos son capaces de mediar transgrediendo los límites del sistema, aunque siempre sea internamente. La forma ortogonal constituida por medio de dos distinciones diferentes - sistema/entorno y elemento/relación-suministra la explicación acerca del hecho de que un sistema es sistema solamente cuando se puede abrir y cerrar simultáneamente a través de su forma (ortogonalidad de dos distinciones - tetradización=entrelazamiento de diferencia y diferenciación). Esta condición de constitución de la complejidad por medio del cierre y la apertura, es factible con la ayuda de dos supuestos, tal como propone Heinz von Foerster con su Cibernética del segundo grado; con el "concepto de la información" que propone Emst von Weizsäcker; con el concepto de información de Claude Shanon; con el concepto de la "autopoeiesis" que fue introducido originalmente por Humberto R. Maturana a la dis-

no, ya que precisamente la hermeticidad "[...] es una forma de la ampliación del contacto posible con el entorno [....". (Luhmann, 1984, p. 63). O sea que por medio de ello aumenta el potencial de determinación de los elementos y la complejidad del ambiente posible para el sistema. Los elementos y grupos de elementos constituidos por el sistema (por ejemplo, acciones o expectativas) pueden permitirse, por así decirlo, adjudicaciones y operaciones más complejas. 
cusión; con la "lógica de las formas" de George Spencer Brown; y finalmente, con el concepto de la "autorreferencia" de Niklas Luhmann.

\section{VALOR-PROPIO, PRIMERA VEZ Y AUTOPOIESIS}

32. Hemos visto que la "calificación" de la cantidad es generada por medio de la "limitación inmanente" de la capacidad de relacionamiento de los elementos de un sistema, y que eso no es otra cosa que la solución provisional del problema de la complejidad a través de la formación específica de sistemas.

Los problemas, al menos los problemas de un grado de generalidad, tal como el problema de la complejidad, generan regularmente varias posibilidades de solución equivalentes, aun más, solamente existen como problemas cuando procesan por lo menos dos posibilidades de solución equivalentes. $Y$ es precisamente este hecho el que los hace insolubles, dado que una solución siempre es diferente de la segunda o de la tercera solución. Por lo tanto, una solución no tiene necesariamente como consecuencia a otra solución, de lo cual se deduce que el problema precisamente "obtiene duración":

Pero con esto no se ha contestado aún la pregunta acerca de la sistematicidad de los elementos. La complejidad, así habíamos dicho, es posible sólo como "complejidad organizada", ya que los elementos son elementos solamente en relación con un sistema. No existen los elementos "en si", siempre requieren una referencia del sistema, la cual los califica precisamente como los elementos de un sistema. Y solamente con referencia a un sistema puede surgir el problema de que no pueden realizarse todas las relaciones potencialmente dadas de un elemento o de un grupo de elementos. ¿Pero cómo se vuelve sistémico el elemento particular? $O$, preguntado con más precisión: àa qué se debe el hecho de que se generen fenómenos heterogéneos (por ejemplo diferentes estilos de expectación) a partir de las unidades homogéneas (los elementos, sucesos, AccioNES)? La respuesta parcial que ya habiamos dado era: por medio de la limitación inmanente de la capacidad de relacionamiento de los elementos, debido a su carácter de acontecimiento. Ahora queremos iluminar el problema de la calificación de la cantidad desde otra perspectiva. Construyendo sobre las propuestas que hizo Heinz von 
Foerster en el marco de su Kybernetik der Kybernetik (Second Order Cybernetics), ${ }^{122}$ se puede explicar la sistematicidad de lo homogéneo de la siguiente manera: debido al hecho de que una circunstancia -del tipo que sea-, choque con otra circunstancia muy similar, surge algo como consecuencia, a lo cual von Foerster llama "valorpropio".

Con ello, se hace referencia al proceso de repetición como tal, el cual es, en su forma más simple - visto lógicamente - una "confirmación primaria". El que la costumbre sea construida operativamente sobre este proceso de repetición ya se había observado. El alcance de este concepto para la sociología consiste en que la mayor parte de aquello que se puede designar como SOCIEDAD, consiste en "costumbres vividas", y por ello, en operaciones de repetición. Regresaremos a ello más adelante.

33. En ese contexto, Günther Teubner opina que al menos una cosa parece clara: "[...] que la hermeticidad autorreferencial se presenta cuando los procesos complejos regresan hipercíclicamente [Eigen y Schuster, 1979], o ultraciclicamente [Ballmer y von Weizsäcker, 1974] a la generación de sus condiciones de partida, y que se hacen independientes [RJ] de su entorno en este proceso ${ }^{n} .{ }^{123}$ Con ello está dicho que la autorreferencialidad tiene el mismo significado que la "hermeticidad organizada", ${ }^{124}$ o que una operación autorreferencial, - la aplicación de una operación a ella misma, puede conducir a estructuras estables, a los valores-propios (Eigen-values) de Heinz von Foerster. Queremos observar esta circunstancia más detalladamente. Jas funciones-propias de von Foerster permiten mostrar que existen formas del comportamiento-propio, ${ }^{125}$ las cuales, aplicadas a sí mismas, producen entidades estables. Con ello, integra a sus trabajos la interpretación de Jean Piaget de cómo los niños alcanzan el concepto de estabilidad del objeto. El punto central de sus reflexiones consiste, en este contexto, en mostrar "[...] que lo que en una epistemología sin observador [lineal, abierta] es considerado como 'objeto', aparece en una epistemología que integra al observador

\footnotetext{
122 Véase acerca de ello, Foerster, H.v., 1985.

123 Teubner, 1989, p. 24.

. ${ }^{124}$ Varela, 1981.

${ }^{125}$ Foerster, H.v., 1985, p. 207.
} 
[circular, cerrada] como 'signo de maneras de comportamiențo estables' $o$, si se utiliza la terminología de la teoría de las funciones recursivas, como 'signo de comportamiento propio' [comprensiblel" ${ }^{126}$ Para obtener una mayor comprensión de la operación del comportamiento-propio, se abordan las reflexiones similares que propone Ernst von Weizsäcker en relación con el concepto de la información. ${ }^{127}$

34. En palabras de Ernst von Weizsäcker, las "circunstancias caóticas" consisten en "primeras veces" (o acontecimientos) que no muestran ninguna referencia de sistema, y que por ello no poseen una estructura.

Ernst von Weizsäcker utiliza el concepto de la "primera vez absoluta" .para designar al caos en el sentido de ausencia total de una estructura. Nos adherimos a esta semántica, aunque, en nuestra opinión, representa una solución embarazosa. Con "primera vez" se quiere decir simple y sencillamente que los sucesos de este tipo no muestran ninguna autorreferencia, y, por lo tanto tampoco estructura alguna. De cierta manera, el concepto de la "primera vez" es idéntico al concepto del suceso de Floyd Allport: "A single event, then, is a 'dichotomizing', non-cuantifiable happening, and nothing more. ${ }^{n 28}$ Por esta razón, la TsS enfatiza justificadamente que un suceso en sí, asi como una acción en sí, permanece "[...] no caracterizado como un punto". ${ }^{129}$

${ }^{126}$ Ibid., pp. 47 y ss., ahí también la discusión sobre el concepto de la obtención infantil del objeto. Von Foerster ofrece como ejemplo de una operación-propia la reproducción de la siguiente operación matemática;

Entrada inicial 4,5, con ello "divide entre dos y suma uno"

$n=1 \quad 4,5: 2=2,25+1=3,25$

$\mathrm{n}=2$ 3,25:2 $=1,625+1=2,625$

$\mathrm{n}=32,625: 2=1,3125+1=2,3125$

$\mathrm{n}=42,3125: 2=1,15625+1-2,15625$

$\mathrm{n}=5$ 2,15625:2=1,078125+1=2,078125

$\mathrm{n}=62,078125: 2-1,0390625+1=2,0390625$

$n-\infty 2,0000000: 2=1,0000000+1=2,0000000$

$n=\infty+12,0000000: 2=1,0000000+1=2,0000000$

Después de un número de input inicial se retroacopla - por medio de la operación-propia- cada output como el siguiente input a la operación. El resultado final siempre será dos. (Ibid., p. 214).

127 Weizsäcker, E.v., 1974.

${ }^{128}$ Allport, 1954, p. 292.

129 Luhmann, 1984, p. 389. 
Ahora bien, si, por las razones que sean (generalmente por azar), una primera vez se encuentra con otra primera vez igual/similar, ${ }^{130}$ y se repite este proceso durante un tramo mayor de tiempo y/o espacio, ${ }^{132}$ por medio de un respectivo condicionamiento, entonces esto puede conducir a un encadenamiento y a una condensación de los sucesos de esta naturaleza. Éstos pierden su carácter de primera vez debido a que se conviertan en una "segunda ve $z$ ", en una "reiteración. ${ }^{132}$ En este nivel de "confirmación de la primera vez", se generan simultáneamente la autorreferencla y la emergencia: un nuevo nivel (emergente), preñado de sentido ${ }^{133}$ surge, en forma de una "segunda vez", cuando una primera vez se asienta sobre una primera vez, y se genera una forma de la primera vez reflexiva.

Günther Teubner formula:

La presunción de la emergergència existe sobre todo cuando se presentan -independientemente de la manera en que esto sucedacírculos autorreferentes. Cuando las comunicaciones se hacen reflexivas, o sea cuando tenga lugar la comunicación acerca de la comunicación... ${ }^{134}$

Con ello, se puede formar un nudo autorreferente a partir del desorden (= primera vez, azar) que se cierra frente a "algo diferente". Por lo tanto, cualquier forma de "confirmación primitiva" está formada autorreferencialmente porque hace referencia a sí misma, y se vuelve efectiva - autoconfirmándose- precisamente por eso. Ahora bien, si se llega a una semejante operación autorreferencial a través

130 No la "misma", sino la "igual" o "similar".

131 Ernst von Weizsäcker formula en este contexto: "Sólo la confirmación le da realidad a la primera vez [...] Sólo la segunda vez le da realidad a la primera vez, la primera vez no existe." (Weizsäcker, E.v., 1974, p. 95).

${ }^{132}$ Emst von Weizsäcker define, sobre esta base, al concepto de la información como el resultado de la primera vez y la confirmación. (Ibid., p. 94).

${ }^{133}$ Entre más simple sea la estructura de un hecho, más grande es su componente de confirmacion: "Entonces, se puede mirar o medir las veces que uno quiera y siempre habrá confirmación." (Ibid., p. 97). Sin embargo, si la estructura es compleja y con ello diversa, entonces su componente de primera vez será más alto: Entre más compleja, pequeña y lâbil... es la estructura, más grande es el componente de primera vez, dado que entonces uno debe estar más atento para obtener resultados de primera vez con la proxima mirada o medición". (Idem).

${ }^{134}$ Teubner, 1987b, p. 93. 
de un proceso de "confirmación secundaria y reiterada", entonces se constituye una operación autorreferente, la cual puede, pero no debe, conducir a la forma a través del condicionamiento.

En el concepto de las autopoiesis se distingue entre "organización" o "reproducción", por un lado, y por el otro lado, "estructura" o "estabilidad de la estructura". En el primer caso, se trata de la asociación autopoiético-recursiva de los elementos, de la forma de la unidad reproductora del sistema como unitlad. Como estructura comprendemos, por otra parte, determinadas formas "concretas", que conforman un tipo de sistema o que guían a la reproducción hacia un tipo determinado. En el capítulo IV acerca de la observación, trataremos esta -importante distinción entre operación y observación (estructura).

35. Ahora llegamos al concepto de la autopoiesis. Si se consulta la definición "oficial" de la autopoiesis de Humberto R. Maturana et al., entonces se puede observar cuán estrechamente asociada está con la second order cybernetics de Heinz von Foerster y con el concepto de información de Ernst von Weizsäcker: "La organización autopoiética se define como una unidad por medio de una red de componentes, las cuales, primero toman parte recursivamente en la misma red de producción de las componentes, quien produce también a estas componentes, y las cuales, segundo, realizan la red de la producción como una unidad en aquel espacio en el cual se encuentran las componentes." 135 Por lo tanto, Günther Teubner es de la opinión de que el concepto de la autopoiesis casi no sería imaginable sin el concepto de la cibernética de segundo grado, ya que la operación de la autopoiesis se hace inteligible sólo por medio de la cibernética de segundo grado. ${ }^{136}$

Generalizando, se puede afirmar ahora que el concepto de la "repetición de un suceso", con el cual la "primera vez" se convierte en "segunda vez y reiteración", y la condensactón y confirmación (desde cierta perspectiva, una condensación siempre es una confirmación y viceversa) ${ }^{137}$ se efectúan dentro de una operación como dos

${ }^{135}$ Maturana, 1985, p. 158.

136 Teubner, 1989, p. 33.

137 "Si el sistema efectúa una operación de conexión, entonces puede condensar a la primera y la segunda operación en una sola. El referente se coloca como idéntico. El saludado no ha notado el saludo, uno saluda otra vez. Pero el mismo hecho se puede leer en otra dirección. Uno confirma el saludo, 
momentos de la misma operación; conforma la base para los conceptos de Ernst von Weizsäcker (teoría de la información), de Heinz von Foerster (cibernética de segundo grado) y de Humberto R. Maturana et al. (autopoiesis). Demostramos algo similar para el concepto de las Laws of Form de Georg Spencer Brown (capítulo I) y para el concepto de la autorreferencia (capítulo III). Por lo menos, los cinco teoremas se pueden integrar bajo este aspecto. Consideramos a una congruencia de este tipo de planteamientos teóricos bastante heterogéneos, como significante y no como casual. Con referencia a la dimensión del sentido social, podemos decir que está dada la "llave" para una teoría sociológica, la cual, debido a un proceso de repetición preñado de sentido, puede hacer evidente, el cómo, por un lado, se puede llegar a la emergencia de la costumbre o del mundo vivencial ("confirmación") y por el otro lado, el cómo, debido al mismo proceso de repetición, puede conducir a la emergencia de lo inusual o de la novedad (expectación condensada). Con otras palabras: en el nivel de la dimensión social del sentido, el proceso de repetición como tal (la operación como tal), constituye simultáneamente el mundo vivencial y la novedad o el sentido y la información.

\section{COMPLEJIDAD Y "TEORIA SOCIOLOGICA"}

36. En lo que concierne a la "teoría sociológica", podemos formular ahora que la pregunta clásica de la teoría de la sociedad: "¿cómo es posible el orden social o de la sOcIEDAD?" ya está contenida también en el problema de la complejidad, más aún, es el mismo problema, solamente visto desde una perspectiva específica.

Esta pregunta se encuentra al principio de los trabajos de, por lo menos, Georg Simmel, Talcott Parsons, Niklas Luhmann, Jürgen Habermas, Richard Münch y Jeffrey Alexander. Posteriormente regresaremos a esto. Nosotros (TgS) preferimos hablar del orden de la SOCIEDAD en vez del orden social, porque para nosotros, la SOcIEDAD consiste en (por lo menos) cuatro estilos de comunicación, o sea un estilo de comunicación corporal, uno afectivo, uno personal y uno social. En este con-

o sea lo que significa, realizándolo nuevamente. Dependiendo de la dirección de la lectura, uno condensa dos actos en uno, o se confirma y amplía un acto por medio de una primera realización $y$ una segunda realización." (Luhmann, 1990a, p. 22). 
texto, el "orden social" pertenece al estilo de comunicación social, con lo cual el orden corporal, afectivo y personal están relacionados con los respectivos estilos de comunicación. Con otras palabras, el problema del ordenamiento superior, desde nuestra perspectiva (TgS), debe rezar: ¿cómo es posible el orden de la SOCIEDAD? Además se puede preguntar acerca del problema específico de ordenamiento de la socialidad, personalidad, afectividad y corporalidad.

Tanto con la SOCIEDAD como con el mundo se trata de la cuestión: ¿cómo es posible la unidad (=orden) de lo diverso? En este sentido, el problema de la complejidad y el problema del orden social tienen el mismo sentido. La distinción resulta debido al hecho de que se encuentren ubicados en diferentes niveles de abstracción: el problema del orden social se refiere, por un lado, a la función reflexiva del subsistema "teoría sociológica" y, por el otro lado, al sistema global de la sOCIEDAD. El problema de la complejidad se refiere, por un lado, a la función reflexiva del subsistema de la ciencia, o sea a la teoria de la ciencia y, por el otro lado, al mundo como la condición de la posibilidad de "algo" (figura 69).

\begin{tabular}{|l|c|}
\hline \multicolumn{2}{|c|}{ ¿Como es posible la unidad de lo diverso? } \\
$\begin{array}{l}\text { Complejidad: } \\
\text { (ciencia) }\end{array}$ \\
$\begin{array}{l}\text { Teoría de la ciencia } \\
\text { mundo }\end{array}$ \\
$\begin{array}{l}\text { Orden social: } \\
\text { (sociologia) }\end{array}$ & $\begin{array}{c}\text { Teoría sociologica } \\
\text { socredAD }\end{array}$ \\
\hline
\end{tabular}

Hemos definido a la observación como el manejo de una diferencia simétrica frente al trasfondo de una diferenciación asimétrica, con la finalidad de generar información. En relación con el problema de la complejidad, esto significa que se trata de la diferencia de elementos y relaciones frente al trasfondo de una diferenciación designada como sistema (iy no como entomo!). Como información resulta - bajo observación de la dinámica ya descrita de las distinciones, elemento/relación y sistema/entorno-, una comprensión por principio $^{138}$ del problema de la complejidad.

138 "Realmente no es sorprendente el hecho de que la explicación del tipo de un esquema pueda ser sumamente significativa en el campo de los fenó- 
37. La complejidad se convierte en problema porque todo lo que sucede sucede simultáneamente. ${ }^{139}$

La tesis presentista de que todo lo que ocurre, sucede simultáneamente no se debe malinterpretar en el sentido de que los sistemas pudieran poner en práctica, de hecho, estos planteamientos. Al contrario, dado que no les es posible poner en práctica este supuesto, pero ya que están obligados simultáneamente a operar en el presente, y con esto presentistamente, deben "alargarse", "digitalizarse" o "asimetrizarse", tan sólo para poder constituirse como sistemas. Los sistemas vivos, 0 , por lo menos, los sistemas del sentido - aquí nos adherimos a Humberto R. Maturana- operan siempre "[...] exclusivamente en el presente[.... ${ }^{n} .{ }^{140}$ Los sistemas del sentido cerrados autorreferencialmente pueden operar solamente en el presente. Por lo tanto, se confrontan con el problema de la simultaneidad de aquello que ocurre, cuando pueden discriminar y distinguir. Su sobrevivencia depende, en última instancia, de cómo solucionan este problema. Cada operación - y un "algo", solamente puede existir cuando opera o, en caso contrario, extinguirse- se encuentra con la "tarea" de realizarse o de no realizarse, y esto quiere decir de operar o de no operar. Tan sólo por eso se constituye la distinción, ya que "algo" debe distinguir entre el operar y el no operar de sí mismo.

Ahora bien, ningún sistema (posible) es capaz de captar la simultaneidad de su propio acontecer total (cualquier cosa que esto sea, para el sistema posible).

También se puede decir que "algo" se convierte en un sistema debido al hecho de que realiza el intento de digitalizar "su" acontecer análogo, o de asimetrizar "su" procesamiento simétrico. ${ }^{141}$

menos complejos, mientras que en el campo de los fenómenos simples, por ejemplo los de la mecánica, quizá fuera de escaso interés. El hecho es que, en la exploración de los fenómenos complejos, los esquemas generales son todo lo que es característico para las totalidades duraderas de esta indole, las cuales conforman el objeto principal de nuestro interés, ya que existe un número de estructuras persistentes que tienen en común el esquema general nada más." Escribe F.A.von Hayek, 1972, pp. 28-29.

139 Luhmann, 1990a, p. 98.

140 Maturana, 1985, p. 17.

14 Acerca de la distinción entre digitalización/analogización, ver ante todo: Watzlawick, Beavin, Jackson, 1985, pp. 61 y ss., y Wilden, 1980a, 6, pp. 155-201. 
Se obtiene una perspectiva adicional del problema de la complejidad cuando (siempre partiendo de que tenemos que observar un entrelazamiento relacional de las dos distinciones elemento/relación y sistema/entorno con ello) se parte del hecho de su operacionalización ya tematizada, o sea que con el crecimiento del número de elementos dentro de un sistema de cualquier tipo, crece sobreproporcionalmente el número de las relaciones posibles entre ellos. Así deviene el hecho de que un sistema empírico, a partir de cierto tamaño, ya no es capaz de relacionar cada elemento con todos los demás. Para hacer visible (=observable) la distinción de capacidad de asociación posible (lógica) y pragmática (empírica), habla la TsS de la asociabilidad selectiva y completa. ${ }^{142}$ Pero un relacionamiento completo, total, de todas las relaciones posibles entre los elementos de un sistema es un problema solamente si todo lo que sucede, sucede precisamente a la vez. La "dominación". del problema de la complejidad consistiria, para el sistema posible, en la invención de las operaciones que puedan capacitarlo para traducir la asociabilidad completa hacia una selectiva (asimetrizar la simetria, convertir la simultaneidad en no simultaneidad). Y esto, naturalmente, con todos los riesgos y peligros que se generarian con la pérdida de información, misma que, con ello, debe tener lugar necesariamente. Pero la formación de un sistema ciertamente es posible solamente de esta manera , lo cual señala que cualquier formación de un sistema representa una empresa arriesgada y peligrosa (dado que está estrechamente relacionada con la pérdida de la información), y no sorprende cuando fracasa.

Obsérvese que la formación de sistemas se encuentra emparejada con la pérdida de información. Aun más, la formación de sistemas es pérdida de información. En este sentido, cualquier sistema es necesariamente siempre parcialmente ciego por razones formales de la constitución. Esto, por otra parte, no es otra cosa que la solución del problema de la complejidad.

En este sentido, cualquier formación de sistemas representa un suceso improbable, y toda queja sobre los riesgos y peligros de un sistema es solamente una observación y descripción aguda de la sistematicidad lábil y simplificadora del mundo de un sistema.

${ }^{112}$ Luhmann, 1990a, p. 62. 
38. Ahora bien, la TsS utiliza la distinción de la asociabilidad selectiva o completa, debido al pensamiento de que la complejidad como problema ya no es explicable adecuadamente a traves de la distinción de complejo/simple, ya que, con toda razón, hoy en día lo simple se puede comprender solamente como complejo: "Los límites de lo posible, en lo grande y en lo pequeño, desaparecen en lo indeterminable [...] Con esto, el concepto de la complejidad pierde su sus- . tento en un contraconcepto [de lo simple RJ]. ${ }^{\text {143 }}$ No obstante, somos de la opinión de que esta deducción es precipitada. Ciertamente estamos de acuerdo con la TsS en que ya no pueden existir "elementos últimos" en el sentido ontológico, pero esto no significa que los "elementos últimos" se hayan vuelto prescindibles para los sistemas. No sería posible ninguna forma de la autopoiesis, no se podría dar ninguna forma de la autorreferencia, no podría tener lugar ninguna observación de una observación, si el sistema en cuestión (y éste puede ser cualquier sistema) no tratara para sía un determinado tipo de elementos como elementos basales, y esto quiere decir, como elementos ültimos, como sucesos simples. Una simple reflexión aclarará esto: el concepto de la asociabilidad, con el cual la TsS introduce la distinción de completo/selectivo, es observable, y esto quiere decir comprensible inteligiblemente (para el sistema observador, el cual bien puede ser un sistema que observa la producción de sistemas), solamente cuando se puede partir del hecho de que los elementos que se están asociando poseen (se les atribuye) una consistencia elemental basal, o sea que se les trata como elementos "simples" y "fundamentales". Si los elementos no fueran —en relación con la actividad de asociación relacional-simples, sino complejos, entonces no se podría formar ninguna relación entre ellos, ya que la operación relacional no tendría ninguna posibilidad fijable, para establecer precisamente determinadas relaciones. Solamente cuando la actividad de asociación relacional logra fijar los elementos como "elementales", puede cumplir con su actividad de asociación relacional. Por lo tanto, la fijabilidad de la terminación de una relación, o sea de los elementos, es la condición para la posibilidad de producción de la asociación relacional. Esta fijabilidad del elemento no es, entonces, otra

${ }^{143}$ Ibid., p. 61. 
cosa que su simplicidad desde la perspectiva de observación de la relación. Con ello no negamos que los elementos, desde otra perspectiva, puedan ser entidades altamente complejas. Sin embargo, solamente desde la perspectiva relacional deben ser simples, en caso contrario, no puede tener lugar ninguna asociación relacional. Precisamente dentro de una teoria de la acción, es indispensable el supuesto de que la acción debe ser considerada como un "suceso simple", porque, en caso contrario, ninguna acción podría conectarse con la siguiente, ya que cada acción podría ofrecer demasiados puntos de conexión, muy diferentes, los cuales impedirían cualquier decisión -y sin la decisión no existe ninguna acción. Esto es exactamente el problema del concepto de la acción de Parsons: su estructura de acciones está diseñada demasiado complejamente como para que pueda actuar. Regresamos a esto en el capítulo $V$ sobre la arquitectura de teorías. Sea dicho expresamente que: esto es válido sólo para la relación de un sistema con sus propios elementos, con lo cual el sistema — como sistema autorreferencial autopoiético-es, en cierta manera, sus elementos mismos. Este hecho es del todo compatible con la observación de un sistema que determina que los elementos de otro sistema sean complejos para el sistema que lo observa. Al contrario de otros sistemas, el sistema de la ciencia parte continuamente de este hecho. Esto lo puede observar porque es "sistema" en sí, y solamente porque trata con toda "inocencia" y despreocupación, con sencilla "simplicidad" a los propios elementos como "últimos". Es decir, como "simples", no más deducibles, algo, por su parte, que un tercer sistema podría - bajo las mismas condiciones- negar. La operación de la asociación tiene sentido para el sistema solamente si trata a las unidades constituyentes de él mismo como "unidades últimas", como "simples" y con ello como "elementos no-transparentes" para él. El sistema debe, por razones de autoconservación existencial como sistema autorreferencial-autopoiético, partir de la ficción de que los elementos que lo constituyen son sus elementos "últimos" y, por lo tanto, "los más simples". Ya Immanuel Kant había visto este problema de la necesaria suposición de una ficción basal, cuando afirmaba que pensaba algo, simplemente porque no sabía decir acerca de ello, nada más que el que "algo" es simple. ${ }^{144}$

${ }^{144}$ Immanuel Kant, 1969, p. 108. 
39. Sabemos que la complejidad solamente es posible como complejidad del sistema; en particular para la distinción de la asociabilidad completa y selectiva de los elementos, dado que, ¿cómo se puede dar la relación de completo y selectivo, en cuanto a la asociabilidad de los elementos, de otra manera que dentro de los limites del sistema que pueden estar definidos de cualquier manera? Sin un límite imaginario (y los límites son siempre y solamente límites del sistema) la operación de la asociación de los elementos simples basales "duraría un tiempo infinitamente largo", y no conduciría en absoluto a la constitución de sistemas, si los sistemas de esta índole consistieran en elementos que se expanden cada vez más; que desaparecen hacia arriba o hacia abajo; ${ }^{145}$ nunca serían fijables, por ello, como unidades "últimas", "simples". Queremos añadir que esto es tanto más acertado cuanto más es el sistema, los elementos que lo constituyen a él mismo, y que sería como una autoaniquilación si prescindiera de un tratamiento simple y "fundamental", de sus últimos elementos, de sus propios acontecimientos. No obstante, si se quiere conservar el concepto de lo simple, ${ }^{146}$ para hacer plausible la constitución de la complejidad del sistema y, con ello, del sistema en general, entonces se debe diferenciar meticulosamente entre un con-

${ }^{145}$ Una observación hecha naturalmente por el sistema de la ciencia con referencia a los otros sistemas del sentido de la SOCIEDAD, porque utiliza como una distinción principal la distinción de análisis/sintesis (en el sentido de una descomposición y recombinación de un objeto analizado). La otra consiste en la diferenciación asimétrica de cierto/falso. Esto significa que liga su capacidad de observación a esta distinción y que solamente es posible así, ya que constituye su propia base elemental precisamente debido a ello. $\mathrm{Si}$ el sistema de la ciencia se observa a sí mismo, entonces solamente puede proceder analizando la propia capacidad de análisis y, por ello, no se puede descubrir a sí mismo, ya que los propios "elementos últimos", o sea, los elementos simples y no-transparentes son precisamente las operaciones analíticas mismas. Y si quiere analizar esta observación recién hecha, entonces terminaría otra vez consigo mismo. Dado que esto es así; el sistema de la ciencia exige demasiado de si mismo y sobre todo, de los demás sistemas sociales con su "actividad de observación analítica", dado que ni la economía ni la religión o la educación se tratan a sí mismas analíticamente, pero ven más a través del lente científico de lo que ellas mismas utilizan empíricamente. Esto naturalmente no excluye el que sean aceptadas las observaciones analíticas hechas por la ciencia y se apliquen a través de este camino finalmente a ellas mismas. Pero esto no puede ser forzado por la ciencia misma.

${ }^{146}$ Lo consideramos como imprescindible en el sentido de una ontologización ficcional de los elementos de un sistema por sí mismo. 
cepto de la unidad ficcional y uno ontológico, con lo cual sólo la simplicidad designada ontologicamente debe estar almacenada en un rincón olvidado de la historia de la ciencia. No así el concepto de la simplicidad necesario ficcionalmente y por lo tanto basal (naturalmente, el sistema podría ontologizar su ficcionalización de la simplicidad, pero esto sería, entonces, su decisión y otro problema). ${ }^{147}$ Por eso contradecimos a la TsS en que por la introducción de la distinción de la asociabilidad completa/selectiva, el concepto de la complejidad se hace independiente "[...] del contraconcepto tradicional [...]". ${ }^{148}$ Si esto ocurriera, entonces la TsS debería también archivar los conceptos del elemento (ficcional, naturalmente necesario) y del acontecimiento, con lo cual, sin embargo, perdería de vista el problema de la complejidad. Por lo tanto, se puede afirmar que el concepto de lo simple (ficcionalmente) aún es, pace Luhmann, constitutivo para el concepto de lo complejo, $y$, que sin su supuesto ni siquiera se podría hablar sobre el relacionamiento completo/selectivo.

40. Ahora bien, si esto es así, ¿dónde dejar la distinción de la asociabilidad completa/selectiva, la cual parece ocupar recientemente una posición tan central para la TsS? Opinamos que, con esta distinción, se ha abordado el problema básico de la forma que se esconde detrás de la pregunta: "¿cómo es posible la forma?" En el capítulo I demostramos con una crítica constructiva al trabajo de George Spencer Brown Laws of Form, decisivo para este cuestionamiento, que para la constitución de la forma se requieren por lo menos cuatro elementos que estén relacionados entre ellos (y no dos, como parecen sugerir Spencer Brown y con él la TsS). Estos cuatro elementos relacionales se presentan en la forma de dos distinciones diferentes, las cuales se encuentran entre sí en una relación de simetría y asimetría, y están provistas de dos lados cada una, de lo cual resulta la forma tetrádica. Spencer Brown y con él la TsS (y lamentablemente la mayoría de los que se adhieren a Spencer Brown y a la TsS) . empiezan con la instrucción: "iHaz una diferenciación!" Pero, y aquí comienza nuestra crítica, esta diferenciación es una diferenciación

${ }^{117}$ Se debe suponer que la ontologización es el medio más comprobado para fijar a los elementos como "simples", "no-transparentes". En ese sentido, se debe tener cuidado con una evaluación negativa de las operaciones ontológicas, al menos en el contexto de la SOCIEDAD.

${ }^{148}$ Luhmann, 1990a, p. 62. 
unilateralmente-denominada y, por ello, una diferenciación unilateralmente-decidida, ${ }^{119}$ una distinción ya no seleccionable, al menos formalmente. Ciertamente, se puede: a) cambiar del lado designado al lado aún no designado, pero solamente con la condición de que no sea borrado el lado originalmente designado, porque entonces dejaría de existir la diferenciación; $b$ ), este cambio se puede efectuar solamente como operación de la asimetría: en el caso de una diferenciación no se tiene otra opción. Por ello opinamos que no se puede explicar plausiblemente el sungimiento de la forma sobre la base de una sola diferenciación denominada, o sea de una distinción asimétrica, como lo proponen Spencer Brown y la TsS. La forma se hace posible sólo cuando se entrelazan de manera determinada una diferencia simétrica y una diferenciación asimétrica, con lo cual el lado no-designado de la diferenciación asimétrica se convierte en el "punto ciego" de la así constituida forma determinada. Si se tratara de hacer plausible la complejidad con la ayuda de una tetradización de esta índole (de cuatro lados por la bilateralidad de la diferencia y de la diferenciación), entonces se debería formular de la siguiente manera: en el entrelazamiento de la asimetría de sistema/ entomo y la simetría de elemento/relación, se organizan los elementos posibles de tal manera que solamente es posible un relacionamiento selectivo entre ellas, con la consecuencia de la formación de complejidad como complejidad del sistema. Como "punto ciego" en el trasfondo, como "suposición ingenua", por así decirlo, el sistema y su relacionamiento de los elementos permanecen como entorno (o mundo) constituyente. Visto así, la distinción del relacionamiento selectivo/completo, expresa precisamente este hecho del entrelazamiento entre la simetría y la asimetría. El relacionamiento completo introduce al juego la modalidad de la simultaneidad (simetría) y representa la condición para la posibilidad de elegir, decidir, designar o referirse. El relacionamiento selectivo introduce a la modalidad de la no simultaneidad (asimetría), la diferenciación ya designada, y representa las condiciones para la posibilidad de la unidad seleccionable, por decidir o denominar. Las posibilidades de selección son

149 Sea dicho ad cautelam que una difenenciación es una distinción siempre ya distinguida y con ello "decidida" y asimetrizada. La pregunta es entonces, ecómo logra una distinción oscilar entre sus dos lados, por así decirlo, y con ello, significar simetria? Esto puede suceder solamente con la ayuda de una diferencia simétrica. 
abiertas, por lo tanto, por medio de las distinciones simétricas (relacionamiento completo), dado que, ciertamente, se generan sólo debido a esto; mientras que las posiciones de lo seleccionable (relacionamiento selectivo) o los "intereses de conocimiento" se construyen sobre la base de asimetrías y se "gastan" o "aniquilan por medio de la utilización de la posibilidad de selección. Se debe observar que se asimetriza una diferencia simétrica y con ello puede convertirse en una diferenciación, mientras que una diferenciación asimétrica en conjunto con otra diferenciación asimétrica puede conducir a la diferencia simétrica. ${ }^{150}$ Además, existe una relaciôn de complementariedad entre ambas distinciones, la cual significa que se necesitan mutuamente, perro que no deben presentarse conjuntamente. Por lo tanto, podemos decir que ya se está considerando, con la ayuda de la distinción de la "diferencia" y la "diferenciación", el hecho del relacionamiento selectivo y completo, sin tener que renunciar a la distinción de simple/complejo. Ambas distinciones son imprescindibles para una explicación del hecho de la "complejidad". ${ }^{151}$ Pero la TsS sustituye la distinción de simple/complejo por la del relacionamiento completo/selectivo, con lo cual pierde la posibilidad de una explicación adecuada de la complejidad.

41. Nuestra impresión es, que debido al hecho de que la TsS opera con una operación de distinción demasiado simple, o sea, con el concepto de una diferenciación denominadora, no logra explicar completa y plausiblemente el problema de la complejidad. Entonces está obligada, por así decirlo, a completar subrepticiamente el concepto de una diferenciación denominadora de complejo/simple con la de completo/selectivo. Pero en el fondo no completa el concepto original, sino que lo sustituye por la distinción de asociabilidad completa/selectiva. ${ }^{152}$ Pero por ello termina otra vez en una diferenciación ya siempre asimetrizada, y con ello ya siempre decidida, con todas las consecuencias problemáticas que resultan de una suposición de esta naturaleza. Resumiendo, se puede decir que el

${ }^{150}$ Más detalles acerca de esto en el capítulo I sobre la forma.

${ }^{151}$ Sin embargo, solamente cuando explicamos la distinción de completo/ selectivo sobre la base de la distinción diferencia/diferenciación, ien caso contrario, no!

152 Por lo demás, en el marco de la complejidad del sistema, la simplicidad siempre es selección. 
concepto de la operación de una "diferenciación denominadora" entendido como una distinción asimétrico-bilateral, tal como lo defiende la TsS, no es suficientemente complejo como para poder captar adecuadamente el problema de la complejidad.

42. No hay elementos simples desde que el movimiento de la ciencia, sobre todo desde el siglo XvII, trata, por medio de las operaciones de temporalización, a lo simple como complejo. La consecuencia es la disolución, volatilización y hasta pérdida de identidad del hecho científico, observable paradigmáticamente dentro de las ciencias fisicas, como la disolución del concepto de la cosa o de la materia. No han faltado las propuestas de solución, con lo cual dos de ellas, el reduccionismo y el holismo, se basan por su lado, en procedimientos reductivos, como ya lo hemos visto. En el fondo, son variantes del intento por introducir nuevamente la pérdida ontológica del elemento, de lo que antaño se llamaba "fundamental". ${ }^{153}$ Pero si hoy en día no hay un punto fijo ontológico, ni visto macro ni microcósmicamente, entonces no puede tener sentido suponer ontologías elementales o totalitarias. Esta pérdida de ontologías de cualquier tipo, implica que la perspectiva se cambia del "producto ontológico" hacia los "productores generadores de ontologías". La observación monovalente de las ontologías, a su vez, se observa ahora, con la consecuencia de que en este momento se encuentra en la mira una observación bivalente de las observaciones de las ontologías. Ahora bien, si todo lo que es, esto quiere decir cualquier información, se debe comprender como el producto de la observación y por ello como una construcción, entonces se procede correctamente al observar al observador, quien observa algo como "algo", para informarse sobre este "algo". Y no se errará con el supuesto de que "algo" sea "algo" solamente debido a la utilización de una distinción por medio del observador observado, o sea una construcción que flota libremente. ¿Dónde encontramos, visto así, un punto fijo cognoscitivo, ya que toda cognición es una construcción generada por observadores? Hay una construcción conocida en el ámbito de la filosofia que dice: ego sum, engo existo. ${ }^{154}$ Esta solución de Descartes del punto fijo $t^{\bullet}$

${ }^{159}$ Glanville, 1988.

134 "[...] me he convencido que realmente no existe nada en el mundo: ningún cielo, ninguna tierra, ningún ser pensante, ningún cuerpo, ¿o sea que 
epistémico es aplicable seguramente sólo a un observador pensante y debería decir realmente: "Pienso, entonces pienso. Por ello soy un ser pensante. " Regresaremos a esto. En todo caso podemos constatar que ahora, después de la pérdida de las ontologizaciones, tenemos solamente al observador, al cual podemos observar en cualquier momento en que haga su observación, y de esta observación podemos obtener la orientación sobre aquello que se está observando. Ahora bien, si esto es así, entonces no nos queda otra cosa - no diferente de la solución cartesiana - que exclamar: "Observa [a ti o a otros], y eres [él, ella es] el observador quien observa esto y/o aquello [...]." Con ello, no importa si se observa a una auto-observación o a una observación ajena. Importa solamente que podamos alcanzar el "punto fijo" 155 que hemos buscado, y que ya no es alcanzable por medio de las ontologías, en la forma de una "observación de la observación", o sea en la forma de un nudo autorreferencial. Con ello se ha alcanzado un punto fijo cognoscitivo sobre la base de la inconsistencia, una solución realmente paradójica y fascinante.

\section{SEMÁNTICA DE ALTO RENDIMIENTO Y DE LA COTIDIANIDAD EN EL CONTEXTO DEL HABLA Y DE LA ESCRITURA}

43. La operación que se efectúa dentro de una comunicación científica con la ayuda de la semántica de la "reducción de la complejidad", reproduce un determinado hecho, el cual también dentro de la soCIEDAD es prociesado como problema. Pero en la SOCIEDAD no se utiliza la semántica (del tipo de escritura y habla) de la "reducción de la complejidad" (por lo menos todavía), una denominación que produce sentido solamente en el contexto de la comunicación científ-

tampoco yo? De ninguna manera; seguramente yo existia, si me había convencido de algo. Pero hay un engañador, no se quién, todopoderoso y altamente astuto, el cual me engaña siempre intencionadamente. Pues, si me engaña, entonces es indudable que yo existo. Me puede engañar todo lo que pueda, nunca logrará que yo no sea nada, mientras yo piense que soy algo. $Y$ así llego - después de haber reflexionado acerca de todo de muchas maneras - finalmente a la confirmación de que esta frase: 'Soy, existo', cada vez que la pronuncio o la pienso, es necesariamente cierta". Meditationen über die Grundlagen der Pbilosofie, 18, Descartes, 1960, pp. 21-22.

${ }^{155} \mathrm{Se}$ admite que sea un "punto fijo flotante". 
ca. ¿Pero, qué se utiliza en cambio? Aquí se debe aclarar que estamos ante un problema para la ciencia, especialmente para la sociología, que se debe tomar en serio. La semántica de alto rendimiento de la "reducción de la complejidad" con su significado especial tiene un efecto pragmático, y esto quiere decir, un valor de conexión, nada más que en el ámbito de los hechos científicos. Solamente aquí, la expresión de la "complejidad" o de la "reducción o aumento de la complejidad" tiene el efecto de fomentar o frenar la investigación; sólo aquí se puede "entender realmente" lo que se quiere expresar con ello; solamente aquí existe un consenso o una divergencia sobre un hecho científico que se llama "reducción de la complejidad". En todo caso, le incumbe a la comunicación científica la decisión de aceptar o rechazar a la "complejidad" como una construcción científica, con lo cual se le carga completamente de "realidad" (cientifica).

La complejidad es científicamente "real" y está preñada de conexión comunicativa, precisamente como construcción científica. En general, la realidad puede ser real sólo en relación con el sistema. No existe una realidad en sí desde la perspectiva de la teoría de las distinciones. Dado que en este contexto se trata nada más de una realidad comprendida desde la perspectiva de la teoría de la comunicación, ésta puede ser definida como el "sentido comunicativo, en relación con el sistema, capaz de la conexión". No obstante, se debe proceder con mucha precaución. Ciertamente, la semántica de la "reducción de la complejidad" desarrolla su significado semántico real en este contexto del habla y la escritura científica. Pero este significado dice que dentro de la sOCIEDAD y con ello también en el ámbito prelinguístico se están procesando "reducciones de la complejidad". Si en la semántica de la cotidianidad se hablaralescribiera de la "reducción de la complejidad", entonces una semántica de este tipo dificilmente encontraría conexión. Pero el problema es que, desde la perspectiva científica, partimos del supuesto de que también dentro de la semántica de la cotidianidad, y esto quiere decir ya en el estadio prelinguístico, se está "reduciendo la complejidad". Aquí no seguimos más detalladamente con este problema. Véase Die Form von Gesellschaft, Jokisch, 1995.

Expresado más corta y equívocamente: la semántica de alto rendimiento de la "reducción de la complejidad" tiene sentido solamente para un cientifico, no para un artista o un político. 
44. Si la semántica de la complejidad en su forma de alto rendimiento produjera su efecto solamente dentro del sistema de la ciencia, y la ciencia fuera un sistema de comunicación que se empeñara en observar agudamente y describir verídicamente la "realidad" supuesta afuera de la ciencia, ¿cómo estarían entonces relacionadas la complejidad y la realidad extracientífica? Partimos del hecho de que la ciencia es un sistema cerrado autopoiético, y esto quiere decir que cualquier observación y descripción científica es una observación o descripción producida exclusivamente bacia el interior de la ciencia. Con esto también está dicho que la comunicación científica no describe realmente a una realidad "ahi afuera". Esta no existe en absoluto en este sentido ${ }^{156}$ y cuando la hay, entonces no sabemos cómo se ve "realmente". La ciencia orienta su comunicación hacia la distinción de cierto/falso, con lo cual la diferenciación (asimétrica) de la certeza y la falsedad es una diferenciación asimétrica utilizada en primer lugar por el sistema de la ciencia.

El código resiste con éxito la prueba solamente cuando se limita cuast científicamente, lo cual, sin embargo; no significa otra cosa sino que sólo el sistema de la ciencia dispone de esta diferenciación, y, con esto, la "administra".

La diferenciación de cierto/falso es, entonces, una diferenciación inmanente a la ciencia, lo que, no obstante, no excluye el hecho de que otros sistemas del sentido también hagan uso de ella, y que, de esta manera, utilicen la reputactón del sistema de la ciencia para sus fines. En todo caso, la administración de la diferenciación de cierto y falso es de incumbencia del sistema de la ciencia.

45. Pero con esto no se ha aclarado aún la relación del problema de la complejidad de la ciencia y de la cotidianidad. Se ha dicho solamente que la construcción de la "reducción de la complejidad" es una construcción científica, la cual no provoca ningún efecto comunicativo particular fuera de este sistema. El sistema de la ciencia es cier-

${ }^{156}$ ¿Cómo debe verse, pues? Y cuando "se ve", ¿quién nos informa sobre su aspecto? ¿El científico? ¿Cuál? ¿El biólogo, el físico, el historiador o aun el filosofo? ¿O quizás el político o el asesor económico o hasta el sacerdote? 
tamente un sistema cerrado autorreferencialmente, el cual efectúa operativamente su hermeticidad sobre la base de la diferenciación de cierto/falso. Pero simultáneamente debe adquirir una forma que lo abra operacionalmente (internamente).

Aqui se observa que una forma en este contexto de la teoría siempre es una "distinción que tiene como efecto una distinción". Por lo tanto, ise requieren dos distinciones para constituir la forma!

La diferencia simétrica del análisis y de la síntesis, una diferencia que integra a la del conocimiento y a la del objeto, ${ }^{157}$ se refiere a esta -claramente interna- operación de la apertura del sistema de la ciencia, dado que "sintético" es siempre aquel "objeto" de la ciencia que luego es procesado, y esto quiere decir descompuesto, por parte del "análisis". Esto significa que el sistema de la ciencia es un sistema cerrado operativamente por medio del código de "cierto/no falso", pero por medio del programa de "comportamiento sintético y/o analítico" es un sistema abierto (internamente), ya que se dirige hacia el exterior (internamente) a través de esta diferencia. Todo lo que está en la mira del sistema de la ciencia como una observación, se observa con la preestablecida meta programática de analizarlo, de descomponerlo, de desensamblarlo. La práctica teórica de la capacidad de resolución y recombinación, del análisis y de la síntesis, es la actividad primordial del sistema de la ciencia. Ni la economía, la política, la familia, la educación, el arte o la religión, para mencionar tan sólo algunos de los sistemas del sentido, han diferenciado como actividad principal o programa el comportamiento analítico (lo que no significa que no empleen esta diferencia).

46. Ahora podemos determinar más exactamente en qué consiste la distinción entre la semántica de la cotidianidad y la de alto rendimien-

157 Aquí dejamos abierto si se puede considerar a la diferencia de conocimiento/objeto al lado de la diferencia de síntesis/análisis, como una diferencia secundaria del sistema de la ciencia. Solamente queremos recordar que la TsS habla, en el mismo contexto, de problemas de codificaciones secundarias. Así, por ejemplo, el sistema jurídico con el código de justicia/injusticia, ' se codifica secundariamente por medio del código de permitido/prohibido. (Luhmann, 1984, p. 511). 
to para el sistema de la ciencia. Siempre que el sistema de la ciencia tiene que tratar con el entorno, observa a todos los objetos como objetos potencialmente analizables, como unidades "compactas" o "sintéticas" cuyas relaciones deben ser averiguadas. Solamente así puede entenderse que para la ciencia todo "lo que hay", lo que son para ella los "objetos" de sus "intenciones del conocimiento", siempre es más complejo de lo que la semántica de la cotidianidad está dispuesta a percibir. En este sentido, la complejidad es un problema genuinamente generado por el sistema de la ciencia.

47. Hemos afirmado antes que el problema de la complejidad, así como lo hemos conocido en el ámbito de la ciencia, se puede encontrar también como un hecho en otros sistemas ajenos a la ciencia. Sólo que aquí no se le denomina o identifica (por medio del habla o de la esrcitura) como el "problema de la complejidad" o como "reducción de la complejidad". Tomemos como ejemplo al sistema personal que se forma por medio de la diferenciación asimétrica (o por el código) de "único, no general", y observemos la siguiente manifestación de Odo Marquard: "Ningún hombre puede - la vida es demasiado corta para ello-arreglar nuevamente todo lo que le concierne, en cuanto a la vida, desde la base; siempre es demasiado para un ser cuya capacidad de dominio es limitada porque siempre se muere demasiado pronto. Por eso, la convencionalidad no sólo es una carga para el hombre, sino que —quizás aun más— una protección. No se debe creer capaz al hombre de demasiadas modificaciones; el porvenir requiere una proveniencia [...]". ${ }^{158}$ Por esta razón, el hombre es un "ser obligado a la conexión". ${ }^{159}$ Marquard utiliza ciertamente una semántica del "hombre" y no una semántica de personas o individuos, pero se señala a la singularidad con la expresión de la "brevedad de la vida del hombre". En todo caso es válido: dado que el hombre está determinado por la brevedad de la vida, debe limitar sus posibilidades a una medida realista y anudar ahí, donde estaban sus antecesores. La semántica de lofinito obliga a la selección. Y precisamente esto es también lo que se quiere decir - visto objetivamentecon la complejidad: "ningún sistema puede realizar la posibilidad lógica de asociar a cada elemento con cada uno de los otros". Esto

${ }_{158}^{159}$ Marquard, 1981, pp. 124-125.

${ }^{159}$ Ibid., p. 18. 
es el punto de partida de toda reducción de la complejidad. Por ello, la complejidad significa obligación a la selección. Entonces es nuestra "brevedad de la vida" la que limita considerablemente a nuestra capacidad de dominio. Nuestro ser de manera finita nos caracteriza como notorios "seres obligados a la conexión". La experiencia de la complejidad se interpreta, dentro del sistema de la ciencia -en la forma de una práctica teórica-como oportunidad y obligación para le selección. En la SOCIEDAD, la misma experiencia se denomina con la ayuda de las semánticas de lo finito: volátil, escaso, de corta vida, etc. Y entre más compleja la SOCIEDAD, más comunes son las semánticas de lo finito. Paradigmática para la SOCIEDAD actual es, sobre todo, la "escasez de tiempo". 


\section{III. ¿QUU ES AUTORREFERENCIA?}

Al alma le es propio aquel sentido que se aumenta a si mismo.

Heráclito, frag.115

...falta el conocimiento de que la realidad esté estructurada en forma circular, también independientemente del conocimiento.

Niklas Luhmann ${ }^{1}$

\section{LA UNIDAD COMO ACONTECIMIENTO TEMPORAL}

1. Tenemos frente a nosotros, guiados por el problema clásico de la complejidad, que por un lado - desde la perspectiva de la observación-, desemboca en la pregunta: "¿cómo es posible la unidad de lo diverso?", y, por el otro - visto desde la perspectiva operacional- ${ }^{2}$ es procesable en la forma de una distinción entre elemento/relación y una de sistema/entorno, a una versión nueva del hecho de la "unidad", anteriormente comprendida ontológicamente: el hecho de la "unidad" parece posible solamente sobre la "base" de las operaciones autorreferenciales", en el sentido de un entrelazamien-

${ }^{1}$ Heráclito, citado por Bruno Snel, 1948, p. 34. La segunda cita es de Niklas Luhmann, 1984, p. 648.

${ }^{2}$ Debe observarse que la distinción de (perspectiva de la) observacion/ (perspectiva de la) operación misma puede obtenerse solamente desde la perspectiva de observación, la cual, sin embargo, se genera solamente cuando se realiza operativamente. La teoría de la acción comunicativa (TkH) habla en este contexto de la perspectiva de observación y de la perspectiva de participación. 
to de las distinciones. Con ello, los conceptos que se ofrecen actualmente respecto a esto, aún están poco comprobados, y no se puede prever cuál obtendrá la versión integrativa más grande y más poder logico. Sin embargo, ya se puede afirmar algo sobre los diferentes conceptos: Todos reproducen distintos aspectos de aquello que se puede denominar generalmente como "autorreferencia". Tanto la "cibernética de la cibernética" (Heinz von Foerster y otros) como la "observación de la observación" (Niklas Luhmann y otros), la "lógica de las diferenciaciones" (Georg Spencer Brown y otros), el concepto de la "autopoiesis" (Humberto R. Maturana, Francisco J. Varela y otros), el concepto del "dialogismo" (Stein Braten y otros) y el "concepto de la conversación" (Gordon Pask y otros), para mencionar tan sólo algunos de los conceptos más conocidos al respecto, se relacionan de manera y tipo diferente con el concepto general de la "autorreferencia ${ }^{n}$. Esto hace necesario ocuparse más detalladamente en aquello que circula generalmente como "autorreferencia".

2. Un "problema" es en sí una unidad que genera "soluciones" funcionalmente equivalentes, las cuales se "mantienen" bajo su custodia. Por ello, la historia de una materia se puede escribir como la historia de su problema y sus respectivas soluciones. Aun más, a través de este camino se puede explicar el surgimiento de una disciplina de la materia como el diferenciamiento de un determinado problema con sus propuestas de solución. En todo caso, existe un consenso amplio sobre aquello que el problema de la sociología, el cual le otorga a la disciplina su unidad peculiar, expresa en la pregunta: "¿cómo es posible el orden social?" Según nuestra opinión no se ha encontrado aún ningún problema de la disciplina de la materia más adecuado que emule la "unidad". Por otra parte, hemos visto que el "problema de la complejidad" dormita en la pregunta acerca de la "unidad de lo diverso". Con ello, el "problema de la sociología" resulta en la pregunta acerca de la "unidad del orden social" como el problema de la complejidad visto desde una perspectiva determinada, o sea desde la perspectiva de la sociedad en su conjunto (-SOCIEDAD). Por lo tanto, los problemas son, con referencia a sus soluciones

${ }^{3}$ Véase entre otros Heinz von Foerster, 1985; Varela, 1975, 1979; Luhmann, 1984, 1990; Spencer Brown, 1969; Maturana, 1985; Braten, 1984; y Pask, 1978a. 
funcionalmente equivalentes, circunstancias que ya implican la "unidad". Si se reflexiona consecuentemente, entonces esta implicación conduce al "problema del problema", el cual debería decir: "¿cómo es posible del todo la unidad?" Esta pregunta expresa por lo tanto el "problema del problema" y es precisamente aquella pregunta que la operación de la "autorreferencia" trata de contestar.

3. La pregunta acerca de la autorreferencia es la pregunta acerca de la posibilidad de la unidad o de la posibilidad de la forma. Esto es precisamente la verdadera afirmación objetiva que se esconde detrás de la semántica de la autorreferencia, de que la "[...] unidad puede generarse solamente por medio de una operación relacionante ${ }^{n}$. $^{4}$ Normalmente se parte del hecho de que las unidades como la "persona", "emoción", "pensamiento", "acción", "percepción" o "sustancia" son unidades ya prefabricadas, mismas que expresan identidades ya preestablecidas. Ahora bien, es precisamente esta circunstancia de una "identidad prefabricada" la que se cuestiona por medio del concepto de la "autorreferencia": las unidades no están dadas, las unidades - del tipo que sean-deben serproductdas. Las unidades son los logros operativos de un observador. Ahora bien, ¿cómo es posible un logro operativo de esta índole? Aqui, esto es exactamente nuestro problema ahora.

Lo cual ya habíamos formulado como el problema del problema, o sea: ¿cómo es posible la unidad del problema como la distinción de presentación del problema y solución del problema?

Con otras palabras: si queremos entender cómo es posible la unidad en general, entonces debemos entender primero, cómo es posible la autorreferencia.

4. En el marco de una "lógica de las distinciones" nos hemos ocupado del aspecto estructural de las distinciones, y hemos designado a

4 "El concepto no sólo define, sino que también contiene una afirmación objetiva, dado que afirma que la unidad se pueda generar solamente por medio de una operación relacionante; o sea que debe ser lograda [R], y que no siempre existe de antemano como el individuo, como la sustancia, como la idea de la operación propia." (Luhmann, 1984, p. 58). 
este aspecto como la forma. Ahora nos queremos dirigir hacia el aspecto temporal de las distinciones, mismo que denominamos como la autorreferencia.

Con esto está dicho que la "autorreferencia" representa el aspecto dinámico de una "lógica de las distinciones". Expresado de otra manera: la autorreferencia es un hecho que no es, sino que se genera."

Podemos formular también en forma abreviada (y por lo tanto también fácilmente equívoca): la forma es la autorreferencia fáctica que se ha generado y la autorreferencia es la forma virtual posible. Con ello, el concepto de la diferencia doblemente contingente jugará un papel importante.

Trataremos de demostrar que en su estructura fundamental, la autorreferencla es comunicativa, dialogica o mutua. Esto se quiere expresar, en una primera aproximación, con el concepto de la diferencia mutua o doblemente contingente.

En el tratamiento del juego conjunto de las distinciones bajo aspectos estructurales hemos puesto en el centro del análisis a la estática (o sea a la perspectiva de la teoría de la observación) de este juego conjunto. Ahora nos queremos dirigir hacia su dinámica (la perspectiva de la teoría de la operación), observar a, por así decirlo, su "movimiento".

Se puede formular también que la forma reproduce el aspecto perfectista del juego conjunto de las distinciones, mientras que la autorreferencia representa al aspecto futurista del mismo juego conjunto. $\mathrm{Na}$ turalmente, aquí se trata de una forma presentista del pasado (forma) y del futuro (autorreferencia). La circunstancia se vuelve complicada por el hecho de que los elementos de la forma y de la autorreferencia, o sea la diferencia, la diferenciación y la denominación reflejan ellas mismas, por su parte, aspectos temporales: la diferenciacion representa una forma del tiempo perfectista, la diferencia representa una forma futurista, la denominación representa una forma presentista. Aquí nos movemos dentro de la esfera de una "lógica de las afirmaciones temporales", como aquélla presentada por C.F.v. Weizsäcker. $^{6}$

sAcerca de ello y con referencia a las ciencias físicas, Ilya Prigogine, Vom Sein zum Werden, 1988.

${ }^{6}$ Weizsäcker, C.F.v., 1992a, pp. 176 y ss. 
Por lo pronto, se debe decir que entre los autopoietas existe un considerable consenso sobre el hecho de que la autorreferencia reproduzca una operactón, la cual a su vez consiste en operaciones. Pero no hay consenso sobre el nümero de las operaciones que se deben suponer con ello, mismas que deben hacer comprensible el hecho de que la autorreferencia sea una operación, la cual, refiriéndose a sí misma, se produce a sí misma. No obstante, se ha establecido la distinción de operaciones del sistema "duras", como la producción y la reproducción, por un lado, y operaciones del sistema "suaves", como la observación y la información, por el otro lado.

Aquí hay una disputa entre los autopoietas acerca de si se puede suponer del todo una pluralidad de operaciones autorreferenciales, $y$ en qué relación se encuentran las operaciones del sistema "duras" como la producción y la reproducción, con las operaciones "suaves" como la observación, la información y el control.' "Resolvemos" este problema primero, mostrando que algo se puede constituir como "algo" solamente si opera de alguna forma. Segundo, una operación -de cualquier tipo- tiene solamente dos posibilidades para su autorrealizacion: o tiene lugar o no tiene lugar. Tercero, por lo tanto, cualquier operación obedece a los principios aristotélico-lógicos de la contradicción y del tercero excluido: como operación no puede realizarse y simultáneamente no realizarse, ni tampoco puede no hacer alguna de las dos cosas. Cuarto, una operación debe, cuando opera, ya poder dominar una distinción, es decir la del tener lugar/no tener lugar de ella misma. Por lo tanto, debe observar que tiene dos posibilidades, las cuales, sin embargo, se pueden efectuar solamente una después de la otra. Con ello se ha dicho que, quinto, cualquier operación debe "examinar" lo simultáneamente dado de sus dos posibilidades del realizarse/no realizarse, con lo cual se encuentra frente a una situación dispuesta simétricamente. Pero, sexto, puede efectuar realmente estas posibilidades alternativas solamente una después de la otra, en forma no simultänea (por regla general operará ciertamente), lo que significa que se puede comportar operativamente solo de manera asimétrica. Ahora podemos resumir: para que algo se pueda constituir como "algo", debe proceder operativamente en secuencia; esto lo logra solamente si puede observar a la simultaneidad de sus posibilidades de realización, de su forma de distinción, dada alternativamente, del tener lugar/no tener lugar. Una operación siempre obliga a una situación con dos distinciones: una simétrica de la observación

${ }^{7}$ Teubner, 1987b, p. 99. 
de las posibilidades alternativas y una asimétrica del poder realizar sólo consecutivamente las posibilidades altemativas percibidas. Si el "algo" no puede observar a sus posibilidades de realización dadas alternativamente, entonces no se puede realizar operativamente; pero si no se puede realizar operativamente, entonces tampoco puede constituir ninguna observación en el sentido de una forma de la distinción, la cual lo capacita para observar la forma de su realización. Con otras palabras, la operación y la observación se pueden constituir sólo simultáneamente; no obstante, están dadas para el "algo" que se constituye por medio de ellas, solamente en la forma de la no simultaneidad: cuando observa, no opera (para sí mismo no, para los otros sí), cuando opera, no puede observar (por lo menos no a la operación que se está efectuando). Naturalmente, cualquier observación es, a su vez, también una operación: puede constituirse solamente como una operación.

Como un representante típico de una explicación exclusivamente "suave" o preñada de cognición del fenómeno de la autorreferencia se debe considerar a Heinz von Foerster, quien se concentra en su "cibernética del segundo grado" en la forma de la operación de un "cálculo del cálculo del cálculo [...]", no obstante, sin exponer más detalladamente el cómo se debería ver la relación de estas operaciones entre sí y hacia la formación de sistemas. Como representante de un concepto de la operación de la autorreferencia "duro" se debe mencionar, por el otro lado, a Humberto R. Maturana, quien trata de explicar la circularidad de la autorreferencia exclusivamente por medio de operaciones libres de cognición. Las operaciones como la "observación", "información" y el "control" son transferidas por él hacia afuera y se abonan a la cuenta de la perspectiva de la observación ${ }^{8}$ $y$, con ello, no se posicionan en el ámbito operativo de la autopoiesis. Francisco J. Varela, Gerhard Roth, Stein Braten, Günther Teubner y la TsS ocupan dentro de esta disputa "silenciosa" una posición intermedia entre las operaciones de operación "duras" y las operaciones de observación "suaves". 9 Somos de la opinión de que es sobre todo

8 "Mientras que von Foerster se concentra en su second order cybernetics en las operaciones suaves de las computations of computations of computations, sin tematizar su relación con la reproducción del sistema, Maturana representa con toda dureza a un concepto behaviorista de la autopoiesis, el cual, con las operaciones de la autorreproducción circular de los elementos y su red, es autónomo." (Idem).

9 Con este problema central de la autorreferencia se trata en primera instancia de encontrar una solución óptima más que participar en la disputa co- 
la "posición". de la TsS y su revisión por Günther Teubner la que ha progresado más en la formulación de un concepto diferenciado de la autorreferencia, y que, por lo tanto, debería ser atractivo el hecho de hacer conexión aquí, para no perder descuidadamente el terreno de la teoría ya obtenido.

\section{OPERACION, OBSERVACION Y AUTO-OBSERVACION}

5. En la controversia entre un concepto de la autorreferencia "duro", independiente de la observación, y un concepto "suave", dependiente de la observación, también se acostumbra partir de la distinción de operacióniobsèrvación. Con ello, debe tomarse en cuenta que el concepto de la "observación" implica al concepto de la "operación", dado que cualquier observación se puede generar solamente por medio de uña operación de la observación, ya que es posible en sí solamente como operacion: Por el otro lado - y esto hace tan problemático al concepto de la "operá̀ión $\rightarrow$ la operación es un logro no cognoscitivo que hace solamente lo que hace. ${ }^{10}$ Regresaremos a este problema. En todo caso, sobre todo Varela, Roth, Braten, Teubner y la TsS hacen el intento de manejar productivamente la distinción de operación/observación. Con ello, se trata principalmente del intento de hacer compatibles una con la otra a la observación y la operación, de no utilizar ambos conceptos en el sentido excluyente como en Heinz von Foerster ("observación") o en Humberto R. Maturana ("operación"). Ahora, observemos algo más detalladamen-

mo tal. Esto al menos parece ser el estado de las cosas, algo que naturalmente se podría cambiar muy rápidamente. Ver por ejemplo Braten, 1984; Luhmann, 1987; Roth, 1986, 1987; Teubner,.1987b, 1989; y Varela, $1981 \mathrm{~b}$.

10 "Acerca del concepto de la operación [...] se debe aclarar que la operación efectúa aquello que efectúa y que no es nada que no es. No obstante, esta afirmación debe manejarse cautelosamente, si uno no se quiere desviar aquí hacia los surcos de lógica clásica de la reflexión. Ciertamente afirma que la operación es aquello que es, y también cuando lo niega. De esto no se puede deducir precisamente un ser diferente, y tampoco un no ser diferente, ya que el 'no' es, en sî, en la operación, aquello que se logra positivamente. Las negaciones se utilizan siempre solamente de manera capaz de conexión pasitiva [R], y siempre se encuentran condicionados a través de los antecedentes dentro del mismo sistema." (Luhmannn, 1990, p. 517). La pregunta que se debería hacer aquí es: ¿cómo se puede captar cognoscitivamente a una operación cognoscitiva en su no cognitividad? 
te el cómo los mencionados autores manejan operativamente la distinción de observación/operación.

6. Francisco J. Varela diferencia entre una explicación "operativa" y una "simbólica", con lo cual hace conexión con la distinción de comprender/explicar, y postula una complementariedad de ambas formas de explicación. En cierta manera, sólo traslada el problema, dado que dentro de su modelo no se puede explicar cómo es posible una integración de la operación y de la observación (o del símbolo). Se presentan dos niveles de abstracción, uno operativo-explicativo y uno simbólico-comprensivo, pero no se demuestra ningún entrelazamiento de los dos niveles. ${ }^{11}$ Por su parte, Gerhard Roth distingue, en el nivel de las operaciones, entre las operaciones "duras", mismas que se reproducen, y las interacciones "suaves", que se reproducen, y que, por su parte, pueden producir cogniciones. Refiere las operaciones duras a los sistemas biológicos (autopoiéticos), como las células y las operaciones "suaves" las refiere a los sistemas (autorreferenciales), como los sistemas personales y sociales. ${ }^{12}$ Stein Braten intenta tomar un tercer camino interesante, distinguiendo un concepto de la autopoiesis mecánico (operativo) y uno simbólico (del tipo observativo), y trata de integrar ambos en un modelo de diálogo, con lo cual la hermeticidad autopoiética y la apertura simbólica deben conducir de manera y tipo oscilante hacia la generación de información: el sistema se cierra por medio de la reproducción autopoiética y se abre nuevamente por medio del acto de la observación. ${ }^{13}$ Somos de la opinión de que Braten hace una considerable aportación a la aclaración de la controversia, y que sobre todo hace evidente que las formas de COMUNICACIón monológicas y dialógicas, o sea, la operación y la observación, no se excluyen, sino que se complementan.

En última instancia, estas observaciones significan — visto desde la teoría de la sociedad-que una perspectiva orientada exclusivamente hacia la teoria de la acción hace visible, nolens uolens, solamente una forma de la práctica monológica. Por otra parte, una perspectiva exclusivamente desde la teoría de la comunicación ciertamente coloca en la mira una forma dialógica; pero ésta no basta para hacer plausible

"Varela, 1981a y 1981b.

12 Por ejemplo Roth, 1986, 1987, 1987a y 1987c.

13 Braten, 1984. 
la formación de los sistemas. $O$, en el discurso de una cibernética del primer grado: la ACCIÓN Sin COMUNINICACION genera sistemas del sentido "sin reflexión", la COMUNICACIÓN sin ACCIÓN genera una cultura "sin sistema". Ambas cosas son posibles y también se procesan, dentro de la SOCIEDAD.

Esta agudización del problema de la comunicación es de interés particular porque podemos observar, por ejemplo con la teoría de la acción comunicativa (TkH), la tendencia de querer proceder exclusivamente de manera dialógica; mientras que la teoria de los sistemas sociales (TsS) parece tomar un camino más bien monológico, por lo menos cuando se trata de aplicar el concepto de la diferenciación de George Spencer Brown. Observemos ahora más detalladamente cómo la TsS opera con la distinción de operación/observación.

7. ¿Cómo maneja la TsS la distinción de la operación y la observación? La TsS es de la opinión de que, con la distinción de operación/observación, "[...se llega R]] a uno de los más difíciles problemas de la discusión sobre la autopoiesis: la relación de la operación y la observación autopoiéticas". ${ }^{14}$ Queremos anticipar ya aqui que la TsS entrelaza ambas formas de operación con la ayuda del concepto de la auto-observación.

No se debe olvidar que cualquier observación es simultáneamente una operación, la cual puede observar a otras observaciones y operaciones; sin embargo, siempre sobre la base de una distinción como por ejemplo la de operación/observación. Expresado de otra manera: cualquier observación representa una operación, pero no cualquier operación es una observación. Una operación no es, visto cognoscitivamente, accesible internamente, mientras que una observación siempre es observable en la forma de una distinción. A pesar de que las operaciones son cerradas u opacas cognoscitivamente, son observables como operaciones, aunque solamente con la ayuda de una observación adicional, misma que utiliza a la distinción de operación/no operación o de operación/observación (una utilización que, por su parte, es posible solamente de modo operativo..., etc.). Dicho de otra manera, una operación como operación no puede realizar ningún logro de observación por sí misma. Sólo una operación como observación es capaz de ob-

${ }^{14}$ Luhmann, 1987 j, p. 317. 
servar si la "próxima" operación que tenga lugar es capaz de conexión o no. Todo esto se puede encontrar ya en: Der Gestaltkreis. Theorie der Einheit von Wabmebmen und Bewegen (publicado en 1940) de Viktor von Weizsäcker. Aquí nos limitamos a indicaciones generales. La relación fundamental dice ("principio de la puerta giratoria"): "Cualquier acto es percepción [=observación RJl y movimiento [=operación RJ. Sin embargo percibiendo no puedo percibir el movimiento que hace posible la percepcion, y no puedo, en movimiento, efectuar la percepción que lo hace posible. En este sentido, el movimiento es un no-percibirlo, y la percepción es un no-moverlo. Se encuentran en una relación tal que se ocultan mutuamente"15 (lo que significa que se encuentran en una relación complementaria). Expresado otra vez en palabras de Viktor von Weizsäcker: no se puede observar, en la obsenvación, a la operación que la hace posible, y en la operación no se puede efectuar la observación que la hace posible.

Y la pregunta cuya respuesta es la "auto-observación" se puede hacer, con Luhmann, de la siguiente manera: "Existen tipos de sistemas autopoiéticos cuya autopoiesis depende de que las operaciones que la efectúan se observen continuamente dentro del mismo sistema? ¿La auto-observación como condición de la autopoiesis? [...] Esto lo he afirmado para los sistemas que operan sensatamente [...], y de esta decisión teórica depende mucho.."16

8. El punto de partida es: para posibilitar la reproducción autopoética, deben efectuarse conjuntamente las operaciones "duras" y las "suaves". Sólo cuando se juntan la auto-observación y la autorreproducción (ó sea la observación y la operación), se puede generar la autopoiesis en el nivel de los sistemas de sentido. Una auto-observación representa en sí una operación autorreproductiva cuya función es garantizar la capacidad de conexión de las operaciones particulares para más operaciones, realzando la pertenencia de la operación que tiene lugar al sistema correspondiente. Por ello introduce la diferenciación de sistema y entorno (re-entry) al sistema y sirve, precisamente por ello, para el control de la autorreproducción del sistema. Se puede comprender con Günther Teubner el concepto de la auto-

15 Weizsäcker V.v., 1973, p. 291.

${ }^{16}$ Luhmann, 1987j, p. 317. 
poiesis de la TsS como una síntesis del concepto de la autopoiesis de Maturana y aquél de von Foerster, de una cibernética del segundo grado. ${ }^{17}$ La auto-observación - como una forma de la observaciónconsiste, por lo tanto, en la introducción de la diferenciación de sistema/entomo al sistema, el cual se constituye precisamente por medio de esta diferenciación. Simultáneamente, la auto-observación es un momento operativo de la operación autopoiética, dado que solamente así se puede garantizar que, en la reproducción de los elementos, éstos sean reproducidos como elementos del sistema en cuestión, y no como cualquier otra cosa. ${ }^{18}$ No queremos profundizar aquí la discusión sobre las diferentes líneas de conceptos de la autorreferencia, ${ }^{19}$ no obstante llamamos la atención sobre el hecho que, por ejemplo, Gerhard Roth ${ }^{20}$ propone la secuencia ascendente de conceptos de auto-organización, autoproducción, auto- conservación y autorreferencialidad; la secuencia de conceptos de Teubner ${ }^{21}$ es, por otra parte: auto-observación, autoconstitución, autopoiesis/ hiperciclo; la TsS finalmente trabaja con tres secuencias de conceptos: 1) autopoiesis, auto-organización; reflexión, 2) autorreferencia basal, reflexividad, reflexión, y 3) auto-observacion, autodescripción, reflexión y racionalidad. ${ }^{22}$

17 Teubner, 1987 b, p. 100.

18 "La auto-observación es, por lo tanto, la introducción de la diferencia de sistema/entomo al sistema, el cual se constituye con su ayuda; $y$, a la vez, es un momento operativo de la autopoiesis, dado que en la reproducción de los elementos debe estar garantizado el que se reproduzcan siempre como elementos del sistema, y no como cualquier otra cosa." (Luhmann, 1987b, p. 102).

${ }^{19}$ Regresaremos otra vez a este problema dentro de la discusión sobre los distintos niveles de abstracción de la observación. Ver capítulo IV sobre la observación.

${ }^{20}$ Roth, 1986.

${ }^{21}$ Teubner, 1987b, p. 102.

${ }^{22}$ Acerca de las correspondientes secuencias de conceptos ver Luhmann, 1984 , p. 24 y ss., 600 y ss. y 593 y ss., y Teubner, 1987b, pp. 95-96. El comentario de Günther Teubner a esto es: "[...] Luhmann aün no ha realizado ninguna aclaración sistemática del campo total de los conceptos, más bien ha desarrollado varias secuencias de conceptos, las cuales, no obstante, aún no producen una imagen global consistente. El problema de este tipo de secuencias de conceptos es, en particular, el que no solamente varian una caracteristica dentro de una dimensión, sino que, simultáneamente, en otras dimensiones, trascienden los fenómenos heterogéneos". (Idem). 
9. En todo caso, se debe afirmar que la solución, la cual ofrece la TsS para poder explicar la unidad autorreferencialmente, no es satisfactoria, dado que, primero, permanece sin aclarar cómo un sistema del sentido llega al re-entry de la distinción de sistema y entorno. Segundo, también permanece sin aclarar cómo un sistema discrimina con la ayuda de la auto-observación. Cierto, una vez introducido el concepto de la auto-observación (cpero cómo llega el sistema a esto?); se puede afirmar, sin más, que el sistema discrimina entre "sí y otras cosas". Tercero, se añade que la TsS identifica precisamente el concepto de la acción como la auto-observación del sistema, ${ }^{23}$ un supuesto que es problemático ya que la acción sugiere semánticamente una falta de reflexión, mientras que la auto-observación señala una operación reflexiva.

Naturalmente, una auto-observación como operación no puede reflexionar sobre sí en el momento de su constitución. En ese aspecto, posee un carácter falto de reflexión, igual que se puede decir que la conciencia es un acto inconsciente. ${ }^{24}$

Nosotros ( $\mathrm{TgS}$ ) pensamos que aquí se debe tomar otro camino para llevar la operación de la autorreferencia hacia una aclaración. De acuerdo con la "lógica de las distinciones" antes propuesta, queremos aproximamos mediante la teoría de las distinciones al fenómeno de la constitución de la unidad en la dimensión del tiempo (=autorreferencia). Tenemos la idea de que la debilidad principal del proyecto global de la TsS consiste en intentar explicar cualquier categoría, cualquier concepto teórico, con la ayuda de una única distinción en conexión con solamente una única operación. ${ }^{25}$ Con ello, muchas veces no es claro si se trata de una operación, una distinción, una observación o incluso simultáneamente de las tres cosas. Tambiến en el caso del concepto de la autorreferencia, se hace no-

23 "Para fines de la auto-observación y autodescripción, se asimetriza la simetría de la comunicación, su excitabilidad se reduce por medio de la responsabilidad de las consecuencias. Y en esta autodescripción abreviada, simplificada y, por ello, más fácilmente comprensible, la acción, no la comunicación, sirve como elemento último." (Iuhmann, 1984, pp. 227-228).

${ }^{24}$ Weizsä̀cker, C.F.v., 1983a, p. 359.

25 Sea observado de paso, que, por medio de ello, la TsS puede lograr pensar conjuntamente la observación y la operación a través de la auto-observación. 
torio el ya varias veces mencionado problema: una diferenciación asimétrica es simplemente demasiado poco compleja como para explicar satisfactoriamente, por ejemplo, la "autorreferencia", "complejidad", "forma" o la "observación", y mucho menos la SOcIEDAD.

La TsS se enreda siempre en los problemas del inicio de un inicio, o en problemas de la emergencia, con lo cual trata de explicar a éstos con la ayuda de los conceptos de la paradoja y la tautología. Sin embargo, tenemos la opinión de que, con ello, se ofrece solamente una solución provisional, dado que estos conceptos solamente oscurecen el problema del origen o de la emergencia de "algo", pero no lo explican (lo que también debe ser supuestamente su "función").

Ahora bien, la decisión de la TsS de comenzar con sólo una distinción única concieme al nivel primario de abstracción de su arquitectura de teoría. Como ya lo formulan Talcott Parsons y Charles Ackerman, una abstracción primaria conceptual de este tipo es de significado decisivo para el éxito o el fracaso de una teoria: "Todo depende de las abstracciones primarias: la fertilidad y el grado de generalidad de la teoría dependen del tipo de abstracción primaria. ${ }^{\text {n2 }}$ Sería del todo posible seguir intentando entender la SOCIEDAD sobre la línea de la arquitectura de la teoría de la TsS. Pero uno se encontraría siempre con esta debilidad: ¿cómo es posible la constitución de algo como "algo" (como autorreferencia, como forma, como observación, como COMUNICACIÓN, COMO SOCIEDAD..., etc.) sobre la base de sólo una distinción única (por lo menos cuando está formada asimétricamente)? Con nuestra propuesta (TgS) de empezar con el comienzo general de la teoría inmediatamente con dos formas de distinción diferentes logramos algo triple: primero, la integración de la TsS al proyecto aquí presentado, dado que para la construcción de la SOCIEDAD requerimos tanto de una diferenciación asimétrica como de una diferencia simétrica; segundo, escapamos al problema de la emergencia en el sentido de una "emanación desde la nada"; y, tercero, esquivamos una explicación comprometedora con la ayuda de los conceptos de la tautología y la paradoja. Visto de esta manera, la constitución de algo como "algo" siempre está ya determinada dialógicamente en el proyecto aquí presentado: son necesarias, por lo menos, dos distinciones, para poder explicar plau-

${ }^{26}$ Ackerman/Parsons, 1976, p. 72. 
siblemente la emergencia de "algo", o de la SOCIEDAD. En este sentido, nos queremos dirigir ahora al concepto de la autorreferencia.

\section{UNIDAD Y AUTORREFERENCIA}

10. Hemos dicho antes que el problema de la autorreferencia se puede expresar con la pregunta del "problema del problema", que dice: "¿cómo es posible la unidad". Esta formulación resulta del hecho de que primero se formula el problema: ¿cómo es posible la unidad de "algo"? pero después se debe constatar que ya el concepto del problema mismo es introducido como unidad, o sea, como $e l$ problema. En un primer plano, la unidad de un problema consiste en el diferenciamiento entre planteamiento del problema y las respectivas soluciones del problema. El planteamiento del problema dirige a las soluciones de problemas, con lo cual las soluciones de problemas "mantienen" la posición de problema..., etc. La pregunta acerca del problema del problema es, por lo tanto, la pregunta acerca de las condiciones de posibilidad de una unidad del problema. Formulado de otra manera: la explicación del concepto de la autorreferencia no puede empezar con una unidad predefinida ontológicamente. La unidad, de cualquier tipo, primero debe ser producida. En este contexto, Günther Teubner opina con razón (y con él Ranulph Glanville):" " $\mathrm{La}$ autorreferencia disuelve la unidad de una unidad y la sustituye por la trinidad [R]] de referente, referido y la relación entre ambos. ${ }^{n 28}$ Ciertamente, la "autorreferencia" es una operación que se constituye por distintos momentos de acontecimientos, sin embargo ¿está - en concordancia con Teubner y Glanville- determinada en forma trinitaria? ¿Consiste, de hecho, solamente en los momentos de acontecimientos "referente", "referido" y la "relación" entre ambos? Para este fin, observemos algo más detalladamente la operación de la autorreferencia.

11. De hecho, existe "el referente", "el referido" y la "relación entre referente y referido", que marca el limite entre ambos, pero también y, sobre todo,. "está una observación" que se ha encaprichado

${ }^{27}$ Glanville, 1988, p. 62.

${ }^{28}$ Teubner, 1987b, p. 103. 
en una "observación de la autorreferencia", con lo cual se quiere decir "nosotros mismos", quienes constatamos esto en el momento presente, o sea como observadores de una observación de esta naturaleza de la autorreferencia. Podriamos haber observado también cualquier otra cosa, u operacionalizar otro "interés de conocimiento" como, por ejemplo, "sistema" o "complejidad" o "sociología". Pero abora dirigimos nuestra atención de observación precisamente a la "autorreferencia" (figura 70).

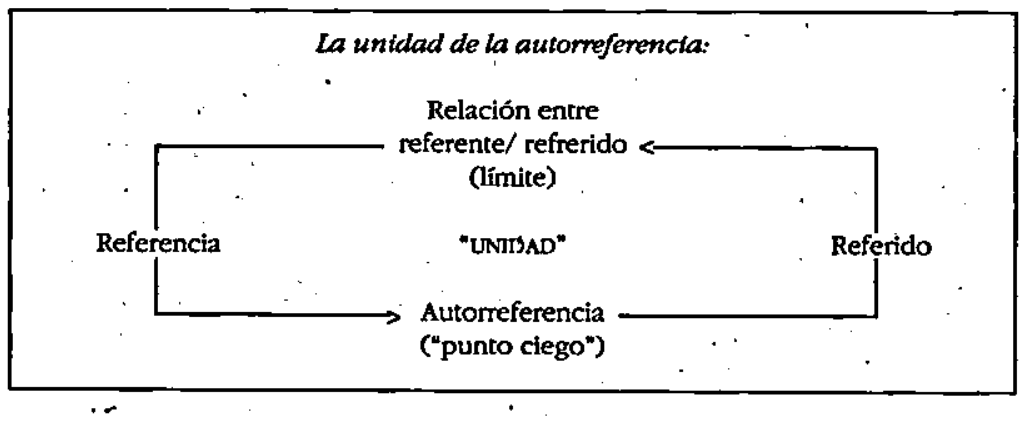

Podemos explicar este heche también con la ayuda del ya propuesto concepto de la observación: existe, primero, el observador, segundo, lo observado, tercero, la relación entre ambos, y, cuarto, la observación misma como forma especial de la observación (se podría tratar, como ya lo hemos dicho, del concepto de la contradicción, de la interpretación, del re-entry, etcétera).

Con "forma especial" se quiere decir que no se trata de la observación de una casa o de un hombre, sino de la observación de la observactón. En este sentido, "forma especial de observación" se refiere al aspecto de su generalidad. No se trata de una observación determinada, sino de la observación como forma.

El cuarto valor de un relacionamiento autorreferencial de esta índole es tan difícil de captar, porque expresa el "interés del conocimiento", el cual realiza el observador observante en el momento de su operación de observación de otro observador. El cuarto valor es el "punto ciego" de un observador, el cual no puede justificar simultâneamente, dentro de su actividad de observación, el que utiliza la 
operación "observación" $y$, a la vez, la observa: sólo puede ser abordada en el "ahora" de la dimensión del tiempo.

Se insinúa brevemente aquí que detrás del "ahora" se esconde un problema profundo y difícil. C. F. v. Weizsäcker, quien relata una conversación sobre el problema del "ahora" entre Albert Einstein, Rudolph Carnap y Karl R. Popper, opina al final de su reporte: "En mi opinión, el ahora es, dentro del marco de la estructura de la temporalidad, la condición previa del habla conceptual, $y$, de esta manera, también de la ciencia. La ciencia puede describir conceptualmente los hechos y las posibilidades (hablariamos de diferencias y diferenciaciones RJ); con ello, siempre presupone implícitamente el ahora. Formula frases generales, las cuales están hechas a propósito de tal manera que en ellas no se menciona el ahora, mismo en el que están dichas; ciertamente, siempre deben ser válidas. Einstein sabe que los conceptos tienen un sentido claro solamente dentro del marco de una teoría, o sea dentro de frases generales. Además, proviene de una versión de la física, la cual describe al tiempo por medio de una coordenada real. De esta manera, se enfrente al hecho fundamental de todo conocimiento, al ahora, como un cuerpo extraño. Tiene el valor de asombrarse de ello. ${ }^{29}$ En el contexto de este trabajo, hablamos también de la inmediatez, un concepto que utilizamos en el mismo sentido que el del ahora, y que ilumina la tesis de partida de este trabajo: todo tiene lugar inmediatamente o "ahora", por lo tanto, todo sucede en el modo de la simultaneidad. El problema para los sistemas del sentido es entonces: ¿cómo logran estos sistemas desarrollarse, a pesar de que están confrontados con el problema de la simultaneidad?, ¿cómo asimetrizan su simetría basal? (figura 71).

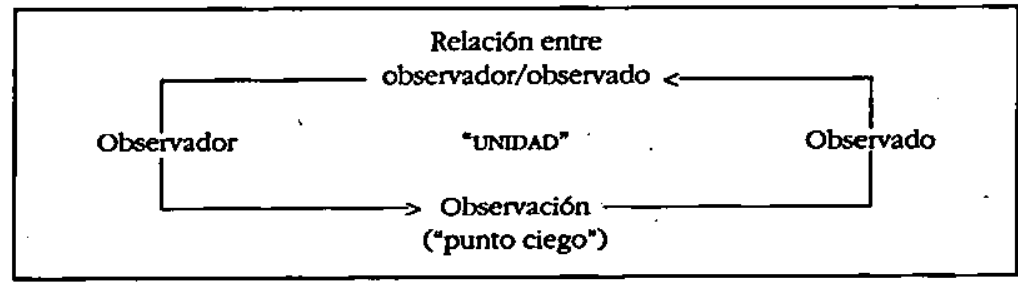

Ciertamente, con la ayuda de la observación, el sistema puede distinguir; no obstante, esto requiere la aplicación de la observación, misma que en el mismo acto no se puede distinguir a sí misma. Con

29 Weizsäcker, C.F.v., 1992a, p. 84. 
otras palabras, cada observación utiliza las distinciones con cuya ayuda puede observar entonces; sin embargo, la operación de esta utilización de las distinciones es observable solamente por otro observador, o por el mismo observador en un momento posterior. Por lo tanto, está excluido el que un observador utilice una observación $y$ la observe en el mismo instante. Por ello, existe un limite absoluto de lo observable (naturalmente desde la perspectiva teórica de la observación), el cual consiste en que la observación actual no puede ser accesible cognoscitivamente para el observador, mismo que la utiliza. Ahora bien, si preguntamos en este contexto, ¿qué sucede si todo lo que sucede, sucede simultáneamente? Entonces podemos contestar: ningún observador es capaz de utilizar y observar simultáneamente a su observación actual. C.F.v. Weizsäcker opina, en vista de la misma circunstancia y con referencia a Niels Bohr, que mientras se esté analizando un concepto, éste no puede ser aplicado; no obstante, si se aplica, entonces ya no se puede analizar: "Existe una relación de exclusividad entre el análisis y su aplicación inmediata. ${ }^{n 30}$ Proponemos denominar esta circunstancia de los conceptos mutuamente complementarios de la operación y la distinción (observación) como el principio de la correspondencia de la operación y la distinción.

Ver acerca de ello directamente el capítulo sobre la complementariedad y la distinción. Sea observado que el supuesto del principio de la correspondencia implica que la razón, por ejemplo, de la observación (=distinción) y/o la operación, no se puede encontrar en la observaclón o en la operación, sino solamente en la relación mutua: si se puede demostrar esta relación, entonces se ha indicado "la razón" de su ser-de-esta-manera. Viktor von Weizsäcker formula esto de la siguiente manera: "Aunque se haya comprobado el movimiento [-operación] como una condición de la percepción [-observación], y la percepción como una condición del movimiento, no es posible ni necesario analizar esta condición a la luz de los límites de esta exigencia mínima. La causalidad especial o el paralelismo regular de los dos momentos, del movimiento físico y de la percepción psíquica, no debe ser ni puede ser indagado; basta que su adjudicación sea. ${ }^{\text {"31 }}$ Debemos realzar el que aquí debería aplicarse la reflexión teórica de la validez, dado que queremos limitar este aspecto a lo más indispensable dentro

30 Weizsäcker, C.F.v., 1984a, p. 283.

31 Weizsäcker, V.v., 1973, p. 244. 
de este trabajo. En La forma de la SOCIEDAD $D^{32}$ abordamos este tema exhaustivamente.

\section{DIFERENCIA Y DOBLE CONTINGENCIA}

12. Hemos denominado el aspecto temporal de una "lógica de las distinciones" como "autorreferencia". Con ello, el hasta ahora aún no tematizado concepto de la "diferencia doblemente contingente" juega un papel especial en este contexto. La "autorreferencia" debe ayudar a sensibilizamos para la pregunta " ¿cómo es posible la unidad?" Queremos acercarnos al concepto de la "autorreferencia" tratando de determinar lo que se podría querer decir, por un lado, con "misma" y, por el otro lado, con "referencia". Observemos para este fin cómo procede la TsS, dado que, en cuanto a la "autorreferencia", la TsS parece ser aquella teoría que ha alcanzado -en la esfera de influencia de la teoría de la sociedad-el nivel teórico más alto. ${ }^{33}$ Por lo pronto: determina el concepto de la referencia de tal manera que lo acerca al concepto de la observación: "Con ello Icon el concepto de la autorreferencia RJ] queremos designar una operación que consiste en los elementos de la diferenciación y la denominación (distinction, indication en el sentido de Spencer Brown). Es decir, que se trata de la denominación de algo, en el contexto de una diferenciación (también introducida operativamente) de otras cosas. ${ }^{n 4}$

La TsS determina la observación como la obtención y la transformación de la información con la ayuda de una diferenciación. Con la ayuda de la diferenciación se puede determinar, por su lado, lo que se excluye por medio de una información. Por lo tanto, una observación es una diferenciación, y esta diferenciación es una separación y, simultáneamente, una asimetrización. Recordamos aquí que, por nuestra parte, hemos distinguido entre la diferencia y la diferenciación: la diferencia como una distinción dispuesta simétricamente, y la diferenciación como distinción formada asimétricamente.

Si se observa más detalladamente esta formación del concepto, entonces se puede constatar que la TsS parte de sólo una diferen-

32 Jokisch, 1995.

${ }^{33}$ Günther Teubner argumenta de manera parecida, 1987b, p. 94 y ss.

${ }^{34}$ Luhmann, 1984, pp. 596-597. 
ciación única: uno de los lados de la diferenciación es designado en el contexto de ella misma, con la consecuencia de un lado no-designado. Pero ¿quién o qué distingue la posible diferenciación dentro de un mundo por lo demás no designado y, por lo tanto, vacío cognoscitivamente (no realmente)?35 Ya hemos mencionado que algo es observable como "algo" solamente a partir de un relacionamiento tetradizante, o sea sólo dialógicamente. La TsS escoge un camino consecuentemente monológico también para la determinación del concepto de la autorreferencia: "Normalmente no es necesario más que una operación con esta condición previa Ide la diferenciación RJ].".

Si se observa èl ejemplo que menciona la TsS para el argumento de que no es necesaria más de una distinción única (como diferenciación, bien entendido), para generar la autorreferencia, entonces, uno solamente puede asombrarse, dado que se mencionan, por lo menos, tres distinciones: "Uno quiere preparar té. El agua aún no hierve. Entonces, uno debe esperar. Las diferencias te/otras bebidas, hervir/no hervir, tener que esperar/poder tomar estructuran la situación [.... ${ }^{36}$ Por lo tanto, se comienza monológicamente, aunque, en última instancia, se comunica/actúa dialógicamente Tenemos la opinión de que no se puede de otra manera que dialógica o mutualmente, pero esto lo debería considerar la TsS ya en sus premisas, lo que, no obstante, según nuestra opinión, deja de hacer. Ciertamente, visto desde la teoría de la operación, sólo se puede comenzar asimétricamente: se opera "de esta manera, no de otra". Sin embargo, ya la distinción "de esta manera, no de otra" muestra en la reflexión que uno, con ello, se debe haber encontrado frente a una bifurcación del camino, para poder haber procedido "de esta manera, no de otra". De acuerdo con el tiempo, uno siempre procede asimétricamente, pero de acuerdo al "espacio" siempre simétricamente. Sin embargo, si se reflexiona acerca del proceso operativo ligado al tiempo, entonces se hace evidente que uno siempre debe haber presupuesto una distinción simétrica, lo que significa que, con ello, siempre están involucrados la generalidad y la necesidad.

13. Si se toma el concepto de la "referencia" adicionalmente a aquél del "uno mismo", y se juntan ambos en el concepto de la autorrefe-

${ }^{35}$ Sea recordado aquí nuestro tratamiento de los conceptos de Spencer Brown, Glanville, Herbst y Günther en capítulo I.

${ }^{36}$ Luhmann, 1984, p. 597. 
rencia, entonces, este concepto significa "[...] que la operación de la referencia se encuentra encerrada en lo denominado por ella. Designa algo a que ella misma pertenece". ${ }^{37}$ Pero, ¿cómo puede referirse a sí misma una diferenciación única, si se encuentra sola, como esto se presupone una y otra vez por la TsS? Referirse a sí misma como diferenciación entera es apenas concebible, dado que no se sabe cómo y por medio de qué ésta se pueda referir a sí misma. ¿Quizá por medio de uno de sus lados? Realizamos esta posibilidad a modo de prueba. Si dentro de una diferenciación que consiste exclusivamente en dos lados, el primer lado se refiere al segundo lado, entonces la diferenciación pierde su primer lado, $y$, con ello, deja de ser diferenciación, ya que se abandona la referencia constitutiva hacia el primer lado.

Bien entendido, éste es el caso porque el punto de salida se conforma con solamente una distinción, o sea con una "diferenciación". Una đistinción puede encontrar un "punto fijo" solamente si se "sujeta" por medio de una segunda distinción. Si éste no es el caso, entonces una distinción planteada monológicamente pierde su apoyo en cualquier crossing (si es que lo tuvo alguna vez), y se disuelve.

Pero a lo mejor lo que se quiere decir la TsS es que zun lado de la diferenciación se refiere a sí mismo? Ya antes habíamos realizada esta maniobra de distinción y habíamos determinado que una "forma de emanación" de este tipo es sólo concebible fenomenológicamente. ${ }^{38}$ Por lo tanto, podemos formular: un concepto de autorreferencia de este tipo sobrepasa la imaginación, si se intenta efectuarlo monológicamente, como, en principio, lo propone la Tss.

Aquí, con monológico se quiere decir que la TsS comienza el primer movimiento de su práctica de la teoría (y supuesta realidad) con sólo una distinción, formada asimétricamente.

Sin embargo, la realización efectuada "prácticamente" de un concepto de autorreferencialidad de esta índole, concebido monológicamente, es resuelto por la Tss, en última instancia, dialógicamente, ya que siempre recalca que la autorreferencia como hermeticidad sis-

${ }^{37}$ Ibid., p. 600.

${ }^{38}$ Con ocasión de la discusión de los trabajos de Spencer Brown y Glanville en el capítulo I sobre la forma. 
témica es posible solamente dentro de un entorno, solamente bajo condiciones ecológicas.

La teoría de los sistemas autorreferenciales sostiene que un diferenciamiento de sistemas se puede generar solamente por medio de la autorreferencia, esto quiere decir por medio del hecho de que los sistemas hacen referencia ... a sí mismos en la constitución de sus elementos y de sus operaciones elementales. Para posibiltar esto, los sistemas deben generar y utilizar una descripción de sí mismos; ellos deben poder utilizar internamente, por lo menos, la diferencia de sistema y entorno como orientación y como principio de la generación de la información. Por lo tanto, la bermeticidad autorreferencial es posible solamente dentro de un entorno, solamente bajo condiciones ecologicas [R]]..$^{39}$ En un nivel operativo, se puede formular también a manera de la teoría de la distinción: una operación debe dominar, por lo menos, la distinción simétrica de operar/no operar, para realizarse a sí misma en forma asimétrica.

Con ello, en la TsS existe una discrepancia fundamental entre su intención de comenzar con solamente una diferenciación y la realización de esta intención, la cual entonces resulta dialógicamente.

Cuando la TsS formula: el concepto de la autorreferencia denomina aquella unidad que un elemento, un proceso, un sistema es para sí mismo. "Para sí mismo" esto significa: independientemente de la confección de la observación a través de otros, ${ }^{40}$ entonces la frase "independientemente de la confección de la observación a través de otros" sugiere un procesamiento completamente monológico. Dado que nosotros ( $\mathrm{TgS}$ ) siempre empezamos con, por lo menos, dos distinciones, no nos exponemos a este peligro de tener que comenzar desde cero. Entonces, la pregunta es naturalmente: ¿̨cómo se puede constituir dialógicamente la hermeticidad autorreferencial ( lo que implica ciertamente el carácter abierto)? Opinamos haber "resuelto" este problema dentro del marco del supuesto-de-la-hermeticidad de una teoría autorreferencial. Ver más adelante.

Ahora bien, ¿cómo se puede imaginar dialógicamente la autorreferencialidad? Si uno mira más detalladamente, resulta que con la auto-

${ }^{39}$ Luhmann, 1984, p. 25.

${ }^{40}$ Ibid., p. 58. 
rreferencia se trata, en última instancia, de un autodiálogo. Pero ¿cómo es posible esto?

14. Partimos del hecho de que el comienzo de algo (lo que sea) siempre es coevolutivo, y esto significa que puede tener lugar solamente sobre la base de, por lo menos, dos distinciones.

Es una posición de salida irrealista, ya que siempre están presentes más que sólo dos "algos": "Con las simplificaciones modelo se parte, a veces, de una medida mínima (sin embargo, un mínimo ilusionario) de dos procesadores como condición de la autorreferencia. ${ }^{\text {(4) }}$ Para el proceso de la argumentación, sin embargo, es suficiente este supuesto de dos procesadores. Por lo demás, existe, en este contexto, un cierto parecido entre, por un lado, la posición representada por la TsS y, por el otro lado, la TaH (Parsons), en el sentido de que ambas teorías presuponen dos black boxes o dos procesadores. Nosotros (TgS) opinamos ir un paso más lejos, presuponiendo las black boxes como white baxes: de esta manera, no es necesario procesar, por ejemplo, la "indeterminación" con la ayuda de una black box invisible. Es suficiente aplicar cualquier distinción simétrica "concreta", ya que una función esencial de la simetría consiste precisamente en la generación de la "indeterminación", a pesar de su determinación respecto a sus dos lados.

A estas distinciones las llamamos diferencia y diferenciación, con lo cual la forma de la diferencia es (entre otras) simétrica, la forma de la diferenciación es (entre otras) asimétrica.

Si a las distinciones se les agrega la dimensión del sentido y se interpreta a manera de teoria de la distinción, entonces se puede formular: el tiempo aparece como la distinción de los lados aún-no-denominado/ya-denominado; el espacio aparece como la distinción de un lado completo/no completo; la objetividad aparece como la distinción de los lados determinado/indeterminado, y finalmente, aparece la socialidad como la distinción de los lados seleccionable/no seleccionable. Ver acerca de esto capítulo I sobre la diferencia y la diferenciación. En el discurso de una "logica de las afirmaciones temporales", como aquélla presentada por $\mathbf{C}$. F .von Weizsäcker, se consideraría la distinción general "diferencia" como perteneciente a la forma de afirmación del

${ }^{11}$ Luhmann, 1981a, pp. 104-105. 
futuro, la "diferenciación" se consideraría comola forma de afirmación del pretérito perfecto. ${ }^{12}$

Diferencia y diferenciación forman un relacionamiento tetrádico entre sí, el cual conduce a la constitución de "algo". Por lo tanto, el mundo no es la "totalidad de las $\operatorname{cosas}^{n}$ y tampoco la "totalidad de los hechos", sino la "totalidad de los relacionamientos tetrádicos".

Esto es naturalmente una alusión al Tractatus Logico-Pbilosophicus de Ludwig Wittgenstein: "I.I El mundo es la totalidad de los hechos, no de las cosas. ${ }^{n 13}$ Aquí existe un cierto parecido con los argumentos de Wittgenstein. No obstante, se debe ver la diferencia decisiva en el hecho de que suponemos las distinciones "diferencia" $y$ "diferenciación" y la unidad tetrádica ligada a ellas, misma que son capaces de formar, no sólo en el ámbito del idioma (verbal y/o escrito), sino que también queremos ver su aplicación en las áreas mental, afectiva y corporalperceptiva. En el ámbito de la percepción, nuestras reflexiones son idénticas a aquéllas de $\mathbf{V}$.v. Weizsäcker, como son explicadas en su trabajo publicado ya en 1940: Der Gestallkneis. Theorie der Einbeit von Wabrnebmen und Bewegen.

Con ello, el mundo es un juego alternante de "diferencias" $y$ "diferenciaciones", mismas que forman entre sí las "unidades" en la forma de las distinciones tetrádicas, entre otras, las, en este contexto, interesantes unidades sociales, las cuales comprendemos como modalidades distintas de la observación. Ahora bien, "algo" es llamado autorreferencial cuando constituye, por sí mismo, los elementos que lo constituyen y cuiando permite que coexista, en las relaciones con estos elementos, una referencia a esta autoconstitución, con lo cual dicha autoconstitución es reproducida continuamente. Por lo tanto, el "algo" opera necesariamente sólo en el contacto consigo mismo, con lo cual toda forma de contacto con lo ajeno o con el entorno puede ser realmente sólo una forma del autocontacto, o sea contacto con el exterior generado internamente. ${ }^{44}$ En consecuencia, la autorreferencia de "algo" se puede realizar solamente, cuando el mismo "algo" es identificado y distinguido contra "algo diferente" por me-

42 Véase por ejemplo Weizsäcker, C.F.v., 1985, pp. 47-99.

${ }^{43}$ Wittgenstein, 1966, pp. 11 y ss.

${ }^{44}$ Luhmann, 1984, p. 59. 
dio de sí mismo. ${ }^{45} \mathrm{O}$ el "algo" se orienta hacia la "identidad" propia y la constituye sólo por el hecho de que se forma una continuidad del "ello mismo", la cual entonces conforma la verdadera "autoidentidad". 46

15. Observemos ahora el juego alternante de las distinciones "diferencia" y "diferenciación" bajo el aspecto de la dimensión del tiem$p o,{ }^{47} \mathrm{y}$ supongamos que se encuentran frente a frente dos "diferencias" distintas, mismas que queremos designar como tomar café/ tomar té y estar-en-la-cocina/permanecer-en-la-cama.

Con estos ejemplos escogemos, a propósito, el nivel del conocimiento cotidiano, no el del conocimiento de alto rendimiento. Con ello se pretende evidenciar que con las respectivas distinciones se trata de distinciones de tipo muy general, que pueden ser relacionadas tanto con el sistema de la ciencia como con cualquier forma de los sistemas del sentido.

Ya que se debe partir del hecho de que ambas "diferencias", por definición, son simétricas, nada puede suceder en el tiempo mientras no resulte de ello, de alguna manera, una operación de diferenciación asimétrica, o sea, que se reduzca por lo menos una de las diferencias a una diferenciación.

Una "diferencia" como distinción bilateral-simérrica puede ser reducida a una "diferenciación" bilateral-asimétrica. La conexión entre sí de dos diferenciaciones asimétricas, por su parte, puede producir una "diferencia" simétrica. Este juego de distinciones, en el cual se trata de la emengencia de siempre nuevas constelaciones de las distinciones, es un logro del observador (el cual puede ser formado en la forma de un "código", como sucede en el caso de los sistemas del sentido), mismo que, dependiendo de la situación, debe aplicar diferentes distinciones, dado que sin la utilización de las distinciones no es posible ninguna observación, y sin la observación no es generada ninguna información.

Si no sucede nada, entonces realmente no sucede nada, y no tiene lugar ninguna operación de conexión entre las distinciones: no se to-

45 Ibid., 1984, p. 26.

${ }^{46}$ Luhmann, 1978, p. 10.

47 Véase capitulo I sobre la forma. 
ma té ni café, uno no permanece-en-la-cama ni está-en-la-cocina. En este lugar, ambas "diferencias" pueden o bien separarse o bien acercarse mutuamente. Si tiene lugar un encuentro, entonces se llega al problema de la indeterminación: las "diferencias" té/café y permanecer-en-la-cama/estar-en-la-cocina giran una alrededor de la otra (figura 72).

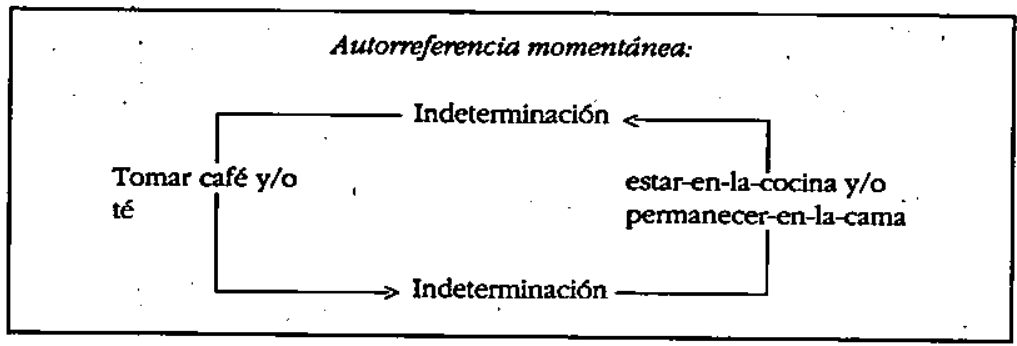

Aquí se trata del problema de la contingencia como el problema de la contingencia dual o doble en el sentido de la TsS. ${ }^{48}$ La formación de un nudo vacío, cerrado, ya que es indeterminable, se genera a través del encuentro de dos diferencias: ya que no tomar café ni té, entonces no permanecer-en-la cama, ni estar-en-la-cocina, entonces no tomar café ni té... etc. Ya aquí se puede hablar de una autorreferencia momentánea, en el sentido de que cada "diferencia" precisamente estấ siendo referida momentáneamente a sí misma ("doblada hacia atrás"), por medio de la otra diferencia correspondiente. Con ello, la autorreferencia se encuentra en el nivel de designación puramente operacional: dado que la "diferencia" A no está siendo determinada, pero que solamente puede ser determinada si se determina la "diferencia" B, pero la "diferencia" B, a su vez, solamente puede ser determinada si se determina la "diferencia" A, lo que, por su parte, presupone que se determine la "diferencia" B, lo que... Solamente sobre la base de la determinación de una de las "diferencias", puede ser determinada la otra, y viceversa. ${ }^{49}$ El cuándo y por qué surge una afinación mutua de "diferencias" específicas vía la determinación y, por lo tanto, un comportamiento de conexión entre ellas, es entonces un problema secundario, dependiente del

48 Luhmann, 1984, pp. 150-151.

4l Ibid., p. 149. 
azar, de la correspondiente situación y, en última instancia, de los medios semánticos de una SOCIEDAD, o sea, de su cultura.

Sea realzado el hecho de que la característica de las distinciones consiste generalmente en el hecho de que - visto cognoscitivamenteponen en marcha las operaciones por medio de la estimulación o de los estímulos determinados. Aquí nos adherimos a Konrad Lorenz, quien parte del supuesto de que tanto los procesos que adquieren solamente informaciones del momento, sin almacenarlas, como también aquellos procesos que tienen lugar en el sistema central nervioso y que implican "la memoria", se basen en la estimulación. ${ }^{50}$ El supuesto de una causalidad de los estímulos es ciertamente un problema, al cual, sin embargo, no queremos dar más seguimiento aquí.

La conexión concreta es, por lo tanto, ciertamente sujeta a los medios semánticos, pero no el problema de la conexión. Al contrario, el problema de la diferencia doblemente contingente y su "solución" produce un orden sólo por medio del mutualismo o del diálogo de las distinciones, el cual nos hemos acostumbrado a llamar SOCIEDAD.

16. La teoría del sistema general de acciones $(\mathrm{TaH})$, para la cual el problema de la contingencia doble es igualmente central, como lo es para la teoría de los sistemas sociales (TsS), también ve claramente que al encontrarse ego y alter, debe surgir una determinación, dado que en caso contrario no se produce ninguna $A C c i o$.

Aquí se puede hablar naturalmente también de dos black boxes o de dos "hombres". En este contexto doblemente contingente, la TaH utili- . za los conceptos ego y alter como una mezcla semántica de organism, bebavtoralsystem, y personality." También la TsS utiliza los conceptos ego y alter, y además el concepto de las black baxes, para poder tratar, sobre la base del teorema de la contingencia doble, tanto los sistema psíquicos como también los sistema sociales. ${ }^{52}$ En el nivel de una "teoría de las distinciones" general, y con referencia al mismo problema de la contingencia doble, nosotros ( $\mathrm{TgS}$ ) utilizamos los conceptos de distinción difenencia y diferenciación (diferencia doblemente contingente). No obstante, en el nivel de la teoría de la sociedad utilizamos

\footnotetext{
so Lorenz, 1973, p. 70.

51 Parsons/Shils (eds.), 1951, pp. 15-16.

52 Iuhmann, 1984, p. 152 y p. 156.
} 
la categoria "hombre" ("hombre" doblemente contingente), para poder comprender "más concretamente" la emergencia de los sistema del sentido, con lo cual nos encontramos entonces, de cierta manera, cerca del concepto de la black box.

Sin embargo, si no sucede ninguna ACCIÓN, entonces tampoco se puede formar ninguna regulación social, y sin una regulación de esta naturaleza, la SOCIEDAD no es posible. Precisamente esto es también el problema central del orden social: si el ego hace depender su ACCION de la ACCION del alter, pero el alter, por su parte, hace depender su ACCión de la ACCIÓN del ego, ${ }^{53}$ ¿cómo es entonces posible un comportamiento regulado entre ambos?

Queremos recordar que comprendemos - desde la perspectiva de la teoria de las distinciones, no desde la perspectiva de la teoría de la operación-cualquier diferencia simétrica como COMUNICACION, cualquier diferenciación asimetrizada la comprendemos cómo Acción. Por lo tanto, se puede formular: sólo una asimetrización de la COMUNICACION - de cualquier tipo- conduce a la ACCOON. Ver capítulo I sobre la COMUNCACIÓN y la ACCIÓN. En cuanto a la teoría de la operación, se deberia formular: las ACCIONES ("practica") presuponen DECISIONES, las DECISIONES, por su parte, presuponen las distinciones o las COMUNICACIONES ("teoría").

¿Como puede surgir el orden social bajo condiciones de esta naturaleza?54 Sabemos que la solución del problema de la afinación del comportamiento entre ego y alter, presentada por la $\mathrm{TaH}$, consiste en el supuesto de una orientación normativa-consensual;"s5 esto es una oferta de solución sobre la cual la Tss llama la atención expresamente $^{56}$ y la cual, por lo pronto, puede reclamar plausibilidad para sí. En última instancia, la TaH hace depender el orden social de los valores de la SOCIEDAD, o sea de una cultura generadora del consenso.57 Una situación de salida de esta índole no es precisamente equivoca-

\$3 Parsons/Shils (eds.), 1951, p. 15.

S4 Simmel, 1983, 7, pp. 275-293; Luhmann, 1981h, pp. 195-285.

"s Parsons/Shils (eds.), 1951, p. 16.

${ }^{\$ 6}$ Luhmann, 1984, pp. 149-150.

57 "If punishment or reward by alter is repeatedly manifested under certain conditions, this reaction acquires for ego the meaning of an appropriate consequence of ego's conformity with or deviation from the norms of a shared 
da, pero: primero, no explica el orden social autorreferencialmente (o sea sólo externamente o desde afuera) es decir por medio de los valores culturales, los cuales "[... se deben considerar $\mathrm{R}]]$ como el elemento primario que une los sistemas sociales y culturales ${ }^{n} ;{ }^{58}$ segundo, con ello no se presenta el mecanismo de la producción y reproducción de la sociedad como el orden social, sino que se presenta solamente una razón (para la TaH, naturalmente, la verdadera razón) para un orden ya establecido: es el consenso sobre los valores, el cual tiene por efecto el orden social. El cómo se genera realmente este orden social no se aclara más detalladamente, sino que se discute solamente el por qué se genera.

Si se pregunta, ¿por qué es posible el orden social?, entonces esta pregunta conduce (seduce) fácilmente hacia la mención de razones, hacia la racionalización de la pregunta, como lo dice Donald Davidson..99 $\mathrm{Si}$ uno pregunta, ¿cómo es posible el orden social?, entonces uno debe, si quiere contestar la pregunta, mencionar "mecanismos", mismos que pueden posibilitar el orden social. La segunda manera de preguntar implica una respuesta más "técnica", la primera manera implica una respuesta más "fundamental" o "de principio". Acerca de la diferencia de las preguntas del tipo por qué y cómo, ver a Karin Knorr-Cetina; ${ }^{60}$ acerca de la diferencia de las preguntas del tipo qué y cómo, ver Niklas Luhmann. ${ }^{61}$

symbolic system [R]. A shared symbolic system is a system of 'ways of orienting', plus those external symbols which control these ways of orienting, the system being so geared into the action systems of both ego and alter that the external symbols bring forth the same or a complementary pattern of orientation in both of them. Such a system, with its mutuality of normative orientation [RJ] is logically the most elementary form of culture [R]]. In this elementary social relationship, as well as in a large-scale social system, culure provides the standards (value-orientations) which are applied in evaluative processes. Without culture neither human personalities nor human social systems would be possible." (Parsons/Shils [eds.], 1951, p. 16).

S8 Acerca de la distinción de normas y valores: los valores tienen una función primaria para el sostenimiento de las estructuras de un sistema social. Las normas son primariamente integrativas: regulan la pluralidad de aquellos procesos que contribuyen a la realización de estructurados compromisos de valores. (Parson, 1975, pp. 34-35).

"9 Davidson, 1990, pp. 19 y ss.

${ }^{\infty}$ Knorr-Cetina, 1984, pp. 48-50.

${ }^{61}$ Luhmann, 1990a, p. 14. 
17. En vista del problema de la afinación del comportamiento entre dos distinciones como "diferencias", las cuales se ofrecen mutuamente lados simétricos ( $\mathrm{y}$, naturalmente, pueden representar "observadores" de cualquier tipo), la solución consiste en: determinación de la diferencia. Esto significaria, referido a nuestras ya mencionadas diferencias, tomar-café/té y estar-en-la-cocina/permanecer-en-la-cama: "tomar-té-en-la-cama" o "tomar-café-en-la-cocina" o "tomar-café-enla-cama"... Se puede alcanzar una solución (provisional) del problema del ajuste del comportamiento, solamente si las diferencias se unilateralizan, si se reducen a sí mismas a diferenciaciones $\mathrm{y}$, con ello, se asimetrizan. La TsS argumenta similarmente; sin embargo, presupone como procesadores dos "[...] sistemas altamente complejos, mismos que utilizan el sentido, y los cuales no son transparentes y tampoco calculables uno para el otro $[. . .]^{n .62}$

Tenemos la opinión de que la finalidad que trata de alcanzar la TsS con el concepto de la no-transparencia, es decir la de emular la indeterminación, puede ser alcanzado también con el concepto de una "transparente diferencia simétrica", con la ventaja, de que la oscuridad de las black boxes puede ser tratada con sabiduría." Una diferencia simétrica está "indeterminada" precisamente por medio del hecho de que está compuesta por dos lados de igual valor, $y$, por lo tanto, es una distinción cargada de indeterminacion.

La TsS limita la base de salida del problema de la contingencia doble al tipo de sistemas del sentido de sistemas "psíquicos": "El problema de la contingencia doble siempre está virtualmente presente en el momento en que esté dado un sistema 'psíquico' [RJ], mismo que experimenta al sentido."

Es muy problemático poder decir con precisión lo que la TsS comprende bajo el concepto de un sistema "psíquico". Con ello se habla, por un lado, de sistemas de la conciencia, los cuales procesan a través de pensamientos; por otra parte, también están integrados los perceptivos sistemas orgánicos. Simplificando, se podría decir que la TsS se refiere con los sistema psíquicos a algo así como a una unidad de sistema orgánico-psíquico-mental; ésta es una unidad muy indeterminada,

${ }^{62}$ Luhmann, 1984, p. 156.

- En el texto original, el autor utiliza el termino alemán "Weisheit", mismo que incluye la palabra "weis[s]", lo que significa "blanco". Nota del traductor. 
la cual se puede exponer naturalmente a muy diversas cosas. Para crear un poco más de claridad, hemos introducido cuatro tipos de sistemas del sentido o estilos de expectación: estilos de expectación corporales, afectivas, personales y sociales. Pensamos poder alcanzar un más alto grado de determinación de aquello que circula como la coMUNICACIÓN. El que aquí nos limitemos mediante una determinación del sistema del sentido de esta índole y que por ello debamos indicar más detalladamente la manera de comunicar de los tipos de sistema del sentido supuestos, puede ser considerado tanto como un peligro así como también la oportunidad de una formación de teoría con la intención de una teoría de la sociedad. Sin embargo, los teoremas de los sistema del sentido sociales, personales, afectivos y corporales están concebidos de tal manera que pueden exigir una cierta autonomia entre sí. Si se desploma uno, entonces no necesariamente se deben ir al fondo también los otros. Este peligro lo vemos sobre todo en la estructura de la arquitectura de teoria de la teoría de la acción comunicativa (TkH) y en la teoria del sistema general de la accion (TaH). Ver acerca de ello el capítulo $V$ sobre la arquitectura de teoría.

Dado que partimos, como será demostrado más adelante, de cuatro tipos de sistemas del sentido, la oferta de solución de la 'TsS no puede ser aceptable para nosotros, ya que esto significaría que nos tendríamos que limitar a los tipos de sistemas del sentido psiquicos (pensamientos) y sociales (comunicaciones), un supuesto que es, para nosotros, poco realista.

La SOCIEDAD ciertamente está determinada, por medio de los "pensamientos" (igual a sistema psíquico, según la TsS) y "comunicaciones" (igual a comunicación verbal/escritura, de acuerdo con la TsS), esencialmente también a través de los "afectos" y "percepciones". Cuando nosotros (TgS) hablamos de los cuatro estilos de expectación, utilizamos el término COMUNicación.

Ya aquí queremos anotar que, en el nivel de la teoría de la sociedad, partimos de (por lo menos) dos procesadores llamados "hombres", y que en este sentido existe una cierta similitud entre el concepto de black bax de la TsS y el aquí representado. Más adelante aclararemos más exactamente el cómo, a partir de las black boxes "hombres" -las cuales utilizan distinciones-, puede emerger algo así como estilos de expectación corporales, afectivos, mentales e institucionales (figura 73). 
Nivel de la teoria de las distinciones:

concepto de "diferencia doblemente contingente"

Nivel de la teoría de sociedad:

concepto del "hombre doblemente contingente"

18. El mundo fenomenal del sentido no está compuesto solamente por pensamientos y comunicaciones (ipor cuáles?), sino tambiên y esencialmente por afectos, gestos y percepciones corporales. Sin embargo, el problema es que los tipos de sistemas del sentido afectivos y corporales son casi desconocidos dentro de la sociología oficial, $\mathrm{y}$, por lo tanto, surge obligatoriamente la pregunta ¿cómo se podría ver una COMUNICACIÓN afectiva o corporal? En todo caso, sea anotado aquí que con el concepto de una diferencia doblemente contingente (en el marco de una "lógica de las distinciones") en la forma de dos diferencias, podemos realizar un planteamiento más general que la TsS y la TaH. Pensamos que con ello tenemos en las manos un teorema eficaz, para poder aclarar el problema del orden social, dado que podemos esquivar la limitación a sólo dos tipos de sistemas del sentido ("pensamientos" y "comunicaciones") impuesta por parte de la TsS, sin que por ello el teorema pierda su capacidad de determinación. Con este concepto de una diferencia doblemente contingente se cumple, sobre todo, con el requerimiento principal que la TsS exige de la "solución" del problema de la doble contingencia: la reducción de la indeterminación (= diferencia o COMUNICACIÓN) a la determinación (= diferenciación o ACCIÓN), para posibilitar el indispensable comportamiento de conexión constituyente de los sistema del sentido. La pura actualidad del encuentro de dos unidades procesadoras del sentido ciertamente no es suficiente, como lo observa con razón la TsS: "El motivador problema de la contingencia doble surge solamente (y con ello: la constitución de los sistemas sociales) si estos sistemas (los sistemas psíquicos) se experimentan y se tratan de manera específica: es decir como posibilidades de la determinación del sentido infinitamente abiertas, las cuales, en el fondo, se escapan al acceso ajeno."

Es un poco irritante que la TsS observa inmediatamente después: "Los conceptos ego y alter [para el procesamiento de la contingencia doble 
RJl deben mantener abierta la posibilidad de que se trate de sistemas psíquicos o sociales. ${ }^{63}$ Comprendemos estas explicaciones en el sentido de que la doble contingencia y con ello la formación de sistemas sociales, ciertamente es posible sólo sobre la base de los sistemas psiquicos, pero también que los sistemas sociales pueden afectar a los sistemas psíquicos, por su parte, sin por ello procesar de manera doblemente contingente con ellos.

En el concepto de la diferencia doblemente contingente representado por nosotros, está implicado este requerimiento por medio de la forma simétrica de sus dos lados: es decir que las diferencias procesan la "apertura infinita" por medio de la forma simétrica de su bilateralidad. Mas no es necesario. Por lo demás, la forma de la diferencia está correlacionada con un aspecto de la versión teórica modal del concepto de la contingencia como algo que no es necesario ni imposible, lo que entonces es así como es, pero que puede ser también de otra manera y que se señala a través de la equivalencia de ambos lados: ${ }^{64}$ con una diferencia simétrica está dado uno de los lados, sin embargo, puede ser también el otro. $Y$ en el caso de que sea el otro lado, puede ser nuevamente el primero... etcétera.

\section{DIFERENCIA DOBLE, EMERGENCIA Y AUTOPOIESIS}

19. Ahora bien, ¿por qué este prefacio con la integración del problema de la contingencia doble, aunque aquí se trata de la aclaración de aquello que puede ser comprendido bajo el concepto de la autorreferencia? Porque el teorema de la diferencia doblemente contingente nos puede informar precisamente acerca de cómo es posible la autorreferencia, o sea cómo "funciona" y, por lo tanto, genera la forma autorreferencial.

El que para este fin hayamos escogido el concepto de la contingencia doble en la forma del teorema de una "diferencia doblemente contingente", tiene su causa en el hecho de que aqui se trata de "teoría so-

${ }^{63}$ Luhmann, 1984, p. 152.

of "La contingencia es algo que no es necesario ni imposible; lo que entonces puede ser como es (era, será), pero que es posible también de otra manera. Por lo tanto, el concepto designa algo dado (experimentado, esperado, pensado, imaginado) respecto a un posible ser de otra manera, designa objetos dentro del horizonte de variaciones posibles." (Idem). 
ciológica", y de que debemos demostrar cómo de una dinámica doblemente contingente de las distinciones, sobre la base de la categoría del "hombre", resultan cuatro estilos de COMUNICACIÓN, mismos que juntos conforman aquello que llamamos la sOcIEDAD.

Suponiendo dos procesadores de diferencias - por ejemplo "tomar-té y/o café" y "estar-en-la-cocina y/o permanecer-en-la-cama"-, podemos demostrar cómo se genera la autorreferencia momentánea.

En cuanto a la teoria de las distinciones, la distinción "diferencia" representa una alternativa simple, con la cual ninguno de los dos lados posibles es más probable que el otro. En este sentido, la "diferencia" se puede interpretar fundamentalmente a manera de la teoría de la probabilidad como el pronóstico o el valor de expectación de una frecuencia relativa. Sin embargo, para ello es necesario que se añada una segunda distinción como "suceso", para que la frecuencia relativa en cuestión se vuelva del todo pronosticable. Como segunda distinción o "suceso" escogemos en este contexto otra "diferencia", dado que solamente de esta manera se puede comprender el problema cognoscitivo doblemente estructurado de una "determinación de lo indeterminado" y de una "desdeterminación de lo determinado". Sea repetido nuevamente que hemos definido la autorreferencia como la posibilidad de la forma (del futuro), la forma está definida como la autorreferencia fáctica (el pretérito perfecto). Aqui no podemos indagar más acerca de este planteamiento del problema de una conexión de la teoría de la probabilidad con la teoría de las distinciones, pero debemos fijar el hecho de que la teoría de las distinciones preve una integración de este tipo.

Con ello queremos suponer (de manera irreal) que existen solamente estas dos diferencias, o sea que no se encuentran disponibles otras. Una de las consecuencias de este supuesto es, por lo pronto, aquélla de que, con la desaparición de sólo uno de los lados de la una o de la otra diferencia, resultaría también la extinción de la correspondiente diferencia.

Ciertamente hemos demostrado que el requerimiento mínimo para la conformación de algo como "algo" es un relacionamientó tetrádico.

Ahora bien, si ambas diferencias se encuentran, entonces se pueden formar, por lo menos, cuatro constelaciones de formas de distin- 
ción: "tomar-café-en-la-cama", "tomar-café-en-la-cocina", "tomar-téen-la-cama" y "tomar-té-en-la-cocina". Ahora se debe observar el hecho de que cada una de estas cuatro constelaciones de distinciones es posible solamente sobre la base, y bajo la estricta condición previa, de ambas diferencias. Queremos observar más detalladamente lo que sucede en cuanto a la pragmática de las distinciones: la diferencia A se encuentra con la diferencia $B$, con lo cual se genera un nudo momentáneo, el cual dice: si "tomar-café y/o té, entonces "estar-en-la-cocina y/o permanecer-en-la-cama", entonces "tomar café y/o té, entonces... La diferencia A hace, por medio de la diferencia $\mathrm{B}$, referencia a sí misma, y la diferencia $\mathrm{B}$ hace, a través de la diferencia A, también referencia a sí misma. La consecuencia del encuentro de ambas diferencias es la indeterminación, ya que la forma de la distinción "diferencia" es simétrica, y esto significa que ningún lado tiene prioridad frente al otro lado. La situación se puede formular también de la siguiente manera: la indeterminación operativa de la diferencia A recae, por medio de la indeterminación de la diferencia B, en la diferencia A y viceversa. Esta forma de la autorreferencia, este nudo autorreferencial, el cual refiere la indeterminación, se puede designar como una forma primaria de la autorreferencia. ${ }^{65}$ En este nivel indeterminado, las diferencias A y B son "[...] altamente sensibles [...] para casi cualquier determinación n" ${ }^{66}$ Aquí, el azar juega un papel excitador de la estructura, también y sobre todo en el contexto de las distinciones "excitables".

20. La indeterminación (y con ello el bloqueo de una forma posible de la ACCIÓN) de la autorreferencia primaria puede ser procesada solamente si las diferencias se determinan mutuamente. Pero sólo de esta manera está garantizada también una conexión de la diferencia A con la diferencia $B$ y viceversa, solamente de esta manera se puede alcanzar una conexión mutual o dialógica. Dado que cada diferencia consiste en una bilateralidad simétrica, puede haber cuatro posibles formas de determinación en el encuentro de dos diferencias, cuatro

6s La TsS dice acerca de ello: "Si un ego experimenta un alter como alter ego, y actúa en este contexto de experiencias, entonces cualquier determinación que el ego da a su acción, hace referencia a sí misma." (Luhmann, 1984, p. 182).

66 Ibid., p. 184. 
constelaciones de distinciones diferentes, las cuales serían capaces de suspender la referencia indeterminada o abierta.

Aquí también sería el lugar de conexión, donde tendríamos que conectar con los cuatro estilos diferentes de expectación, con los cuatro estilos diferentes de sistemas.

Ahora bien, supongamos que por situación y/o preferencia semántica se alcance una determinación mutua de las diferencias $\mathrm{A}$ y B en la forma "tomar-café-en-la-cocina". ¿Qué ha sucedido, debido a esto, en relación con la pragmática de las distinciones? Primero, por medio de ello se produce un nuevo nivel que no existía antes. Se llega a la producción emengente del sentido, a un nuevo nivel del sentido, el cual no estaba representado ni en la diferencia $A$ ni en la diferencia $\mathrm{B}$, sino que se puede comprender solamente como una combinación entrelazada de ambas dimensiones. Segundo, la nueva unidad del sentido "tomar-café-en-la-cocina" hace referencia a las diferencias correspondientes: "tomar-café" como subcomponente de la diferencia A y "estar-en-la-cocina" como subcomponente de la diferencia B. También se puede decir que la diferencia A provoca, por medio de su determinación "tomar-café", en la diferencia $B$, la determinación "en-la-cocina" y viceversa, la diferencia $B$ provoca, en la diferencia A, la determinación "tomar-café". Tercero, ambas diferencias deben conservar su autonomía o independencia, no deben fundirse una con la otra, ya que se disolverían como diferencias, y, por lo tanto, destruirian la unidad del sentido emergente, y esto quiere decir nueva: "tomar-café-en-la-cocina".

21. El "encuentro" entre las dos diferencias ha sido solidificado por medio de una determinación, o sea por medio de una estructura: no se toma té, ni en la cocina, ni en la cama, pero tampoco el café se toma en la cama, sino precisamente en la cocina, se "toma-café-en-la-cocina". Aquí pues, se da una forma secundaria de la autorreferencia, la cual, como ya lo hemos realzado, constituye la determinación, y con ello la estructura. La autorreferencia secundaria se genera debido al hecho de que las diferencias A y B deben hacer referencia a sí mismas en el momento de su conexión específico-determinada: "tomar-café-en-la-cocina", en el caso de la diferencia A, y "tomarcafé-en-la-cocina" en el caso de la diferencia B. Sin embargo, ambas 
diferencias deben abandonar su forma de simetria y reducirse a una diferenciación asimétrica: deben designar los lados preferidos. Por lo tanto, las diferencias se asimetrizan y determinan a sí mismas en el transcurso de su encuentro, hacen referencia a sí mismas y, precisamente debido a ello, se posibilitan a sí mismas el comportamiento de conexión. Entonces, la formación de la estructura es la consecuencia. No obstante, no se debe desatender el hecho de que la historia de la estructura, y con ello la historia de la distinción, es posible solamente si las diferencias iniciales no se borran, sino que permanecen, por así decirlo, recordadas, lo que, de acuerdo con la naturaleza, requiere "memoria". Esta "memoria" la designamos de manera teórica como la "experiencia". Por lo tanto, tenemos una interacción, con lo cual se hacen experiencias a la luz de las expectativas, y las expectativas, por su parte, se "corrigen" con la ayuda de las experiencias. Solamente de esta manera es imaginable una condensación del sentido de las distinciones. ${ }^{67}$

22. Hemos hablado de una autorreferencia primaria que tiene lugar por medio de la indeterminación, y de una autorreferencia secundaria que se efectúa por medio de la determinación. Ambas autorreferencias tienen lugar sobre la base del problema de la diferencia doblemente contingente y su solución provisional: la asimetrización de la simetría. En el encuentro de dos diferencias, el problema consiste en su indeterminación fijada y la incapacidad de conexión ligada a ello. Solamente por medio del hecho de que las diferencias se (jauto!) reducen a diferenciaciones, o sea que se asimetrizan o causalizan, se alcanza una conexión entre ambas formas de distinción, un ajuste cognoscitivo del comportamiento. En referencia con el concepto de sistema, la TsS formula el mismo hecho de la siguiente manera: "El sistema pierde la apertura para lo discrecional y gana sensibilidad para lo determinado. ${ }^{n 68}$ En un nivel elemental se alcan-

${ }^{67}$ Actualmente, en la SOCIEDAD está presente un cambio de las capacidades para la reproducción y el almacenamiento de la COMUNCACIÓN. Con ello se modifica también la forma de memoria de la SOCIEDAD, y, por lo tanto, su capacidad de acordarse. Aquí no podemos profundizar más acerca de estos pensamientos. Se tratarían en el marco de una teoría de la sociedad con la integración del sistema del sentido de la técnica. Ver acerca de ello más anotaciones de la TsS en Luhmann, 1989b.

${ }^{68}$ Luhmann, 1984, p. 185. 
za, debido al encuentro mutuo de dos diferencias, la indeterminación, se genera el problema del ajuste del comportamiento, el cual es resuelto posteriormente a través de la reducción de las diferencias a diferenciaciones: se toma café en la cocina. En un nivel emergente, las diferenciaciones asimétricas que se han encontrado para el comportamiento de conexión, alcanzan una cierta bistoria de la distinción, la cual aparece ahora bajo la luz de otras asimetrizaciones posibles, precisamente por medio de la determinación efectuada: ciertamente, se toma café en un la cocina, pero la bebida podría haber sido té, y el acto podría haber tenido lugar en la cama. Ya hemos visto que algo es contingente, si es como es, pero puede ser también de otra manera. Se ha determinado café-en-la-cocina, "té-en-la-cocina", "té-en-la-cama" y "café-en-la-cama" sobran como posibilidades. Esto significa que para cada diferenciación realizada se deben considerar tres posibles diferenciaciones. Si el problema de la diferencia doblemente contingente fue resuelto originalmente a través de la transformación de la indeterminación en determinación, entonces reaparece inmediatamente precisamente debido a la solución efectuada: cada realización de una determinación es también posible de otra manera y, en un nuevo nivel emergente del sentido.

Cualquier determinación produce, precisamente debido a su fijación, un sentido de indeterminación: ¿por qué exactamente de esta manera y no de otra?

Eśto indica, a su vez, que cualquier encuentro de las distinciones, en este nuevo nivel del sentido, se encuentra nuevamente frente al problema de la diferencia doblemente contingente: transformar el correspondiente encuentro de distinciones en un diálogo capaz de la conexión o del mutualismo, o no hacerlo.

23. Las diferencias "tomar-café y/o té" y "en-la-cocina y/o en-la-ca$\mathrm{ma}^{\prime}$ han sido asimetrizadas a diferenciaciones en el sentido de que "tomar-café-en-la-cocina" se ha hecho posible, solamente porque las diferencias han asimetrizado sus lados (y con ello se han convertido en diferenciaciones); no obstante, precisamente debido a ello se han hecho posibles cuatro diferencias nuevas: tomar-café/en-la-cocina, tomar-té/en-la-cocina, tomar-café/en-la-cama y tomar-té/en-la-cama. Ahora se puede decir que las "diferencias" se pueden convertir en 
"diferenciaciones", y que a su vez las "diferenciaciones" pueden resultar en "diferencias". $Y$ todo esto en un nivel completamente nuevo, y esto significa emengente, del sentido. Sin embargo, este desarrollo es posible solamente porque ha pasado 'tiempo desde la determinación inicial de la situación indeterminada, doblemente contingente de la diferencia, el cual pudo ser utilizado para el acondicionamiento de las diferencias recién surgidas. Por lo tanto, se puede formular: a partir de dos diferencias relativamente inofensivas pueden resultar diferenciaciones, las cuales, por su parte, generan diferencias, las cuales, por su parte, producen... Como punto de partida han sido escogidas dos diferencias, como punto final tenemos ahora dos diferentes niveles del sentido, los cuales consisten en dos diferentes tipos de diferencias: en el nivel de la autorreferencia primaria, se encuentran las dos diferencias originarias tomar té/café y en la cocina/en la cama; en el nivel de la autorreferencia secundaria se encuentran las cuatro diferencias tomar café/en la cocina, tomar té/en la cocina, tomar café/en la cama y tomar té/en la cama; es una estructura de distinción que se parece fundamentalmente a la teoría de la información matemática.

Sea insertado el hecho de que, en este nivel, la conexión entre la teoria delas distinciones y la teoria matemätica-cuantitativa de la información es estrecha, como ya se ha dicho. Esto significa que una teoria de las distinciones, por principio, permanece accesible para una cuantificación. Sólo se debe traducir el concepto de la diferencia al concepto del código binario: un bit (- binary digit) se debe concebir entonces como una distinción prendido/apagado, si/no o 0/1. Si se juntan varios bits, entonces se pueden expresar todas las informaciones en un código de 1 y 0 . Con dos bits (=dos diferencias) se obtienen cuatro códigos diferentes, o sea $00,01,10$ y 11 , los cuales corresponden a tomar-cafe/enla-cocina, tomar-té/ en-la-cocina, tomar-café/en-la-cama y tomar-té/ en-lacama. Ya con ocho bits se obtienen 256 combinaciones diferentes de 0 y 1 , las cuales conforman el asíllamado código Ascu. Esta unidadde-8 bits se llama un byte. La unidad central de una computadora trabaja con esta unidad-de-byte: por consiguiente, un byte puede ser representado con la ayuda de un número o de una letra. De esta manera, para una computadora, la letra A es la combinación de bits 01000001 , la cual corresponde al número 65 del código Ascil estandarizado.

En última instancia, esta "complicación improbable" es el resultado - esto debe ser realzado especialmente- de un supuesto no 
realista. Se sabe que hay tantas y tan diferentes distinciones "como arena en el mar" (pero seguramente no un número infinito). ${ }^{69}$ Con ello se pretendía solamente aclarar que la SOCIEDAD es posible en su complejidad incalculable como la forma del orden social por excelencia, sobre la base de módulos cognoscitivos, aparentemente simples, los cuales son llamados distinciones.

24. Hemos descrito la operación de la autorreferencia como una operación que, refiriéndose a algo diferente, se refiere, precisamente por ello, a sí misma. Para poder realizar una operación de esta naturaleza, son necesarios dos procesadores, dispuestos simétricamente, los cuales hemos llamado "diferencias". Ahora bien, si están dadas, por lo menos, dos diferencias de cualquier contenido, y si tiene lugar la conexión entre ambas, entonces se generan dos autorreferencias diferentes: una primaria y una secundaria. La autorréferencia primaria consiste en un nudo, el cual, por medio de la diferencia indeterminada B, regresa la diferencia indeterminada $A$ hacia sí misma: a través de la indeterminación ajena, la indeterminación propia regresa hacia la propia indeterminación. Aquí, el problema es: o determinación o indeterminación. La autorreferencia secundaria consiste también en un nudo, el cual se genera precisamente por medio de la determinación de dos diferencias, esto es, mediante su correspondiente asimetrización en diferenciaciones. La operación de la determinación produce una simultaneidad de "también-posible-de-otramanera". Aquí, la curva transcurre de la diferenciación asimetrizada $A$, pasando por la diferenciación asimetrizada $B$, de regreso hacia la diferenciación A, etc. El problema con este nudo autorreferencial es, por su parte: si es que hay determinación, entonces epor qué pre-

${ }^{69}$ Aquí hacemos conexión con la teoría del conocimiento finitista, la cual dice: "Estos conocimientos se pueden resumir en el siguiente planteamiento de una teoría del conocimiento finitista: dentro de una teoría que se refiere al mundo verdadero, físico, ciertamente es permitido utilizar números de cualquier magnitud como número de posibilidades; sin embargo, en principio no tiene sentido realizar, en los análisis y pruebas, ni siquiera en el experimento de ideas, operaciones en cantidades que sobrepasen la magnitud de diez a la potencia de 120 [R]]. Un catálogo imaginado de todas las posibilidades o una decisión imaginada acerća de todos los posibles casos particulares carece de sentido científico-filosófico, especialmente si el número de los casos posibles sobrepasa diez a la potencia de 120". (Gierer, 1985, p. 57 ). 
cisamente ésta y no otra? En esta circunstancia se observa que ambas autorreferencias dependen mutuamente: la determinación debe tener lugar, ya que solamente de esta manera se puede dominar la indeterminada situación de diferencias. Pero precisamente por medio de la determinación se produce nuevamente la indeterminación, dado que a uno se le exige determinar "de esta manera o de otra". Naturalmente, la circunstancia del "encuentro de dos distinciones" permanece como condición previa. La circunstancia de si hace conexión una con la otra, y el por qué hacen esto, si es que lo hacen, es cosa del azar, de la situación, de las existencias semánticas de una sociedad, de la calidad cognoscitiva de excitabilidad de la correspondiente distinción. En todo caso se puede constatar que la autorreferencia primaria es condición para la constitución de la autorreferencia secundaria y viceversa. Con ello, las distinciones producen sus propias distinciones, las cuales, por su parte, producen sus propias distinciones, etc. Con el concepto de la autopoiesis se quiere expresar precisamente esto: las distinciones posibilitan, por medio de otras distinciones similares, una referencia a sí mismas y se posibilitan por medio de ello precisamente a sí mismas. Ahora queremos cambiàr del nivel general de una lógica de las distinciones hacia el nivel de la teoría de la sociedad y analizar si se debe aplicar y cómo, en este nivel menos abstracto, el teorema de la diferencia doblemente contingente.

\section{SEMÁNTICA DEL "HOMBRE" Y EMERGENCIA}

\section{DE LOS TIPOS DE SISTEMAS DEL SENTIDO}

25. En el nivel de una teoría de la sociedad "realista", "el hombre" como black bax fenomenológica es el punto de salida. La situación doblemente contingente es entonces el encuentro COMUNICATIVo de dos hombres (ego y alter), los cuales intentan procesar su indeterminación autorreferencial primaria sobre la base de la diferencia

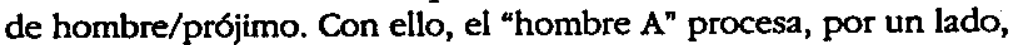
a través de la diferencia "hombre (a)/prójimo (a)", y el "hombre $B^{n}$, por el otro lado, procesa a través de la diferencia de "hombre (b)/ prójimo (b). Esto quiere decir que cada hombre se experimenta a sí mismo - visto desde la propia perspectiva interna-como ego, y al otro hombre como alter ego, como "yo" y como "otro yo en el sentido del tú" (este otro yo se experimenta en el propio yo y, por lo tan- 
to, se podria denominar también como "tú como yo".) Transferida al siguiente esquema, la relación se ve de la siguiente manera (figura 74).

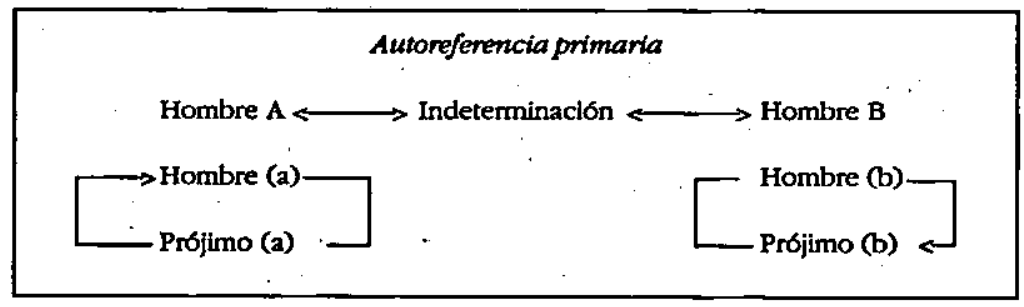

26. El esquema anterior representa solamente un registro de un momento del encuentro comunicativo de dos "hombres", de acuerdo con el con el teorema "¿qué sucede, si todo lo que sucede, sucede simultáneamente?" $\mathrm{Si}$, a partir de este contacto momentáneo, se desarrolla una relación, y más si se genera un ligamiento, entonces esto conduce a una bistoria de la distinción de los originarios momentos COMUNICATIvos de hombre A, hombre (a), prójimo (a), hombre $\mathrm{B}$, hombre (b) y prójimo (b). Las posibilidades de diálogo se multiplican considerablemente, dado que las primeras diferencias pueden ser condensadas y condicionadas. La formación de la estructura (expectativas y estilos de expectativas) es la consecuencia. Debido a ello, los "hombres" son capaces de constituir, a través de sí mismos, una relación con ellos mismos y con otros próximos y, dado el caso, éstabilizarla. Tiene lugar - a través de un encuentro doblemente contingente, condensado diaológicamente- un diferenciamiento exterior e interior respectivamente interno.

27. El diferenciamiento interno del sistema de un hombre es una relación comunicativa que él mismo produce consigo mismo en forma más diferenciada. Puede hacer conexión con el "uno mismo" de sí mismo (hombre A $\rightarrow$ hombre (a)) o con lo ajeno de sí mismo (hombre $\rightarrow$ prójimo (a)). Comprende el "uno mismo" de su "uno mismo" como la conciencia, comprende lo otro de su "uno mismo" como la intimidad (figura 75). 


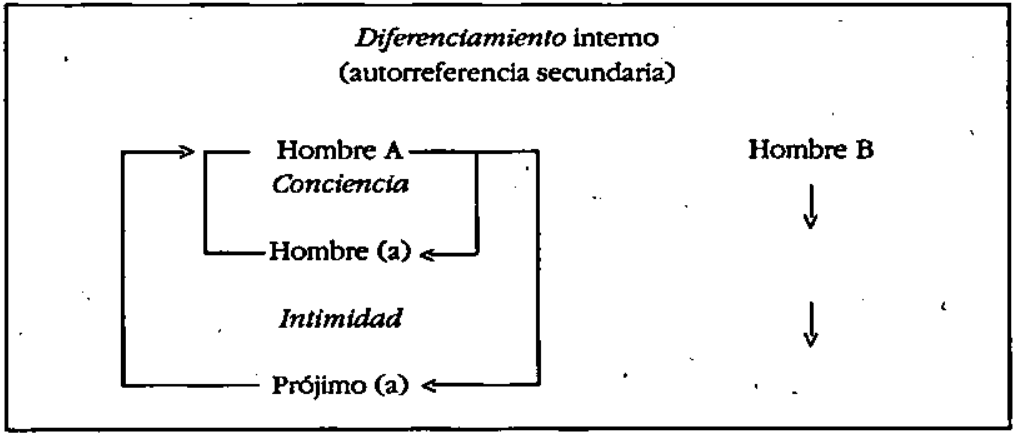

Se debe realzar el hecho de que una relación de esta naturaleza es posible solamente "en vista de otro hombre", y solamente sobre la base de la condensación y el condicionamiento del encuentro, 0 sea, por medio de la historia de la estructura. Solamente si el tiempo se sedimenta en la historia de la distinción, una distinción de este tipo puede desarrollar suficiente estabilidad como para permitir contactos diferenciados. Un "hombre" sin un "prójimo" ni siquiera sería capaz de percibirse a sí mismo. En este sentido, lo que aquí llamamos la conciencia y la intimidad puede ser solamente una forma determinada de la COMUNICACIÓN, o sea, solamente una forma específica del diálogo.

28. Ahora bien, es posible - visto fundamentalmente- un segundo nivel de diferenciamiento, es decir un diferenciamiento exterior -visto internamente-, con el cual se encuentran el "hombre $\mathbf{A}^{n} \mathbf{y}$

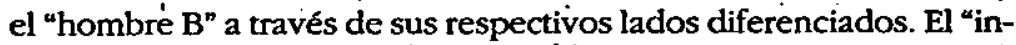
terno encuentro exterior" produce, a través del hombre (a) y del hombre (b), la COMUNICACION corporal: es el estilo de encuentro con que el hombre A y el hombre B se perciben corporalmente. La otra posibilidad, o sea, a través de los lados prójimo (a) y projiimo (b), conduce a la forma social de la COMUNICACIÓN. Si este encuentro se quiere expresar lingüísticamente, uno tendría que decir: la COMUNICAGIÓN social se genera si el hombre se observa a sí mismo como el otro de sí mismo, y si conecta con una segunda observación del otro como éste, por su parte, se ve a sí mismo como el otro del otro. Un encuentro comunicativo de esta índole puede ser designado, si se 
presenta como uno altamente improbable. Queremos documentar ahora ambos "interiores diferenciamientos exteriores" de la COMUNICACIÓN con la ayuda del siguiente esquema (figura 76).

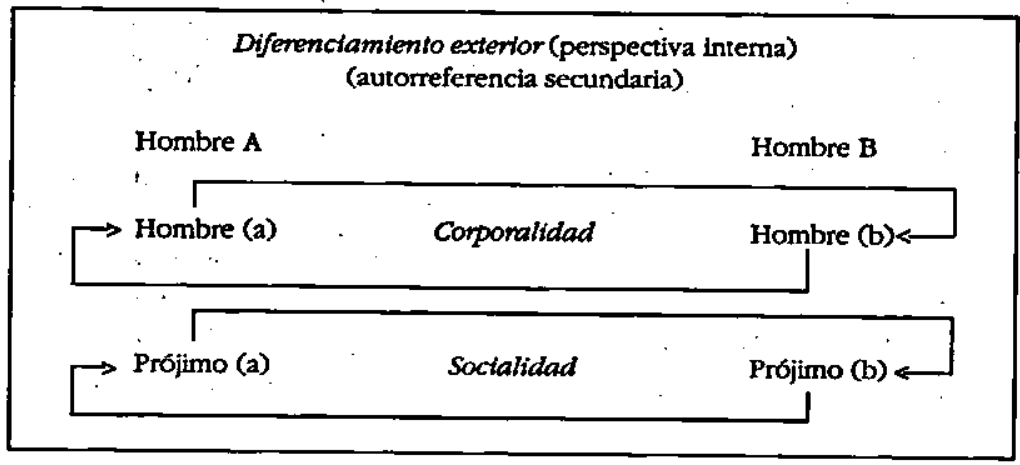

29. Con ello se puede demostrar que en el transcurso de una historia de la distinción se pueden generar - visto desde la perspectiva de la pragmática de las distinciones-, por lo menos, cuatro estilos de COMUNCACION, sobre la base de cualquier encuentro casual de dos "hombres" y la diferencia simétrica de hombre/prójimo que se constituye con ello; éstos, entonces, tienen lugar a través de las diferenciaciones asimétricas (o sea diferencias unilateralizadas, reducidas). La unilateralizacion de las diferencias, siempre formadas simétricamente, es necesaria debido al hecho de que sólo de esta manera es posible -como ya lo hemos dicho detalladamente- el comportamiento de conexión. Si traducimos la black bax de la cotidianidad "hombre" al concepto de la observación, entonces se puede bosquejar el surgimiento de diferentes estilos de COMUNICAción de la siguiente manera (figura 77 ).

Observación A $\left[\begin{array}{ccc}\text { Auto-observación (a) } & \text { Auto-observación (b) } \\ & & \\ \text { observación ajena (a) } & \text { observación ajena (b) }\end{array}\right]$.


- La observación de la propia auto-observación produce la "conciencian".

- La observación de la propia observación ajena produce la "intimidad $^{n}$.

- La auto-observación de la auto-observación ajena produce la "corporalidad".

- La observación ajena de la observación produce la "socialidad".

- La observación de la propia auto-observación de la propia observación ajena conforma una figura especial, la cual procesa la forma de observación "autoconciencia" (figuras 78 y 79 ).

(Figura 78)

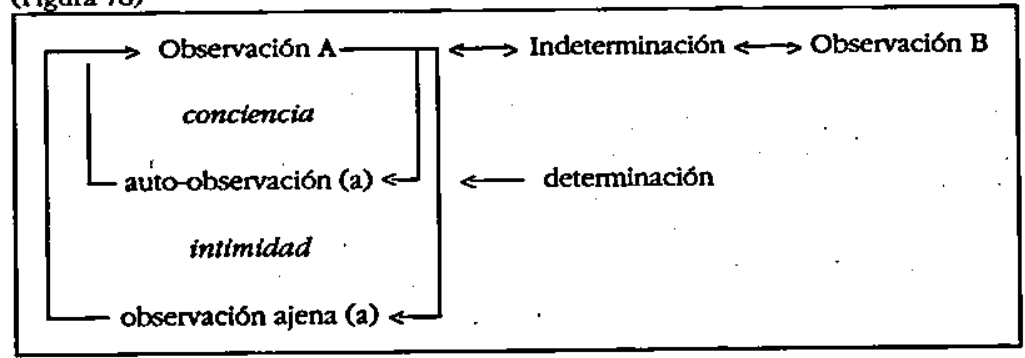

(Figura 79)

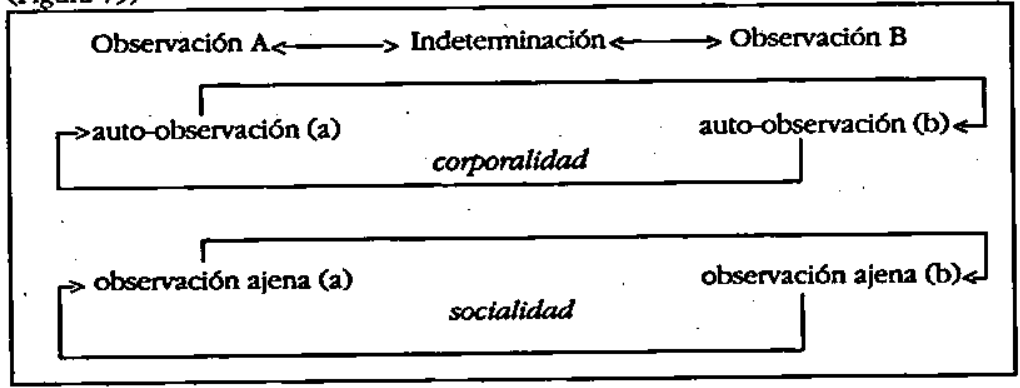

En referencia con los "nudos" particulares podemos representar los cuatro estilos de COMUNICACIÓN de la siguiente manera (figura 80). 


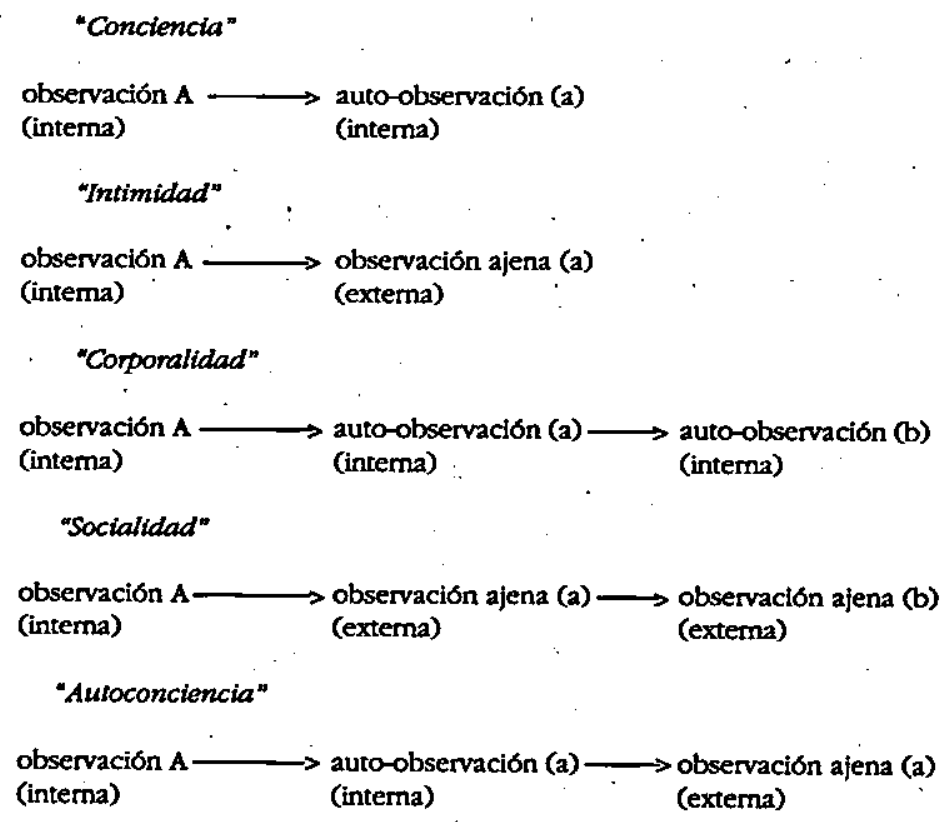

30. Visto desde la perspectiva de la lógica de las conexiones, las diferenciaciones asimétricas son distinciones que tienen sólo una posibilidad de conexión. Por lo tanto, son monovalentes y, con ello, distinciones "decididas", que ya no obligan al observador a tener que decidir (explícita o no explícitamente). $O$ hacen conexión entre sí o la conexión se interrumpe, pero ya no es fácil tener posibilidades de elección entre sus lados.

Para prevenir malentendidos, sea observado que una diferenciación asimétrica naturalmente puede ser reasimetrizada, y con ello se puede transferir la "preponderancia" de uno de los lados hacia el otro. No obstante, permanece asimétrica. Es concebible ciertamente una resimetrización de una distinción asimétrica, para ello, sin embargo, es necesario que la semántica de la distinción en cuestión experimente un cambio o una media vuelta "radical". Normalmente, una distinción simétrica emerge como el resultado del encuentro de dos diferenciaciones asimétricas, como ya lo hemos descrito. 
Por lo tanto, las diferenciaciones asimétricas poseen un carácter inherentemente monológico, dado que procesan solamente una clase de elementos de COMUNICACIÓN.

Aquí se trata de los así llamados medios simbólicamente generalizados de comunicación como, por ejemplo, "verdad", "amor", "sexo", "poder", "dinero", "belleza", "crítica", "eficiencia", "respeto", "seguridad" o "credo". Son instituciones comunicativas que posibilitan "[...] que se procure éxito para las comunicaciones que, en sí, son improbables". ${ }^{70}$ Es precisamente la forma unilateralizada de la distinción, o sea su asimetrización o "monología", la que garantiza la conexión de la correspondiente COMUNICACIÓN. Por lo tanto, tenemos la opinión de que la forma de los códigos de los sistemas del sentido debe ser asimétrica: "no falso, sino cierto", "no injusticia, sino justicia", etcétera.

Solamente de esta manera puede conectarse la observación a la observación, la acción a la acción, la auto-observación a la auto-observación, etcétera. En última instancia, se puede dar la formación del sistema solamente por medio de una conexión de los elementos del mismo sentido. La reproducción autopoiética requiere la estricta observación de la reproducción de elementos iguales, dado que en caso contrario el sistema no puede desarrollar ninguna "sistematicidad"; ni siquiera podría formar la identidad del sistema, ya que la desigualdad de los elementos basales tendría que boicotear esto. Esto explica también el por qué la única relación de observación que aún resta, o sea, la observación $A$ de una auto-observación (a) de una observación ajena (b) (ver figura arriba), no puede conducir a un sistema. ${ }^{71}$ Esta es la distinción clásica de "personalidad/socialidad", la cual, sin embargo, no es capaz de conexión. Por lo tanto, se le puede dar la razón a la teoría general de la acción (TaH) y a la teoría de los sistemas sociales (TsS), en cuanto que intentan realzar, una y otra vez, el hecho de que la sociedad (como "socialidad" en la semántica de la TgS aquí utilizada) no está compuesta por personas (u hombres, como se formula frecuentemente). La personalidad no puede conectarse de manera doblemente contingente y, con ello, autorreferencialmente, a la sociedad (socialidad).

${ }^{70}$ Luhmann, 1982b, p. 21.

${ }^{71}$ Desde de la perspectiva del observador B, es la auto-observación (b) de la observación ajena (a). 
31. Todos los cuatro estilos de comUNICACión están dados desde el mismo origen, con lo cual surgen y están disponibles simultáneamente en el momento de un encuentro comunicativo doblemente contingente. Surge entonces la pregunta, por medio de cuál estilo de COMUNICACIÓN planean comunicar. Se puede decir que cada unidad comunicativa se dirige hacia los cuatro niveles, y que sólo una bistoria específica de la distinción conduce al hecho de que los sistemas se comprometen con determinados estilos de cOMUNICACION, y por lo tanto, ya no se deben poner de acuerdo sobre el cómo (por ejemplo "corporal", "afectivo", "personal" parte "social"), sino solamente sobre el qué habria que comunicar (un "pensamiento" determinado, un "sentimiento" específico, una determinada percepción o afirmación). El concepto del "hombre" en el nivel de la teoría de la sociedad tiene por efecto, por medio de su generalidad y esto quiere decir "falta de contenido", que el proceso doblemente contingente $y$ autorreferencial puede empezar siempre de nuevo. En la mañana uno se encuentra, en el nivel de la comunicación social, por ejemplo, como elector político, y al medio día uno se encuentra, en el nivel corporal, en el restaurante como hombre y mujer. Esto significa que la black box "hombre" siempre amenaza con borrar la historia de la COMUNICACION, y con ello la expone al peligro, hasta que se haya sedimentado suficiente estructura de comunicación en la forma de estilos de expectación, los cuales posibilitan comunicar la socialidad, la personalidad, la intimidad y la corporalidad con más seguridad de expectativa. El concepto del "hombre" siempre posibilita, con ello, por un lado, debido a su indeterminación, un nuevo comienzo; por el otro lado, puede tener lugar, mediante la condensación y el condicionamiento de determinados estilos de expectación e historia de expectación, un comportamiento de conexión casi "libre" entre "hombres", los cuales, sin embargo, ya no se encuentran como "hombres", sino como conciencias, intimidades, corporalidades y socialidades. Esta indeterminación de la semántica "hombre" presuntamente parece ser responsable de las diferentes manifestaciones negativas y positivas frente a este concepto. 


\section{IV. ¿QUÉ ES LA OBSERVACIÓN?}

Al contrario del planteamiento del problema clásico de la investigación cientifica, la cual postula, por de pronto, un mundo que no varía en su descripción (como si bubiera algo asi), y que intenta entonces elaborar su descripción, boy en dia se nos exige desarrollarun "mundosubjetivo" queno varie en su descripción. Esto es el problema.

Heinz von Foerster ${ }^{1}$

Apenas la teoria liy esto significa otra observación! RJ decide sobre el qué es lo que se puede observar.

A. Einstein en una conversación con

W. Heisenberg ${ }^{2}$

\section{OBSERVACIONES DE OBSERVACIONES}

\section{Observamos al sistema global de la sociedad}

1. Aquí, comprendemos con el concepto de SOcIEDAD cualquier COMUNCACIÓN que produce sentido. A ello pertenecen tipos tan distintos de sistemas del sentido como las instituciones, conciencias, afectos y sistemas del sentido corporales (no orgánicos). La SOCIEDAD es un logro particular de reducción de la complejidad, un sistema del sentido

${ }^{1}$ Foerster, H.v., 1985, p. 82.

${ }^{2}$ Heisenberg, W., 1969 , p. 89. 
especial, el cual hace accesible el sentido como dimensión social. Con la ayuda de una formulación de la TsS podemos decir que la SOCIEDAD es aquel sistema, "[...] cuyas estructuras deciden sobre el grado de complejidad que el hombre puede aguantar, o sea que puede transformar en experiencias y acciones razonables" (Luhmann, 1971a, pp. 15-16). La SOCIEDAD presenta la "[...] última causa del ordenamiento de la convivencia humana [...]". (lbtd.) en la forma de una dimensión social de cualquier sentido, con lo cual "[...] excluye la complejidad no manipulada y [...] preestructura las posibilidades que pueden ser elegidas y realizadas en la sociedad" (ibid., p. 24). En este contexto, se presenta la pregunta acerca de qué sentido del sistema puede tematizar y con ello representar la socieDAD "como tal", dado que todos los sistemas del sentido existentes pueden ser solamente aspectos parciales de aquello que se comprende como la SOCIEDAD. Aquí nosotros ( $\mathrm{TgS}$ ) ubicamos el sistema "sociología" como el sistema del sentido que es capaz de tematizar la sociEDAD como tal, sabiendo que la sociología es un sistema parcial del sistema de la ciencia del sistema global de la socreDAD. El potencial inmenso de generalización de la "teoría sociológt$c a$ " (la cual asume la función de la reflexión frente al sistema parcial de la sociología) se limita considerablemente, debido a la perspectiva de sistema parcial, a su carácter específico y a su perspectiva de observación, lo que termina en una correlación del aumento de generalización y de especificación. A pesar de los numerosos traslapes del concepto de la SOCIEDAD aquí representado y el concepto "sociedad" de la TsS (como sociedad se designa aquel sistema social que incluye toda comunicación razonable...) (Luhmann, 1986a, p. 267), existe una distinción fundamental entre ambos conceptos en el hecho de que nosotros ( $\mathrm{TgS}$ ) comprendemos no solamente los sistemas sociales como una forma de la SOCIEDAD. Aplicamos la dimensión social de cualquier sentido (no solamente del sentido comprendido orgánicamente) a la socialidad (=sistemas sociales en el sentido de la TsS), a la personalidad (=sistemas de la conciencia en el sentido de la TsS), a la afectividad y a la corporalidad.

Realizamos esto desde la perspectiva de una teoría de la sociedad orientada hacia una teoría de los sistemas, la cual pertenece al ámbito de la "teoría sociológica".

Realmente podriamos hacer las mismas observaciones exclusivamente desde la perspectiva de una teoria de la sociedad orientada hacia la teoría de las distinciones; no obstante, en este contexto queremos integrar la perspectiva de la teoria de los sistemas, dado que su instrumental teorico ya ha alcanzado un nivel conceptual considerable. Se 
debe decir generalmente que la distinción asimétrica de sistema/entorno, perteneciente a la teoría de los sistemas, tiene el mismo sentido que la distinción de diferenciación/diferencia, perteneciente a la teoría de las distinciones. Un sistema consistiría - visto desde la teoría de las distinciones - en un determinado relacionamiento asimetrizado de las distinciones diferenciación y diferencia. Con ello, no se debe olvidar que la diferenciación, por su parte, representa una distinción asimétrica, la diferencia reproduce una distinción simétrica. Con otras palabras, en todos los lugares donde procedemos desde la perspectiva de la teoría de los sistemas, podriamos proceder igualmente desde una perspectiva de la teoría de las distinciones. Ya que para este planteamiento hemos escogido como guía la perspectiva de la teoría de los sistemas sociales (TsS) orientada hacía la teoría de los sistemas, procedemos por regla general desde la perspectiva de la teoría de los sistemas, sin embargo, intentamos echar un breve vistazo a los contextos de argumentación de la teoría de las distinciones.

Ahora bien, si partimos del hecho de que la materia sociología tiene carácter de sistema, o sea, que es sistema parcial del sistema parcial de la ciencia, entonces se pueden divisar, de acuerdo con los criterios de una teoría del diferenciamiento de los sistemas, tres referencias fundamentales del sistema para el sistema de la sociologia. ${ }^{3}$ La referencia funcional del sistema parcial sociología a su sistema global ciencia está orientada metodológicamente. Con ello, se trata de una optimización de la investigación respecto a su función de la verdad. La referencia a su entorno, relacionada con el rendimiento del sistema parcial sociología, se produce mediante los problemas que este entorno quisiera haber resuelto, sobre la base de la investigación social empírica vinculada con la aplicación. Finalmente se debe realzar la referencia reflexiva del sistema parcial sociología, la cual procesa, por medio del nivel de la "teoría sociológica" la unidad de un planteamiento de preguntas generador de teorías." Aquí se trata de la capacidad y posibilidad de identidad de la materia sociología, o de la exigencia de su unidad vía la teoría.

${ }^{3}$ Véase acerca de ello las explicaciones en Luhmann/Schorr, 1983, pp. 34 y ss. Cada sistema parcial puede formar, por lo menos, tres referencias al sistema: la referencia al sistema global (su función), la referencia a otros sistemas parciales (su rendimiento) y la referencia a sí mismo (su reflexión). Con ello, naturalmente se alude a distintos entomos correspondientes.

' La TsS trata estas tres referencias del sistema de la materia de sistema sociología en el contexto de una problematización de la sociología norteamericana por Talcott Parsons, el cual, a su vez, realiza, reflexiones similares. 
La ocupación con la "teoría sociologica" no representa - con referencia a la disciplina sociología - ningún asunto inofensivo, como quizá se podría pensar. Precisamente porque se trata de la identidad de la materia, el sistema parcial "teoria sociológica" debe poder representar la "unidad" de la materia, es una tarea no precisamente fácil de resolver, si es que se puede resolver del todo. En el contexto de una argumentación desde la perspectiva de la teoría de las distinciones, se debe observar al hecho de que la unidad -y con ello también cualquier forma de la identidad-siempre es la "unidad de la distinción de diferencia y diferenciación".

Aquí se nota inmediatamente que una observación de esta indole implica varios niveles de abstracción, los cuales pueden ser caracterizados por medio de las siguientes distinciones: sociología/socre-

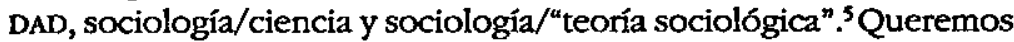
introducir una cuarta referencia al sistema, misma que nosotros ( $\mathrm{TgS}$ ) queremos designar como referencia ecológica del sistema sociología, y la cual se debe hacer responsable de la información que recibe el sistema en cuestión, si refiere reflexivamente a sí mismo las consecuencias del rendimiento, de la función y de la identidad.

\begin{abstract}
Existe una estrecha correlación entre la referencia ecológica de un sistema y la forma reflexiva de diferenciamiento de la SOCIEDAD, ya que la referencia ecológica puede ser considerada como el "disparador" para la producción de la forma reflexiva de diferenciamiento del sistema: solamente por medio de una forma de diferenciamiento de esta naturaleza se permite, si no manejar, pues, al menos percibir las consecuencias del rendimiento, de la función, y de la identidad. También pensamos que los sistemas del sentido como la economía, la ciencia, el derecho y la política ya se han diferenciado reflexivamente. En este contexto, son de interés para el sistema del derecho, sobre todo, los trabajos de Günther Teubner y Hellmut Willke. ${ }^{6}$
\end{abstract}

${ }^{5}$ Dejamos abierto el problema de si la referencia reflexiva al sistema de la sociología, o sea, la teoría sociológica, por su parte, también es sistema y de que manera. En todo caso, hay bastantes indicios que apoyan esta suposición. De todas maneras, se cumple con el requerimiento mínimo: diferenciamiento complementario de roles de los productores de las teorías, y receptores para este producto de rol de servicio y de recepcion. (Luhmann, 1977c, p. 35).

${ }^{6}$ Teubner/Willke, 1984. 
Se trata adicionalmente de posibles "bendiciones" $\mathrm{y}$ "daños" que las operaciones sociológicas ocasionan dentro de la SOCIEDAD, con lo cual esta referencia es representada institucionalmente, por ejemplo, a través de distintos gremios de la disciplina. Los trabajos clásicos referentes a esta temática provienen, por ejemplo, de Helmut Schelsky, Friedrich H. Tenbruck ${ }^{8}$ y Alvin W. Gouldner' (figura 81).

Referencias de sistema de la soctología como sistema:

Función $\rightarrow$ Ciencia investigación adecuada para la verdad y orientada hacia los métodos

Rendimiento $\longrightarrow$ SOCIRDAD investigación empírica de los problemas sociales

Reflexión $\longrightarrow$ Teoría soclológica exigencia de identidad de la materia por medio de la teoria sociológica

Ecologia $\longrightarrow$ Sociología de la sociología consecuencias funcionales, reflexivas y en cuanto al rendimiento

2. Sólo en el ámbito "teoría sociologica" dentro del sistema parcial sociología, nos encontramos ( $\mathrm{TgS}$ ) como observadores - no como teoría de la acción, teoría de los conceptos, teoría dialéctica-crítica, neomarxismo, teoría estructural-funcional, teoría del sistema general de la acción (TaH), teoría de los sistemas sociales (TsS) o teoría de la acción comunicativa (TkH), sino como una forma de teoría del sistema, o sea como la teoria de los sistemas sociales $(\mathrm{TgS}) .{ }^{10} \mathrm{Y}$ si queremos observar a la sociedad desde esta perspectiva, podemos hacerlo solamente con la ayuda de un concepto extremadamente formal de la observación, el cual definimos como el entrelazamiento operativo de la diferencia y la diferenciación.

${ }^{7}$ Helmut Schelsky, "Die Arbeit tun die Anderen. Klassenkampf und Priesterschaft der Intellektuellen". (Schelsky, 1975).

${ }^{8}$ Tenbruck, 1980.

'Gouldner, 1974.

${ }^{10}$ Hubiéramos podido realizar una argumentación similar con la ayuda de una teoría de la sociedad, como teoría de la expectacion. No obstante, dado que argumentamos paralelamente con la TsS, nos apegamos al concepto del sistema. 
Acerca de un concepto similarmente formal del observador, ver Niklas Luhmann. ${ }^{11} \mathrm{La}$ operación de la observación representa una forma de la abstracción, la cual señala simultáneamente el problema general y el problema específico de la cognición. El problema general es: ¿có'mo es posible la cognición? Correspondientemente, el problema específico es: ¿cómo es posible un estilo de cognición determinado? Ploman escribe -con relación a la operación de la observación- acerca de ello: "The observer is not a concrete individual but an abstraction: the 'ideal physical observer' is made up of methods used for the measurement of a phenomenon plus the state of the art in the concerned discipline."

Sin embargo, aquí no se trata de cualquier entrelazamiento arbitrario, sino de una forma determinada del entrelazamiento. Debemos considerar que se trata de una observación de los sistemas autorreferenciales, o sea de sistemas que producen y reproducen, por sí mismos, los elementos de los cuales están compuestos. Los sistemas autorreferenciales de esta naturaleza son sistema cerrados, lo que significa que no tienen ningún acceso directo hacia afuera: pueden producir el contacto exterior solamente a través de un autocontacto. Ahora bien, no solamente los sistemas observados sino también los sistemas observadores ${ }^{13}$ son sistemas autorreferencialmente cerrados. Con otras palabras, la observación en el sentido aquí definido es, por un lado, la observación de los sistemas autorreferencialmente cerrados, por el otro lado, sin embargo, ella misma es el instrumento de un sistema autorreferencialmente cerrado. Por lo tanto, está bloqueado para cualquier observación el acceso directo hacia la "realidad".

En este contexto hablamos también de una realidad accesible real y cognoscitivamente. Tenemos acceso solamente a la realidad cognoscitiva, no obstante, necesitamos la distinción hacia la realidad, la cual permanece irreconocible para poder decir lo que queremos decir cuando nos referimos a lo real.

"Luhmann, 1990, p. 73.

12 Ploman, 1985, p. 12.

${ }^{13}$ Observing Systems y no Obsenved Systems es el título de la versión inglesa de la obra de H.v. Foerster Sicbt und Einsicht. Versucbe zu einer operationalen Erkenntnistbeorie. (Fnerster, H.v., 1985). 
Para ella es válido que todo lo que no es sistema o que se encuentra operacionalmente afuera del sistema observado, permanece inaccesible en cuanto al acceso directo, a pesar de que el sistema podría tener la opinión de lograr, de manera circunstancial, un contacto directo con su entorno. Por lo tanto, la observación es una operación que puede observar a algo como "algo" solamente por medio de la exploración. ${ }^{14}$

3. Dado que la observación - la cual es posible solamente como observación del sistema o de la distinción- no puede observar directamente a ningún otro sistema desde afuera, ya que ella y los sistemas que observa son sistemas autorreferencialmente cerrados, debe explorar las unidades propias y ajenas por medio de las distinciones constituidas internamente. Por lo tanto, cada observación utiliza un esquema de distinción con cuya ayuda explora la unidad de su observación. Una observación es, por ello, una operación que utiliza una distinción para determinar la unidad del objeto observado desde su posición. Con la observación se trata entonces del manejo de una diferencia con cuyo auxilio se genera la unidad. No obstante, esto sucede frente al trasfondo de una diferenciación. La diferenciación sirve para determinar la observación como una observación específica: por ejemplo, se trata de la observación de "niños jugando", no de la observación de "vacas pastando", etc. Con ello, se trata de la unidad "niños", no de la diferencia entre chicas y chicos o entre niños altos y bajos, etc. Por lo tanto, la observación es el manejo operativo de una diferencia con la finalidad de la exploración de la unidad frente al trasfondo de una diferenciación. Con ello se debe considerar que en el marco de la pragmática de las distinciones aquí aplicada, las diferencias siempre indican una forma simétrica, las diferenciaciones siempre señalan una forma astmétrica.

4. Iniciamos una definición formal de esta naturaleza de la observación antes de cualquier observación "concreta": no se trata de la observación de la "cultura", "idioma"o de "sillas". Se trata de la primera forma de la observación en general y, con ello - dentro del marco

${ }^{14} \mathrm{La}$ TsS realza, en este contexto, explícitamente: "Toda observación depende de la explotación [R] de la unidad." (Luhmann, 1984, p. 654). 
de una "lógica de las distinciones" - de la unidad misma de la diferencia y la diferenciación. Se trata de la forma "pura" de una observación, la cual es explorable solamente por el hecho de que puede ser observada, como una observación (3) observa a otra observación (2), la cual, por su parte, observa nuevamente a otra observación (1) "concreta", misma que observa "algo". Una "observación de una observación de una observación" de esta naturaleza es, dentro del sistema parcial sociología del sistema parcial ciencia, la regla: de esta manera, los sociólogos (3) observan cómo los científicos economistas observan, por su parte, al sistema de la economía (2), cómo éste observa por su lado (1). Por lo tanto, se trata de la "observación de la observación de la observación de 'algo". Una operación de esta indole se presenta como una forma especialmente elaborada de la exploración cognoscitiva, a la cual se puede designar como una observación de tercer grado. Ahora bien, para hacer accesible una observación de tercer grado de este tipo a otra observación, ${ }^{15}$ queremos observar, como ejemplo, a la "observación de la acción". Con una acción "pura"16 se trata del manejo de una diferencia con cuya ayuda se constituye no la unidad sino la diferencia, y esto sucede nuevamente frente al trasfondo de una diferenciación: "afuera llueve, adentro está seco". Me quedo adentro. El observador observa a la diferencia "afuera llueve"/“adentro está seco", como diferencia y se decide por uno de los lados de la diferencia, es decir, permanecer en el interior. Naturalmente, el observador de la acción no debe tomar una decisión de este tipo, no obstante, también entonces toma una decisión, o sea, no hacer nada al respecto. ${ }^{17}$ Se debe distinguir minuciosamente entre la observación general de la "observación de una observación" y la observación general de la "observación de una acción". Desde la perspectiva de un observador del tercer

${ }^{15}$ Lo que implica ciertamente una observación de cuarto grado, etcétera.

${ }^{16}$ Con accion "pura" se quiere decir una operación que descubre al "mecanismo" de la acción "en sî". Esto es posible solamente en el nivel de una observación de tercer grado: por medio de una observación que observa (3) cómo otra observación (2) observa, por su parte a una observación (1), la cual observa, por su parte, a una acción "concreta".

${ }^{17}$ No se debe perder de vista el hecho de que una observación de la acción se trata de la observación de una diferencia simétrica en la forma "A y/o B" y no de la observación de una contradicción en la forma "A no es A". Acerca de la forma de la contradicción, véase Luhmann, 1984, p. 493. 
grado se puede decir que: una observación de la acctón "directa" o "ingenua" expone al observador a una presión de decisión, mientras que una observación de la observación "directa" o "ingenua" conduce al observador hacia la suposición de la unidad (la cual, por lo demás, puede ser unidad solamente dentro de un contexto, y, por lo tanto, siempre porta el germen de una distinción; la unidad sin trasfondo no sería observable) ${ }^{18}$ Sólo una observación del tercer grado puede aclarar esta relación de las exigencias de decisión y unidad, con lo cual se le exige a ella misma, por su parte, una unidad más abstracta, la cual se puede observar precisamente entonces como una "observación de tercer grado" en el sentido de una unidad desde la perspectiva de una "observación de cuarto grado"... etcétera (figura 82).

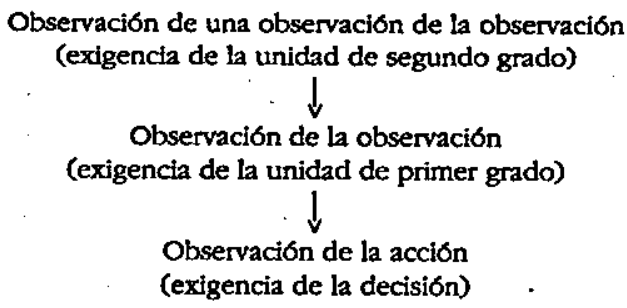

5. Una "observación de una observacion" o una "observación de una acción" reproduce una operación que tiene lugar cotidianamente: observo, estando sentado en el camión, cómo el chofer corta la curva fuertemente (actúa) y cómo dos pasajeros lo observan con miedo. Observo (3), con ello, por un lado a una acción (1) y, por el otro lado, a una observación (2), iy esto casi simultáneamente! Sólo el análisis de una operación de observación de este tipo, la cual es posible solamente en el nivel de una observación del tercer grado (4), da por resultado que ella reproduce una operación altamente sofisticada y extremadamente complicada y que ciertamente representa una operación bastante improbable (figura 83 ).

${ }^{18}$ En este sentido uno puede estar de acuerdo con Eva Meyer en que "las diferencias crean los entornos", aunque con el concepto de la diferencia utilizado por ella permanece abierta la cuestión acerca de en qué consiste semánticamente aquello que constituye su diferencia específica. (Meyer, 1990, pp. 100 y ss.). 


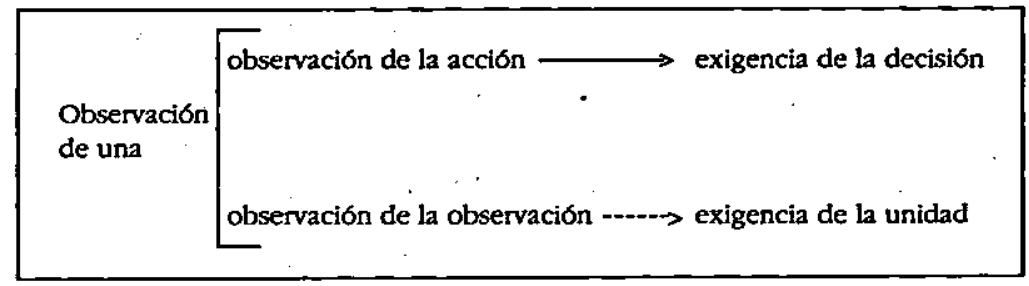

Para la aclaración: una acción en sí no puede observar en el sentido de una distinción. Una acción solamente puede conectar o no conectar, con otras palabras, tiene solamente un valor de conexión. No obstante, una observación puede observar aquello que se requiere para aplicar o rechazar la capacidad de conexión de una acción. Tengo hambre y observo las posibilidades (= comunicación): calentarme en casa la comida de ayer $O$ ir al restaurante más cercano y comer una pizza. Me quedo en casa y caliento la comida de ayer. En la cotidianidad, una operación de acción de esta índole ciertamente no se desarrolla tan explícitamente como lo presentamos aquí. Por otro lado, no se puede efectuar ninguna acción si no tiene lugar ninguna observación de la comunicación, o sea, la observación de la diferencia.

\section{EL CONCEPTO DE OBSERVACIÓN DE LA TEORIA DE LOS SISTEMAS SOCIALES (TSS)}

6. Sabemos por George Spencer Brown que se puede construir, sobre la base de una sola operación, ${ }^{19}$ un cálculo, del cual se deduce entonces el álgebra y la aritmética. Ahora bien, si uno como observador utiliza las operaciones en el sentido de Spencer Brown y, con ello, sigue las instrucciones que resultan de la operación inicial, entonces uno se convierte en matemático: una operación de observación de este tipo representa una forma específica de observación, es decir, una matemática. ${ }^{20} \mathrm{Si}$ uno elige otra secuencia de operaciones y persigue con ello otros valores y objetos del conocimiento, entonces uno se convierte posiblemente en físico, biólogo o sociólogo. Queremos subrayar especialmente la ventaja de un concepto de la observación

19 Distinction e indication como única forma de operación. Postulamos una relativa autonomía en cuanto a la operación indication como designación o DECISIÓN, interpretamos la distinction como diferenciación asimétrica e introducimos la distinción de la "diferencia simétrica".

${ }^{20}$ Luhmann, 1990, p. 74. 
formal de este tipo, dado que con ello son observables y comparables entre sí distintos intereses del conocimiento, sin que uno tenga que apoyarse en "intereses de conocimiento fundamentados antropológicamente $^{n}$, como es el caso, por ejemplo, con la TkH. ${ }^{21}$

\section{La TsS define la observación como una operación del diferen-} ciamiento con el auxilio de una denominación ${ }^{22}$ y obtiene como re-

${ }^{21}$ Vale la pena abordar brevemente la historia del surgimiento de los "intereses de conocimiento" de la teoría de la acción comunicativa (TkH): mientras que la TkH habla, con su primer intento temático, de la representación del concepto de la teoria de tres intereses fundamentales y antropológicamente arraigados de conocimiento, a los cuales designa como interés de conocimiento técnico, práctico y emancipatorio, introduce, dentro del marco de reflexiones más recientes, tres conceptos del mundo, los cuales acopla a distintos conceptos de la acción. Ambos conceptos de comunicación, aquel del "conocimiento e interés" y aquel que fue proyectado posteriormente dentro del marco de la acción comunicativa, están concebidos como conceptos téricos constitutivos. Con referencia al concepto dentro del marco de la "teoría de los intereses de conocimiento", J. Habermas expresa en la cátedra de presentación en Frankfurt en 1965 ["conocimiento e interés"] de la siguiente manera: "La orientación hacia la disposición técnica, hacia la comunicación práctica de la vida y hacia la emancipación de la obligación nanural determina realmente los puntos de vista específicos, bajo los cuales podemos percibir la realidad como tal" (Habermas, 1969a, p. 162). Años después, y en el marco de la teoría de la acción comunicativa, la tesis de la constitución es formulada de la siguiente manera: los tres mundos, el objetivo, el social y el subjetivo, forman "[...] en su totalidad un sistema de referencia presupuesto en los procesos de comunicación. Con este sistema de referencia, los participantes determinan aquello sobre lo que es posible la comunicación en general [...]. Locutor y oyente manejan un sistema (jsic! RJ) de mundos de igual origen." (Habermas, 1981b, 1, p. 126). Con ello, la TkH integra de manera teorica la teoría de los tres mundos de la acción, para demostrar que la racionalidad de las acciones correspondientes depende de la selección de las referencias al mundo: "de la referencia al mundo que imputamos al actor, dependen [...] los aspectos de la posible racionalidad de sus acciones" (idem). Primero, consideramos como problemático un entrelazamiento tan estrecho de conceptos muy variados, mismo que es típico para la TkH (véase acerca de ello capítulo V sobre la arquitectura de la teoría). Segundo, los "intereses de conocimiento" de este tipo representan supuestos cuasi a priori, cuya problemática debería conocerse, por lo menos desde Kant. Pensamos que, con la elección de un concepto de observación formal, ambos conceptos se pueden esquivar y resolver más elegantemente.

22 "Nuestro punto de partida está situado en un concepto extremadamente formal del observador, mismo que se define como la operación del diferenciar y observar." (Luhmann, 1990, p. 73). 
sultado una distinciôn ya asimetrizada: "no hoy, sino mañana", "en Francia, no en Inglaterra". Hemos observado críticamente ${ }^{23}$ que una forma de distinción asimétrica (en cuanto a la teoría de las distinciones, no en cuanto a la teoría de la operación) representa una distinción de diferenciamiento o (visto desde la perspectiva de la teoria de la sociedad) una distinción de la ACCIÓN. Con cualquier forma de la asimetría (la cual naturalmente siempre puede ser solamente bilateral, pero que en su bilateralidad es enfáticamente unilateral) siémpre está realizada una correspondiente denominación ( $=$ DECISION) en favor de uno de ambos lados. Ciertamente se puede anular nuevamente la distinción en cuestión, aunque con la consecuencia de que, con ello, es alcanzada de nuevo una asimetria: "hoy, no mañana", "no en Francia, sino en Inglaterra". En todo caso, la definición que ofrece la TsS acerca de la observación, no permite otra alternativa que formular: una distinción de observación es siempre una operación del diferenciamiento y de la denominación en una sola. Por lo tanto, siempre está conformada asimétricamente. ${ }^{24}$ Ahora bien, estamos de acuerdo con la TsS en que la semántica de la operación de la diferenciación expresa de hecho una forma asimétrica, no obstante, completamos esta distinción por medio de una segunda formada simétricamente, o sea, por medio de una diferencia. Solamente en el sentido de una relación complementaria, ${ }^{25}$ ambas formas de distinción poseen una autonomía relativa, con lo cual uno siempre puede partir del hecho de que detrás de una diferencia se esconde una diferenciación que permanece latente, y detrás de una diferenciación se esconde una diferencia que permanece latente.

8. Es posible estar de acuerdo con la afirmación de que: "[...] ya con la elección de una diferenciación se encuentran conectadas las determinaciones [...]". ${ }^{26}$ ¿Pero, qué significa más detalladamente una determinactón de este tipo? Si se dispone solamente de una diferenciación, la cual está además formada asimétricamente, entonces

${ }^{23}$ Capítulo I sobre la forma.

${ }^{24}$ Precisamente la simultaneidad de la diferenciación y la designación, representa un supuesto lleno de problemas para nosotros. Decididamente negamos una simultaneidad de este tipo en ambas operaciones.

${ }_{25}$ Véase capítulo I acerca de la complementariedad y la distinción.

${ }^{26}$ Luhmann, 1990, p. 74. 
"determinación" significa en realidad mucho, es decir, la determinación producida asimétricamente de todo aquello que se observa: "bien, no mal" o "mal, no bien". Esto no sería precisamente un supuesto realista. En todo caso, no puede-de acuerdo con la definición propuesta por la TsS- haber otras posibilidades. Sin embargo, si el observador tiene la posibilidad de oscilar entre "diferencia" y "diferenciación" (dado que la observación consiste, de acuerdo con nuestra definición, ciertamente en un entrelazamiento de ambas distinciones), o sea, de cambiar de un lado a otro, entonces puede vislumbrar la unidad de la diferencia: entonces puede identificar la distinción de bien y mal como categoría moral frente a una categoría juridica. Esto lo puede hacer solamente frente al trasfondo de una diferenciación, ya que sólo de esta manera se hace visible la unidad de la diferencia. ${ }^{27}$ Ciertamente, la TsS presupone que, sobre la base de su propuesta de definición de la observación, sea explorada la unidad; no obstante, de acuerdo con nuestra opinión, esto no es posible con base en la diferenciación y la designación como distinción única, sobre todo cuando está formada asimétricamente. Esta circunstancia se puede formular también de la siguiente manera: la unidad de la diferencia de bien y mal se hace accesible para mi solamente como observador (=la diferencia se encuentra en el primer plano), no como actor (=la diferenciación está en el primer plano). En este contexto, la diferenciación asimétrica "derecho", misma que permanece latente, es la que procesa a espaldas del observador, y que observa la "moral", la cual hace accesible a éste la unidad de la diferencia de bien y mal (=moral). La diferencia sola, debido a su forma simétrica, y esto quiere decir, oscilante y por ello, "indecisa", no es capaz de constituirse como unidad diferente, ya que ella mis$\mathrm{ma}$, si se puede decir así, requiere la unidad. La unidad como unidad se puede explorar únicamente a través del camino de la diferenciación asimétrica, con lo cual, en esta exploración de la unidad, la diferenciación misma permanece latente y, generalmente, escondida para el observador. A su vez se puede hacer accesible por medio de otra observación.

Como observación se procesaría la sirnetría de "bien y/o mal", como acción se procesaría la asimetría de "bien, no mal" o "mal, no bien". Con ello se debe observar el hecho de que una de ambas distinciones

77 Véase capítulo I acerca de la diferencia y la diferenciación. 
principales (diferencia o diferenciación, dependienrio del rendimiento cognoscitivo), siempre debe permanecer latente cuando se manifiesta la otra. Por lo tanto, no existe ninguna diferencia sin diferenciacion y ninguna diferenciación sin diferencia. Noobstante, ambas distinciones nunca se presentan conjuntamente. En este sentido, tienen una relación complementaria entre sí (figura 84).

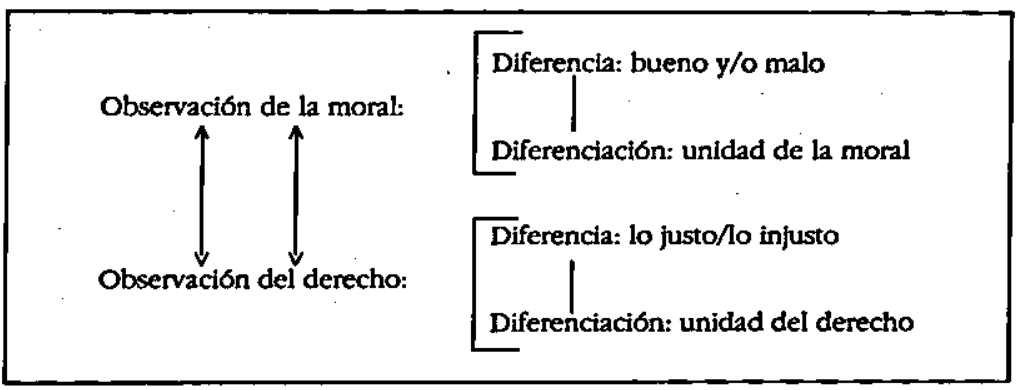

9. La operación de la observación solamente es posible sobre la base de un sistema,' $e$ incluso la operación de la observación misma es una operación ligada al sistema de un sistema cerrado autorreferencialmente. Debido a la hermeticidad del sistema, condicionada autorreferencialmente, no es posible el hecho de que un sistema observe directamente a otro. La observación y su "unidad" constituida por medio de esta operación, no es la unidad de la circunstancia observada, sino una unidad constituida por medio del observador, es decir, una unidad explorada y, por ello, la unidad del sistema observante.

Toda observación utiliza (esto define al concepto), un esquema de diferencias. Con ello, la unidad de la diferencia se define por medio del observador, no por medio de su objeto. ${ }^{28}$ Con referencia a los sistemas autorreferenciales, se debe distinguir cuidadosamente entre una observación como unidad de observación y la utilización de una unidad de esta naturaleza, es decir, de la unidad de utilización. De esta manera, una observación que está siendo utilizada inmediatamente, no puede ser analizada simultáneamente. Por el otro lado, una observación determinada puede ser observada (esto es, analizada), si es utilizada otra observación. Transferido al nivel conceptual se puede decir

${ }^{28}$ Luhmann, 1984, p. 654. 
que existe una relación exclusivamente complementaria entre el análisis de un concepto y su utilizactón inmediata. ${ }^{29}$

Lo mismo es válido no sólo para la observación ajena, sino también para la auto-observación del sistema, la cual no puede ser otra cosa que una autosimplificación del sistema, el cual, por así decirlo, se observa a sí mismo en forma de miniatura, y con ello puede observar siempre solamente de manera "incompleta" o "falsa".

\section{OBSERVÁCION DE ACCIÓN Y OBSERVACIÓN DE LA OBSERVACIÓN}

10. Hemos definido a la observación como una operación mediante la cual se trata de una diferencia frente al trasfondo de una diferenciación. Una observación más detallada de esta observación resulta en sets niveles de abstracción diferentes o "mundos ontológicos", si se considera que la observación de la unidad de la observación se observa como el entrelazamiento de las distinciones "diferencia" $\mathrm{y}$ "diferenciación".

Estos mundos son relacionales para el sistema ciencia; para la socieDAD representan las distintas dimensiones ontologicas. Aquí también se encuentra el punto de conexión para las referencias al mundo introducidas de manera formal y pragmática por la teoría de la acción comunicativa (TkH), es decir, la referencia al mundo objetiva, social y subjetiva. ${ }^{30}$

Queremos observar ahora uno por uno los niveles particulares de abstracción de la observación. Existe primero, el contacto cotidiano del sistema con sólo una distinción, o sea, con una diferenciación, con lo cual el sistema utiliza únicamente uno de los lados de la diferenciación: emplea la diferenciación asimétrica, sin permitir que aparezca en la mira lo asimétrico de la diferenciación. Simplemente hace algo sin pensar si aquello que realiza también sería posible de otra manera. No actúa en el sentido de tomar una decisión sobre la base de una diferenciación, sino que hace simplemente aquello que hace, no más, pero tampoco menos. En este nivel de la operación de observación tienen lugar operaciones de rutina y costumbre.

29 Véase también Weiszäcker, C.F.v., 1984a, pp. 283 y ss.

${ }^{30}$ Véase Habermas, 1981b, 1, pp. 114 y ss. 
El sistema se comporta de manera fáctica hacia sí mismo y hacia el mundo, tiene que tratar con el procesamiento de la acción tradicional en el sentido de Max Weber: "Frecuentemente es sólo una reacción a los estímulos acostumbrados, apagada, que se desarrolla en dirección hacia la posición resultado de la experiencia. La masa de todas las acciones cotidianas, resultado de la experiencia, se acerca a este tipo. ${ }^{n 1} \mathrm{~A}$ ello se añade el hecho de que todo lo que sucede, sucede en un nivel fáctico. Aun las formas de observación, tales como la reflexión o la autorreflexión procesan en forma fáctica: tienen lugar cuando tienen lugar y no tienen lugar cuando, precisamente, no tienen lugar. Por lo tanto se deben realizar dos momentos en la observación de una forma fáctica de observación, los cuale podemos designar tambiér $\_$como comportamientos condicionados socialmente: por un lado, la mayor parte de aquello que es denominados como sOCIEDAD consiste en maneras de comportamiento fácticas de este tipo.

Aqui remitimos al concepto del comportamiento en el sentido de Paul Watzlawick y otros, ${ }^{32}$ y Bemhard Waidenfels ${ }^{33}$ para notar el carácter reflexivo del concepto de comportamiento: uno siempre puede referirse a su comportamiento, esto es, comportarse.

Por otro lado, el comportamiento fáctico es la forma basal de todas las demás formas de observación y, en este sentido, aquí es homólogo al concepto de la operación representado en un nivel menos abstracto ${ }^{34}$ (figura 85).
a) Observación de acción =
1. Facticidad o comportamiento =
solo uno de los lados de una diferenciación asimétrica

31 Weber, 1972, p. 12. También la observación de Simone de Beauvoir "una costumbre es casi una sociedad, así como una sociedad frecuentemente es solo una costumbre" (Beauvoir, 1969, p. 106) es muy ilustrativa en ese contexto.

${ }_{32}$ Watzlawick/Beavin/Jackson, 1985, pp. 50 y ss.

${ }^{33}$ Waldenfels, 1980 , pp. $69-70$.

34 Véase el capítulo I acerca de la forma y la operación. 
11. Un sistema alcanza un segundo nivel de abstracción de la operación de observación si también utiliza esta vez, explícitamente, sólo una única distinción, o sea, una diferenciación asimétrica, pero cuando no deja fuera de consideración a la simetría de la diferenciación, de tal manera que el sistema puede cambiar de un lado de la diferenciación hacia el otro. Así, por ejemplo, la "verdad" es considerada dentro del sistema de la ciencia como el verdadero valor institucional del sistema, pero la "verdad" (lo que quiera que esto sea), puede ser explicada solamente a través de la "falsedad" (cualquier cosa que esto sea).

Esto es necesario por razones teóricas de la información, ya que no se puede generar ninguna información si no se procesa una "distinción de una distinción": el terminustecnicus, "información" puede ser definido provisionalmente como cualquier diferencia que conforma una diferencia en un suceso posterior. ${ }^{35}$

Por lo tanto, la ciencia se constituye con la ayuda de la diferenciación asimétrica de la "verdad" (que se debe preferir) y la "falsedad" (la cual siempre permanece latente). El hecho de que también el otro lado de la diferenciación pueda hacerse relevante para el proceso de investigación es mostrado por la metodología del falsificacionismo. ${ }^{36}$ Con ello se trata de localizar frases basales, mismas que la teoría en cuestión intenta presentar como no-ciertas, como falsas, como falsificadas.

Es una metodología por lo demás poco realista, ya que aun las frases basales se encuentras preñadas de teoría, como es sabido hoy en día. Esto significa que no puede haber ninguna demostración independiente sin consideración de la forma. Esto demuestra a su vez, que la nece-

${ }^{35}$ Bateson, 1983, p. 448.

${ }^{36}$ Aquí deberia comenzar el planteamiento de la teoría del aprendizaje, dado que el hecho de aprender seguramente no puede significar que uno afirma lo ya existente, sino que lo amplia, lo cual, en cierta manera, va a la par con una disonancia cognoscitiva. La afirmación pura y, con ello, la redundancia pura, no puede ser comprendida como aprendizaje cognoscitivo, sino más bien como aprendizaje normativo, con lo cual, la designación "aprender" ya no es completamente correcta (figura 85). Aprendizaje congnoscitivo: el componente informativo de novedad se encuentra en el primer plano (-ciencia). Aprendizaje normativo: la parte informativa de confirmación se encuentra en el primer plano (=derecho). 
sidad de cambiar la forma de teoría en vista del problema de una teoría que se afirma a sí misma, es adecuada, para después adoptar inmediata y explicitamente una posición frente a este problema, es decir, autorreferencialmente. Alfred Gierer opina, en relación con un falsificacionismo metodológico: "El filosofo Karl Popper afirmaba l...] que el sentido de cualquier teoría es aquél de provocar intentos de refutación. Sin embargo, con ello se subestima la exigencia de la ciencia: las teorías se elaboran con la expectativa de que se evidencien como la explicación verdadera de la naturaleza, no para ser refutadas alguna vez. Ningún científico abandona una teoría solamente porque se le opone algún experimento; más bien tratará de refutar el experimento, de localizar supuestos dudosos escondidos en la interpretación o, si esto es imposible, reparar la teoría. Las teorías científicas no se abandonan cuando no concuerdan con algunos hechos, sino cuando ya no vale la pena la reparación y cuando las suposiciones de una teoría altemativa son más simples y convincentes. ${ }^{\text {"37 }}$

La ganancia de abstracción de esta observación de operación consiste en el hecho de que lo fáctico se registra como tal y, con ello, es comprendido como algo posible. El sistema ciertamente permanece unilateral en su comportamiento de observación, ya que prefiere lo "cierto", lo "correcto", el "amor" o el "poder" antes que "mal", "falso", "injusticia", "odio" o "impotencia"; sin embargo, puede variar esta unidad y servirse de la relación de tensión entre la facticidad y la posibilidad por medio de la observación. Solamente de esta manera, para dar un ejemplo, es posible la moral como la relación de tensión entre ser (factum) y lo intencionado (posibilidad). Queremos designar esta observación de operación como la acción del sistema (figura 86).

a) Observación de acción -

2. Posibilidad o acción -

ambos lados de una diferenciación asimétrica

12. Se hace posible un tercer nivel de la abstracción si el sistema, en la forma de un comportamiento de observación, plantea una diferencia simétrica como diferencia.

${ }^{37}$ Gierer, 1985, p. 60. 
Para prevenir malentendidos sea dicho: una acción es -idesde la teoría de las operaciones!-siempre una distinción asimétrica, la cual sin embargo puede surgir cuando esté presente lo anteriormente elegible en el sentido de una diferencia simétrica o comunicactón de "esto y/o aquello". En este sentido, la distinción "diferencia" es la condición de la posibilidad de la realización de la acción en el sentido clásico de la palabra: como decisión entre "algo y algo distinto". No obstante, la percepción de la diferencia es un logro que presupone una perspectiva desde la teoría de la observación.

El sistema "daña” al mundo con el apoyo de una distinción de lados iguales. En este nivel de observación, se ve obligado a operar con decisiones o denominaciones, para conservar su capacidad de conexión. El sistema percibe a sí mismo y a su entorno en la forma de alternatividades y actúa en el sentido literal de la palabra: se decide por algo y contra algo distinto, denomina a esto, no a aquello. En este nivel de la observación, la unidad de la diferencia es explorada con la ayuda de una diferenciación, la cual permanece latente. Queremos definir a esta operación como acción. Ya desde aquí se nota que la acción es posible solamente en con tacto estrecho con una observación observante-de-diferencias, la cual procesa como diferencia simétrica. Solamente en el caso de que se pueda construir una alternativa real entre, por ejemplo, andar-en-carro y andar-en-bicicleta, se puede decidir entre ambas formas de traslado $y$, por lo tanto, actuar. No obstante, si la diferencia ya esta asimetrizada como diferenciación - como lo exige el concepto de observación de la TsS - de tal manera que el andar-en-carro tenga prioridad frente al andar-en-bicicleta, entonces, una decisión (o denominación en el sentido de Spencer Brown) y con ello también una acción, es superflua (figura 87).
a) Observación de acción -
3. Alternatividad o acción =
ambos lados de una diferencia simétrica como diferencia

13. Un cuarto nivel de la observación resulta cuando el observador presupone una diferencia simétrica como unidad, no como diferencia. En este nivel de la operación de observación, aquello que es 
observado se observa explicitamente de forma homogénea y esto se expresa de manera ligada al contexto: libros en anaqueles, peces en el agua, hombres en el parque, cuadros en el marco, etc. Denominamos a esta forma de la observación como la observación, ya que la diferencia no será separada por una decisión o denominación (figura 88).
b) Observación de la observación =
4. Observación =
ambos lados de una diferencia simétrica como unidad

14. Se hace posible un quinto nivel de la operación de observación cuando se observa a una observación con la ayuda de otra observación: cuando un sistema se observa a sí mismo (en un momento posterior) o cuando observa a otro sistema en su observación. De esta manera se da una "observación de la observación", una cibernetic of cibernetics en el sentido de Heinz von Foerster: una observación observante. Esta forma de operación la denominamos como reflexión (figura 89).
b) Observación de la observación =
5. Reflexión -
observación de una observación

15. Finalmente existe, en sexto lugar, la posibilidad de observar a la observación de una observación o la operación de la reflexión, por su parte, lo que es lo mismo. Esto lo puede lograr solamente un sistema bastante complejo, observando cómo alguien por su lado, observa a la observación de otro observador. Designamos a esta forma de la operación de observación como autorreflexión u observación del tercer grado. La TsS expresa, con referencia a una observación de tercer grado de este tipo: "Mientras tanto hay [...] ya un tercer nivel de la observación de la observación de observaciones: el comentario acerca de la literatura que se ocupa de la descripción crítica referente a las operaciones codificadas de la realidad social, por ejemplo, de la literatura del tipo Hegel o Marx. Hoy en día, el más 
competente observador de este tercer nivel es probablemente Jürgen Habermas. ${ }^{n 8}$

Numerosas operaciones de observacion, que la TsS denomina como observaciones del segundo grado, son en realidad observaciones del tercer grado. Sobre todo la teoría de la ciencia y la "teoría sociológica" se han socializado cognoscitivamente en esta forma de observación.

Aquí se trata de la operación de un sistema complejo del sentido, el cual es capaz de reflexionar acerca de la reflexión, o sea, de realizar la reflexión del segundo grado (figura 90).
b) Observación de la observación -
6. Autorreflexión -
reflexión de una reflexión

En resumidas cuentas podemos reproducir las modalidades de observación comentadas de esta manera (figura 91).

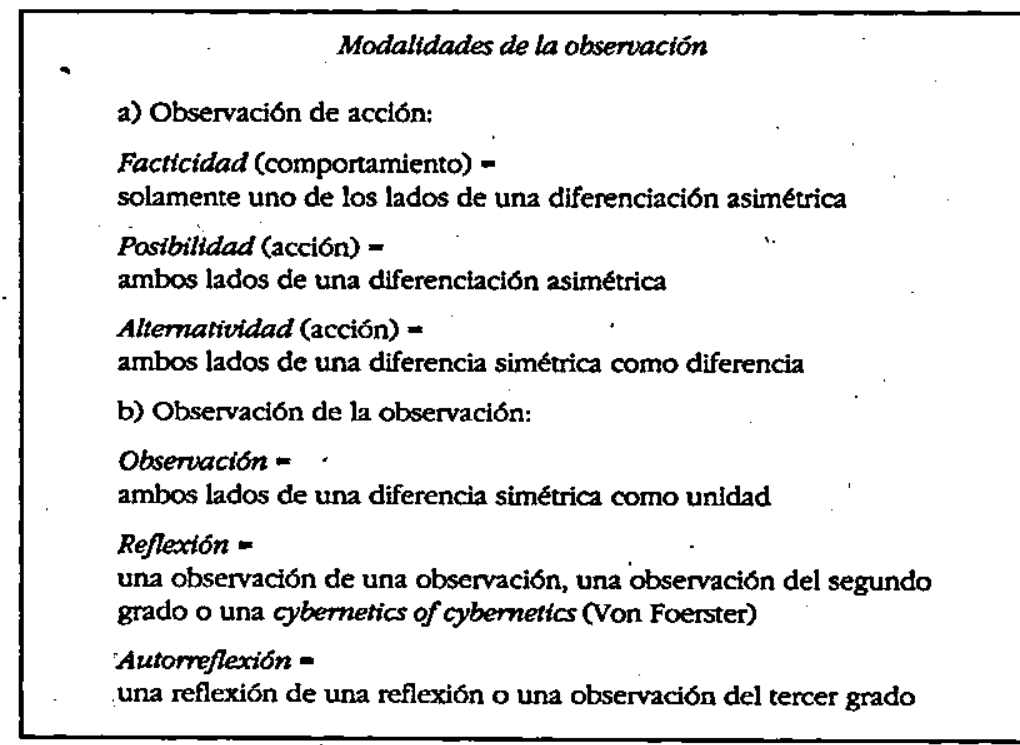

${ }^{38}$ Luhmann, 1987c, p. 31. 
16. Con la ayuda de un concepto de la observación planteado de esta manera, como el manejo de una diferencia simétrica frente al trasfondo de una diferenciación asimétrica, con la consecuencia de la generación de información, somos capaces de obtener un acceso teórico de constitución hacia las más diversas ontologizaciones del mundo. Dependiendo de qué distinción de observación en cuál tipo de constelación es utilizada por un sistema, el sistema puede obtener acceso a lo fáctico, posible, alternativo, relacionado con la observación, lo reflexivo y lo autorreflexivo. El mundo (y el entomo) de los sistemas autorreferencialmente observantes no está dado ni fáctica ni posible ni mucho menos reflexivamente. El mundo es como es y no es como no es, más no puede decirse de él. Esto ya lo sabía Parménides. ${ }^{39}$ Con ello, es el sistema mismo, sobre la base de una situación doblemente contingente, el que, con la ayuda de sí mismo, o sea, con la ayuda de las distinciones "diferencia" y "diferenciación" que lo constituyen, explora de manera teórica constitutiva lo fáctico, lo posible, lo alternativo, lo relacionado con la observación, lo reflexivo o lo autorreflexivo (en sí mismo y en otros sistemas del sentido). Esta forma de seis niveles de la operación de observación - la cual hemos obtenido a partir de la operación de la observación, como el entrelazamiento de las distinciones "diferencia" y "diferenciación" - expresa:

a) visto desde la perspectiva de la teoría de sistemas, diferentes relaciones modales entre sistema y entomo;

b) visto desde la perspectiva de la teoria de las distinciones, aclara los diferentes tipos de relaciones de simetría/asimetría;

c) visto de la perspectiva de la teoría de la sociedad, se hacen efectivas distintas formas de relacionamiento de la COMUNICACION y la ACCION, las cuales, sin embargo, no se pueden encontrar "allá afuera en el mundo", sino que ellas mismas son el sistema, el cual observa de manera específica.

39 "Se debe afimar y reconocer que ello es lo existente: ya que es el caso que es, pero no que no es nada; te exhorto a permitir que esto valga" (Parménides, 1981, p. 9). Hegel opina acerca de ello: "Con Parménides empez6 el filosofar real; en ello se debe ver la elevación al reino de lo ideal. Un hombre se libera de todas las opiniones e ideas, les niega toda verdad: solamente la necesidad, el ser, es lo verdadero. Sin embargo, este comienzo es aún turbio e indeterminado; no se puede explicar más lo que en ello subyace, pero precisamente esta explicación es la formación de la filosofía misma, la cual aquí aún no está presente." (Hegel, 1970, 18, p. 290). 
17. Hemos obtenido todas estas modalidades de observación sobre la base de una observación la cual, por su parte, es capaz de observar a la observación de las observaciones. Una observación de este tipo representa una observactón del tercer grado o una autorreflextón. Visto exactamente, con una "cibernética del tercer grado" de este tipo, se trata del hecho de que un primer observador observe el cómo un segundo observador observa a un tercer observador en su operación de observación. Vista desde la perspectiva de la ciencia, esta afirmación, bastante compleja acerca de una operación de observación del tercer grado, no solamente se puede encontrar dentro del sistema ciencia, aunque aquí esta forma es procesada en el sentido explícito. Una operación de la observación semejante tiene lugar implícitamente también en las situaciones cotidianas, tal como lo muestra el ejemplo siguiente: una madre puede observar cómo su hijo observa a otros niños estando sentado en su columpio. Este puede observar, por su lado, al padre que se encuentra detrás de ella: él observa la observación de la madre, la cual, por su parte, observa la observación de su hijo. El hecho de que un posible abuelo del niño - en el nivel de abstracción de una observación del quinto grado- pueda observar todo esto, o sea, cómo su hijo, el padre del niño, observa a su esposa cómo ésta observa al niño, cómo éste, por su parte, observa a otros niños, muestra qué tan improbable y simultáneamente habitual resulta una operación de observación de este tipo. Precisamente, una operación de observación de varios niveles de este tipo puede ser explorada con el apoyo de una observación del tercer grado o una autorreflexión. Se entiende por sí mismo el hecho de que, en la cotidianidad, semejante operación no necesariamente se debe manifestar, y que, generalmente, no lo hace (figura 92).

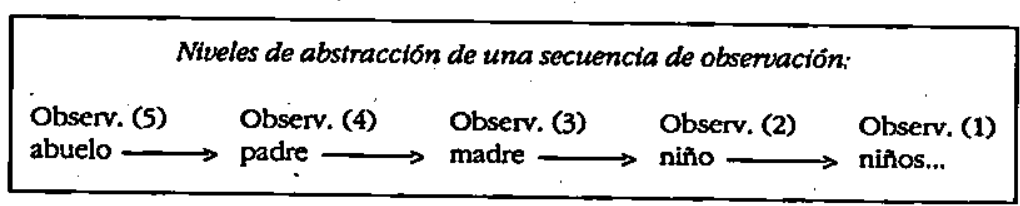

18. La forma de seis niveles de la operación de observación conduce al hecho de que, dependiendo de la operación de observación, se constituyan diferentes "mundos" $u$ ontologias, los cuales posteriormente permiten emerger diferentes niveles de lo social: un mundo 
fáctico, uno posible, uno alternativo, uno observante, uno reflexivo y uno autorreflexivo. Sólo en el nivel reflexivo de una observación de una observación es posible observar, tematizar y, con ello, experimentar contingentemente lo social como tal. Únicamente este nivel de la operación de observación posibilita la pregunta: “ ¿cómo es posible el orden social?", dado que en este nivel de la operación de observación lo social puede ser observado no solamente como una "posibilidad" o "alternatividad" frente a lo "fáctico", sino como una observación posible.

Entendido correctamente, sólo en este "nivel del mundo" es posible una observación de este tipo. La constitución de la socieDAD tiene lugar ya en el nivel fáctico "más bajo". Sin embargo, esta operación no puede ser observada mientras que no haya sido alcanzado - visto SOCIALMENTE- un nivel de abstracción al cual designamos como reflextón. De otra manera, se podría opinar que ya Aristóteles y Platón habían visto el problema genuinamente sociológico del orden social, lo cual precisamente no hicieron. No por casualidad se encuentra en Augusto Comte y los filósofos escoceses de la moral, el inicio de aque... . llo que hoy en día es denominado como sociología.

Ahora bien, los seis niveles de la operación de observación en la versión descrita antes, representan un instrumento de observación del sistema parcial social "ciencia" del sistema parcial "sociologia" del sistema parcial "teoría sociológica". Con la ayuda de dicho instrumento se puede observar cuáles ontologias sociales deben ser presupuestas para que los sistemas del sentido se "comporten", "realicen algo", "actúen", "observen", "reflexionen" o "realicen una autorreflexión" en la forma de la teoría de los sistemas; asimismo, como los collages (en la forma de la teoría de la expectación) o las distinciones lo efectúen (en la forma de la teoría de las distinciones). Como se puede ver, se obtiene una generalización social global de este tipo sólo sobre la base de una especificación de la materia sociología, es decir, sobre la base de la "teoría sociológica" con la ayuda de un concepto de observación planteado muy abstractamente basado en la pragmática de las distinciones.

19. La TsS ha ofrecido un instrumental teórico social para hacer plausible, generalmente, el que los sistemas del sentido actúen y cómo observan. Emplea para ello un concepto de observación en el cual se 
utiliza una diferenciación asimétrica como el manejo de una diferenciación denominadora: "Nuestro punto de partida se encuentra en un concepto extremadamente formal del observador, definido como la operación de diferenciar y denominar. ${ }^{n 40}$ Sin embargo, puesto que las acciones implican decisiones (desde la perspectiva de la teoría de las operaciones) y que pueden ser hechos plausibles solamente a través de este camino, la TsS no puede enfocar el fenómeno de la acción: sus diferenciaciones siempre son simultáneamente "diferenciaciones designadas" y, por lo tanto, "decisiones ya decididas". Sin embargo, una acción es realmente una operación que se genera únicamente si entre los dos lados de una distinción simétrica se encuentran dadas verdaderas posibilidades alternativas de la denominación, decisión o de la referencia. Sólo en este nivel de una situación de decisión es posible designar, referir o decidir el uno o el otro lado de la distinción. Por ello, la distinción puede obtener, apenas abora, una forma asimétrica, esto es, adoptar una forma de diferenciación y convertirse de hecho en "ACCION". Según nuestra opinión, la TsS se mueve, sin embargo, en el nivel de la facticidad monovalente y de la alternatividad asimétrica, y puede introducir su concepto de acción solamente ad boc, sin poder legitimarlo en relación con la técnica de su construcción teórica. Su afirmación de que las acciones se desarrollan a través de los procesos de atribución y de que etiquetan responsabilidades ${ }^{4 \prime}$ es seguramente acertada, sólo que con ello no se considera suficientemente la semántica de las acciones en el proceso de la formación de sistemas del sentido. Esto significa (desde la perspectiva de la teoría de las operaciones) que para realizar una acción debe existir anteriormente una situación de decisión, lo cual impliça la presencia de una diferencia simétrica con dos posibilidades decidibles. Esto resulta válido mutatis mutandis también para el supuesto de que una acción (desde la perspectiva de la teoría de las distinciones) se desarrolle por medio de procesos sociales de atri-

${ }^{40}$ Luhmann, 1990, p. 73.

11 "Ias acciones se constituyen por medio de los procesos de adjudicación. Se generan sólo debido al hecho de que las selecciones se adjudican a sistemas, independientemente de las razones de los contextos y de la ayuda de cuáles semánticas ('intención', 'motivo', 'interés'). En la formación de concepto aquí seleccionada, es de importancia el hecho de que las selecciones puedan ser referidas [...] a sistemas, no a sus entornos, y que, sobre esta base sean determinados destinatarios para mayor comunicación y puntos de conexión para más acción [....]". (Luhmann, 1984, p. 228). 
bución, dado que la atribución de cualquier tipo presupone que se pueda preguntar acerca de la "responsabilidad" del actor (cuando se pregunta), lo que, por su parte, implica la atribución de la capacidad de decisión y, con ello, la imputación de la posibilidad de distinción en el sentido de una diferencia simétrica -independientemente de la circunstancia de si el actor actúa realmente o no, de si es capaz de distinción o no.

20. Los seis niveles de la operación/observación significan que se puedè observar el "comportamiento", la "actuación", "acciones", "observaciones", "observaciones de observaciones" (reflexión) y "observaciones de observaciones de observaciones" (autorreflexión). El hecho de que aquí el concepto de la observación juegue un papel tan central descansa en que las acciones son ciertamente observables, pero que, por otro lado, las observaciones no sean observables por medio de las acciones. La semántica de las acciones no permite una operación de este tipo.

Esto es seguramente una convención semántica, la cual se podría fijar también de otra manera. Aquí resulta de importancia el hecho de que existan operaciones que no son capaces de observación. Y esta circunstancia es, por su parte, observable por medio de la utilización semántica de la acción, lo cual, naturalmente, sigue siendo un constructo de observación del observador. Anotamos de manera adicional que las operaciones comportamiento, actuación y acción son ciertamente observables, pero no son capaces de observación ellas mismas.

Por consiguiente, sólo las operaciones que operan en el nivel de una observación de la observación son reflexivas, ya que una observación puede observar tanto a una acción como también a otra observación. Una acción como suceso sólo puede hacer conexión con la acción siguiente. ${ }^{12}$ Una acción representa, por lo tanto, a una operación, la cual tiene lugar cuando tiene lugar y no es capaz de observar por sí misma. Las formas de ACCION, tales como el comportamiento, la actuación o las acciones (así como generalmente las operaciones del referir o designar de una distinción) representan las operaciones, las cuales en la forma de sucesos tienen solamente un valor de

${ }^{12}$ Sea realzado expresamente que esto es posible sólo con la ayuda de una estructura, o sea, solamente en el marco de una expectacion. 
conexión. Este valor de conexión no lo portan "en sî", sino sólo a través de una forma de estructura en el sentido de una determinada expectación o de un determinado estilo de expectación. No obstante, para poder conectar, una ACCION semejante debe poder ser observada, lo cual — visto desde la perspectiva de la teoría de la sociedadpuede tener lugar sólo a través de la COMUNICACión.

21. Dentro del marco de un concepto de observación de este tipo debe diferenciarse minuciosamente entre la semántica de la ciencia y de la cotidianidad.

Con lo cual, la semántica de la ciencia representa también, con referencia al sistema ciencia, un fenómeno de la cotidianidad. Precisamente porque la acción analítica dentro del contexto científico determina su cotidianidad, esta operación colorea la acción científica. Ahora bien, opinar que una acción analítica es mejor que una económica o una religiosa, sería falso. No es mejor, sino diferente. Ningún sistema del sentido se puede observar de la misma manera en que el sistema del sentido ciencia es capaz de observar y describir. En este sentido, la acción analítica (y la posición) sobrecarga a cualquier sistema del senti- do (también el propio) con mayor complejidad de la que el sistema correspondiente es capaz de observar en sí mismo y de procesar.

Dentro de una semántica cotidiana, las acciones y observaciones tienen lugar en forma sencilla: se efectúa esto y se observa aquello. Sólo dentro del marco de una semántica de la ciencia se puede, sobre la base de un comportamiento analítico pero "sencillo", observar analíticamente a las acciones u observaciones. Ahora bien, las observaciones de esta naturaleza que proceden analíticamente, representan formas del comportamiento científico, las cuales son posibles solamente frente al trasfondo de una operación irreflexiva, la cual determina tanto el comportamiento científico como el no-científico. Con otras palabras, también el comportamiento reflexivo del científico puede tener lugar, por lo pronto, solamente en la forma de una operación "sencilla". Por ello comprendemos como concepto de operación el aspecto dinámico del entrelazamiento de las distinciones. Esto implica que los "momentos" de las distinciones que se entrelazan deben ser comprendidos como "elementos temporalizados" y que conforman aquello que se llama un sistema autorreferencial. Dependiendo de la constelación de entrelazamiento pueden 
resultar sistemas del sentido y niveles de sistemas del sentido, mediante los encuentros doblemente contingentes. Por lo tanto, no hay ninguna diferencia entre el comportamiento científico y el cotidiano en el nivel basal: ambos presuponen un trasfondo común, mismo que se puede denominar como el mundo vivencial. Esto significa que la distinción entre una observación económica, política o religiosa por un lado, y una observación analítico-científica por el otro, solamente se puede realizar en el contexto de una observación de operaciones específicas, pero que la base operativa de todas las modalidades de observación es la misma para todos los sistemas. Aun más, realmente no hay modalidades de observación privilegiadas, ${ }^{43}$ puesto que cualquier observación puede explorar una unidad de diferencia solamente frente al trasfondo de una diferenciación que permanece constantemente latente. Esta por su parte puede ser observada, sin embargo, solamente con la ayuda de otra observación, para la cual vale lo mismo... etcétera.

22. Los sistemas, por lo menos los sistemas autorreferencialmente cerrados, siempre son sistemas observadores, lo que significa que siempre operan sobre la base de un entrelazamiento de la diferencia y la diferenciación capaz de la observación: distinguen sobre la base de una distinción. Dicho más exactamente, el sistema es la operación dinámica de las respectivas distinciones. Operación es la expresión para la componente temporal como intervalo del tiempo, misma que aparece en el dinámico juego combinatorio de las distinciones "diferencia" y "diferenciación" (los cuales producen las estructuras). La operación es, por asi decirlo, el movimiento que se genera debido al hecho de que se encuentran por lo menos dos distinciones de manera de conexión y con ello se entrelazan. La forma de seis niveles de las modalidades de observación se genera debido a la circunstancia de que el sistema, como sistema de observación, maneja a la observación de manera respectivamente selectivo-abstractiva, con lo cual se trata de diferentes modalidades de selección, mismas que producen una forma semejante de seis niveles. De ello resulta, como ya lo hemos visto, el comportamiento de observación fáctico, posible, alternativo, observativo, reflexivo y autorreflexivo. Esto significa que el mundo no es ni fáctico, ni posible, ni alternativo, ni observa-

${ }^{13}$ Véase acerca de ello el estudio de Richard Rorty, 1984, p. 185. 
tivo, ni reflexivo ni autorreflexivo. Son solamente los sistemas observadores los que eligen entre si y para sí a semejantes mundos específicos "ontológicos", los que "dañan" al mundo de manera selectiva y con ello constituyen diferentes dimensiones ontológicas del mundo jindependientemente del tipo de reflexión funcional!

\section{OBSERVACIÓN Y OPERACIÓN, UTTLIZACIÓN Y REALIZACION}

23. Hemos definido el concepto de la observación como el manejo de una diferencia frente al trasfondo de una diferenciación con la consecuencia de la generación de información. Esta definición altamente abstracta debe posibilitamos, en un nivel de la teoría de la sociedad, el observar a tales fenómenos como la "percepción", "imaginación", "sentimiento" o "descripción" como tipos de COMUNICACIÓN particulares, los cuales procesan solamente bajo la batuta de una determinada producción autopoiética. Ahora bien, ¿qué es una producción autopoiética? ¿En qué se distinguen la observación y la producción autopoiéticas? Queremos acercarnos a la contestación de esta pregunta por medio del concepto de la operación. ${ }^{44}$ En todo caso, una cosa parece ser clara: las observaciones reproducen determinadas operaciones. Se puede decir también, en forma general, que cualquier observación representa una operación, pero no que cada operación representa a una observación.

Semejante implicación es posible debido al hecho de que definimos

- el concepto de la observación hacia el nivel del concepto del sentido. Ciertamente se podria colocar más abajo y se podría partir entonces, con Ranulph Glanville, de la capacidad de auto-observación de los objetos en general. ${ }^{45}$ Aquí no tomamos este camino porque no deseamos hacer biología ofísica, sino sociología. (Sin embargo, se puede abordar la formación de acontecimientos biológicos o fisicos desde la perspectiva de observación de una sociología orientada hacia la teoría de los sistemas, pero también esta posibilidad la dejamos desaprovechada aquî).

44 En este contexto citamos nuevamente a la TsS: aquí llegamos "[...] a uno de los más dificiles problemas de la discusión sobre la autopoiesis: la relación de operación y observación autopoiéticas". (Luhmann, 1987j, p. 317 ).

is Glanville, 1988. 
Se hace más comprensible la circunstancia de que cualquier observación incluye a una operación cuando se muestra la siguiente distinción: una observación puede ser realizada, pero también utilizada. De esta manera puedo bacer la observación de que "el día es largo". Para este fin, debo utilizar la observación que presupone a las distinciones día/noche y largo/corto, en la forma entrelazada. Naturalmente puedo observar a esta observación a su vez (o sea, hacerla), lo cual nuevamente presupone una observación observante de esta observación, etc. Expresado negativamente: sin la utilización de cualquier observación no se puede bacer ninguna observación.

24. Con la distinción de la observación y la operación aterrizamos, por lo tanto, en la distinción de utilización y realización de una observación y podemos determinar ahora más detalladamente la circunstancia. Para poder realizar una observación, ésta debe ser utilizada y esto significa que su utilización es la condición previa de su realización. De esta manera, la realización de la observación teórica del sistema implica una observación que "introduce forzosamente" el universo total al diferenciamiento sistema/entorno, o sea, la utilización de la distinción espacial adentro/afuera. Su "punto ciego" sería su forma espacial. Esta circunstancia se puede formular aún más drásticamente diciendo: la exploración de un mundo visual presupone órganos para la vista, así como la de un mundo acústico presupone órganos para la audición, la de un mundo olfatorio presupone órganos para el olfato, etc. ${ }^{46}$ Ahora bien, una observación ciertamente puede observar a otras observaciones y operaciones, pero no a la propia utilización momentánea de sí misma. Esto lo pueden observar solamente otras observaciones, o ella misma, pero en un momento posterior. Con ello está dicho que cualquier utilización de la observación es incapaz de observar a su propia utilización durante su realización de la observación. Con razón la TsS formula: “la operación

${ }^{46}$ De acuerdo con Herbert W. Franke, el ojo es el "canal de percepcion" dominante en el hombre. Con referencia a los cuatro sentidos de la percepción, Franke ha establecido los siguientes valores en bits por segundo: ojo $=10^{7}$, oreja $=1.5 \times 10^{6}$, tacto $=5 \times 10^{5}$, olfato $=30$ y gusto $=12$. (Franke, 1975 , p. 34). 
es [...] referencia sin objeto". ${ }^{47}$. Por lo tanto, a la constitución del sentido dinámico de la observación pertenece la siguiente tétrada compuesta de dos distinciones: de una diferencia simétrica de la observación y operación y de una diferenciación asimétrica de utilización y realización (figura 93).

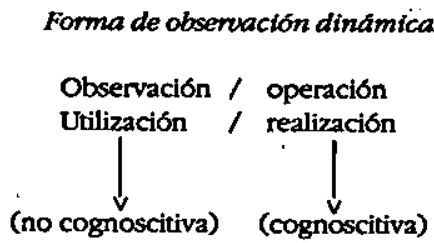

25. Ahora bien, si la forma dinámica de la observación es observada, como un entrelazamiento tetrádico de distinciones, entonces el lado de utilización de la diferenciación implica carencia de cognición, mientras que su lado de realización siempre estará ligado a un logro cognoscitivo. Así, se puede deducir que cualquier utilizactón de una operación de observación implica la ausencia de cognición y, con ello, la ceguera de ella misma. No obstante, su realizactón significa la constitución de la cognición. Por lo tanto, cualquier operación de observación implica la ceguera cognoscitiva y el logro cognoscitivo en una: puede observar solamente sobre la base de la ausencia de auto-observación, o incluso que su capacidad de auto-observación y observación ajena queda implicada en su carencia de auto-observación. Ahora podemos formular que cualquier observación representa una operación, pero que existe una forma de utilización y una de realización de ella misma, las cuales se encuentran en una relación complementaria entre sí: ${ }^{8}$ uno de los lados puede hacerse efectivo únicamente cuando el otro lado permanece escondido. Si la observación es observada como una operación utilizada, entonces se trata de una operación de observación sin objeto; sin embargo, si es observada como una operación que se efectúa, entonces se trata de una operación preñada de objeto.

17 Luhmann, 1990, p. 707.

${ }^{48}$ Acerca de la complementariedad y distinción, véase capítulo I. 
26. La TsS define el concepto de la observación en el nivel de abstracción del concepto de la autopoiesis: "Denomina la unidad de una operación que utiliza a una diferenciación para designar a uno u otro lado de esta diferenciación. ${ }^{n 49}$ Y el problema general que debe resolver un sistema autopoiético de este tipo, para garantizar su autopoiesis, consiste en posibilitar el comportamiento de conexión de sus elementos, de los cuales está compuesto: el sistema debe estar seguro de que uno de sus elementos hace conexión con otro y éste con el siguiente... etc. En caso contrario, no se puede formar el carrusel autopoiético y tampoco el cierre sistémico, mismo que constituye al sistema como tal..$^{\text {so }}$ Con los sistemas de sentido autorreproductivos $y$, con ello, en el nivel de abstracción de la teoria de la sociedad, se trata de elementos que desaparecen en el momento de su surgimiento y, por lo tanto, de elementos fuertemente temporalizados, o sea, de acontecimientos: se trata de COMUNICACIONES, las cuales pueden ser reducidas a ACCIONES, con lo cual el aspecto de ACCIÓN de una COMUNICACIÓN de este tipo puede ser sólo de corta duración.

Nosotros (TgS) distinguimos entre coMUNCACIÓN y comunicación por un lado, y entre ACCION y acción por el otro. La característica de las COMUNICACIONES consiste en que tienen carácter simétrico y se encuentran compuestas por diferencias por esta razón. Las Acciones, por su parte, poseen una forma asimétrica y consisten en diferenciaciones. Esta formación de conceptos se ha convertido en una necesidad debido al hecho de que se trata aqui de -contrariamente a la TsS-cuatro estilos de COMUNICACION, o sea, de socialidad, personalidad, afectividad y corporalidad. La TsS comprende más estrechamente al concepto de la comunicación y lo refiere exclusivamente a los sistemas sociales o a la socialidad en el sentido aquí definido. El mismo problema resulta cuando hablamos de las ACCIONES: distinguimos por lo menos cuatro distintos estilos de ACCIÓN, mismos que correlacionamos con los cua-

49 Luhmann, 1986a, p. 266.

so Recordamos que sin una pendiente de complejidad entre sistema y entomo no surge ninguna constitución de sistema, con lo cual el sistema resulta siempre típicamente más pobre, en cuanto a la complejidad, que el entomo correspondiente. Por lo tanto, con cualquier formación de sistema, es siempre indispensable un cierre del nivel en el cual se constituye el sistema. De esta manera, el sistema del amor se encuentra naturalmente cerrado al nivel afectivo de los sentimientos, sin embargo, está abierto en el nivel social, mental, corporal, orgánico o aun en el químico-físico. 
tro diferentes estilos de COMUNCACION, mientras que la TsS solamente habla de acciones en el contexto de los sistemas sociales.

Ahora bien, si un sistema comunicativo del sentido desea conservarse, entonces solamente lo podrá lograr ocupándose del correspondiente comportamiento de conexión con referencia a aquellos acontecimientos de acción que lo constituyen a él mismo. Precisamente es este proceso de la reproducción de los elementos con carácter de acontecimiento el designado por la TsS es la operación. "Por lo tanto, reproducción no significa simplemente repetición de la producción de lo mismo, sino producción reflexiva, producción a partir de productos. Para acentuar con mayor claridad que no se habla del mantenimiento del sistema, sino de un proceso en el nivel de los elementos, el cual es indispensable para cualquier conservación y modificación del sistema, deseamos designar a la reproducción de los elementos que poseen el carácter de acontecimiento como la operación. ${ }^{\text {"5I }}$ Ahora bien, ¿cuál es la forma de los elementos con carácter de acontecimiento que se reproducen dentro de un sistema del sentido autorreferencial-autopoiético - a través del comportamiento de conexión-y solamente con ello constituyen al sistema?

Se trata aquí de los sistemas del sentido y no de sistemas orgánicos, físico-químicos o mecánicos. Además partimos del hecho de que solamente los sistemas del sentido desarrollan la capacidad de la autoobservación. De esta manera, los sistemas orgánicos son ciertamente capaces de discriminar, pero no son capaces de observarse a si mismos. La TsS argumenta de manera similar. ${ }^{22}$ De otra manera, Ranulph Glanville desea aplicar la operación de la auto-observación a los objetos en general. ${ }^{53}$

Son las observaciones en la forma de auto-observactones las que se encargan del proceso reproductivo de un sistema semejante. Es precisamente este proceso en su forma autorreproductivo-dinámica el que es designado por la TsS como operación. Consideramos a una definición de la operación de esta naturaleza como imprecisa, ${ }^{34}$ aun-

st Luhmann, 1984, p. 79.

${ }^{32}$ Ibid., pp. 63-64.

${ }^{53}$ Glanville, 1988 , pp. 61 y ss.

44 Imprecisa por el hecho de que los problemas semánticos relacionados con ello no son suficientemente reflexionados. Esto lo trataremos luego más detalladamente. 
que debemos admitir que en este contexto de la semántica se trata de circunstancias fuertemente abstractas, mismas que, visto informativamente, no ofrecen mucho. Hemos definido a la observación como el entrelazamiento de dos distinciones diferentes con carácter de acontecimiento, $y$, en este sentido, resulta fácilmente comprensible el designar a la dinámica de un entrelazamiento de distinciones de este tipo como operación. Por lo tanto, queremos definir a la operación, con la integración del concepto de operación de la TsS, como transformación dinámica de distinciones con carácter de suceso. Aquí queda implicado, primero, que las operaciones siempre se encuentran compuestas por los entrelazamientos de distinciones. Ahora bien, ya que cualquier observación está compuesta de un entralazamiento operativo de las distinciones, es observable, en segundo lugar, la observación como operación. Tercero, finalmente se debe decir que ningún sistema tiene la posibilidad de observar a la propia utilizactón de la observación como realización de la observación. La utilización de cualquier observación está dada para el sistema siempre antes que su realización, lo cual conduce a una ceguera inherente hacia un "punto ciego" de cualquier observación frente a sí misma. Por lo tanto, se deduce que una observación siempre sabe qué es aquello que observa, pero no sabe cómo. Este "cómo" puede ser observado solamente por medio de otra observación o por medio de ella misma, aunque en un momento más tardio.

27. La circunstancia de que hayamos definido a la operación como la transformación dinámica de distinciones con carácter de evento parece torpedear, por el momento, al concepto de la operación en el aspecto de que esto puede conducir fácilmente al hecho de entender a la operación como una "característica" de las circunstancias o aun de las cosas.

Sea llamada la atención sobre el hecho de que comprendemos a las distinciones como sucesos y, por lo tanto, como elementos distintos, temporalizados, de un sistema del sentido.

No obstante, no podría existir nada más equivocado que un supuesto de este tipo. Anatol Rapaport, refiriéndose a una forma operacional de la filosofia, menciona como ejemplo de una definición operacional a la definición del peso: "La definición operacional del peso 
implica [...] que el concepto 'peso' no se deja separar de las operaciones por medio de las cuales es medido." ${ }^{n 5}$ Por lo tanto, no se trata del hecho de que los cuerpos tengan la "característica" peso sino de cómo se genera o es posible aquello que llamamos "peso". En todo caso, la afirmación de la TsS de que una operación consiste en la transformación de los elementos en elementos, de acontecimientos en acontecimientos, ${ }^{56}$ no permite reconocer claramente qué es lo que se puede comprender generalmente como operación. Sobre todo: ¿con la operación de la operación se trata de un continuo o de una forma discreta? Esta pregunta es tan decisiva debido a que por medio de una forma continua se perdería lo "operativo" de la operación. En un caso así ya no sería posible proceder operativamente. Apenas una forma discreta lo permitiría. Dentro de la psicología experimentalcognoscitiva se demuestra cómo es posible leer -como una forma de la observación operativa-, por un lado, se fijan determinadas palabras y letras y, por el otro se efectúan los así llamados brincos de la vista o "escaleras de lectura". Por lo tanto, la lectura tiene lugar sobre la base de las fijactones y brincos de mirada, del detenimiento y movimiento, de la observación fija y operación visual a brincos. Cada salto de la mirada registra una parte de la fijación anterior, y con ello crea una conexión con la siguiente fijación. Se puede generalizar esta observación de la lectura y decir que la lectura se genera a través de la observación (fijación) y operación (salto de la mirada). Con ello, el brinco de la mirada (=operación) es la fijación aún no realizada, y la fijación (=observación) es el salto de la vista ya realizado. No obstante, la experiencia fenomenológica de la lectura resulta "[...] como si nuestra mirada se deslizara homogéneamente sobre lo escrito [...]".57 Sobre la experiencia fenomenológica de la lectura y del tiempo, Ernst Pöppel expresa el hecho de un "movimiento deslizante": "El hecho de que el tiempo subjetivo corra continuamente, aunque no siempre en forma homogénea, corresponde a nuestra experiencia inmediata, así como corresponde a nuestra experiencia no crítica el que con la lectura la mirada se deslice homogéneamente sobre los renglones leídos. Sin embargo, la experiencia efectuada por medio de la lectura de que un proceso se desarrolla continuamente, siendo que tiene lugar de hecho en pasos temporales cortados,

35 Rapaport, 1953, P. 39.

${ }^{56}$ Luhmann, $1985 f$, p. 406.

5 PÖppel, 1985, p. 9. 
debería provocar desconfianza. ${ }^{358}$ Por lo tanto, en el concepto de la operación no queda implicada ninguna forma continua, sino una discreta, "aislada", "a saltos", "cuanteada". Por ello podemos formular: la SOCIEDAD consiste en brincos de ACCTONES determinados COMUNICATTVAMENTE, los cuales, sin embargo, son reducidos a continuidades con la finalidad de una comunicación "fluida".

28. Entonces, si hablamos de las operaciones, se quiere decir que aquello que tiene lugar como operación sucede paso a paso. El carácter ilusorio de una lectura deslizante o de un tiempo deslizante (o de un programa de procesamiento de texto) representa una considerable reducción de la complejidad de estos fenómenos, sin la cual no podemos disponer sobre la lectura o el tiempo, tal como de hecho lo estamos realizando. Ciertamente, si las operaciones se definen como la transformación de distinciones con carácter de suceso en distinciones, entonces tenemos frente a los ojos el aspecto general de la semántica de la "operación". Pero el aspecto interesante de una posición operativa frente al mundo consiste en averiguar cómo algo es lo que es y no que algo es lo que es. La pregunta sobre el "cómo" dirige la mirada hacia el mecanismo que produce algo como "algo", mientras que la pregunta acerca del "qué" presupone como naturalmente dado aquello que se define como "algo". Ahora bien, realcemos aquí el hecho de que no se trata de la exclusividad del cómo o del qué, ya que la respuesta al "cómo" siempre implica el "qué". Si deseo, por ejemplo, saber quées la identidad, entonces puedo proceder operacionalmente y efectuar la pregunta acerca del cómo de su surgimiento. Con ello, la pregunta ¿cómo? reconstruye operacionalmente aquello que se encuentra incluido en la pregunta ¿qué? Por esta razón, la pregunta ¿qué? conforma el marco dentro del cual es posible responder a las preguntas ¿cómo? de manera razonable.

Ahora resumimos lo dicho hasta aquí en referencia con la operación: puesto que la semántica de la "operación" implica: $a$ ) la semántica del "acontecimiento" ("salto de la mirada"), b) la interacción del "suceso" y de la "estructura" ("salto de la mirada" y "fijación") y c) una "identidad" procesal ("la lectura") es comprensible el porqué una semántica (de la operación) de esta naturaleza resulta tan ambigua y difícil de comprender. Generalmente, queremos designar como ope-

S8 Ibid., p. 16. 
ración el lado de utilizactón de una distinción, sin tomar en consideración el hecho de si se trata de sucesos, procesos, estructuras, identidades, límites; etc. Recordemos: el lado de utilización de una distinción tiene lugar cuando ella tiene lugar y se desarrolla en una forma libre de cognición. Únicamente su realización constituye la cognición. Ya en el capítulo sobre la operación y la forma hemos demostrado que en este nivel operativo "carente de cognición" puede generarse, sin embargo, la constitución de algo como "algo" $y$, por lo tanto, también de la sOcIEDAD.

\section{LA AUTOO-OBSERVACIÓN COMO DIFERENCIACIÓN ASIMETRICA}

29. Debe suponerse que el concepto de la operación junto con el concepto de la observación contribuye a una dinamización del teorema de la autorreferencia. Pero la finalidad verdadera de la introducción de una distinción semejante de la operación y la observación tiene su razón en el hecho de que únicamente por este medio es posible hablar razonablemente de una autorreproductividad de los sistemas autorreferenciales. Con ello se trata, expresado con mayor exactitud, de operaciones de auto-observación que pueden ser concretizadas en diferentes formas y asegurar así la autorreproducción del sistema correspondiente. Aquí se trata de la equivalencia de la auto-observación y la autorreproducción, misma que representa la posibilidad de la autopoiesis. En referencia con la forma de observación "descripción", Günther Teubner se expresa en este contexto de la siguiente manera: "La autopoiesis puede surgir únicamente a partir de la conyuntura [R]] de la autodescripción y de la autorreproducción. "59 Consideramos (junto con Teubner) ${ }^{60}$ a la distinción propuesta por la TsS de la auto-observación y la operación como muy productiva y creemos que esto representa, por el momento, el único concepto serio que puede explicar, con algo de plausibilidad, el teorema de la autorreproducción de sistemas autopoiéticos del sentido. Sin embargo, irrita el hecho de que el concepto de la auto-observación dentro del marco de la TsS resulte equivalente al concepto de la acción, con

59 Teubner, 1987b, p. 100.

60 "Considero a esta síntesis [Luhmaniana, R] de la autopoiesis (Maturana) y la Second Onder Cybernetics (Von Foerster), como extraordinariamente fructífera [....]." (Teubner, 1987b, p. 100). 
lo cual la TsS no le hace justicia a la distinción semántica de la acción y la auto-observación. Ya hemos criticado esto y hecho la propuesta de interpretar al concepto de la auto-observación como reflexión, e interpretar a la acción como una forma de la observación de acción, con lo cual existirian tres posibilidades de ello: la observación de la acción fáctica, posible y alternativa. ${ }^{61}$ Ahora nos preguntamos: ¿cómo llega el uno mismo a constiturirse a sí mismo como un uno mismo?

30. Observemos más detalladamente cómo es utilizada, por parte de la TsS, la distinción de auto-observación y auto-operación con referencia a los sistemas sociales en el sentido de la TsS. Para este fin queremos citar un lugar característico del fundamento teórico de los "sistemas sociales": ${ }^{62}$ "Por lo tanto, un sistema social se constituye como un sistema de la acción sobre la base del acontecimiento fundamental de la comunicación y con sus medios operativos. Elabora dentro de sí una descripción de sí mismo, para dirigir [RJ] el futuro desarrollo de los procesos o de la reproducción. Para los fines de la auto-observación y la autodescripción, la simetría [RJ] de la comunicación es asimetrizada [R]], su abierta excitabilidad es reducida a través de la responsabilidad respecto a las consecuencias. Y en esta autodescripción abreviada, simplificada, y por ello, más fácilmente comprensible, la acción [RJ] sirve como último elemento y no así la comunicación. ${ }^{663}$ Podemos decir, generalizando, que un sistema del sentido se genera debido al hecho de que elabora, dentro de sí.. mismo, una descripción de sí mismo, para poder dirigirse reproductivamente. Para esto resulta indispensable que el sistema sea capaz,

${ }^{61}$ Véase este capítulo en lo que se refiere a la observación de la acción y la observación de la observación.

${ }^{62} \mathrm{La}$ TsS formula: eexisten tipos de sistema autopoiéticos cuya autopoiesis dependa del hecho de que, dentro del mismo sistema, estén siendo observadas las operaciones que la realizan? Es decir, ¿existe la auto-observación como la condición de la autopoiesis? (RJ). [...]. "Esto lo he afirmado para los sistemas que operan razonablemente, o sea, para los sistemas sociales y para los sistemas psíquicos, y de esta decisión de la teoría dependen muchas cosas." (Luhmann, 1987j, p. 317). En este sentido, la TsS remite a la cita representada por nosotros en el texto, para aclarar la relación de auto-observación y operación, con relación a los sistemas sociales.

${ }^{63}$ Luhmann, 1984, pp. 227-228. 
por el momento, de observarse a sí mismo, ya que solamente sobre la base de una auto-observación puede tener lugar una autodescripción. Además, se afirma que para los fines de la auto-observación (y la autodescripción) se deba asimetrizar ${ }^{64}$ a la simetria de la comunicación en dirección hacia la acción, ya que solamente en el plano de una unilateralidad comunicativa de este tipo es posible producir la "responsabilidad" y, con ello, la capacidad de conexión dentro de un acontecimiento comunicativo por lo demás equivalente, lo cual significa simétrico. ${ }^{65}$ En última instancia, estas afirmaciones significan que la auto-observación es procesada como acción, lo cual es un supuesto problemático debido a que el concepto de la auto-observación expresa una semántica completamente distinta al concepto de la acción. Por lo tanto, proponemos el hablar de una autoindicación en lugar de una auto-observación, por medio de lo cual señalamos la función que debe cumplir la auto-observación en la dicción de la TsS, sin tener que usarla para este fin en calidad de concepto.

31. Una observación es generada, de acuerdo con la teoría de las distinciones representada por nosotros, mediante una transformación de una diferencia simétrica, én forma de suceso, hacia una diferenciación asimétrica; con lo cual pueden resultar, a partir de un relacionamiento tetrádico de acontecimientos, las más diversas modalidades de aćción y observación. En el caso de que una constelación semejante de sucesos sea repetida -aquí el proceso del mundo vivencial de la "costumbre" juega un papel decisivo-, entonces podría conducir a la formación de la estructura. Expresado al nivel de la teoría de la sociedad esto significa que: una unidad social de su-

${ }^{64}$ Llamamos la atención sobre el hecho de que la TsS procede, en el nivel de abstracción de la teoría social, tal y como lo proponemos a nivel de la teoría general: debe tener lugar una interacción de simetría y asimetria, para referir tanto la operación de la comunicación como también la acción, de tal manera que ambas operaciones resulten comprensibles cognoscitivamente. Sobre todo se debe observar la unidad de su distinción, esto es algo quie la TsS logra en el nivel de la teoría social.

${ }^{65} \mathrm{La}$ TsS destaca, en el mismo contexto, el hecho de que una operación semejante conlleve una fuerte autosimplificación del sistema: "Por ello, no es falso nunca, sin embargo si es unilateral el caso de que un sistema de comunicación [RJ] se comprenda a sí mismo como sistema de acción [RJ]. Sólo por medio de la acción es fijada la comunicación como suceso simple en un momento temporal." (Luhmann, 1984, p. 227). 
cesos es generada debido a la transformación de la cOMUNICACIÓN en ACCión. Esto es una constelación de acontecimientos que puede desembocar en expectativas y experiencias, si es que la constelación de acontecimientos se repite, para lo cual se requiere del tiempo. Entonces se forma la estructura como la historia de la condensación y el condicionamiento de una COMUNICACIÓN específica, por medio del mecanismo de la aceptación o el rechazo comunicativos; ésta puede ser registrada entonces como una "experiencia". Ahora bien, un sistema del sentido se puede generar solamente si es capaz de manejar el uno mismo de tal manera que sea capaz de distinguir entre sí mismo y otras cosas, entre aquello que es "sistema" para él y aquello que es "entorno" para él. Esto significa que el sistema en cuestión debe indicar con cada COMUNICACION una distinción entre "sí mismo y otras cosas", ya que solamente de esta manera es posible garantizar su capacidad de conexión, de la cual depende ciertamente en gran medida su futura existencia. Aun más, un sistema del sentido puede existir solamente mientras permanece capaz de conexión. Si pierde su capacidad de conexión, por la razón que fuere, entonces simple y sencillamente deja de existir. A través de diferentes formas de la autoindicación (- auto-observación en la formulación de la TsS) se cumple con esta condición de la indicación de la pertenencia, dependiendo del tipo de sistema del sentido y de la peculiaridad del sistema del sentido. Ahora bien, ¿cómo surge la génesis de una autoindicación semejante?

32. En el nivel general de una "lógica de las distinciones", la génesis de la autoindicación presupone dos diferencias simétricas, mismas que se transforman o se reducen con los encuentros exitosos y mediante la diferencia doblemente contingente, en diferenciaciones asimétricas. Hemos tratado exhaustivamente este procesamiento de dos diferencias en el capítulo III acerca de la autorreferencia. Una transformación y autorreducción semejante implica siempre, dentro del contexto de la SOCIEDAD, tiempo: solamente dentro de una secuencia temporal puede tener lugar la transformación de diferencia hacia la diferenciación. Con ello, es producida simultáneamente la historia de la distinción, aunque sea historia solamente en el sentido de una única secuencia operativa de una diferencia determinada hacia una diferenciación determinada. Sobre la base de la diferencia doblemente contingente, cualquier distinción simétrica puede 
- con la integración del tiempo- alcanzar la formación de la diferenciación asimétrica. Hemos definido a la observación como el manejo de una diferencia frente al trasfondo de una diferenciación con el fin de generar información. Por esta razón, un sistema del sentido no es otra cosa que el condicionamiento y la condensación de una observación específica. La autoindicación no es otra cosa que la autorreducción del sistema de una diferencia simétrica hacia una diferenciación asimétrica, una reducción que será generada obligadamente por medio de una situación de diferencia doblemente contingente. Con otras palabras, en el nivel de una lógica de las distinciones, la autotndicación no es otra cosa que una diferenciación asimétrica o una diferencia simétrica que se encuentra asimetrizada, es decir, una diferencia unilateralizada. Una precisión del concepto de la auto-observación de la TsS de este tipo, como diferencia transformada (= diferenciación), permite reconocer en cualquier distinción una posiblidad potencial de la formación de sistema, ya que las distinciones que se transforman en un sistema (de una diferencia simétrica en una diferenciación asimétrica) indican, por un lado, por medio del proceso de asimetrización, la pertenencia-al sistema o "responsabilidad". Por el otro lado, una transformación de este tipo representa una operación, misma que, precisamente debido a su "transformación operativa", origina la formación de sistema. En ese sentido, la operación autopoiética y la "autoindicación" se conjuntan en el sentido de una diferenciación asimétrica, aun cuando, semánticamente, significan diferentes cosas. Con ello interpretamos el concepto autopoiético de la consititución de la TsS desde la perspectiva teórica de la distinción como la coincidencia de las semánticas "operación" y "autoindicación" (= "auto-observación" según la TsS) en el concepto de la "diferenciación asimétrica", con lo cual queda contestada la pregunta referente a la génesis del uno mismo en el contexto de una teoría de las distinciones: como la coincidencia de la operación y la autoindicación con la integración del tiempo.

33. Si se transfiere el concepto antes explicado al nivel de la observación, entonces el concepto de la formación de sistemas significa, desde la perspectiva de la teoría de las distinciones: un oscilamiento y una condensación constituyente del tiempo constante entre los componentes de la observación "diferencia" y "diferenciamiento". En el nivel de la teoría de la sociedad, la formación de sistema signi- 
fica: el continuo oscilamiento relacionado con el tiempo y la sedimentación, en el mundo vivencial, de una determinada constelación de la COMUNICACIÓN simétrica y la ACCIÓN asimétrica, algo que es posible solamente en el marco de una situación doblemente contingente, misma que es constituida por medio de la distinción de la "diferencia". Si -dentro de una secuencia temporal- se llega a la repetictón ${ }^{66}$ de una observación especifica $y$, con ello, a la formación de la costumbre, entonces resulta la estructura como historia de la distinción, la cual se da a conocer como la codificación de una COMUNICACIÓN determinada. En este nivel de una esquematización binaria de la COMUNCACIÓN, los sistemas del sentido no representan otra cosa que códigos específicos y simétricos, los cuales se asimetrizan dentro de situaciones doblemente contingentes que indican la pertinencia al sistema, o sea que constituyen la auto-observación en el sentido de la TsS. Ahora podemos determinar más detalladamente la conexión entre autoindicación y operación, desde la perspectiva de la teoría de las distinciones. Un sistema puede ser comprendido como una determinada observación condicionada, misma que se constituye a lo largo del tiempo por medio del entrelazamiento de la diferencia simétrica y la diferenciación asimétrica. Con la condición previa de la diferencia doblemente contingente y la finalidad de la futura existencia del sistema, se alcanza la asimetrización de la diferencia hacia la diferenciación: la simetría de "odio y/o amor" se transforma en la diferenciación "no odio, sino amor" y conduce hacia el sistema afectivo "amor"; la simetría de "cierto y/o falso" se transforma en la diferenciación "no falso, sino cierto" y conduce hacia el sistema de la ciencia; la simetría de "justicia y/o injusticia" se reduce a la diferenciación "justicia, no injusticia" y constituye el sistema del derecho, etc. Así, las diferenciaciones asimétricas "no odio, sino amor", "no falso, sino cierto" $y$ "no injusticia, sino justicia" forman operaciones y, a la vez, indicaciones de la pertenencia, las cuales precisamente debido a su coincidencia como operación e indicación de la pertenencia (=auto-observación en la dicción de la TsS) posibilitan la formación de los sistemas del sentido que se-producen-así-mismos. Ya que una operación no es otra cosa que la utilización

${ }^{6}$ La operación de la repetición como confirmación (=estrechamiento de la identidad) o condensación (-ampliación de la identidad) se encarga de que, por medio de determinadas distinciones - no por medio de cualquiera-, surja la sedimentación de la estructura. 
de una distinción, la conexión entre la indicación de la pertenencia y la operación significa: por medio de la utilización operacional de una indicación de la pertenencia, en la forma de una diferenciación asimétrica, se constituye el sistema a si mismo a través de la repetición de esta operación. En las palabras de la Tss: la observación se utiliza a sí misma como observación reducida en el sentido de una auto-observación (- diferenciación asimétrica) y se constituye sólo a través de ello a sí misma como observación sistémica. Si esto sucede por lo menos una segunda vez con la misma observación ("segunda vez"), entonces se forma la estructura en la forma de una historia de la distinción de expectación y experiencia.

34. Si es transferido nuevamente el concepto de la diferenciación asimétrica ( $=$ indicación de la pertenencia) y la operación (en el sentido de una utilización de una indicación de la pertenencia de este tipo ${ }^{67}$ a la observación del mundo, entonces se podría formular: para que el mundo se pueda observar a sí mismo se debe dividir internamente en una mitad que "ve" y una mitad que es "vista". La diferencia simétrica de la observabilidad y de la no-observabilidad es reducida a la diferenciación "visibilidad, no ceguera". La autoindicación de mundo se puede fijar, por lo tanto, solamente en su lado visible, su "lado ciego" no solamente no es observable sino que también es condición para la constitución de su propia visibilidad, es la realización operativa sin observación de su lado de observación como forma de la autoindicación. Expresado en el discurso de Kant: la ceguera es la condición de la posibilidad de la visibilidad. En este contexto se puede mencionar también a Spencer Brown, quien formula: "[...] we cannot escape the fact that the world we know is constructed in order (and thus in such a way as to be able) to see itself [...] But in order to do so, evidently it must first cut itself up into at least one state which sees, and at least one other state which is seen. In this severed and mutilated condition, whatever it sees is only partially itself. We may take it that the world undoubtedly is itself [i. e. indistinct from itself], but, in any attempt to see itself as an objet, it must, equally undoubtedly, act so as to make itself distinct from, and therefore false to,

${ }^{67}$ Recordemos: la operación es una operación no-distinta (sic). 
itself. In this conition it will allways elude itself ${ }^{68}{ }^{68}$ Ningún observador y tampoco ningún superobservador ${ }^{69}$ es capaz de observar al mundo como "mundo completo", puesto que la observación es posible solamente en la forma de una distinción y, por lo tanto, siempre es necesaria una "primera" operación de la observación para observar en general. Querer presuponer al mundo como "mundo completo" con cualquier observación, significaria haber marcado la distinción de "mundo/no mundo" ya dentro del mundo, una operación interna del mundo, una operación dentro del mundo.

\section{LA FORMA DE LA SOCIOLOGIA}

35. Después de haber explicado el concepto de la observación en el marco de una teoría de la distinción y de haber discutido las previas condiciones generales de un concepto de este tipo, queremos referirlo ahora más directamente a la teoría de la sociedad.

En el nivel de abstracción de una "lógica de las distinciones" se trata de las distinciones "diferencia" " " diferenciación"; en el nivel de la teoría de la sociedad se trata de las distinciones "COMUNICACION" y "ACcrón". El presente trabajo se formula en el nivel de abstracción de una "logica de las distinciones", con algunos vuelos bajos sobre el nivel de la teoría de la sociedad. Un tercer nivel de abstracción que dejamos aquí prácticamente sin utilizar es el sistema del sentido de la SOcIEDAD (figura 94).

\section{Niveles de la abstracción de la teoria:}

Lógica de las distinciones: nivel de abstracción 3

Teoría de la sociedad: nivel de abstracción 2

Sistemas del sentido "concretos": nivel de abstracción 1

${ }^{68}$ Spencer Brown, 1969, p. 105, y también Luhmann, 1990b, p. 8, anotación 5.

${ }^{6}$ Acerca del concepto de un superobservador, véanse las explicaciones de Humberto R. Maturana, 1985, pp. 2264-2267. 
Actualmente -después de una cierta consolidación y también aceptación social de la grand theory sociológica a la que se dirigen trabajos como los de Jeffrey Alexander, Richard Munch, Jürgen Habermas y Niklas Luhmann- se puede formular con mayor confiabilidad y evidencia el planteamiento real del problema de la sociología, un planteamiento del problema acerca del cual se afirma que ha constituido a la sociología como disciplina científica: ¿cómo es posible el orden social? $?^{70} \mathrm{El}$ hecho de que en este contexto el pequeño trabajo de Georg Simmel "Excurso acerca del problema: ¿cómo es posible la sociedad?" del año 1908, sirva como modelo se entiende actualmente por sí mismo. ${ }^{71}$ Con ello la pregunta no es ¿qué es la sociedad?, sino ¿cómo es posible el orden social o la sociedad? Esta forma ¿COMO? del planteamiento de la pregunta tiene sus raíces en Immanuel Kant, quien en la forma de pregunta "¿cómo es posible algo?" ve el punto de partida de cualquier futura metafisica. ${ }^{72} \mathrm{La}$ forma ¿QUte? del cuestionar atestigua una observación fäctica aún no inmediatamente relacionada con el objeto, la cual nunca se presenta como tal: se describe aquello que es, o sea, uno procede de manera ontológica y no alcanza a ver la actividad de la observacion (hablando en el sentido de Kant: de la experiencia), puesto que se ha fundido en una unidad con las cosas, lo cual, en el verdadero sentido de la palabra, significa ontología, es decir la naturaleza del ser de lo lógico.

La mirada está enfocada sobre las cosas, sobre lo existente, no sobre la observabilidad (o experimentabilidad) de lo existente. Mientras que la tradición platónico-aristotélica comprende lo lógico tambiên como un óntico y piensa por ello, ontológicamente, Kant parte del su-

70 "En el centro del interés teórico de la siguiente disertación se encuentra un planteamiento del problema [" ¿cómo es posible el orden social?" R]] -un planteamiento del problema del cual se puede decir que constituye a la sociología como disciplina científica. El planteamiento del problema se ha desarrollado a sí mismo en un muy largo proceso de trabajo en las teorías y es, en este sentido, componente de las teorías, así como una comprensión adecuada de una teoría presupone el conocimiento del planteamiento del problema el cual la guia." (Luhmann, 1981h, pp. 195 y ss.).

"Simmel, 1983, p. 7.

72 Ver, el ensayo de Kant: "Prologomena zu einer jeden Künftigen Metaphysik die als Wissenschaft wird autreten können", sobre todo: "Allgemeine Frage. Wie ist Erkenntnis aus reiner Vernunft möglich?", en Kant, 1977, 5b, pp. 136 y ss. 
puesto de que lo óntico mismo siempre es también un lógico, un logico-óntico. Por lo tanto, la posición ontológica se refiere a la forma del ser de lo lógico, la posición trascendental se refiere a la logicidad del ser: la ontología está relacionada con el "carácter del ser de lo lógico", el trascendentalismo está relacionado con la "logicidad del ser".73

A través de la pregunta ¿COMO?, la cual apunta hacia las "condiciones de la posibilidad de algo", se hace posible la actividad y el hacer de una observación durante la "observación de algo". En la terminología especializada de la tradición filosófica este acceso se llama entonces teoria del conocimiento. ${ }^{74}$

36. La forma ¿COMO? del cuestionar implica una componente técnica del sentido, una componente de realizabilidad, la cual ocasiona una distancia entre el observador y lo observado. Por medio de la forma ¿Cómo? del preguntar, uno es exhortado a convertir en problemático lo obvio y evidente, anota Karin Knorr-Cetina. ${ }^{75}$ Con esta observación de la distinción de la forma de preguntar ¿QUÉ/COMO? nos encontramos en el área de influencia de la, en conexión a Heinz von Foerster, llamada second order cybernetics, ${ }^{76}$ una cibernética comprendida en el sentido de una red circular de las operaciones del conocimiento. Una cibernética del segundo grado de este tipo pone a distancia la observación fáctica observando por su lado a ésta por medio de una segunda observación y, con ello, poniendo en marcha una "observación de la observación". La distinción de las preguntas ¿QUE/COMO? apunta en última instancia, por su lado, hacia

73 Entonces V. v. Weiszäcker formula: "Ontología significa la naturaleza del ser de lo logico, trascendentalismo significa la logicidad del ser." En Kroner, 1961, p. 56.

${ }^{74} \mathrm{El}$ concepto de las cosas no se determina con base en el aspecto reconocido de las cosas, sino sobre la base de su experimentabilidad, misma que es precisamente "logica": "El reconocimiento del ser se reconoce, y este reconocimiento del reconocimiento del ser no es en sí ningún reconocimiento del ser, sino reconocimiento del conocimiento, teoría del conocimiento, crítica del conocimiento, logica del conocimiento." (Kroner, 1961, p. 57).

75 "Preguntar cómo requiere frecuentemente que adoptemos una posición radicalmente ingenua y que convirtamos lo obvio en problemático." (KnorrCetina, 1984, p. 49).

${ }^{76}$ Foerster, H. B., 1985. 
una distinción de dos niveles de observación: un nivel posible y uno fáctico. 7

37. Debe realzarse expresamente que con estos niveles de observación se trata de niveles de intención empírica, y que no se trata de jerarquías de niveles lógicas o lingüisticas en el sentido de una jerarquía de tipos de Russell. La noción realista que se transmite por este medio y que circula actualmente como "constructivismo radical"78 es: no existe la observación como observación pura, como observación en sí, sino solamente en la forma de una observación de una observación. Cualquier conocimiento es por ello dependiente del sistema o de la distinción, es observador del segundo orden, con lo cual se debe entender la dependencia del sistema del conocimiento como una operación real del observador y que, en este sentido, tiene la intención de ser una operación empírica. ${ }^{79} \mathrm{La}$ operación de una observación del primer grado y su dependencia de la operación de una observación del segundo grado se encuentra estrechamente relacionada: no existe ningún conocimiento de algo "en si", sino solamente un conocimiento en la forma de dos distinciones, o sea, de dos observaciones, mismas que están equipadas con dos lados correspon-

"Recordamos que realmente existen seis niveles de la observación: uno fáctico en el cual se hace efectivo solamente uno de los lados de la diferenciación asimétrica; uno posible, con el cual se hacen efectivos ambos lados de la diferenciación asimétrica; uno alternativo, con el cual es observada la distinción simétrica como diferencia; la observación, con la que se trata de la observación de una diferencia como unidad; uno reflexivo con el cual se trata de la observación de una observación y a la cual se podría designar como reflexión; y, finalmente, de una forma autorreflexiva, con la cual se trata de una reflexión del reflexionar.

${ }_{78} \mathrm{~V}$ Éase, especialmente en este contexto, "Das Erkenntnisprogramm des Konstruktivismus und die unbekannt bleibende Realität" de Niklas Luhmann, 1990a, 2, pp. 31-58. Además, "Der Diskurs der radikalen Konstruktivismus", de Siegfried J. Schmidt (ed.), 1987.

79 "La referencia (aquello que designa una observación) se debe distinguir ciertamente de la operación que refiere. Pero esta diferencia es meramente funcional y no se debe entender ontológicamente; no se refiere a mundos separados ónticamente (ser o pensar), sino que caracteriza solamente a la correspondiente operación de observación. Esta debe efectuarse siempre en el mundo y se expone, con ello, por su parte, a la observación. Esto significa también: siempre se trata de una operación condicionada empíricamente." (Luhmann, 1990, p. 70). 
dientes. Esto conduce entonces a la forma tetrádica, cuando algo es observado como "algo". Por ello, una observación siempre es una "observación de una observación" y siempre es una constelación tetrádica que consiste en dos distinciones: una diferencia y una diferenciación. La teoría tradicional del conocimiento procede aquí fundamentalmente de otra manera: la dependencia de una observación de un observador es para ella una medida para la subjetividad del conocimiento y por consiguiente, una medida para su no-objetivizabilidad. Para un constructivismo de cuño actual no existe ninguna inconmensurabilidad, ninguna irreconciabilidad, ninguna contradicción entre la dependencia de la observación de cualquier observación (en la manera de expresión de la filosofía de la consciencia: dependencia del sujeto del conocimiento) y el estatus real de una operación de esta naturaleza (por así decirlo su "objetividad").

38. Una disciplina como la sociología puede adoptar un carácter generalizante cuando se constituye por medio de un planteamiento de un problema. Mientras que su constitución sea definida a través de los objetos y los tipos de objetos (a través de la modalidad de observación "fáctica"), "está adheriđa" aún demasiado a la realidad, como para poder alejarse de ella en un plan autónomo. Sólo la mirada "libre" hacia un planteamiento de un problema conduce a su autonomización, puesto que así ya no tiene que identificarse con su área de objetos solamente, sino que - por medio de la distinción de conocimiento/objeto- pueden distinguirse los problemas de un conocimiento sociológico y los problemas de un área de objetos sociológica. Con su propio planteamiento del problema, el surgimiento de su unidad resulta ser una operación que solamente se tiene que agradecer a sí misma. ${ }^{\circ}$ Sin embargo, en la problematización del orden social mediante la pregunta "icómo es posible la sociedad?"81 ya se parte del hecho de que el problema del orden so-

- Naturalmente con una mirada lateral hacia otros planteamientos de problemas de otras disciplinas dentro del sistema de la ciencia. En este sentido, la autonomía de una disciplina científica solamente es posible sobre la base de una ciencia que ya se haya hecho autónoma. Acerca de ello véase también Luhman, $1981 \mathrm{~h}, 4$, pp. 196 y ss.

${ }^{81}$ Preferimos hablar de la posibilidad de la SOCIEDAD en vez de la posibilidad del orden social. Con ello se alude a la simultaneidad de, por lo menos, cuatro estilos de comunicación, los cuales comprendemos como estilos corporales, afectivos, personal/subjetivos y sociales. 
cial está resuelto, dado que la pregunta no es en absoluto: “¿es posible el orden social?", sino " ¿cómo es posible el orden social?" Esta forma del planteamiento del problema identifica al problema de la sociología como un problema autorreferencial y paradojico, puesto que el problema a resolver es un problema ya resuelto, en caso contrario no sería posible la pregunta ¿cómo es posible el orden social? Se construye ya sobre la solución del problema ${ }^{82}$ y lo puede tratar, precisamente debido a ello, como uno a resolver, lo cual presupone que ya está resuelto... etc. Por el otro lado, se hace posible a sí misma por medio de su propio problema, lo que significa que la sociología es sociología porque es sociología, porque... etc., lo que representa una operación tautológica.

39. Los nudos autorreferenciales son desagradables porque -intrincados en sí mismos- discurren infinitamente y no muestran ni principio ni fin. Una sociología que, guiada por su propio problema, se forma a sí misma, tendrá que vérselas con un nudo autorreferencial de esta naturaleza, volviéndose paradójica y tautológica. Con semejante forma tautológica y paradójica de la sociología, ésta, sin embargo, gira alrededor de sí misma. Aplicar la sociología a sí misma no parece tener mucho sentido, ya que por medio de ello no se obtiene mucha información, y como operación tautológica o paradoja, no genera realmente ninguna información. ${ }^{83}$ Por lo tanto, debemos en-

82 'La pregunta 'ccómo es posible el orden social?' es posible solamente cuando el orden social es posible: esto significa entre otras cosas que los planteamientos de problemas constituyentes siempre afectan a los problemas ya resueltos, en caso contrario no serían posibles ellos mismos, tampoco pueden, debido a su construcción autorreferencial, ser justificados realmente. Pero cualquier teoría contestataria debe pasar por el test adicional acerca de si es capaz de integrar también las condiciones de la posibilidad de su planteamiento del problema. El lugar de una justificación se encuentra, por así decirlo, ocupado por este test de autorreferencia." (Luhmann, 1981h, 4, p. 196). Aquí deseamos anotar que la TsS evita por principio abordar reflexivamente la pregunta acerca de la validez. Se puede decir también que aborda fácticamente la pregunta de la validez: el test de autorreferencia tiene lugar o no. En "Die Form der GESEuSCHAFT" (Jokisch, 1995) trataremos esto con mayor detalle.

${ }^{83}$ Una tautología no procesa ninguna información nueva, es, por lo tanto, vacia, mientras que una paradoja, debido al hecho de que afirma precisamente lo contrario de lo que intenta decir, procesa la arbitrariedad: todo es posible. 
contrar una posibilidad que permita desdoblar informativamente una forma tautológica y (paradojica) de este tipo, ${ }^{84}$ en transformar el circulusvitiosus de la autorreferencia (pura) en un circulusvirtuosus. ${ }^{\text {.5 }}$

40. Una sociología que procede de manera teórica del sistema y que reclama una exigencia de universalidad, ${ }^{86}$ observa todo lo que observa como sistema. Ahora bien, bajo la égida de una exigencia de universalidad de este tipó está obligada a observarse a sí misma como sistema. Como ya lo anotamos, el planteamiento del problema es: "¿cómo es posible el orden social?", un planteamiento del problema que ternatiza a la sociedad global (= sOCIEDAD) e integra también a la sociología misma - como sistema parcial del sistema parcial ciencia, mismo que a su vez es sistema parcial del sistema global de la SOCIEDAD. La exigencia de la universalidad obliga a la sociología orientada hacia la teoría de los sistemas a aplicar a sí misma el planteamiento de la sociedad global. En relación con la sociología, su propio problema de ordenamiento es: " ¿cómo es posible un discurso ordenado sociológicamente?" En última instancia, el planteamiento de problema de una sociología orientada hacia la teoría de los sistemas, cubierto de una exigencia universal, obliga a ésta a observar el cómo ella misma - por medio de su propio planteamiento del problema- es posible. Con ello, está obligada a la auto-observación, lo que, a su vez, informa sobre su observación ajena (figura 95).

Planteamiento del problema de una sociologfa orientada hacia la teoría de los sistemas:

Observación ajena: "¿Como es posible el orden social?" Auto-observación: "¿Cómo es posible un discurso ordenado sociologicamente?"

B4 Partimos — como la TsS- del hecho de que cualquier tautología descansa, en última instancia, sobre una paradoja. Véase Luhmann, 1987k.

Bs Acerca de estas dos versiones del concepto véase Varela, 1981, p. 294.

${ }^{86}$ Ciertamente, no necesita exigir esto. Si no lo exigiese, no podría entrar en competencia con otras empresas sociológicas, las cuales también proceden de manera universal, como la teoría de la acción comunicativa (TkH), la "teoría de los sistemas sociales" (TsS) o la "teoría del sistema general de la 
Si se puede demostrar - por medio de la observación o la descripción-qué y cómo es posible la sociEDAD como orden social -por ejemplo en la forma de los sistemas del sentido ordenados-, entonces una descripción de este tipo implica una comunicación ordenada sociológicamente también con carácter sistémico. Por lo tanto, la piedra de toque para la posibilidad de la sociología en el sentido aquí representado, está estrechamente ligada a la posibilidad de la soCIEDAD como orden social, misma que a su vez depende de un discurso ordenado sociológicamente..., etcétera.

41. Fijamos nuevamente: la sociología es sistema parcial del sistema de la ciencia, el cual es sistema parcial del sistema global de la SOCIEDAD. El planteamiento del problema "¿cómo es posible la sOcIEDAD?" se refiere al sistema global de la SOCIEDAD. En este aspecto, la sociología se presenta como la ctencia de reflexión del sistema global SOCIEDAD y, con ellò, es la teoría del sistema de la SOCIEDAD dentro del sistema de la SOCIEDAD. Simultáneamente es sistema parcial del sistema parcial de la ciencia, cuya teoria de reflexión es la teoría de la ciencia. Con ello, la sociología es simultáneamente miembro de dos sistemas: del sistema parcial de la ciencia y del sistema global de la SOCIEDAD. Precisamente con una doble referencia o pertenencia al sistema puede proceder, a la vez, universal y especificamente: está orientada hacia el sistema global de la SOCIEDAD, sin embargo, desde la perspectiva del sistema parcial de la ciencia. Por lo tanto, la sociología observa al sistema global de la sOcIEDAD desde la perspectiva del sistema parcial de la ciencia, y con la observación de la ciencia observa a la sociología. Con ello se observa - por medio de la SOCIEDAD y la ciencia- a sí misma (figura 96).

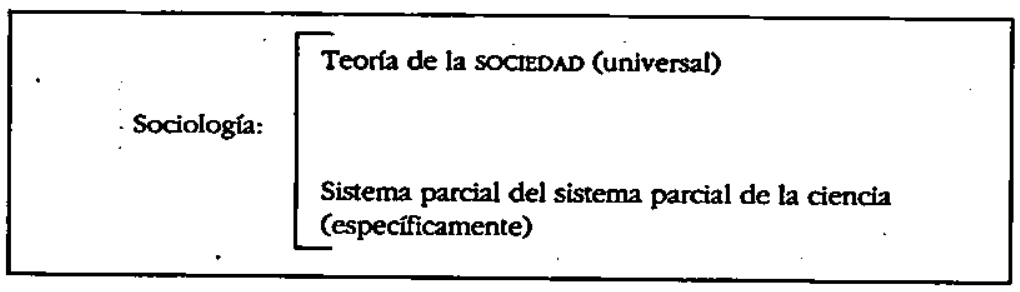

acción" (TaH), para mencionar solamente algunas de las arquitecturas de teorías sociológicas que proceden universalmente. 
Una operación sociológica de la autoreferencia pura $^{87}$ haría corto circuito con la sociología y no se generaría ninguna información útil: la sociología es sociología porque es sociología, porque es ...Sólo por medio del desdoblamiento de la autorreferencia en el sentido de una autorreferencia impura o paralela, el circulus vitiosus es transformado en un circulus virtuosus, o es desdoblada la tautología sociológica.

42. Ahora queremos observar a la forma de la observación que utiliza la sociología para abordar el problema del orden social o de la sociedad. Visto formalmente, la sociología, por un lado observa a la SOCAEDAD a través de la ciencia, por el otro lado a la ciencia a través de la SOCIEDAD. Con ello observa cómo la ciencia observa a la soCIEDAD y cómo la SOCIEDAD observa a la ciencia, con lo cual - por medio de una operación autorreferencial paralela - termina en ella misma. No obstante, no es la sociología la que realiza esta maniobra de la observación de la posibilidad de ordenamiento social global, sino el sistema parcial "teoría sociológica": con el apoyo de una teoría sociológica orientada hacia la teoría de los sistemas pueden ser distinguidos tres niveles de observación, o sea, uno sociológico, uno científico y uno social global. En última instancia, aquí se trata de un relacionamiento tetrádico, el cual consiste en dos distinciones: en la diferencia "ciencia y/o SOcIEDAD" y la diferenciación "teoria sociológica/sociología" (figura 97).

$$
\text { (Sociología)/teoria sociológica': }\left[\begin{array}{l}
\text { SOCIEDAD } \\
\text { ciencia }
\end{array}\right.
$$

Únicamente una secuencia de observación tetrádica de este tipo conduce a la necesaria estabilización de la autorreferencia socioló-

${ }^{87}$ Acerca del concepto de la autorreferencia pura, la TsS formula: "La autoreferencia pura que no toma el camino más largo a través de otras cosas, termina en una tautología. Las operaciones reales o los sistemas reales dependen de un 'desdoblamiento' o una destautologización de esta tautología, ya que solamente de esta manera pueden registrar que, dentro de un entomo real, son posibles solamente de manera limitada, no arbitraria." (Luhmann, 1986a, p. 269). 
gica, al ocultamiento de la tautología sociológica de la observación (la sociología es sociología, porque es sociología, porque...), por medio del suficiente distanciamiento de ella misma. Precisamente debido a la circunstancia de que la observación $A$ no debe reaccionar inmediatamente a la reacción de la observación $\mathrm{B}$, sino sólo a través de las observaciones $\mathrm{C}$ y $\mathrm{D}$, surge una estructura de observación más estable, misma que en ese caso es capaz de sostenerse a sí misma. Si la sociología observara a la SOCIEDAD con un acceso directo, estaría obligada a reaccionar directamente a esta observación, sin zona de amortiguación. Esta estructura de observación dual e ilusionaria, típica del surgimiento de los conflictos, ${ }^{88}$ está afectada por demasiada inseguridad como para permanecer estable por periodos del tiempo más largos. Sólo la introducción de un tercer y cuarto nivel de la observación ocasiona que la observación sociológica autorreferencial efectúe el necesario ocultamiento de su propia operación (el nudo autorreferencial). Por ello, se forma suficiente estabilidad para procesar dentro de sí misma, y no poner la mirada siempre sobre esta autoproducción y autorreproducción. Una modalidad semejante de observación (de paradoja y/o tautología) debería conducir naturalmente a una parálisis de la operación y, por lo tanto, al abandono de la observación sociológica. Sabemos: el orden social está dado realmente como objeto del conocimiento de la sociología, tiene lugar continuamente. Y la pregunta acerca de cómo es posible, la transfiere al nivel reflexivo: si existe el orden social, ¿cómo se genera en general? ${ }^{69}$ Esta reflexión como operación sociológica ciertamente tiene lu-

${ }^{88}$ Es típica de los conflictos la severa reducción de la COMUNCACIÓN a una rivalidad entre dos (Luhmann, 1984, p. 534), misma que naturalmente siempre permanece ilusionaria ya que cualquier constitución de un suceso está formada tetrádicamente; es un hecho que no es observado, por parte de la TsS, con el escrutinio necesario. Se puede formular también: los conflictos surgen debido a una rivalidad social entre dos, una ilusión que como se sabe puede tener consecuencias mortales: "El fin [del sistema de conflicto RJ] no puede resultar de la autopoiésis misma, sino solamente del entorno del sistema - por ejemplo, por medio del hecho de que uno de los dos adversarios mate al otro y, con ello, éste ya no entra en consideración para la continuación del conflicto." (Ibid., pp. 537-538).

${ }^{89}$ Se debe recordar que el modo de preguntar de Kant " ¿cómo es [...] posible?" surge en una época en la que la forma cartesiana de la conciencia de la conciencia, o sea, la autoconciencia, ha alcanzado un alto nivel como modo de observación. También es la época en que la escritura de la historia empieza a reflexionar sobre su propia historia. 
gar dentro de la sociología como ciencia especializada, sin embargo, no se debe comprender ni como operación metodológica ni como empírica referida a la aplicación, sino como operación reflexiva, como reflexión del sistema parcial de (la materia) sociología, como ya lo hemos determinado, con lo cual la sociología, por su parte, funge como reflexión del sistema global sociEDAD (figura 98).

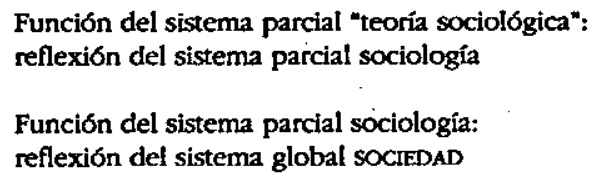

43. Una observación de los tres niveles del sistema "sociología", "ciencia" y "SOCIEDAD", tiene lugar a través del nivel del sistema "teoría sociológica": se trata de un relacionamiento tetrádico. Ahora dirigimos nuestra atención hacia el sistema parcial "sociología". La disciplina especializada de la sociología es una disciplina internamente diferenciada, o sea, un sistema en sí, y está equipada, como cualquier sistema dentro de sistemas, con diferentes referencias de sistema: con una referencia de sistema de rendimiento, de función, de reflexión y de ecología.

Aquí nos desviamos del supuesto de la TsS, la cual, dentro de su marco del concepto de diferenciación, postula solamente tres referencias de sistema: la referencia al sistema global (functón), la referencia a otros sistemas parciales (rendimiento) y la referencia a sí misma (reflexiôn). ${ }^{90}$ Postulamos otra referencia, es decir, la referencia ecológica, misma que reflexiona sobre la reflexión que surge a través de la distinción de rendimiento, función y reflexión/identidad. Con ello, se trata de la integración de las consecuencias, las cuales se generan debido al efecto retroactivo de la propia acción, a la acción futura. Se trata, formulado en el discurso de la TsS, de la consideración de la comunicación ecológica para la propia acción.

Como disciplina especializada debe alcanzar un rendimiento frente a otros sistemas del sentido. Esto lo realiza tratando de resolver los problemas, los cuales le presenta el entorno, de forma empírica prác-

${ }^{90}$ Luhmann, 1988, pp. 34-35. 
tica. Su función, que se refiere (por de pronto y sobre todo) a su entorno interno "ciencia", se debe ver en el hecho de que trata de impulsar la investigación a través de los problemas planteados metodologicamente. En lo que concierne a la autorreferencia reflexiva de la sociología, se trata del enfoque y el tratamiento teórico de su unidad en la forma de un problema guía a la disciplina. Esta posición de la sociología, reflexiva hacia sí misma, su identidad, por así decir, genera aquello que se puede llamar la producción sociológica de teoría. La ya mencionada referencia ecológica representa a una cuarta referencia, misma que tiene lugar por medio de las consecuencias de la propia acción, en la forma de una sociología de la sociología, la cual se expresa institucionalmente como gremio central de la disciplina. Resumiendo se puede decir que en el ámbito de la teoría sociológica pisamos un cuarto nivel sistémico de abstracción: nos encontramos - como "teoría sociológica" - dentro del sistema parcial sociología, dentro del sistema parcial ciencia, dentro del sistema global sOcIEDAD (figura 99).

Niveles de abstracción condicionados sistémicamente:

Sistema parcial "teoría sociológica"

Sistema parcial sociología

Sistema parcial ciencia

Sisterna global sOCIEDAD

44. La "teoría sociológica" no es -dentro de la materia de la disciplina sociología- ni metodología ni tampoco investigación social empírica. Aun más, esta reflexión misma acerca de la observación de la SOCIEDAD, es, por su parte, un sistema, como lo hemos postulado varias veces, ya que necesita una forma especial "esotérica" de la coMUNICACION, la debe cuidar para hacer justicia a los requerimientos de abstracción de una reflexión de la observación de la SOcreDAD. En este contexto, es interesante realzar el hecho de que Talcott Parsons vea a la sociología americana como consecuencia del diferenciamiento, por un lado frente a los aplied interests y, por el otro lado frente a la social pbilosopby. ${ }^{91} \mathrm{la}$ "teoría sociológica", por lo menos la teoría 91 Parsons, 1959, y también las explicaciones de la TsS, en Luhmann,
1981h, a, p. 201. 
planteada universalmente o la grand theory, no es, dentro de la disciplina especializada de la sociología, "cosa de todos" y tampoco lo puede ser ya que los puntos esenciales como la investigación social, la metodología y la "teoría sociológica" se han vuelto tan voluminosos y diferenciados que las posibilidades de la carrera solamente se pueden abrir a través de las correspondientes especializaciones. El tratamiento de la sociología especializada de un planteamiento del problema bajo aspectos teóricos requiere preparativos especiales de la materia, sobre todo de un fundamento más allá de los intereses de investigación personales, mismo que debe hacer buen papel en su capacidad de conexión, no solamente con los colegas de la disciplina, sino también con antecesores y sucesores. ${ }^{92}$ En este nivel de abstracción sistémico puede suceder fácilmente, "[...] que la crítica hasta aquí publicada [referido a la recepción de la obra de Talcott Parsons dentro del espacio europeo RJ] no alcance el nivel de la teoría, y en el nivel de la intención de la teoría, esto significa en el nivel del planteamiento del problema, no permite reconocer ninguna alternativa. Esto habla fuertemente en favor de los motivos latentes del rechazo o de la elusiónn ${ }^{93}$ Ahora bien, la lenta recepción antes mencionada de la obra de Talcott Parsons en Europa puede estar relacionada con el hecho de que el establecimiento de la sociología tiene lugar en Estados Unidos antes y mucho más ampliamente que en Europa, y que por ello, en Estados Unidos se busca antes que en Europa una síntesis entre las diferentes tradiciones de teorías - y se encuentra realizada, de manera ejemplar, en la teoría funcional-estructural de Parsons. Pero la reservada posición "normal" frente a la producción de las teorías universales de la disciplina ${ }^{94}$ no puede ser explicada solamente debido a supuestos defectos de la teoría o a la

92 'Ya el punto de partida del trabajo de teoría de Parsons, la confrontación con la tradición específica de la materia, presupone un establecimiento académico de la materia. Para que surja, en forma general, la necesidad de definirse en un sentido orientado hacia los problemas o la materia, como continuador, mediador o completados, debe estar dado un fundamento diferenciado en cuanto a los errores, más allá de los intereses de investigación personal." (Luhmann, 1981h, a, pp. 265-266.

${ }^{93}$ Ibid., p. 265.

' A diferencia de los logros dominantes de la materia, mismos que se deben considerar más bien en el sentido de Robert K. Merton como teorías de alcance mediano, cuya proyección está guiada más bien por actuales motivos específicos de la investigación. 
oposición política. ${ }^{95}$ Una grand theory supuestamente puede desarrollarse solamente dentro de un ambiente específico, solamente en un nicho especial de la materia de la disciplina sociología. Con ello se quiere decir que la producción de teoría universal de la materia requiere especialistas para lo general dentro de la materia sociología. Esta forma de la especialización de la teoría conduce - como cualquier forma de la especialización-al hecho de que surge una terminología y conceptualidad y que se formulan preguntas de decisión, las cuales pueden parecer no-transparentes, arbitrarias o incluso contradictorias para el colega de la disciplina no especializado en "gran teoría". Por lo tanto, no puede esperarse que la empresa "teoria sociologica" pueda estar soportada por un consenso relacionado con el presente e integrador de toda la disciplina de la materia. Si esto fuera el caso, o sea, que la empresa "teoría sociológica" dependa de un consenso de este tipo, entonces no habría actualmente ni una teoría de la acción general (TaH), ni tampoco una teoría de la acción comunicativa (TkH), y mucho menos una teoría de los sistemas sociales (TsS).

45. El consenso para la aceptación de la grand theory está dado como consenso institucionalizado, y se expresa en el área del lenguaje de la República federal en la forma de una "sección teoría sociológica". Ahora bien, es precisamente este diagnóstico empírico de la institucionalización de la "teoría sociológica" dentro de la materia de la disciplina sociología el que caracteriza a la reflexión sobre la observación de la SOCIEDAD. Con ello también está dicho que la observación de la observación de la operación "teoría sociológica" implica cuatro diferentes niveles de diferenciamiento, como lo hemos explicado antes: es sistema parcial del sistema parcial "sociología" del sistema parcial "ciencia" del sistema global SOCIEDAD. El hecho de que entonces la "teoría sociológica" no puede cumplir con las necesidades prácticas de una investigación social empírica, o con los requerimientos metodológico-estadísticos de la materia sociologia, es solamente una consecuencia del nivel "teoría sociológica",

95 Como ejemplo sirve el siempre destacado conservadurismo de la teoría del sistema general de la acción (TaH) de Talcott Parsons, mismo que está muy pronunciado en Gouldner, 1974, y Dahrendorf, 1974. 
mismo que se ha vuelto sistémico. El nivel de abstracción en forma sistémica representa, por su parte, hacia afuera una forma estratégica de la inmunización, y se podría añadir: una forma consecuentemente correcta de inmunización, ya que "algo" puede evolucionar hacia un sistema solamente si se cierra contra todo lo postble y permite solamente lo determinado. En este sentido, tales logros de teorias como los de la TaH (Parsons), laTkH (Habermas) o la TsS (Luhmanin) son, en gran medida, inmunes contra la crítica general hacia afuera $-y$ esto significa ya dentro de la materia sociología. Sólo una especializada crítica por parte de los colegas y, con ello, una crítica desde el ámbito interior del sistema parcial "teoría sociológica", puede contar con una cierta resonancia. Esto también hace evidente que solamente una comunicación ya socializada hacia adentro de la "teoría sociológica" puede esperar un eco serio a las manifestaciones críticas. Por lo tanto, el sistema "teoría sociológica" gira alrededor de sí mismo también en cuanto a la crítica.

46. Ahora bien, ¿qué posibilidades hay de romper este círculo autoconfirmante, con el cual el postulado clásico de la teoría de la ciencia - la confirmación independiente de la exigencia de verdad de la teoría- no está vigente $y$, con ello, cualquier discusión se puede llevar hacía lo indecidible? ${ }^{96}$ Lo único que se puede hacer, aparentemente, es $-\mathrm{y}$ esto ya es mucho- desarrollar alternativas adecuadas, ${ }^{97}$ propias de la materia para el área de afirmaciones de la teoría a criticar, esto significa no descartar simplemente la teoría criticada. Ahora, antes de ocupamos de las teorías sociológicas universales de la disciplina, ${ }^{98}$ necesitamos un punto de referencia, el cual

${ }^{6}$ Esto está relacionado con la universalidad de cualquier global theory, ya que esta exigencia implica que debe aparecer como su propio objeto; un entrelazamiento de la referencia ajena y la autorreferencia, conocido en la fisica cuántica.

'7 "Con ello, cualquier discusión se puede llevar hacia lo indecidible. Sin embargo, se puede exigir que el crítico desarrolle alternativas adecuadas para el área de afirmaciones, y que no se dé por satisfecho con la referencia a su teoría, de acuerdo con la cual, la realidad no puede ser comprendida dentro del contexto de ofuscamiento del capitalismo tardio." (Luhmann, 1984, p. 9).

9 Sea anotado que la teoría de los sistemas sociales (TsS) nos está acompañando desde el principio de este trabajo como guía para nuestras re- 
nos permite comparar lo incomparable. Para esta finalidad escogemos un problema, que nos puede servir como punto focal de comparación en la forma de un problema funcionalmente equivalente: ¿Cómo es abordado el problema que se oculta detrás de la pregunta: "cómo es posible el orden social o la SOcIEDAD", por parte de las teorias universales de la materia dentro del sistema "teoría sociológica"? La obligación de abstracción de los conceptos y términos, la cual resulta tan sólo debido al diferenciamiento de sistema cuádruple del sistema "teoría sociológica", implica el peligro de que el operar con semejantes abstracciones conceptuales y generalizaciones se haga incontrolable. La aplicación del "análisis funcional" a la "teoría de los problemas" ofrece una salida a esta difícil situación: el juicio de équidad se transfiere al problema "¿cómo es posible la SOCIEDAD?", y se observa cuáles son las soluciones del problema funcionalmente equivalentes presentadas para ello por las diferentes teorias. Este procedimiento, que no se puede llamar inductivo ni tampoco deductivo, sino heurístico, 99 posibilita, por lo tanto, una comparación de las teorias heterogéneas bajo el aspecto de su rendimiento específico en cuanto a sus propuestas de solución frente al problema "¿cómo es posible la SOCIEDAD?" Dicha posibilidad de comparación analíticafuncional orientada hacia el problema se basa en el método funcional: se observan varias causas bajo el aspecto de un efecto, o varios efectos bajo el aspecto de una causa, y se plantea la unidad de referencia escogida como problema. La relación de las diferentes causas o efectos entre sí -aquí las soluciones del problema de las distintas teorías - puede conducir, entonces, a la determinación de las equivalencias funcionales. ${ }^{100}$ Un método semejante muestra lo desigual como equivalente, sin embargo, debe pagar por esto con el hecho de que mantiene invariada la identidad de la unidad de refe-

flexiones, y que en este sentido nos encontramos desde hace tiempo en medio de una teoria universal de la materia.

99 "Los análisis funcionales no hacen conexión con razones seguras, conocimiento comprobado, oportunidad presente, para obtener de ello un conocimiento secundario, sino que se refieren, en ültima instancia, a los problemas y tratan de encontrar las soluciones para estos problemas. Por lo tanto, no proceden de manera inductiva ni tampoco deductiva, sino de manera heurística, en un sentido muy especial. Como palanca de la problematización les sirve [...] la pregunta acerca de la identidad dentro del mundo real." (Luhmann, 1973, p. 2).

${ }^{100}$ Ibid., p. 3. 
rencia escogida - aquí, del problema. El problema relacionado con la materia se convierte, de esta manera, en la base de explicación y en la razón esencial del análisis. ${ }^{101}$ En este nivel, naturalmente se podría objetar que el problema escogido no fuera ningún problema, o ninguno tan importante. Pero esto es otro problema.

${ }^{101}$ La teoría de los sistemas sociales dice explícitamente que el análisis funcional es posible solamente si la unidad de referencia es "congelada", y si se prescinde de los efectos laterales: "Con ello, la apertura de una posibilidad de comparación de las causas descansa en el hecho de que, en el área de los efectos, se elige y se abstrae, como punto de referencia, uno solo. Esta abstracción tiene un estilo propio, el cual se distingue claramente de la abstracción clasificatoria de los conceptos de especie y género: no se prescinde de las características individuales de la pieza particular, sino de los efectos secundarios. Si uno quisiera considerar todos los efectos secundarios, entonces ya no habría ninguna elección entre las causas; se integrarian a la observación de manera completamente individualizadas $\mathrm{y}$, con ello, de manera incomparable." (Luhmann, 1970a, 1, p. 17). Dentro del marco de este trabajo no podemos tratar más el importante problema que surge debido al hecho de que el análisis funcional es posible solamente a través de la extinción del problema de las consecuencias secundarias (de lo que sea). 


\section{ARQUITECTURAS DE TEORIAS}

...todas las teorias son [R]] indicaciones para comparaciones. Entre más distinto es aquello que puede ser comparado, más eficiente es la teoría. En este sentido, la ciencia consiste en la brisqueda de las posibilidades de tratar lo desigual como igual.

Niklas Luhmann ${ }^{1}$

Si la filosofia pinta sugris en gris, entonces una forma de la vida se ba vuelto vieja, y no se puede rejuvenecer con gris en gris, sino solamente reconocer. El bübo de la Minerva emprende su vuelo sólo en el ocaso.

Georg Friedrich Wilhelm Hegel ${ }^{2}$

PROBLEMA Y FORMA

La filosofia es necesarta, pero es demasiado dificil para nuestra razón bumana, sin embargo, es necesaria.

Carl Friedrich von Weizsäcker ${ }^{3}$

1. Con la ayuda de los problemas se pueden identificar las continuidades dentro de la historia de una ciencia o disciplina de la materia,

${ }^{1}$ Luhmann, 1986a, p. 160.

${ }^{2}$ Hegel, 1970, 7, p. 28.

3 Weizsäcker, C.F.v., 1990, p. XIv. 
con lo cual el verdadero contexto permanece posible vía los problemas, aun cuando surgen respuestas a los problemas y problemas en secuencia: entonces, es posible escribir una historia de las conexiones entre los problemas. Por lo demás, sin la articulación de los problemas ni siquiera es posible diseñar intentos de teoría altemativos y considerarlos cuidadosamente: "La alternatividad de los intentos de teorías en competencia [...] no sería reconocible como alternatividad, sin la unidad de una [...] referencia del problema. ${ }^{n 4}$ Esta tesis central de una teoría del problema significa que la identidad de una ciencia esta ligada a su referencia del problema, y que las teorias son formas, mismas que sirven para la interpretación de los problemas. Las teorías van y vienen, los problemas perduran.

2. Por lo tanto, son los problemas articulados (formados), los que logran controlar la abstracción conceptual y la generalización dentro de una teoría. Sin embargo, con esto nos metemos en el problema de una elección arbitraria del problema, de una decisión decisionista por algún problema. ¿Con base en qué podemos saber que el problema en cuestión es un problema relevante para la correspondiente teoria, y que no representa un problema lateral, sin importancia? Resolvemos este problema de la selección arbitraria de un problema relacionado con la disciplina por medio de la teoría de la observación, misma que dice: " $\mathrm{j}$ Observa al observador del problema relacionado con la disciplina en cuestión!" (de tu materia y/o de cualquier otra materia). Con la ayuda de una observación de una observación, misma que procede empíricamente, podemos observar, por lo tanto, la conciencia del problema de aquellas teoria universales de la materia que circulan en el sistema "teoría de la sociedad" o "teoría sociologica". No obstante, antes de dirigirnos a semejante observación queremos observar más detalladamente cuál es el problema que adquirimos con la "teoria del problema" aquí postulada. Observemos entonces cómo son posibles los problemas.

4 más: "De ello se debe deducir que los problemas forman el núcleo de identidad de una ciencia, con cuya ayuda puede cambiar las teorias." (Luhmann, 1974a, 1, p. 260).

${ }^{5}$ Resaltamos este punto, no obstante, somos de la opinión de que las teorías son menos generales que los problemas. 
3. Para Aristóteles, un problema es "[...] una pregunta hecha para su análisis, la cual se refiere a hacer u omitir, o también sólo al conocimiento general y el conocimiento de la verdad, sea para sí misma, o como apoyo para otra frase de este tipo, sobre lo cual, o no existe ninguna opinión determinada, u opiniones opuestas entre el pueblo y el sabio, o también en cada una de estas dos parte en sî". ${ }^{6}$ Con ello, desde Aristóteles, un problema puede concebirse como una pregunta teórica o práctica sobre la cual no existe ninguna opinión unánime. "Problema" significa algo como "lo presentado", lo "planteado", con lo cual se puede plantear algo verbal o escrito de manera razonable si se pregunta adecuadamente. ${ }^{7}$ La unidad del concepto del problema implica, en el sentido de una teoría del problema -en el contexto de la opinión no unánime- a la pregunta como una forma semántica generadora de problemas. Partiendo de la estructura tetrádica de algo como "algo" preguntamos: ¿cómo son posibles los problemas? Una pregunta puede plantearse cuando el mundo como "mundo dado" pierde su obviedad, su -visto cognoscitivamente- fijación en el mundo vivencial. Se llega a la pérdida de una obviedad perteneciente al mundo vivencial, por el hecho de que no se cumple una expectativa, sino que se convierte en o produce asombro y/o decepción (figura 100).

\begin{tabular}{|l} 
expectativas \\
no se cumplen:
\end{tabular}$\left[\begin{array}{l}\text { cumplimiento: } \\
\text { asombro } \\
\text { decepción }\end{array} \quad \begin{array}{l}\begin{array}{l}\text { mundo vivencial sin preguntas } \\
\text { por medio de la repetición } \\
\text { en el conexto de } \\
\text { diferencias de opinion }\end{array} \\
\hline\end{array}\right.$

Tanto con el "asombro" como con la "decepción", se parte de un mundo vivencial, presupuesto por de pronto como libre de preguntas, se cae en el área de una sensibilidad aumentada, con lo cual puede comenzar el preguntar como tal. ${ }^{8}$ Por lo tanto, la estructura de

${ }^{6}$ Aristóteles, Topik, A $104 \mathrm{~b}$.

7 Ver acerca del contexto sistemático e historico del concepto del problema. (Wild, 1973).

${ }^{8}$ Aristóteles ve en el asombro la razón de la actividad de la filosofia: "Los hombres empezaron, y empiezan ahora, con la filosofia, gracias a su asom- 
un preguntar: "¿Por qué no había visto esto hasta ahora?" es una distinción con dos lados: algo que percibo ahora, no lo había percibido anteriormente. ${ }^{9}$ Se puede decir, parafraseando a Gerd Brand: por el hecho de que un sistema (o un colage de expectativas) se da cuenta (se le hace "consciente"), asombrándose y/o decepcionándose, de la distinción en cuestión, puede preguntar explícitamente acerca de la distinción correspondiente. ${ }^{10}$

4. Por lo tanto, el problema se pone en marcha operativamente debido al hecho de que surge un hiato entre, por un lado, la obviedad del mundo vivencial (costumbre, rutina) y, por el otro lado, el asombro o la decepción sobre esta obviedad ya no obvia. Hemos definido la forma como un entrelazamiento de dos distinciones. Ahora bien,

bro [RJ]; originalmente se asombran de los problemas evidentes, después, avanzando paso a paso, descubren problema fabulosos [...]" (Aristóteles, $\mathrm{Me}$ tafísica, 1982c, 12) y Carlos Federico de Weizsäcker platica: "¿Cuánto pasto crece en la tierra? ¿Y qué es la tierra? El otro día, una mañana de enero aún completamente oscura, vi en el horizonte sur a la Luna y a Venus, lado a lado, muy arriba en el cielo Júpiter y mis viejos amigos Arktur y la Osa Mayor, la noche anterior había visto a Orión, Sirio, las Pléyadas. La luz de allí viaja por algunas décadas hacia la Tierra y a los alrededores de las nubes de estrellas locales. La Vía Láctea tiene cien mil millones de soles semejantes, nuestros instrumentos ven, por lo menos, a mil millones de vías lácteas. ¿Qué leyes obedecen los astros? La física nuclear nos enseña algo. ¿Qué sé de los átomos, qué de las estrellas, qué de sus quizás inteligentes habitantes? ¿Qué es la inteligencia? ¿Qué es la conciencia? [...] Acabo de platicar puras trivialidades. Todos sabemos esto. La filosofia comienza con el asombro. Con el asombro [R]] sobre lo trivial." (Weizsäcker, C.F.v., 1992a, p. 592).

${ }^{9}$ Ludwig Wittgenstein es de la opinión de que algo es reconocible como "algo" solamente por medio de las distinciones: "Sin embargo, ¿no se puede decir: 'Si existiera solamente una sustancia, no se tendría ningún uso para la palabra "sustancia'." El concepto "sustancia" presupone el concepto de la "diferencia de la sustancia" (como aquel del rey de ajedrez, el de la jugada de ajedrez, o como el del color aquel de los colores). (Wittgenstein, 1984, pp. 355-356, ficha 356 ).

10 "Notando, asombrándome la diferencia, puedo preguntar acerca de la diferencia" (Brand, 1971, p. 218). "En el asombro hay un preguntar doble. El asombro, en su aspecto determinante, dice: ah sí, es asi. Sin embargo, en ello subyace: ya estaba así, ślo que no lo había visto así. Y el asombro, en su aspecto interrogativo, no sólo pregunta: ¿por qué es as??, sino que formula una pregunta, misma que me lleva hacia mi: ¿por qué no habia visto, hasta ahora, que había estado así como es?" (Idem). 
¿qué aspecto tiene, en este contexto, la forma del problema? El preguntar genera el contestar, el problema procesa las soluciones. La unidad del problema - su forma - se ve, entonces, de la manera siguiente (figura 101).

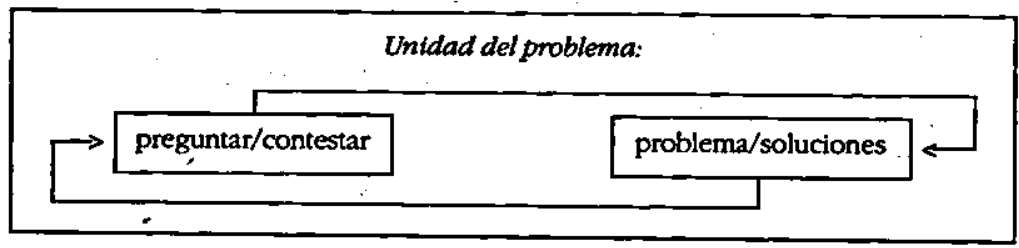

La distinción del mundo vivencial obvio/no-obvio produce el preguntar: en general, puedo preguntar solamente porque existe la diferencia. Si sólo existiera una monotonía sin diferencias, no existiría ningún preguntar. ${ }^{11}$ Preguntar, a su vez, implica contestar, con lo cual, la comprensión de algo como "algo" tiene lugar por medio del hecho de que la respuesta se refiere a la pregunta. Esto es también el procedimiento clásico de la bermenéutica: "Ciertamente, el texto se comprende en su sentido si uno obtiene el horizonte de la pregunta, el cual, como tal, también comprende necesariamente otras respuestas posibles. En este sentido, el sentido de una frase es relativo a la pregunta, la cual es una respuesta [....". ${ }^{12} \mathrm{El}$ problema es ahora aquello que se supone como unidad (de la distinción de problema y soluciones) detrás de la distinción pregunta/respuesta. En este sentido, el problema siempre es algo explorado: es la circunstancia a la que se refiere la distinción de pregunta/respuesta.

5. Ya hemos vestido el problema de la complejidad con la pregunta "cómo es posible algo?" y presentado la circunstancia compleja como la simultaneidad de la homogeneidad $y$ la variedad. Con ello se hace evidente el hecho de que este problema de la complejidad es equivalente con la pregunta: "¿cómo es posible la unidad de lo variado?", dado que todo lo que sucede, sucede inmediatamente y, precisamente debido a esto, simultáneamente. La unidad de lo que tiene lugar simultáneamente genera al problema de la complejidad, ya que

"Brand, 1978, p. 346.

${ }^{12}$ Gadamer, 1960, p. 352. 
lo variado debe meterse en una forma capaz de la operación, para que, por medio de ello, pueda ser constituida la unidad de una pluralidad. Transferido al sistema "teoría sociológica", el problema de la complejidad debería ser: ¿cómo es posible la unidad de una disciplina de la materia tan compleja? Sin embargo, una pregunta semejante es, en esta forma, aún demasiado general e indeterminada como para poder ser suficientemente informativa y generar "soluciones" razonables. Un problema de este tipo puede tener un sentido práctico para la investigación solamente por medio de su descomposición y parcelación. ${ }^{13}$ De esta manera, la formación de la teoría puede integrar, a través de sus generalizaciones necesarias, a suficientes momentos específicos, los cuales, entonces, pueden ser designados como uno de varios intentos de solución de teoría de un planteamiento más general del problema. Solamente de esta manera surge también una secuencia de teorías, mismas que, entonces, se llaman "teoría del sistema general de la acción" (TaH) o "teoría de los sistemas sociales" (TsS), que constituyen una tradición de la teoría dentro de una materia y que pueden posibilitar teóricamente su unidad en general. Por el otro lado, una parcelación de una teoría concerniente al problema fundamental es necesaria tan sólo por el hecho de que, en caso contrario, cualquier modificación o relevo de la propia teoría por medio de una teoría diferente debería llevar siempre a un nuevo comienzo. Por lo tanto, las teorías "buenas resuelven", en la forma de teorías parciales, solamente las formas descompuestas de un problema fundamental, con lo cual, en este contexto, aun se puede preguntar si la supuesta solución, ofrecida por la correspondiente teoria, de hecho ha registrado, o no, semánticamente al problema descompuesto. Por consiguiente, una teoría "buena” está compuesta siempre por teorias parciales, cuyas partes intentan conducir hacia una "solución" las parcelas particulares del problema fundamental. En este contexto, con el tiempo resulta obvio el hecho de que las parcelas del problema fundamental son interpretadas por parte de los clásicos, y que las interpretaciones, a su vez, son sometidas a nuevas interpretaciones, etc... Ejemplo de ello son la Theoretical Logic in Sociology (T1S) de Jeffrey Alexander, la "teoría de la acción comunicativa" (TkH) de Jürgen Habermas o la "teoría de la acción" (TdH)

${ }^{13}$ Acerca de esta formulación véase Luhmann, 1981h, 4, p. 206.

${ }^{14}$ Cuando se trata de la obra completa de T. Parsons utilizamos generalmente la abreviación TaH (-teoría del sistema general de la acción). 
de Richard Münch. El ejemplo clásico en este sentido es y será The Structure of Social Action (SsA) de Talcott Parsons. ${ }^{14}$

6. Hemos introducido la operación de la observación como la complementaridad de la diferencia y la diferenciación, como la relación de asimetría/simetría, como la unidad de la diferencia y la diferenciación. ${ }^{15}$ Ahora aplicamos esta definición formal-pragmática de la operación "observación" al objeto de nuestra observación, es decir, al problema fundamental del sistema "teoría sociológica". Éste se expresa en la pregunta de ¿cómo es posible el orden social? Ahora queremos referir lo que observamos con ello.

La pregunta "¿cómo es posible el orden social?" fue planteada en forma sistemática en el año 1908 por Georg Simmel, ${ }^{16}$ quien se orienta en la forma de preguntar de Kant "icómo es [...] posible?" servamos más detalladamente esta pregunta, entonces se hace evidente: no se trata sólo del "orden social", sino de la posibilidad de la "SOCIEDAD", esto es, de la dimensión social total.

Para recordar: por SOCIEDAD comprendemos (TgS) un tipo de orden global, el cual reúne como componentes fundamentales, por lo menos, lo social (comunicación en el sentido de la TsS), lo personal (conciencia en el sentido de la TsT), lo afectivo (la economía de los sentimientos) y lo corporal (como forma de integración de la percepción corporal). Llamamos a la comunicación de este tipo de orden, que no debe ser confundido con la "comunicación" en el sentido de la TsS, COMUNCACION. Generalmente se entiende la SOCIEDAD exclusivamente como tipo de orden social en el sentido de una "teoría de los sistemas sociales". No obstante, incluimos la dimensión social, o sea, también las estructuras de expectación prelingüísticas, mismas que procesan ya en el nivel de la percepción (oír, ver, oler, saborear, tacto).

is Véase el capítulo IV sobre la observación.

${ }^{16}$ El título del pequeño trabajo de Simmel es, entonces, "Exkurs über das Problem: Wie ist Gesellschaft möglich?". (Simmel, 1983, 7, pp. 275-293).

17 "Kant pudo hacer la pregunta fundamental de su filosofia: ‘ć6mo es posible la naturaleza? Y contestarla, porque para él la naturaleza no era otra cosa que la noción de la naturaleza l...] Sería muy natural tratar de manera análoga a las preguntas acerca de las condiciones a priori, sobre cuyas bases es posible la sociedad." (Simmel, 1983, 7, pp. 275-270). 
Es del todo posible definir la "SOCIEDAD", con Georg Simmel, como "orden social". ${ }^{18}$ Esto sucede frecuentemente.

De esta manera, la TsS designa la sociedad como sistema social, “[...] el cual incluye toda comunicacion razonable $[. . .]^{n},{ }^{19}$ con lo cual se refiere, sobre todo, a las instituciones, las cuales utilizan la escritura o sus derivados como medios de comunicación. Sin embargo, jconsiste la soCIEDAD solamente de fijaciones por escrito? Ciertamente, dentro del contexto de la ciencia se puede señalar lo no-escrito sólo por medio de lo escrito. Esto es un problema seguramente importante, empero, es otro problema.

No obstante, tenemos razón al proceder de manera cuidadosa con la formulación del problema de la posibilidad de la SOCIEDAD, ya que podría ser que también las preguntas orientadas hacia los problemas "¿cómo es posible el orden de la conctencia?", "¿cómo es posible el orden afectivo?", “¿cómo es posible el orden de la percepción?" sean preguntas parciales de una pregunta que concierne a la sociedad global: "¿cómo es posible el orden de la SOcrEDAD?"

Es nuestra intención presentar, sobre la base de la "logica de las distinciones" aquí explicada, una teoría de la sociedad que, sin embargo, no queremos proponer dentro del marco de este trabajo, ya que aquí nos ocuparemos, en primer orden, de la elaboración de las condiciones previas de una teoría social. Para una teoria social de este tipo, como teoria de los sistemas sociales ( $\mathrm{TgS}$ ), misma que integra una teoría de los tipos de expectación, se presenta el problema del orden en el ámbito de la dimensión del sentido de lo social en forma quíntuple: ¿cómo son posibles la socialidad, conciencia, afectividad, corporalidad y la percepción? Únicamente la repuesta a estos cinco problemas del orden puede informar acerca el problema fundamental: ¿c6mo es posible el orden como órden dentro de la dimensión del sentido social? En ello se puede ver qué tan complejo es, en última inastancia, aquello que acostumbramos denominar en la cotidianidad como "la sociedad".

Para poder observar más detalladamente el problema de la dimensión social ( $\rightarrow$ SOCIEDAD) lo formulamos, por de pronto, en su forma más general por medio de la pregunta: “ ¿cómo es posible en general

${ }^{18}$ Por ejemplo, Simmel, 1983, 7, p. 285.

19 Luhmann, 1986a, p. 267. 
el orden como 'orden'?" y observamos ¿qué es aquello que podemos llevar a la luz del día con una observación semejante?

7. Como posición de salida no escogemos un acceso descriptivo hacia el problema del orden, como lo hacen Edmund Husserl o Jürgen Habermas, sino uno operativo, como lo hacen George Spencer Brown o Niklas Luhmann. Por lo tanto, partimos del hecho de que todo comienza siempre operativamente. Y sabemos que la puesta en marcha de una operación constituye la forma de una "diferencia diferenciadora", con lo cual está dicho que cualquier operación está compuesta de dos distinciones: de una "diferenciación" y de una "diferencia". Ambas distinciones se posibilitan mutuamente. La diferencia obtiene su unidad precaria debido al hecho de que es constituida como unidad desde una perspectiva específica: esto tiene lugar mediante una diferenciación, misma que opera asimétricamente. Por el otro lado, una diferenciación asimétrica se puede constituir solamente por medio de la reducción de una diferencia simétrica mediante la asimetrización de la forma simétrica, y convirtiendo la indeterminación en determinación. Ahora bien, denominamos como observación la operación de una "diferencia diferenciadora".

8. Queremos observar el problema comprendido en la pregunta "¿cómo es posible el orden como 'orden'?" No obstante, el problema no es observable en esta forma, ya que la pregunta planteada contiene sólo un elemento, es decir, el "orden". Entonces debemos "desdoblar" la semántica del "orden". Para esta finalidad introducimos la diferencia de orden/desorden, una distinción que resulta ya de la semántica del orden, y que, con ello, está incluida en ella. Con ello hemos formado una diferencia simétrica que, sin embargo, aün no nos informa sobre la prioridad de uno de los lados. Mediante la introducción de una perspectiva, por ejemplo desde la complejidad social, podemos transferir de un lado al otro el peso de los lados de la diferencia y -sobre la base de los ya realizados análisis acerca del problema de la complejidad (capítulo III)- decir: el orden siempre debe ser menos complejo que el desorden, de otra manera ni siquiera se generaria. Desde ahí debería surgir una diferencia de complejidad entre orden y desorden, si se llega del todo a la formación del orden y desorden. Por lo tanto, primero hemos "desdo- 
blado" la semántica del orden en dirección hacia la diferencia de orden/desorden. Luego hemos introducido, con la ayuda de la diferenciación "complejidad social/no biológica, química, física [....", una perspectiva (un "interés"), "adecuada" para ello. Ésta se refiere a la diferencia orden/desorden y con ello transforma el "orden" en el "problema del orden social", ordenándolo de manera cognoscitivasemántica.

9. Despues de esta primera vuelta queremos observar nuevamente a la misma circunstancia. Ahora observamos a la observación del problema general “¿cómo es posible el orden como ‘orden'?” y preguntamos acerca de la posibilidad de esta observación. Con ello nos damos cuenta de que no avanzamos con el aislado elemento semántico "orden": en este nivel, aún no hemos podido obtener ninguna observación de la semántica correspondiente. Sabemos, por otra parte, que una observación está compuesta de cuatro elementos/sucesos que como entrelazamiento de las distinciones "diferencia" y "diferenciación" forman una forma tetrádica. Esta tétrada, por su parte, está —como lo hemos demostrado antes-formada autorreferencialmente: las diferenciaciones se realizan mediante las diferencias, y las diferencias mediante las diferenciaciones. Sin embargo, para que de ello resulte la estructura se debe implicar el tiempo, dado que un entrelazamiento semejante puede obtener una forma determinada y, a la vez, duradera, solamente dentro del tiempo. El instante momentáneo está caracterizado por medio de un "entrelazamiento momentáneo" de este tipo: una observación de una observación del orden se hace posible si se entrelaza una diferencia simétrica en la forma de "orden/desorden" con una diferenciación asimétrica complejidad social/no biológica, química, fisica o..., misma que expresa el interés del conocimiento. No el desorden, sino el orden $-\mathrm{y}$ esto desde la perspectiva social- constituye la observación especial que buscamos y que tiene la forma "¿cómo es posible el orden social?"

10. Una observación de esta índole del entrelazamiento de una "diferencia diferenciadora" como "orden social" no posee - como suceso momentáneo, simultáneo y, con ello, aün-no-condicionadoninguna estructura. Aún es una observación "de primera vez" o "sin- 
gular". Sólo la repetición de la observación, su "forma de segunda vez", conduce a la condensación en ella misma y al condicionamiento de una forma determinada de la observación, a una determinada estructura de la observación. Y es esta operación de la repetición de la observación, el acto operativo de una segunda, tercera, múltiple repetición de la misma operación, la que tiene efectos de formación de sistema, la que, en última instancia, hace posible el "orden" mismo. Esto tiene lugar tanto en el nivel del comportamiento de conocimiento ("conocimiento" significa ciencia), como también en el nivel de la SOCIEDAD (como "objeto" de la ciencia). La distinción de "orden" y "desorden" (o "azar" y "necesidad") representa, desde la perspectiva de la "dimensión del sentido social", a una distinción momentánea: si no perdura dicha forma de primera vez de observación, entonces no se alcanza ningún comportamiento operativo ordenado; sin embargo, si se efectúa una forma de segunda vez de la observación, entonces se alcanza, por lo menos, una forma mínima del orden en el ámbito del comportamiento de conocimiento. Si preguntamos otra vez, ¿c6mo es posible el orden ahora?, entonces podemos contestar: el orden es posible mediante la repetición $-\mathrm{y}$, con ello, mediante la operación que implica el tiempo- de una observación, la cual consiste en el entrelazamiento de los sucesos de distinción "orden y/o desorden" (= diferencia) y "dimensión del sentido social/no biológica, etcétera" (= diferenciación).

11. El "problema" del orden social, así lo podemos formular ahora, es la expresión semántica de la circunstancia de que la observación y la descripción de la pregunta del problema: "¿cómo es posible el orden social?" ya poseen valor de estructura. El "problema", vestido de la pregunta: “cómo es posible el orden social?", es, en última instancia, la expresión de la sedimentación del tiempo, es decir, del proceso de repetición del planteamiento del problema, mismó que forma la condición de la posibilidad del sistema "teoría sociológi$\mathrm{ca}^{\prime}$. Entonces, si se realiza una segunda operación de observación similar - por ejemplo, con la revisión de textos sóciológicos clásicos- entonces, esta repetición de la misma observación conduce a la condensación y confirmación de la primera operación de observación. Una segunda observación de este tipo condensa y confirma a la primera operación de observación, misma que sin el proceso de la repetición hubiera simplemente desaparecido. Se comprende por 
sí mismo que la observación actual, comparada con la de mañana, es tanto igual como desigual: la concentración de observación puede haber estado disminuida, por ejemplo, debido a un precedente sueño corto; hoy es más grande etc. En última instancia, mediante un proceso semejante de la condensación y confirmación se genera la identidad, y con referencia a la pregunta de planteamiento del problema: “¿cómo es posible el orden social?", se genera la identidad especializada del sistema "teoría sociológica". ${ }^{20}$.

12. Por medio de la repetición de una observación específica (a la cual, a la vez, hemos intentado observar) se logra su sedimentación y confirmación. Esto es un proceso de operación que tiene efectos de formación de identidad y, con ello, de orden y de sistema. ${ }^{21}$ Sin embargo, en este caso no es completamente idéntica la actual segunda operación de observación con la primera operación de observación. Esto significa que la primera observación no es procesada en su identidad total por medio de la segunda, sino que tiene lugar una segunda similar: después de tres meses, uno está aún ocupado con la averiguación de ¿cómo es posible el orden social?, sólo que ahora es invierno y que además se ha publicado más literatura acerca del mismo problema, la cual uno quiere conocer. Esto significa que el contexto del problema ha cambiado. Resumiendo, se puede decir que cualquier observación de la condensación y confirmación, por lo tanto cualquier observación de un proceso de repetición, siempre debe ser una observación de segundo orden, puesto que necesariamente presupone la observación de primer orden y que se construye sobre la base de ésta. En caso contrario, no se podría observar a la observación "simple" de que "algo" sucede otra vez o se repite. Con ello, cualquier operación de repetición (por más mínima que sea) se basa en la operación de una observación de segundo orden.

${ }^{20} \mathrm{Se}$ debe decir que generalmente en el ámbito del sistema parcial ciencia, cualquier formación de problema conduce a la autonomización de determinadas áreas, mismas que entonces procesan como disciplinas específicas de la materia.

"21 La génesis de algo como "algo" se puede explicar con la ayuda de una argumentación análoga. Véase acerca de ello capítulo I sobre la forma. La TsS, explica la génesis del sentido con el mismo concepto de repetición. (Luhmann, 1990A, p. 22). 
13. Sin embargo, debido al hecho de que observamos a la observación de la pregunta "¿cómo es posible el orden?", estamos obligados a observar cómo es posible la observación misma. Así, se hace evidente que el orden es posible solamente en el contexto de un relacionamiento tetrádico de acontecimientos, el cual surge mediante. el entrelazamiento de las distinciones orden y/o desorden y modalidad del orden social/no biológica, física... etc. La observación es el manejo de una diferencia simétrica frente al trasfondo de una diferenciación asimétrica, con la consecuencia de que con ello se genera la información. La observación del problema en la pregunta "¿cómo es posible el orden social?" da por resultado, que, frente al trasfondo del "interés de conocimiento", mismo que es señalado por medio de la diferenciación "social", unilateralizamos la diferencia dada, por de pronto, en forma simétrica de "orden y/o desorden" a "orden" y, con ello, permitimos que surja una diferenciación a partir de una diferencia.

14. Este procedimiento operativo hace evidente el hecho de que la observación del problema, el cual se expresa a través de la pregunta " ¿cómo es posible el orden social?", refleja a un proceso que se desarrolla en primer lugar, en el área del comportamiento de conocimiento y de teoria, antes de ser referido al objeto "orden social". Se puede decir también que el problema del orden social puede producir el contacto ajeno (nivel del objeto) solamente por medio del autocontacto (nivel del conocimiento). Dicho de otra manera: antes de que el problema "¿cómo es posible el orden social?" alcance al objeto del orden social mismo, se debe ordenar a sí mismo socialmente, y solamente llevándose a sí mismo socialmente al orden es capaz de dar informes acerca de otra forma de orden. Por el hecho de preguntar acerca de la posibilidad de orden, y de responder a esta pregunta con una semántica ordenada que explica el proceso de repetición de la operación de observación, producimos exactamente aquello acerca de lo que preguntamos. Ias condiciones de la posibilidad de orden están, por lo tanto, incluidas en las condiciones de la posibilidad de un discurso ordenado sobre el orden. Así, sin embargo, desaparece la distinción entre orden ajeno y auto-orden, o el problema del orden social ya no se distingue de aquél de una semántica operativa, misma que genera el problema de manera discursiva dentro del sistema "comportamiento de conocimiento". La circunstancia se puede for- 
mular también de la siguiente manera: la distinción de conocimiento y objeto se colapsa. Estando en esta situación, uno podría -irritado por semejantes relaciones autorreferenciales- emprender la fuga hacia adelante, con la afirmación de que el problema del orden social es una quimera que no juega ningún papel dentro de la formación de la teoría sociológica. No obstante, esta afirmación tendría que legitimarse, lo que no sería tan fácil en vista del material aplastante que indica que el problema es central dentro del sistema "teoría sociologica" (también en la forma de su rechazo), es decir, que es observable 'empíricamente.

Resumamos: el problema del orden social se puede referir a los ordenes ajenos solamente mediante un auto-orden cognoscitivo del sisterna "teoría sociológica". Con ello, nos encontramos ya en el mero principio del tratamiento del problema dentro de un nudo autorreferencial y dentro del sistema cerrado "teoría sociológica", con la característica de que es capaz de producir un contacto ajeno (como "objeto": ¿cómo es posible la SOcIEDAD o la dimensión del sentido socialidad?) solamente a través del autocontacto (como "conocimienton: respuesta ordenada discursivamente a la pregunta acerca de la posibilidad del orden social). Sin embargo, esto es posible solamente desde la perspectiva interior del sistema. En este sentido, el problema: "¿cómo es posible el orden social?" es un problema genuino formado autorreferencialmente, mismo que es el problema que presenta: se genera por el hecho de que él mismo constituye los elementos, de los cuales se compone..$^{22}$ De esta situación - de que el objeto del conocimiento es el conocimiento del objeto- podemos salir solamente si observamos sí y cómo, dentro del sistema "teoría sociológica", las otras teorías manejan el susodicho problema de la posibilidad del orden social.

\section{LA TEORIA DEL SISTEMA GENERAL DE LA ACCIÓN (TaH)}

Todo depende de las abstracciones primarias: La fertilidad y el grado de generalidad de las teorias dependen del tipo de las abstracciones primarias.

Talcott Parsons y Charles Ackerman ${ }^{23}$

${ }^{22}$ Acerca del concepto de la autorreferencia aquí empleado, véase Luhmann, 1984, pp. 25 y ss.

${ }^{23}$ Parsons/Ackermann, 1976, p. 72. 
Nadie entre los contemporáneos ba desarrollado una teoría comparable de la sociedad ... La obra actualmentepresentenotiene competencia en cuanto a la altura de abstracción y diferenciación, alcance teórico soctal y sistemático, con simultánea conexión con la literatura de diferentes äreas de investigactón. No obstante que el interés en esta teoria baya disminuido desde mitades de los años sesenta y que el planteamiento de Parsons baya sido empujado momentáneamente bacia el trasfondo por parte de planteamientos de investigación bermenéuticos y orientados bacia la crítica, actualmente no se puede tomar en serio ninguna teoría social que, por lo menos, no se refiere a la de Parsons. Quien se equitoca acerca de esta circunstancta, se deja capturar por las actualidades, en vez de estar sensible frente a ellas.

Jürgen Habermas ${ }^{24}$

....pienso que uno debería someterse sin reservas a las necesidades objetivas y que la comprensibilidad no debe ser un principio que impida que se diga lo que es posible decir.

Niklas Luhmann ${ }^{25}$

1. Observemos ahora en forma ejemplar cómo es posible el orden social dentro del marco del sistema "teoría sociológica". Para esta finalidad hacemos un intento por ver con la lupa algunas de las teorías sociales, las cuales se han vuelto relevantes, dentro del marco de este problema.

Se comprende que aquí no aspiramos a una indagación completa y amplia de las teorias de la sociedad en cuestión. Su discusión tendră lugar solamente en cuanto a algunos aspectos, con lo cual está dicho, a la vez, que seguramente no podemos hacer justicia a la correspondiente teoría social en su totalidad. En este contexto, son, por lo menos, dignas de mención las observaciones de Jürgen Habermas: "Creo que,

${ }^{24}$ Habermas, 1981b, 2, p. 297.

${ }^{25}$ Luhmann, 1981f, 10, p. 176, véase también la anotación 37. 
visto hemenéuticamente, me apodero de las lenguas ajenas de manera brutal. Aunque hago muchas citas y adopto otra terminología, sé exactamente que mi utilización a veces tiene poco que ver con aquello que los autores querían decirn. ${ }^{26}$

Queremos comenzar con una investigación y un tratamiento sobre algunos aspectos del sistema general de la acción (TaH) de Talcott Parsons. Preguntamos: ¿qué podemos ver si observamos a la TaH bajo el aspecto del problema del orden social? Por lo pronto, partimos de la unidad precaria de la obra completa de Talcott Parsons. Esto significa que estamos conscientes de su periodo de acción del trabajo de fundación The Structure of Social Action ${ }^{27}$ y de su periodo de sistema, mismo que se acostumbra ubicar en su trabajo The Social Sistem, como los dos puntos esenciales de su creación, y que en este aspecto los queremos mantener a la vista.

En el tratamiento de la obra completa de Parsons, que es considerada como inconclusa, ${ }^{28}$ para nosotros no se trata de si su interpretación de las obras de Max Weber, Wilfrido Pareto, Alfred Marshall o Émile Durkheim son suficientemente consistentes; de si éstas se deberían modificar, en caso dado, desde la perspectiva actual y en qué aspectos. Ciertamente, este problema de su interpretación y asimilación de los clásicos de la sociología existe, sobre todo, respecto a su primer trabajo más grande The Structure of Social Actions, sin embargo, puesto que este trabajo, primero, es considerado como documento de fundación y segundo, que alcanza un grado de teoría abstracto y capaz de generalización en un alto nivel, la crítica ha dirigido su atención especialmente a este trabajo, en comparación con las obras de creación posterior. A esto se añade el hecho de que Max Weber, Wilfrido Pareto y Émile Durkheim, clásicos de la sociología europea, son tratados por un sociólogo de los Estados Unidos; una circunstancia que naturalmente incita la ambición hermenéutica-interpretativa de los sociologos europeos. En este contexto, no se debería dejar sin mención el hecho de que el esfuerzo de familiarización,

${ }^{26}$ Habermas, 1985, p. 206.

${ }^{27}$ Acerca del carácter de un documento de fundación de este trabajo, véase Camic, 1989.

${ }^{23}$ De esta manera, la TsS: "Talcott Parsons nos dejó al morir su obra completa inconclusa. La forma en que estáa presente es el resultado de un proceso de trabajo de un desarrollo de teoría continuo a lo largo de varias décadas." (Luhmann, 1980b, p. 5). 
el cual debería ser realizado por parte de la adecuada crítica objetiva de la teoría del sistema general de la acción ( $\mathrm{TaH})$, es grande, ${ }^{29} \mathrm{sin}$ considerar su estilo de escritura: "There is the matter of Parsons' tortuous often elephantine style wich makes acces to his ideas a strenuous undertaking. ${ }^{n 0}$ No obstante, ahí donde Parsons inserta formulaciones de teoría decisivas y características, y éste es al caso en las más altas capas de abstracción, sus maniobras son suficientemente reconocibles y fijables.

2. La empresa arriesgada de formulación de una teoría universal de la materia de Parsons, ${ }^{31}$ siempre debe considerarse en la recepción de su obra completa, ya que en caso contrario permanece incomprensible lo decisivo que la teoria de Parsons ofrece y presenta en el diseño. No somos de la opinión de que el alto nivel de abstracción, el cual caracteriza a las formulaciones de teoria de la $\mathrm{TaH}$, es solamente una cuestión de gusto de su autor. Antes bien, es de suponerse que solamente a través de semejante camino abstracto es explicable la unidad teórica de la materia "sociología" en el sentido de una unitas multiplex. Ya antes hemos expuesto que la independencia de una disciplina de la materia científica está ligada esencialmente al hecho de que la materia en cuestión se da su propio problema, por medio de lo cual alcanza una relativa autonomía frente a otras disciplinas de la materia. ${ }^{32}$ Afirmamos que el problema del sistema "teoría sociológica" encuentra su expresión en la formulación "¿cómo es posible el orden social?" y que debe hacerse responsable de la relativa independización del sistema parcial "teoría sociológica". Ahora bien, es precisamente este sistema el que apoya el rol precario del teórico y que se encarga de que se tolere la formación de teoría so-

29 "El esfuerzo de familiarización que debe ser realizado por una adecuada crítica objetiva es grande, es desalentadoramente grande", opina la TsS. (Luhmann 1980b, p. 5).

${ }^{30}$ Bershady, 1973, p. 7. Sin embargo, Bershady argumenta en lo sucesivo: "Agreed. Yet, in the exposition to follow there will be exhibited many examples of Parsons' writing that are perfectly clear." (Idem).

${ }^{31}$ "Se trata de la formulación de una teoría universal de la materia, misma que desde Parsons ya no se ha arriesgadon (1984, p. 10), asi formula la TsS con referencia a la propia empresa de teoría.

${ }^{32}$ En este contexto, una teoría sería una forma de la interpretación de un problema respecto a sus posibles respuestas de solución. La TsS lo formula de manera similar. (Luhmann, 1974 ha, 12, p. 260). 
ciológica, misma que para muchos científicos sociales es una incomprensible terminologia especializada. ${ }^{33}$ La teoría del sistema general de la acción (TaH) no representa ninguna excepción en ese aspecto, y las quejas sobre la dificultad de comprensión de las obras de este tipo, como la teoría de la acción comunicativa $(\mathrm{TkH})$ o la teoría de los sistemas sociales (TsS), pertenecen al repertorio estándar de las manifestaciones críticas frente a las teorias de esta índole, y solamente reflejan la circunstancia mencionada.

3. El verdadero logro en la formación de teoría de Talcott Parsons comienza con el trabajo The Structure of Social Action. Se trata del intento de presentar una teoría sociológica general como ciencia de la acción por medio de la comprobación de una sintesis (científica de la acción) de las obras de Alfred Marshall, Wilfredo Pareto, Émile Durkheim y Max Weber. Y es del todo adecuado decir que Parsons efectúa la historia de la teoría con intención sistemática, ${ }^{34}$ con lo cual afirma una convergencia en las obras de los mencionados autores respecto a una "teoría de la acción". ${ }^{35}$ En realidad, Parsons está buscando una categoria social basal, misma que le pueda permitir el desarrollo de un concepto general de la acción. Con ello, localiza una racionalidad intrínseca de la acción, con la consecuencia de que puede explicar la "acción como sistema". Un análisis de su concepto de la acción (unit act) resulta, entonces, en que la acción está compuesta de los elementos "finalidad", "condición", "medio" y "norma": "It

${ }^{33} \mathrm{La}$ "ciencia incomprensible" es tolerable solamente cuando estể protegida sistémicamente, o sea, cuando se haya convertido en "sistema", cuando se haya consolidada como una forma de expectación cerrada, misma que muestra calidades comunicativas tanto esperables como experimentables.

${ }^{34}$ Las teorías tienen, como lo diría Parsons, un carácter no-empírico, una significancia simbólica, remiten tan sólo por eso a la autonomía de la abstracción teórica frente al empirismo. Precisamente en ello radica una asombrosa concordancia de Parsons, quien ha publicado la obra clásica The Structure of Social Action, en la cual está asociada la bistoria de la teoria clásica con la intención de formación de la teoria sistemática [RJ]; "a classic of classics", con aquellas ideas modernas de la bistoriografia y filosofia de la ciencia, para las cuales el sentido propio de las teorias programas de investigación, paradigmas, se ha convertido en un hecho obvio. (Wenzel, 1990, p. 11).

${ }^{35}$ Acerca de la tesis de convergencia de Talcott Parsons, véase Parsons, 1949a, pp. 722 y ss. 
[the 'unit' act RJl is to be thought of as composed of the 'concrete' elements of action. It takes a certain number of these concrete elements to make up a complete unit act, a concrete end, concrete conditions, concrete means, and one more norms governing the choice of means to the end. ${ }^{n 36}$ Esto significa que el concepto de la acción de Parsons muestra dos caras, las cuales deberian hacerse compatibles una con la otra: por un lado, la acción es comprendida como $u l$ timate unit basal, por el otro lado, como complex entity: "Though this unit act is an ultimate unit [R]] wich can be thought of as a subsystem of action it is still not, from the point of view of the theory of action, an unanalyzable entity but is complex [R] ${ }^{\text {n37 }}$ (figura 102).

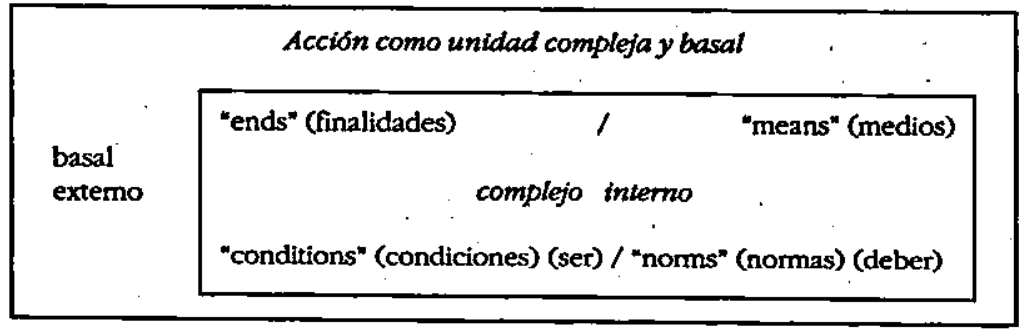

4. Sobre la base de un concepto semejante de la ación basal y complejo, la TaH trata de mostrar la dinámica de la acción (condicionada complejamente), relacionando los diferentes elementos de la acción ("finalidad", "condición", "medio", "norma") de manera específica. Por lo tanto, existe, primero, un estado de tensión entre condición y norma: "Action must always be thought of as involving a state of tension [RJ] between two different orders of elements, the normative and the conditional. ${ }^{n 38}$ Este tiene por efecto que la acción está obligada a tomar una dirección, por lo pronto, general, la cual es designada como orientación normativa. Se produce una segunda relación basal entre finalidad y medio, una relación que causaliza la acción y, con ello, también la dinamiza. ${ }^{39}$ Mientras que la

${ }^{36}$ Parsons, 1949a, p. 731.

${ }^{37}$ Idem.

${ }^{30}$ Ibid., p. 732.

39 El qué tan central es este esquema de finalidad y medio para la TaH lo hace evidente el lema Max Weber de su trabajo The Structure of Soctal ACtion. Cualquier reflexión acerca de los últimos elementos de la razonable 
relación de condiciones y normas se debe entender más bien en un sentido espacial, en la relación de medio y finalidad se hace efectiva la dimensión temporal: "It is only in temporal terms that the relations of these elements [means and ends RJ] to each other can be stated. ${ }^{\text {t0 }}$ Después de haber explicado el aspecto dinámico-temporal de la unidad de acción, la TaH realza su aspecto subjetivo (condicionado basalmente). Con ello, se trata de la circunstancia de que un "actor" (...) puede concebir only in (bis) mind los elementos normativos apropiados como existing. ${ }^{41}$ Esta introducción del sujeto a la unidad de acción, sin embargo, no se mantiene firmemente por parte de la TaH, lo que señala una cierta inseguridad o ambivalencia de su condición

acción humana está ligada, por lo pronto, a las categorías de la "finalidad" y del "medio" (Parsons, 1949a, p. Xm). Tenemos la opinión de que el esquema finalidad/medio es especialmente relevante para el concepto de la ACCón y formulamos la ACCIÓN sobre la base de la unidad de la de finalidad/ medios y aceptación/rechazo de acuerdo con nuestra tesis tetrádica. Finali$\mathrm{dad} /$ medio y aceptacion/rechazo, por su parte, son naturalmente distinciones específicas. Véase acerca de ello capítulo I. Asimismo, es interesante anotar que la teoría de los sistemas sociales (TsS) también utiliza la distincón de finalidad/medio para la explicación del suceso acción de manera autorreferencial: "La acción como suceso capaz de conexión, como elemento de reproducción del sistema de acción, constituido en el sistema de acción, por lo pronto es una unidad de la identidad y la diferencia, y esto es una unidad, la cual puede ser adjudicada a un actor con una determinada ubicación temporal. La interpretación de la acción de acuerdo con finalidad y medio parece ser una interpretación determinada de esta condición basal. La diferencia es articulada como la diferencia de finalidad y medio y, simultáneamente, es practicada como la unidad de la acción. Tanto los medios como la finalidad, son, al utilizar esta interpretación, los componentes de la acción misma, o sea, que se deben distinguir tanto de los instrumentos, mismos que se encuentran disponibles para la aplicación en combinación con la acción instrumental, como también de los resultados, los cuales son fácticamente originados por la acción" (Luhmann, 1982d, p. 370). Podemos anotar solamente que es alcanzable, sobre la base de sólo una distinción, es decir, la de finalidad/medio, solamente una explicación incompleta del acontecimiento acción. Por lo tanto, procedemos de manera tetrádica e intentamos explicar el fenómeno de la ACCIÓN sobre la base de la unidad de finalidad/medios y aceptación/ rechazo.

${ }^{40}$ Parsons, 1949a, p. 733.

"L La cita completa es: "Finally, the schema is inherently subjective [...] This is most clearly indicated by the fact that the normative elements can be conceived as 'existing' only in the mind of the actor." (Parsons, 1949a, pp. 732733). 
dentro de la unidad de acción. ${ }^{42}$ Suponemos que Parsons somete su concepto de la acción a una subjetivación, debido al hecho de que quiere realzar su aspecto externo basal, y porque solamente de esta manera su concepto de acción puede hacerse capaz de la acción. Queremos demostrar así que esto, en última instancia, no es posible.

5. Con la ayuda del concepto de la acción interno-complejo, con el cual los componentes de la acción (su estructura o unit acts) son relacionados de manera determinada (su proceso o frame of reference), está garantizado el hecho de que cualquier indagación comienza referida exclusivamente a la acción y que, por lo tanto, no se integran elementos ajenos a la acción (elementos biológicos, fisicos, espirituales etc.). ${ }^{43}$ Los "niveles de la realidad de otro tipo" de esta índole ciertamente se presuponen como obvios, no obstante, el análisis real comienza sólo con el fenómeno de la emergencia "acción". Sin embargo, ya aquí surge el problema de que las unidades de acción deben ser elementos basal-ontológicos para un sistema real, es decir, que deben-aparecer, dentro del correspondiente sistema, como unidades no disolubles, dado que en caso contrario el sistema que las utiliza no sería capaz de actuar realmente. ${ }^{44}$ No obs-

${ }^{12} \mathrm{La}$ introducción explícita del sujeto a la unidad de acción, ciertamente tiene lugar al principio de la indagación (Parsons, 1949a, pp. 44-45), sin embargo, al final no siempre se mantiene (ibid., p. 731), de manera que se puede obtener la impresión de que la TaH no está segura respecto al estado de este elemento (de una unidad de acción).

43 "Certainly the situation of action includes parts of what is called in common sense termsth physical environment and the biological organism - to mention only two points. [...] must the student of action, then, become a physicist, chemist, biologist in order to understand his subject? In a sense, this is true, but for the purpose of the theory of action it is not necessary or desireable to carry such analysis as far as science in general is capable of doing. $A$ limit is set by the frame of reference with wich a student of action is working [R]." (Parsons, 1949a, p. 47).

${ }^{44}$ Ontológica, esto es, no más disoluble, es la acción solamente para aquel sistema que la efectúa. Desde la perspectiva de un sistema de la ciencia, las acciones de otros sistemas, por ejemplo, son enteramente complejas e indivisibles. ¿Por qué las acciones deben tener un estado "ontológico" para un sistema? Porque solamente de esta manera el sistema correspondiente puede asegurar la capacidad de conextón. Si se descompone la acción utilizada por el sistema en más elementos y "subacciones", entonces, para el sistema no habría ninguna posibilidad de actuar realmente, ya que la unidad de acción 
tante, el concepto de análisis de la TaH descompone estas unidades, concebidas como lógicamente necesarias, en subunidades, y la pregunta es consecuentemente: ¿pero, puede un sistema de este tipo, entonces, aún actuar? Esta pregunta se puede delegar al sistema "ciencia" (o al sistema "teoría sociologica)", ya que es este sistema el que descompone analíticamente las unidades de acción de otros sistemas del sentido, o sea, que disuelve las unidades unit acts de otros sistemas en el sentido de la $\mathrm{TaH}$. La pregunta es entonces: ¿puede el sistema "ciencia" permitirse descomponer él mismo analíticamente sus propias unidades de acción basales? Si esto fuera el caso, entonces se deberia verificar que el sistema de la ciencia es incapaz de procesar las acciones, dado que sus unidades de acción no serían observables como unidades simples, compactas y no-descompuestas. Pero sabemos que el sistema de la ciencia no sólo observa, sino que también es capaz de la acción, de esto no hay duda. Por lo tanto, debe ocuparse de alguna forma de la "ontologización" de las propias unidades de acción, dado que solamente así puede también encontrar aplicación lo por él observado. Y solamente utilizando algún elemento/suceso ( $\Rightarrow$ acción) "propio" es también capaz de actuar. La pregunta es ¿cómo? Además, la TaH comprende las "unidades de acción" como "sistema", con la consecuencia de que los elementos de acción pierden en gran medida, como parte del sistema "acción", su autonomia ${ }^{45}$ y, con ello, descienden casi a epifenómenos. Ahora bien, la TaH parece estar consciente de esta circunstancia, ya que acepta el hecho de que, por medio de ello, un sistema social es degradado

estaría presente en la forma de numerosas subunidades de acción y, con ello, surgiría el problema de decisión acerca de que con cuál subunidad de acción se debería conectar otra subunidad de acción de la unidad de acción. Con el fin de mantenerse capaz de conexión, una acción debe tener, para el correspondiente sistema, un aspecto compacto o de unidad de suceso invisible, en caso contrario, se "dispersa" y se vuelve incapaz de conexión. La circunstancia se puede formular también de otra manera: la unidad de utilización de un sistema siempre debe ser una unidad no-analizable para el sistema; la unidad de observación siempre está provista de capacidades analíticas.

${ }^{45}$ Lo que, desde la perspectiva de la ACCION, es solamente consecuente, ya que por medio de ello la ACción puede conservar su homogeneidad como suceso y permanecer capaz de conexión. Sin embargo, desde la perspectiva del sistema, un concepto de esta naturaleza es fatal, dado que debe conducir a la disolución del sistema, en este caso, a la disolución de la autonomía de sus sistemas parciales. 
a un medio analítico del mero relacionamiento de los centros de acción: "por lo tanto, un esquema social no es [...] ninguna unidad, sino un medio para producir determinadas relaciones entre los componentes de la 'acción', mismos que se distinguen entre sí, correspondiendo a la pluralidad de la realidad concreta" ${ }^{46} \mathrm{La}$ "logica interna" del concepto de acción de la TaH conduce, en última instancia, al hecho de que, primero, se debe atestiguar la incapacidad de acción de cualquier sistema imaginable, ya que plantea analíticamente su concepto de la acción. ${ }^{47}$ Segundo, no se puede alcanzar - precisamente debido al mismo concepto- ningún diferenciamiento de sistemas parciales, dado que éstos son comprendidos solamente como momentos, como "medios" del único sistema basal "acción", como ya hemos visto. ¿Pero qué vale una teoría de sistema que no puede explicar las operaciones de acción, ni tampoco las operaciones de diferenciamiento?

6. Aseguramos que la TaH introduce la acción como relación, no como suceso; por lo demás, es una decisión, por de pronto, extraña, dado que dentro de la tradición de la teoría sociológica no es poco común introducir la "acción" como una unidad de acontecimiento no disoluble. Sin embargo, si una acción es concebida como una forma de estructura relacional, ¿qué o quién causa entonces su unidad? ¿La acción misma? Esto sería pensar autorreflexivamente, y de hecho, dentro de la $\mathrm{TaH}$ se encuentran algunos indicios para una posibilidad de este tipo, mismos que están relacionados con el postulado de una orientación normativa: entre ser (conditions) y deber (normative rules) existe un estado de tensión, de tal manera que las con-" ditions y norms se ligan con ello: "Action must always be thought of as involving a state of tension between two different orders of elements, the normative and the conditional. ${ }^{\text {48 }} \mathrm{A}$ ello se añade el rendimiento del esquema de finalidad/medio, con lo cual se presenta la posible unidad del unit act: "[...] conditions may be conceived at

46 Parsons, 1975a, p. 17.

${ }^{47}$ Para Parsons el planteamiento del problema decisivo resulta del concepto [R]] (y esto es para ella, a la vez, el becbo [R]] de la acción) de la acción, mismo que implica el problema del orden social de Hobbes: "Por lo tanto, tiene y mantiene un carácter analitico [RJ] dentro de la teoria de sistema deducida de ello [...]". (Luhmann, 1974a, 12, p. 260).

${ }^{48}$ Parsons, 1949a, p. 732. 
one pole, ends and normative rules at the other, means and effort as the connecting links between them" ${ }^{49}$ Una interpretación posible del contexto aquí presentado, en el sentido de la TaH (unidad de la acción), sería entonces aquélla de que los medios (means) y el esfuerzo/trabajo (effort) tienen que ocuparse de la producción de la unidad de la acción. Sin embargo, esto puede ser pronunciado solamente como una suposictón, ya que la TaH no tematiza explícitamente, en ninguna parte, la autorreferencia. Contra una suposición de esta indole habla la circunstancia de que la TaH introduce un factor subjetivo, ${ }^{50}$ ya que de acuerdo con su opinión, solamente de esta manera está garantizado que, por ejemplo, la orientación normativa gane realidad: "[...] the normative elements can be conceived of as 'existing' only in the mind of the actor". ${ }^{51}$ Ya antes hemos mencionado que la introducción del factor subjetivo puede estar relacionada con el hecho de que Parsons se da cuenta que una acción concebida exclusivamente como analítica no es capaz de la acción. No obstante, como lo hemos dicho, esto es también solamente una suposición.

7. Habiendo llegado a este punto, queremos detenemos brevemente y preguntar: ¿qué es aquello que motiva a la TaH en sus esfuerzos de determinar la estructura y la dinámica de la acción en la forma ya antes explicada? Pensamos poder contestar inequívocamente: con ello apunta a una solución del problema del orden social. En la formulación de la TaH: "No obstante de que estaba participando un considerable número de temas primariamente importantes en el desarrollo del esquema teórico de la Structure of Social Action [...], uno se colocaba en el primer plano y alli [...] ha permanecido desde entonces: aquel que designaba, con referencia a la naturaleza humana en general y al sistema social en particular, como el 'problema del orden'. Su formulación moderna clásica estaba dada con el concepto del 'estado

49 Parsons, 1949a, p. 732.

so Es precisamente el sentido de la autorreferencia concebir la unidad de unidad ("sujeto", "conciencia", "identidad", "esquema", "expectación", etc.) de manera relacional, por asi decirlo, abandonar su compatibilidad y mostrar cómo son posibles "sujeto", "sistema" o "identidad". Con otras palabras, la autorreferencia es precisamente aquel modo de operación que conduce a la formación de "identidad", "sistema", "subjetividad" o "conciencia".

si Parsons, 1949a, p. 733. 
natural' de Hobbes y, con ello, surgió la pregunta acerca de, ¿por qué las sociedades humanas no habían recaído, en vista de sus penurias, en un estado natural de la 'guerra de todos contra todos'." 52 La confrontación de la TaH con los clásicos de la sociología, o sea con Max Weber, Émile Durkheim y Wilfredo Pareto, se basa igualmente en el problema del orden: "Una de las más importantes razones de que buscaba una conexión entre Weber y Durkheim con las concepciones latentes en Pareto, consistía en el cada vez mayor conocimiento de que los tres estaban conscientes de la importancia dentro de este problema (del orden social). "53 Ahora podemos afirmar que los esfuerzos de la TaH acerca de una aclaración de la categoría "acción" están relacionados con el problema "¿cómo es posible el orden social?" Si esta afirmación es acertada, entonces el problema del orden, visto desde la perspectiva de la $\mathrm{TaH}$, debería ser exactamente: "¿cómo es posible la acción?" Con ello, Parsons traslada el problema basal de la "teoría sociológica", es decir, la pregunta acerca de la posibilidad del orden social, al problema parcial de la posibilidad de la acción, la cual, según él, debería de explicar adecuadamente el mencionado problema.

8. Hemos visto que la $\mathrm{TaH}$ trata de responder a la pregunta acerca del orden social de la acción, que muestra la relacionabilidad de las componentes analíticas de la acción y, sobre esta base, muestra como fenómeno emergente al unit act (la unidad de acción). No obstante, esta solución específica del problema del orden o del problema de la posibilidad de la SOCIEDAD está, por su parte y como lo hemos expuesto, cargada con numerosos problemas de arquitectura de la teoría, de los cuales, desde nuestra perspectiva (TgS), algunos serían accesibles para una solución. Para mostrar esto queremos observar más de cerca a algunos grupos centrales de problema y, con ello, integrar a este contexto, en el aspecto objetivo, tanto el periodo de acción como el periodo de sistema de la creación de teoría de Talcott

52 Parsons, 1975a, pp. 53-54.

${ }^{53}$ Ibid., p. 54.

54 Y de hecho, la TsS formula: "El framework 'General Action Analysis' [...], desarrollado en consecuencia de ello, responde a un planteamiento modificado a continuación de Max Weber. La pregunta central es ahora: ¿como es posible la acción?" (Parsons, 1981h, 4, p. 260). 
Parsons. Queremos proceder de la siguiente manera: $H$ ) en lo que concierne al periodo de acción, abordamos el concepto de la acción y cuatro problemas específicos estrechamente relacionados con ello, mismos que ya hemos explicado brevemente: $H 1$ ) la acción no se concibe como acontecimiento, sino como relación analítica; $H 2$ ) una acción de este tipo concebida analíticamente parece poner en tela de juicio la propiedad sistémica de los sistema parciales; $H 3$ ) por lo tanto, no puede posibilitar un diferenciamiento de sistemas parciales; $y$ H4) no es claro quién o qué garantiza, en última instancia, la unidad de acción. En lo que concierne al periodo de sistema $S$ ) queremos analizar el concepto del sistema y del entonces problema resultante de S1) una ampliación demasiado fuerte y de S2) estrechamiento demasiado restrictivo de limitacionalidad de la teoría, consecuencia de la introducción del "paradigma-de-cuatro-funciones" (AGI). En este contexto, tematizamos también el problema de la técnica de las tablas de cruz. Después de haber tratado los grupos de problema del periodo de acción y de sistema, nos queremos dedicar al punto más débil de la arquitectura de la teoría: al intento de Parsons por unificar la acción y el sistema. Con ello, intentamos demostrar de manera inmanente al objeto, que una identificación de la acción y del sistema puede reclamar suficiente plausibilidad para sí, tanto dentro del marco del esquema AGIL $H S 1$ ), como dentro del marco del frame of reference HS2). En este contexto examinamos también el supuesto fenómeno lateral del estilo de escritura de Parsons $H S 3$ ) y podemos demostrar que este estilo de escritura también es una consecuencia de la unificación de las semánticas de acción y sistema. Finalmente se debe observar más de cerca el problema metodológico-teórico del conocimiento del realismo analítico $A R$ ). Demostraremos que este problema actualmente se puede resolver de manera elegante. Anticipando, podemos anotar como resultado global de nuestras reflexiones provisionales que la TaH le da al problema basal de la teoría sociológica, o sea, ¿cómo es posible la sociedad? una interpretación basada en el concepto de la acción y, con ello lo descompone de manera estratégica para la investigación. Esto es naturalmente laudable y parece ser, a primera vista, una decisión inteligente. Sin embargo, dado que esta decisión lleva consigo a resolver el problema y sus consecuencias exclusivamente sobre la base de la acción, sobrecarga el concepto de la acción con el resultado contradictorio de que proyecta y pone a disposición un concepto de la acción incapaz de acción. 
9. Empezamos con el periodo de acción $H$ ). En lo que concierne al problema de la "naturaleza" de la acción $H 1$ ), es decir, al aspecto dinámico de los elementos de la unidad de acción (frame of reference), su estatus parece ser inseguro..$^{55} \mathrm{La} \mathrm{TaH}$ ha hablado en este contexto del realismo analítico. Esto parece ser una maniobra conceptual-semántica de la lógica (analítica) y la realidad (realismo), misma que no es fácil de reproducir. El problema que produce el supuesto de un realismo analítico surge debido al hecho de que la $\mathrm{TaH}$, por un lado, afirma que "[...] the 'frame of reference' do not constitute 'data' of any empirical problem; they are not 'components' of any concrete system of action" ${ }^{.56}$ Por el otro lado afirma: "It is impossible to have a meaningful description of an act without specifying all four [end, means, condition, norms RJ]. ${ }^{\text {"57 }}$ Con referencia a los conceptos "analítico" y "realismo" se dice entonces: "[...] it is maintained that at least some of the general concepts of science are not fictional but adecuately 'grasp' aspects of objectiv external world. This is true of the concepts here called analytical [R]] elements. Hence the position here taken is, in an epistomological sense, realistic [RJ] [...] Hence it is necessary to qualify the term realism [RJ] with 'analytical' [RJ]"..$^{58}$ Igualmente interesante es la comparación por analogía proveniente de la fisica, misma que efectúa la $\mathrm{TaH}$ para contrarrestar una supuesta "disparidad" entre la logica y la realidad, en conexión con el concepto del realismo analítico: "They [el relacionamiento de los elementos del unit act (RJ)] are in this respect analogous to the space-time framework of physics. Every physical phenomenon must involve processes in time, wich happens to particles wich 'can be located in space. It is impossible to talk about physical processes in any other terms, at least so long as the conceptual scheme of physics is employed. Similary, it is impossible even to talk about action in terms that do not involve a means-end relationship with all the im-

55 "It should be noted that the sense in wich the unit act is here spoken of as an existent entity is not that of concrete spatiality of otherwise separate existence, but of conceivability as a unit in terms of a frame of reference [R]]." (Parsons, 1949a, pp. 43-44).

${ }^{5}$ Ibid., p. 733.

57 Ibid., p. 732. En la página 44 se habla de cinco elementos: actor, end, conditions, means y normative orientation. Resalta a la vista el hecho de que aquí se habla del "actor" como uno de los elementos de la accion: ¿es el actor parte de la acción, o la acción parte del actor? Dejamos abierto este problema.

${ }^{58}$ Ibid., p. 730. 
plications just discussed. This is the common cenceptual framework in which all change and process in the action field is grasped. ${ }^{59}$ Por lo tanto, el problema del realismo analítico está dado debido al hecho de que el concepto de acción es interpretado, por un lado, como una relación solamente analítica de finalidad, medio, condición y norma; por el otro lado, se afirma en el mismo instante, que es precisamente este relacionamiento condicionado analíticamente de los elementos de la acción el que garantiza la realidad del concepto de acción. Si se interpreta la distinción conditions (ser)/norms (deber) como una diferencia simétrica y la distinción ends (finalidad)/means (medios) como una diferenciación asimétrica, entonces se tendría, de acuerdo con la "lógica de las distinciones", un relacionamiento teträdico, mismo que como tal puede constituir algo como "algo". Nosotros (TgS) tenemos la idea de que la distinción de conditions/ norms también representa una diferenciación asimétrica, y que solamente debido a ello la TaH puede caracterizar su relación entre sí como effort (esfuerzo). Debido a la forma asimétrica de ambas distinciones, es decir no se puede formar ninguna unidad, no se puede generar ninguna unidad de acción, puesto que, como recordamos, la unidad (de lo que sea) es posible solamente si se puede llegar a un entrelazamiento ( = interpenetración) de diferencia simétrica y diferenciación asimétrica. Vemos que el error que comete la TaH con este concepto está ocasionado por el hecho de que hace entrar por fuerza en la misma unidad de acción a dos "factores de incitación",

"99 Ibid., p. 733. Esta analogización de un "acto" físico con uno social dentro del marco de la TaH es ilustrativo para nosotros, debido al hecho de que aspiramos a una meta similar, misma que hemos formulado en la pregunta: ¿cómo es posible algo como "algo"? Con ello, vemos ( $\mathrm{TgS}$ ) la "unidad de algo" (equivalente al unit act de Parsons) en un entrelazamiento específico con carácter de acontecimiento de la diferenciación asimétrica y la diferencia simétrica. La formulación de la TaH con referencia a la analogización mencionada dice: "In the first chapter attention was called to the fact in the process of scientific conceptualization concrete phenomena come to be devided into - units or parts [...] The basic unit may be called the 'unit act'. Just as the units of a mechanical system in a classical sense, particles can be defined only in the terms of their properties, mass, velocity, location in space, direction of motion, etc. [...] so the units of action systems also have certain basic properties without wich it is not possible to conceive of the units as 'existing' "(Parsons, 1949a, p. 43); por lo demás, hemos expuesto antes que la existencia de algo como "algo" debe ser tetrádica. Con su observación, la TaH se refiere a algo similar. 
es decir, dos "direcciones". o "colages de responsabilidad" -o sea, finalidad/medios y ser/deber. También se podría formular: el concepto de la unidad de acción consiste en dos unidades actores, las cuales no se pueden determinar mutuamente porque ya están determinadas: en una racionalidad de finalidades y una racionalidad de norma. Y dos unidades capaces de acción dentro de una sola unidad de acción solamente pueden estorbarse una a la otra. Aun más, ipor medio de ello se arruina el concepto de la acción como unidad! ${ }^{60}$ Por supuesto que ésta es una solución posible, misma que proponemos con la ayuda de la lógica de las distinciones. Por lo demás, se puede decir que es poco clara hasta hoy en día la relación entre analítica y realidad dentro de la recepción de la TaH. Aun más, esta relación problemática se puede denominar como el problema enigmático de la TaH. En este contexto se habla frecuentemente de un "kantianismo" de la TaH. El representante más prominente de esta posición en el área de habla alemana es Richard Münch. ${ }^{61}$ En todo caso, la TaH no parece haber expuesto a una aclaración fundamental y explícita su posición metodológica de un realismo analítico, no obstante, la presupone de manera continua. Más adelante haremos una propuesta acerca de cómo se podría comprender, según nuestra opinión, la relación de lógica (analítica) y acción (realismo), y de cómo se tendría que interpretar desde la perspectiva actual la posición del realismo analitico. ${ }^{62}$ En todo caso, ningún sistema puede ser ca-

${ }^{60}$ Sea recordado: el surgimiento de una acción es posible solamente si una distinción presenta libertad de elección (una diferencia simétrica) y otra distinción muestra una "dirección" o "responsabilidad" (una diferenciación asimétrica). Dos distinciones asimétricas no pueden disparar ninguna acción en el sentido clásico de la palabra, solamente pueden hacer conexión una con la otra, lo que podría conducir a un medio de comunicación, pero no precisamente a una acción en el sentido de un suceso, mismo que implica la alternatividad, o ésta se le adjudica.

61 Münch, 1982a, pp. 17 y ss.

${ }^{62}$ Anticipamos: en este contexto, se puede formular — desde la perspectiva teórica de la operación-: para poder constituirse una acción requiere una estructura de decisión, la cual designamos como diferencia simétrica: "¿se debería hacer esto y/o aquello?" Las acciones dependen, con ello, de los lados de distinción binariamente equivalentes. Dicho de manera simple: para poder actuar se debe poder decidir; para poder decidir, se debe poder distinguir. Por lo tanto, una acción requiere una situación de distinción binariamente estructurada, para poderse realizar. En referencia al realismo analítico: el supuesto analítico se refiere a la distincion binariamente procesante y refleja una perspectiva de la teoria de las distinciones; el supuesto de la realidad se 
pacitado para la acción sobre la base de un concepto de la acción que está formulado "exclusivamente" de forma analítica: un sistema del sentido debe poder utilizar operacionalmente el acontecimiento "acción" para poder actuar, no solamente para poder observarlo analíticamente. ${ }^{63}$

10. El segundo $H 2$ ) aspecto del problema del concepto de la acción de la TaH consiste en el hecho de que él mismo pone en téla de juicio las características sistémicas de los sub-sistemas del sistema principal "acción". La TaH define en un lugar determinado la acción como sistema: "Action I define as a system [...]" ${ }^{64}$ Una definición de este tipo tiene su (buena) causa en la circunstancia del relacionamiento especifico de las componentes de acción de una unidad de acción ("finalidad", "medios", "condiciones", "orientaciones normativas"). La "acción como sistema" es, por lo pronto, una interpretación posible, la cual resulta de una manera más bien libre de las exposiciones de la TaH. Ahora bien, ya hemos visto que la acción en el sentido de una ultimate reality, ${ }^{65}$ por un lado puede ser definida como suceso singular, por el otro lado - como lo realiza la TaH-como relación

refiere al procesamiento de la acción y representa una perspectiva de la teoría de la operación. En todo caso es una interpretación posible (figura 103).

ACCION $\rightarrow$ DECISION $\rightarrow$ DISTINCIÓN
Transferido al nivel de la teoría social, aquí se debe hablar de
ACCION $\rightarrow \quad$ DECISION $\rightarrow \quad$ COMUNICACIÓN

${ }^{63} \mathrm{~L}$ a misma circunstancia se puede formular con Niels Bohr y C.F.v. Weizsäcker de manera de la teoría del conocimiento. (Weizäcker, C.F.v., 1991, p. 132).

${ }_{64}$ Parsons, 1968, p. 14.

${ }^{65} \mathrm{Si}$ la TaH formula: "Though this unit is the ultimate unit [R]] wich can be thought of as a subsystem of actionit is still not, from the point of view from the theory of action, an unanalyzable entity but is complex" (Parsons, 1949a, p. 731), entonces surgen varias preguntas: ¿cómo se puede obtener una concordancia entre el supuesto de una "última realidad" y su descomponibilidad analítica? ¿Por qué es la unidad de acción como "última realidad" un sistema parcial? ¿Qué es un subsistema en el sentido de la TaH? Esperamos aclarar un poco, por lo menos, la primera pregunta. 
de elementos. La "acción como relación" es entonces acción con base en su estructura analítica interior. Si dentro del marco de la TaH, el problema "¿cómo es posible el orden social?" es trasladado hacia el problema "¿cómo es posible la acción?", entonces este problema se debería cubrir con la pregunta: " ¿cómo son posibles las relaciones entre los elementos analíticos de la acción $?^{n 66}$ Con ello está implicado el que los sub-sistemas, los cuales constituyen el sistema de acción real del unit act -la unidad de acción-, son solamente momentos de este sistema fundamental. El problema, que es generado a través de esta arquitectura de la teoría es que los sistemas parciales del sistema fundamental "acción", como la cultura, personalidad, economía etc., ya no pueden ser identificados inequívocamente como sistema. Esto es una consecuencia de la extrema conexión de estos sistemas parciales con el concepto del sistema de la acción. ${ }^{67}$ Por lo tanto, es solamente consecuente si la TaH opina que los sistemas parciales "deducidos" del sistema principal "acción", como el "sistema social" o la "sociedad", no son unidades sistémicas, sino solamente medios para asegurar el potencial de relacionamiento del sistema fundamental "acción".68

11. Vemos un tercer $H 3$ ) aspecto del problema del concepto de la acción de la TaH en el hecho de que con un concepto de este tipo no logra explicar plausiblemente el diferenciamiento del sistema. Es decir, ¿como se pueden formar sistemas parciales a partir del sistema fundamental "acción" si estos sistemas parciales tienen la función de fungir solamente como momentos de relacionamiento de la "ac-

${ }^{66} \mathrm{La}$ TsS sugiere precisamente esta forma de pregunta del problema para la TaH. (Luhmann, 1981h, 4, p. 260).

${ }^{67}$ Tenemos la misma opinión que la teoría de la acción comunicativa (TkH) de que, de hecho, la TaH "[...] presupone [R] en un lugar demasiado abajo los puntos de conexión entre los modelos de sistema y acción (Habermas, $1981 b, 2$, p. 304). Se pueden suponer más arriba con el apoyo de la distinción de mundo vivencial y sistema, como lo propone la TkH, pero también más abajo de como lo ha hecho la $\mathrm{TaH}$, es decir, con la ayuda de la distincion de diferencia y diferenciación, como nosotros ( $\mathrm{TgS}$ ) lo proponemos.

${ }^{60}$ Citamos otra vez el mismo lugar: "Por lo tanto, un sistema social - por ejemplo una 'sociedad'- no es ninguna unidad, sino un medio [R]] para producir determinadas relaciones entre las componentes de la 'acción', mismas que se distinguen entre sí, de acuerdo con la pluralidad de la realidad concreta." (Parsons, 1975a, p. 17)'. 
ción"? El aspecto interdependiente de los "subsistemas impropios" del sistema fundamental "acción" conduce al hecho de que dentro del marco de la $\mathrm{TaH}$ no es posible adjudicar las acciones especificas a un sistema específico. Se le debería dar la razón, en este punto, a la crítica algo ruda y demasiado compacta de Alwin W. Gouldner frente a la TaH: "Ahora bien, si se comprende el sistema en el sentido de "interdependencia' de sus elementos, entonces uno no tiene menos razón en definir el sistema como grupo de elementos, mismos que poseen poca 'autonomía funcional' entre sí [...]. El delinear los sistemas conceptualmente en relación con sus interdependencias, como lo realiza Parsons, conduce al hecho de concentrarse, sobre todo, en el 'todo' y en el tipo de conexión de sus partes. Esto tiende a la acentuación de la unidad del todo [...]. Este concepto de la interdependencia se interesa por las partes, solamente en consideración de su condición dentro de un sistema; son 'reales' solamente dentro de y para un sistema [...]".69 Esto es la consecuencia de la circunstancia de que la TaH escoge solamente una forma "propia" (unit act) para los más diversos tipos de sistema, misma que además está concebida de tal manera que pone en peligro la autonomía de otros sistemas del sentido, como el "sistema de personalidad", el "sistema social", el "sistema de la sociedad" o el "sistema económico".

No obstante, la integración del mayor número posible de alternativas es una característica de una grand theory, como lo es la TaH. Su observación: " $[. .$.$] acts do not occur singly and discretly, they are$ organized in systems ${ }^{770}$ sugiere, por un lado, concebir la acción ciertamente como suceso y, con ello, comprender un sistema del sentido como una asociación de acontecimientos de acción. Por el otro lado se hace referencia a la forma analítica de la acción en el sentido de un sistema. Nos decidimos aquí por la versión: "acción = sistema", por la cuasi-fundición de las semánticas de "acción" y "sistema". En todo caso, la realización efectiva del programa de la teoría de la TaH hace parecer a esta versión como posible y plausible. La determinación difusa (‘a propósito?) de la relación de acción y sistema, que caracteriza la teoría del sistema general de la acción (TaH), sigue siendo, sin duda, una piedra de escándalo dentro de su diseño de teoría. Mientras que, por ejemplo, la teoría de los sistemas sociales

${ }^{6}$ Gouldner, 1974, pp. 265-266.

To Parsons, 1970a, p. 7. 
(TsS) entraña la relación interna de "acción y sistema" en la TaH, la teoría de la acción comunicativa (TkH) opina que la TaH ubica demasiado abajo los puntos de conexión entre las teorías de acción y de sistema, con lo cual aparentemente subestima la estrategia de análisis y de conceptos de la teoría de la acción. ${ }^{72}$ Esto indica lo cen-

71 "En todo caso, la interpretación de la acción como sistema conduce en Parsons a decisiones de teoría, mismas que nopueden ser deducidas del análisis de la acción. El problema de la emergencia de la unidad de acción generalizada simbólicamente no resulta como el único problema fundamental de la teoría. Se paraliza en cierto modo y se substituye por un planteamiento del problema específicamente teórico de los sistemas, el cual entonces asume la dirección. El planteamiento del problema se traslada desde la acción bacta el sistema [RJ] y, precisamente debido a ello, la determinación exacta y lo más estrechamente posible de la relación de los conceptos de acción y sistema es un problema central para la teoria." (Luhmann, 1980b, p. 9). "A pesar de las manifestaciones contrarias del autor, me parece que la segunda versión, la tesis: acción es sistema, es más adecuada para la teoría de la teoría general, ya completamente madurada, de la acción [...]" (ibid., pp. 8-9). Para aclarar: pensamos que la TaH, por un lado, interpreta el sistema como acción, por el otro lado, la acción como sistema es una particularidad que se le escapa a la teoría de los sistemas sociales. Ciertamente formula: "el planteamiento del problema se traslada de la acción hacia el sistema [...]". La TaH quiere realizar las dos cosas en una: la acción debería ser sistema (es decir, una unidad analítica), sin embargo, el sistema debería ser comprendido como acción (o sea, como una unidad de acción). Esto parece ser uno de los problemas, si no el problema central, de la teoría del sistema general de la acción (TaH).

72 "De acuerdo con mi impresión, Parsons subestima la capacidad y el grado de autarquía de una estrategia de análisis y de conceptos de la teoria de la acción y, por lo tanto, plantea demasiado abajo los puntos de conexión entre los modelos de acción y de sistema" (Habermas, 1981b, 2, p. 304). Con referencia al propio planteamiento del problema, y considerando la relación entre acción y sistema en Parsons, Habermas opina ahora: por lo tanto parto del hecho de que el problema de construcción de cómo pueden ser asociadas la teoría de la acción y la del sistema con conceptos basales, existe con razón. Mi proposición provisional de que las sociedades deberian ser comprendidas como relaciones de acción sistémicamente [R]] estabilizadas entre los grupos socialmente [R] integrados, ya contiene estos dos aspectos (Habermas, 1981b, 2, p. 301). ¡Cierto! Sólo que la TaH paga por esta solución con una dicotomización entre sistema y acción. Por lo tanto, proponemos observar tanto a la unidad como a la distinción de acción y sistema (tan sólo porque la unidad - visto generalmente- es posible solamente como unidad de la distinción). Si en este nivel de abstracción de la TkH preguntáramos, cómo evalúa la posibilidad de la sociedad, tendría que responder: como dicotomía de acción y sisterna, por medio de lo cual, sin embargo, perdería 
tral, pero también problemático, que es la relación de “acción” y "sistema" dentro de la arquitectura de teoría de la "teoría del sistema general de la acción" (TaH). Optamos, como ya lo hemos dicho, por la versión de una cuast-fundición de las semánticas "acción" y "sistema" y opinamos que la TaH trata de realizar ambas cosas simultáneamente desde la perspectiva de la arquitectura de teoría: por un lado "acción como sistema", por el otro lado "sistema como acción" ${ }^{73}$

12. El cuarto aspecto de problema $H 4$ ) - dentro del $H$ ) periodo de acción- del concepto de acción de la TaH se refiere a la unidad de la acción: ¿quién o qué garantiza la unidad de la acción? Hasta ahora nos hemos referido, con la ecuación precaria "acción $=$ sistema", más fuertemente a aquello que la TaH entiende como acción y a los problemas producto de ello. Ahora queremos dirigirnos - para poder captar mejor el problema de la unidad de la acción-al lado de su noción del sistema. Si la acción es comprendida como sistema, entonces esta cuasi-igualacion de "acción = sistema" conduce a que el centro de acción -expresado a la manera de la vieja Europa: el sujeto-, en el sentido de medio de decisiones, se pierda de vista. Ciertamente, el "actor" ${ }^{n 4}$ de la TaH es elemento parcial de la unidad de

la unidad de la sociedad. Véase acerca de ello explícitamente capítulo V sobre la teorías de la acción comunicativa.

${ }^{73}$ Un consejo para la lectura: cuando, dentro del marco de la TaH, se habla del sistema, siempre se debe interpretar también como acción, y cuando se habla de la acción, siempre se debe interpretar también como sistema. Deducimos la legitimación de un supuesto de este tipo, por un lado, de la circunstancia de la acción y del sistema como la explica la TaH; por el otro lado, del problema del estilo de escritura en el cual la TaH ha sido redactada. Más adelante regresaremos a esto.

${ }^{74} \mathrm{La}$ inconsistencia de la TaH en cuanto al supuesto de un "actor" como elemento de la unidad de acción se hace evidente cuando se debe comprobar que, dentro de la misma obra (The Structure of Social Action), por un lado lo incluye (Parsons, 1949a, p. 44), por el otro lado lo omite (Parsons, 1949a, p. 731). Podemos explicarnos esta inconsistencia solamente por el hecho de que la TaH realmente trata con dos actores diferentes, mismos que no logra integrar, o sea, con el "actor" como elemento de esta unidad de acción (unidad de análisis) por un lado, y con el "actor" como unidad de acción (unidad de suceso). Formulado de otra manera: oscila entre un concepto del "actor" desde la perspectiva de la teoría de la acción y uno desde la perspectiva de la teoría de los sistemas. Esta ambivalencia de su diseño de teoría se hace notoria sobre todo en su recepción, puesto que se puede suponer, primero, 
acción y está integrado en el unit act. En este aspecto, se puede por lo menos sospechar que para la TaH existe un centro de acción, mismo que distingue y decide qué hacer. No obstante, mediante la igualación de "acción = sistema" se extingue prácticamente la operación del actuar. La teoría de la acción comunicativa (TkH) acierta al nervio del problema cuando formula: "con el concepto del sistema de acción [R]] desaparecen los actores como sujetos actuantes [...."75 y Max Black opina: "A curious feature of Parsons theory of action, remarked upon by several critics, is the extended to wich action [RJ], in any ordinary sense of that term, fails to get discussed at all. ${ }^{76}$ Por más extraño que esto suene: el concepto de acción de la TaH es un concepto sin acción, por lo menos en el nivel general de teoría. Una posible solución de este problema de un centro de acción ausente consistiria en la interpretación autorreferencial del concepto de la acción, puesto que en este caso no sería necesario introducir un sujeto antropológicamente real, bumano, sino que bastaría con la explicación de la autorreferencia desde la perspectiva de la teoría de la acción. ${ }^{77}$ Sin embargo, hemos anotado antes que la TaH proce-

la "acción como sistema", segundo, el "sistema como acción" y, tercero, una distinción precaria de "ación y sistema". Como consecuencia de esto, el receptor puede adoptar la versión que mejor le parece.

${ }^{73}$ Habermas, 1981b, 2, p. 353. Partimos del hecho de que el concepto del sujeto debe ser comprendido autorreferencialmente. Con ello, se puede formular: también los sistemas biológicos son "sujetos" en la medida en que son interpretados como sistemas autorreferenciales. Aun con un robot, se debería implicar la "subjetividad", tan pronto como se logren constituir nudos autorreferenciales mediante un "mecanismo" de esta índole. A pesar de la propia aversión de la TkH en contra del planteamiento de la identidad, en el sentido de una determinada forma de la autorreferencia, también afuera de los individuos se reproduce la cita siguiente, misma que deja sospechar que la TkH no exluye la posibilidad de suponer una "autorreferencia no-humana": "Ya las plantas y los animales ciertamente son sistemas dentro de un entorno, de tal manera que no solamente poseen, como cuerpos en movimiento, una identidad 'para nosotros' (los observadores identificantes), sino también, en cierto sentido, una identidad 'en sî́." (Habermas, 1976a, 4, p. 94).

${ }^{76}$ Black, 1976, pp. 274-276, añade: "There is consequently a serious question wether any description of this type, valueable as it might be in other respects, will yield prediction as to how the actor will move (i. e., will act in ordinary sense of the term)."

"La observación de la TkH: "Con ello, el [Parsons, RJ] distingue entre el actor como unidad de un sistema de acción y éste mismo: un sistema de acción no actúa, sino que funciona" (Habermas, 1981b, p. 352) se basa en el supuesto de que la subjetividad se puede adjudicar solamente a los "hom- 
de autorreferencialmente sólo de manera inicial. ${ }^{78} \mathrm{Si}$ uno pretende mantener los alcances de conocimiento y el nivel teórico de la $\mathrm{TaH}$, entonces debería encontrar las soluciones correspondientes de los cuatro aspectos del problema antes mencionado y estrechamente relacionados. El problema de la "naturaleza" de las acciones se puede formular mediante la pregunta: ¿cómo se puede reformular el problema del concepto de la acción de la TaH de manera que permanezca, por un lado, como suceso y por el otro lado y simultáneamente como unidad analítica? Más adelante se demostrará que solamente se requiere una solución de este problema para resolver los problemas de $H 1$ ) la acción concebida exclusivamente de manera relacional, de la H2) ausente característica sistémica de los sistemas parciales, de la $H 3$ ) no diferencialbilidad de los sistemas parciales y de la H4) carencia de una garantía de la unidad de acción.

13. Ahora llegamos al $S$ ) periodo de sistema. En lo que concierne a este periodo, los análisis teóricos de sistema de la TaH giran en primer lugar alrededor del problema del equilibrio de un sistema. ${ }^{79}$ Este problema de la estabilidad está expresado en la interdependencia de los elementos del sistema de acción. Aun más, en este contexto se relaciona el problema del orden social con una adecuada capacidad de autoconservación del sistema en el sentido de una interdependencia de los elementos bien formada: "The most general and fundamental property of a sistem is the interdependence of parts or variables [...]

bres". Sin embargo, si la "subjetividad" se interpreta como un caso especial de la autorreferencia, entonces, de repente se cambia la situación de la teoría. Compartimos la concepción de la TsS, "[...] de que la autorreferencia no es una particularidad de la conciencia [es decir, no referida exclusivamente al sujeto u 'hombre' RJ, sino que está presente en el mundo de la experiencia" (Luhmann, 1984, p. 648). Aun más, "[...] falta el conocimiento de que la realidad estä estructurada de manera circular, también independientemente del conocimiento [RJ]". (Idem).

${ }^{78}$ No obstante, al final de nuestras exposiciones acerca de Parsons demostraremos que procede autorreferencialmente en un lugar central, sin embargo, esto no lo resalta especialmente. Se debe suponer que Parsons no estaba consciente de este hecho.

"Max Black es de la opinión de que a la TaH le importa solamente esto: "I think we can generalize somewhat and say that Parsons, conciously or not, is primarily interested in the equilibrium conditions of social sistems." (Black, 1976, p. 276). 
interdependence is order in the relationship among the components which enter into a sistem. This order must have a tendency to selfmaintanance, which is very generally expressed in the concept of equilibrium. ${ }^{n 80}$ Aquí S1), la TaH está confrontada con el problema de que las numerosas interdependencias de los elementos abren, dentro de una unidad de acción, una libertad de movimiento combiatorio en tal grado que ninguna teoria la podría agotar de manera realista. Esto significa que se deben tomar precauciones estructurales para garantizar la practicabilidad del proyecto teórico. En el año 1951 se publican Toward a General Theory of Action ${ }^{81}$ y The Social System. ${ }^{82}$ Estos "[...] dos libros del año 1951 representan, de cierta manera, un punto culminante [...] forman la base de salida para un nuevo desa- rrollo. La aportación redactada conjuntamente por mí y Shils ["Part 2. Values, Motivs and Systems of Action" en: Toward a ...RJ], estaba basada en el esquema de las pattern-variables, mismo que "[...] transferimos al nivel de la acción en general ${ }^{n}{ }^{83}$ Dos años más tarde (1953) se publican los Working Papers in the Theory of Action ${ }^{84}$ El resultado decisivo de estos dos trabajos "[...] consistia en el four-function-paradigm, como lo llamamos actualmente. Se generó sobre la base de una combinación del esquema de las cuatro pattern-variables y el sistema de categorías elaborado por Bales en el Interaction Process Analysis". 85

Con el apoyo de este four-function-paradigm, la TaH quiere demostrar ahora que la solución del problema de la estabilidad de un sistema de acción está acoplada a la solución de cuatro problemas interpretados funcionalmente, mismos que se designan como adaption (A), goal attainment (G), integration (I) y latent pattern maintanance (L) (el llamado esquema AGI). Con ello, este esquema de cuatro funciones es obtenido por medio de la división categorial del problema de la estabilidad en un marco de dimensiones espaciales y una de dimensiones temporales: la presente acción consumatoria se encuentra en una relación de tensión con la futura acción instrumental, su orientación interna-sistémica contrasta con su orienta-

\footnotetext{
Ta Talcott Parsons, en Parsons/Shils, 1951, p. 107.

${ }^{81}$ Parsons/Shils, 1951.

82 Parsons, 1970a.

${ }^{83}$ Parsons, 1975a, p. 23.

${ }^{4}$ Parsons/Bales/Shils, 1981.

${ }^{85}$ Parsons, 1975a, p. 23.
} 
ción externa-referida al entorno. Toda acción se desarrolla solamente dentro del esquema AGIL. Con la ayuda de este diseño de teoria, la TaH puede limitar estructuralmente en forma considerable la $\mathrm{li}$ bertad de movimiento combinatoria de su unidad de acción, de su unit act. Sin embargo, la pregunta es si el precio de dicha limitación de la libertad de movimiento de la arquitectura de la teoría no es demasiado alto. Esto concieme directamente al S2), problema que resulta de la aplicación de la técnica de las tablas de cruz. Queremos tratar más detalladamente esta técnica y observarla más exactamente (figura 104).

\begin{tabular}{|cccc|}
\hline & \multicolumn{3}{c|}{ Unidad de acción referida al sistema: } \\
& instrumental & consumatorio \\
intemo & L & I \\
extemo & A & G \\
\hline
\end{tabular}

14. Sobre la base de la estructura doblemente binaria del concepto de orientación (instrumental/consumatorio e interno/externo) se elabora una tabla de cruz, la cual resulta en un esquema de cuatro campos. Por medio de ello, la TaH puede formar una "forma lógica" con la cual describe al sistema de acción hacia la dirección de los sistemas de funciones. Parsons formula: "He conservado este modelo básico desde que surgio - como un punto de referencia para mi trabajo teórico completo. ${ }^{n 87}$ Ahora bien, con la ayuda de esta tabla de cruz se pueden especificar más exactamente los elementos de la unidad de acción. Pero, sobre todo, cualquier acción debe realizar, a partir de ahora, simultáneamente cuatro funciones de manera satisfactoria, no más, ni tampoco menos. Si se genera, mediante la circunstancia que sea, un diferenciamiento de un sistema parcial del sistema principal "acción", entonces este sistema parcial emergente debe realizar simultáneamente cuatro funciones. Preguntamos: ¿de qué manera estructural se puede postular un diferenciamiento de sistema realista? La "lógica" del esquema de cuatro funciones implica

${ }^{2}$ Parsons/Platt, 1990, p. 26.

${ }^{87}$ Parsons, 1975a, p. 24. 
que debe tener lugar una repetición exacta de la tabla de cruz, dentro de cada uno de los campos, si debe emerger realmente un diferenciamiento semejante: el subsistema A se puede constituir solamente si también se constituyen un subsistema $\mathrm{G}$, un subsistema I y un subsistema L. Esta rara obligación a la repetición del esquema AGIL completo, en cada nivel de formación de sistemas parciales, resulta por "necesidad lógica" de los supuestos de la arquitectura de la teoría de la TaH, misma que determina que cualquier sistema de acción es concebible solamente de esta manera y, con ello, diferenciable sólo de esta forma.

15. A partir del concepto inicial de un unit act y su libertad de movimiento combinatorio (el llamado Newtonian space), misma que no se puede agotar desde la arquitectura de la teoría, resulta una tabla' de cruz con una fuertemente limitante libertad de movimiento de limitabilidad de la teoría. Sin embargo, no es solamente el esquema de cuatro funciones el que tiene efectos limitantes sobre la formación de teorías y, con ello, sobre el registro cognoscitivo de la circunstancia SOCIEDAD, sino también la puerta de entrada hacia los requerimientos funcionales del sistema de acción, es decir las variables periféricas consumatorio/insrumental (dimensión del tiempo) e interno/externo (dimensión espacial), mismas que sirven como orientación para la acción. Estas variables periféricas son prácticamente el motor de la tabla de cruz, el cual le otorga una dinámica particular. A la vez, son los destiladores que limpian a su manera la información entrante: cumplen una función de filtro. En este sentido, una operación cognoscitiva puede ser registrada como acción en forma de tabla de cruz sólo cuando puede "comprobar", por su lado, que aspira a una satisfacción inmediata o postergada y si, por el otro lado, procesa de acuerdo a criterios externos o intemos. Se debe observar que la tabla de cruz de la TaH está logicamente cerra$\mathrm{da}$, es decir, que es de cierto modo "sistema". De acuerdo con este concepto, el unit act es posible solamente si se refiere, sobre la base de las variables periféricas, a los requerimientos de funciones. Con otras palabras, la acción es posible solamente si se puede referir, por un lado, a las dos variables periféricas formadas dicótomamente, $o$ sea, a la distinción de consumatório/instrumental y a la distinción de interno/externo, y, por el otro lado, si es capaz de cumplir con los cuatro requerimientos de funcion (AGI). ¡Y todo esto simultánea- 
mente! Una restricción "lógica" de este tipo tiene consecuencias, y opinamos que con dicho diseño de la teoría no puede lograrse una comprensión coherente-consistente $\mathrm{y}$, sobre todo, realista de la soCIEDAD.

16. Vemos (TgS) la verdadera razón de la circunstancia limitante de la acción en el hecho de que la "lógica" de la tabla de cruz está diseñada demasiado restrictivamente -esto es algo que debe conducir a una fuerte limitación de una arquitectura de la teoría, misma que la presupone como fundamento. Sin embargo, la "logica" de la tabla de cruz es ella misma el producto de una concepción de la teoría, misma que considera, por así decirlo, como idénticos a la "acción" y al "sistema".88 Esta identidad exclusiva de acción y sistema - ya lo expresamos antes de esta manera- es la que consideramos como el punto más débil de la TaH. Contrariamente a la concepción de la

8i Si se emplea "orden" en vez de "sistema" (Parsons/Ackerman, 1976, pp. 73 y ss), entonces se puede demostrar que el problema de la relación entre acción y orden es central para el sistema "teoría sociológica", como lo hace evidente la formulación de Harald Wenzel: "Todos los intentos mencionados [Habermas, Luhmann, Münch, Alexander (RD)] de desarrollar una posición autónoma de una teoría social en la discusión con Parsons colocan el tema de la relación entre acción y orden en el centro de su argumentación. Independientemente de si se trata de la acción comunicativa y su relación con el orden duplicado en el mundo vivencial y en el sistema de Habermas, del sistema social autopoiético constituido y reproducido por acciones comunicativas de Luhmann, del concepto de acción que resulta de la interpenetración de órdenes de elementos racionales en cuanto a una finalidad y elementos categóricamente obligatorios de Münch o de la rigurosa separación de los problemas de accion y orden, misma que asegura la multidimensionalidad de Alexander: a todos estos intentos de teorías, los cuales son simultáneamente interpretaciones de Parsons les es común el esfuerzo de ubicar la relación conceptual entre acción y orden en un nivel deproblema más abstracto y más general de lo que está descrito mediante el consenso ortodoxo y por medio de la respuesta de Parsons al problema de Hobbes" (Wenzel, 1990, p. 20). En el nivel de la teoria de las distinciones, nuestra "solucion" del problema del orden consiste en el hecho de que demostramos cómo es posible la unidad como unidad de la distinción de diferencia y diferenciamiento, en el nivel de la teoría social; consiste también en el hecho de que demostramos cómo es posible el orden social como unidad de la distinción de cOMUNICACIÓN y ACCIÓN, en el nivel désistemas del sentido singulares; y consiste en el hecho de que demostramos cómo es posible la unidad del sistema del sentido correspondiente en la distinción de código y programa. 
teoría de la acción comunicativa (TkH), ${ }^{89}$ tenemos la opinión de que la estrecha conexión de ambos conceptos es contraproducente en cuanto a la arquitectura de la teoria, puesto que la teoría del sistema general de la acción ( $\mathrm{TaH}$ ) no comienza lo suficientemente abajo con su acoplamiento de "acción" y "sistema". Dicho más exactamente: ya que la TaH no nota que "acción" y "sistema", por un lado, contienen una componente idéntica, pero que, por el otro lado, deben ser distinguidos estrictamente, se mete en el problema de tener que levantar su edificio de teoría completo de un solo golpe. La explicación de esta "obligación" de la simultaneidad de la arquitectura de la teoria se puede detectar fácilmente: está relacionada con las semánticas de "acción" y "sistema". La acción es - desde la perspectiva operativa - , por lo pronto y sobre todo, un acontecimiento y como tal es posible solamente dentro del y gracias al tiempo: ${ }^{90}$ debe tener lugar, tiene lugar $y$ ha tenido lugar. Por lo tanto, cada acontecimiento efectúa “[...] una modificación global del pasado, del presente y del futuro [...]".91 La conexión semántica de esta "actualidad momentánea", de dicha "transitoriedad inmediata", con el concepto del "sistema" ${ }^{n 2}$ de la TaH tiene la consecuencia de que el "sistema" se debe actualizar momentáneamente. Para la TaH, el "sistema" es el sistema fundamental "acción", mismo que representa la sociedad global. Se puede formular la circunstancia inminente de la siguiente manera: si la "acción" (¡como "sistema"!) debe tener lugar, entonces, jcon el suceso "acción" como "actualidad momentánea" emerge simultáneamente la sociedad global! Consecuentemente, Stefan Jensen formula de manera acertada: "La tarea de Parsons es difícil, ya que siempre debe convertir en tema [la 'acción' RJ] al mundo completo [el 'sistema' RJ]. ${ }^{93}$

Ahora queremos echar un vistazo al problema de la unificación de acción y sistema por parte de la TaH $H S$ ). Con ello queremos demos-

${ }^{89}$ Habermas, 1981b, 2, pp. 304-305.

${ }^{\infty}$ Luhmann, 1984, pp. 389-390.

"Idem.

${ }^{92} \mathrm{La}$ TaH comprende a la acción como sistema y al sistema como orden (Parsons/Ackerman, 1976, pp. 73 y ss.). Su problema es consecuentemente -comprendido como el clásico problema sociológico del orden- ¿ ¿cómo es posible la acción? Si "acción" significa "orden" y, sin embargo, el "orden" se comprende como "orden social", entonces se deben considerar como iguales la "acción" y el "orden social".

${ }^{93}$ Jensen, 1976, p. 49. 
trar - cuasi en un segundo intento- esta "unificación" con la ayuda de una argumentación inmanente al objeto, misma que se debería referir tanto al esquema AGIL $H S 1$ ) como también al frame of neference HS2). Además, queremos demostrar, con apoyo en la observación del estilo de escritura $H S 3$ ), con el cual la TaH ha sido redactada, que este estilo no representa ningún fenómeno periférico, sino que refleja la intención consecuentemente perseguida por parte de su autor de asegurar la unificación de la acción y del sistema también por escrito. Comenzamos HS1) con el esquema AGIL.

17. El esquema de cuatro funciones que se conoce como AGIL es desarrollado a partir de dos ejes, es decir, de un eje que se orienta hacia , las referencias internas y externas, y uno que se orienta hacia las referencias instrumentales y consumatorias. Este último eje "[...] corresponde a la acostumbrada diferenciación entre finalidades y medios, ${ }^{n 94}$ formula la TaH, y aclara más abajo que con estos dos ejes se debe registrar la dimensión del tiempo y del espacio de cualquier sentido:"95 "a partir de estos ejes se pueden [...] deducir las 'dimensiones' de las estructuras del sistema [dimensión espacial RJ] y el proceso del sistema (dimensión temporal)" ${ }^{96}$ Como se sabe, la TaH “deduce" a partir del cruzamiento de ambos ejes los cuatro problemas funcionales: " $1^{\circ}$, la referencia externo-consumatoria, misma que he llamado 'consecución de la meta' [goal-attainment $\mathrm{RJ}$ ]; $2^{\circ}$, la referencia externo-insrumental, misma que llamo 'adaptación' [adaption RJ]; $3^{\circ}$, la referencia interno-consumatoria, es decir la 'integración' lintegration RJ]; y finalmente, $4^{\circ}$, la referencia interno-instrumental: 'sostenimiento de la estructura y procesamiento de la tensión' [pattern-mainta-

${ }^{9}$ Parsons, 1976a, 1, p. 87.

-95 Se entiende que esto sucede desde la perspectiva de la dimensión social. Esta circunstancia se puede formular también de la siguiente manera: la sociología como disciplina representa, en el nivel de su sistema parcial "teoria sociol6gica", el intento de registrar las dimensiones del sentido en su forma general, desde la perspectiva de observación de la dimensión social del sentido. A ello pertenecen -desde la perspectiva de la dimensión social del sentido- el "espacio", el "tiempo", la "objetividad" y la "socialidad" (jsic!). Aquí, uno ha leído correctamente: también se trata del registro de lo social desde la perspectiva social de la observación. En este sentido, el negocio de la sociologia consiste, entre otros, en el registro de sí misma y por medio de ella misma.

${ }^{9}$ Parsons, 1976a, 1, p. 87. 
nance $\mathrm{RJ]} .{ }^{\text {"97 }} \mathrm{La}$ TaH efectúa explícitamente la identificación de la distinción interno/externo con aquella de sistema/entorno: "para la dimensión del primer eje [...] escogemos las denominaciones interno-externo. Se refiere a la relación del sistema de acción con su entorno [...]" ${ }^{98}$ Independientemente de si el segundo eje, designado como instrumental/consumatorio, se puede relacionar con la distinción medio/finalidad, como lo propone la misma TaH, ${ }^{99}$ o no: en este contexto, es relevante sobre todo el hecho de que la distinción de sistema/entorno se refiere inequívocamente a la circunstancia "sistema", mientras que la distinción instrumental/consumatorio se orienta hacia la circunstancia "acción" (en el sentido de una acción instrumental o consumatoria).

18. Como ya lo hemos realzado, la arquitectura de la teoría de la $\mathrm{TaH}$ se concibe, en este nivel de abstracción, de tal manera que con cualquier "acción del sistema" se debe iniciar una simultaneidad de ambos ejes. Esto lo ve también la teoría de la acción comunicativa $(\mathrm{TkH})$, y formula: “ El dominio simultáneo de ambos problemas [del sostenimiento de los límites y la consecución de estados de meta RJ] debe ser analizado simultáneamente en las dimensiones de espacio y tiempo; esto significa que un sistema debe asegurar su existencia simultáneamente [R]] en la relación hacia el entomo del sistema y hacia sí mismo (interior/exterior), como también en la relación de los estados actuales de comienzo y los estados anticipados de meta linstrumental/consumativo]. ${ }^{n 00}$ Tenemos exactamente la misma opinión: de acuerdo con el supuesto de la TaH, el "sistema" (interior/exterior) y la "acción" se deben procesar simultáneamente. Este es también nuestro argumento relacionado con el objeto para el supuesto de que la TaH ligue o interpenetre las semánticas de "sistema" y "acción". Contrariamente a la concepción de la teoría de la acción comunicativa (TkH) de que la TaH haya, con ello, "abandonado la perspectiva de la teoría de la acción ${ }^{n 101}$ tenemos la opinión de que la TaH intenta mantenerse consistente en cuanto a la teoría de la acción. Es pre-

\footnotetext{
"I Idem.

${ }^{98}$ Parsons/Platt, 1990, p. 23.

99 Parsons, $1976 \mathrm{a}, 1$, p. 87.

${ }^{100}$ Habermas, 1981b, 2, p. 366.

${ }^{101}$ Ibid., p. 366.
} 
cisamente la distinción instrumental/consumatorio (=finalidad/medios) la que debe rendir la parte teórica de la acción, con lo cual, de acuerdo con nuestra concepción, la TaH simple y sencillamente sobreestima la capacidad de abstracción de esta distinción. Si a lo largo de este eje del tiempo se pretenden integrar tales sistemas del sentido, como el organismo de comportamiento, la personalidad, el sistema social, el sistema cultural o incluso el sistema fundamental "acción", entonces el potencial de integración de esta distinción simplemente no es suficiente. Tampoco si la TaH la traduce semánticamente a una concepción de los recursos orientada hacia la economía, como lo sugiere la siguiente formulación: "Sobre esta base, se puede dicotomizar la variable definida por el segundo eje como instrumental-consumativo. Se trata de una diferenciación entre los procesos que generan los recursos para una utilización posterior linstrumental RJ] y aquellos que efectúan esta utilización [consumativo RJ], con lo cual destruyen los recursos a través de la utilización. Ahora bien, podemos entender esta diferenciación de manera que no solamente define a un punto dentro de un continuo, sino que también define, mediante el tiempo, al carácter del proceso del sistema. ${ }^{n 102}$

19. ¿Se puede comprobar también para HS2) el frame of reference, para el esquema originario de una unidad de acción relacionada con el actor, una mezcla parecida de las semánticas de "acción" y "sistema"? Opinamos que sí, aunque, en otro nivel de abstracción. Con el esquema de una unidad de acción referida al actor, la TaH presenta un concepto con el cual, de acuerdo con su concepción, se puede comprender cualquier sociedad. Harold J. Beshardy formula esta exigencia de la manera siguiente: "Parsons believes the schema developed in his first major work, upon which all of his later efforts are based, has a 'phenomenological status' in Husserl's sense, that is, the schema is supposed to be essential to any comprehension of society, for it is utterly co-extensive with everything that may be affirmed of society. Parsons believes [...] that the schema he has brought forth is the conceptual bedrock upon which even the most diverse thinkers, wether they know it or not, find a common fundation. ${ }^{n 103}$ En este contexto se puede comprender la afirmación de la TaH cuando dice:

102 Parsons/Platt, 1990, p. 25.

${ }^{103}$ Bershady, 1973, p. 10. 
"It [el esquema RJ] is the indispensable logical framework in which we describe and think about the phenomena of action." ${ }^{104}$ Sabemos que el esquema o la unidad de acción relacionada con el actor consiste en los elementos end, means, conditions, norms y actor. Ahora bien, una unidad de esta índole se vuelve interesante sólo cuando aclara su estructura relacional. Referiéndose a esta circunstancia, la TaH describe la relación entre los elementos de la unidad en la forma siguiente: "Conditions may be conceived at one pole, ends and normative rules at the other, means and effort as the connecting links between them. ${ }^{n 105}$ Si se añade el "actor", entonces tenemos frente a nosotros este esquema (figura 105).

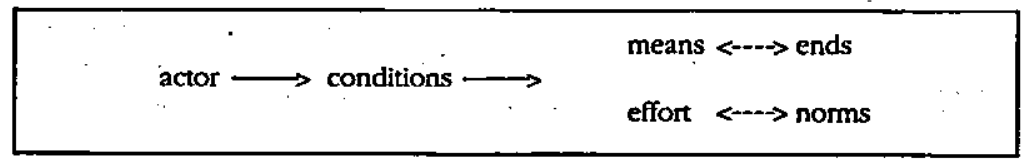

20. Con este concepto, la TaH de hecho puede afirmar: "There are no group properties that are not reducible to properties of sistems of action and there is no ananytical theory of groups which is not translateable into terms of the theory of action. ${ }^{106}$ Sin embargo, ¿aquí se trata realmente de una teoria? Nosotros (TgS) opinamos que no. Realmente es sólo un esquema que está conceptuado en el nivel de la acción y que —en este nivel- no excluye casi nada. Si quisiera ser una teoría debería poder limitar o seleccionar más fuertemente la libertad de movimiento operacional. Basta con observar al aparato clasificatorio que proyecta la $\mathrm{TaH}$, para poder integrar a cualquier fenómeno social dentro del marco de su unidad de acción referida al actor, ${ }^{107}$ para tener que observar inmediatamente: "Parsons has deliberately gauged his schema to provide an immensely broad sweep of generalization. But on the matter of generality a difficulty arises which may be unsuperable. ${ }^{108}$ Hemos visto que debido al hecho de que la unidad de acción referida al actor abre un Newtonian space infinito, mismo que ninguna teoría puede agotar razonablemente, se

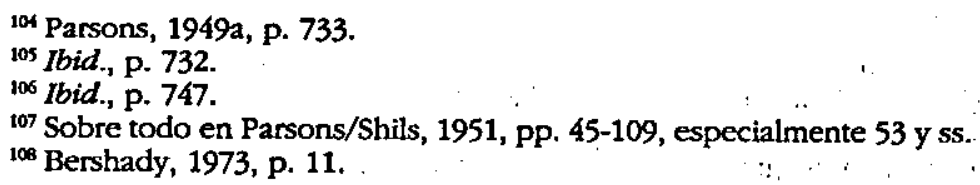


hacen necesarias disposiciones estructurales que obligan a la TaH al desarrollo de una unidad de acción referida al sistema: entonces, la TaH desarrolla, a partir de una arquitectura del frame of reference extremadamente libre de limitaciones, una técnica de construcción de teorías de tablas de cruz igualmente restringente. Ahora bien, si tenemos razón con nuestra afirmación de que la TaH funde las semánticas de "acción" y "sistema", entonces ¿dónde se debe ubicar lo sistémico dentro de la unidad de acción referida al actor? El frame of refenence ciertamente se puede designar como la unidad de acción referida al actor. ¿Pero dónde queda el sistema? ¡El mismo esquema es el sistema! Nuestro testigo es nuevamente la misma TaH: "The term 'system' has been employed throughout in two different senses which should be made clear. On the one hand, it refers to a body of logically interrelated phenomena, a 'theoretical system'; on the other, to a body of empirically interrelated phenomena, an 'empirical system'. The first kind of system is not only not a 'real' system at all, it does not state any facts in an ordinary sense. It merely defines general properties of empirical phenomena and states general relactions between their values. In applying the theoretical system to empirical phenomena, data, ordinarly called facts, must be supplied. These data continue the specific 'values' of the general categories which make up the system of theory. ${ }^{109}$

Podemos formular ahora de la siguiente manera las más importantes deducciones de la comprobación inmanente al objeto de una interpenetración de "acción" y "sistema": primero, la TaH aspira al procesamiento simultáneo de "acción" y "sistema", tanto dentro del marco de una unidad de acción referida al actor (periodo de acción), como también en el nivel de la unidad de acción referida al sistema (periodo de sistema). Una unidad semejante es especialmente interesante debido al hecho de que ambos conceptos, es decir, el frame of reference y el esquema AGIL, están diseñados de manera fundamentalmente diferente.

21. Ahora llegamos a la observacion del $H S 3$ ) llamado fenómeno del estilo de escritura en el cual fue redactada la TaH. Sobre todo quere-

${ }^{109}$ Parsons, 1949 a, p. 71, nota al pie 1 . En otro lugar dice: "Not only is theory an independent variable in the development of science, but the body of the theory in a given field at a given time constitutes to a greater or less degree an integrated system." (lbid., p. 7). 
mos observar qué efectos tiene el supuesto de la simultaneidad de "acción" $y$ "sistema" sobre su forma de expresión escrita. Con ello, se trata del estilo de escritura en el cual ha sido redactada la TaH, mismo que frecuentemente es denominado como dificil e incomprensible, y que Alvin W. Gouldner trata de caracterizar con las palabras siguientes: "Los trabajos de Parsons son tan [...] délficamente enigmáticos, tan'oscuros de manera alemana, tan confusos y confundidores como los de ningún otro sociólogo [...] que conozco [...] Desde el principio, el estilo de Parsons se consideraba entre los sociólogos americanos como sinónimo de la 'dificil comprensibilidad' [...]. El que no solamente los laicos encuentran su estilo ahuyentador, sino también otros sociólogos, es un hecho.'Esto, a la vez, parece indicar que no le importa mucho comunicar razonablemente con sus iguales, ni tampoco que lo entiendan. ${ }^{\text {"10 }}$ En 1941, Alfred Schütz reseñaba la obra de Parsons The Structure of Social Action; Parsons leyó la (aún no publicada) reseña y reaccionó severamente a ella, ${ }^{111}$ en consecuencia de lo cual —aún con buena disposición- Schütz escribió a Parsons: "Por lo pronto, usted critica de mi papel el hecho de que contiene malentendidos de sus ideas. No me sorprende escuchar esto, dado que era una de mis principales intenciones la de aclarar mis interpretaciones.. Usted seguramente está consciente de que su libro no es fácil de leer [RJ], tampoco para lectores cuya lengua materna es el inglés y que han crecido en la tradición de pensar angloamericana. ${ }^{n 12}$

22. No es necesario realzar el hecho de que se puede afirmar algo parecido sobre el estilo de escritura en que han sido elaboradas, por ejemplo, la TkH o la TsS. Y las dificultades de comprensión de textos como los de Immanuel Kant, Johan Gottlieb Fichte, Georg Friedrich Wilhelm Hegel, Theodor W. Adomo o Martin Heidegger son bien conocidas. Ahora bien, el problema de la dificil comprensibilidad del estilo de la TaH, de acuerdo con nuestra opinión, tiene que ver me-

${ }^{110}$ Gouldner, 1974, p. 248. Ralf Dahrendorf escribe: "La crítica de Parsons más escuchada se dirige contra la incomprensibilidad de su terminología técnica, contra la innecesaria complicación de su aparato de conceptos [...]". (Dahrendorf, 1974, p. 234).

111 Talcott Parsons a Alfred Schütz: "PS.: He formulado mis observaciones de manera bastante severa [....]", en Schütz/Parsons, 1977, p. 85.

${ }^{112}$ Alfred Schütz, en Schütz/Parsons, 1977, p. 112. 
nos con cualquier rareza de su autor (la opinión de Gouldner acerca del estilo de escritura de Parsons) que con el hecho de que éste se esfuerza en desarrollar una arquitectura del sistema, la cual va a parar en conflictos con la digitalización o secuenciación del lenguaje escrito. Y es nuevamente Alvin Gouldner el que designa acertadamente la circunstancia en cuestión, aunque sea con intenciones polémicas: "Para Parsons se trata sobre todo del todo y de su capacidad personal de mantenerse en contacto con la percepción relámpago del todo [RJ]. Él está en una carrera contra la temida pérdida de su imagen del todo [.... $]^{n} .{ }^{113}$ No obstante, la reprobación del autor de la TaH por parte de Gouldner, de que dicha empresa teórica es una audaz empresa, ${ }^{114}$ ciertamente desacierta el problema que se está discutiendo aquí. Hemos escogido como guía de este trabajo al problema de que "[...] todo lo que sucede, sucede simultáneamente". ${ }^{115} \mathrm{La} \mathrm{TaH}$ está consciente de esta tesis seguramente tan trivial (como excitante), en el sentido de que exige que se debería asumir una posición de simultaneidad con cualquier análisis desde la perspectiva de la teoría de los sistemas, como lo demuestran las manifestaciones siguientes: "La condición decisiva de cualquier análisis dinámico exitoso es

${ }^{113}$ Gouldner, 1974, p. 253.

114 Las estructuras que Parsons "ve" carecen de cualquier realidad social, "[...] en el sentido específico de que no son apoyadas por definiciones culturales y tradiciones generalmente aceptadas; más bien son diferenciaciones muy personales y como tales solamente de una realidad dudosa. Se deben fijar por escrito muy rápidamente, ya que pueden parecer reales mediante una realización literaria de este tipo. Mucho del trabajo teórico de Parsons es, debido al hecho de que se ocupa exclusivamente de la fijación y profundización de su imagen imprecisa de un todo social, una audaz empresa altamente privatizada [R]], misma que es bastante insensible frente a las reacciones previsibles de los demás y, por lo tanto, también está ciega frente a la dificil comprensibilidad de sus comunicaciones". (Gouldner, 1974, p. 253).

"1s Luhmann, 1990a, p. 98. Para prevenir malentendidos: consideramos la tesis del supuesto de la simultaneidad como un problema que se debe resolver, no como una exigencia con la cual se debe cumplir. Precisamente debido al hecho de que no es posible resolver todo simultáneamente, los sistemas del sentido deben buscar estrategias que les permitan procesar secuencialmente el problema de la simultaneidad. Por el otro lado, siempre están confrontados con el problema de la simultaneidad cuando operan en lo inmediato. Las operaciónes siempre tienen lugar solamente en el presente. Si no operan, dejan de existir. Por lo tanto, deben operar para constituirse y, entonces, sostenerse; se les confronta con el problema de la simultaneidad por razones inherentes. 
la de relacionar permanente y sistemáticamente cualquier problema con el estado del sistema como un todo." ${ }^{n 16}$

23. No es posible sin más una solución textual del supuesto de que todo lo que sucede, sucede simultáneamente. Con ello, por un lado se trata de la presencia simultänea de las circunstancias complejas, por el otro lado, esta presencia simultánea de las circunstancias complejas se puede presentar solamente en forma sucesiva o digital, se puede efectuar solamente con la ayuda de los medios de un lenguaje escrito, mismo que procede secuencialmente. Con ello, nos encontramos en el centro del problema de la "formación de teorías sociológicas" en el sentido de la TaH: ccómo se puede serializar (Sartre) la teoría de tal manera que, a pesar del supuesto de una objetiva presencia simultánea, por un lado, se conserve la tesis de la presencia simultánea y, por el otro lado, la empresa de teoría pueda generar suficientes distinciones para que las partes reproducidas conserven una relativa autonomía semántica, a pesar de la representación simultánea-presentista de la teoria? $\mathrm{La} \mathrm{TaH}$ no formula casualmente que en el nivel categorial general de la teoría, "[...] una función principal del carácter de sistema de la teoria [RJ] es la de asegurar la integridad, o sea, hacer metódicamente imposible que algo importante pase desapercibido, para garantizar que todos los elementos estructurales y las relaciones del sistema se describan explícitamente" ${ }^{117}$ Se puede mencionar nuevamente la observación de Stefan Jensen antes presentada de que "[...] la tarea de Parsons [...] es difícil [R]I, dado que siempre debe tematizar al mundo completo. Su teoría es, en cierta forma, 'holista', consiste - no obstante de que lingüisticamente esté estructurada en muchas frases- en una sola afirmación muy larga y monstruosamente compleja, misma que debe ser considerada como unidad. Algunos críticos parecen haberlo notado en forma rudimentaria, pero, acerca de este punto, no han reflexionado consecuentemente hasta el final de manera teórica de la ciencia". ${ }^{118}$ El qué tan importante es de hecho esta circunstancia para la TaH lo muestra la siguiente observación, misma que hace evidente por qué debería llevar realmente el concepto doble "funcionalismo-estructural" como p. 253.

${ }^{116}$ Talcout Parsons, citado por Alvin W. Gouldner, en Gouldner, 1974,

117 Parsons, $1968 \mathrm{a}, 1$, p. 39.

${ }^{118}$ Jensen, 1976, p. 49. 
su lema: "La relación funcional de cada singular y de cada proceso, con el estado del sistema global representa, por lo tanto, el equivalente lógico de las ecuaciones de simultaneidad [RJ] dentro de un sistema completamente desarrollado de la teoría analítica. Éste parece ser el único camino a través del cual se puede analizar la interdependencia de los factores variables de un sistema, si faltan condiciones previas operacionales y empíricas pará su aplicación. Por ello, el sistema teórico general aquí explicado puede designarse, de acuerdo con su tipo lógico, como 'sistema estructural-funcional' [...]". ${ }^{119}$

24. Naturalmente, el problema de la "presencia simultánea" no es solamente un problema de representación textual, es decir, no es sólo un problema de la realización verbal o por escrito de un supuesto semejante. La realización por escrito de la "presencia simultánea" tiene que tratar, sobre todo, con la dificultad de que los supuestos compactos como la "materia" o el "sujeto", mismos que anteriormente se concebían como unidades con propiedades, ahora se relacionan $y$, con ello, se "volatilizan", se integran á los relacionamientos. Aquello que se presenta entonces como elemento se disuelve en un relacionamiento de relaciones, mismas que, por su parte, remiten a otros relacionamientos. ${ }^{120}$ Uno se podría ahorrar los problemas de representación que se generan necesariamente con el pensamiento racional formulando: "Todo está relacionado con todo." Aunque una afirmación semejante contiene, visto seriamente, una verdad profun$\mathrm{da},{ }^{121}$ realmente no es científicamente satisfactoria. Finalmente, uno quiere saber cómo está relacionado todo con todo, y no simplemente que si lo está. Ahora bien, es esta disolución de las unidades compactas en relaciones la que libera y jsimultáneamente! hace problemático el camino para el supuesto de una presencia simultánea (por

19 Parsons, 1968a, 1, pp. 38-39.

${ }^{120}$ Hemos tratado este hecho extensivamente en el capítulo II sobre la complejidad como la transición de lo simple hacia lo complejo, y hemos tratado de hacer plausible el por qué determinadas unidades complejas deben ser tratadas como unidades "simples": porque solamente de esta manera es posible, por ejemplo, el fenómeno de la ACCión como acontecimiento.

121 "No existen objetos o alternativas estrictamente separables del resto del mundo. Todo está relacionado con todo", formula C.F.v. Weizsācker, en Weizsäcker C.F.v., 1991, p. 134. 
escrito). Con referencia a esta dificultad, o sea, la disolución de los supuestos compactos en relaciones, resultan, por lo menos, dos problemas de representación. El primer problema de representación se refiere a la representación textual de aquellas relaciones que relacionan otras relaciones: ¿qué tan profunda y/o amplia debe ser la realización escrita para poder representar de manera suficientemente plausible los relacionamientos en cuestión, sin sobrecargar la capacidad de comprensión del lector/escucha? El segundo problema de representación, mismo que está estrechamente relacionado con el primero, consiste en considerar siempre el "todo" en la representación sucesiva de las partes. Con ello, puede suceder fácilmente que las partes pierdan su autonomía mediante el supuesto presentista del "todo", o incluso se conviertan en epifenómenos, esto es un reproche estandar frente a la teoría del sistema general de la acción (TaH): "[...] esta idea organicista, misma que implica el hecho de que sus partes no poseen, en su totalidad, ninguna realidad además de la de ser miembro, ocasiona esta prisa hacia la pluralidad/simultaneidad, la cual contribuye en gran medida a la dificultad de comprensibilidad de Parsons". ${ }^{122}$ Se debe lamentar que Alvin W. Gouldner comprenda el supuesto de la simultaneidad de la $\mathrm{TaH}$, en primer orden, como un problema textual-estético $\mathrm{y}$, por lo demás, como una pose idiosincrática de su autor. Esto es, de acuerdo con nuestra opinión, una evaluación falsa de este problema difícil de manejar.

25. Según nuestro punto de vista, la teoría del sistema general de la acción (TaH) se ha cargado de un problema por medio de la igualación de "acción" y "sistema", mismo que también determina la forma de su estilo de escritura. Ahora bien, uno podría opinar que un problema semejante no sería demasiado relevante, ya que finalmente representa un problema estético y que las cuestiones del estilo verbal/escrito son algo completamente distinto a la observación de los sistemas del sentido. ${ }^{123} \mathrm{~A}$ ello se debe responder: precisamente los sistemas del sentido tales como el derecho, la política, la ciencia, la economía o incluso la religión se basan en verbalizaciones o

${ }^{122}$ Gouldner, 1974, p. 254.

${ }^{123}$ Se puede comprender como sistémica la COMUNICACIón por escrito frente a la verbal, con lo cual el problema de la secuencialidad de ambas formas obtendría un estatus completamente diferente. 
fijaciones por escrito, las cuales procesan secuencialmente (diálogos, discursos, sermones, constituciones, leyes, contratos, acuerdos comerciales, publicaciones científicas, la biblia, etc.) Ahora bien, la $\mathrm{TaH}$ no se encuentra frente al problema objetivo del supuesto de la simultaneidad solamente como problema, sino también como una exigencia a ser cumplida. iY precisamente esto es también su problema! Se genera - como ya se ha demostrado antes varias veces-debido al hecho de que conecta la acción (como acontecimiento canjeable momentáneamente) con el sistema (en el sentido de la TaH como estructura relacional), de tal manera que se ve obligada a permitir, con cada acto de acción, la emergencia de la sociedad global, iy esto ya en el nivel de la escritura! Se entenderá por sí mismo que la TaH no es capaz de resolver estilísticamente esta circunstancia. Sin embargo, nos importa destacar el hecho de que persigue al problema -como exigencia- hasta adentro de la estrategia de formulación por escrito. Ahora bien, ¿existe una solución de este problema en el nivel de la arquitectura de la teoría de la TaH? Opinamos que sí. Por lo pronto, y sobre todo, se debe verificar: si todo lo que sucede, sucede simultáneamente, entonces se trata realmente de un problema serio: tenemos que trasladar lo simultáneo hacia lo no-simultáneo, serializar el problema en cuestión o traducirlo en secuencias: "primero viene esto, después lo otro" o first things first. La técnica del distinguir, que denominamos como la "lógica de las distinciones", representa una estrategia exitosa para la transformación de la simultaneidad en no-simultaneidad. Ya hemos visto que la TaH se enreda, al principio de su arquitectura de la teoría, en problemas serios, puesto de que trata cuasi identicamente a las semánticas de la "acción" y del "sistema". Si aplicamos el escalpelo de la "lógica de las distinciones", entonces podemos decir: La "acción" es de hecho, por un lado, "sistema", sin embargo, la "acción" es distinta del "sistema". ¿Cómo es esto posible? ¿Cómo se puede explicar el supuesto de que, por un lado, la "acción" se debe comprender como "sistema", pero, por el otro lado, no debe ser comprendida como "sistema"? Observemos esta circunstancia más de cerca.

26. Cada teoría que parte del hecho de que todo lo que sucede, sucede simultáneamente - y esto es, así lo queremos decir aquí generalizando la premisa de cualquier forma de la teoria de los sistemas, dado que se erige sobre una distinción de interior/exterior que siempre in- 
dica la presencia simultánea (Heidegger) del sistema $y$ del entorno- debe poder resolver, por lo menos, dos problemas, los cuales están estrechamente conectados con su correspondiente supuesto fundamental (independientemente de cuál es). Éstos son: el problema del relacionamiento $a$ ) estructural-espacial y $b$ ) dinámico-temporal del mencionado supuesto fundamental, mismo que siempre juega el papel de una abstracción primaria. Primero, queremos dirigir nuestra mirada sobre el problema espacial.

En vista de la circunstancia de que la TaH parte de la tesis de la simultaneidad, el supuesto de una abstracción primaria tiene un significado decisivo, ya que es esta abstracción primaria la que debe sostener la presencia simultánea de la circunstancia principal de la correspondiente teoría. Ahora bien, la TaH está consciente de este problema de la selección de un nivel de abstracción primario, como lo documenta la siguiente manifestación: "Todo depende de las abstracciones primarias: la productividad y generalidad de una teoría dependen del tipo de las abstracciones primarias. El dónde delimitamos las fronteras, qué incluimos y qué excluimos, es una diferencia. La manera de determinar los puntos de importancia es una diferencia. ¿Analizamos, por ejemplo, el 'grupo humano' o analizamos el 'sistema social'? No son los mismos objetos, y la decisión de cuál escogemos hace una diferencia. ¿Analizamos el 'comportamiento' o analizamos la 'acción'? No son los mismos objetos, y la diferencia hace una diferencia [RJ]." ${ }^{\text {224 }}$ Sabemos que la TaH escoge a la "acción como unidad analítica", como abstracción primaria, con lo cual se decide entonces por la action unit, de lo que depende, posteriormente, el grado de productividad y generalidad de su diseño de teoría. El supuesto de la acción como una unidad formada analíticamente tiene por efecto un problema relacional. Los problemas relacionales siempre poseen un carácter espacial-estructural, ya que se trata de registrar la estructura de relaciones de "algo". No obstante, esto es posible solamente cuando se presenta una estructura de relaciones precisamente de modo "espacial". Con ello, el problema espacial-

${ }^{124}$ Parsons/Ackerman, 1976, p. 72. Aquí es de interés la coincidencia entre Parsons/Ackerman, 1976 y Bateson, 1983, en cuanto al supuesto teórico de la información de que sólo la diferencia de una diferencia hace una diferencia. Preferimos la formulación: "apenas la distinción de una distinción forma una distinción", ya que hemos comprobado semánticamente los conceptos de "diferenciacion" y "diferencia" de manera específica. 
estructural de la TaH es, en este contexto: ¿cómo es posible la acción como relación? ${ }^{125}$

27. Dentro de esta dimensión, vemos el problema en el hecho de que la "acción como relación" no puede ser capaz de integrar y diferenctar adecuadamente la presencia simultánea de los hechos sociales. Y asombrosamente no debido a la circunstancia de que "acción", en el sentido de la TkH, por un lado representa una categoría demasiado concreta y, por el otro lado es demasiado abstracta. Es demasiado concreta en cuanto a la integración de, por ejemplo, diferentes "tipos de sistemas" como el "organismo", la "personalidad", el "sistema social" y el "sistema cultural". Preguntamos: ¿cómo se vería la unidad de acción de un organismo? zo la de un sistema de personalidades? ¿cómo la de un sistema social o de un sistema cultural, etc.? En este contexto se debería poder ofrecer una tipología de las acciones es en el sentido de un tipo de acción "orgánico", "personal", "social" o "cultural". Precisamente esto es lo que la teoría de la acción comunicativa (TkH) intenta con sus diferentes tipos de acción comu-

${ }^{125} \mathrm{Ya}$ arriba intentamos explicar que la TaH escoge a la action unit como unidad de su arquitectura de la teoría, o sea, que procede desde la perspectiva de la teoría de la acción. Sin embargo, posteriormente define la action unit completamente como system unit. Opinamos que la intención de la TaH es la de utilizar la action unit como unidad basal; no obstante, luego efectúa esta unidad como system unit desde la perspectiva de la pragmática de la investigación. Consideramos a esta circunstancia de una delimitación insuficiente entre action unit y system unit como el problema principal del diseño de la teoría de la TaH. Ambos supuestos son correctos, sin embargo, cada sistema del sentido debe, si se interpreta como capaz de la accion, tratar las propias (no las ajenas) unidades basales como action units -aunque otros sistemas del sentido como la ciencia creen observar que semejantes unidades basales representan realmente system units. Aun más, el mismo sistema de la ciencia no puede - si quiere mantenerse capaz de la acciónescapar a la obligación de observar a las propias unidades basales como action units compactas, simples e intransparentes. Repetimos: que la TaH trata a las action units como system units y a las system units como action units hace que se meta en dificultades insuperables. "Resolvemos" este problema tematizando - de acuerdo con la tesis de que la unidad se puede comprender solamente como la unidad de la distinción de diferencia y diferenciación-tanto la unidad de acción y sistema como también su distinción. Nuevamente, la TkH tematiza - supuestamente como reacción a la "solución de unidad" de la TaH— solamente su distinción como dicotomía de la acción y el sistema. 
nicativa, pero también nosotros ( $\mathrm{TgS}$ ) tomamos un camino parecido y, por lo tanto, nos vemos frente a la necesidad de hablar de "ACCION"; cuando se trata de reducir a un denominador común las diferentes formas de acción. ${ }^{26}$ Sin embargo, el concepto de acción de la TaH es demasiado abstracto como para poder comprender adecuadamente el fenómeno "acción" como acontecimiento social: puesto que la TaH descómpone otra vez la unidad de acción (unit act) para los sistemas que la utilizan, la "acción" no puede ser utilizada como suceso por parte de estos sistemas. No obstante, la acción es capaz de conexión solamente en su forma de utilización, con lo cual es precisamente la capacidad de conexión de semejantes sucesos de acción la que constituye los "sistemas". Los sucesos posibilitan la capacidad de conexión, la capacidad de conexión conduce a las formas sistémicas, mismas que entonces procesan como sistemas del sentido.

28. El otro problema que una teoria del estilo de la TaH debe resolver - un tipo de teoría que parte de la simultaneidad del sistema y del entorno- es aquél del relacionamiento dinámico-temporal de la abstracción primaria en cuestion. Dicho de otra manera: ¿cómo puede surgir el tiempo a partir de una presencia simultánea con referencia espacial-temporal (sistema/entorno como distinción de adentro/ afuera)? O: ¿cómo se puede explicar, dentro del marco de una teoría del sistema del tipo presentista-simultáneo, el cambio y, con ello, la evolución sociocultural? El que supuestamente no sea capaz de tematizar el aspecto dinámico de la SOCIEDAD, pertenece a las críticas estandar frente a cualquier teoría del sistema y especialmente fren-' te a la teoría del sistema general de la acción (TaH). Nuevamente, la TaH misma es una de las primeras arquitecturas de teoría que está consciente de esta situación problemática: "It has persistently been alleged that the 'structural-functional' approach to the problems of theory in the sociological field suffers from a 'static' bias. It has been held that the problems of change were outside its purview and since... these are obviously the really important problems, such a theory only suceeds in cutting itself off from genuine empirical relevance.".2?

${ }^{126}$ Aquí (TgS) nos importan las formas de la acción sociales (institucio-' nes), personales (conciencia), afectivas (sentimientos) y corporales (percepción).

127 Parsons, 1970a, p. 535. 
Ahora bien, la -TaH se ocupa detalladamente, dentro del marco del trabajo The Social System, del problema del cambio y observa al final del capitulo "The Processes of Change of the Social System": "If theory is good tbeory, whichever type of problem it tackles most directly, there is no reason whatever to believe that it will not be equally applicable to the problems of change and to those of process within a stabilized system. ${ }^{n 128}$ En todo caso, de acuerdo con las manifestaciones de su autor, la TaH es capaz de abordar y solucionar adecuadamente los problemas del cambio e incluso, en forma general, los problemas de la teoría con la dimensión del "tiempo". Sin embargo, ¿esto sucede realmente?

29. De acuerdo con nuestra opinión, para la TaH el problema consiste, dentro de la dimensión temporal-dinámica, en poder explicar adecuadamente la emergencia. Aquí estorba nuevamente la fundición de las semánticas de "acción" y "sistema": con la ayuda de una "acción sistémica" de esta naturaleza se hace el intento de determinar el cambio y la emergencia. No obstante, la TaH permanece adherida a la dimensión espacial-estructural: realmente nunca hace suyo seriamente el problema del tiempo. Se puede decir también que su procedimiento de la tabla de cruz ${ }^{129}$ presenta el problema de la emergencia como siempre-ya-resuelto.

Esto se deduce del hecho de que los sistemas parciales del sistema fundamental "acción" "[...] nunca pueden separarse de la formación, nunca se pueden hacer autarcas [...]", como lo formula la teoría de los sistemas sociales. ${ }^{130}$ No obstante, la TaH debería explicar dicha

${ }^{128}$ Ibid., p. 535.

129 Vemos el problema principal de un procedimiento semejante en el hecho de que las relaciones dentro de una tabla de cruz, pueden ser solamente simétricas (¿para qué más el cruzamiento entre las distintas circunstancias?), salvo que se señale explícitamente una determinada relación asimétrica, con la consecuencia de que la tabla se debe modificar considerablemente o que se hace inservible. Desde la perspectiva de la pragmática de la investigación, la técnica de la tabla de cruz tiene sentido solamente cuando forma los relacionamientos entre los diferentes items generalmente en forma simétrica. Con la ayuda de la técnica de la pragmática de las distinciones llegamos a un acuerdo entre a) una técnica de tabla de cruz, que genera demasiada convergencia; y b) la técnica de diferenciación demasiado limitante -dado que en realidad solo permite formas asimétricas-de Spencer Brown y de la TsS.

${ }^{330}$ Luhmann, 1980 b, p. 9. 
separación de la formación, o diferenciamiento, si quisiera comprender la emergencia y, con ello, el tiempo dentro del marco de su diseño de la teoría. El hecho de politizar, desde la perspectiva de la crítica, el problema de la TaH acerca de la emergencia e interpretarlo como su conservatismo secreto, como lo realiza Alvin W. Gouldner, ${ }^{131}$ representa una incomprensibilidad de este problema objetivo. Opinamos que la TaH percibe enteramente el hecho de que existe un problema del cambio, mismo que, sin embargo, es dificilmente solucionable en el marco de su arquitectura de la teoría. ¿Cómo se deberían interpretar las manifestaciones, en caso cońtrario enigmáticas, al final del trabajo The Social System?: "[...] while we repeat we do not have a complete theory of the processes of change in social systems, we do have a canon of approach to the problems of constructing such a theory. When such a theory is available the millennium for social science will have anived. This will not come in our time and most probably never". ${ }^{132}$

30. Nos queremos dirigir finalmente al problema metodológico del "realismo analítico" $A R$ ) y demostrar que solucionando este problema se pueden solucionar conjuntamente aquellos problemas que surgen debido al hecho de que Parsons funde hasta la irreconocibilidad uno con el otro los conceptos de "acción" y "sistema". Naturalmente, una solución posible del problema del "realismo analítico" modifica al concepto de la "acción" en la forma presentada por Parsons. La TaH ha afirmado siempre la primacía de la acción, aunque se sabe

${ }^{131}$ Gouldner, 1974, pp. 423 y ss. El tenor de las formulaciones de Gouldner no es precisamente agradable: "Su (Parsons) 'sistema social' es un mundo social con una ramificada estructura propia de defensa contra la tensión, el desorden y el conflicto: si una pieza de esta ramificación se rompe, entonces se erige inmediatamente otra para amortiguar el golpe [...] Parsons diseñ 6 un sistema social cuyo equilibrio, una vez establecido, está asegurado para ahora y para toda la eternidad [...] (p. 424). El problema social de Parsons es un perpetuum moblle [...] (p. 425). Tan solo el pensamiento de ocuparse del problema del cambio del sistema, parece causar un tipo torturador de dolor, comparable con el de un té́logo moderno a quien se le exhorta a discutir la naturaleza del diábolo" (pp. 426-427). Tenemos la opinión de que Gouldner ciertamente describe el problema en cierto aspecto, sin embargo, no lo puede comprender realmente $y$, por lo tanto, huye hacia dentro de una polémica innecesaria.

${ }^{132}$ Parsons, 1970a, p. 534. 
que mueve la mirada - sobre todo despues de 1951- de la "unidad de acción" (action unit) hacia el "sistema de acción" (action system). Opinamos (TgS) que se penetra más rápidamente en el centro del Problem of Theory Construction ${ }^{133}$ de la TaH si se observa que imagina las semánticas de "acción" y "sistema" de manera unificada. En todo caso, permanece laudable el hecho de su búsqueda de un $u n i t$, de una unidad basal en el ámbito de la dimensión social del sentido. La comparación de la unit of action sociológica con la unit of matter ${ }^{134}$ fisica da testimonio, como ya lo hemos explicado antes, de esta búsqueda radical de una unidad de construcción elemental de la SOCIEDAD, misma que tendría que explicar su complejidad y estabilidad dinámica. Metodológicamente, la posición de la TaH es, como ya lo dijimos, la de un "realismo analítico": una posición que debería significar que los conceptos y categorías que utiliza el sistema de la ciencia para explorar el mundo científicamente deben ser analíticos. Sin embargo, estos conceptos y categorías forman parte del sistema de la ciencia, con la propiedad de poder captar la realidad adecuadamente. $\mathrm{O}$, en las palabras de la $\mathrm{TaH}:{ }^{~ "[. . .] ~ i t ~ i s ~ m a i n t a i n e d ~}$ that at least some of the general concepts of science are not fictional but adequately 'grasp' aspects of the objective external world. This is true of the concepts here called analytical elements. Hence the position here taken is, in an epistemological sense, realistic". ${ }^{135}$ Hasta aquí, todo va bien. De acuerdo con la TaH, la unidad basal de la dimensión social del sentido es la "acción" (el unit act), misma que está compuesta por diversos elementos y que presenta una unidad analítica indivisible. Pero, asi se puede preguntar, ¿qué estatus tiene dicha unidad analitica, si, primero, es referida retroactivamente a los sistemas ajenos a la ciencia $y$, segundo, al sistema que la genera y utiliza, o sea, al sistema parcial de la ciencia misma? Con otras palabras, ¿pueden los sistemas del sentido, cuya unidad de acción tiene carácter analítico, actuar sobre la base de una "unidad analítica" de esta índole? ¿Es la teoría de la acción de la TaH, en su redacción analítica, capaz de la acción? No por casualidad la teoría de los sistemas sociales (Tśs) dirige hacia la teoría del sistema general de la acción (TaH) la pregunta justificada: ¿es el análisis, por su parte, acción o qué

133 Véase Jürgen Habermas, Talcott Parsons: Problems of Theory Construction. (Habermas, 1981).

134 Parsons, 1949a, p. 43.

135 Ibid., p. 730. 
más es la base social de su propia realidad? $Y$, aun más radicalmente: ¿puede un sistema de acción analizador de acciones analizar también a su propia acción analizadora, aunque la acción tiene, dentro del sistema, una "función de elemento [RJ]"? ${ }^{136}$ Sea realzado aquí el hecho de que detrás de estas preguntas se ocultan problemas que, de acuerdo con nuestra opinión, pueden ser resueltos solamente de modo autorreferencial. Queremos descomponer en dos problemas parciales el problema epistemológico del "realismo analítico" y -en el contexto del sistema de la ciencia- cubrirlo con las siguientes preguntas: a) ¿cómo es posible el análisis? y b) ¿cómo es posible la acción?

31. El dilema en el que se encuentra la TaH es: solamente aquel sistema que puede procesar la acción como suceso (o función elemental) es realmente capaz de acción, puesto que así se puede garantizar la necesaria capacidad de conexión. Sin embargo, la "acción" pierde su función de elemento simple, intransparente y elemental mediante la descomposición analítica del acontecimiento elemental "acción", con lo cual la hace inservible como suceso constituyente de la acción. ${ }^{137} \mathrm{LaTaH}$ parece no haber defendido más al "realismo analitico", en su forma anterior, durante su periodo funcionalista de sistema. La "teoría de la acción comunicativa" (TkH) incluso opina que con la TaH, las "manifestaciones acerca de las relaciones analíticas se convierten [R]], por debajo del agua, en afirmaciones acerca de las relaciones empíricas entre los componentes del sistema". ${ }^{138}$ En todo caso, el problema de la TaH persiste, de modo que con una concepción de la acción de esta naturaleza ni la ciencia ni los sistemas ajenos a la ciencia pueden ser capaces de la acción. No obstante, si el mismo sistema de la ciencia y, con él, el sistema "teoría sociológica" no son capaces de la acción, ya que solamente observan a sus propias unidades de acción (de manera analítica), pero no las pueden utilizar (de manera de suceso), entonces ¿cuál estatus tienen sus afirmaciones? Y más: sabemos que el sistema de la ciencia actúa (jtan sólo este proyecto es prueba de ello!), pero ¿cómo? Dentro del marco de la arquitectura de teoría de la $\mathrm{TaH}$, este problema no se discute más, sin

${ }^{136}$ Luhmann, 1980 b, p. 6.

${ }^{137}$ Ciertamente una unidad analítica semejante no es utilizable en la forma de un suceso, sin embargo es observable analiticamente.

${ }^{136}$ Habermas, 1981 b, 2, p. 356. 
embargo - perisado consecuentemente-, sus afirmaciones (las de la $\mathrm{TaH}$ ) no pueden clamar ninguna resonancia social ya que carecen, debido a su condición analítica, de cualquier forma de ación y, con ello, de cualquier forma de efecto social. Esta circunstancia se puede dramatizar diciendo: la teoría de la acción de la TaH es una teoría sin acción. No obstante, sabemos que la teoría del sistema general de la acción ( $\mathrm{TaH}$ ) ha desarrollado un gran efecto dentro del marco del sistema "teoría sociológica" y que hasta la actualidad ise ha mantenida capaz de acción! Por lo tanto, este problema debe tener una solución, la pregunta es solamente: ¿cuál sería?

32. En cuanto a la teoría del conocimiento, la TaH habla de un "realismo analítico" y, con ello, se refiere al hecho de que el análisis está - como asunto del conocimiento- relacionado con la realidad. En lo que concierne al objeto del conocimiento, tiene la idea de que el análisis del concepto puede conducir a resultados que pueden asegurar el contacto con la realidad de la teoría. ${ }^{139}$ No obstante, no tematiza el objeto del conocimiento. Aquí es nuevamente útil el supuesto de la autorreferencia, mismo que conduce al problema del círculo en el cual el objeto de conocimiento es simultáneamente conocimiento del objeto. Hemos visto que una tautología de este tipo ciertamente no es evitable como autorreferencia "pura", sin embargo, se puede "desdoblar" mediante la interrupción con la ayuda de las distinciones. En el caso de la teoría del conocimiento, esto sucede por medio de la distinción entre conocimiento y objeto. ${ }^{140}$ Pero, y esto era nuestro problema, ¿cómo se puede controlar una estructura autoconstituyente? Nuevamente, ipor medio de la autorreferencia! El

${ }^{139}$ La TsS formula en este contexto que el planteamiento estructuralista de la TaH consiste en el supuesto "[...] de que mediante el análisis de las componentes mínimas del concepto de la acción se pueden alcanzar resultados, mismos que pueden asegurar suficientemente el contacto con la realidad de la teoría, independientemente de las desviaciones del modelo de teoría encontradas en la realidad empírica". (Luhmann, 1984, p. 379).

${ }_{140} \mathrm{La}$ distinción entre objeto y conocimiento asegura la capacidad de conexión del sistema de la ciencia, debido al hecho de que se evita el corto circuito de la autorreferencia dentro del sistema en la forma "el objeto de conocimiento es el objeto del conocimienton, mediante una binarización de esta naturaleza. Estos esquemas o códigos binarios representan formas del aseguramiento de la capacidad de conexión dentro de los sistemas autorreferenciales. Váse acerca de ello, Luhmann, 1980a, 5, pp. 310-311. 
conocimiento no puede, a través de su "objeto", afirmar algo que "él mismo" no está dispuesto a aceptar como afirmación. Todo lo que afirma ácerca de su objeto, también debe ser cierto para él mismo, se debe referir también a sí mismo. Visto desde esta perspectiva, la autorreferencia conduce al hecho de que la teoria es sometida a una presión de autocomparación y, con ello, nolens wolens ejerce el control en la forma del autocontrol. Hasta aquí concordamos ampliamente con las propuestas de la teoría de los sistemas sociales (TsS) y opinamos que la tèoría del sistema general de la acción (TaH) se debe considerar realmente como insuficiente.

33. Ahora bien, el verdadero problema de un "realismo analítico" consiste en el hecho de que, desde la perspectiva de observación del sistema parcial ciencia (o del sistema parcial "teoría sociológica"), se puede observar a otros sistemas ajenos a la ciencia, a los cuales, sin embargo, no se les puede atribuir la calidad de realidad que califica al sistema observador -en este caso la ciencia. Por lo tanto, existe una separación esencial entre sistemas observadores y observados, misma que tiene efectos sobre el proceso de producción de la información: el sistema observador siempre ve más, y simultáneamente siempre menos, que el sistema observado. Ve más porque ve al sistema desde afuera; a la vez, ve menos, ya que no es capaz de ver al sistema desde adentro. Ahora bien, ¿qué sucede cuando la ciencia observa? La teoria del sistema general de la acción (TaH) diría que analiza los acontecimientos reales. En este contexto, realidad significa que existe de hecho una realidad empirica, a la cual se refiere la teoria. En las palabras de la TaH: "[...] scientific theory implies that empirical reality in this sense is a factual order" ${ }^{14 t}$ Analítica significa que la teoría proyecta un modelo de la realidad que no puede concordar completamente con ésta. Acerca de ello dice la TaH: "[...] scientific theory is not itself an empirical entity; it is an ideal representation of empirical phenomena or aspects of them". ${ }^{142} \mathrm{La} \mathrm{TaH}$ resume la posición teórica de conocimiento del "realismo analítico" de la manera siguiente: "As opposed to the fiction view it is maintained that at least some of the general concepts of science are not fictional but adequately 'grasp' aspects of the objective external world [...] Hence

141 Parsons, 1949a, p. 753.

142 Ibid., p. 754. 
the position here taken is, in an epistemological sense, realistic [RJ]. At the same time it avoids the objectionable implications of an empiricist realism. These concepts correspond, not to concrete phenomena [...] There is no implication that the value of any such element, or even of all those included in one logically coherent system, is completely descriptive of any particular thing or event. Hence it is necessary to qualify the term realism with 'analytical' [R]. It is the possibility of making this qualification which renders the resort to fictionalism unnecessary. ${ }^{\text {1143 }}$

34. ¿Cómo es posible el análisis en el contexto del sistema ciencia? ¿Aquello que es observado con è apoyo del análisis científico, es real o ficticio? Preguntado de manera aún más radical: ¿es la observación analítica una ficción? Lo último seguramente no es el caso, ya que uno se puede asegurar de su realidad todo el tiempo mediante la observación del sistema ciencia, y se verá: la "actividad analítica", en cierta manera, se debe considerar como igual a la "actividad cientifica". Sin embargo, ¿es ficticio el contenido de una observación analítica de los sistemas ajenos a la ciencia? Aquí se debe observar más detalladamente lo que se puede querer decir con "contenido". Por lo tanto, procedamos cuidadosamente. El sistema "ciencia" observa, por ejemplo, al fenómeno "hombre", una semántica altamente compacta y estorbosa, misma que es procesada diariamente. El biólogo vería "células" y "organismos", el físico "moléculas" y "átomos", el psicólogo "afectos" y "emociones", etc. Ahora bien, la tarea específica y seguramente no sencilla de una sociología consiste en el hecho de observar el cómo otros sistemas procesan la semántica "hombrè, y cómo registran a estas observaciones - desde la perspectiva de la observación ajena del sistema ciencia- como supuestos sintéticos. La economía considera al "hombre" como "comprador" (o como "suceso monetario"), la política lo ve como "elector", el arte lo vè como "objeto pintable", la educación lo ve como "alumno", la religión lo ve como "miembro de la comunidad" ("laico"), etc. Desde la perspectiva de una sociología, el comportamiento analítico consistiría entonces en el hecho de descubrir estas perspectivas diferentes y coordinarlas. Se puede decir que generalmente los sistemas ajenos a la ciencia no ven a sus elementos de la misma manera como

${ }^{143}$ Ibid., p. 730. 
lo efectúa el sistema ciencia, aunque también los desmiembran analîticamente: la economía ve al "hombre" no como "hombre", sino como "comprador" o como "suceso capaz de pagar"..., etc. No obstante, existe la posibilidad de que estos sistemas se adueñen de los conocimientos realizados por la ciencia a través del análisis.

35. Ciertamente, también los sistemas ajenos a la ciencia utilizan la distinción análisis/sintesis. Sin embargo, es central, debido a su carácter constituyente, solamente para el sistema ciencia. Aun más, la forma de acción de este sistema está vinculada estrechamente a esta distinción, al comportamiento científico, el cual disuelve y recombina nuevamente los conceptos semánticos. Ni la economía, ni la educación o el arte y mucho menos la religión actúan descomponiendo analíticamente sus conceptos para recombiriarlos posteriormente. Se puede anotar que el modo de acción del sistema ciencia consiste en el análisis y la nueva recombinación de los sucesos conceptuales. Pero ¿qué estatus tienen los conceptos de esta índole? ¿Son nada más modelos de sistemas ajenos? ¿Inventa la ciencia simplemente una determinada semántica, con la cual forma aquello que considera como "realidad"? Sobre la base de la teoria de observación aqui representada, la ciencia está obligada a observar exactamente cómo observan y actúan los otros sistemas. $\mathrm{X}$ aquello que observa, lo denomina entonces como "sintético" o "compacto" y "se apropia de ello" para descomponerlo y analizarlo. Resumimos: primero, la arbitrariedad de una observación científica se detiene mediante la indicacion: "¡observa al observador!"; segundo, la actividad de observación científica se dirige sobre las unidades sintéticas, mismas que procesan sucesos "reales"; tercero, los sucesos sintéticos se desmembran por medio del comportamiento analítico y, de esta manera, son cientificados. También se puede formular: de la misma manera en que la economia guía todo aquello que observa por el cuello de botella del "dinero", la ciencia transforma todo lo que observa en "suceso analítico". En este contexto y de acuerdo con el supuesto tetrádico proponemos ${ }^{144}$ observar al sistema ciencia como constituido por medio de dos distinciones: su código o diferenciación asimétrica es:

${ }^{144}$ Argumentamos de manera similar en el capítulo II sobre la complejidad. Véase alli, sobre todo: elemento ültimo, ficcional y ontológico. 
"cierto/no falso", su programa o su diferencia simétrica tiene la forma: "comportamiento analítico y/o sintético" (figura 106).

\begin{tabular}{cll|}
\hline & \multicolumn{1}{c|}{ Ciencta: } \\
Código & (diferenciación asimétrica): & "cierto, no falso" \\
Programa & (diferencia simétrica): & "análisis y/o síntesis" \\
\hline
\end{tabular}

Con esta propuesta parecemos haber esquivado la importante distinción de conocimiento/objeto - sin embargo, no completamente. En el comportamiento "sintético" está contenida implícitamente la "observación del objeto", como en el comportamiento "analítico" lo está la "observación del conocimiento". Por lo tanto, el sistema ciencia está cerrado mediante el código de "cierto, no falso", y mediante el programa "análisis y/o síntesis" está abierto (internamente) hacia afuera.

36. ¿Cómo es posible la acción en el contexto del sistema ciencia? Se debe realzar especialmente que cualquier sistema trata la ACCION como suceso y no como unidad analitica, como lo realza una y otra vez la teoría del sistema general de la acción (TaH). El comportamiento de conexión se puede generar solamente por medio de una constelación de sucesos: una ACCIÓN hace conexión con la siguiente, ésta con la próxima, etc. La solución real del problema de la TaH - el querer dejar valer a la acción solamente en su forma analítica, con la consecuencia de que se le debe negar toda capacidad de acción a dicho concepto de la acción-consistiría entonces en el hecho de ver el modo de Acción del sistema ciencia especial y exclusivamente en el "comportamiento analítico". Ahora bien, ino existe aquí el peligro de que el sistema ciencia se haga incapaz de la acción, como lo pudimos observar con la $\mathrm{TaH}$, ya que afirmamos igualmente que el modo de operación de la ciencia es, entre otros, analítico? Se debe reflexionar más exactamente: si el sistema ciencia se observa a) a símismo, entonces puede proceder solamente analizando la propia capacidad de análisis. Sin embargo, se debe preguntar si ¿posiblemente no puede fallar en la observación en tal grado que debe anotar que los propios últimos elementos $\longrightarrow$ sea, los propios elementos 
"simples" e "intransparentes" - son las operaciones analiticas mismas? Se reflexiona otra vez: si quisiera, por su parte, analizar a esta observación (janalítica!) del análisis recién hecha, entonces terminaría otra vez en sí mismo, o sea, en el "comportamiento analítico". Esto significa que el "análisis" dentro del sistema ciencia es real. Aun más, el suceso "análisis" es un momento parcial de la tipificación de la acción de la ciencia, una tipificación que es procesada como la distinción de análisis/sîntesis. Si b) el sistema ciencia observa a los sistemas ajenos a la ciencia, entonces debe apegarse, en cuanto a la observación, a los modos de operación de estos sistemas. El si la insolvencia es el modo de operación real para la economía, y la trascendencia el modo real de operación para la religión, sigue siendo una pregunta abierta y puede, desde la perspectiva de la observación, ser comprobada o, en caso dado, corregida mediante los mismos sistemas correspondientes. El sistema de la ciencia no puede tener una seguridad absoluta acerca de ello. Con otras palabras: para el sistema ciencia, las teorias son operaciones reales, con las cuales asegura su autorreferencia. Las afirmaciones teóricas pueden, pero no deben, ser ciertas para los demás sistemas. No obstante, las mismas afirmaciones y, sobre todo, la distinción de comportamiento analítico/sintético, son existencialmente importantes para la ciencia. La deducción de estas reflexiones es: jel comportamiento analítico es real para el sistema ciencia! Es un momento constituyente de ella misma. Puesto que los sistemas ajenos a la ciencia se realizan por medio de otros modos de comunicación y acción, o sea, que no necesitan la distinción analítico/sintética para el condicionamiento de sus propias posibilidades, no se puede generar el problema de que aquello que la ciencia observa mediante otros sistemas "sea solamente analítico". Naturalmente, sus observaciones están determinadas analíticamente, pero jéste es precisamente su modo de operación real! Solamente por medio de la observación puede afirmar en la forma de las observaciones ajenas, mismas que pueden proceder sólo internamente de la ciencia, algo acerca de la realidad de los sistemas ajenos a la ciencia. En última instancia, no es ella quien decide sobre la aceptación o el rechazo de las observaciones ajenas, sino los sistemas ajenos a la ciencia, observados por parte de ésta. Ahora bien, podemos contestar las preguntas hechas antes. Habiamos preguntado acerca de la posibilidad de análisis y acción en el contexto de la ciencia. Ahora podemos contestar: el análisis es posible porque representa al modo de acción del sistema ciencia, y la acción es posible 
porque el análisis es el elemento último, el suceso del sistema ciencia, mismo que no puede ser descompuesto más. la TaH no puede ver esta posibilidad de solución debido al hecho de que no separa el modo de ACCIÓN de la ciencia del modo de ACCIÓN de los sistemas ajenos a la ciencia. Una solución de este tipo no le es posible porque no distingue entre action unit y system unit, o sea entre la unidad de acción y la unidad de sistema y, con ello, entre teoría de la acción y teoría de los sistemas. Por medio de la identidad de la unidad de acción relacionada con el actor y aquella relacionada con el sistema, no debería perder de vista la distinción aún vigente. Solamente de esta manera puede lograr procesar la acción tanto como unidad de utilización como también como unidad analítica de observación, como suceso simple y también como fenómeno complejo, sin entrar en contradicciones.

37. Resumimos: cuando la distinción de la acción como unidad de utilización (suceso) y como unidad de observación (unidad analítica) se puede hacer plausible más allá de su unidad, los problemas, mismos que la TaH produce con la igualación de las semánticas de "acción $n^{n}$ y "sistema", se disuelven. Bien entendido, tenemos la opinión de que "acción" y "sistema" deben, en ciertas circunstancias, ser tratados idénticamente, pero que, y esto no lo observa la TaH, en otras circunstancias representan formas distintas: pensamos conjuntamente la "acción" y el "sistema", sin reducir la una al otro. ${ }^{145}$ Si esto es así, entonces ya no existe más el problema de que un sistema del sentido coincida exclusivamente con el suceso de acción presentista, como lo implica la arquitectura de la teoría de la TaH. Concebido de esta forma, los sucesos de acción pueden formar diferentes estructuras resistentes al tiempo, mismas que posteriormente incitan a la constitución de diferentes sistemas del sentido. La TaH no puede ver una posibilidad semejante debido al hecho de que, de acuerdo con su arquitectura de teoría, conoce solamente un ünico tipo de acción, o que realiza el intento titánico de permitir que la sociedad global sur-

${ }^{145}$ Esto es una maniobra no tan descomunal dentro del ámbito de la ciencia, como lo demuestra la siguiente observación de Herbert Schnädelbach frente a la teoría de la acción comunicativa (TkH): "Es importante que la teoría piense conjuntamente la acción y la comunicación, sin reducir una a la otra." (Schnādelbach, 1986, p. 17). 
ja sobre la base de una sola acción fundamental. No obstante, si las semánticas de "acción" y "sistema" se pueden separar más allá de su unidad, entonces uno puede buscar formas específicas de acción, a las cuales se les puede hacer responsables de la emergencia de determinados sistemas del sentido: el acto del pago no es el acto jurídico, el acto del amor (nivel afectivo, o sea, el "amor romántico") no es el acto sexual (nivel corporal, o sea, la sexualidad). Los sistemas economía, derecho, amor y sexo requieren correspondientemente de otros sucesos de acción para poder constituirse. No obstante, si se tiene a disposición solamente una única acción fundamental, entonces no puede ser explicada plausiblemente la emergencia de los sistemas parciales. En este contexto, la teoría de los sistemas sociales (TsS) formula: "Dado que la interdependencia necesariamente tiene carácter de aspecto, para Parsons solamente la formación analítica de sistema es, en el sentido estricto, una formación de sistema: Sigue siendo una pregunta abierta la de en qué grado se logra adjudicar las acciones concretas primariamente a sólo un sistema parcial y diferenciarlas específicamente del sistema en este sentido. A la teoria [quiere decir a la TaH, RJ] le faltan los instrumentos para tratar esta pregunta. En este sentido, esquiva los problemas verdaderos de una sociedad funcionalmente diferenciada, o las consecuencias del uso exclusivo de la acción concreta para funciones especificas." 146 En lo que se hace comprensible la distinción de la "acción" y el "sistema" mediante su unidad, también es soluble otro problema, es decir el de la pregunta acerca de la unidad de la acción. Ya hemos explicado que, dentro del marco de la arquitectura de teoría de la TaH, la unidad de la "acción" está concebida asombrosamente de manera ambigua: por un lado, la "acción" es presentada sistémicamente con la ayuda del elemento "actor", por el otro lado, sin la integración de un elemento semejante. Si generalmente partimos del hecho de que una acción emula semánticamente un proceso de adjudicación, indica una dirección y, con ello, indica "al actor" (quien o lo que sea), ${ }^{247}$ entonces, ¿qué muestra la "acción" de la TaH si como elemento adicional integra un "actor" (actor) a la unidad de acción? ¿Utiliza el actor (actor) a la unidad de acción (unit act), o la unidad de acción al actor? En todo caso, en este nivel la TaH sabotea la función de adjudicación "direccional", misma que está dada con la semántica de la acción. Por

${ }^{146}$ Luhmann, 1980 b, p. 8.

${ }^{147}$ Sobre este aspecto de la acción, véase Luhmann, 1981f, 8, pp. 67-80. 
lo tanto, la teoría de los sistemas sociales opina, en vista de este problema, que para la confusión de las mentes europeas se debe formular: "El sistema de acción es el sujeto del actor."

38. Es muy conocido el hecho de que la $\mathrm{TaH}$, durante su periodo de acción, ${ }^{149}$ ha presentado una solución normativa para el problema de la unidad de acción, adjudicando la verdadera función selectiva de dicha unidad al elemento "norma": "Within the area of control of the actor, the means employed cannot, in general, be conceived either as chosen at random or as dependent exclusively on the conditions of action, but must in some sense be subject to the influence of an independent, determinate selective factor, a knowledge of which is necessary to the understanding of the concrete course of action. What is essential to the concept of action is that there should be a normative orientation, not that this should be of any particular type. ${ }^{m 150}$ De acuerdo con este tipo de lectura, se puede decir: la unidad de la "acción" se genera normativamente, o sea que se constituye normativamente. Hasta aquí, todo va bien. Hemos intentado siempre hacer plausible que la TaH funde la "acción" y el "sistema" en una unidad, con la consecuencia de que se puede decir que la acción es el sistema. El sistema -en el sentido del sistema fundamental acción- posibilita, a su vez, la sociedad. Si en este contexto preguntamos, ¿cómo es posible el orden social?, entonces debemos preguntar, en el sentido de la TaH: ¿cómo es posible la acción? La respuesta sería entonces: la acción es posible mediante el factor selectivo "norma". No obstante, la norma es concebida por parte de la TaH como elemento del sistema acción, por lo menos, esto es una posible manera de lectura. Sin embargo, si la norma es elemento del sistema acción, y la unidad de la acción se produce normativamente, entonces, itenemos aquí una forma genuina de la autorreferencia? Esto puede sorprender, puesto que uno está acostumbrado a ver uno de los problemas principales de la TaH en la no-más-deducible justificación

- 160 Luhmann, 1980 b, p. 7.

${ }^{149}$ Aquí nos referimos sobre todo al trabajo The Structure of Social ACtion. La fase posterior, o sea, el llamado periodo de sistema, la dejamos fuera de consideración en cuanto a la pregunta acerca de la unidad de acción, ya que merecería un tratamiento especial que no queremos efectuar por razones de espacio.

${ }^{130}$ Parsons, 1949a, pp. 44-45. 
normativa. Y visto de esta manera es del todo comprensible el hecho de que una solución semejante del problema de la posibilidad de la sociedad ya no puede ser satisfactoria actualmente, sobre todo en una época en la cual se establecen cada vez más semánticas autorreferenciales, ya que éstas aparentemente no satisfacen cognoscitivamente, a pesar de todos los problemas secundarios que surgen en consecuencia de ello. Sin embargo, si realmente es cierto que la unidad de la acción es determinada normativamente, y que la norma es elemento de la acción, entonces la $\mathrm{TaH}$ posee una llave autorreferencial que podría utilizar, por lo menos, ocasionalmente. La incógnita de si Talcott Parsons estaba expresamente consciente de ello, es harina de otro costal y es otro problema.

Una teoría de tan profundo sentido y de tan amplio alcance, construida tan complejamente como la $\mathrm{TaH}$, no se puede simplemente pasar por alto, mucho menos si se trata del problema del orden social, y aún menos si se trata de la "teoría sociológica". Si dentro de este contexto autorreferencial se le pregunta a la TaH, ¿cómo es posible el orden social?, entonces la respuesta sería: el orden es posible mediante las acciones, mismas que son constituidas por medio de las normas, las que, a su vez, son constituidas a través de las acciones, mismas que... i?

\section{LA TEORfa DE LA ACCIÓN COMUNICATIVA (TKH)}

En mi biblioteca privada be seleccionado a siete autores del orden sistemático de los libros y los be puesto en un estante aparte. Dos de ellos ban redactado una obra delgada de gran fuerza sistemática: $m i$ maestro filosófico Jasef König (Sein und Denken. Der Begriff der Intuition) y el amigo de mucbos años y colega Heinricb Popitz, con joyas de treinta páginas como el efecto preventivo de la ignorancia, o los procesas de la formactón del poder. Otras dos están representados por libros muy gordos, los cuales reprocesan todos los pasibles antecesores. Uno de ellos es Hans Küng, el otro Jürgen Habermas. (Los otros tres son Max Weber, Karl Popper y Raymond Aron) Q Quizás se debe dectr que ambos, Küng y Habermas, ban fracasado con su proyecto más grande. Perdura una grieta entre la 
argumentación explícita y bien documentada, y la . ultima intenctón. Tampoco Habermas puede justificar el contrato social sin contrato de dominio. Sin embargo, el esfuerzo del intento, la crítica detallada de lo antecedido, no solamente vale la pena de la reproducción, sino que es en si un logro que merece respeto.

Ralf Dahrendorf'st

Si uno quiere analizar, por ejemplo, las crisis de control de la economía, se debe bacer uso de un instrumental teórico de los sistemas. No parece baber alternativa a ello, después de que la dialéctica objetiva y los conceptos de totalidad de la teoría de Hegel ya no despiertan confianza, o sea, después de que se ba roto aquello que en aquel entonces se mantenía junto: la teoria de los sistemas y la teoria de la acción.

Jürgen Habermas ${ }^{152}$

1. La teoría de la acción comunicativa ( $T$ kH) desarrolla un concepto de la racionalidad comunicativa orientándose en el "[...] hilo guía de la comunicación lingüística" ${ }^{153}$ A la vez, el concepto de la comunicación lingüistica está vinculado estrechamente con el proceso de un consentimiento motivado racionalmente. Este consentimiento se mide, a su vez, con exigencias de validez criticables. Por lo tanto, dentro del marco de la teoría de la acción comunicativa (TkH), la racionalidad comunicativa remite a la comunicación lingüística, ésta, a su vez, remite al consentimiento racional y este consentimiento, por su parte, remite a exigencias de validez criticables (figura 107).

racionalidad comunicativa comunicación lingústica consentimiento racional $\rightarrow$ exigencias de validez criticables

. 151 Dahrendorf, 1989b, p. 484.

... 152 Habermas, 1985, p. 190.

${ }^{153}$ Habermas, 1981b, 1, p. 114. 
Si se considera que con los conceptos mencionados se han colocado solamente demarcaciones burdas del diseño de teoria, entonces esto es un relacionamiento de conceptos muy estrecho.

Consideramos como una de las debilidades fundamentales del proyecto global de la estrategia de conceptos de la TkH, de conectar conceptualmente los diferentes conceptos entre sí tan estrechamente que la autonomía relativa de los conceptos singulares ya no estí garantizada. No obstante, este destino lo comparte con la "teoría del sistema general de la acción" (TaH) de Talcott Parsons, aunque con la TaH tenemos la impresión de que hay algo más de "aire" entre los conceptos que con la TkH. Para dar un ejemplo de la estrategia de argumentación de malla tupida de la TkH, se reproduce la cita siguiente: "Por lo pronto podemos anotar que el concepto de la racionalidad comunicativa debe ser analizado con el hilo guía de la comunicación lingǘstica. El concepto de la comunicación remite a un consentimiento motivado racionalmente entre los participantes, mismo que se mide con exigencias de validez criticables. Las exigencias de validez (verdad proposicional, corrección normativa y veracidad subjetiva) caracterizan las distintas categorías de un conocimiento, el cual está representado simbolicamente en las manifestaciones. Estas manifestaciones pueden ser analizadas más de cerca, es decir, por un lado bajo el aspecto de cómo pueden ser justificadas semejantes manifestaciones, por el otro lado bajo el aspecto de cómo, con ellas, los actores se refieren a algo en un mundo. El término de la racionalidad comunicativa remite hacia un lado a las distintas formas de cumplimiento discursivo de las exigencias de validez - por ello, Wellmer habla de la racionalidad 'discursiva'; hacia el otro lado remite a las referencias al mundo, mismas que retoman los actores comunicadores clamando exigencias de aceptación para sus manifestaciones-, por ello, la descentralización de la comprensión del mundo se ha evidenciado como la más importante dimensión del desarrollo del concepto del mundo." ${ }^{134}$ La pérdida de la autonomia conceptual, que se puede demostrar en este lugar solo alusivamente, es un problema, sobre todo porque un juicio acertado puntualmente, o sea, la referencia a solamente un concepto, casi no es posible sin que con ello esté afectada la estructura global de la arquitectura de la teoría. Gabor Kiss opina: "El modo de operación sin registro objetivo de Habermas dificulta resumir sus intrincados pensamientos de manera clara. "155 La pérdida de autonomía que caracteriza al instrumental categorial de la TkH se manifiesta como "[...] carencia de la sistemati-

14 Habermas, 1981, 1, p. 114.

${ }^{235}$ Kiss, 1987, p. 93. 
zación categorial de sus [Habermas Rn] pensamientos [...] y ésta [...] convierte lo que de por sí estaba difícilmente digerible en una verdadera "inmensidad de lo moderno": 156

Ahora bien, la TkH analiza las exigencias de validez en dos aspectos diferentes: "[...] por un lado, en el aspecto de cómo semejantes manifestaciones pueden ser justificadas, por el otro lado en el aspecto de cómo los actores se refieren, con ellas, a algo en un mundo". Aquí nos queremos dedicar sobre todo al aspecto de la racionalidad de la acción, o sea, a las referencias al mundo que los actores comunicativos constituyen con ello (naturalmente con la integración de las exigencias de aceptación, las cuales claman por sus manifestaciones) y, por lo tanto, observar cómo los actores se refieren al mundo con la ayuda de semejantes exigencias de aceptación. En lo que concierne a la exigencia de un discurso racional, el cual se ocupa de las diferentes formas de cumplimiento de las exigencias de validez, tocaremos brevemente este aspecto más adelante.

2. El pensamiento fundamental de la $\mathrm{TkH}$, mismo que expresa la relación entre referencia al mundo y racionalidad de la acción, dice: "[...] que nos [...] comprometemos con determinadas condiciones previas ontológicas cuando elegimos determinados conceptos de acción sociológicos. Los aspectos de la posible racionalidad de su acción dependen de las referencias del actor al mundo, las cuales suponemos para él" ${ }^{158}$ En lo que concierne al aspecto de la racionalidad de la acción, la TkH realiza el intento de explicar "[...] cuatro (conceptos de acción), mismos que se han hecho relevantes para la formación de teoría de las ciencias sociales [...] ${ }^{n}{ }^{159}$ con lo cual analiza las implicaciones de racionalidad de estos conceptos de acción con el apoyo de las supuestas referencias entre actory mundo. Ahora bien, de acuerdo con la concepción de la $\mathrm{TkH}$, generalmente no se produce ninguna conexión entre acción y referencia-del-actor-al-mundo, dentro de las teorias de acción sociológicas acostumbradas. Una

\footnotetext{
156 Ibid., p. 114.

${ }^{15}$ Habermas, 1981, 1b, p. 114.

${ }^{138}$ Ibid., p. 126.

159 Ibid., p. 115.
} 
excepción es el sociólogo británico y antropólogo social I.C. Jarvie con su trabajo "La lógica de la sociedad" ${ }^{160}$ con la cual "hace uso de manera interesante de la teoría de los tres mundos de Popper". ${ }^{161} \mathrm{La}$ TkH recurre al concepto teorico del conocimiento de la teoria de tres mundos de Karl R. Popper considerando su realización desde la perspectiva de la teoría de la acción por parte de Jarvie. Es sobre todo la versión, desde la perspectiva de la teoría de la acción, del concepto de Jarvie, la que alcanza un significado especial para la TkH.

3. Los tres mundos de Popper son fáciles de mencionar: el mundo de los objetos o estados físicos, llamado mundo 1 ; el mundo de lö̀ estados de conciencia o disposiciones de comportamiento para la acción, o mundo 2; finalmente el mundo de los contenidos de lospensamientos óbjetivos (de Frege) como productos del espíritu humano, o mundo $3 .^{162}$ El último es el mundo de las teorías y de sus reláciones lógicas "en sî", el mundo de lós argumentos y de las situaciones problemáticas "en si”. Ahora bien'; la TkH critica al concepto de los tres mundos de Popper, sobre todo su interpretación del mundo 3: supuestamente es una interpretación abreviada cognitivistamente, ya que tiene como contenido solamente las comporientes procesables científicamente. Sin embargo, se debe realzar el hecho de que la TkH considera iguales el mundo 3 de Popper y la esfera cultural de la socie$\mathrm{dad}^{163}$ y que, debido a ello, puede hablar de una interpretación abreviada cognitivistamente. No obstante, es una interpretación que Popper no realizo de esta manera. El intento de Jarvie de trasladä la' teoría de tres mundos de Popper desde el nivel del conocimiento al nivel de la teoría de la accióni es, como ya lo dijimos, de interés especial para la TkH. Sin embargo, de acuerdo con su concepción se deben verificar tres debilidades' sensibles en la propuesta de Jarvie: primero, Jarvie no diferencia entre una posición performativa orientada hacia la cotidianidad y una científica, y tampoco entre éstas y las tradiciones culturales; segundo, descuida las componentes culturales en el concepto del mundo 3 , mismas que no se pueden reducir solamente a los pensamientos y los problemas científicos y,

160 Jarvie, 1974.
${ }^{162}$ Habermas, 1981b, 1, p. 115.
162 Popper, 1973, p. 174.
163 Habermas, 1981, 1, p. 119, sobre todo pp. 120 y ss. 
tercero, finalmente no distingue entre valores culturales y normas institucionales. ${ }^{164}$

4. La TkH desarrolla, en el transcurso de la crítica de la teoría de los tres mundos de Popper y su realización desde la perspectiva de la teoria de la acción por Jarvie, tres conceptos del mundo determinados desde la perspectiva de la teoría de la constitución: uno objetivo, uno social y uno subjetivo. Estos conceptos se pueden identificar como los conceptos de Popper del mundo 1, 2 y 3. Por el otro lado, la TkH aborda los conceptos de acción relevantes para la formación de teorías de las ciencias sociales y los divide en cuatro grupos: los conceptos de acción teleológico-estratégicos (Aristóteles, von Neumann, Morgenstern), los regulados por normas (Durkheim, Parsons), los dramatüngicos (Hoffmann) y los comunicativos (Mead, Garfinkel, Habermas). Estos cuatro conceptos de acción, destilados a partir de las ciencias sociales, se relacionan con los ya mencionados conceptos del mundo. ${ }^{165} \mathrm{La}$ acción teleológico-estratégica implica solamente un mundo, el objetivo, ya que con ello se trata de la relación entre un actor y un mundo de circunstancias existentes; la acción reguladora de normas implica dos mundos, el mundo objetivo y el mundo social; en este caso se trata de la relación entre un actor y las circunstancias vinculadas con los roles regulados por normas. La acción dramatúrgica también implica dos mundos, uno subjetivo y uno objetivo, con lo cual se trata de la relación de un actor con sus manifestaciones expresivas-subjetivas en la separación de un mundo exterior, hacia el cual puede comportarse solamente desde una posición objetivizante. ${ }^{166}$ Finalmente se debe mencionar la acción comunicativa, con la cual "[...] locutor y escucha se refieren simultóneamente, desde la perspectiva de su mundo vivencial preinterpretado, a algo en el mundo objetivo, social y subjetivo, para negociar definiciones conjuntas de las situaciones" ${ }^{167}$ Con ello, se trata de una

16 Habermas, 1981b, pp. 120-123. Por lo demás, es una diferencia que, en esta forma aguda, extrañamos también en la TsS. Tanto la TaH como la TkH se comprometen decididamente con una distinción de normas sociales y valores culturales.

${ }^{165}$ Ibid., pp. 129-142.

166 Ibid., p. 140.

${ }^{167} \mathrm{Ibid}$., p. 142. 
"[...] interacción de por lo menos dos sujetos capaces de acción y habla, mismos que forman una relación interpersonal". ${ }^{169}$

5. Después de haber efectuado una adjudicación de los tres conceptos del mundo a las cuatro teorias de acción relevantes para las ciencias sociales, la TkH asocia a estas cuatro teorias de acción con cuatro conceptos distintos del lenguaje, con lo cual surge la pregunta acerca de cómo relaciona la coordinación de las acciones con los correspondientes conceptos del lenguaje. El acto de hablar de un locutor frente a un escucha puede adoptar una forma prelocutiva (influencia de la contraparte), una forma constativa (exposición de las circunstancias), una forma regulativa (producción de relaciones interpersonales) y una forma expresiva (autorrepresentación) ${ }^{169}$ (véase figura 108 en la página siguiente).

La TkH relaciona las exigencias de aceptación que se deben hacer valer con ello, o sea, la efectividad (perlocuciones), verdad (constativos), correctón (regulativos) y la veractdad (expresivos) con los dos modos principales de la orientación de las acciones: los actos perlocutivos, mismos que claman una validez de efectos, están orientados bacia el éxito: los actos del habla constativos, regulativos y expresivos, mismos que claman correspondientemente una validez de verdad, correctividad y veracidad, están ortentados bacia la comunicación $^{170}$ (figura 109).

\begin{tabular}{|lll|}
\hline Actos del habla & Exigencias de validez & Orientaciones de las acciones \\
perlocutivos & efectividad & orientado hacia el exito \\
constativos & verdad & $\begin{array}{l}\text { orientado hacia la comunicación } \\
\text { regulativos }\end{array}$ \\
expresivos & $\begin{array}{l}\text { correctividad } \\
\text { veracidad }\end{array}$ & $\begin{array}{l}\text { orientado hacia la comunicación } \\
\text { orientado hacia la comunicación }\end{array}$
\end{tabular}

Queremos anotar que la TkH dicotomiza la circunstancia de la coordinación de las acciones hacia el ejercicto de influfo (en el sentido de la efectividad) y la comunicación (en el sentido de la verdad, correctividad y veracidad). Con ello, integra las unilateralidades de

${ }^{160}$ Ibid., p. 128.

${ }^{169}$ Ibid., p. 439.

${ }^{170}$ Igualmente la misma tabla. 


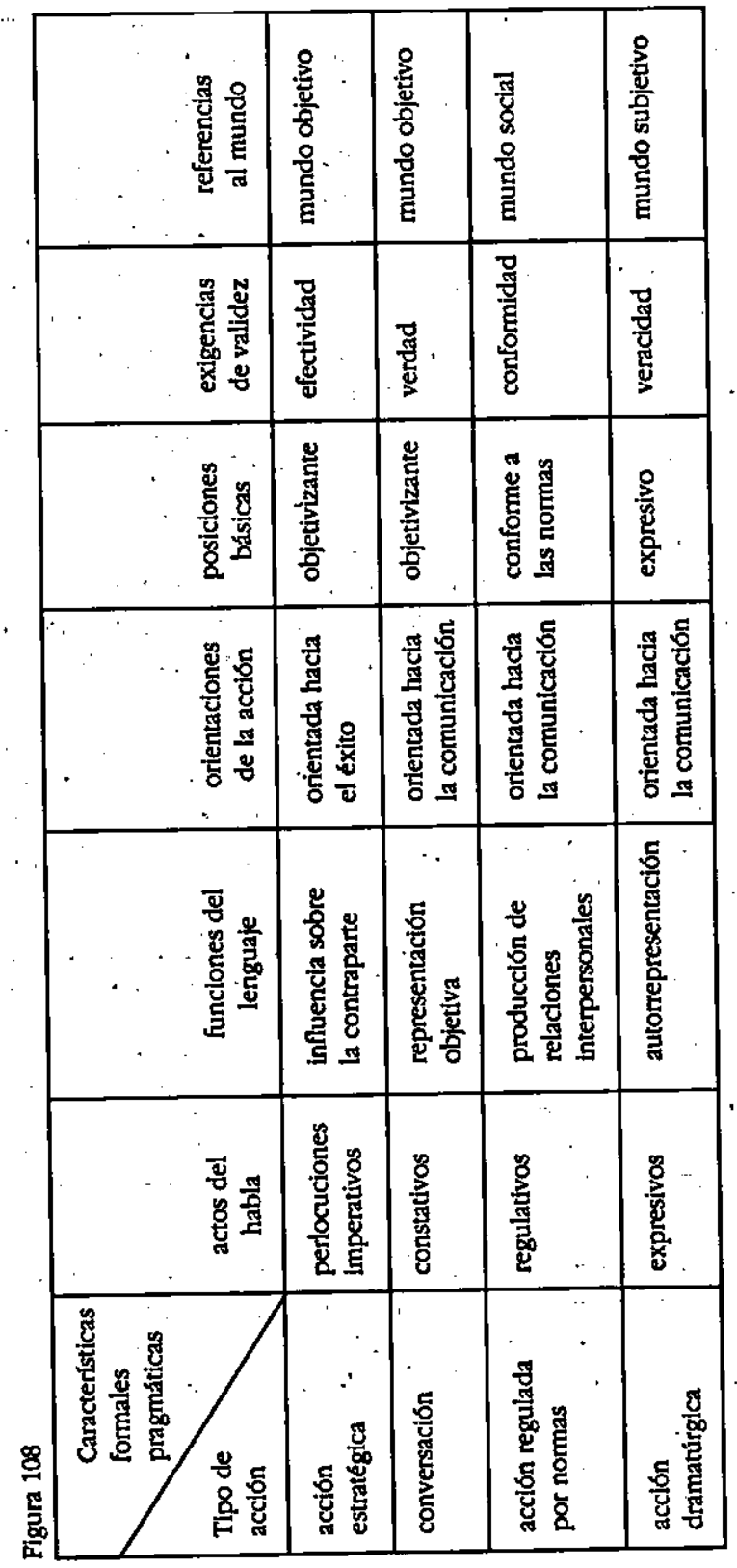


comunicación de la acción regulada por normas, conservaciones y dramatúrgica mediante el concepto de la acción comunicativa, mismo que integra las tres formas de comunicación. Por lo tanto, las reúne en una unidad de comunicación llamada consentimiento. La TkH formula: el "[...] modelo de acción estratégico se conforma con una explicación de las caracteristicas de la acción orientada inmediatamente hacia el éxito $[. . .]^{n},{ }^{171}$ mientras que los otros modelos de acción comprenden la coordinación de la acción social "[...] como el encadenamiento de cálculos de provecho egocéntricos [...], como un consentimiento social-integrativo acerca de las normas y valores, regulado por medio de la tradición cultural y la socialización [...] o [...] como relación consensual entre público y actores [...]". ${ }^{172}$ Por lo tanto, se puede decir que "[...] en estos modelos de acción [...] el lenguaje se concibe, en los otros aspectos correspondientes, unilateralmen$t e^{n} .{ }^{173}$ Solamente el modelo de acción comunicativo implica un locutor, el cual clama "[...] verdad para las afirmaciones o presuposiciones de existencias, corrección para las acciones reguladas legítimamente y su contexto normativo, y veracidad para la manifestación de vivencias subjetivas [...]". ${ }^{274}$ Si para la acción comunicativa es válido que el lenguaje se utiliza con una orientación hacia la comunicación, "[...] y esto no sólo directamente con la acción teleológica, guiada por normas o dramatúrgica, sino de una manera reflexiva [R]]": $:^{175}$ ¿qué se debe comprender entonces como una acción "orientada hacia la comunicación" en el sentido de una acción comunicativa? La TkH opina acerca de esto: "Comunicación significa la comunicación con miras a un consentimiento válido." ${ }^{n 176}$ Resumimos: las acciones se coordinan, de acuerdo con la TkH, a través de dos mecanismos, osea, por mediodel influjo, mismo que se practica paradigmáticamente en la acción estratégica, y mediante el consentimiento, mismo que se produce con la ayuda de la acción comunicativa.

6. Para la TkH, la mencionada dicotomización de "consentimiento" y "ejercicio del influjo" forma - como los verdaderos mecanismos

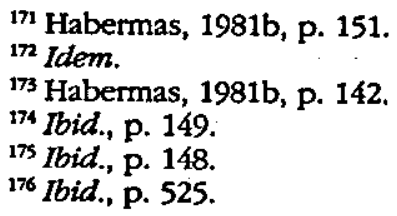


que coordinan las acciones dentro de la SOCIEDAD- un punto de salida central de su arquitectura de la teoría: "Por lo pronto, quiero caracterizar con 'consentimiento' y 'ejercicio del influjo' dos mecanismos para la coordinación de acción, mismos que son la base de las acciones sociales más importantes [...] Estos conceptos de la acción también deciden sobre el hecho de cómo puede ser pensado correspondientemente el orden social [RJ]." ${ }^{n] 7} \mathrm{El}$ interés de la TkH en referencia con las diversas teorías de acción sociológicas está relacionado estrechamente con este supuesto dicótomo: "Por lo demás, los planteamientos teóricos de la acción se distinguen dependiendo de si postulan un consentimiento para la coordinación de la acción, es decir, un conocimiento común, o solamente un mutuo ejercicio del influjo externo." ${ }^{178}$ Ahora bien, si se introduce el mundo vivencial como concepto complementario a la acción comunicativa, ${ }^{179} \mathrm{con}$ lo cual este concepto de la acción se puede designar con consentimiento, entonces se sugiere considerar el sistema como concepto complementario al concepto de la acción estratégica. Y de hecho, la TkH realza que existe una adjudicación inequívoca , primero "[.... entre la acción estratégica por un lado, y los sistemas de acción diferenciados mediante los medios, por el otro lado", ${ }^{180} \mathrm{y}$, segundo, "[...] entre la acción comunicativa y la integración social" ${ }^{182}$ Resulta la siguiente adjudicación conceptual (figura 110):

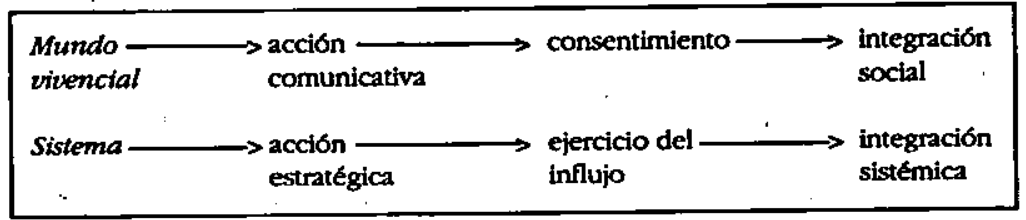

Si se parte del hecho de que el contexto complejo del "mundo vivencial" (acción comunicativa-consentimiemto-integración social) se puede comprender como "acción" y que el contexto de acción es-

in Habermas, 1984, p. 572.

179 Ibid., p. 573.

$17 x$ "He introducido ocasionalmente [...] el concepto del mundo vivencial. Forma un concepto complementario para la acción comunicativa." (Habermas, 1981 b, 2, p. 182).

${ }^{180}$ Habermas, 1984 , p. 604.

281 Ibid., p. 603. 
tratégica-ejercicio del influjo-integración sistémica, se puede comprender como "sistema", entonces la TkH ha propuesto una arquitectura de teoria, misma que se puede caracterizar por medio de una dicotomía de "acción" y "sistema". De hecho, esta dicotomizactón forma uno de los momentos centrales del concepto de la teoría social de la TkH: "La forma en que las sociedades representan contextos establlizados sistémicamente de grupos socialmente integrados, requiere seguramente de una explicación más exacta; por lo pronto, representa la propuesta heurística de considerar la sociedad como una entidad, la cual, en el transcurso de la evolución se diferencia como sistema y como mundo vivencial. ${ }^{\text {n182 }}$

7. Se hace evidente que para la TkH la acctón está ligada estrechamente con la comunicación lingüústica en el sentido de un consentimiento lingüístico, dado que para ella la formación del consenso se encuentra en el primer plano de la actividad lingüistica. No consideramos a este supuesto (el consenso como consentimiento siempre ya otorgado) como suficientemente plausible y realista, ya que la operación de un consenso resulta razonable solamente con la integración de una operación generadora de la disensión ${ }^{183}$ A ello se añade que solamente frente al trasfondo de la operación del yababer-entendido de una expresión lingüística, se hace posible la

182 Habermas, 1981b, 2, p. 228.

${ }^{183}$ La TsS formula críticamente acerca de la primacía del supuesto del consenso de la TkH: "Frecuentemente se imputa más o menos explícitamente que la comunicación aspira al consenso, que busca consentimiento. La teoría de la racionalidad de la acción comunicativa desarrollada por Habermas, se erige sobre la base de esta premisa. Sin embargo, ya empíricamente es simplemente falsa. También se puede comunicar para marcar el disenso, uno puede querer pelearse, y no hay ninguna razón para considerar la búsqueda del consenso como más racional que la búsqueda del disenso. Esto depende enteramente de los temas y los afectados. Obviamente, la comunicación es imposible sin algún consenso; pero también es imposible sin ningün disenso. Aquello que presupone obligatoriamente es: que se pueda dejar sin consideración la pregunta acerca del consenso o disenso para los temas que por el momento no son actuales. $Y$ aun con temas actuales -aunque finalmente se encontró un lugar para estacionarse, y después de largas caminatas se lleg $\delta$ al café donde se supone que hay el mejor café de Roma, y entonces uno toma las pocas gotas- ¿dónde hay entonces consenso o disenso, mientras no se pierda el buen humor por medio de la comunicación?" (Luhmann, 1987e, p. 10). 
adopción de una postura de consentimiento o de rechazo frente a ella. En caso contrario se trata de formas de comunicación que producen el consentimiento sin referirse a operaciones consensuales o con tendencias al disenso. Semejantes formas de un "consentimiento ${ }^{n 184}$ implícito forman consabidamente la mayor parte del acontecer comunicativo dentro de una SOcreDAD. Esto son, sobre todo, la "costumbre", la "rutina", el "comportamiento tradicional"185 en el sentido de Max Weber y los llamados medios de comunicación. Los últimos forman formas de sistemas del sentido comunicativas especialmente potentes: son comunicaciones altamente abreviadas, mismas que, sobre la base de los medios como el "dinero", "dios" o el "poder" posibilitan las operaciones como "comprar", "rezar" o "elegir", sin incluir explícitamente los procesos de decisión. Los medios de comunicación de este tipo canalizan las operaciones comunicativas en una forma particular de tal índole que el "comprar", el "rezar" o el "elegir" no requieren ninguna operación explícitamente consensual. ${ }^{186}$ Ia función de los medios de comunicación simbólicamente generalizados consiste en la tarea de hacer la complejidad comunicativa, ya extremadamente reducida, transferible "sin problema" y, con ello, hacerla capaz de conexión. En este contexto estamos de acuerdo con la TsS, la cual opina que semejantes medios "aumentan la disposición para la comunicación de tal manera [...] que la comunicación puede ser arriesgada y que no se omite desde el principio por falta de esperanza [...]" ${ }^{187}$ Los medios de esta naturaleza disminuyen los umbrales de desaliento condicionados comunicativamente y, así, incitan a la formación de sistemas del sentido. Aun más, precisamente debido a ello se constituyen los sistemas del sentido, puesto que en el nivel

${ }^{184}$ Aquí se trata de algo como un "consentimiento sin estar de acuerdo".

18s Max Weber identifica la "masa de toda acción cotidiana asumida por vivencia" con la acción tradicional, misma que realmente se describe como "comportamiento". (Weber, 1972, pp. 12-13).

${ }_{186} \mathrm{La}$ TkH realza con razón que un medio de control como el "dinero" o el "poder" está hecho de tal manera que "[...] las acciones del alter pueden ser 'conectadas' con las del ego, aun esquivando los arriesgados procesos de formación de consenso". (Habermas, 1984, p. 578).

${ }_{187}$ La cita completa es: "En general, con los medios de comunicación simbólicamente generalizados se trata de instituciones semánticas que posibilitan el éxito para comunicaciones, las cuales, en sí, son improbables." Con ello, "posibilitar el éxito" significa: aumentar la disposición para la recepción de la comunicación de tal manera que se pueda arriesgar la comunicación, y que no se omita, desde el principio, por falta de esperanza. 
general de los valores y las normas ya no es necesario, para podèr encontrar una conexión, exponer cualquier manifestación y/o acción a una legitimación de si/no fundamental y general. Esto naturalmente no significa que una legitimación de si/no interna al sistema sea superflua, una vez que existiría un sistema semejante. Seguro que no lo es. De esta manera, dentro del sistema de, por ëjemplo, la economía o la política, donde se puede tratar de decisiones del tipo $\mathrm{si} / \mathrm{no}$, puede concernir a las cuestiones de una determinada inversión o de una constelación específica de los grupos de poder; sin embargo, no puede afectar a la decisión fundamental de si dentro del marco de la economía o la política se deba comunicar o no. Una comunicación "primaria" de este tipo es presupuesta como "obviamente" dada. En caso de que sea poco más o menos cierta nuestra suposición de que grandes partes de la comunicación social se realizan a través de la costumbre, la rutina, la acción tradicional y los medios simbólicamente generalizados, entonces la operación del consenso representa una forma de la realización más bien marginal o interna al sistema. Se súpone que esto se aplique en situáciones particulares, en las cuales se trata de decisiones explícitas. Con el concepto del consenso, la TkH no se refiere a un "acuerdo-ya-alcanzado" en el sentido de un consentimiento, y tampoco a aquello que la operación consensual implica semánticamente. Ésta sugiere ciertamente, por lo pronto, el "haber entendido" de la expresión lingưistica, con la implicación de que uno puede estar de acuerdo - o nocon aquello que ha entendido. ${ }^{188}$ Esto implica la distinción de consenso/disenso y la competencia de decidir acerca de ello de esta $u$ otra manera.

Despues de una minuciosa examinación analítica de la semántica del consenso de la TkH, Gabor Kiss llega a la conclusión: "Se construye [...] un consenso, mismo que es explicado mediante el consenso acerca del consenso. ${ }^{1189}$ Con referencia a la formación de sistemas, consideramos inevitable una tautologia de esta naturaleza. No obstante, si es inevitable, entonces esto también debería formularse. Sin embargo, la TkH no lo efectúa debido precisamente al hecho de que no tiene reservado ningún lugar para el problema de las tautologías/paradojas dentro de su arquitectura de la teoría.

188 Naturalmente, uno puede imaginarse haber entendido algo de ésta u otra manera. Pero esto es otro problema que aquí no trataremos más.

${ }^{199}$ Kiss, 1987, p. 111. 
8. En contacto directo con el concepto de la racionalización de Max Weber y la tesis de la descentración de Jean Piaget, la TkH parte de un diferenciamiento y, con ello, de una racionalización de la conciencia modema y sus correspondientes supuestos de la concepción del mundo. Se genera, como ya lo hemos explicado, una formación de un mundo objetivo, uno social y uno subjetivo. Este desarrollo se correlaciona con los correspondientes estilos de acción: el teleológico-estratégico está orientado hacia el mundo objetivo, el normativo hacia los mundos objetivo y social, el dramatüntco hacia los mundos objetivo y subjetivo. A su vez, estos estilos de acción expresan tres posiciones fundamentales del actor frente a los mundos concebidos formalmente: una objetivizante, una conforme a las normas y una expresiva. ${ }^{190}$ Para la comprensión de estas posiciones fundamentales es central el hecho de que "[...] el sujeto actuante y perceptivo puede adoptar distintas posiciones fundamentales frente a los componentes del mismo mundo" ${ }^{191}$ Ahora bien, la TkH combina las posiciones fundamentales con los conceptos del mundo formales, con lo cual esta combinación resulta en "[...] nueve relaciones fundamentales [...]". De estas nueve relaciones pragmáticas formales entre los actores y sus mundos, solamente sets combinaciones se consideran adecuadas para cumplir con el criterio de la racionalización en el sentido de una acumulación del conocimiento. Aquí llamamos la atención sobre el hecho de que la $\mathrm{TkH}$ - a la par con la TaH - utiliza un modo de procedimiento de tabla de cruz para legitimar los problemas de la constitución del mundo y de la teoría.

El problema fundamental de dicho modo de procedimiento de tablas de cruz es que la tabla puede indicar solamente relacionamientos simétricos. Esto es - visto desde el mundo vivenciał- un supuesto no realista.

En cuànto a la relación entre los actores y sus mundos, la TkH opina: "[...] que solamente algunas de estas relaciones pragmáticas formales son adecuadas para la acumulación del conocimiento. Por lo tanto, debemos intentar identificar aquellas relaciones que, bajo el aspecto de la adquisición del conocimiento son suficientemente productivas como para permitir un desarrollo de acuerdo con leyes propias de las esferas de valores culturales en el sentido de Max We-

${ }^{190}$ Habermas, 1981b, 1, pp. 321 y ss.

${ }^{191}$ Ibid., p. 324. 
ber". ${ }^{192}$ Las seis relaciones escogidas se integran finalmente a tres complejos de ractonalidad, con lo cual cada complejo especifica una posición fundamental: el estilo de acción objetivizante, que está relacionado con el mundo objetivo y el social, requiere una ractonalidad instrumental-cognoscitiva (ciencia, técnica y tecnología social); el estilo de acción conforme a las normas, que está relacionado con el mundo social y el subjetivo, requiere una racionalidad práctico-moral (derecho, moral); el estilo de acción dramatúrgico-expresivo, que está relacionado con el mundo subjetivo y el objetivo, requiere una racionalidad práctico-estética (erótica, arte).

9. Por lo tanto, la TkH parte de un estrecho encadenamiento semántico de los conceptos del mundo, tipos de acción y complejos de racionalidad: los conceptos del mundo de un mundo objetivo, social y subjetivo se engranan a las posiciones fundamentales objetivizantes, conforme a las normas y expresivas, con lo cual ambas categorías, es decir, las posiciones frente al mundo y la acción, se funden con los correspondientes complejos de racionalidad: con la racionalidad instrumental-cognoscitiva, con la moral-normativa y con la prácticaestética. No obstante, no termina con ello este encadenamiento de las categorías conceptuales. De acuerdo con la TkH, la ciencia, la esfera de los valores éticos y el arte se han diferenciado, en continuación a MaxWeber, como las tres esferas de valores culturales de la modernidad europea, dentro de las cuales "[...] [reconocemos RJ] las componentes cognoscitivas, normativas y expresivas de la cultu$\mathrm{ra}^{n} .{ }^{193}$ En este lugar, dejamos fuera de consideración como problema la difícil circunstancia de las exigencias de aceptación, misma que se refiere a las manifestaciones de los actores. Sólo queremos llamar la atención sobre el hecho de que la TkH también relaciona la racionalidad de la acción con la racionalidad del discurso. Con las exigencias de aceptación se trata consabidamente de la verdad proposicional, la corrección normativa y la veracidad subjetiva de las manifestaciones, ${ }^{194}$ las cuales reflejan las concepciones de un mundo objetivo, social y subjetivo. En todo caso, podemos anotar que el estrecho encadenamiento y la interpenetración semántico-concep-

192 Ibid., pp. 325-326.

${ }^{193}$ Ibid., p. 323.

194 Ibid., 1, p. 114. 
cionales, mismos que la TkH postula como estilos de acción y modos del mundo, representan, desde la perspectiva de la arquitectura de la teoria, un procedimiento problemático ya que, por un lado, dicho relacionamiento interdependiente de los conceptos difícilmente puede permitir el aislamiento de partes de la teoría, para fines de una evaluación crítica. Es decir que el autor siempre puede reclamar (con razón) no haber sido entendido correctamente, ya que ésta o aquella parte de la teoría ha sido desatendida, o que ésta o aquella parte aún se debe integrar a la teoría. Por el otro lado, un diseño de teoría proyectado en forma interdependiente alcanza una unidad de mucho bulto, de manera que las distinciones existentes no se hacen valer correctamente. Si se derrumba un aspecto parcial de la estructura de la teoría, entonces toda la estructura amenaza con colapsarse. Esto: es un asunto sumamente delicado, no sólo para el crítico, sino tam- . bién para el autor mismo, ya que para él puede hacerse actual la de-: molición completa de la estructura de la teoría. ¿Y quién derrumba voluntariamente su "obra de toda la vida"?

Visto desde la perspectiva de la arquitectura de teoría, la estructura de la teoría se debería construir de tal manera que se hagan posibles las reparaciones en diversas partes de la estructura, sin que con ello em:piece a sacudirse la estructura global. En vista de esta circunstancia, la TsS formula: "En la mayoría de los casos, las teorías no son capaces. de corregir posteriormente las decisiones de conceptos, con las cuales comienzan. Las cargas que resultan de una situación inicial pueden ser retocadas o atenuadas. Pueden ocasionar importantes innovaciones 0 incluso 'revoluciones científicas' en el sentido de Thomas Kuhn. Sin embargo, puede suceder también que todo el esfuerzo se haga simplemente inútil y se pueda desechar como una inversión intelectual fracasada, en caso de que sea posible ordenar nuevamente el área de teoria desde otras decisiones iniciales." 195

10. ¿Qué se puede decir, desde la perspectiva de una teoría de las distinciones aquí representada, acerca de la actual arquitectura de teoría de la teoría de la acción comunicativa ( $T k H)$ con relación al aspecto de la racionalidad de acción? Vemos: a) el problema general de esta arquitectura de teoría en el hecho de que laTkH plantea sus conceptos de una manera demasiado estrecha, lo que Gabor Kiss critica como "[...] deficiencia de la sistematización de sus pensamien-

${ }^{195}$ Luhmann, 1986f, p. 41. 
tos [de Habermas RJ] [...]" ${ }^{196}$ Por lo tanto, la conclusión debería ser un desentrelazamiento de su estructura concepcional de construcción; $b$ ) vemos otro problema en el hecho de que la TkH operacionaliza insuficientemente los conceptos como "accionn", "sistema", "mundo vivencial" y "comunicación". Su arquitectura de teoría consiste más bien en una sinóptica fenomenológico-clasificatoria, con la consecuencia de que no resulta precisamente fácil trabajar con sus conceptos porque no permiten un manejo teórico-operacional; ${ }^{197}$. c) y vemos un tercer problema en una dicotomización periódica de conceptos tan centrales como:

"acción"/"sistema"
"consentimiento"/"ejercicio del influjo"
"racionalidad de acción comunicativa"/racionalidad de acción estratégica"
"integración social"/"integración de sistema"
"intenciones de acción"/"consecuencias de la acción"
"perspectiva del participante"/"perspectiva del observador"
"razón comunicativa"/"razón funcional"

En última instancia, sobre la base de una teoría social planteada dicótomamente, se supone un aspecto de dos niveles de la SOCIEDAD, mismo que se muestra en el nivel de la arquitectura de teoria, como tensión entre la teoría de la acción y la teoría del sistema. ${ }^{198}$ Por ello, la TkH consecuentemente parte del hecho de que "[...] el problema de construcción de cómo pueden ser asociadas las teorías de acción y de sistema mediante conceptos básicos, existe con razón. Mi formula propuesta provisionalmente, de comprender las sociedades como contextos de acción estabilizados sistémicamente [RJ] de los grupos integrados socialmente [RJ], ya contiene estos dos aspectos $^{n}{ }^{199}$ Nosotros (TgS) negamos que los conceptos básicos "sistema" $\mathrm{y}$ "acción" pueden ser registrados solamente en forma dicótoma, aunque queremos admitir que este procedimiento dicótomo de la TkH es comprensible en el sentido de que es el resultado de la crítica jus-

${ }^{16}$ Kiss, 1987, p. 114.

197 No son, si se quiere decir así, concebidos lo suficientemente "técnicos", lo que corresponde seguramente más al "espíritu" de la TkH.

${ }_{198}$ Habermas, 1981b, 2, p. 300.

${ }^{199}$ Ibid., p. 301. 
tificada de la teoría del sistema general de la acción (TaH), misma que "[...] (plantea RJ) demasiado abajo los puntos de conexión entre los modelos de sistema y de acción" . 200 Mientras que la TaH utiliza semánticamente ambos conceptos de manera indistinta - como lo hemos mostrado antes-, la TkH trata de relacionarlos exclusivamente de forma dicótoma. Tenemos la opinión de que aquí no sé trata de una unidad, como en el caso de la TaH, ni tampoco de una distinción, como en el caso de la TkH. Postulamos que el problema de la posibilidad de la SOCIEDAD solamente puede ser comprendido adecuadamente cuando uno está dispuesto a examinar, desde la perspectiva de la arquitectura de teoría, tanto la unidad de "acción" y "sistema", como también su distinción.

11. Intentemos abordar, por lo pronto, a) el problema del aspecto concepcional de malla cerrada de la TkH y $b$ ) el problema vinculado estrechamente con ello, de una construcción conceptual, misma que se opone a una posible operacionalización: ¿de qué manera se podría efectuar un desentrelazamiento de la arquitectura de teoría de la TkH? Como primer ejemplo nos debe servir su concepto de las referencias al mundo, el cual conecta con cuatro conceptos sociológicos de acción. Recordamos brevemente: la acción teleológico-estratégica implica solamente al mundo objetivo; la acción regulada por normas implica dos mundos: el mundo objetivo y el social; la acción dramatúrgica implica igualmente dos mundos: el objetivo y el subjetivo; finalmente, la acción comunicativa presupone simultáneamente el mundo objetivo, el social y el subjetivo. ${ }^{201}$

Nuestra impresión es que la TkH aún no se ha liberado completamente del paradigma de la filosofia de la conciencia, como lo muestran, por lo menos, los conceptos utilizados "subjetivo" y "objetivo". No obstante, tenemos la opinión de que la filosofía de la conciencia merece ser integrada en una arquitectura de teoria, si se libera el "espacio" correspondiente. Por lo tanto, tratamos la filosofia de la conciencia dentro del marco de una teoría de los sistema sociales (TgS), como teoría de los sistemas personales del sentido.

¿Se puede proceder aquí de otra manera? Con el apoyo del concepto de la observación, mismo que hemos presentado en el capítulo IV,

200 Ibid., p. 304.

${ }^{201}$ Ibid., p. 142. 
se puede observar una transición paulatina de la operación observación y, con ello, esquivar de momento la dicotomización de sujeto/ objeto presupuesta en el concepto del mundo de la TkH. Hemos propuesto, como lo recordamos, seis modalidades de observación que se dividen en observaciones, las cuales producen la operación de la acción (de observación acción) y observaciones, las cuales constituyen la operación de la observación (observación de la observación). Las modalidades de observación referidas a la acción son: "facticidad"(comportamiento), "posibilidad" (actuación) y "alternatividad" (acción real). Las observaciones referidas a la observación son: "observación", "reflexión" y "autorreflexión". La "facticidad" refleja una relación monovalente del observador observante $y$, en este sentido, sería equivalente al concepto del mundo objetivo de la $\mathrm{TkH}$ (o al mundo 1 de Popper). La "posibilidad" consiste en una relación bivalente $y$, en este sentido, es equivalente al concepto del mundo social de la TkH. La "alternatividad" consiste en una relación trivalente y constituye a la acción real en el sentido de una decisión explícita entre "algo" y "algo distinto". Este lugar no está ocupado en el marco de la arquitectura de teoría de la $\mathrm{TkH}$, dado que presenta solamente un concepto de acción rudimentario. Finalmente, existe la verdadera "observación" como un relacionamiento tetrádico de cuatro valencias, mismo que forma el equivalente al concepto del sujeto de la TkH: el observador observa "esto, no aquello" y es accesible a sí mismo como observador observante (no como actor). Los conceptos de observación de la "reflexión" y la "autorreflexión" no son tematizados en este contexto, ya que no son relevantes en referencia a los conceptos del mundo de la TkH. Dentro del marco de una teoría de la observación de esta naturaleza, uno tiene la posibilidad de asistir a la constitución de las modalidades paulatinas de observación y es'capar simultáneamente a la clásica dicotomización europea antigua de subjetividad/objetividad. En todo caso, la ventaja de una teoría de la observación ligeramente ligada a toda la arquitectura de teoría de la TgS consiste en el hecho de que puede ser criticada, mejorada o desechada, sin qué con ello peligre la estructura global de la arquitectura de teoría, como parece ser el caso con la TkH. A ello se añade la circunstancia de que los conceptos de la "objetividad", "subjetividad" y "socialidad" pueden ser comprendidos como constituidos desde la perspectiva de la observación y que, en este sentido, carece de objeto el supuesto de una ontologización de los mundos, como es el caso con la TkH (figura 111). 
Facticidad

Posibilidad

Altematividad

Observación
Objetividad

Socialidad

?

Subjetividad

12. Se podría plantear una segunda propuesta de desentralazamiento con el modelo de los complejos de racionalización, el cual está relacionado estrechamente con los correspondientes sistemas de acción. La TkH parte del hecho de que con la paulatina descentración de la conciencia se pueden relacionar las posiciones fundamentales referidas a la acción de la objetivización, normación y expresión con los conceptos del mundo formalmente introducidos de un mundo objetivo, uno social y uno subjetivo. Ahora bien, la TkH combina a manera de una tabla de cruz las posiciones fundamentales referidas a las acción con los mundos formalmente introducidos y obtiene, por medio de ello, nueve relaciones formal-pragmáticas que afectan a las relaciones específicas entre los actores y sus mundos ${ }^{203}$ (figura 112).

\begin{tabular}{|c|c|c|c|c|}
\hline $\begin{array}{l}\text { Mosiciones } \\
\text { fundamentales }\end{array}$ & 1 & 2 & 3 & , 1 \\
\hline 3 & ane & & & \\
\hline 1 & $\begin{array}{l}\text { racionalidad instr } \\
\text { ciencia, técnica }\end{array}$ & $\begin{array}{l}\text { mental-cognoscitiva } \\
\text { |récnicas sociales }\end{array}$ & $\mathrm{x}$ & $\cdot$ \\
\hline 2 & $\mathbf{x}$ & $\begin{array}{c}\uparrow_{\text {derecho }}^{\text {macionalidad prác }} \\
\cdot\end{array}$ & $\downarrow^{\text {moral }}$ & . \\
\hline 3 & - & $\mathbf{x}$ & $\begin{array}{c}\text { 个racio } \\
\text { práctic } \\
\text { enófica }\end{array}$ & $\begin{array}{l}\text { lidad } \\
\text { estética } \\
\text { arte }\end{array}$ \\
\hline
\end{tabular}

${ }^{202}$ Naturalmente, estas equivalencias son correctas sólo condicionalmente, ya que con la ayuda del concepto de la observación esquivamos la dicotomía de sujeto/objeto.

${ }^{203}$ De Habermas, 1981b, 1, p. 326. 
De las nueve posibilidades de una relación entre actor y mundo sirven "[...] solamente algunas de estas relaciones formal-pragmáticas para la acumulación del conocimiento [...]", ${ }^{204}$ dicho exactamente: solamente seis. ${ }^{205}$ Ahora bien, estas seis relaciones se juntan en tres complejos de racionalidad. El complejo de la racionalidad instrumental-cognoscitiva, que requiere una posición objetivizante hacia el mundo objetivo y el social; el complejo de la racionalidad prácticomoral, que requiere una posición de conformidad con las normas hacia el mundo social y el objetivo; finalmente, el complejo de la racionalidad práctico-estética, que hace necesaria una posición expresiva hacia el mundo subjetivo y el objetivo. ${ }^{206}$ Los dos criterios para el desarrollo de acuerdo con las propias leyes de las seis relaciones, que son condensadas en los tres complejos de racionalidad, son: primero, que son apropiados para "la acumulación del conocimiento. Por lo tanto debemos intentar identificar aquellas relaciones que con el aspecto de la adquisición del conocimiento son lo suficientemente productivas como para permitir un desarrollo de las esferas culturales de acuerdo con leyes propias, en el sentido de Max Weber"; ${ }^{207}$ segundo, "si las esferas culturales destacan por su producción del conocimiento diferenciada y perpetuada de acuerdo a las exigencias de acéptación, y si la continuidad de esta producción del conocimiento puede ser garantizada mediante el surgir de la reflexividad de los procesos de aprendizaje, o sea, por medio del reacoplamiento con las formas institucionalmente diferenciadas de la argumentación, entonces se deben poder comprobar, para las esferas culturalmente acuñadas [...], relaciones plausibles con una respectiva forma de argumentación típica, especializada en una exigencia de aceptación universal ${ }^{208}$ En resumidas cuentas: para que se puedan diferenciar como esferas de valores culturales las seis relaciones preñadas de cultura ciencia/técnica, tecnologías sociales, derecho, moral, erótica y arte, se requiere, por un lado, la acumulación del conocimiento y, por el otro lado, del desarrollo de una forma especial de la argumen-

${ }^{204}$ Ibid., p. 325.

${ }^{205}$ Con ello, la TkH se adhiere a Max Weber: "El [M. Weber RJ] tiene aparentemente la idea de que solamente seis de las clasificadas relaciones entre actor y mundo pueden ser 'racionalizadas y sublimadas' conscientemente [...]." (Ibid., p. 326).

${ }^{206}$ Ibid., Pp. 326-327.

${ }^{207}$ Ibid., pp. 325-326.

${ }^{208}$ lbid., pp. 327-328. 
tación, misma que permite correspondientemente su institucionalización.

13. Al complejo de la racionalidad instrumental-cognoscitivo pertenecen, según la $\mathrm{TkH}$, la ciencia/técnica y las tecnologías sociales; al complejo práctico-moral pertenecen el derecho y la moral; y al complejo práctico-estético pertenecen la erótica y el arte. ${ }^{209}$ Aplicando el criterio de la acumulación del conocimiento, preguntamos con Thomas McCarthy: ¿existe, dentro de los ámbitos del arte y de la moral algo como una producción de conocimiento continua y acumulativa? Dudamos de esta posibilidad, puesto que aun en el área de ciencia y técnica actualmente -como lo ha mostrado sobre todo Thomas $S$. Kuhn- ${ }^{210}$ ya no se puede partir del hecho de que estas áreas estuvieran caracterizadas por una acumulación continua del conocimiento. Por ello, McCarthy resume: “Los adelantos en el nivel estructural no necesariamente generan una acumulación del conocimiento en el nivel del contenido. Esto señala que no podemos adjudicar demasiada importancia al carácter 'continuo' y 'acumulativo' de la producción del conocimiento, dentro del esquema de referencias de actormundo capaces de racionalización de Habermas. "211 Ahora bien, si la mirada se dirige desde el criterio de la acumulación del conocimiento hacia el criterio de la institucionalización, entonces se debe preguntar: “En que grado está institucionalizada o es institucionalizable la racionalidad práctico-moral?"212 McCarthy responde: “[...] el punto decisivo sigue siendo el de que una ética comunicativa despegada de sus bases religiosas ha encontrado hasta ahora solamente un débil amarre institucional, tanto dentro de las instituciones culturales como en las sociales". ${ }^{213}$ Resumimos: ni el criterio de la acumulación del conocimiento, ni aquél de la institucionalización son suficientes, de acuerdo con nuestra opinión, como para legitimar los complejos de racionalización en el sentido de la TkH.

14. En el contexto de un relacionamiento en forma de tabla de cruz de las posiciones basales referidas a la acción y los correspondientes

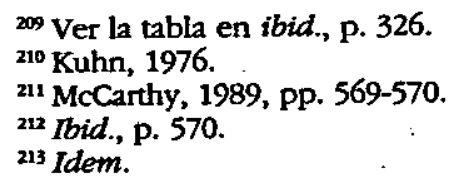


conceptos del mundo, la TkH deja tres campos vacíos (ver la figura acerca de los complejos de racionalización), ya que tiene la idea de que estas relaciones actor-mundo no son "racionalizables y conscientemente sublimables". ${ }^{214}$ Se trata a) de la posición objetivizante frente al mundo subjetivo (campo 1.3), b) de la posición expresiva frente al mundo social (campo 3.2) y c) de una posición conforme a las normas frente al mundo objetivo (campo 2.1). ¿Qué se puede decir acerca de ello? Queremos abordar una por una estas relaciones particulares de actor-mundo: por lo pronto, con el apoyo de una posición objetivizante frente al mundo subjetivo (campo 1.3), de acuerdo con la TkH, "[...] no se puede aprender nada".215 ¿Qué tan plausible es un supuesto semejante? Las formas de, por ejemplo, las terapias teóricas del comportamiento o las formas de consulta de dirección orientadas psicológicamente pueden adoptar una posición objetivizante frente a un mundo subjetivo, pero también la psicología de publicidad actualmente en boga. ¿Cómo está la situación de la posición expresiva frente al mundo social (campo 3.2)? La TkH piensa "[...] que determindas formas expresivas de la interacción (por ejemplo, las formas de vida de la contracultura) no forman ninguna estructura capaz de racionalización por sí misma, sino que son parasitarias en el sentido de que permanecen en dependencia de las innovaciones de las otras esferas de valores". ${ }^{216}$ Aquí se debe preguntar: ¿no hay grandes áreas del arte actual que se ocupen de verter la SOCIEDAD en formas expresivas? Piénsese tan sólo en Joseph Beuys, cuyo programa ha sido declarar la cotidianidad social como arte $y$, con ello, cubrir la SOCIEDAD con expresividad artística. ${ }^{217}$ Y finalmente, ¿cuál es la situación del campo sin llenar, de una posición conforme a las normas frente al mundo objetivo (campo 2.1)? De acuerdo con la TkH, el estado vacío de este campo significa "escepticismo frente a la posibilidad de formar racionalmente el contacto fratemal con una naturaleza no-objetiva, por ejemplo, en la figura de los conocimientos filosóficos naturales, los cuales podrían competir con las modernas ciencias naturales." ${ }^{\text {218 }}$ En contra de esta posición,

${ }^{214}$ Habermas, 1981b, 1, p. 326.

${ }^{215}$ Ibid., p. 327

216 Idem.

${ }^{217}$ Véase acerca de este complejo de problemas los trabajos de Ernst $\mathbf{H}$. Gombrich, por ejemplo: Gombrich, 1978; Gombrich/Hochberg/Black, 1981 y Gombrich, 1984.

${ }^{218}$ Habermas, 1981 b, 1, p. 327. 
Thomas McCarthy menciona la "crítica de la razón" de Immanuel Kant como modelo teleológico de la explicación de la naturaleza, mismo que no se encuentra en competencia con la explicación causal de una ciencia natural objetiva, sino que se encuentra en una relación de complementariedad. ${ }^{219}$ En este contexto se debe realzar que precisamente el ejemplo de gala de las modernas ciencias naturales, o sea, la física cuántica, es posible solamente con la integración del observador y, con ello, esquiva la vieja distinción europea de sujeto/objeto. C.F.v. Weizäcker escribe acerca de esto: "La teoría de los cuantos se ha visto obligada a discutir explícitamente el papel del observador, es decir, de un sujeto del conocimiento. Trataré de demostrar que esto hace necesaria una crítica de la descripción clásica de Descartes de la relación entre el sujeto y el objeto del conocimiento." 220

La teoría cuántica suspende la separación limpia supuesta por la fisica clásica entre sujeto y objeto: “Bohr describía esto a veces en la plática mediante el problema del determinismo y la libertad con las palabras: 'Dentro de la fisica clásica, el comportamiento del objeto está determinado estrictamente de manera causal, mientras que el observador se describe como completamente libre: libre de medir lo que quiera, sea la ubicación y el impulso de una partícula, sea la longitud de onda o la frecuencia de una onda. Dentro de la física cuántica, el observador ya nó es completamente libre, por ejemplo, puede decidir si quiere medir la ubicación o el impulso, pero no ambos simultáneamente El objeto se libera precisamente en esta medida: su comportamiento ya no es totalmente determinable.' Esto era sólo un aperçu. Sin embargo, su núcleo duro era, desde la perspectiva de la teoría del conocimiento, la inseparabilidad de sujeto y objeto [RJ]. Dentro de la teoría cuántica, el contenido del conocimiento, o sea lo sabido, es solamente un catálogo de probabilidades, es decir, en sí un conocimiento. ${ }^{221}$

Con la entrada del observador a la física cuántica como relación constituyente de aquello que desde la perspectiva de la física cuántica se puede llamar "realidad", se "subjetiviza" necesariamente la cir-

219 "El [contramodelo RJ] más prominente de todos es quizás la crítica de la capacidad de juicio de Kant. En este modelo, la explicación teleológica de la naturaleza no está en competencia con la explicación causal, sino en una relación de complementaridad [...]". (McCarthy, 1989, p. 577).

${ }^{200}$ Weizsäcker, C.F.v., 1977, p. 171.

221 Weizsäcker, C.F.v., 1985, p. 528. 
cunstancia física, no obstante, sin implicar un equivalente al concepto de la objetividad. Sea como sea, pensamos que el rechazo de la posibilidad de una posición conforme a las normas frente al mundo objetivo por parte de la TkH (no se debe tratar precisamente del "contacto fraternal") se puede relacionar simplemente con el desconocimiento de la estructura profunda de las actuales reflexiones $\mathrm{fi}^{-}$sico-cuánticas. Resumiendo, se puede decir: no se requiere un esfuerzo mental especial para mencionar los casos de: $a$ ) una posición objetivizante frente al mundo subjetivo; $b$ ) un posición expresiva frente al mundo social; $\mathrm{y} c$ ) una posición conforme a las normas frente al mundo objetivo. Por lo tanto, no consideramos una "causalización" de este tipo de los conceptos del mundo, por lo menos de los ontológicamente concebidos, y posiciones fundamentales condicionadas por la acción, primero, como lo suficientemente documentada empíricamente. Segundo, representa una limitación innecesaria de la arquitectura de teoría de la $\mathrm{TkH}$, misma que ciertamente clama una exigencia universalista, la cual se hace problemática debido a una limitación de su diseño de teoría.

15. Con ello, la construcción de teoría de malla cerrada de un contexto de racionalidad de la acción y conceptos del mundo no está de acuerdo con nuestra idea, primero, lo suficientemente asegurada empíricamente, con lo cual la misma TkH tiene la opinión de que se trata de "[...] un modelo despeñadizo [...]". ${ }^{222}$ Por ello, Thomas McCarthy resume su análisis crítico del modelo de la TkH con las palabras: "Quiero [...] mostrar [...] qué tan extremadamente problemático es este esquema y, con ello, evitar cualquier abreviación injustificada de las posibilidades de la racionalización en el nivel analítico.?:223 ' Segundo, tenemos la opinión de que la $\mathrm{TkH}$ se esfuerza en convertir las posiciones básicas de acción y los conceptos del mundo en relaciones actor-mundo inequívocas, ${ }^{224}$ sin embargo, se priva de la posibilidad de abordar con acciones correspondientemente específicas, por ejemplo, la ciencia, técnica, derecho, moral, erótica o el arte

\footnotetext{
22 Habermas, 1981 b, 1, p. 328.
}

223 McCarthy, 1989, p. 579.

224 "[...] las tres esferas de valores culturales se deben conectar con los respectivos sistemas de acción de tal manera que esté asegurada una producción y transferencia del conocimiento especializada de acuerdo con las exigencias de aceptación [...]". (Habermas, 1981b, 1, pp. 328-329). 
como formas de comunicación autónomas. Desatendiendo la adjudicación problemática de, por ejemplo, la ciencia o el derecho al ámbito de la cultura - ¿por qué no son entonces la política o la economía también cultura?-- este carácter inequíuco de la adjudicación bloquea la comprensión de la emergencia de otras relaciones actor-mundo. Solamente si la respectiva arquitectura de teoría permite diseñar el "sistema" o los "complejos de racionalidad" de manera que se pueda producir un acoplamiento entre la comunicación específica y una acción específica, la cual le corresponde, se puede resolver adecuadamente el problema de la emergencia de tan diversos sistemas del sentido como el arte, la religión, política, economía, sexo, familia, salud, moral, ciencia, derecho, técnica, deporte, educación, etc. Sin embargo, de esta manera la TkH corre peligro de caer presa de una preferencia idiosincrática de los modelos de cultura de Occidente, como lo formula McCarthy cuidadosamente: "Habermas está consciente de que su esquema aparta solamente 'de manera imprecisa las tres esferas de valores culturales, mismas que han sido diferenciadas en la moderna Europa [...]'; no obstante, insiste en el hecho de que '[...] esto aun no es una objeción contra el valor sistemático del [...] esquema [...]'. Por el otro lado: entre más problemático se haga este valor de posición, más claramente la preferencia de solamente estos tres complejos parece reflejar los 'rasgos ideosincráticos de la cultura occidental' . 225 Con este ejemplo se hace evidente cuáles . cadenas se pone la TkH a si misma debido al alto grado de hermeticidad de su arquitectura de teoría.

16. ¿Hay otra posibilidad del tratamiento de aquello que la TkH quiere decir con las posiciones básicas en cuanto a la acción "objetivizante", "conforme a las normas" y "expresivo" en conexión con los conceptos del mundo objetividad, socialidad y subjetividad? Tenemos la opinión de que se puede proceder de otra manera. Solo que las posiciones básicas y los conceptos del mundo se deben desentramar, y ambos conceptos deben ser tratados aisladamente. Hemos señalado varias veces que la SOCIEDAD es aquel sistema del sentido que está compuesto por cuatro estilos de expectación, o sea, de las constelaciones de expectativas corporales, afectivas, personales y sociales (figura 113).

${ }^{225}$ McCarthy, 1989, ip. 579. 
Estilos de expectación

naturales/corporales afectivos personales/individuales normativos
Tipos de sistemas del sentido sistemas del sentido corporales sistemas del sentido psiquicos sistemas del sentido personales sistemas del sentido sociales

$\because \quad$ A su vez, la formación de los estilos de expectación tiene lugar mediante las diferenciaciones siguientes (figura 114).

\begin{tabular}{llll|} 
*2. $\begin{array}{lll}\text { sistemas corporales } \\
\text { sistemas psiquicos } \\
\text { sistemas personales } \\
\text { sistemas sociales } & \longrightarrow & \text { corporal/espiritual } \\
\text { afectual/neutral } \\
\text { consciente/inconsciente } \\
\text { normativo/cognoscitivo }\end{array}$ \\
\hline
\end{tabular}

17. Dentro del marco de una teoría de los estilos de expectación es natural esperar que un tipo de sistema del sentido "espere" como su igual a otro tipo de sistema del sentido distinto, sin considerar su carácter diferente. Esto sucede tan sólo por el hecho de que cada tipo de sistema del sentido procede de manera universalista: todo lo que espera, lo puede esperar solamente dentro del marco de su propio estilo de expectación. Para demostrar esto solamente debemos observar las acuñaciones concretas de los sistemas del sentido, mismos que operan en el marco de un determinado tipo de sistema del sentido (figura 115).

\begin{tabular}{ll|}
\hline Tipo de sistema del sentido & Sistema del sentido \\
corporal & sexo, edad... \\
afectual & amor, envidia .... \\
personal & $\begin{array}{l}\text { conciencia, imaginación ... } \\
\text { social }\end{array}$ \\
\hline
\end{tabular}

Entre las distintas acuñaciones de los tipos de sistemas no existen relaciones a priori, no existen determinadas relaciones, como lo es el caso con la TkH: para poder determinar cómo se efectúan real- 
mente las relaciones se requiere una observación que procede empiricamente. Sin embargo, es posible por principio que, por ejemplo, el sexo "sexualice" 0 "erotice" al amor, a la persona y a la economía (bajo esta perspectiva, el amor no se presenta como "amor romántico", es decir, como expresión de sentimientos, sino como sexualidad; la persona no se presenta como individuo, sino como hombre o mujer; la economía se presenta, por ejemplo, como prostitución, etc.). En cuanto al amor, algo similar se podría establecer para el sexo, para la persona y para la economía. El hecho de que la economia pueda "convertir todo en dinero", y que la persona sea capaz de "individualizar todo", lo queremos dejar como una posibilidad.

Aquí, la tarea de una teoría social es la de penetrar más profundamente. Sin embargo, por razones sistemáticas no queremos cumplir con esta tarea dentro del marco de una "lógica de las distinciones".

En este lugar, para nosotros no se trata de mostrar que la universalización de estos estilos de expectación sería deseable o errada. Nos importa solamente la presentación de la posibilidad de una observación de este tipo, con lo cual el interés de observación y una correspondiente investigación deben decidir sobre la universalización real de un determinado estilo de expectación. ${ }^{226}$ Ahora bien, si se intenta relacionar la teoría de los estilos de expectación brevemente presentada aquí con la teoría de los complejos de racionalidad de la $\mathrm{TkH}$, entonces podemos establecer: la posición objetivizante se puede encontrar nuevamente en el ámbito del estilo de expectación fisico/corporal;" la posición expresiva está representada en el estilo afectivo de expectación; y finalmente, la posición conforme a las normas se puede considerar en gran medida como igual al estilo social de expectación. Es asombrosa la circunstancia de que entónces la TkH no puede ofrecer una posición equivalente al estilo personal de

${ }^{226}$ Un ejemplo clásicio para la era moderna es el "estilo de expectación económico" del sistema economía, supuestamente aquel sistema con la influencia más fuerte sobre la sociedad global. Sustituía al "estilo de expectación religioso" en cuanto al alcance social global y la amplitud del efecto.

- Nota del traductor: en el la obra alemana original, el autor utiliza los conceptos leiblicb/körperlich, que se utilizan generalmente como sinónimos, sin èmbargo, la raíz etimológica del término leiblich remite al alto alemán antiguo lif, que significa vida y que está relacionado también con la palabra inglesa life. 
expectación, por lo menos no dentro del marco de las posiciones fundamentales referidas a la acción ${ }^{227}$ (figura 116).

\begin{tabular}{|ll|}
\hline Estilos de expectactón & Complejos de racionalización \\
corporal & posición objetivizante \\
afectual & posición expresiva \\
personal & posición conforme a las nomas \\
\hline social
\end{tabular}

18. Ahora abordaremos el tercer problema de la arquitectura de teoría de la TkH: la siempre repetida dicotomización de conceptos como el consentimiento/ejercicio de la influencia, racionalidad de acción comunicativa/racionalidad de acción estratégica, integración social/ integración del sistema, intenciones de acción/consecuencias de la acción, perspectiva del participante/perspectiva del observador, razón comunicativa/razón funcional. En última instancia, estas dicotomizaciones, desembocan, por un lado, en el nivel de la SOCIEDAD, en la dicotomía de "acción" y "sistema"; por el otro lado, en el nivel de la teoría, en la dicotomía de teoria de la acción y teoría de los sistemas. No obstante, el problema de la dicotomización, mismo que produce la TkH tanto en el ámbito de la teoría general como también en el ámbito de la teoría de là sociedad, está ligado estrechamente al segundo problema, o sea, al hecho de que antes que someter los conceptos como "acción", "sisterna" o "comunicación" a un tratamiento operacionalizante, la TkH más bien los describe fenomenológicamente y los ordena clasificatoriamente. Dicho de otra manera: la imprecisión de la conceptualidad ofrecida, que caracteriza a la arquitectura de teoría de la TkH, le permite efectuar una dicotomización, la cual consideramos como objetivamente inadecuada. Por lo tanto, queremos tratar conjuntamente el problema de la dicotomización y el de la operacionalización insuficiente de los conceptos centrales. Con ello, queremos proceder de tal manera que en el ámbito de la teoria social reducimos las diferentes dicotomizaciones a una sola, es

${ }^{227}$ Encontramos nuevamente el estilo de expectación personal como mundo subjetivo dentro del marco de los conceptos del mundo cie la TkH y anotamos que consideramos problemática dicha ontologización de la comunicación personal. 
decir, a "acción"/"sistema", para, en el ámbito de la teoría, rozar brevemente la dicotomización de teoría de acción y teoría del sistema con la ayuda de la dicotomía de la perspectiva de participante/perspectiva del observador.

19. Por lo pronto: ubicamos la razón objetiva del procedimiento dicótomo de la TkH en su crítica justificada de la teoría del sistema general de la acción (TaH), misma que "[...] [plantea RJ] demasiado abajo los puntos de conexión entre el modelo de acción y el del siste$\mathrm{ma}^{\text {n228 }} \mathrm{O}$ "integra la diferenciación de conceptos básicos entre sistema y mundo vivencial [...]".229 $\mathrm{La}$ TkH parte del supuesto de la teoria de la sociedad de que "[...] desde Marx existen dos paradigmas que constituyen independientemente toda teoría de la sociedad: el paradigma de los sistemas sociales y el paradigma del mundo de vida, paradigmas que no han sido relacionados el uno con el otro. Éste es el problema de toda teoría de la sociedad hoy en día" ${ }^{230}$ Por lo tanto es válido "[...] que existe justificadamente el problema de construcción, de cómo se pueden entrelazar con conceptos fundamentales la teoría de la acción y la de los sistemas". ${ }^{231}$ En este sentido, la TkH formula, como ya lo hemos mencionado, su programa teórico social: "Mi fórmula propuesta provisionalmente, de comprender a las sociedades como contextos de acción estabilizados sistémicamente [RJ] de los grupos socialmente [RJ] integrados, ya contiene ambos aspectos [el aspecto de acción y el aspecto de sistema RJ]." 232

20. Empecemos con el concepto de la acción y analicemos más exactamente para esta finalidad su reconstrucción tipológica de los conceptos teóricos de la acción. Preguntamos: ise puede partir, de.ttro de la formación de teorías de las ciencias sociales, de solamente cuatro conceptos relevantes de la acción, es decir, de uno teleológico, uno normativo, uno dramatúrgico y uno comunicativo? Esto sería una pregunta que se debería contestar, por lo pronto, empíricamente. Ahora bien, el problema de la determinación de aquello que pue-

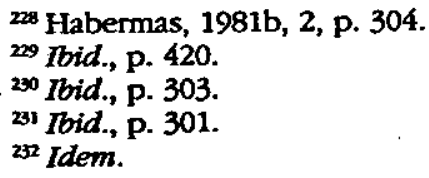


de ser comprendido como acción, está vinculado estrechamente con la pregunta acerca de una tipologización de los conceptos de la acción dentro del marco de la formación de teorías de las ciencias sociales. ¿Cómo más debería resolverse un problema de la tipologización de la acción si no se dispone de una semántica de la acción, si no se sabe que se debe comprender como acción ${ }^{2233}$ Por ello preguntamos: ¿qué comprende la TkH como acción? En el contexto de una definición del concepto de la acción comunicativa dice: "Hasta ahora hemos comprendido la acción como el dominio de las situaciones." Y unas páginas más adelante: " $\mathrm{La}$ acción o el dominio de las situaciones [...]". ${ }^{234}$ Ambas definiciones son demasiado poco expresivas e informativas, como para poder seleccionar con ellas, dentro de la formación de teorías de las ciencias sociales, conceptos de la acción tipológicamente distintos. Si ábordamos la primera definición, entonces podemos decir: cualquier sistema domina su situación en el sentido de que se encarga de su propia constitución. Una no-dominación de su situación sería igual a la destrucción del sistema. En este sentido, se puede decir que el dominio de la situación se puede poner prácticamente en la misma categoría que la conservación del sistema -naturalmente sólo si se trata de un dominio general, no de un dominio puntual de la situación. No obstante, econ ello no está dicho nada de contenido acerca de la acción? Supuestamente no. La segunda definición añade el entorno al sistema. Con lo cual se de-

${ }^{233}$ Aunque una concepción de este tipo fuera, por lo pronto, intuitiva y rudimentaria.

${ }^{234}$ Las citas dicen: "Hasta ahora hemos comprendido la acción como el dominio de las situaciones. El concepto de la acción comunicativa separa sobre todo dos aspectos del dominio de la situación: el aspecto teleológico de la realización de las finalidades (o la realización de un plano de acción) y el aspecto comunicativo de la interpretación de la situación y la obtención de un consentimiento. Con la acción comunicativa, los participantes persiguen conjuntamente sus planes sobre la base de una definición común de la situación" (Habermas, 1981b, 2, p. 193). La segunda cita dice: "La acción o el dominio de la situación se presenta como proceso circular, dentro del cual el actor es ambas cosas a la vez: el iniciador de acciones adjudicables y el producto de las tradiciones, dentro de las cuales está ubicado [....]" (ibid., p. 204). En un trabajo publicado dos años después de la aparición de la TkH, encontramos también dos definiciones de la acción: $a$ ) "Si comprendemos la acción generalmente como el dominia de las situaciones [...]" (Habermas, 1983a, p. 145) y b) "Si partimos, con Piaget, de la acción, es decir, de la confrontación activa de un sujeto aprendiendo constructivamente con su entomo [...]". (Ibid., p. 150). 
be decir que ningún sistema puede existir si no se encarga de su ambiente de una manera constructiva y con disposición al aprendizaje. Precisamente en la distinción de sistema y entorno está incluido el problema de que el sistema siempre está menos complejo que su entorno, y que este declive de complejidad puede ser compensado solamente con la ayuda de las categorias del sentido, mismas que toman en consideración dicho declive.

21. Por ello, consideramos las dos definiciones de la acción, mismas que presenta la TkH y que hemos mencionado antes, como descripciones generales del problema de la conservación del sistema o del sujeto. Sin embargo, si esto es así, entonces la TkH no dispone de ninguna semántica adecuada de la acción. Por lo tanto, su tipología de acción solamente puede ser una aproximada descripción empírica de los conceptos de la acción, las cuales están presentes en el ámbito de la formación de teorías de las ciencias sociales. No obstante, la TkH exige universalidad en cuanto a su tipologización de los conceptos de acción presentada. ${ }^{235}$ Sin embargo, de acuerdo con nuestra opinión, no se puede cumplir con esta exigencia en estas condiciones. ${ }^{236}$ Es solamente justo si Hans Joas critica que con el modelo de la acción teleológico falta por completo la distinción entre una acción realizadora de finalidades y aquel tipo de la acción realzado por la fenomenología y el pragmatismo que "[...] encuentra sus finalidades apenas en las situaciones [... $]^{n} .{ }^{237}$ El tipo de acción de un manejo juguetón de los objetos y las situaciones no se menciona en absoluto, y en el ámbito del modelo de acción regulador de las normas falta el tipo de la acción regulada normativamente sólo en pequeñas proporciones, la cual juega un papel especial en el interaccionismo simbólico y en la etnometodología. Pero tampoco se menciona el modelo expresivo de la autoexpresión sin intenciones estratégicas. Joas concluye su comentario con la observación: "Esta revisión resulta en una impresión irrechazable de que aquí no se trata de una adecuada recopilación de los conceptos comunes de la acción ni de una amplia

${ }^{235}$ Habermas, 1981b, 1, pp. 115 y ss.

${ }^{236}$ Hans Joas opina: "Ya una breve confrontación de esta tipología con los conceptos de la acción realmente acostumbrados dentro de las ciencias sociales o en la filosofia indica fuertes deficiencias de esta tipología." (Joas, 1986, p. 148).

237 Idem. 
tipología de una teoría general de la acción, sino de una clasificación; la cuál está dispuesta desde el principio con miras a la diferenciación de las posibles referencias al mundo." ${ }^{238}$

22. Ahora bien, ¿cuál es la situación del concepto del sistema en el marco de la arquitectura de teoría de la TkH? Si a la TkH se le planteara la pregunta de cómo, de acuerdo con su opinión, sería posible el orden social o la SOCIEDAD, entonces podría responder: como acoplamiento de los tipos sistémicos de coordinación de la acción $y$ del mundo vivencial.

Consideramos como problemático el hecho de querer explicar la soCIEDAD en última instancia y exclusivamente sobre la base de la teoria de la acción. La TkH relaciona la emergencia de la socieDAD con la coordinación de dos tipos de formas de acción dispuestos dicótomamente: por un lado las intenciones de la acción, por el otro lado las consecuencias de la accion. Las acciones solas (aunque se les interprete una vez sistémicamente, y la otra vez desde la perspectiva del mundo vivencial) no pueden hacer plausible el cómo emerge la soCIEDAD. Para ello es indispensable el concepto de la COMUNICACION, ya que solamente de esta manera puede hacerse comprensible realmente a qué se refieren las acciones. En vez de ello, la TkH utiliza la lengua, con la consecuencia de que, dentro del área de integración del sistema determinado por ella, está obligada a hablar de "medios de comunicación privados del lenguaje": "Las sociedades modernas alcanzan [...] un nivel de diferenciamiento del sistema en el cual las organizaciones, mismas que se han vuelto autónomas, están relacionadas por medio de međios de comunicación privados del lenguaje. ${ }^{\text {239 }} \mathrm{El}$ hecho de que se supone que la SOCIEDAD se genere exclusivamente mediante la comunicación verbal y/o por escrito (-lenguaje), nos parece poco realista.

Con referencia a la TaH, la TkH opina: "La pregunta inicial de Parsons acerca de cómo la sociedad es posible como un contexto ordenado de las acciones, justificaba una aplicación con el problema de la coordinación de la acción. ¿Cuál es la naturaleza de los mecanis-

${ }^{238}$ Finalmente, Joas establece: "Se debería anotar como resultado intermedio el hecho de que, en cuanto a la teoría de la acción, Habermas no ha intentado realmente hacerle justicia a la pluralidad fenomenologica." (Joas,
1986 , p. 149).

239 Habermas, 1981b, 2, p. 230. 
mos que conectan de tal manera las acciones del alter con las del ego que los conflictos, los cuales podrían amenazar al contexto de acción dado, pueden ser evitados o bien suficientemente limitados? Hemos distinguido entre los mecanismos de una integración social [RJ], que comienza con la orientación hacia la acción, y una integración sistémica [R]], que abarca todas las orientaciones hacia la acción. ${ }^{n 20} \mathrm{De}$ acuerdo con esta distinción, la coordinación de las acciones tiene lugar, por un lado, mediante "[...] un ajuste de las orientaciones de la ¿cción [...]", por el otro lado, "[...] por medio de un entrelazamiento funcional de las consecuencias de las acciones". El resultado es la integración social y la del sistema. ${ }^{241}$ Ahora, la SOcıEDAD se define, con la ayuda de esta distinción de tipos de integración de la acción, como "[...] contextos de la acción sistémicamente [RJ] estabilizados de los grupos socialmente [RJ] integrados [...]". ${ }^{242}$ Con otras palabras, según su opinión, la TkH procede simultáneamente desde la perspectiva de la teoría del sistema y de la teoría de la acción, y por medio de ello puede superar una debilidad importante de la teoría del sistema general de la acción, es decir, su entrelazamiento demasiado estrecho de las semánticas de "acción" y "sistema". Ahora bien, ya hemos demostrado que una unidad de "acción" y "sistema" como la concibe la TkH es posible e incluso necesaria, mientras y en la medida que uno no pierda de vista su distinción. La debilidad real de construcción de la teoría del sistema general de la acción (TaH) consiste, por lo tanto, en el hecho de que ya no tematiza su distinción mediante la unidad de ambas semánticas. Antes hemos expuesto de manera clara y explícita los argumentos acerca de esta circunstancia y no es necesario repetirlos aquí.

23. Hemos observado que la TkH no está dispuesta a explicar su concepto de la acción en aquella forma que podría resultar en un sentido utilizable en la arquitectura de teoria. Si uno de sus objetivos centrales de la teoría representa la formulación de un concepto de la socie-

${ }^{240} \mathrm{Ibid}$. pp. 301-302.

${ }^{241}$ Se sabe que David Lockwood (1984) ha propuesto esta distinción en su crítica a Parsons. LaTkH no menciona este trabajo, el cual, en última instancia, ocupa un lugar especial para ella dentro de su arquitectura de teoria. No sabemos por qué Lockwood no se menciona dentro del marco de la obra principal. Sin embargo, véase Habermas, 1979, p. 17.

${ }^{242}$ Habermas, 1981b, 2, p. 301. 
dad, "[...] mismo que reúne las teorías de acción y de sistema [...]", y esto supuestamente deba suceder de una manera no trivial, ${ }^{243}$ entonces se genera una pregunta similar frente a la semántica de "sistema" y frente a la semántica de "acción". Por lo tanto, preguntamos nuevamente: ¿qué comprende la TkH como sistema? En otro lugar decisivo dice: "Hablamos de la integración del sistema respecto a los logros específicos de control de un sistema autorregulado; las sociedades aparecen aquí con el aspecto de la capacidad de conservar sus límites y su existencia mediante el dominio de la complejidad de un entorno continuamente cambiante. ${ }^{n 244}$ Es sintomático para la TkH el hecho de que se presenta en forma fenemenológico-descriptiva y, por lo tanto, esquiva el estilo de preguntar de Kant con su forma de respuesta más bien "técnica" ${ }^{245}$ Ciertamente, la definición de un sistema como "algo" que reduce la complejidad del entorno, tiene su sentido, sin embargo, es - dejándola en esta forma- trivial. ${ }^{246}$ En todo caso, por medio de este camino de una explicación semántica no se puede alcanzar, en el sentido de la $\mathrm{TkH}$, ninguna claridad acer-

243 "Dado que la teoría de la sociedad hegeliana-marxista desarrollada en categorías de totalidad se ha desintegrada en sus elementos, es decir, por un lado en teorías de la acción y, por el otro lado en teorías del sistema, la tarea actual es la de reunir estos dos paradigmas de manera no-trivial, es decir, no solamente de modo eclecticista y aditivo." (Habermas, 1985, p. 180).

${ }^{244}$ Habermas, 1979, p. 14.

${ }^{245}$ La TsS formula: “'Qué o cómo?' - esto se dice fácilmente. El reordenamiento de las preguntas ¿qué? transmite una imagen de refinamiento intelectual-sobre todo desde que Kant le ha recomendado la forma de pregunta 'ccómo es algo posible?' a cualquier metafísica como punto de partida [...]. El qué (RJl es el mundo, y lo que no es, incluyendo la razón del por qué es lo que es, ya no se podia inferir sin más del mundo mismo. Por lo pronto se tenia que observar cómo [R]] es observado, para corregir eventualmente el modo de observación" (Luhmann, 1990a, p. 14). Karin Knorr-Cetina opina: "Las nuevas orientaciones metodológicas frecuentemente van a la par con un traslado del planteamiento del problema y de las finalidades del análisis." Después de haber dado la espalda a las herramientas frigidas de la investigación sociológica, algunos planteamientos microsociológicos le han dado la espalda también a los planteamientos establecidos de preguntas de la sociología. Se han dirigido a una pregunta, la cual ya desde hace mucho está dominando a la investigación dentro de la antropología. Esto es la insignificante pregunta del cómo en lugar del por qué establecido. (Knorr-Cetina,
1984, p. 48).

${ }^{246}$ Un planteamiento del problema no-trivial es un planteamiento del problema trivial, mismo que muestra su no-trivialidad mediante las conclusiones
relevantes. 
ca de su utilización. ${ }^{247}$ Es seguro que ambas categorías iluminan el centro de la arquitectura de teoría de la $T \mathrm{kH}$, misma que de acuerdo a sí misma se esfuerza en no cometer el mismo error que cometió la TaH en este aspecto: presentar "[...] los contextos inmediatamente como sistema [...]". ${ }^{248}$ Compartimos enteramente esta concepción de la TkH y la radicalizamosen el sentido de que mostramos: la TaH funde las semánticas de la "acción" y del "sistema" en la unidad de un "suceso de sistema". En todo caso, consideramos imprecisa la comprensión que tiene la TkH de la semántica del "sistema", demasiado imprecisa como para que se pudiera trabajar operativamente (iy distintamente!) con ella.

24. Hans Joas no considera el supuesto de la TkH de posicionar a la "teoría de la acción" en una relación de competencia con la "teoría del sistema o del orden", como el resultado de una discusión objetiva y substancial de ambos paradigmas de teoria. Supone que más bien es la consecuencia de una predecisión teórica de valores, de un supuesto cuasi-antropológico: “No es la teoría de la acción la que se encuentra en una relación de competencia con la teoría de sistemas funcionalista, sino que una teoría fundamentada antropológicamente de la acción humana y de las estructuras basales de la socialidad humana se opone [RJ] a una concepción sin formalismos del área de objetos de las ciencias sociales en categorías de una teoria de los sistemas [RJ], misma que aun como tal no está confeccionada en absoluto con orientación hacia lo específico de esta área de objetos. La teoría de los sistemas misma es, por de pronto, frente a lo social, [...] solamente una propuesta metafórica para la solución de los problemas teóricos del orden. ${ }^{249}$ Puede ser que la TkH tenga un "fuerte resentimiento" contra las figuras de argumentación teóricas del sistema, las cuales amenazan con "tecnificar" al "hombre", y que, por ello, no le pueden hacer justicia. Sin embargo, su recepción intensiva de pensa-

${ }^{247}$ Se podría decir que la TkH intenta dar una respuesta a la pregunta "¿qué es el orden social?" Si se dejara guiar por la pregunta "¿cómo es posible el orden social?", entonces sus explicaciones resultarian menos fenomenológico-descriptivas y más constructivista-operativas. No obstante; esta observación representa una fuerte estilización del estilo de escritura de la TkH, misma que seguramente no le hace justicia.

${ }^{248}$ Habermas, 1981b, 2, p. 303.

249 Joas, 1986, p. 156. 
mientos funcionalistas - su tratamiento minucioso y multifacético de la TaH se puede considerar muy bien logrado- habla en todo caso otro idioma. A ello se añade su relación pragmática con el problema de la recepción de los pensamientos ajenos al objeto: "Me comporto totalmente de manera pragmática frente a la pregunta, la cual formuló demasiado dramáticamente McCarthy, acerca de cuántos 'préstamos' de la teoría de los sistemas son necesarios para continuar en el mejor nivel posible aquello que Marx comenzó con su crítica de la economía política." 250 De todas maneras, en este contexto nuestra tesis es: mientras que los problemas que tiene la TaH con su arquitectura de teoría resultan de la mezcla semántica de "acción" y "siste$\mathrm{ma}^{n}$, o del planteamiento exclusivo de su unidad, la $\mathrm{TkH}$ se mete en problemas debido al hecho de que polariza las semánticas de "acción" (comunicación) y "sistema" (ejercicio de la influencia), o que enfoca solamente su distinción, con lo cual no es capaz de reflejar su unidad. Formulado de otra manera: lo que la TaH (Parsons) omite, es decir, imaginarse, más allá de la unidad de "acción" y "sistema", su distinción, lo realza demasiado la TkH (Habermas): absolutiza la distinción de "acción" y "sistema", con la consecuencia de que se le escapa su unidad. Citando nuevamente a Hans Joas: "Por más impreciso que haya sido el intento de la formulación de un motivo interesante [social integration y system integration de Lockwood RJ], era evidente que aquí la integración del sistema y la integración social se referían a dos dimensiones de integración siempre presentes simultâneamente, y que no designaban a dos áreas distintas de la sociedad [como con la TkH RJ]. ${ }^{n 251}$ En todo caso, la definición de la sociedad que la TkH ofrece como "contextos de acción sistémicamente estabilizados de los grupós socialmente integrados", ayuda a evidenciar la dicotomía de "acción" (integración social como la coordinación de las intenciones de la acción) y "sistema"(integración del sistema como la coordinación de las consecuencias de la acción) condicionada por la arquitectura de la teoría.

25. En cuanto al contenido, la TkH legitima al dualismo semántico de "acción" y "sistema" o de "mundo vivencial" y "sistema" de la manera siguiente: "El análisis de estos contextos lde acción y sìstema

${ }^{250}$ Habermas, 1986a, p. 390.

${ }^{251}$ Joas, 1986, p. 164. 
RJ es posible solamente si distinguimos entre aquellos mecanismos de la coordinación de la acción que afinan las orientaciones de la acción de los participantes entre sí, y aquellos mecanismos que estabilizan los contextos de acción no-intencionados mediante el entrelazamiento funcional de las consecuencias de la acción. En uno de los casos, la integración de un sistema de la acción se produce mediante un consenso asegurado normativamente $u$ obtenido comunicativamente; en el otro caso, por medio de una regulación no-normativa de las decisiones particulares más allá de la conciencia de los actores. La diferenciación entre una integración social, que comienza con las orientaciones de la acción, y la integración sistémica, que atraviesa a las orientaciones de la acción, hace necesaria un diferenciamiento correspondiente en è concepto mismo de la sociedad. ${ }^{\text {n252 }}$ Anotamos: se trata de dos formas distintas de integración de la sociedad, las cuales representan simultáneamente dos mecanismos diferentes de coordinación de la acción, lo que hace evidente que la TkH procede, en este contexto, exclusivamente desde la perspectiva de la teoría de la acción. ${ }^{253}$ Por un lado, se trata de la integración social de las intenciones de la acción, por el otro lado, se trata de la integración sistémica de las consecuencias de la acción. La TkH comprende la coordinación de las intenciones de la acción con la ayuda del concepto de la acción, mientras que, de acuerdo con su opinión, la coordinación de las consecuencias de la acción puede aclararse solamente en el contexto de un concepto del sistema. Se utiliza la semántica de la "acción" para hacer comprensible la coordinación intencional de las acciones, la semántica de "sistema" sirve para iluminar la coordinación de las acciones no-intencionadas. ${ }^{254}$ En el mismo contexto, se argumenta que, por un lado, es la perspectiva de participante de los actores la que ocasiona que la SOCIEDAD aparezca como la coordinación de las intenciones de la acción, pero que, por el otro lado, se debe hacer responsable la perspectiva del observador de los mismos actores por la experiencia de la sOcIEDAD como la coordinación de las consecuencias de la acción. Formulado de forma abreviada: dentro del marco de las acciones sociales, los participan-

252 Habermas, 1981b, 2, p. 179.

${ }^{253}$ Y esto naturalmente en contra de la propia intención, es decir, de proceder tanto desde la perspectiva de la acción como también desde la perspectiva de la teoría de los sistemas.

${ }_{2 s 4}$ Véase acerca de este complejo de problemas a Jokisch, 1981. 
tes experimentan la SOCIEDAD como "acción", los observadores experimentan la misma SOCIEDAD como "sistema".2ss

26. Parece que la TkH podría opinar: la SOCIEDAD aparece como "acción" (ino enajenada?) solamente desde la perspectiva de un participante, sin embargo, aparece como "sistema" (ienajenado?) desde la perspectiva de un observador. Por el otro lado, la sOcIEDAD se define explícitamente como contexto sistémico de las acciones de los grupos integrados socialmente, con lo cual la SOCIEDAD es dicotomizada en "accion" y "sistema". 256 En vista de estas definiciones ambiguas, optamos(TgS) por la interpretación de una dicotomización de la soCIEDAD en "acción" y "sistema", con lo cual tenemos la opinión de corresponder mejor a las intenciones de la TkH.

El qué tan problemático es éncontrar aquí una cierta claridad, lo hacen evidente las exposiciones de Johannes Berger, el cual se refiere a la dicotomización de la acción comunicativa y la acción estratégica: "La acción comunicativa es esencialmente el consentimiento; su núcleo yace en el común acuerdo. Al contrario, quien actúa estratégicamente, solamente quiere ejercer influencia sobre otros [...] Lo problemático de esta versión de la diferencia entre dos tipos de acción no es solamente la dicotomización de las acciones concretas, de modo que una acción puede ser solamente una cosa o la otra, sin embargo, no se pueden entrelazar continuamente ambas perspectivas en ella, sino que se mueve la delimitación entre ambos tipos de acción. Por ejemplo, el tipo de acción no comunicativo se documenta alternando con conceptos como acción teleológica, acción racional de finalidad, etcétera, (véase, por ejemplo, Habermas, 1981b, 1, p. 320)..$^{\text {257 }}$

255 Independientemente de si se parte con Mead de los conceptos básicos de la interacción social o con Durkheim de los conceptos básicos de la representación colectiva, en ambos casos la sociedad se concibe desde la perspectiva del participante [R]] de los sujetos actuantes como el mundo vivencial de un grupo social. Frente a esto, desde la perspectiva de observación de un no-participante, la sociedad se puede comprender solamente como un sistema de acciones, con lo cual estas acciones merecen una posición funcional.

256 "El [la TkH] dicotomiza a ésta la coordinación de la acción R] de acuerdo a una coordinación mediante las intenciones de la acción versus una coordinación mediante las consecuencias de la acción." (Joas, 1986, p. 156).

${ }^{257}$ Berger, 1986c, pp. 266-267. 
27. La propuesta de la TkH de relacionar disyuntivamente los paradigmas de "sistema" y "acción" se discute en el lugar donde se trata el análisis de las forma de cambio de la solidaridad social en cuanto a la división social del trabajo de Émile Durkheim. ${ }^{258}$ Con ello, la TkH quiere hacer plausible que cada sociedad se basa tanto en una integración social de sus acciones como en una sistémica. Por lo tanto, curalquier sociedad está confrontada con el problema de cómo acoplar ambas maneras de integración de la acción, e incluso la evolución social se define precisamente con la ayuda de ambas formas de integración: "Comprendo la evolución social como un proceso de diferenciamiento del segundo grado: el sistema [RJ] y el mundo vivencial [R]] se diferencian por el hecho de que la complejidad del uno y la racionalidad del otro crecen, no solamente como sistema y como mundo vivencial, ambos se diferencian, a la vez, también entre $s_{i}$ [RJ]. ${ }^{n 259}$ Con el apoyo de esta formulación se puede realzar nuevamente que, de hecho, la TkH dispone la "acción" (- mundo vivencial) y el "sistema" de manera dicótoma, aunque bajo la consideración de los desarrollos social-evolucionarios, mismos que muestran dicha dicotomización comó contingente en el sentido de un suceso bistórico. La primacía dentro de la separación de "sistema" y "mundo vivencial" (por ejemplo "acción") la obtiene el mundo vivencial, puesto que "[...] define al estado del sistema social en total". ${ }^{260}$ La consecuencia es que el sistema, si es que debe poder existir socialmente del todo, requiere un anclaje dentro del mundo vivencial, lo que significa que debe ser institucionalizado. ${ }^{261}$

28. Repetimos: la teoría del sistema general de la acción (TaH) tiene el problema de que funde a la "acción" y al "sistema" en una sola unidad semántica, sin considerar su distinción; el problema de la teoría de la acción comunicativa ( $\mathrm{TkH}$ ) consiste en el hecho de que solamente enfoca la distinción de "acción" y "sistema", sin pensar en su unidad. Preguntamos ahora —en el nivel de la teoría social: ¿cuándo

${ }^{258}$ Habermas, 1981b, 2, pp. 173 y ss.

239 Ibid., p. 230.

${ }^{200}$ Idem.

${ }^{261} \mathrm{La}$ TkH formula: "A la vez, el mundo vivencial permanece como el subsistema, mismo que define a la existencia del sistema social en total. Por lo tanto, los mecanismos sistémicos requieren un anclaje dentro del mundo vivencial -deben ser institucionalizados." (Idem). 
una acción es un suceso, cuándo es un sistema? Contestamos la pregunta ya desde ahora: desde la perspectiva del observador (como unidad de observación), la acción es posible solamente como sistema; desde la perspectiva participativa (como unidad de utilización), es posible solamente como suceso. Con ello estamos en concordancia con la $\mathrm{TkH}$, aunque con la gran diferencia de que tenemos la opinión que las perspectivas de participante y de observación se encuentran en una relación complementaria, no en una exclusivamente dicótoma. ${ }^{262}$ Aclaramos esta afirmación. Una acción es un suceso siempre y cuando - condicionado autopoiéticamente- es requerida como unidad de utilización. Solamente los sistemas que utilizan acciones constituyen en un acontecimiento aquello que exploran. La razón de esto se puede ver en el hecho de que los sistemas cerrados-autorreferenciales se pueden conservar solamente debido a que conectan un suceso con el siguiente. No obstante, esto puede lograrse solamente si el suceso - en este caso la ACCION- emerge, está presente y desaparece para cederle el espacio al siguiente suceso de conexión (a la siguiente ACCiON...), el cual, por su parte, emerge, está presente y desaparece... Si no tiene lugar ninguna acción de conexión, entonces el sistema deja de existir: toco el timbre y espero que se me abra la puerta. La puerta permanece cerrada. Me voy. Ahora bien, es trivial decir que los sistemas utilizan acciones para poder actuar, ¿cómo más pueden actuar? Menos trivial es que el suceso "acción" representa, desde la perspectiva de la observación, una estructura compleja de relaciones, misma que puede ser realizada solamente dentro del marco (o sea, como "sistema") de una diferenciación asimétrica y una diferencia simétrica: yo, no tú (asimétrica), me encuentro ante la alternativa de tocar el timbre o no tocarlo (simetría). Toco el timbre (entonces "actúo") (figura 117).

\begin{tabular}{|ll|}
\hline no tú, & no tocar el timbre \\
sino yo $\longrightarrow$ proceso de la acción $\longrightarrow$ tocar el timbre
\end{tabular}

Ciertamente se puede decir también que la acción se presenta en el proceso de denominación, mismo que puede generarse solamente si desde una posición asimétrica se decide sobre una situación si-

${ }^{262}$ Véase Habermas, 1981b, 1, pp. 152 y ss. 
métrica: hoy, no mañana, tengo la posibilidad de ver la película de Woody Allen en el cine o de ver en la televisión el juego de basquetbol entre los americanos y los croatas. Me decido por el juego de basquetbol. El suceso "acción" ya está presente en el proceso de denominación o decisión que se genera mediante la constelación de una distinción simétrica y una distinción asimétrica preñada del sentido. Bien entendido, la acción no es idéntica con el proceso de denominación o de decisión. Éste sólo la produce. Se puede formular también de la siguiente manera: la "acción" es el proceso de unidad que surge cuando las distinciones se refieren mutuamente una a la otra y, con ello, atribuyen "responsabilidad", lo que, desde la perspectiva de observación, aparece como una atribución o una diferenciación asimétrica en el discurso de la teoría de las distinciones.

29. Todo esto se puede observar. Sin embargo, podemos efectuar esta observación solamente porque nosotros mismos hemos actuado anteriormente: nosotros (la TgS), y no la TkH (y mucho menos la TsS), nos encontrábamos frente a la situación de utilizar la "acción" (realizarla) o de observarla. Nos hemos decidido por su observación (y con ello hemos actuado) (figura 119).

no la TkH, utilización de la acción sino la TgS $\longrightarrow$ proceso de la acción $\longrightarrow$ observación de la acción

Mediante su observación la podemos ver tanto como suceso como también en forma de estructura relacional y, con ello, como "siste-

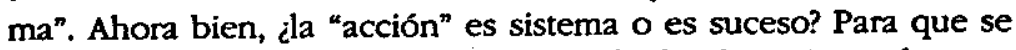
genere una acción deben estar involucradas las distinciones, las cuales originan el proceso de la decisión.

Para prevenir malentendidos: se trata tanto de los procesos de decisión explícitos como de los no-explícitos. Los medios de comunicación, por ejemplo, contienen formas de acción ya predecididas y, por ello, sirven muy bien para formar sistemas del sentido, puesto que extinguen al procedimiento de decisión explícito. Igualmente la acción de rutina y costumbre. 
Sin embargo, una decisión (denominación) solamente es posible sobre la base de las distinciones: ¿deseas comer (o sea tú, no yo) en"salada con pescado o con came? Con came, por favor. El suceso de la "acción" une, si se puede decir así, a la relación tetrádica de la diferencia simétrica y la diferenciación asimétrica. Esto significa que las acciones como sucesos particulares nunca pueden presentarse aisladamente: son posibles solamente dentro de una situación preñada de decisión y caracterizada por medio de las distinciones, misma que les proporciona el estímulo de decisión. La cuestión de si, en última instancia, se actúa "de ésta o de otra manera". naturalmente permanece como contingente, con lo cual la contingencia ya está canalizada de manera binaria y, con ello, obtiene solamente un pequeno margen de acción: "de ésta o de otra manera". En todo caso, esta exposición hace evidente que una acción requiere las distinciones, y esto quiere decir que necesita la COMUNCACIÓN en la forma de las distinciones (consideradas o no consideradas) para poder realizarse. Resumiendo podemos formular: la acción es un suceso, que se puede realizar solamente de manera sistémica, con lo cual la constitución del sistema, por su parte, solamente es posible con la ayuda de la acción. Ningún sistema sin acción, pero tampoco ninguna acción sin sistema, esto sería la versión breve de esta relación. Con ello hemos comprobado nuestra afirmación inicial de que tiene sentido tratar el sistema y la acción tanto como unidad como también como distinción. El aspecto distinto se pierde de vista debido al hecho de que la utilización de una acción excluye la simultánea observación de la misma acción. Ahora bien, hemos demostrado que estamos obligados a actuar ${ }^{263}$ en una forma determinada para observar la acción: solamente debido a esto podemos explorar la unidad de la distinción de acción y sistema.

30. Traslademos las explicaciones hechas antes a la teoria de la sociedad. La ACCION y la COMUNICACION forman una unidad en la distinción: la COMUNICACIÓN suministra el material necesario de estímulo en la forma de la distinción simétrica; la ACCION produce, como distinción asimétrica, la relación entre las distinciones simétricas. ${ }^{264}$

${ }^{263}$ Desde la perspectiva del sistema de la ciencia: iluminar analíticamente lo sintético estorboso de la acción.

${ }^{264}$ Véase acerca de ello el capítulo I sobre la logica de las distinciones. 
Una teoria de las distinciones trata lo distinto dentro de un mundo del sentido como estímulo disparador, mismo que puede posibilitar el comportamiento de conexión a través de la Acción. En cuanto a la teoría de la evolución, podemos anotar que los estímulos producen la libre movilidad en los animales más altamente organizados, una movilidad, la cual se puede describir como el comportamiento. Este comportamiento, a la vez, "[...] se puede describir como la reacción a los estímulos. Los estímulos pueden indicar el peligro o alimento, la presa [...]" ${ }^{265}$ Y Konrad Lorenz tiene la idea de que tanto los procesos, los cuales solamente adquieren la información del momento sin almacenarla, como también aquellos procesos que se desarrollan en el sistema nervioso central y que implican la memoria, se basan en la estimulabilidad. ${ }^{266} \mathrm{Si}$ se puede hacer plausible que las distinciones tienen la función de constituir los "estímulos" dentro de un mundo del sentido, entonces no se requieren motivos externos, o razones antropologicas profundamente arraigadas, mismas que deben explicar el por qué los sistemas del sentido son del todo capaces de actuar. Solamente se debe aclarar de manera interna cuáles estímulos del sentido o distinciones están presentes para explorar la acción consistentemente. El hecho de que alguien actúa en última instancia "de ésta y no de otra manera" se debe en parte al margen de movimienio, mismo que está determinado mediante una contingencia relativa de la ACCIÓN, o sea, su forma binaria.

Con ello se conserva un momento de incertidumbre que se puede designar como el aspecto de contingencia de la ACCiÓN, el cual, sin embargo, se limita considerablemente en cuanto a una situación abierta del sentido estructurada binariamente en: "¿se debe seguir escribiendo o se debe terminar?", "¿nos quedamos en casa o salimos", "ise debe actuar u observar?" [...] Llamamos sistema del sentido, en concordancia con las explicaciones hechas, a aquella forma que surge cuando la ACCIÓN y la COMUNICACIÓN se refierer. una a la otra en cuanto a las distinciones; cuando - formulado en el nivel de abśtracción de la teoría de las distinciones-la "diferencia" y la "diferenciación" se conectan mediante la designación (O DECISION) de manera razonable. No obstante, con ello es posible solamente un sistema dado momentáneamente, mismo que puede desaparecer nuevamente: “Me puedes prestar diez pesos? Lo siento, pero no tengo ni un centavo." Ahora bien, si se repite el proceso de entrelazamiento de

265 Weizsäcker, C.F.v., 1991, p. 138.

${ }^{266}$ Lorenz, 1973, p. 70. 
ACCIÓN y COMUNICACIÓN, entonces se puede alcanzar la formación de expectativasy, con ello, la constitución de sistemas del sentido duraderos: "En el desayuno siempre tomó café" se ha convertido en un sistema después de que el proceso de decisión entre "tomar café o tê" se haya normado en "café", y en este sentido ya no es necesaria ninguna forma explícita de decisión. En este aspecto, un sistema del sentido duraderu implica estructuras de expectación, mismas que seleccionan los correspondien!les sucesos. A la vez, una estructura de expectación depende de los sucesos de acción que la confirman. Por lo tanto podemos decir que los sistemas del sentido duraderos. se constituyen a par itr de un juegu cambiante entre las estructuras de expectación y los correspondientes sucesos de acción, con lo cual la estructura de expectación escoge al tipo del suceso de acción, y el suceso de acción asegura la estructura de expectación.

31. El lugar central que ilumina al problema de la dicotomización de la TkH en el nivel general de la teoria es: "No la respuesta de Durkheim, sino su planteamiento del problema es ilustrativo. Dirige la mirada sobre las conexiones empíricas entre los niveles de diferenciamiento del sistema y las formas de la integración social. El análisis de estas conexiones es posible solamente, si distinguimos entre los mecanismos de la coordinación de la acción, mismos que afinan a las orientaciones de acción de los participantes entre sí, y aquellos mecanismos que estabilizan los contextos de acción no-intencionados mediante el entrelazamiento de las consecuencias de la acción. En uno de los casos, la integración de un sistema de acción se produce mediante un consenso alcanzado comunicativamente y asegurado normativamente; en el otro caso, a través de una regulación no-normativa más allá de la conciencia de los actores. La diferenciación entre una integración social de la sociedad, misma que comienza con las orientaciones de la acción, y una sistémica, misma que atraviesa a las orientaciones de acción, obliga a un diferenciamiento del concepto mismo de la sociedad. Independientemente de si uno parte con Mead de los conceptos básicos de la integración social, o con Durkheim de los conceptos básicos de la representación colectiva, en ambos casos, la sociedad es concebida, desde la perspectiva del $\dot{p} \bar{a}$ ticipante [RJ] de los sujetos actuantes, como mundo vivencial de un grupo socialmente integrado [RJ]. En cambio, desde la perspectiva de observación de un no-participante, la sociedad solamente puede per- 
cibirse como un sistema de acciones, con lo cual estas acciones merecen una posición funcional en dependencia de su aportación a la conservación de la existencia del sistema." ${ }^{267}$ Abreviamos la cita a la formulación: mediante la perspectiva del observador, la socieDAD es comprendida como integración social ( $=$ "acción"); mediante la perspectiva de observación, como integración del sistema (= "sistema"). Por medio de la observación se constituye el "sistema", por medio de la participación se constituye el "mundo vivencial" o la "acción". Ya antes hemos sometido este supuesto a una crítica, sín considerar el aspecto del observador. Queremos realizarlo finalmente. Observemos más detalladamente a un observador y a un participante de este tipo. Ya hemos expuesto que la ACCION puede emerger solamente con la ayuda de la COMUNCACIÓN, en la forma de que una acción es posible solamente sobre la base de una decisión, y ésta, a su vez, puede realizarse solamente por medio de una forma de distinción. Si se debe realizar una ACCION, entonces es indispensable una observación de la cOMUNICACión como forma de distinción: "pastel o pizza", "cerveza o limonada", "bañarse o ducharse".

Sea realzado el hecho de que aquí tratamos el caso de una Acción, con la cual se trata de una decisión expresa. El caso normal es una ACción, con la cual el aspecto de decisión ya ha sido "tragado", como es el caso de los medios de comunicación, que son tan exitosos en la formación de sistemas debido al hecho de que en ellos, la acción manifiesta ha sido convertida en una acción latente.

En caso de que se haya efectuada una observación de la cOMUNCACION de esta naturaleza, se puede ACTUAR como participante de lo que sea. También podemos formular: si uno quiere participar en una COMUNICACION, entonces la debe observar; sólo su observación puede posibilitar la participación en "ésta, no aquella" comunicaCION. Thomas MCCarthy llega, sobre la base de otros supuestos, a una conclusión parecida a la nuestra: "La diferenciación entre la perspectiva interior del participante y la perspectiva exterior del observador es demasiado imprecisa como para cumplir con su función, dado que cualquier planteamiento exitoso de la investigación social, desde la fenomenología y etnometodología hasta el análisis funcional y reconstructivo, integra, de cierta manera, a ambas. ${ }^{n 268}$ Ya que la TkH

${ }^{267}$ Habermas, 1981b, 2, p. 179.

${ }^{268}$ McCarthy, 1989, p. 692. 
dispone su arquitectura de teoría exclusivamente de manera dicótoma, falla constantemente en su intento de comprender lo unitario por medio de lo distinto. En seguida podemos formular con McCarthy: "Por lo tanto, la diferenciación general entre la perspectiva interpretativa [perspectiva del participante RJ] y la objetivizante [perspectiva del observador RJl no puede suministrar la diferenciación específica entre análisis del mundo vivencial y del sistema. ${ }^{\text {269 }}$ Si preguntamos, dentro del marco de la teoría de la acción comunicativa (TkH), acerca de las condiciones de la posibilidad del orden social, entonces podemos responder: el orden social es posible mediante la dicotomización de la acción ( - mundo vivencial) y el sistema. El que aquí se ofrece cuasi naturalmente una forma de dos niveles, nos lo demuestra luego la misma TkH: "La historia de la teoría desde Marx se puede concebir como separación de dosparadigmas, mismos que ya no podian ser integrados en un concepto de dos niveles que asociara al sistema con el mundo vivencial. ${ }^{\text {270 }}$

La TkH ha sido desarrollada explícitamente para revertir esta separación. Nuestra impresión es que su aparato técnico de teoría no es lo suficientemente complejo como para mantener enfocado, por medio de lo distinto, también la unidad de lo distinto. Si preguntamos desde la perspectiva de la TkH, ¿cómo es posible la sociedad?, entonces se debe responder: la sociedad es posible como la dicotomía exclusiva de las intenciones de la acción y las consecuencias de la acción.

${ }^{269}$ Ibid., p. 604.

${ }^{200}$ Habermas, 1981b, 2, p. 303. 
En el capítulo V sobre las arquitecturas de teoria hemos intentado demostrar que tanto la TaH (Parsons) como la TkH (Habermas) se esfuerzan en erigir la sociedad sobre una plataforma de la teoría de la acción. Mientras que la TaH parte de una cuasi identidad de sistema y acción, la TkH trata de proceder de manera dicótoma, separando por completo la acción ( mundo vivencial) del sistema. En ambos casos se generan como consecuencia problemas específicos, de los cuales hemos presentado a algunos y hemos propuesto soluciones para ellos. En lo que concierne a la TsS (Luhmann), se ha demostrado (sobre todo en el capítulo I sobre la forma) que para ella el problema de la posibilidad de la sociedad se trata exclusivamente desde la teoría de la comunicación. Aun más, algunas curiosidades de esta teoría resultan del hecho de que no posee ninguna teoría de la acción, por lo menos en el nivel de la teoría general de la diferenciación. Sin embargo, ésta representa la medida para la teoría de los sistemas sociales. Naturalmente se trata con ello de estilizaciones burdas, mismas que no le pueden hacer justicia a las arquitecturas de teoria aquí tratadas. Nuestra propuesta de teoría - la pragmática de las distinciones- estaba, en este contexto, caracterizada desde el principio por el intento de mantener el equilibrio entre ambos caminos reales de la argumentación teórica social, es decir, no meterse en el callejón sin salida de un tipo de procedimiento exclusivamente teórico desde la perspectiva de la acción, ni tampoco dejarse seducir por las sirenas encantadoras de un tipo de procedimiento exclusivamente teórico desde la perspectiva de la comunicación. Las dificultades que ofrece la teoria de la acción consisten, sobre todo, en el hecho de que su fuerza es simultáneamente su debilidad: tiene la plausibilidad cotidiana de su lado. Por el otro lado, una teoria exigente de la acción requiere también de argumentos exigentes, mismos que consisten 
sobre todor en el hecho que se debe demostrar: la teoría de la acción compone solamente uno de los lados del negocio de una teoría social. La otra mitad debe ser cubierta - por lo menos parcialmentemediante las reflexiones teóricas desde la perspectiva de la comunicación. Ciertamente, la teoría de la comunicación está cada vez más de moda, sin embargo tenemos la opinión de que es correcta objetivamente. El problema de una teoría de la comunicación orientada sociológicamente se ubica en la circunstancia de que con ella se puede, de hecho, cubrir todo aquello que parece relevante sociologicamente. Esto se puede expresar también de la manera siguiente: los argumentos de la teoría de la comunicación le facilitan demasiado a los sociólogós interesados èn la teoría social la explicación de cómo es posible el orden social. Se podría contestar seguramente: ¿por qué no hacer las cosas fáciles? ¿es la verdad siempre dificil? En todo caso, la teoría de la comunicación representa una condición de explicación ciertamente necesaria, pero no suficiente, de las conexiones teóricas sociales. De la teoría de la acción se puede decir lo mismo. Basándonos en argumentos de la pragmática de las distinciones y de la teoría de la operación, interpretamos a la acción y a la comunicación respectivamente de manera doble, dependiendo de si nos dirigimos a una circunstancia social desde la perspectiva de la observación, u operativamente. Con ello, la acción siempre aparece, por un lado, como una forma de la diferenciación, por el otro lado, como el resultado operativo de un sistema. La comunicación se presenta, por un lado, como una forma de la diferencia, por el otro lado, es indispensable como condición operativa de la decisión de sistema. Esto seguramente no facilita más el negocio de la teoría social, y mucho menos lo hace más claro. $Y$ aquí seguramente hay puntos ciegos. Dichos puntos ciegos de las construcciones de teoría están relacionados, sobre todo, con determinadas distinciones directrices, sin las cuales, no obstante, no habría ninguna dirección de teoría, y con las cuales es inevitable una determinada idealización. De èsta manera, el esquema AGIL de Parsons es una directriz de investigación, asimismo, el postulado de una "comunicación libre de dominio" de Habermas y el supuesto de una "autorreferencia pura" de Luhmann. A ello están ligados los puntos fuertes y los débiles de una correspondiente arquitectura de teoria. Se entiende que nuestra teoría no es ninguna excepción. Nuestra directriz de investigación consiste en la combinación ideal de la diferencia y la diferenciación. Esto es, por así decir, el punto ciego de nuestra teoría. Visto exactamente, estas 
directrices de investigación, guías del negocio de la teoría, son banales en su forma general. Se hacen relevantes s 6 lo cuando se pueden demostrar las consecuencias resultantes. Y precisamente aquí dormita, por lo menos, una forma de la ceguera: no se pueden tener presente todas las consecuencias de un supuesto de este tipo. ${ }^{1}$ El lector interesado puede decidir por sí mismo acerca de si hemos logrado demostrar por lo menos algunas consecuencias de la propuesta pragmática de las distinciones, relevantes para la teoría sociológica.

En el nivel de abstracción en el cual está dispuesta la teoría de las distinciones, un tratamiento del planteamiento de preguntas teóricas sociales era posible sólo rudimentariamente. Esto naturalmente no significa que las cosas permanecerán de esta forma, ya que la verdadera intención relacionada con el proyecto de la pragmática de las distinciones es la elaboración de una teoria social, incluyendo singulares áreas sociologicas relevantes. Con ello se puede mostrar qué se gana y qué se pierde si se procede desde la teoría de las distinciones. Ya se está preparando una publicación que tiene como contenido la aplicación a la teoría social.

' Karl R. Popper formula la misma circunstancia con la ayuda del contenido informativo y lógico de una teoria de la manera siguiente: "Existe un numero infinito de frases no-triviales impredecibles y un numero infinito exactamente correspondiente de frases, las cuales pertenecen a su contenido 16 gico. Por lo tanto no podemos nunca conocer o entender todas las implicaciones de una teoría -es decir, su significado completo." (Popper, 1979, p. 33). 


\section{RESUMENES de LOS CAPÍtulos I A V}

\section{Captrulo I. ¿QUE es Forma?}

En el primer capítulo se hace referencia al problema de la forma, mismo que se expresa en la pregunta ¿cómo ès posible algo como "algo"? Con ello se hace énfasis en dos puntos: por un lado, la forma se describe como la figura de una 'logicidad de lo social', por el otro lado, como la figura de una 'socialidad de lo lógico'. En la parte acerca de la forma se demuestra que lo social (o to RELACIONADO CON LA SOCIEDAD, èn el discurso del proyecto aquí presentado) posee una forma lógica en el sentido bien definido, en el nivel de una teoría general de las distinciones, misma que se desarrolla completamente en la tercera parte del capitulo. Segundo, en la parte Sociedad de lo lógico, se hace plausible, independientemente de la tesis de la logicidad de lo social, que lo lógico posee, por su parte, una dimensión social del sentido, en el nivel de la teoría de las distinciones. Si lo lógico está determinado socialmente, y lo social está determinado lógicamente, con lo cual se pueden demostrar la logicidad de lo social y la socialidad de lo lógico, independientemente una de la otra, entonces se puede proyectar una teoria de las distinciones, la cual tiene un significado fundamental para una teoria de la sociadad, ya que siempre el elemento básico de una teoría social de cualquier tipo es lo 'social' (o lo RELACIONADo CON LA SOCIEDAD). Esto es también el contenido de capítulo I: el proyecto de una teoría de las distinciones, misma que se orienta hacia la cotidianidad fenomenológica.

\section{LA LOGICA DE LO SOCIAL}

Cómo logicidad de lo social comprendemos el hecho de que la dimensión social del sentido se puede explorar con la ayuda de dos 
distinciones, es decir, diferencia y diferenciación. Con ello, se trata de dos distinciones con sus respectivas formas diferentes. La diferenciación muestra una forma asimétrica, la diferencia una forma simétrica. Se demuestra, en el nivel de una teoría general de las distinciones y con la integración de distintos planteamientos, que las condiciones de la posibilidad de la constitución de forma, objeto o "algo" se basan en una constelación tetrádica de sucesos. Algo, lo que sea, es comprensible cognoscitivamente, solamente si se relacionan uno con el otro, por lo menos cuatro sucesos, en la forma de dos distinciones, llamadas diferencia y diferenciación. No se puede evitar el círculo que se genera debido al hecho de que la emergencia de la forma se demuestra con la ayuda de las distinciones bien formadas. Sin embargo, se puede demostrar que la forma es posible solamente si ambas distinciones se procesan de manera específica. En este sentido, procedemos, por lo pronto, de manera fáctica, utilizando simplemente las distinciones; sin embargo, a continuación demostraremos que la forma de estas distinciones es la condición de su propia posibilidad y, con ello, muestra un carácter autorreferencial. Esta autorreferencialidad se explora en el capítulo I, en La lógica de lo social, por medio de la operación de la observación y en Socialidad de lo lógico, por medio de la operación de la operación. La exploración de la dimensión social del sentido tiene lugar con la ayuda de las distinciones objetivas diferencia y diferenciación, de tal manera que referimos la forma de ambas distinciones a las distinciones COMUNICACIÓN y ACCIÓN. Luego podemos afirmar que la forma de la lógica y la forma de la SOCIEDAD se corresponden, de tal modo que se debe procesar la COMUNICACIÓN como distinción asimétrica, la ACCIÓN Como asimétrica, si es que se debe constituir la dimensión social del sentido ( $=$ SOCIEDAD).

\section{Acerca de la forma de la forma}

El capítulo I, acerca de la forma, trata la pregunta acerca de la forma de la forma, misma que se comprende como un entramado de las distinciones diferencia y diferenciación, dejando fuera de consideración la dimensión del tiempo. Se demuestra que la forma conduce necesariamente, como una simultaneidad de autoigualdad y autodesigualdad, a paradojas y tautologías, las cuales se pueden superar solamente si se reacciona de manera reflexiva a la forma de la forma, con lo cual se involucra el tiempo. Esta forma reflexiva de la forma es discu- 
tida en el capítulo III, acerca de la autorreferenćia. Luego se menciona el hecho de que algo es posible como "algo" solamente como un relacionamiento tetrádico de sucesos. Esta tesis se discute nuevamente de forma explícita en el capítulo acerca de las relaciones. Con la tesis del relacionamiento tetrádico de sucesos se tematiza el problema del comienzo de un comienzo y se demuestra que cualquier comienzo consiste en varias relaciones de sucesos (por lo menos cuatro) y que, por ello, contiene una forma comunicativa. El conocimiento de este relacionamiento es posible, sin embargo, solamente a través de una operación reflexiva. Dado que la ComuntCACIÓN en la cotidianidad no se desarrolla generalmente de manera reflexiva y que, además, es frecuentemente necesario marcar un comienzo en ceros, se pueden generar fácilmente formas de COMUNCACIÓN paradójicás y tautológicas. El significado de una teoría de las distinciones para la teoría social yace en el hecho de que cualquier teoría social compleja implica una distinción dominante como distinción principal (sistema/entorno, mundo vivencial/sistema, acción/sistema), con la cual organiza su material teórico. A partir del supuesto de que una teoría social puede observar solamente aquello que su distinción principal le permite observar, se puede deducir que el significado de la teoría de la distinción se basa en posibilitar una observación del tipo y de la manera, en la cual una determinada teoría social organiza su material de información. Al final del capítulo I se aclara que la unidad elemental de la realidad interpretada cognoscitivamente, se puede comprender como un relacionamiento de las distinciones "diferencia simétrica" $y$ "diferenciación asimétrica", con lo cual se debe interpretar la unidad elemental de la dimensión social del sentido como un relacionamiento de COMUNICACIÓN simétrica y ACCIÓN asimétrica. Con ello, unidad siempre significa, en el nivel de una teoría general de la distinción, unidad de la distinción de diferencia y diferenciación.

\section{Diferenciaciones}

El capítulo acerca de las diferenciaciones es una discusión de la teoría de las diferenciaciones (Laws of Form) de George Spencer Brown. El significado de esta teoria yace, para nosotros, sobre todo en el hecho de que tenemos la opinión de que la arquitectura de la teoría de la teoría de los sistema sociales (N. Luhmann, TsS) se basa, en gran parte, en supuestos, los cuales se pueden reducir directa o indirectamen- 
te a la teoría de la diferenciación de Spencer Brown. Otra razón de la discusión del trabajo de Spencer Brown se debe ver en el hecho de que su influencia ha aumentado considerablemente dentro de la teoría de la información, de la cibernética reciente, de la teoría de la observación y de la teoría general de los sistemas. A continuación se demuestra que la teoría de la distinción dispone dos condiciones previas, mismas que no refleja más y que, sin embargo, tienen un significado central para una transferencia hacia la teoria social: la forma de la distinción y la operación de la denominación. Spencer Brown (y con él la TsS) comprende la distinción como una diferenciación asimétrica y relaciona la operación de la denominación con esta diferenciación, de tal manera que ya no es posible ninguna distinción adicional entre ambas. La consecuencia es que se requiere solamente una operación única, es decir, una "diferenciación denominadora", para marcar el comienzo de un comienzo de lo que sea. A continuación, podemos demostrar que la distinción representa una relación compleja de sucesos, con la cual se deben efectuar las siguientes condiciones: primero, debe existir una distinción simétrica, que designamos con "diferencia". Luego, es necesaria una distinción asimétrica, que designamos con "diferenciación". Finalmente, la operación de la "denominación" debe ser definida como una operación autónoma, para que pueda arrancar en general el proceso del distinguir.

Con la integración de una teoría del sentido fenomenológica se puede mostrar entonces la utilizabilidad y fertilidad de una teoria revisada de la diferenciación. Podemos mostrar, con la ayuda de una combinación de las teorías de COMUNICACIÓN y ACCIÓN - que reproduce al núcleo de la teoría de la distinción representada por nosotros, en el nivel de la teoría social-, que dentro de la teoría de la diferenciación falta la dimensión de la ACción. Con ello, también está dicho que cualquier teoría social, la cual se apoya en la propuesta de Spencer Brown - y esto es especialmente valido para la teoría de los sistema sociales (TsS)_- debe tomar en consideración con esta insuficiencia. Ahora bien, la TsS se apropia de la teoría de la diferenciación sin comprobar este aspecto, con lo cual se debe presentar como una teoría social "sin acción". Dentro de este contexto, introducimos explícitamente los conceptos de la teoría de la distinción "diferencia", "diferenciación" y "denominación", y las relacionamos con los conceptos de la teoría de la sociedad COMUNICACIÓN, ACCIÓN y DECISIÓN, mismos que también introducimos aquí explícitamente. Al final se demuestra que ni Spencer Brown ni la TsS proceden real- 
mente de manera monológica o "sin acción" lo que, no obstante pretenden hacer de acuerdo con su arquitectura de la teoría.

\section{Objetos}

El capítulo acerca de los objetos, aborda aquellos trabajos de Ranulph Glanville que se ocupan de una revisión y ampliación de la teoría de la diferenciación de Spencer Brown. Observamos uno por uno los argumentos que motivan a Glanville (y con él a Francisco J. Varela) a someter a una revisión las Laws of Form de Spencer Brown y determinamos que, en última instancia, Glanville no procede, desde un comienzo, de manera distinta de Spencer Brown en la solución del problema del comienzo de un comienzo. Aun más, existe la misma discrepancia que con Spencer Brown, es decir, querer proceder monológicamente y, no obstante, hacerlo realmente de manera dialógica. Nosotros mismos (teoría de los sistemas de la socie$\mathrm{dad}=\mathrm{TgS}$ ) comprendemos la constitución de un objeto - de lo que sea- como un relacionamiento tetrádico de sucesos que tiene lugar sobre la base de los conceptos de distinción "diferencia" y "diferenciación", con lo cual, de antemano concebimos el suceso total de la constitución del objeto como eminentemente dialógico.

La forma dialógica se señala por medio de la forma tetrádica. En este sentido, es suficiente demostrar que todo lo que "es" puede "ser" solamente de forma tetrádica.

\section{Relaciones}

El capítulo acerca de las relaciones se ocupa de un trabajo de Ph. G. Herbst, en el cual se intenta desarrollar más la teoría de la diferenciación de Spencer Brown. Herbst realza las condiciones minimas con las cuales debe cumplir una forma, dentro del marco de las Laws of Form, para que se constituya como forma. Así, ve claramente el problema de un comienzo monológico y sugiere comprender la constitución de la forma (o de "algo") como un relacionamiento triádico de sucesos. En el contexto de una discusión de tres posiciones teóricas globales (o metafísicas), mismas que identifica como idealismo, empirismo y el planteamiento de Kant, Herbst realza las ventajas de la teoría de la diferenciación, sobre todo, la circunstancia de que la teoría de la diferenciación no trata con diferenciaciones como trascendental/empírico, ser/nada o casualidad/necesidad, sino con 
la operación de la diferenciación en general. A continuación hacemos plausible que la constitución de algo como "algo", de la forma como forma, no es posible como un relacionamiento de tres elementos/sucesos, como lo supone Herbst, sino como un relacionamiento de cuatro elementos/sucesos. Una constelación tetrádica de sucesos de este tipo puede considerarse como la condición mínima para la constitución de forma, objeto o "algo". Un segundo punto crítico que realzamos en el desarrollo de la teoría de la diferenciación por medio de Herbst, se refiere a la forma de la distinción utilizada por él: se utilizan solamente distinciones simétricas. Aclaramos que esto refleja un supuesto no realista, ya que la observación de la ACCIÓN es posible solamente sobre la base de una distinción asimétrica.

\section{Contextos}

El capítulo acèrca de los contextos, presenta el concepto de la monocontexturalidad y su crítica por parte de Gotthard Günther: todo lo que es, pertenece al contexto del ser; lo que no es, precisamente no es "nada". A continuación se demuestra que no puede haber un observador (en el discurso de la vieja Europa: sujeto), dentro de tal contexto bivalente. Por ello, se puede resolver el problema de la existencia de un observador solamente de manera negativa: como suceso negativo, el cual no pertenece al ser. La solución de Günther es: policontextualidad. Con ello él quiere decir que las formas, objetos o "algos" pueden surgir solamente dentro del contexto de, por lo menos, dos estructuras bivalentes. Demostramos que este supuesto policontextual es idéntico con nuestro supuesto de una constelación tetrádica de acontecimientos.

\section{SOCIALIDAD DE LO LOGICO}

Este capítulo delimita aquello que se debe comprender como problema con la socialidad de la lógico y demuestra que la tradición que trata a este problema es eminentemente filosófica. Se identifica el principio de transferencia, conocido dentro de la literatura (entre otros, Karl R. Popper y Konrad Lorenz) como problema particular del problema general de una socialidad de lo lógico: lo que tiene validez dentro de la lógica, también tiene validez dentro de la psicología. En 
este contexto, se introducen explícitamente los conceptos relevantes para una teoría de la sOciedad COMUNICACIÓN, ACCION y DECISION, mismos que ya se habían utilizado, y se relacionan con una pragmática de las distinciones. Se presentan uno por uno los argumentos, mismos que deben hacer plausible una socialidad de lo lógico, sobre la base de propuestas ya realizadas por C.F.v. Weizsäcker y Ernst Tugendhat. Se menciona el hecho de que las tres teorias escogen una ruta formal pragmática; y proceden de manera universal (teoria del sistema general de la acción [TaH], teoría de la acción comunicativa [TkH] y la teoría de los sistemas sociales [TsS]), por lo cual ciertamente se desvía de la pragmática de las distinciones aquí presentada, sin embargo, permanece como igual en cuanto a la función.

\section{Operación y forma}

Este capítulo ocupa un lugar particular dentro del trabajo, en el sentido de que aquí los principios lógicos de la identidad, la contradicción, del tercero incluido, la forma de negociación y la distinción de observación/operación se deducen exclusivamente sobre la base del operar de una operación. Se demuestra que, por un lado, la operación se basa en la observación de la distinción y que, por el otro lado, la observación de la distinción se constituye mediante la operación, con lo cual nos referimos a una constitución recíproca de operación y observación. En lo que concierne a la distinción diferencia/ diferenciación, se presenta la forma de su reproducción: dos diferenciaciones pueden constituir una diferencia, una diferencia puede constituir una diferenciación. Además, se aclara que, si es adecuada toda la lógica aristotélica, ya en el nivel operacional, esto es mucho más acertado para el ámbito de la COMUNICACIÓN corporal o afectiva. Con ello se señala con énfasis la forma predicativa - ya mostrada por Viktor von Weizsäcker - de cualquier percepción, misma que justifica hablar de COMUNICACIÓN ya en este nivel. La relación operación/ observación/negación/auto-observación requiere una atención especial: se argumenta que la observación o autoobservación se constituye mediante la ausencia de la operación, dentro de un mundo del sentido, con la posibilidad de poder introducir la negación al mundo. Al final se demuestra cómo es posible el sentido, mediante una identidad operativamente constituida, con lo cual nos desviamos del concepto del sentido de la TsS en el sentido de que reducimos el sentido a la distinción de facticidad y posibilidad. 


\section{Predicación y forma}

En el centro de este capítulo se encuentra la forma de la frase afirmativa como distinción específica de sujeto y predicado. Sobre la base de propuestas realizadas por C. F. v. Weizsäcker y Ernst Tugendhat se comprende la unidad de la frase afirmativa de manera pragmática de las distinciones. Con ello, podemos hacer plausible que la unidad de la frase predicativa "funciona" en cuanto a la teoría de las distinciones: se puede interpretar el sujeto como una forma de diferenciación, el predicado como una forma de diferencia. Además, es posible demostrar que la estructura de la lógica aristotélica se puede relacionar con la verdad -comprendida pragmáticamentede una frase predicativa; por el otro lado, la frase predicativa se puede relacionar, con la ayuda de la pragmática de las distinciones e interpretada operativamente, con la estructura de la lógica aristotélica, como ya se ha demostrado en el capítulo acerca de "operación y forma”. Así, se puede afirmar que son funcionalmente equivalentes la lógica de la frase afirmativa y la lógica de la operación, en lo que concierne a su capacidad de verdad; de lo cual se puede deducir, con muchas consecuencias, que ya la estructura de una operación "primitiva" es lógica -como comportamiento, ACCión o denominación-, en el sentido bien definido.

\section{LA LOGICA DE LAS DISTINCIONES}

\section{Diferencia y diferenciación}

La parte acerca de diferencia y diferenciación aborda más detallada- mente los componentes de la teoría de las distinciones - diferencia, diferenciación, designación. Con ello, los aspectos formales de las distinciones diferencia y diferenciación, o sea, simetría y asimetría, se someten a una observación más éxacta. Se debe realzar que no se requiere del planteamiento teórico sistémico para hacer plausible el entrelazamiento de diferenciación asimétrica y diferencia simétrica. Aun más, es también una insuficiencia de la reciente teoría de los sistemas, el hecho de que procede o que pueda proceder exclusivamente de manera asimétrica, ya que su distinción de sistema/entorno tiene sentido solamente en forma asimétrica. A continuación se pueden introducir los aspectos de simetría solamente ad boc. Comenzando desde el inicio, tanto de manera simétrica como asimétrica, 
obtenemos un radio teórico más grande que aquel que puede ofrecer . la teoría de los sistemas. Luego, se menciona el problema de la constitución del sentido y sus dimensiones, sobre la base de una complementaridad de simetria/asimetría. Con ello, se presenta el sentido desde la perspectiva de la teoría de las distinciones, como entramado de los lados fáctico y posible de la distinción correspondiente; el tiempo como distinción de los lados designado/no designado; el espacio como distínción de los lados completo/incompleto; la objetividad como distinción de lado determinado/indeterminado, y la socialidad como distinción de lado seleccionable/no seleccionable. A continuación se explica la coexistencia mutua de la mencionada dimensión del sentido. El tercer componente de la teoría de las distinciones, es decir, la denominación, se somete igualmente a una observación, y se señalan tres modalidades de denominación.

\section{Comunicación y acción}

La parte acerca de COMUNICACIÓN y ACCrón se ocupa de la transferencia de la distinción diférencia/diferenciación hacia la distinción de la teoría social COMUNICACION/ACCION. Con ello, COMUNCACIÓN se interpreta como oferta de selección, Acción como determinación de la selección y DECISIÓN como proceso de selección. Sobre esta base, se define luego la unidad social de la distinción de COMUNICACIÓN y ACCIÓN como la determinación de una oferta de selección mediante una selección ya determinada, por su lado, mediante un proceso de selección. A continuación, se presentan los niveles de abstracción que debe tomar en cuenta la aplicación de la teoria de las distinciones a la teoría social: el sistema de las distinciones diferencia y diferenciación, el sistema de la SOCIEDAD como distinción de COMUNCACIÓN y ACcrón, el nivel de los tipos de sistemas del sentido como distinción de información y comunicación, finalmente, el nivel de un sistema del sentido particular como distinción de codificación y programación. Al contrario de la TsS, dentro del contexto de este proyecto se introduce el código de un sistema del sentido como distinción asimétrica, el programa como una distinción simétrica.

\section{Complementaridad $y$ distinción}

En el párrafo acerca de complementaridad y distinción, primero, se presenta el concepto de la designación como forma del supuesto 
presentista por excelencia y se discute en relación con el concepto de la teoría social de la DECISIÓN. A continuación se intenta transferir el concepto de la complementaridad, como lo conciben sus creadores Niels Bohr y luego C.F.v. Weizsäcker, hacia la teoría de las distinciones. Entonces, se puede demostrar que forman una relación complementaria en el sentido clásico de la palabra, las distinciones diferencia y diferenciación -y con ellas naturalmente también las distinciones determinadas desde la perspectiva de la teoría social COMUNICACION Y ACCION.

\section{CAPITULO II. ¿QUE ES COMPLEJDAD?}

Abordamos los comienzos de la semántica de complejidad e intentamos mostrar el lugar central que esta semántica ocupa en la empresa actual de la ciencia, con la ayuda de numerosas disciplinas cientificas y áreas de disciplinas. La tesis de partida es que no se pueden registrar adecuadamente aquellos problemas que se procesan dentro de la disciplina sociología y, sobre todo, en el área "teoría sociológica", sin un concepto de complejidad. Observamos la utilización del concepto de la complejidad como distinción de simple/complejo, sobre la base de un concepto elaborado de observación - como manejo de una diferencia simétrica frente al trasfondo de una diferenciación asimétrica con la finalidad de constituir información. Se puede demostrar - con la ayuda del problema de la identidad de la circunstancia científica-que lo simple se comprende, en el contexto de tendencias de temporalización en el desarrollo de. la ciencia a partir del siglo XvII, como cada vez más complejo, debido a lo cual pierde aparentemente su función como distinción reguladora de lo complejo, la distinción de simple/complejo. Las soluciones posibles para un reestablecimiento de la distinción se efectuaron dentro del marco de procedimientos reductivos que, sin embargo, no logran convencer. Partiendo del supuesto presentista central de que todo lo que sucede, sucede simultáneamente, intentamos encontrar otro acceso hacia la distinción de simple/complejo. Sometemos el problema de la complejidad a una operacionalización, con la ayuda de la distinción de elementos y sus relacionamientos, y demostramos que la complejidad no es otra cosa que el problema del relacionamiento de sus elementos constitutivos. Precisamente esto se designa como "sistema". Se argumenta demostrando que se requiere un entra- 
mado de dos distinciones para el registro de la complejidad, es decir, de la simetría de elementos y sus relaciones, por un lado, de la asimétrica de sistema y entomo, por el otro lado. A la vez, se hace evidente que este conocimiento es posible solamente con la ayuda de otra distinción, o sea, la de la observación del hecho complejidad y su operacionalización. Ahora bien, si los elementos homogéneos y su relacionamiento conforman lo complejo, entonces se genera la pregunta urgente acerca de la cualificación de la cantidad, ya que se distinguen aparentemente el mundo y la SOCIEDAD por medio de heterogeneidad y cualidad. La respuesta es: la cualidad se genera debido a la especificidad de la limitación inmanente de los elementos, mismos que pueden mostrar solamente una capacidad de relacionamiento limitada como sucesos temporalizados. Sin embargo, esto puede valer, a su vez, como condición de la posibilidad de la cualificación de cantidad y, con ello, como razón de la heterogeneidad de mundo y SOCIEDAD. A continuación se demuestra que "formación de sistema" es equivalente con la "solución" del problema clásico de la complejidad de cómo es posible la unidad de lo diverso. La constitución de sistemas se comprende como entramado tetrádico de las distinciones elemento/relación y sistema/entorno, y se señala que este entramado aparece, en el nivel de una lógica de las distinciones, como una de diferencia simétrica y diferenciación asimétrica. Con ello, está definido simultáneamente un concepto elaborado de observación. Estos supuestos se hacen posibles con la ayuda del concepto de la cibernética del segundo grado (von Foerster), del concepto de la autopoiesis (Maturana et al.) y del término de la información, con apoyo en C. Shannon (E.v. Weizsäcker). A la vez, se hace evidente que los conceptos de las Laws of Form (Spencer Brown) y de la autorreferencia (Luhmann), son funcionalmente equivalentes con los otros tres conceptos, con lo cual anunciamos un tratamiento detallado de las Laws of Form y de la autorreferencia correspondientemente en los capítulos I y III.

Como resultado de la condensación semántica de estos cinco conceptos surge la tesis de que la operación de la repetición ( $=$ "confirmación primaria") conduce desde la información preñada de sentido hacia la emergencia de estructuras de expectación, misma que genera tanto lo acostumbrado (confirmación) como lo nuevo (condensación). Esta tesis es relevante para una sociología, en el nivel de la teoria social. Conduce hacia la afirmación de que el surgimiento de la SOCIEDAD es explicable solamente sobre la base de la operación 
de repetición de un contenido arbitrario, dentro de un mundo impregnado con sentido. En el nivel de la teoría general -aquí denominado como lógica de las distinciones-se puede demostrar que el problema de la complejidad es equivalente al problema de la "teoría sociológica": la pregunta "¿cómo es posible la unidad de lo diverso?" tiene el mismo sentido que la pregunta " ¿cómo es posible el orden social?". Al final del capítulo se ofrecen justificaciones para el hecho de que la distinción de simple/complejo es indispensable aún actualmente para el concepto de complejidad: cualquier sistema autorreferencial-cerrado depende de la ficción de simpleza de sus propios elementos, en caso contrario, ni siquiera no se puede constituir como sistema. Con ello, contradecimos a la teoría de los sistema sociales (TsS) que afirma que la distinción de simple/complejo debería estar en el cuarto de los cachivaches de la historia de la ciencia y que se debería sustituir por la de completo/selectivo. Cierra este capítulo la oferta de una solución para la autoconservación del concepto central de la observación, misma que se adhiere a la propuesta cartesiana de la autoconservación de la conciencia, así como algunas reflexiones acerca de la relación entre la semántica de alto rendimiento y de la cotidianidad.

"Observa y serás [...]" en el sentido de "y es [...]", lo que sea esto, en última instancia, en lo particular. Dentro del contexto de una teoría de la observación existen sólo observaciones que observan a otras observaciones, mismas que observan, por su parte, a éstas..., etc. La realidad cognoscitiva cuenta con la interacción de observaciones.

\section{CAPITULO III. ¿QUE ES AUUTORREFERENCIA?}

En este capítulo se intenta comprender la formación de la unidad en el aspecto de la dimensión del tiempo. En este sentido, se trata de la pregunta: ¿cómo es posible la unidad de "algo" dentro de la dimensión del tiempo? Visto exactamente, comprendemos como autorreferencia la posibilidad de forma, mientras que la forma se comprende como autorreferencia fáctica, ya realizada. Esta pregunta es de gran relevancia para la teoría sociológica debido al hecho de que la forma del problema teórico de la sociología, o sea, la pregunta acerca de las condiciones de la posibilidad de la unidad social de orden, tiene el mismo sentido que la forma de la pregunta acerca de la posibilidad de la unidad de "algo". El concepto de la autorre- 
ferencia parte del hecho de que la unidad no refleja algo dado, sino algo que, primero, se debe producir. Esto significa, transferido a la teoría social, que la SOCIEDAD como unidad es algo que se debe constituir. Después de una introducción al contexto del problema de la autorreferencia y de la colaboración crítica de algunos planteamientos acerca de ello, se hace el intento de observar el concepto de la autorreferencia con la ayuda de la pragmática de las distinciones, por un lado, en el nivel de la teoría general, por el otro lado, en el nivel de la teoría social. En el nivel de abstracción de la teoría de las distinciones, se trata del desarrollo del concepto de una diferencia doblemente contingente, con el cual se puede demostrar cómo lo indeterminado se puede transformar en lo determinado y éste, a su vez, nuevamente en lo indeterminado. Se aclara también cómo se genera la emergencia de nuevos niveles capaces de cognición - como surgimiento de nuevas distinciones. En el nivel de la teoría social, se explica el mismo mecanismo de la diferencia doblemente contingente con la ayuda de la semántica "hombre" y se demuestra cómo se pueden alcanzar cuatro tipos diferentes de COMUNCACIÓN de manera formal pragmática, que se pueden designar con "conciencia", "intimidad", "corporalidad" y "socialidad". El verdadero problema de la COMUNICACIÓN se ubica en el hecho de que la COMUNICACIÓN, como suceso que siempre tiene lugar en la forma presentista, constituye simultáneamente todos los cuatro tipos de COMUNICACION. Sin embargo, la posibilidad de COMUNICACIÓN sólo está dada cuando -por lo menos dos- "hombres" se deciden por un determinado tipo de COMUNICACIÓN.

Naturalmente, también un "hombre" solo puede procesar, sin embargo, en la figura doble de "conciencia" y "autoconciencia".

El concepto de decisión designado con DECIsIón incluye también sucesos de decisiones debajo del nivel manifiesto. Una "decisión tomada conscientemente" es, visto SOCIALMENIE, un suceso antes bien improbable. La mayoria de las decisiones se toma, por así decir, "automáticamenten ${ }^{n}$ esto significa, no conscientemente.

\section{CAPfTULO IV. ¿QUE ES OBSERVACIÓN?}

Primero, se hace el intento de determinar los diferentes niveles de abstracción que puede adoptar una observación de la SOCIEDAD, y se marca aquel nivel de abstracción del cual parte este análisis, es decir, 
del sistema parcial "teoría sociológica". Luego, se define formalmente la operación de la observación desde la perspectiva de la teoría de las distinciones, como el manejo de una diferencia frente al trasfondo de una diferenciación, con la finalidad de generar información. Con ello, se puede decir que cualquier observación de la acción termina en una exigencia de decisión, cualquier observación de una observación termina en una exigencia de unidad. Con el siguiente paso, se introducen los seis niveles de abstracción de un concepto, desde la perspectiva de la teoría de las distinciones, de observación, es decir fácticidad, posibilidad, alternatividad, observación, reflexión y autorreflexión, y se demuestra su alcance. Se presenta rudimentariamente el ensamble de las formas de observación en una teoría social, con lo cual la posibilidad del orden social se interpreta como la consecuencia del nivel reflexivo de abstracción de la observación. Sigue una caracterización más exacta de la observación, con la ayuda de los conceptos operación, realización y utilización, con lo cual se hace plausible que una misma observación no puede ser realizada como distinción y, simultáneamente, utilizada como operación. Esto se interpreta como su ceguera inherente y como el límite de lo generalmente observable. Partiendo del supuesto central de la TsS de que la autopoiesis de los sistemas del sentido es posible solamente por medio de una coincidencia de los conceptos auto-observación y operación proponemos, en el contexto de la teoría de las distinciones, comprender la auto-observación como diferenciación asimétrica e interpretar el concepto de la auto-observación como reflexión, o sea, como observación de una observaciôn. Entonces, concebimos la constitución de la autopoiesis, dentro del marco del sentido (jNo de la vida!), como la coincidencia de operación y autoindicación dentro del concepto de la diferenciación asimétrica, misma que se puede comprender naturalmente sólo dentro del contexto de una diferencia simétrica. Al final del capítulo abordamos la forma de la sociología. Con este concepto comprendemos la inclusión relativa del sistema de la comunicación sociológica en el sistema global sociedaD. Demostramos que como comunicación cerrada solamente puede girar alrededor de sí misma y, con ello, es inherentemente tautológica (y paradoja). Para evitar un bloqueo de la comunicación sociológica ocasionado por medio de la tautología, la comunicación debe tener lugar a través de las referencias de sistema, las que le posibilitan a ella y a otros sistemas del sentido oscurecer su tautología y desarrollarse exitosamente. 


\section{CaPfrulo V. ARQuTtrcturas de TEORIAS}

\section{PROBLEMA Y FORMA}

El capitulo comienza con la pregunta, dentro del marco de una teoría del problema, acerca de las condiciones de la posibilidad de problema. Con ello, se relaciona la teoría del problema como distinción de planteamiento del problema y propuestas de solución, con la teoría de la observación. La cuestión del surgimiento de un problema en la forma de una pregunta, se explica como el incumplimiento de una expectativa, con el cual se genera el preguntar tanto en el asombro como también en la desilusión. En seguida, se presenta como unidad del problema, la distinción de pregunta/respuestas y proble$\mathrm{ma} /$ soluciones: un problema es, entonces, aquello que exploramos con la ayuda de las operaciones del preguntar y responder, y que relacionamos con una solución posible. A continuación, se designa el problema del orden como el problema central, con lo cual se plantea la pregunta general acerca de las condiciones de la posibilidad del orden del orden. En el marco de la teoría de las distinciones se aclara entonces que el orden puede tener sentido solamente en el contexto de la distinción simétrica de orden/desorden. Sin embargo, esta distinción requiere, por su lado, un centro gravitacional, y, con ello, de ótra distinción más, esta vez de una distinción asimétrica en el sentido de una perspectiva "no física, sino social" del problema del orden. Con ello, terminamos en la conocida constelación tetrádica de acontecimientos. Ahora se demuestra que el problema como tal se estabiliza y obtiene un valor de estructura, solamente debido al proceso de repetición de una observación del problema en la pregunta "¿cómo es posible el orden social?" Por lo tanto, se genera la identidad del problema desde la perspectiva de la materia -a través de las distinciones de pregunta/respuestas y problema/solucionesmediante una observación, por lo menos doble, del problema en cuestión. Así, se hace evidente que ya en el nivel de la observación, donde se trata de una observación de una observación, siempre se efectúa una operación doble, misma que, por ello, puede tener potencialmente efectos de formación de identidad.

TEorfa del sistema general de La acción (TAH)

A través de la teoría del problema nos acercamos a la observación del problema central de cualquier teoría sociológica, es decir, el pro- 
blema de cómo es posible el orden social. Este subcapítulo se ocupa de la observación de la teoría del sistema general de la acción (TaH) de Talcott Parsons. Primero, abordamos el periodo de acción de la TaH y demostramos que intenta encontrar una categoría basal de lo social, una "lógica de lo social", en nuestro discurso. La forma basal de lo social se identifica como unit act, por medio del análisis del concepto de acción, con lo cual se concibe como entidad última y, simultáneamente, como unidad compleja (ends, means, conditions, norms). En este nivel de teoria, se desarrolla luego el así llamado frame of reference, mismo que no es otra cosa que la dinamización de las componentes del unit act. Llamamos la atención sobre el hecho de que se debe comprender la acción esencialmente y sobre todo, como unidad de suceso ( $\mathrm{jNo}$ solamente!) y que, sin embargo, la TaH la introduce como unidad exclusivamente analítica, como unidad relacional, con la consecuencia de no poder explicar realmente cómo es posible la acción. Además, demostramos que la intención de la TaH de determinar de la manera antes mencionada la estructura $(=$ unit act) y la dinámica (= frame of reference) de la acción, está estrechamente relacionada con su esfuerzo de poder ofrecer una solución adecuada para el problema de Hobbes del orden social. Con ello, se traslada la pregunta acerca del problema del orden desde la perspectiva de la TaH, de tal manera que ahora se debe preguntar: ¿cómo es posible la acción?, para lo cual ofrece una solución especifica. En total, localizamos cuatro complejos de problemas que le impiden a la TaH, de acuerdo con nuestra opinión, una solución posible del problema de Hobbes del orden, mismo que ahora debe formularse como la condición de la posibilidad de acción. El concepto de acción de la TaH no se concibe, primero, como unidad de suceso, sino, por lo pronto y sobre todo, como relación analítica de unidad; segundo, el concepto de acción desarrollado de esta manera cuestiona, de manera fundamental, la autonomía sistémica de los sistemas parciales; tercero, no se puede explicar plausiblemente el diferenciamiento o la emergencia de subsistemas, sobre esta base conceptual teórica de la acción; $y$, cuarto, no es posible indicar quién o qué garantiza la unidad de la acción. Luego, abordamos uno por uno estos aspectos de problema de la unidad de acción concebida analíticamente por la TaH. Ahora bien, en lo que concierne a su periodo de sistema, se demuestra que se introduce en lo siguiente, el "paradigma de cuatro funciones", llamado AGL, debido al margen de acción demasiado grande dentro del cual se le puede limitar (margen de acción 
limitacional) y que ofrece el sistema basal teórico frame of referen$c e$, propuesto primeramente por ella. Esto tiene como consecuencia que el margen de acción teórico limitacional se reduce de tal modo que ahora tiene efectos demasiado restrictivos, es decir que cualquier sistema como sistema de acción siempre y simultáneamente debe poder efectuar de manera suficiente cuatro funciones (AGIL), si se quiere realizar como sistema. A ello se añade que debe producir una concordancia con las dos variables marginales del esquema AGIL, o sea, consumatorio/instrumental e interno/externo. Debido a ello, se limita considerablemente el corsé teórico, con la consecuencia de una arquitectura de teoria que ya no se puede designar como realista. Realzamos que la técnica de las tablas de cruz, introducida conjuntamente con el esquema AGI, no muestra ninguna lógica interna, sino que muestra solamente posibilidades combinatorias, mismas que se pueden realizar, en gran parte, de manera arbitraria. A continuación, abordamos la -de acuerdo con nuesta opinión- insuficiencia principal de la teoría del sistema general de la TaH: su igualación de acción y sistema. Demostramos que se genera el problema de que se debe realizar momentáneamente la sociedad global - comprendida como unidad de acción y sistema-, desde la perspectiva de la TaH, debido al hecho de que, por un lado, la TaH comprende explícitamente la acción como sistema, en el sentido de una relación analítica de unidad; por el otro lado, sin embargo, trata implícitamente de introducir la acción finalmente como unidad con carácter de suceso. Esta conclusión problemática de una constitución social global de simultaneidad resulta, por lo tanto, de un amalgamamiento semántico, mismo que no es analizado suficientemente, de la acción como unidad relacional (explícitamente) y, simultáneamente, como unidad con carácter de suceso (implícitamente). Primero, por nuestra parte se identifica de manera inmanente al objeto con la ayuda del esquema AGI, por el otro lado, con la ayuda del problema del cambio social, y se somete a un análisis crítico. Segundo, intentamos hacer plausible, por medio del estilo de esritura de la TaH, que se puede identificar el mismo hecho problemático de una emergencia momentánea de la sociedad global (acción $=$ siste$\mathrm{ma}$, como problema de su intención de encontrar una forma discursivo-textual para las circunstancias complejas, que muestran una forma simultáneo-presentista, sin que por ello se pierda la forma presentista-simultánea de la totalidad. Además, se argumenta que la semántica de la acción como abstracción primaria, guía de la teoría 
refleja, por un lado, una categoría demasiado concreta en cuanto a la integración de distintos tipos de sistema del sentido como organismo, personalidad, socialidad, cultura, etc,; por el otro lado, refleja una categoría demasiado general, cuando se trata de deducir de ello las tipologías de acción, para poder concebir adecuadamente la manera de funcionar de los sistemas del sentido "más concretos" como la ciencia, èducación, política, arte, religión, etc. Al final abordamos el problema de la teoría del conocimiento acerca de un realismo analítico y demostrámos cómo la TaH podría haber conducido a ambas cosas, al análisis y al realismo, a una solución, considerada por nuestra parte. Para este fin, nos ocupamos más detalladamente del sistema del sentido ciencia, mismo que interpretamos desde la perspectiva de la teoría de las distinciones como un relacionamiento tetrádico del código asimétrico "cierto, no falso" y del programa simétrico "analítico y/o sintético". Se demuestra que cualquier sistema del sentido se ve obligado a adoptar elementos últimos, los cuales no se pueden disolver más por sí mismos, para poder realizar la operación de la ACCión como unidad de suceso. Desde nuestra posición, proponemos 'operaciones analíticas' como elementos últimos no más disolubles para el sistema de la ciencia, ya que solamente de esta manera se puede cumplir con el requerimiento del elemento último, dentro de este sistema: si el sistema quisiera someter un elemento último de este tipo a una disolución analítiça adicional, por medio de una operación analítica, entonces se encontraría nuevamente con otra operación analítica, es decir, consigo mismo. Mediante este limite "absoluto" se puede ilustrar a sí mismo, no obstante, no se puede suspender por medio de un conocimiento semejante.

\section{TEORLA DE LA ACCIÓN COMUNICATTVA (TKH)}

El capítulo V se ocupa de la observación de la teoría de la acción comunicativa (TkH) de Jürgen Habermas. Se intenta localizar también en el caso de la $\mathrm{TkH}$, con la ayuda del problema del orden social, como en el caso de la teoría del sistema general de la acción (TaH), aquellos contextos de argumentación que sugieren hermenéuticamente una solución para la pregunta: ¿cómo es posible el orden social? La TkH desarrolla un concepto de racionalidad comunicativa a lo largo del hilo guía de la comunicación lingüística, mismo que, por su lado, está acoplado estrechamente al proceso de un acuerdo motivado racionalmente. Ahora bien, un acuerdo semejante se mide con 
las pretensiones criticables de aceptación que se pueden analizar en dos aspectos diferentes: por un lado, el aspecto dé cómo se pueden justificar las afirmaciones de este tipo; por el otro lado, en el aspecto de cómo se refieren los actores a ellas, dentro de un mundo social, es decir, con el aspecto de la racionalidad de la acción. Por lo tanto, se podría formular el problema clásico del orden, desde la perspectiva de la TkH, en la pregunta siguiente: ¿cómo se refieren los actores, con la ayuda de pretensiones de aceptación semejantes, a un mundo como dimensión social del sentido? No fijamos el punto de partida de nuestro análisis en el problema mencionado de una justificación de afirmaciones, las presuponemos como justificadas, para la finalidad de este análisis.

Tenemos la opinión de que es problemático el contexto de justificación de afirmaciones, como lo presenta la TkH. En el contexto de la TkH, el orden social se comprende normativamente, con lo cual se supone que el actor esta comprometido moralmente con él. Sin embargo, esto lo puede afirmar solamente si logra demostrar que la comunicación se produce bajo un efecto normativo de cohesión. No obstante, la TkH no lo logra, no puede excluir efectivamente la contingencia de los éxitos de comunicación. Se puede formular también de esta manera: para alcanzar un acuerdo se debe haber comprendido primero, acerca de que se desea lograr un acuerdo. Si esto se ha comprendido, entonces se puede aceptar o rechazar con el paso siguiente. No debería ser difícil comprender que la $\mathrm{TkH}$ no puede lograr convertir inmediatamente comprensión en acuerdo.

Nuestra atención se dirige en primera instancia hacia el segundo torrente del centro gravitacional de investigación de la TkH: hacia la racionalidad de la acción y, con ello, hacia la relación entre referencia al mundo y forma de acción. Se refiere, extensamente ante todo, a la posición de contenido de la $\mathrm{TkH}$ a este respecto $\mathrm{y}$, luego, se hace referencia más detalladamente a tres problemas de la técnica de construcción de la teoría. Primero, se critica un relacionamiento de conceptos de malla demasiado tupida, mismo que hace problemático un desentramado regular de los conceptos. A ello está ligado el hecho de que la TkH describe sus conceptos solamente de forma vaga, lo que indica una deficiencia en la sistematización categorial. Segundo, se demuestra que los conceptos presentados se cierran, en gran parte, a una operacionalidad semántica debido al tipo de formación de conceptos, mismo que antes bien tiene carácter de una sinopsis fenomenológico-clasificatoria. Una formación de conceptos 
semejante dificulta considerablemente un trabajo de teoría que intenta construir sobre la base de dichos conceptos. Intentamos hacer plausible con dos ejemplos, es decir, con el entrelazamiento conceptual-semántico de referencia al mundo y conceptos sociológicos de acción por un lado, y con los complejos de racionalización y sus posiciones fundamentales relacionadas con la acción por el otro lado, cómo se podría ver un posible desentrelazamiento conceptual. Nos apoyamos en una teoría de la observación y en una teoría de la expectación, las cuales interpretamos con la ayuda de la pragmática de las distinciones. Tercero, se demuestra que las categorías centrales de la arquitectura de la teoría de la TkH, están dispuestas esencialmente de manera dicótoma, con la consecuencia de que debe resultar precisamente como dicótomo el problema del orden social, dentro de la pregunta acerca de las condiciones de la posibilidad del orden social y sus soluciones: no es más que consecuente si la TkH comprende la posibilidad de sociedad como de 'dos niveles': precisamente como un contexto de acción estabilizado sistémicamente (= sistema) de grupos integrados socialmente (= acción). Estos dos niveles se reflejan, en el nivel de abstracción de una teoría general, como dicotomía de teorías de acción y de sistema, por un lado, de perspectivas de participante y observador, por el otro lado. Después de haber reducido las diferentes dicotomizaciones conceptuales que utiliza la de TkH a la, de acuerdo con nuestra opinión, dicotomía principal, o sea, a la de acción (mundo vivencial) y sistema, analizamos de manera más cercana la semántica de estos conceptos y mostramos sus insuficiencias. A continuación abarcamos más detalladamente los conceptos de las perspectivas de participante y observador, igualmente planteados de manera dicótoma. En este nivel teórico; se puede demostrar que ambos conceptos se pueden comprender solamente si también se tematiza su unidad por medio de su distinción. Finalmente comprobamos que la insuficiencia principal del proyecto de una teoría de la acción comunicativa (TkH) consiste - con referencia al centro gravitacional de investigación racional de la acción- en el hecho de que estiliza como exclusivamente distintas acción (= mundo vivencial) y sistema. Esto es una insuficiencia que se comporta como una imagen en el espejo respecto a la insuficiencia principal de la teoría del sistema general de la acción (TaH), misma que, por su parte, considera como iguales la unidad de sistema y acción. Si se plantea la pregunta acerca de cómo es posible la sociedad, desde la perspectiva de la TkH, entonces se puede 
contestar: la sociedad es posible como distinción de acción y sistema planteada dicotomamente en dos niveles, como dicotomía de distinción de integración social y de sistema, como desigualdad exclusiva de intenciones de acción coordinadas por el mundo vivencial y consecuencias de acción captadas sistémicamente. 


\section{Bibliografia}

Adorno, Theodor W., "Zur Logik der Sozialwissenschaften", en Adorno, Th.W. y otros, 1970, pp. 125-143.

Dahrendorf, R., Pilot, H., Albert, H., Habermas, J., Popper, K.R., Der Positivismusstreit in der deutschen Soziologie, Neuwied, Berlin, Luchterhand, como Adomo, Th.W., u.a., 1970.

Aida, S., "A Concept of Eco-Technology: Technological Approaches to Complexity", en The Science and Praxis..., 1985, pp. 245251.

Albert, Hans, Traktat über kritische Vernunft, Tübingen, J.C.B. Mohr, 1969.

Alexander, Christopher, "A City is Not a Tree, Part 2", en Arcbitectural Forum 122, mayo de 1965, pp. 58-61.

Alexander, Jeffrey C., "Revolution, Reaction, and Reform: The Change Theory of Parsons' Middle Period", en Social Inquiry, vol. 51, núms. 3-4, 1981, pp. 267-280.

,Theoretical Logic in Sociology, vol. 1, Positivism, Presuppositions and Current Controversies, Londres, Routledge \& Kegan Paul, 1982a.

Theoretical Logic in Sociology, vol. 2, The Antinomies of Classical Thought: Marx and Durkheim, Londres, Routledge \& Kegan Paul, 1982b.

, Theoretical Logic in Sociology, wol. 3, The Classical Attempt at Theoretical Synthesis: Max Weber, Londres, Routledge \& Kegan Paul, 1983a.

Theoretical Logic in Sociology, vol. 4, The Modern Reconstruction of Classical Thought: Talcott Parsons, Londres, Routledge \& Kegan Paul, 1983b.

, Giesen, B., Münch, R., Smelser, N.J. (eds.), The Micro-Macro Link, Berkeley/Los Angeles/Londres, University of California Press, 1987. 
, Giesen, Bernhard, "From Reduction to Linkage: The Long View of the Micro-MacroDebate", en Alexander/Giesen/Münch/ Smelser (eds.), 1987, pp. 1-42.

Allen, Peter M., "Towards a New Science of Complex Systems", en The Science and Praxis..., 1985, pp. 268-297.

, Sanglier, Michèle, "Order by Fluctuation and the Urban System", en Zeleny (ed.), 1980a, pp. 109-132.

Allport, Floy H., "The Structuring of Events: Outline of a General Theory with Applications to Psychology", en The Psychological Review, 61, Pp. 281-303.

An der Heiden, Uwe, "Self-Organized States of Neural Networks", en Roth/Schwegler (ed.), 1981, pp. 62-72.

Roth, Gerhard, Schwegler, Helmut, "Principles of Self-Organization and Self-Maintenance", en Acta Biotbeoretica, 34, 1985, pp. 125-138.

Apel, Karl-Otto, Der Denkweg von Charles S. Peirce. Eine Einfübrung in den amerikanischen Pragmatismus, Frankf. a.M., Suhrkamp, 1975.

Transformation der Pbilosophie, Bd. 1, Spracbanalytik, Semiotik, Hermeneutik, Frankf. a.M., Suhrkamp, 1976a.

, Transformation der Pbilosophie, Bd. 2, Das Apriori der Kommunikationsgemeinschaft, Frankf. a.M., Suhrkamp.

"Transformation der Transzendentalphilosophie: Versuch einer retrospektiven Zwischenbilanz", en A. Mercier, M. Svilar (eds.), Philosophische Selbstbetrachtungen, vol. 4, Bern, Peter Iang, 1978, pp. 9-23.

"The Erklären-Verstehen Controversy in the Philosophy of the Natural and Human Sciences ${ }^{n}$, en Flístad (ed.), 1982, pp. 19-49.

, Diskurs und Verantwortung. Das Problem des Übergangs zur postkonventionellen Moral, Frankf. a.M., Suhrkamp, 1990. "Wittgenstein und Heidegger: Kritische Wiederholung und Ergänzung eines Vergleichs", en McGuinness et al., 1991, pp. 27-68.

Arendt, Hannah, Vita Activa oder vom tätigen Leben, München, Piper, 1960.

Vom Leben des Geistes, Bd. I, Das Denken, München, Zürich, Piper, 1979a.

Vom Leben des Geistes, Bd. II, Das Wollen, München, Zürich, Piper, 1979b. 
Argyle, Michael, "Non-Verbal Communication in Human Social Interaction", en Hinde (ed.), 1972, pp. 243-268.

Aristoteles, Metaphysik, München, Rowohlt, 1966. , Topik (Onganon V), Hamburg, Felix Meiner, 1968.

Ars electronica (Hrsg.), Im Netz der Systeme, Berlin, Merve, 1990. Ashby, W. Ross, "Principles of Self-Organizing Systems", en Foerster, von/Zopf (eds.), 1962, pp. 255-278.

, "Variety, Constraint, and the Law of Requisite Variety", en Buckley (ed.), 1968, pp. 129-136. 303.

Atlan, Henri, "Hierarchical Self-Organization in Living Systems", en Zeleny (ed.), 1981, pp. 185-208.

"Natural Complexity and Self-Creation of Meaning", en The Science and Praxis..., 1985, pp. 173-192.

Aulin, Arvid, "Sociocybernetics as the Science of Self-Steering Human Action", en Kybernetes, vol. 13, 1984, pp. 147-155.

Bachelard, Gaston, Epistemologie, Ausgewäblte Texte, Berlin, Ullstein, 1974.

Baecker, Dirk, "Die Freiheit des Gegenstandes: von der Identität zur Differenz. Perspektivenwechsel in den Wissenschaften"; en Delfin $V$, septiembre de 1985 , pp. 76-88.

"Explosivstoff Selbstreferenz. Eine Paraphrase zu Niklas Luhmann, Soziale Systeme: Grundriss einer allgemeinen Theorie", en Archiv für Rechts- und Sozialphilosopbie, vol. 76, Heft 2, 1986, pp. 246-256.

.., Markowitz, J., Stichweh, R., Tyrell, H., Willke, H. (eds.), Theorie als Passion, Niklas Luhmann zum 60, Geburtstag, Frankf. a.M., Suhrkamp, 1987.

"Die Beobachtung der Politik durch die Wirtschaft", en Glagow/Willke (eds.), 1987, pp. 65-73.

"Steuerung im Markt: Zur These paradoxer Systemkonstitution am Beispiel einer Analyse der Wirtschaft", en Glagow/ Willke (eds.), 1987a, pp. 136-154.

Information und Risiko in der Marktwirtschaft, Frankf. a.M., Suhrkamp, 1988.

, "Ranulph Glanville und der Thermostat. Zum Verständnis, von Kybernetik und Konfusion", en Merkur, Heft 6, 1989, pp. 513-524. 
"Die Dekonstruktion der Schachtel. Innen und Aussen in der Architektur", en Luhmann/Bunsen/Baecker, 1990, pp. $67-$ 104.

Womit bandeln Banken? Eine Untersuchung zur Risikoverarbeitung in der Wirtschaft, Frankf. a.M., Suhrkamp, 1991.

Balla, B. Lint, Soziologie der Knappheit.Zum Verständnis, individueller und gesellschaflicber Mängelzustände, Stuttgart, Enke, 1978.

Barral, W.J., "Merleau-Ponty. The Role of the Body-Subject", en Interpersonal Relations, Pittsburgh, Louvain, 1965.

Barth, Frederik, Ritual and Knowledge among the Baktaman of New Guinea, Oslo, New Haven, Yale University Press, 1975.

Bateson, Gregory, Okologie des Geistes, Frankf. a.M., Suhrkamp, 1983. Geist und Natur. Eine notwendige Einbeit, Frankf. a.M., Suhrkamp, 1984.

Bayer, Hans, "Zur Soziologie des mittelalterlichen Individualisierungsprozesses. Ein Beitrag zu einer wirklichkeitsbezogenen Geistesgeschichte", en Archiv für Kulturgeschichte, Heft 1, 1975, pp. 115-153.

Beauvoir, Simone de, In den besten Jabren, Reinbek b.H., Rowohlt, 1969.

Die Zeremonie des Abscbieds und Gespräcbe, mit JeanPaul Sartre. August-September 1974, Reinbek, Rowohlt, 1983.

Beck, Ulrich, Risikogesellschaft. Auf dem Wege in eine andere Moderne, Frankf. a.M., Suhrkamp, 1986.

Becker, Werner, Selbstbewusstsein und Spekulation. Zur Kritik der Transzendentalphilosophie, Freiburg, Rombach, 1972.

Ben-Eli, Michael V., "Self-Organization, Autopoiesis, and Evolution", en Zeleny (ed.), 1981, pp. 169-182.

Benseler, F., Hejl, P.M., Köck, W.K. (eds.), Autopoiesis, Communication and Society, Frankf. a.M., Nueva York, Campus, 1980.

Berger, Johannes, "Autopoiesis: Wie 'systemisch' ist die Theorie sozialer Systeme?", en Haferkamp/Schmid (eds.), 1987, pp. 129152.

Bergmann, Werner, "Das Problem der Zeit in der Soziologie. Ein Literaturübetblick zum Stand der 'zeitsoziologischen' Theorie und Forschung", en KZfSS, Heft 3, 1983, pp. 462-504.

Bershady, Harold J., Ideology and Social Knowledge, Blackwell, Oxford, 1973.

Bertalannffy, Ludwigvon, "General Systems Theory-A Critical Review", en Buckley (ed.), 1968, pp. 11-30. 
Black, Max (ed.), The Social Theories of Talcott Parsons. A Critical Examination, Southern Illinois University Press, 1976.

, "Some Questions about Parsons' Theories", en Black (ed.), 1976, pp. 268-288.

Blumenberg, Hans, "Ordnungsschwund und Selbstbehauptung. Uber Weltverstehen und Weltverhalten im Werden der technischen Epoche", en Kuhn, H., Wiedmann, F. (eds.), Das Problem der Ordnung, Meisenheim am Glan, 1962, pp. 37-57.

Böhler, Dietrich, Rekonstruktive Pragmatik. Von der Beurusstseinsphilosopbie zur.Kommunikationsreflexion, Frank. a.M., Suhrkamp, 1985.

Bohr, Niels, "Einheit des Wissens", en Krüger (ed.), 1970, pp. 389402.

Bollnow, Otto Friedrich, Mensch und Raum, Stuttgart, Berlín, Köln, Mainz, Kohlhammer, 1984.

Boulding, Kenneth E., "Learning by Simplifying Complexity: How to Tum Data into Knowledge", en The Science and Praxis..., 1985, pp. 25-34.

Brand, Gerd, Die Lebenswelt. Eine Pbilosopbie des konkreten Apriori, Berlín, Walter de Gruyter, 1971.

Bräten, Stein, "Model Monopoly and Communication: Systems Theoretical Notes on Democratization", en Acta Sociológica, vol. 16, núm. 2, 1972, pp. 98-107.

"Systems Research and Social Sciences", en George J. Klir (ed.), Applied General Systems Research: Recent Developments and Trends, Nueva York, Londres, 1978, pp. 655-685.

"Simulation and Self-Organization of Mind", en Contemporary Pbilosopby, G. Flфstad (ed.), vol. 2, The Hague, Martinus Nijhoff, 1982, pp. 189-218.

, "The Third Position-Beyond Artificial and Autopoietic Reduction", en Kybernetes, 13, 1984, pp. 157-163.

Brunner, Otto, "Feudalismus. Ein Beitrag zur Begriffsgeschichte", en ibid., Neue Wege der Verfassungs und Sozialgescbichte, Göttingen, Vandenhoeck \& Ruprecht, 1968, pp. 128-159.

Buckley, Walter (ed.), Modern Systems Research for the Bebavioral Scientist, Chicago, Aldine Publishing Company, 1968.

, "Society as a Complex Adaptive System", en Buckley (ed.), 1968, pp. 490-513.

Bühl, Walter L., "Grenzen der Autopoiesis”, en KZfSS, Heft 2, 1987, pp. 225-254. 
Bunge, Mario, Ontology 1: The Furniture of the World, Dordrecht, Holland, Reidel, 1977.

Ontology II: A World of Systems, Dordrecht, Holland, Reidel, 1979.

Camic, Charles, "Structure after 50 Years: The Anatomy of a Charter", en American Joumal of Sociology, 95, 1989, pp. 38-107.

Campbell, Donald T., Pattern Matching as an Essential in Distal Knowing, Nueva York, Holt, Rinehard \& Winston, 1966.

Cassirer, Ernst, Substanzbegriff und Funktionsbegriff. Untersuchungen über die Grundfragen der Erkenntniskritik, Berlín, 1910.

Zur Einstein'schen Relativitatstbeorie, Erkenntnistbeoretische Betrachtungen, Berlin, 1921.

"Das Erkenntnisideal der Biologie und seine Wandlungen", en ibid., Das Erkenntnisproblem in der Pbilosopbie und Wissenschaft derneueren Zeit. Von Hegels Tod bis zur Gegenwart (1832-1932), Zweites Buch, Stuttgart: Kohlhammer, 1957, pp. 125-222.

Castoriadis, Cornelius, Gesellschaft als imaginäre Institution. Entwurf einer politischen Pbilosophie, Frankf. a.M., Suhrkamp, 1984.

Chapman, Graham P., "The Epistemology of Complexity and some Reflections on the Symposium", en The Science and Praxis..., 1985, pp. 357-374.

Churchman, C. West, "A Philosophy of Complexity", en Linstone, Simmonds (eds.), 1977, pp. 82-90.

Claessens, Dieter, Instinkt, Psyche, Geltung.Zur Legitimation menschlicben Verbaltens. Eine soziologische Antbropologie, Köln/Opladen, Westdeutscher Verlag, 1970.

, Das Konkrete und das Abstrakte. Soziologische Skizzen zur Anthropologie, Frankf. a.M., Suhrkamp, 1980.

Cramer,' K., Fulda, H.F., Horstmann, R.-P., Pothast, U. (eds.), Theorie der Subjektivitat, Frankf. a.M., Suhrkamp, 1987.

Dahrendorf, Ralf, Gesellschaft und Demokratie in Deutschland, München, Piper, 1968.

, “Anmerkungen zur Diskussion der Referate von Karl R. Popper und Theodor W. Adorno", en Adorno, Th.W. u.a., 1970, pp. 145-153.

Konflikt und Freibeit. Aufdem Weg zurDienstklassengesellscbaft, München, Piper, 1972.

, Pfade aus Utopia. Zur Theorie und Metbode der Soziologie, München, Piper, 1974. 
; "Zeitgenosse Habermas. Jürgen Habermas zum sechzigsten Geburststag", en Merkur, Heft 6, 1989b, pp. 478-487.

; "Einführung in die Soziologie", en Soziale Welt, Heft 1/2, 1989c, pp. 2-10.

Davidson, Donald, Handlung und Ereignis, Frankf. a.M., Suhrkamp, 1990.

Dörner, Dietrich, "Über die Schwierigkeiten menschlichen Umgangs mit Komplexität", en Psych. Rundschau XXXII, 3, 1981, pp. 163179.

Dress, A., Henrichs, H., Küppers, G., Selbstonganisation.Die Entstebung von Ordnung in Natur und Gesellschaft, München, Piper, 1986.

Druwe, Ulrich, "Selbstorganisation" in den Sozialwissenscbaften. Wissenschaftstbeoretiscbe Anmerkungen zur Ubertragung der naturwissenschaflichen Selbstorganisationsmodelle aufsozialwissenschaftlicbe Fragestellungen, en KZfSS, Heft 4, 1988, pp. $762-775$.

Duby, George, Die Drei Ordnungen. Das Weltbild des Feudalismus, Frankf. a.M., Suhrkamp, 1986.

Duby, George, Ritter, Frau und Priester. Die Ebe im feudalen Frankreich, Frankf. a.M., Suhrkamp, 1988.

Dummett, Michael, Ursprünge der analytischen Pbilosophie, Frankf. a.M., Suhrkamp, 1992.

Dumont, Louis, Homo Hierarchicus: The Caste System and Its Implications, Londres, 1970.

Dupuy, Jean-Pierre, "Autonomy and Complexity in Sociology", en The Science and Praxis..., 1985, pp. 255-267.

, Varela, FranciscoJ., "Kreative Zirkelschlüsse: Zum Verständnis der Ursprünge", en Watzlawick/Krieg (Hg.), 1991, pp. $247-$ 275.

Durkheim, Émile, Regeln dersoziologischen Metbode, en Réne Kónig (ed.), Darmstadt/Neuwied, Luchterhand, 1976.

Mauss, Marcel, Primitive Classification, Caxton Hill, Hertford, Stephen Austin \& Sons Limited, 1963.

Ebeling, Hans, "Erhaltungssätze als Grundsätze, einer Theorie der Subjektivität", en Kant-Studien, 64, Jahrg., 1973, pp. 466-483.

Eccles, John C., The Human Psyche. The Gifford Lectures, University of Edinburgh 1978-1979, Berlín, Heidelberg, Nueva York, Springer, 1980.

Eco, Umberto, Einfübrung in die Semiotik, München, Wilhelm Fink, 1972. 
Eigen, Manfred, Perspektiven der Wissenschaft. Jensettsvon Ideologien und Wunschdenken, Stuttgart, dtv, 1989.

Winckler, Ruthild, Das Spiel. Naturgesetze steuern den Zufall, München, Zürich, Piper, 1990.

Stufen zum Leben. Die frübe Evolution im Visier der Molekularbiologie, München, Piper, 1992.

Eisenstadt, Shmuel N., "Die soziologische Tradition: Ursprünge, Grenzen, Innovationsmuster und Krisenformen", en KZfSS, Heft 3, 1983, pp. 205-229.

Elias, Norbert, "Zur Grundlegung einer Theorie sozialer Prozesse", en ZfS 6, 1977, pp. 127-149.

Die Gesellschaft der Individuen, Frankf. a.M., Suhrkamp, 1988.

Elsasser, Walter M., "The Role of Individuality in Biological Theory", en C.H. Waddington (ed.), Towards Theoretical Biology, Edinburgh University Press, 1970.

Elster, Jon, Logik und Gesellschaft: Widersprüche und mögliche Welten, Frankf. a.M., Suhrkamp, 1981a.

Esposito, Elena, "Paradoxien als Unterscheidungen von Unterscheidungen", en Gumbrecht/Pfeiffer (eds.), 1991, pp. 35-57.

Esser, Hartmut, "Der Doppelpass als soziales System", en Zeit.f. Soziologie, Heft 2, 1991, pp. 153-166.

Flфstad, G. (ed.), Contemporary Pbilosophy, The Hague, Martinus Nijhoff, 1982.

Foerster, Heinz von, Zopf, G.W. (eds.), Principles of Self-Organization. The Illinois Symposium on Theory and Technology of Self-Organizing Systems, Londres, 1962.

Foerster, Heinz von, "The Curious Behavior of Complex Systems", en Linstone, Simmonds (eds.), 1977, pp. 104-113.

Sicht undEinsicht. Versuchezu eineroperativen Erkenntnistheorie, Braunschweig/Wiesbaden, Vieweg, 1985.

"Entdecken oder Erfinden. Wie lässt sich Verstehen verstehen?", en Gumin/Mohler (eds.), 1985a, pp. 27-68.

Foucault, Michel, Die Ordnung der Dinge, Frankf. a.M., Suhrkamp, 1974.

Archdologie des Wissens, Frankf. a.M., Suhrkamp, 1981.

Frank, Manfred, Die Unbintergebbarkeit von Individualität. Reflexionen über Subjekt, Person und Individuum aus Anlass ibrer postmodernen Toterklärung, 1986. 
Franke, Herbert W., "Sehen und Erkennen", en Bild der Wissenschaft 12, 1975, pp. 32-40.

Frege, Gottlob, Funktion, Begriff, Bedeutung. Fünflogiscbe Studien, Günther Patzig (ed.), Göttingen, Vandenhoeck \& Ruprecht, 1962.

Logiscbe Untersucbungen, Günther Patzig (ed.), Göttingen, Vandenhoeck \& Ruprecht, 1966.

Freud, Sigmund, "Über den Gegensinn der Urworte", en Ibid., Studienausgabe Bd. IV., Psychologische Schriften 1910, 1970, pp. 228-234.

Frostholm, B., Leib und Unbewusstes. Freuds Begriff des Unbewussten interpretiert durch den LeibbegriffMerleau-Pontys, Bonn, 1978.

Gadamer, Hans-Georg, Wabrbeit und Metbode. Grunzüge einerphilosopbischen Hermeneutik, Tübingen, J.C.B. Mohr, 1960.

Gadamer, H.-G., "Das Vaterbild im griechischen Denken", en Das Vaterbild in Mythos und Gescbicbte, Stuttgart, 1976.

Gaines, Brian R., "Autopoiesis: Some Questions", en Zeleny (ed.), 1981, pp. 145-154.

Gans, Herbert J. (ed.), Sociology in America, Newbury Park, California, Sage Publications, 1990.

Ganssmann, Heiner, "Kommunikation und Reproduktion", en Leviatban, Heft 1, 1986, pp. 143-156.

, Labour and Autopoiesis, Berlín, Ms., 1987.

Gehlen, Arnold, "Reflexionen über Gewohnheit", en Ibid., Pbilosophiscbe Schriften I, Frankf. a.M., Klostermann, 1978, pp. 99111.

Gehlen, Arnold, 'Die Bedeutung Descartes' für eine Geschichte des Bewusstseins", en Ibid., Pbilosophiscbe Scbriften $I I$, Frankf. a.M., Klostermann, 1980 , pp. 363-376.

Geitel, Max, Geschicbte der Dampfmaschine bis James Watt, Leipzig, Voigtländer Quellenbuch, 1911.

Gẹnz, Henning, Symmetrie-Bauplan derNatur, München, Zürich, Piper, 1992.

Gerhards, J., Soztologie der Emotionen. Fragestellungen, Systematik und Perspektiven, München, Juventa, 1988.

Giddens, Anthony, The Constitution of Society. Outline of the Theory of Structuration, Berkeley, Los Angeles, University of California Press, 1984.

Gierer, Alfred, "Socioeconomic Inequalities: Effects of Self-Enhancement and Depletion", en Zeleny (ed.), 1980, pp. 133-149. 
, Die Physik, das Leben und die Seele, München, Zürich, Piper, 1985.

Giesen, Bernhard, Die Entdinglicbung des Sozialen. Eine evolutionstheoretiscbe Perspektive auf die Postmoderne, Frankf. a.M., Suhrkamp, 1991.

Glagow, Manfred/Willke, Helmut(eds.), Dezentrale Gesellschaftssteuerung. Probleme der Integration polyzentrischer Gesellschaft, Pfaffenweiler, Centaurus, 1987.

Glanville, Ranulph, A Cybernetic Development of Epistemology and Observation, Applied to Objects in Space and Time (as seen in Arcbitecture), Thesis, Uxbridge, Brunel University, 1975.

Glanville, Ranulph, Objekte, Berlín, Merve, 1988.

Glasersfeld, Ernst von, Wissen, Sprache und Wirklichkeit, Braunschweig, Wiesbaden, Vieweg, 1987.

Goguen, J.A./Varela, Francisco J., "Systems and Distinctions: Duality and Complementarity", en International Joumal of General Systems, 5 (4), 1979, pp. 31-43.

Gombrich, Ernst H., Meditationen uber ein Steckenpferd. Von den Wurzeln und Grenzen der Kunst, Frankf. a.M., Suhrkamp, 1978. Gombrich, Ernst H., Hochberg, Julian, Black, Max, Kunst, Wabmehmung, Wirklichkeit, Frankf. a.M., Suhrkamp, 1981.

Gombrich, Ernst H., Bild und Auge. Neue Studien zurPsycbologie der bildlichen Darstellung, Stuttgart, Klett-Cotta, 1984.

Goode, W.J., "The Theoretical Importance of Love", en American Sociological Review 24, 1959, pp. 38-47.

Goody, Jack, Watt, Ian, Gough, Kathleen, Entstebung und Folgen der Scbriftkultur, Frankf. a.M., Suhrkamp, 1986a.

"Funktionen der Schrift in traditionalen Gesellschaften", en Goody, Watt, Gough, 1986a, pp. 25-61.

, Watt, Ian, "Konsequenzen der Literatität", en Goody, Watt, Gough, 1986b, pp. 63-122.

, Die Logik der Schrift und die Onganisátion von Gésellscbaft, Frankf. a.M, Suhrkamp, 1990.

Gömitz, Thomas, Carl Friedricb von Weizsäcker. Ein Denker an der Scbuelle zum neuen Jabrtausend, Freiburg, Basel, Wien, Herder, 1992.

Gouldner, Alvin W., Die westliche Soztologie in der Krise, Bde. 1 y. 2, Reinbek b.H., Rowohlt, 1974.

Reztprozttat und Autonomie. Ausgewablte Aùfs, Frankf. a.M., Suhrkamp, 1984. 
Gumbrecht, Hans Ulrich, Pfeiffer, K. Ludwig (eds.), Materialitāt der Kommunikation, Frankf. a.M., Suhrkamp, 1988.

,Paradoxien, Dissonanzen, Zusammenbrücbe. Situationen offener Epistemologie, Frankf. a.M., Suhrkamp, 1991.

Gumin, H., Mohler, A. (ed.), Einfübrung in den Konstruktivismus, München, Oldenbourg, 1985.

Guntern, Gottlieb, "Auto-Organization in Human Systems", en Bebavioral Sciences, vol. 27, 1982, pp. 323-337.

Günther, Gotthard, Das Bewusstsein der Mascbinen. Eine Metapbysik der Kybernetik, Krefeld/Baden-Baden, Agis, 1963.

Idee und Grundriss einer nicht-Aristoteliscben Logik, Hamburg, Felix Meiner, 1978.

Grundzüge einer neuen Theorie des Denkens in Hegels Logik, Hamburg, Felix Meiner, 1978a.

,Beiträge zur Grundlegung eineroperationsfäbigen Dialektik II, Hamburg, Felix Meiner, 1979. 307-335. 306.

BeiträgezurGrundlegung eineroperationsfabigen Dialektik III, Hamburg, Felix Meiner, 1980.

Habermas, Jürgen, Erkenntnis und Interesse, Frankf. a.M., Suhrkamp, 1969.

, Technik und Wissenschaft als "Ideologie", Frankf. a.M., Suhrkamp, 1969a.

, Luhmann, Niklas, Theorie der Gesellschaft oder Sozialtechnologie? - Was leistet die Systemforscbung?, Frankf. a.M., Suhrkamp, 1971a.

"Vorbereitende Bemerkungen zu einer Theorie der kommunikativen Kompetenz", en Habermas, Luhmann, 1971a, 1, pp. 101-141.

"Theorie der Gesellschaft oder Sozialtechnologie? Eine Auseinandersetzung mit Niklas Luhmann", en Habermas, Luhmann 1971a, 2, pp. 142-290.

Tbeorie und Praxis. Soztalphilosophiscbe Studien, Frankf. a.M., Suhrkamp, 1971b.

; ZurRekonstruktion des Historiscben Materialismus, Frankf. a.M., Suhrkamp, 1976a. 
, "Einleitung: Historischer Materialismus und die Entwicklung normativer Strukturen", en Habermas, 1976a, 1, pp. 9-48.

"Moralentwicklung und Ich-Identität", en Habermas, 1976a, 3, pp. 63-91.

“Können komplexe Gesellschaften eine vernünftige Identität ausbilden?", en Habermas, 1976a, 4, pp. 92-126.

, "Zur Rekonstruktion des Historischen Materialismus", en Habermas, 1976a, 6, pp. 144-199.

," Geschichte und Evolution", en Habermas, 1976a, 7, pp. 200-259.

, "Legitimationsprobleme im modernen Staat", en Habermas, 1976a, 9, pp. 271-303.

. $\quad$,Zwei Bemerkungen zum praktischen Diskurs", en Habermas, 1976a, 12, pp. 338-346.

Legitimationsprobleme im Spätkapitalismus, Frankf. a.M., Suhrkamp, 1979.

"Talcott Parsons: Problems of Theory Construction", en Sociological Inquiry, vol. 51, núms. 3-4, 1981, pp. 173-196.

, Theorie des kommunikativen Handelns, Bd. 1: Handlungsrationalitat und gesellschaftliche Rationalisierung, Frankf. a.M., Suhrkamp, $1981 \mathrm{~b}, 1$.

Theorie des kommunikativen Handelns, Bd. 2: Zur Kritik der funktionalistiscben Vermunft, Frankf. a.M, Suhrkamp, $1981 b, 2$.

, Moralbewusstsein und kommunikatives Handeln, Frankf. a.M., Suhrkamp, 1983a.

, Vorstudien und Ergänzungen zur Theorie des kommunikativen Handelns, Frankf. a.M., Suhrkamp, 1984.

, Die neue Unübersichtlicbkeit. Kleine politische Schriften $V$, Frankf. a.M., Suhrkamp, 1985.

, Der philosopbische Diskurs der Moderne. Zwölf Vorlesungen, Frankf. a.M., Suhrkamp, 1985a.

___ "Law as Medium and Law as Institution", en Teubner (ed.), 1986, pp. 203-220)

"Entgegnung", en Honneth, Joas (eds.), 1986a, pp. 327-405.

_ , Nachmetaphysisches Denken. Philosophiscbe Aufs., Frankf. a.M., Suhrkamp, 1998a.

Haferkamp, Hans, Schmid, Michael (eds.), Sinn, Kommunikation und soziale Differenzierung. Beitrdge, zu Lubmanns Tbeorie sozialer Systeme, Frankf. a.M., Suhrkamp, 1987. 
"Autopoietisches soziales System oder konstruktives soziales Handeln? Zur Ankunft der Handlungstheorie und zur Abweisung empirischer Forschung in Niklas Luhmanns Systemtheorie", en Haferkamp, Schmid (ed.), 1987, pp. 51-88.

Hägerstrand, T., "Time-Geography: Focus on the Corporeality of Man, Society, and Environment", en The Science and Praxis..., 1985, pp. 193-216.

Hahn, Alois, "Sinn und Sinnlosigkeit", en Haferkamp, Schmid (ed.), 1987a, pp. 155-164.

Haken, Hermann, "Synergetics and the Problem of Selforganization", en Roth, Schwegler (eds.), 1981, pp. 819-13.

Handke, Peter, Aber ich lebe nur von den Zwischenräumen. Ein Gespräch, gefübrt von Herbert Gamper, Zürich, Ammann, 1987.

Harrison, Randall P., "Nonverbal Communication: Advances and Anomalies", en B. Dervin, M. Voigt (eds.), Progress in Communication Sciences 5, Norwood, New Yersey, Ablex, 1984, pp. 255274.

Haverlock, Eric A., Preface to Plato, Cambridge, Mass., The Belknap Press of Harvard University Press, 1963.

The Muse Learns to Write, New Haven, Londres, Yale University Press, 1986.

Hawking, Stephen, Eine kurze Geschicbte der Zeit. Die Sucbe nach der Urkraft des Universums, Reinbek b. Hamburg, Rowohlt, 1991.

Hayek, Friedrich August von, "The Use of Knowledge in Society", en The American Review, 1945, pp. 185-187.

, "Über den 'Sinn' sozialer Institutionen", en Schwetzer Monatsbefte, núm. 36, 1956, pp. 512-524. 1969.

FreiburgerStudien. Gesammelte Aufs, Tübingen, J.C. Mohr,

, "Arten der Ordnung", en Hayek, F.A.v, 1969a, pp. 32-46.

, "Bemerkung über die Entwicklung von Systemen von Verhaltensregeln", en Hayek, F.A.v, 1969b, pp. 144-160.

Die Theorie komplexer Pbänomene, Vortr. u. Aufs. 36, Walter Eucken Institut, Tübingen, J.C.B. Mohr, 1972. Law, Legislation and Liberty, vol. I, Rules and Order, Londres, Routledge \& Kegan Paul, 1973.

The Sensory Order. An Inquiry into the Foundations of Theoretical Psychology, Londres, Routledge \& Kegan Paul, 1976. 
Hegel, Georg Friedrich Wilhelm, Theorie-Werkausgabe, Frankf. a.M., Suhrkamp, 1970.

Hegel, Georg Friedrich Wilhelm, "Phänomenologie des Geistes", en Hegel, 1970, 3, Bd. 3.

"Grundlinien der Philosophie des Rechts", en Hegel, 1970,

7, Bd. 7.

"Vorlesungen über die Geschichte der Philosophie I", en Hegel, 1970, 18, Bd. 18.

Heidegger, Martin, Einfübrung in die Metaphysik, Tübingen, Max Niemeyer, 1976.

"Brief über den Humanismus", en Ibid., Wegmarken, Frankf. a.M., Klostermann, 1976a, pp. 313-364.

Sein und Zeit, Tübingen, Max Niemeyer, 1979.

, Hegels Pbänomenologie des Geistes. Freiburger Vorlesung

Wintersemester 1930/31, Ingtraut Görland (ed.), Frankf. a.M.,

Vittorio Klostermann, 1980.

Heisenberg, Werner, Der Teil und das Ganze. Gespräch im Umkreis der Atomphysik, München, Piper, 1969.

, "Die Entwicklung der Deutung in der Quantentheorie", en

Krüger (ed.), 1970, pp. 412-427.

, Scbritte über Grenzen. Gesammelte Reden und Aufs, Mün-

chen, Piper, 19791.

Physik und Pbilosopbie, Stuttgart, Hirzel, 1984.

Heider, Fritz, "Ding und Medium”, en Symposium I, 1926, pp. 108157.

Hejl, Peter M., "Die Theorie autopoietischer Systeme: Perspektiven für die soziologische Systemtheorie", en Rechtstbeorie 13, 1982, pp. 45-88.

, Sozialwissenschaft als Tbeorie selbstreferentieller Systeme (Tesis. Bielefeld), Frankf. a.M., Nueva York, Campus, 1982a.

"Soziale Systeme: Körper ohne Gehirne oder Gehirne ohne Körper? Rezeptionsprobleme der Theorie autopoietischer Systeme in den Sozialwissenschaften", en Delfin $V, 1986$, pp. 56-67. "Konstruktion der sozialen Konstruktion: Grundlinien einer konstruktivistischen Sozialtheorie", en Schmidt (ed.), 1987, pp. 303-339.

Henrich, Dieter, Hegel im Kontext, Frankf. a.M., Suhrkamp, 1971. "Hegel und Hölderlin", en Henrich, 1971, 1, pp. 9-40.

"Anfang und Methode der Logik", en Henrich, 1971, 3, pp.

73-94. 
_. "Hegels Logik der Reflexion", en Henrich, 1971, 4, pp. 95156.

"Karl Marx als Schüler Hegels", en Henrich, 1971, 6, pp. 187-207.

1982.

Flucbtlienten. Philosophische Essays, Frankf. a.M., Suhrkamp,

"Lebensdeutungen der Zukunft", en Henrich, 1982, 1, pp. $11-42$.

"Das Selbstbewusstsein und seine Deutungen", en Henrich, 1982, 4, pp. 99-124.

, "Selbstbewusstsein und spekulatives Denken", en Henrich, 1982, 5, pp. 125-181.

, Konzepte, Frankf. a.M., Suhrkamp, 1987.

"Was ist Metaphysik - was Moderne? Zwölf Thesen gegen Jürgen Habermas", en Henrich, 1987, 1, pp. 11-43.

- "Philosophy and the Conflict between Tendencies of Life", en Henrich, 1987, 7, pp. 117-127.

Herbst, Ph. G., Altermatives to Hierarchies, Leiden, 1976.

Herzog, Reinhart/Koselleck, Reinhart (eds.), Epochenscbwelle und Epochenbewusstsein, München, Wilhelm Fink, 1987.

Hinde, R. A. (ed.), Non-Verbal Communication, Cambridge, Engl., 1972.

Hintikka, Jaakko, "Die Intention der Intentionalität", en Neue Hefte für Pbilosopbie, 8, Semantik und Ontologie, 1975, pp. 65-95.

Hösle, Vittorio, Hegels System. Der Idealismus der Subjektivitat und das Problem der Intersubjektivitat, Hamburg, Meiner, 1988. , Praktische Philosophie in der modernen Welt, München, Beck, 1992.

Hofstadter, Douglas R., Gödel, Escher, Bach, Stuttgart, Klett-Cotta, 1985.

Hohl, Ludwig, Die Notizen oder Von der unvoreiligen Versöhnung, Frankf. a.M., Suhrkamp, 1984.

Holmes, Stephen, Larmore, Charles, Translator's Introduction to Niklas Luhmanns "The Differentiation of Society", en Luhmann, 1982a, pp. XIII-XXXVII.

"Differenzierung und Arbeitsteilung im Denken des Liberalismus", en Luhmann (ed.), 1985, pp. 9-41.

Hondrich, Karl Otto, "Wovon wir nichts wissen wollen ('über das Versagen der Soziologie')", en Die Zeit, núm. 40, 25, septiembre de 1992. 
Honneth, Axel/Joas, Hans (eds.), Kommunikatives Handeln. Beiträge, zu Jürgen Habermas' "Tbeorie des kommunikativen Handelns", Frankf. a.M., Suhrkamp, 1986.

"Kritische Theorie. Vom Zentrum zur Peripherie einer

Denktradition", en KZfSS, Heft 1, 1989, pp. 1-32.

Howe, Richard Herbert/Foerster, Heinz von, "Introductory Comments to Francisco Varela's Calculus for Self-Reference", en Int. $J$. General Systems, vol. 2, 1975, pp. 1-3.

Husserl, Edmund, Ideen zu einer reinen Pbänomenologie und pbänomenologischen Pbilosopbie, 1. Buch, W. Biemel (eds.), Husserliana III, Den Haag, 1950.

Erfahrung und Urteil. Untersucbungen zur Genealogie der Logik, Hamburg, Claasen, 1964.

Die Krisis der europäiscben Wissenschaften und die transzendentale Phänomenologie, E. Ströker [ed.], Hamburg, Felix Meiner, 1977.

Jakob, François, Die Logik des Lebenden. Von der Urzeugung zum genetischen Code, Frankf. a.M., Fischer, 1972.

Jakobson, Roman, Poetik. Ausgewäblte Aufs," 1921-1971, E. Holenstein/T. Schelbert (eds.), Frankf. a.M., Suhrkamp, 1979.

Janich, Peter, Mittelstrass, Jürgen, "Art. Raum", en Handbucb pbilosophischer Grundbegriffe, Bd. 4, H.Krings, H.M. Baumgartner, Ch.Wild (eds.), München, Kösel, 1973.

Jarvie, I. C., Die Logik der Gesellschaft, München, List, 1974.

Jensen, Stefan, "Einleitung zu Talcott Parsons 'Zur Theorie sozialer Systeme'", en Parsons, 1976a, pp. 9-67.

Joas, Hans, "Die unglückliche Ehe von Hermeneutik und Funktionalismus", en Honneth, Joas (eds.), 1986, pp. 144-176.

Jokisch, Rodrigo, "The Origin of Modem Biology in the Organological Discourse", en Roman de Vicente (ed.), Replies from Biological Research, Madrid, Consejo Superior de Investigaciones Científicas, 1979, pp. 101-117.

"Technologischer Wandel in Gesamtdarstellungen. Probleme seiner Strukturierung für die Frühindustrialisierung (zusammen mit H. Lindner)", en Kölner Zeitschrift für Soziologie und Sozialpsycbologie, Hf. 4, 1979a, pp. 672-688.

"Die nichtintentionalen Effekte menschlicher Handlungen. Ein klassisches soziologisches Problem", en KZfSS, Jg. 33, Bd. 3, 1981, pp. 547-575. 
"Kraft und Identität. Überlegungen zur anthropologischen Voraussetzung der neuzeitlichen Wissenschaft", en Zeitscbrift für allgemeine Wissenschaftstheorie, XII/2, 1981a, pp. 250-262. " "Probleme der spanischen Wissenschaftsentwicklung. Die Institutionalisierung der spanischen Histologie im 19. Jahrhundert als Beispiel", en: Bd.XXVII, Congreso Internacional de Historia de la Medicina, 31 agosto-6 septiembre 1980, Barcelona, Academia de Ciencies Mediques de Catalunya i Baleares, $1981 \mathrm{~b}$, pp. 522-529.

(ed.), El Salvador. Freibeitskämpfe in Mittelamerika. Guatemala, Honduras, El Salvador, Reinbek, Rowohlt, 1981c. (ed.), Mann-Sein. Identitätskrise und Rollenfindung des Mannes in der beutigen Zett, Reinbek, Rowohlt, 1982. (ed.), Tecbnik-Soziologie, Frankf. a.M., Suhrkamp, 1984. "Macht-Frauen-Individualität", en B. Schaeffer-Hegel (ed.), Frauen und Macht, Publica, Berlín, 1984a, pp. 167-182.

"Die Beobachtung der Fotographie. Systemtheoretische Bemerkungen", en Brennpunkt, Magazin für Fotografie, Hefte 1 bis 4; Berlín, 1990.

"Die Beobachtung der Theorie", en Soziologie und Technik, U. Tasche (ed.), Institut für Soziologie, Berlín, Universitätsbibliothek der TU-Berlín, 1992, pp. 38-43.

Die Form der gesellscbaft. Kommunikation, Erwartung, Gedacbtnis und Konflikt (MS), 1995.

Können wir obne Gescblecbtsidentität auskommen? Zur Codierung von Sexualität (MS), $1995 \mathrm{a}$.

Kann es eine Logik der Wissenschaften geben? Zur Logikvon "Natur" und "Gesellschaft". Distinktionspragmatische Uberlegungen (MS), $1995 \mathrm{~b}$.

Warum wir "Technik" nicht versteben können. Zur Codierung von Technik (MS), 1995c.

Observaciones sociológicas desde el punto de vista de la teoría de las distinciones, 1999.

Kamlah, Wilhelm, Pbilosopbiscbe Anthropologie. Sprachkritiscbe Grundlegung und Etbik, Mannheim, Wien, Zürich, BI Hochschultaschenbücher, 1973.

Kant, Immanuel, “Träume eines Geistessehers, erläutert durch Träume der Metaphysik", en Vorkritische Schriften bis 1768, Bd. 2 (Werkausgabe Bd. II), W. Weischedel (ed.), Frankf. a.M., Suhrkamp, 1997, 2a, pp. 923-988 (A3-A128). 
"Über eine Entdeckung, nach der alle neue Kritik der reinen Vernunft durch eine ältere entbehrlich gemacht werden soll", en SchriftenzurMetaphysik und Logik, Bd. 1, (Werkausgabe Bd. v), W. Weischedel (ed.), Frankf. a.M., Suhrkamp, 1997, 5a, pp. 297-373 (BA 3-BA 126).

"Prolegomena zu einer jeden künftigen Metaphysik, die als Wissenschaft wird auftreten können", en Scbriften zurMetaphysik und Logik, Bd. 1, (Werkausgabe Bd. V), W. Weischedel (ed.), Frankf. a.M., Suhrkamp, 1977, 5b, pp. 109-264 (A 3A 222):

Kelley, Harold H., Berscheid, Ellen, Christensen; Andrew, Harvey, John H., Huston, Ted L., Levinger, George, McClintock, Evie, Peplau, Letitia Anne, Peterson, Donald R., Close Relationships, Nueva York, San Francisco, W.H. Freeman \& Company, 1983. Kelly, George A., The Psychology of Personal Constructs, 2 Bd., Nueva York, 1995.

"Man's Construction of His Alternatives", en Gardner, Lindzey (eds.), Assessment of Human Motives, Nueva York, 1958, pp. 33-64.

Kettering, Emil, Näbe, Das Denken Martin Heideggers, Pfullingen, Neske, 1987.

Kiss, Gábor, Grundzüge und Entwicklung der Lubmannscben Systemtheorie, Stuttgart, Enke, 1986.

Paradigmawechsel in der Kritischen Theorie: Jürgen Habermas' intersubjetiver Ansatz, Stuttgart, Enke, 1987.

Klir, G.J., "The Many Faces of Complexity", en The Science and Praxis..., 1985, pp. 81-98.

Knorr-Cetina, Karin, Die Fabrikation von Erkenntnis. Zur Antbropologie der Wissenschaft, Frankf. a.M., Suhrkamp, 1984.

Kolakowski, Leszek, Die Sucbe nacb der verlorenen Gewissbeit. Denkwege mit Edmund Husserl (1975), München, Piper, 1986. Königswieser, Roswita, Lutz, Christian (eds.), Das systemisch evolutionire Management. Der neue Horizont für Unternebmer, Wien, Orac, 1992.

Koselleck, Reinhart, "Einleitung", en Gescbichtliche Grundbegriffe, O. Brunner, W. Conze, R. Koselleck (eds.), Stuttgart, Ernst Klett, 1972, Pp. XIII-XXVII.

Vergangene Zukunft, Frankf. a.M., Suhrkamp, 1985a.

Koyré, Alexandre, Von der geschlossenen Welt zum unendlichen Universum, Frankf. a.M., Suhrkamp, 1969. 
Kuhn, Thomas S., Die Struktur wissenschaftlicher Revolutionen, Frankf. a.M., Suhrkamp, 1976.

Krawietz, Werner, Welker, Michael (eds.), Kritik der Tbeorie sozialer Systeme. Auseinandersetzungen mit Lubmanns Hauptwerk,

Frankf. a.M., Suhrkamp, 1992.

Krippendorf, K., "Paradox and Information", en Dervin, B., Voigt, M.J. (eds.), Progress in Communication Sciences 5, 1984, pp. 45-74.

Krohn, Wolfgang, Küppers, Günther, Paslack, Rainer, "Selbstorganisation-Zur Genese und Entwicklung einer wissenschaftlichen Revolution", en Schmidt, S.J. (ed.), 1987, pp. 441-465.

Krohn, Wolfgang, Küppers, Günther, Die Selbstongantsation der Wissenschaft, Frankf. a.M., Suhrkamp, 1989.

(eds.), Selbstorganisation. Aspekte einer wissenschaftichen Revolution, Braunschweig/Wiesbaden, Vieweg, 1990.

Kroner, Richard, Von Kant bis Hegel, Tübingen, J.C.B. Mohr, 1961. Krüger, Lorenz (ed.), Erkenntnisprobleme der Naturwissenschaften, Köln, Berlín, Kiepenheuer \& Witsch, 1970.

Kuhlmann, Wolfgang, Reflexive Letztbegründung. Untersucbungen zur Transzendentalpragmatik, Freiburg, München. Alber, 1985.

Kuhn, Thomas S., Die Struktur wissenschaflicher Revolutionen, Frankf. a.M:, Suhrkamp, 1976.

La Porte, Todd R. (eds.), Organized Social Complexity. Challenge to Politics and Policy, Princenton, Nueva York, Princenton University Press, 1975.

Laudan, Larry, Progress and its Problems. Toward a Theory of Sctentific Growth, Berkeley, Los Ángeles, Londres, University of California Press, 1977.

Leach, Edmund R., Social Antbropology, Nueva York, Oxford University Press, 1982.

Lepenies, Wolf, Melancholie und Gesellschaft, Frankf. a.M., Suhrkamp, 1969.

Das Ende der Naturgescbichte, München, Wien, Hanser, 1976.

"Das Ende der Naturgeschichte. Verzeitlichung und Enthistorisierung in der Wissenschaftsgeschichte des 18. und 19. Jahrhunderts", en Lepenies, 1976, 1, pp. 9-130.

"Der Wissenschaftler als Autor. Buffons prekärer Nachruhm", en Lepenies, 1976, 2, pp. 133-168. 
"Normalität und Anormalität. Wechselwirkungen zwischen den Wissenschaften vom Leben und den Sozialwissenschaften im 19. Jahrhundert", en Lepenies, 1976, 3, pp. 169-196.

"Wandel der Mentalitäten und Wissenschaftsgeschichte", en Lepenies 1976, 4, pp. 197-214.

(ed.), Gescbicbte der Soziologie, Bde. 1-4, Frankf. a.M., Suhrkamp, 1981.

Die Drei Kulturen. Soziologie zwiscben Literatur und Wissenschaft, München, Wien, Hanser, 1985a.

"Auguste Comtes Wandlungen. Wissenschaft und Literatur im frühen Positivismus", en Lepenies, 1985a, 1, pp. 15-48.

, "Fakten und Gefühlskultur: John Stuart Mill", en Lepenies, 1985a, 3, pp. 105-127.

Lettvin, J.Y., Maturana, H.R., McCulloch, W.s., Pitts, W.H., "What the Frog's Eye Tells the Frog's Brain", en Proceedings of the Institute of Radio Engineers 47, 1940-1951, 1959.

Lipp, Wolfgang, "Autopoiesis biologisch, Autopoiesis soziologisch. Wohin führt Luhmanns Paradigmawechsel?", en KZfSS, Jg. 39, 1987, pp. 452-470.

Linstone, Harold A., Simmonds, W.H.Clive (eds.), Future Researcb: New Directions, Reading, Mass., 1977.

Locker, Alfred, "Metatheoretical Presuippositions for Autopoiesis", en Zeleny (ed.), 1981, pp. 211-233.

Lockwood, David, "Soziale Integration und Systemintegration", en Wolfgang Zapf (ed.), Theorie des sozialen Wandels, Köln, Berlín: Kiepenheur \& Witsch, 1984, pp. 124-137.

Lögren, Lars, "Life as an Autolinguistic Phenomenon", en Zeleny (ed.), 1981, pp. 236-249.

Lohmann, Georg, Indifferenz und Gesellschaft. Eine kritische Auseinandersetzung mit Marx, Frankf. a.M., Suhrkamp, 1991.

Lorenz, Konrad, Die Rückseite des Spiegels, München, Zürich, Piper, 1973.

Ober tierisches und menschliches Verbalten, Bd. I, München, Piper, 1974b.

Lorscheid, B., Das Leibphänomen. Schelers Wesenssoziologie des Leiblicben, Bonn, 1962.

Lovejoy, Arthur O., The Reason, the Unterstanding and Time, Baltimore, The John Hopkins Press, 1961.

Löwe, J., Der Kampf zwiscben Nominalismus und Realismus, Prag, 1876. 
Luhmann, Niklas, Grundrechte als Institution. Ein Beitrag zur politiscben Soziologie, Berlín, 1965.

"Klassische Theorie der Macht. Kritische Prämissen", en Zeit. f. Politik, 16, 1969, pp. 149-170.

, "Normen in soziologischer Perspektive", en Soziale Welt 29, 1969b, pp. 28-48.

, "Institutionalisierung-Funktion und Mechanismus im sozialen System der Gesellschaft", en Zur Tbeorie derInstitutionen, Helmut Schelsky (ed.), Bielefeld, Bertelsmann Universitätsverlag, 1970b, pp. 27-41.

"Sinn als Grundbegriff der Soziologie", en Habermas, Luhmann, 1971a, pp. 25-100.

-, "Moderne Systemtheorie als Form gesamtgesellschaftlicher Analyse", en Habermas, Luhmann, 1971a, pp. 7-24.

, "Systemtheoretische Argumentationen. Eine Entgegnung auf Jürgen Habermas", en Habermas, Luhmann, 1971b, pp. $291-405$.

, Rechtssoziologie Bd. 1, Reinbek b. Hamburg, Rowohlt, 1972a, 1. $1972 a, 2$.

, Vertrauen. Ein Mechanismus der Reduktion sozialer Komplexität, Stuttgart, Enke, 1973.

, Zweckbegriff und Systemrationalität. Uberdie Funktion von Zwecken in sozialen Systemen, Frankf. a.M., Suhrkamp, 1973b. Soziologiscbe Aufklarung. Aufsätze zur Theorie sozialer Systeme, Bd. 1, Opladen, Westdeutscher Verlag, 19742.

, "Funktion und Kausalität", en Luhmann, 1974a, 1, pp. 9-30. "Funktionale Methode und Systemtheorie", en Luhmann, 1974a, 2, pp. 31-53).

91.

"Soziologische Aufklärung", en Luhmann, 1974a, 4, pp. 66-

"Soziologie als Theorie sozialer Systeme", en Luhmann, 1974a, 6, pp. 113-136.

"Selbststeuerung der Wissenschaft", en Luhmann, 1974a, 11, pp. 232-252). 267.

"Die Praxis der Theorie", en Luhmann, 1974a, 12, pp. 253-

Soziologiscbe Aufklärung 2. Aufsatze zur Theorie der Gesellschaft, Opladen, Westdeutscher Verlag, 1975a. 
"Interaktion, Organisation, Gesellschaft", en Luhmann, 1975a, 1, pp. 9-20).

, “Die Weltgesellschaft", en Luhmann, 1975a, 4, pp. 51-71. "Weltzeit und Systemgeschichte", en Luhmann, 1975a, 6,

pp. 103-133.

"Einführende Bemerkungen zu einer Theorie symbolisch generalisierter Kommunikationsmedien", en Luhmann, 1975a, 9, pp. 170-192.

, "Komplexität", en Luhmann, 1975a, pp. 204-220.

; Politische Planung. Aufs $s_{n}$ zur Soziologie von Politik und

Verwaltung, Opladen, Westdeutscher Verlag, 1975b.

"Öffentliche Meinung", en Luhmann, 1975b, 1, pp. 9-34.

"Politische Planung", en Luhmann, 1975b, 5, pp. 66-89.

, "Lob der Routine", en Luhmann, 1975b, 7, pp. 113-142.

, "Opportunismus und Pragmmatik in der öffentlichen Ver-

waltung", en Luhmann, 1975b, 10, pp. 165-180.

"Reform des öffentlichen Dienstes: Zum Problem ihrer Pro-

blemen, en Luhmann, 1975b, 11, pp. 203-256. Macbt, Stuttgart, Enke, 1975 e.

"Generalized Media and the Problem of Contingency", en

Jan J. Loubser et al. (ed.), Explorations in the General Theory in Social Science: Essays in Honor of Talcott Parsons, Nueva York, Bd. 2, 1976, pp. 507-532.

"The Future Cannot Begin: Temporal Perspectives in Mo-

dern Society", en Social Researcb 43, 1976a, pp. 130-152.

"Komplexität", en Historiscbes Worterbucb der Pbiloso-

phie, Bd. 4, Basel,1976b, pp. 939-941.

, Funktion der Religion, Frankf. a.M., Suhrkamp, 1977a.

"Arbeitsteilung und Moral. Durkheims Theorie", en Émile

Durkheim; Dber die Tetlung der sozialen Arbeit, Frankf. a.M., Suhrkamp, 1977b, pp. 17-35.

"Differentiation of Society", en Canadian Journal of Socio$\log y$ 2, 1977c, pp. 29-53.

"Soziologie der Moral", en Ibid. u. Stephen H. Pförtner (eds.), Tbeorietecbnik und Moral, Frankf., a.M., Suhrkamp, 1978, pp. 8-116.

"Geschichte als Prozess und die Theorie sozio-kultureller

Evolution", en Karl-Georg Faber, Christian Meier (eds.), Historische Prozesse, München, 1978a, pp. 413-440. 
"Interpenetration bei Parsons", en Zeit. f. Soziologie, Heft 3, 1978c, pp. 299-302.

"Temporalization of Complexity", en Soctocybernetics, R.F. Geyer, J. van der Zouwen (eds.), vol. 2, Leiden, Boston, Londres, Martinus Nijhoff Social Science Division, 1978d, pp. 95-111.

, "Suche der Identität und Identität der Suche. Uber teleologische und selbstreferentielle Prozesse ${ }^{n}$, en Marquard, Odo, Stierle, Karlheinz (eds.), Identitat't (Poetik und Hermeneutik Bd. VIII), München, Wilhelm Fink, 1979a, pp. 593-594.

"Wie man Erwartungen bündeln Kann", en Marquard, Odo, Stierle, Karlheinz (eds.), Identität (Poetik und Hermeneutik Bd. VIII), München, Wilhelm Fink, 1979b, pp. 594-596.

; Gesellschaftsstrukturund Semantik. Studien zur Wissensso-

ztologie der modernen Gesellschaft, Bd. 1, Frankf. a.M., Suhrkamp, 1980a.

; "Gesellschaftliche Struktur und semantische Tradition", en Luhmann, 1980a, 1, pp. 9-71.

"Interaktion in Oberschichten: Zur Transformation ihrer

Semantik im 17. und 18. Jahrhundert", en Luhmann, 1980a, 2, pp. 72-161.

$\longrightarrow$, "Selbstreferenz und binäre Schematisierung", en Luhmann, 1980a, 5, pp. 301-313.

"Talcott Parsons-Zur Zukunft eines Theorieprogramms", en Zeitschrift für Soziologie, Jg. 9, Heft 1, 1980b, pp. 5-17. Ausdifferenzierung des Recbts. Beiträge zur Recbtssoziologie und Rechtstbeorle, Frankf. a.M., Suhrkamp, 1981.

—_ "Evolution des Rechts", en Luhmann, 1981, 1, pp. 11-34.

; "Die Funktion des Rechits: Erwartungssicherung oder Verhaltenssteuerung?", en Luhmann, 1981, 4, pp. 73-91.

, "Positivität des Rechts als Voraussetzung einèr modernen Gesellschaft", en Luhmann, 1981, 6, pp. 113-153.

; "Systemtheoretische Beiträge, zur Rechtstheorie", en Luhmann, 1981, 10, pp. 241-272).

"Selbstreflexion des Rechtssystems: Rechtstheorie in gesellschaftstheoretischer Perspektive", en Luhmann, 1981, 16, pp. 419-450.

, "Die Ausdifferenzierung von Erkenntnisgewinn: Zur Genese von Wissenschaft", en Nico Stehr, Volker Meja (eds.), Wissenssoziologie, Sonderbeft 22. der K'lner Zeitschrift für Soziologie 
und Sozialpsychologie, Opladen, Westdeutscher Verlag, 1981a, pp. 101-139.

\section{1d.}

, Politische Theorie im Woblfabrtsstaat, München, Olzog,

, "Kommunikation mit Zettelkästen: Ein Erfahrungsbericht", en Horst Baier et al. (eds.), Offentliche Meinung und sozialer Wandel: Für Elisabeth Noelle-Neumann, Opladen, 1981e, pp. 222-228.

, Soziologische Aufklärung 3. Soziales System, Gesellschaft, Organisation, Opladen. Westdeutscher Verlag, 1981f.

, "Handlungstheorie und Systemtheorie", en Luhmann, 1981f, 4, pp. 50-66.

"Erleben und Handeln", en Luhmann, 1981f, 5, pp. 67-80.

, "Zeit und Handlung-Eine vergessene Theorie", en Luhmann, 1981f, 7, pp. 101-125.

, "Temporalstrukturen des Handlungssystems: Zum Zusammenhang von Handlungs-und Systemtheorie", en Luhmann, 1981f, 8, pp. 126-150.

, "Interpenetration-Zum Verhältnis personaler und sozialer Systeme", en Luhmann, 1981f, 9, pp. 151-169.

, "Unverständliche Wissenschaft: Probleme einer theorieeigenen Sprache", en Luhmann, 1981f, 10, pp. 170-177.

, "Identitättsgebrauch in selbstsubstitutiven Ordnungen, besonders Gesellschaften", en Luhmann, 1981f, 12, pp. 198-227. ., "Theoretische und praktische Probleme der anwendungsbezogenen Sozialwissenschaften ${ }^{n}$, en Luhmann, 1981f, 19, pp. 321-334.

, Gesellschaftsstruktur und Semantik, Bd. 2, Frankf. a.M., Suhrkamp, $1981 \mathrm{~h}$.

, "Selbstreferenz und Teleologie in gesellschaftstheoretischer Perspektive $^{n}$, en Luhmann, 1981h, 1, pp. 9-44.

"Theoriesubstitution in der Erziehungswissenschaft", en Luhmann, 1981h, 3, pp. 105-194.

"Wie ist soziale Ordnung möglich?", en Luhmann, 1981h, 4, pp. 195-285.

Schorr, Karl Eberhard, "Wie ist Erziehung möglich?", en Zeitschrift für Sozialisationsforschung und Erziebungssoziologie I, 1981, pp. 37-54.

$\therefore$ 1982a. 
"Politics as a Social System", en Luhmann, 1982a, 1, pp. 138-

Liebe als Passion. Zur Codierung von Intimitat, Frankf. a.M., Suhrkamp, 1982b.

"Territorial Borders as System Boündaries", en Raimondo Strassoldo, Giovanni Delli Zotti (eds.), Cooperation and Conflict in Border Areas, Mailand, 1982c, Pp. 235-244.

"Autopoiesis, Handlung und kommunikative Verständigung", en Zeit.f. Soziologie, Heft 4, 1982d, pp. 366-379.

"Die Voraussetzung der Kausalität", en Luhmann, Schorr (eds.), 1982f, pp. 41-50.

"Personale Identität und Möglichkeiten der Erziehung", en Luhmann, Schorr (eds.), 1982g, pp. 224-261.

-.., "Prologo", en Darío Rodríguez Mansilla, Formación de oligarquias en procesos de autogestión. La experiencia chilena entre 1967 y 1970, Santiago, Chile, Instituto de Sociología Pontifica Universidad Católica de Chile, 1982i, pp. 7-11.

Schorr, Karl Eberhard (eds.), Zwischen Tecbnologie und Selbstreferenz, Frankf. a.M., Suhrkamp, 1982.

, Schorr, Karl Eberhard, "Das Technologiedefizit der Erziehung und die Pädagogik”, en Luhmann, Schorr (eds.), 1982h, pp. $11-40$. 1983.

"Die Einheit des Rechtssystems", en Recbtstbeorie 14, 1983f, pp. 129-154.

"Insistence on System Theory: Perspectives from Germany", en Social Forces 61, 1983g, pp. 987-998.

Soziale Systeme. Grundriss einer allgemeinen Theorie, Frankf. a.M., Suhrkamp, 1984.

"Die Theorie der Ordnung und die natürlichen Rechte", en Recbtstbeoretisches Journal 3, 1984a, pp. 133-149.

"Die Differenzierung von Interaktion und Gesellschaft: Probleme der sozialen Solidarität", en Robert Kopp (ed.), Solidaritat in der Welt der 80er Jabre: Leistungsgesellscbaft und Sozialstaat, Basel, 1984b, pp. 79-96.

"The Self-Description of Society: Crisis Fashion and Sociological Theory", en International Journal of Comparative Sociology 25, 1984d, pp. 59-72. 
, "Das Kunstwerk und die Selbstreproduktion der Kunst", en Delfin III, 1984e, pp. 51-69.

, "Helmut Schelsky zum Gedenken", en Zeit.f. Rechtssoziologie

6, Heft 1, $1984 \mathrm{~g}$, pp. 1-3.

"Einige Probleme mit reflexivem Recht", en Zeit.f. Rechtsso-" ziologie 6, Heft 1, 1985, pp. 1-18.

(ed.), Soziale Differenzierung. Zur Geschichte einer Idee, Opladen, Westdeutscher Verlag, 1985.

"Zum Begriff der sozialen Klasse", en Luhmann (ed.), 1985a, pp. 119-162.

"Society, Meaning, Religion-Based on Self-Reference", en Sociological Analysis 46, 1985c, pp. 5-20.

"Die Soziologie und der Mensch", en Neue Sammlung 25, 1985d, pp. 33-41.

"Die Autopoiesis des Bewusstseins", en Soziale Welt, Heft 4, 1985f, pp. 402-446.

, "Complexity and Meaning", en The Science and Praxis..., 1985i, pp. 99-104.

Okologiscbe Kommunikation, Opladen, Westdeutscher Verlag, 1986a.

, Die soziologische Beobacbtung des Rechts, Frankf. a.M., Alfred Metzner, 1986b.

. $\quad$,Die Codierung des Rechtssystems", en Rechtstheorie 17, 1986c, pp. 171-203.

, "Die Lebenswelt-nach Rücksprache mit Phänomenologen", en Arcbiv $f$. Rechts-und Sozialphilosopbie, vol. 76, Heft 2, 1986e, pp. 176-194.

"Intersubjektivität oder Kommunikation: Unterschiedliche Ausgangspunkte soziologischer Theoriebildung", en Arcbivio di Filosofia, núm. 54, 1986f, pp. 41-60.

,"The Autopoiesis of Social Systems", en Felix Geyer, Johannes van der Zouwen (eds.), Sociocybernetic Paradoxes: Observation, Control and Evolution of Self-Steering Systems, Londres, Beverly Hills, $1986 \mathrm{~g}$, pp. 172-192.

"Das Medium der Kunst", en Delfin, Heft 1, 1986j, pp. 6-15. "The Individuality of the Individual: Historical Meanings and Contemporary Problems", en Thomas C. Heller, Morton Sosna, David E. Wellbery (eds.), Reconstructing Individualism: Autonomy, Individuality and the Self in Western' Thought, Standford, Cal., 1986k, pp. 313-325. 
, "The Theory of Social Systems and Its Epistemology: Reply to Danilo Zolo's Critical Comments", en Pbilosopby of Social Sctences 16, 1986m, pp. 129-134.

, "Systeme verstehen Systeme", en Luhmann, Schorr (eds.), 1986n, 1; pp. 72-117).

, Schorr, Karl Eberhard (eds.), Intransparenz und Verstehen. Fragen an die Pädagogik, Frankf. a.M., Suhrkamp, 1986n.

, Arcbimedes und wir, Berlín, Merve, 1987a.

, Soziologische Aufklärung 4, Betträge zur funktionalen Differenzierung der Gesellscbaft, Opladen, Westdeutscher Verlag, 1987c.

, "Distinctions Directrices. Uber Codierung von Semantiken", en Luhmann, 1987c, 1, pp. 13-31.

, "Gesellschaftsstrukturelle Bedingungen und Folgeprobleme des naturwissenschaftlich-technischen Fortschritts", en Luhmann, 1987c, 3, pp. 49-63.

, "Die Unterscheidung von Staat und Gesellschaft", en Luhmann, 1987c, 4, pp. 67-73.

,' "Gesellschaftliche Grundlagen der Macht: Steigerung und Verteilung", en Luhmann, 1987c, 7, pp. 117-125.

; "Codierung und Programmierung. Bildung und Selektion im Erziehungssystem", en Luhmann, 1987c, 14, pp. 182-201.

___ _ "Lässt unsere Gesellschaft Kommunikation mit Gott zu?", en Luhmann, 1987c, 18, pp. 227-235.

236-253.

"Die Unterscheidung Gottes", en Luhmann, 1987c, 19, pp.

; "Was ist Kommunikation?", en Information Pbilosophie 1, 1987e, pp. 4-16.

"Sprache und Kommunikationsmedien. Ein schieflaufender Vergleich", en Zeit. f. Soziologie, Heft 6, 1987f, pp. 467-468. 1987h, pp. 36-49.

"Paradigmawechsel in der Systemtheorie. Ein Paradigma für Fortschritt?", en Reinhart Herzog/Reinhart Koselleck (eds.), Epocbenscbwelle und Epocbenbewusstsein (Poetik und Hermeneutik Bd. XII), München, Wilhelm Fink, 1987i, pp. 305322.

"Autopoiesis als soziologischer Begriff", en Haferkamp, Schmid (eds.), 1987j, pp. 307-324. 
"Tautologie und Paradoxie in den Selbstbeschreibungen der modernen Gesellschaft", en Zeit. f. Soziologie, Heft 3, $1987 \mathrm{k}$, pp. 161-174.

1988.

Die Wirtschaft der Gesellschaft, Frankf. a.M., Suhrkamp,

"Die Wirtschaft der Gesellschaft als autopoietisches System", en Luhmann, 1988, 2, pp. 43-90.

"Der Markt als innere Umwelt des Wirtschaftssystems", en Luhmann, 1988, 3, pp. 91-130.

"Kapital und Arbeit: Problem einer Unterscheidung", en Luhmann, 1988, 5, pp. 151-176.

, "Knappheit", en Luhmann, 1988, 6, pp. 177-229.

"Geld als Kommunikationsmedium: über symbolische und diabolische Generalisierungen", en Luhmann, 1988, 7, pp. 230271.

"Soziologische Aspekte des Entscheidungsverhaltens", en Luhmann, 1988, 8, pp. 272-301.

349.

"Grenzen der Steuerung", en Luhmann, 1988, 10, pp. 324-

, "Frauen, Männer und George Spencer Brown", en Zeit.f. Soziologie, Heft 1, 1988a, pp. 47-71.

"Warum AGI?", en KZFSS, Heft 1, 1988b, pp. 127-139.

, "Neuere Entwicklungen in der Systemtheorie", en Merkur, Heft 4, 1988c, pp. 292-300.

"Stenographie", en Delfin, Heft 2, 1988d, pp. 4-12.

"Positivität als Selbstbestimmtheit des Rechts", en Rechtstheorie 19, 1988e, pp. 11-27.

, "Closure and Openness: On Reality in the World of Law", en Teubner (ed.), 1988f, pp. 335-348.

"Wie ist Bewusstsein an Kommunikation beteiligt?", en Hans Ulrich Gumbrecht, K. Ludwig Pfeiffer (eds.), Materialität der Kommunikation, Frankf. a.M., Suhrkamp, 1988i, pp. 884-905.

, Erkenntnis als Konstruktion, Bern, Benteli, 1988j.

,Schorr, Karl Eberhard, Reflexionsprobleme im Erziehungssystem, Frankf. a.M., Suhrkamp, 1988.

, Gesellschaftsstruktur und Semantik, Studien zur Wissenssoziologie der modernen Gesellschaft, Bd. 3, Frankf. a.M., Suhrkamp, 1989a. 

11-64.

"Am Anfang war kein Unrecht", en Luhmann, 1989a, 1, pp.

"Individuum, Individualit, Individualismus", en Luhmann, 1989a, 3, pp. 149-258.

, "Ethik als Reflexionstheorie der Moral"; en Luhmann, 1989a,

5, pp. 358-447).

… "Kommunikationsweisen und Gesellschaft1", en Technik und Gesellschaft, Jahrbucb 5: Computer, Medien, Gesellschaft, W. Rammert (ed.), 1989b, pp. 11-18. 1989.

, Fuchs, Peter, Reden und Schweigen, Frankf. a.M., Suhrkamp, 1990.

Die Wissenschaft der Gesellschaft, Frankf. a.M., Suhrkamp,

Soziologiscbe Aufklärung 5. Konstruktivistiscbe Perspektiven, Opladen, Westdeutscher Verlag, 1990a.

, "Identität-was oder wie?"; en Luhmann, 1990a, 1, pp. 14-30.

, "Das Erkenntnisprogramm des Konstruktivismus und die unbekannt bleibende Realität", en Luhmann, 1990a, 2, pp. 3158.

"Haltlose Komplexit", en Luhmann, 1990a, 3, pp. 59-76.

, "Gleichzeitigkeit und Synchronisation", en Luhmann, 1990a, 5, pp. 95-169.

"Risiko und Gefahr", en Luhmann, 1990a, 6, pp. 131-169.

, "Gesellschaftliche Komplexität und öffentliche Meinung", eri Luhmann, $1990 \mathrm{a}, 7$, pp. 170-182:

, "Ich sehe was, was Du nicht siehst", en Luhmann, 1990a, 11, pp. 228-234.

45.

"Weltkunst", en Luhmann, Bunsen, Baecker, 1990b, pp. 7-

"General Theory and American Sociology", en Gans (ed.), 1990c, pp. 253-264.

"Anfang und Ende: Probleme einer Unterscheidung", en Luhmann, Schorr (eds.), 1990d, pp. 11-23.

"Die Homogenisierung des Anfangs: Zur Ausdifferenzierung der Schulerziehung", en Luhmann, Schorr (eds.), 1990e, pp. 73111.

, "Paradigm lost: über die ethische Reflexion der Moral. Rede anlässlich der Verleihung des Hegel-Preises 1989", Frankf. a.M., Suhrkamp, 1990 f, pp. 7-48. 
Bunsen, Frederick, Baecker, Dirk, Unbeobachtbare Welt. Uber Kunst und Architektur, Bielefeld, Cordula Haux, como Luhmann, Bunsen, Baecker, 1990.

, Schorr, Karl Eberhard (eds.), Zwiscben Anfang und Ende. Fragen an die Pädagogik, Frankf. a.M., Suhrkamp, 1990.

"Wie lassen sich latente Strukturen beobachten?", en Watzlawick, Krieg (eds.), 1991, pp. 61-74.

, Soziologie des Risikos, Berlín, Nueva York, Walter de Gruyter, 1991a.

"Am Ende der Kritischen Soziologie", en Zeit.f. Soziologie, Heft 2, 1991b, pp. 147-152.

"Wer kennt Will Martens? Eine Anmerkung zum Problem der Emergenz sozialer Systemen, en KZfSS, Heft 1, 1992, pp. 139-142.

,Universität als Milieu, Andr, Kieserling (ed.), Bielefeld, Haux, $1992 a$.

"Die Universität als organisierte Institution", en Luhmann, 1992a, 9, pp. 90-99.

, "Erfahrungen mit Universitäten: Ein Interview", en Luhmann, 1992a, 10, pp. 100-125.

"Die gesellschaftliche Verantwortung der Soziologie", en Luhmann, 1992a, 11, pp. 126-136.

, "Die Selbstbeschreibung der Gesellschaft und die Soziologie", en Luhmann, 1992a, 12, pp. 137-146. , "Kommunikationssperren in der Unternehmensberatung", en Königswieser, Lutz (eds.), 1992c, pp. 236-249. , "Glück und Unglück der Kommunikation in Familien", en Königswieser, Lutz (eds.), 1992d, pp. 298-306.

371-386.

Lyotard, Jean-François, Der Widerstreit, München, Fink, 1987.

Mackay, Donald M., Information, Mechanism and Meaning, Cambridge, Mass., MrT, 1969.

Mackensen, Rainer, "Nerven statt Muskeln-über Frieden im Verständnis von Karl Deutsch", Laudatio zur Ehrenpromotion am 14. Januar 1983 in der TU Berlín, Berlín: WZB-Mitteilungen, 1983, pp. 21-25.

Mackensen, Rainer, Neue Dimensionen der Stadt-und Regionalsoziologie. Peter Atteslander zum 17.3.1991, Berlin: Ms., 1992. 
Marquard, Odo, Abschied vom Prinzipiellen. Pbilosopbiscbe Studien, Stuttgart, Reclam, 1981.

.. "Abschied vom Prinzipiellen. Auch eine autobiographische Einleitung", en Marquard, 1981, 1, pp. 4-22.

, "Frage nach der Frage, auf die die Hermeneutik die Antwort ist", en Marquard, 1981, 6, pp. 117-146.

, Apologie des Zufalligen. Pbilosophische Studien, Stuttgart, Reclam, 1986a.

"Uber die Unvermeidlichkeit der Geisteswissenschaften", en Marquard, 1986a, 6, pp. 98-116.

-., "Apologie des Zufälligen. Philosophische Überlegungen zum Menschen", en Marquard, 1986a, 7, pp. 117-139.

Martens, Wil, "Die Autopoiesis sozialer Systeme", en, KZfSS, Heft 4, 1991, 625-646.

Martens, "Wil, Die partielle Uberschneidung autopoietischer Systeme", en KZfSS, Heft 1, 1992, 143-145.

Maruyama, Magoroh, "The Second Cybernetics: Deviation-Amplifying Mutual Causal Processes", en Buckley (ed.), 1968, pp. 304-313.

Matthiesen, Ulf, Das Dickicht der Lebenswelt und die Theorie des kommunikativen Handelns, München, Wilhelm Fink, 1985.

Maturana, Humberto R., Erkennen: Die Organisation und Verkörperung von Wirklicbkeit, Braunschweig/Wiesbaden, Vieweg, 1985.

, "Biologie der Kognition", en Maturana, 1985, 1, pp. 32-80. , "Die Organisation des Lebendigen: eine Theorie der lebendigen Organisation", en Maturana, 1985, 4, pp. 138-156.

, "Autopoietische Systeme: eine Bestimmung der lebendigen Organisation (Co-Autor, F.J. Varela)", en Maturana, 1985, 6, pp. 170-235.

"Biologie der Sprache: die Epistemologie der Realität", en Maturana, 1985, 7, pp. 236-271.

, "Repräsentation und Kommunikation", en Maturana, 1985, 8, pp. 272-296.

"Kognitive Strategien", en Maturana, 1985, 9, pp. 297-318. ,Varela, FranciscoJ., Uribe, R., "Autopoiesis: die Organisation lebender Systeme, ihre nähere Bestimmung und ein Modell", en Maturana, 1985, pp. 157-169.

, Varela, Francisco J., Der Baum der Erkenntnis. Die biologischen Wurzeln des menscblicben Erkennens, Bern, München, Wien, Scherz, 1987. 
Mayntz, Renate, Rosewitz, Bernd, Schimank, Uwe, Stichweh, Rudolf, Differenzierung und Verselbstständigung. Zur Entwicklung gesellschafticher Teilsysteme, Frankf. a.M., Nueva York, Campus, 1988.

McCarthy, Th. A., Kritik der Verständigungsverbälnisse, Frankf. a.M., Suhrkamp, 1989.

McGuinness, B., Habermas, J., Apel, K.-O., Rorty, R., Taylor, Ch., Kambartel, F., Wellmer, A., "Der Löwe spricht...und wir können ihn nicht verstehen. Ein Symposion an der Universität Frankfurt anlässlich des hundertsten Geburtstags von Ludwig Wittgenstein", Frankf. a.M., Suhrkamp. Zitiert als: McGuinness u.a., 1991.

Mertens, Klaus, "Kommunikationsmodell und Gesellschaftstheorie", en KZfSS, Jg. 30, 1978, pp. 572-595.

Meyer, Eva, Zählen und Erzählen. Für eine Semiotik des Weiblichen, Wien, Berlín, Medusa, 1983.

" "Der Unterschied, der eine Umgebung schafft", en Ars electronica (eds.), 1990, pp. 110-122.

Mittelstrass, Jürgen, Die Möglichkeit von Wissenschaft, Frankf. a.M., Suhrkamp, 1974.

Monod, Jacques, Zufall und Wirklichkeit, München, dtv, 1975.

Morin, Edgar, El método I. La naturaleza de la naturaleza, Cátedra, Madrid, 1981.

"On the Definition of Complexity", en The Science and Praxis..., 1985, pp. 62-68. El método III. El conocimiento del conocimiento, Cátedra, Madrid, 1988. , El método IV. Las ideas, Cátedra, Madrid, 1992. , El método II. La vida de la vida, Cátedra, Madrid, 1993.

Münch, Richard, Tbeorie des Handelns. Zur Rekonstruktion der Beiträge, von Talcott Parsons, Emile Durkbeim und Max Weber, Frankf. a.M., Suhrkamp, 1982a.

Die Struktur der Moderne. Grundmuster und differentielle Gestaliung des institutionellen Aufbaius der modernen Gesellschaften, Frankf. a.M., Suhrkamp (Sonderausgabe), 1984.

Dialektik der Kommunikationsgemeinschaft, Frankf. a.M., Suhrkamp, 1991.

Needham, Rodney (ed.), Right and Left: Essays on Dual Symbolic Classification, Chicago, Londres, The University of Chicago Press, 1973. 
Nelson, Benjamin, The Idea of Usury. From Tribal Brotberbood to Universal Otberbood (1949), Chicago, Londres, The University of Chicago Press, 1969.

Opp, Karl-Dieter, Verbaltenstheoretiscbe Soziologie. Eine neue soziologische Forscbungsricbtung, Reinbek b.H., Rowohlt, 1972.

, “DDR '89. Zu den Ursachen einer spontanen Revolution", en KZfSS, Heft 2, 1991, pp. 302-321.

Orchard, Robert A., "On the Laws of Form", en Int.J. General Systems, vol. 2, 1975, pp. 99-106.

Østerberg, Dag, Meta-Sociological Essay, Pittsburgh, Duquesne University Press, 1976.

Parmenides, Uber das Sein. Die Fragmente des Lebrgedichts, Hans von Steuben (ed.), Stuttgart, Reclam, 1981.

Parsons, T., Bales, R.F., Shils, E.A., Working Papers in the Theory of Action (1953), Wesport, Connecticut, Greenwood Press, 1981.

Parsons, Talcott, The Structure of Social Action. A Study in Social Theory with Spectal References to a Group of Recent European Writers [1937], Nueva York, The Free Press, 1949a.

"Some Problems Confronting Sociology as a Profession", en American Sociological Review 24, 1959, pp. 547-559.

, "The Position of Identity in the General Theory of Action", en Ch. Gordon, $\mathrm{K} . \mathrm{J}$. Gergen (eds.), The Selfin Sociallnteraction, Bd. 1, New York, 1968, pp. 11-23.

Beitrdge, zur soztologischen Theorie, D. Rüschemeyer (ed.), Neuwied, Berlin, Luchterhand, 1986a.

, "Systematische Theorie in der Soziologie.' Gegenwärtiger Stand und Ausblick", en Parsons,1968a, 1, pp. 31-64.

1970 a.

The Social System, Londres, Routledge \& Kegan Paul,

, Gesellscbaften. Evolutionäre und komparative Perspektiven, Frankf. a.M., Suhrkamp, 1975.

"Die Entstehung der Theorie des sozialen Systems: Ein Bericht zur Person", en Parsons, Shils, Lazarsfeld, 1975a, pp. 168.

Zur Theorie sozialer Systeme, Stefan Jensen (ed.), Opladen, Westdeutscher Verlag, 1976a.

"Zur allgemeinen Theorie in der Soziologie", en Parsons, 1976a, 1, pp. 85-120.

"Der Begriff der Gesellschaft: Seine Elemente und ihre Verknüpfungen", en Parsons. 1976a, 2, pp. 212-160. 
161-274.

"Grundzüge des Sozialsystems", en Parsons, 1976a, 3, pp.

, "Sozialsysteme", en Parsons, 1976a, 4, pp. 275-318.

Ackerman, Charles, Der Begriff Soztalsystem, 1976.

Shils, Edward, Iazarsfeld, Paul F., Soziologie-autobiogra-

phisch, Stuttgart, Enke, 1975.

, Shils, Edward A. (ed.), Toward a General Theory of Action,

Cambridge, Massachussetts, Harvard University Press, 1951.

Pask, Gordon, "A Conversation Approach to Social Systems", en

Sociocybernetics, R.F. Geyer, J. van der Zouven (eds.), Leiden,

Boston, Londres, Martinus Nijhoff, 1978b, pp. 15-26.

Peirce, Charles Sanders, Schriften II. Vom Pragmatismuszum Pragma-

tizismus, Karl-Otto Apel (ed.), Frankf. a.M., Suhrkamp, 1970.

Peirce, Charles Sanders, Pbänomen und Logik der Zeichen, Helmut

Pape [ed.], Frankf. a.M., Suhrkamp, 1983.

, Naturordnung und Zeichenprozess. Schriften ÜberSemiotik

und Naturpbilosophie (Vorwort von Ilya Prigogine), Helmut

Pape (ed.), Frankf. a.M., Suhrkamp, 1991.

Picht, Georg, Der Gott der Pbilosophen und die Wissenschaft der Neuzeit, Stuttgart, Klett, 1966.

Wabrbeit, Vernunft, Verantwortung. Philosophiscbe Studien, Stuttgart, Klett, 1969a.

, "Die Voraussetzungen der Wissenschaft", en Picht, 1969a,

1, pp. 11-35.

, "Die Epiphanie der ewigen Gegenwart. Wahrheit, Sein und

Erscheinung bei Parmenides", en Picht, 1969a, 2, pp. 37-86.

"Der Sinn der Unterscheidung von Theorie und Praxis in

der griechischen Philosophie", en Picht, 1969a, 4, pp. 108-140.

281-317.

Ploman, Edward W., "Introduction", en The Science and Praxis..., 1985, pp. 7-22.

Polanyi, Karl, The Great Transformation. Politische und ökonomische Ursprünge von Gesellschaften und Wirtschaftssystemen, Frankf.

a.M., Suhrkamp, 1978.

Polanyi, Michael, The Logic of Liberty. Reflections and Rejoinders, Londres, Routledge and Kegan Paul, 1951.

Personal Knowledge. Towards a Post-Critical Philosophy,

Londres, Routledge \& Kegan Paul, 1973.

; Implizites Wissen, Frankf. a.M., Sührkamp, 1985. 
Póppel, Emst, Grenzen des Beunusstseins. Über Wirklicbkeit und Welterfabrung, Stuttgart, dva, 1985.

Popper, Karl R., Logik der Forschung, Tübingen, J.C.B. Mohr, 1969. "Die Logik der Sozialwissenschaften", en Adorno, Th.W. u.a.,1970, pp. 103-123.

, Objektive Erkenntnis. Ein evolutionärer Entwurf, Hamburg, Hoffmann und Campe, 1973.

Ausgangspunkte. Meine intellektuelle Entwicklung, Hamburg, Hoffmann und Campe, 1973.

Prigogine, Ilya, "New Perspectives on Complexity", en The Science and Praxis..., 1985, pp. 107-118.

Vom Sein zum Werden. Zeit und Komplexit in den Naturwissenschaften, München, Zürich, Piper, 1988.

Purpus, Wilhelm, Zur Dialektik des Bewrusstseins nach Hegel. Ein Bettrag zur Würdigung der Pbänomenologie des Geistes, Berlín, Trowitzsch \& Sohn, 1908.

Quine, Willard Van Orman, Die Wurzeln der Referenz, Frankf. a.M.; Suhrkamp, 1989.

, Theorien und Dinge, Frankf. a.M., Suhrkamp, 1991.

Rapaport, Anatol, Pbilosopbie beute und morgen. Einfübrung ins operationale Denken, Darmstadt, Verlag Darmstädter Blätter, 1953.

Rapp, Friedrich, Jokisch, Rodrigo, Lindner, Helmut, Determinanten dertechnischen Entwicklung. Strukturmodelle in der Gescbichtsscbreibung. Ober die Industrialisierung in Europa, Berlin, Universitätsbibliothek, 1980.

Riedel, Rupert, Biologie der Erkenntnis, Berlín, Hamburg, Paul Parey, 1980.

Die Strategie der Genesis, München, Zürich, Piper, 1984a. Die Spaltung des Weltbildes. Biologische Grundlagen des Erklärens und Verstebens, Berlín, Hamburg, Paul Parey, 1985a. Riegas, Volker, Vetter, Christian (eds.), Zur Biologie der Kognition. Ein Gesprāch mit Humberto R. Maturana und Beiträge, zur Diskussion seines Werkes, Frankf. a.M., Suhrkamp, 1991.

Ritter, Joachim, Metaphysik und Politik. Studien zu Aristoteles und Hegel, Frankf. a.M., Suhrkamp, 1988.

Rorty,' Richard, Der Spiegel der Natur. Eine Kritik der Pbilosophie, Frankf. a.M., Suhrkamp, 1984.

Roth, Gerhard, "Biological Systems' Theory and the Problem of Reductionism", en Roth, Schwegler (ed.), 1981, pp. 106-120. 
Schwegler, Helmut (ed.), Self-Organizing Systems. An Interdisciplinary Approach, Frankf. a.M., Nueva York, Campus, 1981.

"Selbstorganisation-Selbsterhaltung-Selbstreferentialität:

Prinzipien der Organisation der Lebewesen und ihre Folgen für die Beziehung zwischen Organismus und Umwelt", en Dress, Heinrichs, Küppers, 1986, pp. 149-180.

"Autopoiese und Kognition: Die Theorie H. R. Maturanas und die Notwendigkeit ihrer Weiterentwicklung", en Schmidt (ed.), 1987, pp. 256-286.

Die Entwicklung kognitiver Selbstreferentialität im menschlichen Gehirn", en Baecker u.a. (eds.), 1987a, pp. 394-422. "Erkenntnis und Realität: Das Gehirn und seine Wirklichkeit", en Schmidt (ed.), 1987c, pp. 229-255.

Rusch, Gebhard, Erkenntnis, Wissenschaft, Gescbichte. Von einem . konstruktivistischen Standpunkt, Frankf. a.M., Suhrkamp, 1987.

Russell, Bertrand, Pbilosopbie. Die Entwicklung meines Denkens, Frankf. a.M., Fischer, 1988.

Schelsky, Helmut, Die Arbeit tun die anderen. Klassenkampf und Priesterberrschaft der Intellektuellen, Opladen, Westdeutscher Verlag, 1975.

Schimank, Uwe, "Gesellschaftliche Teilsysteme als Akteurfiktionen", en KZfSS, Heft 4, 1988, pp. 619-639.

"Erwartungssicherheit und Zielverfolgung. Sozialität zwischen Prisoner's Dilemma und Battle of the Sexes", en Soziale Welt, Heft 2, 1992, pp. 182-200.

Schluchter, Wolfgang, Die Entwicklung des okzidentalen Rationalismus, Tübingen, J.C.B. Mohr, 1979.

(ed.), Verbalten, Handeln und System. Talcott Parsons'Beitrag zur Entwicklung der Sozialwissenschaften, Frankf. a.M., Suhrkamp, 1980.

Schmid, Michael, "Autopoiesis und soziales System: Eine Standortbestimmung", en Haferkamp, Schmid (eds.), 1987, pp. 25-50. Schmidt, Siegfried J. (ed.), Der Diskurs des Radikalen Konstruktivismus, Frankf. a.M., Suhrkamp, 1987.

, Gedäcbtnis. Probleme und Perspektiven der interdisziplināren Gedācbtnisforschung, Frankf. a.M., Suhrkamp, 1991.

', Kognition und Gesellschaft. Der Diskurs des Radikalen Konstruktivismus 2, Frankf. a.M., Suhrkamp, 1992.

Schmitz, Hermann, "Der Leib”, en Ibid., System der Pbilosophie, Bd. 2, Teil 1, Bonn: Bouvier, 1965. 
Schnädelbach, Herbert, "Transformation der Kritischen Theorie", en Honneth, Joas (eds.), 1986, pp. 15-34.

Schulz, Walter, Das Problem der absoluten Reflexion, Frankf. a.M., Klostermann, 1963.

, Icb und Welt. Pbilosophie der Subjektivitätt, Pfullingen, Neske, 1979.

Schütz, Alfred, Collected Papers II. Studies in Social Tbeory, The Hague, Martinus Nijhoff, 1967.

, Collected Papers I. The Problem of Social Reality, The Hague, Martinus Nijhoff, 1971.

, Parsons, Talcott, Zur Theorie sozialen Handelns. Ein Briefwecbsel, Walter M. Sprondel (eds.), Frankf. a.M., Suhrkamp, 1977.

Schütz, Alfred, Theorie der Lebensformen, Iljy Srubar [ed.], Frankf. a.M., Suhrkamp, 1981.

Sebeok, Thomas A. (ed.), Sight, Sound and Sense, Bloomington, Londres, Indiana University Press, 1978.

Segal, Lynn, Das 18. Kamel oder Die Welt als Erfindung. Zum Konstruktivismus Heinz von Foersters, München, Zürich, Piper, 1988.

Seiffert, Helmut, Einfübrung in die Wissenschaftstbeorie, Bd. 1, München: Beck, 1972.

Sellars, Wilfrid, "Time and World Order", en Scientific Explanation, Space, and Time, Herbert Feigl, Grover Maxwell (ed.), Minnesota Studies in the Philosophy of Science, vol. II, Minneapolis: University of Minnesota Press, 1962, pp. 527-616.

Simon, Fritz B., Unterschiede, die Unterscbiede macben: Kliniscbe Epistemologie: Grundlagen einer systemischen Psychiatrie und Psychosomatik, Berlín, Springer, 1988.

Simon, Herbert A., The Sciences of the Artificial, Cambridge, Mass., 1969.

Simon, Josef, Sprache und Raum. Pbilosophiscbe Untersucbungen zum Verbaltnis zwischen Wabrbeit und Bestimmtheit von Sätzen, Berlín, de Gruyter, 1969. 1989.

Simmel, Georg, Schriften zur Soziologie. Eine Auswabl, H.-J. Dahme, O. Rammstedt (eds.), Frankf. a.M., Suhrkamp, 1983.

37-50.

"Das Gebiet der Soziologie (1917)", en Simmel, 1983, 1, pp. 
, "Das Geld in der modernen Kultur (1896)", en Simmel, 1983, 4, pp. 78-94.

, "Die Arbeitsteilung als Ursache für das Auseinandertreten der subjektiven und der objektiven Kultur", en Simmelm 1983, 5, pp. 95-128.

"Soziologie des Raumes (1903)", en Simmel, 1983, 8, pp.

221-242.

"Exkurs Über das Problem: Wie ist Gesellschaft möglich?"; en Simmel 1983, 7, pp. 275-293.

Snell, Bruno, Die Entdeckung des Geistes. Studien zur Entdeckung des europäischen Denkens bei den Griechen, Hamburg, Claassen \& Goverts, 1948.

Snyder, Glenn H., "Prisoner's Dilemma and Chicken Models in International Politics", en International Studies Quarterly, vol. 15, núm. 1, 1971, pp. 66-103.

Spaemann, Robert, Pbilosophische Essays, Stuttgart, Reclam, 1983. "Niklas Luhmanns Herausforderung der Philosophie. Laudatio anlässlich der Verleihung des Hegel-Preises $1989^{n}$, en Niklas Luhmann, Frankf. a.M., Suhrkamp, 1990, pp. 51-73

Spencer Brown, George, Laws of Form, Londres, George Allen and Unwin Ltd., 1969.

Stegmüller, Wolfgang, Hauptströmungen der Gegenwartspbilosophie. Eine kritiscbe Einfübrung, Stuttgart, Kröner, 1969.

Stichweh, Rudolf, Ausdifferenzierung der Wissenschaft-Eine Analyse am deutscben Beispiel, Bielefeld,' Wissenschaftsforschung 8 Report, 1977.

Tarski, Alfred, "Die semantische Konzeption der Wahrheit und die Grundlagen der Semantik", en Johannes Sinnreich, (ed.), Zur Pbilosopbie der idealen Spracbe, München, dtv, 1972, pp. 53100.

Taylor, Charles, Hegel, Frankf. a.M., Suhrkamp, 1983. , Negative Freibeit? Zur Kritik des neuzeitlicben Individualismus, Frankf. a.M., Suhrkamp, 1992.

Tenbruck, Friedrich H., "Freundschaft. Ein Beitrag zur Soziologie der persönlichen Beziehung", en KZfSS, 16, 1964, pp. 431-456.

, "Die unbewältigten Sozialwissenschaften", en Zeitscbrift für Politik, Jg. 27, Heft 3, 1980, pp. 219-230.

Teubner, Gunther, Willke, " Helmut, Kontext und Autonomie: Gesellschaftliche Selbststeuerung durch reflexives Recht", en Zeitschrift für Recbtssoziologie 6, Heft 1, 1984, pp. 4-35. 
(ed.), Dilemmas of Law in the Welfare State, Berlín, Nueva York, Walter de Gruyter, 1986.

"Hyperzyklus in Recht und Organisation: Zum Verhältnis von Selbstbeobachtung, Selbstkonstitution und Autopoiesis", en Haferkamp, Schmid (eds.), 1987b, pp. 89-128.

(ed.), Autopoietic Law: A New Approach to Law and Society, Berlín, Nueva York, Walter de Gruyter, 1988.

1989.

The Science and Praxis of Complexity; Contribution's to the Symposium Held at Montpellier, France 9-11, Tokyo, Japan, The United Nations University, 1985.

Theunissen, Michael, Negative Theologie der Zeit, Frankf. a.M., Suhrkamp, 1991.

Thompson, John W.. "The Importance of Opposites in Human Relationships", en Human Relations, vol. 16, núm. 1, 1963, pp. 161-169.

Touraine, Alain, The Self-Production of Society, Chicago, Londres, The University of Chicago Press, 1977.

Tugendhat, Ernst, Der Wabrbeitsbegriff bet Husserl und Heidegger, Berlín, 1967.

; Vorlesungen zur Einfübrung in die spracbanalytische Pbilosopbie, Frankf. a.M., Suhrkamp, 1979.

, Selbstbeunistsein und Selbstbestimmung. Sprachanalytiscbe Interpretationen, Frankf. a.M., Suhrkamp, 1981.

Tyrell, Hartmann, "Probleme einer Theorie der gesellschaftlichen Ausdifferenzierung der privatisierten modernen Kernfamilie", en ZfS 5, 1976, pp. 393-417.

; "Anfragen an die Theorie der gesellschaftlichen Differenzierung", en Zeit.f. Soziologie 7, 1978, pp. 175-193.

Unverferth, Hans-Jürgen (ed.), System und Selbstproduktion: Zur Erscbliessung eines neuen Paradigmas in den Sozialwissenschaften, Frankf. a.M., Peter Lang, 1986.

Vanberg, Viktor, Die zwet Soztologien. Individualismus und Kollektivismus in der Sozialtbeorie, Tübingen, J.C.B. Mohr, 1975.

; "Unsichtbare-Hand Erklärung und soziale Normen", en: Horst Todt (ed.), Normengeleitetes Verbalten in den Sozialwissenschaften, Berlin, 1984, pp. 115-147.

Varela, Francisco J., "A Calculus for Self-Reference", en Int.J. General Systems, vol. 2, 1975, pp. 5-24. 
, Principles of Biological Autonomie, Nueva York, Oxford, Elsevier North Holland, 1979.

315.

"Der kreative Zirkel", en Watzlawick (ed.), 1981, pp. 294

"Autonomy and Autopoiesis", en Roth, Schwegler (ed.), 1981a, pp. 14-23.

, "Describing the Logic of the Living. The Adequacy and Limitations of the Idea of Autopoiesis", en Zeleny (ed.), 1981b, pp. 36-48.

, Kognitionswissenschaften-Kognitionstechnik. Eine Skizze aktueller Perspektiven, Frankf. a.M., Suhrkamp, 1990.

Vollmer, Gerhard, Was können wir wissen? Bd. 2, Die Erkenntnis der Natur. Beiträge, zur modernen Naturpbilosophie, Stuttgart, S. Hirzel, 1986.

Waddington, C. H., Die biologischen Grundlagen des Lebens, Braunschweig, Vieweg, 1966.

Waldenfels, Bernhard, Der Spielraum des Verbaltens, Frankf. a.M., Suhrkamp, 1980.

In den Netzen der Lebenswelt, Frankf. a.M., Suhrkamp, 1985. 1992.

Watson, James D., Die Doppel-Helix, Reinbek 'b.H., Rowohlt, 1973.

Watzlawick, Paul (ed.), Die erfundene Wirklichkeit. Wie wissen wir, was wir zu wissen glauben? Beiträge, zum Konstruktivismus, München, Piper, 1981.

Beavin, J.H., Jackson, D.D., Menschliche Kommunikation. Formen, Störungen, Paradoxien, Bern, Stuttgart, Toronto, Hans Huber, 1985.

, Krieg, Peter (ed.), Das Auge des Betrachters. Beiträge, zum Konstruktivismus. Festschrift für Heinz von Foerster, München, Zürich, Piper. 1991.

Weber, Max, Wirtschaftsgeschicbte, Berlín, Duncker \& Humblot, 1958.

Metbodologische Schriften, Frankf. a.M., Fischer, 1968.

Wirtschaft und Gesellschaft (1921), Tübingen, J.C.B. Mohr, 1972.

Weingart, Peter, Wissensproduktion und soziale Struktur, Frankf. a.M, Suhrkamp, 1976. 
Weiss, Johannes, "Verstänndigungsorientierung und Kritik. Zur "Theorie des kommunikativen Handelns' von Jürgen Habermas", en KZfSS, Heft 1, 1983, pp. 108-120.

Weizsäcker, Carl Friedrich von; Zum Weltbild der Physik, Stuttgart, Hirzel, 1976b.

, "Die Einheit der Physik als konstruktive Aufgabe”, en Krüger (ed.), 1970, pp. 372-388.

"Der zweite Hauptsatz und der Unterschied von Vergan-, genheit und Zukunft", en Krüger (ed.), 1970a, pp. 468-475. Zum Weltbild der Pbysik, Stuttgart, Hirzel, 1976b.

, "Das Verhältnis der Quantenmechanik zur Philosophie Kants", en Weizsäcker; C.F.v, 1976b, 4, pp. 80-117.

"Beziehungen der theoretischen Physik zum Denken Heideggers", en Weizsäcker; C.F.v, 1976b, 12, pp. 243-245. , "Die. Bedeutung der Logik für die Naturwissenschaft", en Weizsäcker, C.F.v, 1976b, 16, pp. 266-280.

"Komplementarität und Logik", en Weizsäcker, C.F.v, 1976b; 17, pp. 281-231.

"Gestaltkreis und Komplementarität", en Weizsäcker, C.F.v, 1976b, 18, pp. 332-366.

, DerGarten des Menscblicben. Beiträge, zurgescbicbtlicben Antbropologie, München, Wien, Hanser, 1977.

, "Wer ist das Subjekt in der Physik?", en Weizsäcker, C.F.v, 1977, 10, pp. 169-186.

., "Die Rückseite des Spiegels, gespiegelt", en Weizsäcker, C.F.v, 1977, 11, pp. 187-205.

$\longrightarrow$._._._. "Die Einheit von Wahrnehmen und Bewegen", en Weizsäcker, C.F.v, 1977,12, pp. 206-224.

. . , "Die Verminft der Affekte", en Weizsäcker, C.F.v, 1977,13; pp. 225-252. .

"Biologische Präliminarien zur Logik", en Weizsäcker, C.F.v, 1977, 15, pp.;314:

"Platonische Naturwissenschaft im Laufe der Geschichte", en Weizsäcker, C.F.v, 1977, 17, pp. 319-345.

-, "Heidegger und die Naturwissenschaft", en Weizsäcker, C.F.v, 1977, 21, pp. 413-431.

.._._. "Die Zeit und das Eine”, en Weizsäcker, C.F.v, 1977, 22, pp. 432-437. 1983a. 
, Die Einbeit der Natur, München, Wien, Hanser, 1984.

, ', "Ein Entwurf der Einheit der Physik", en Weizsäcker, C.F.v, 1984, 10, pp. 207-222.

, "Die Quantentheorie", en Weizsäcker, C.F.v, 1984, 11, pp.

223-275.

"Materie, Energie, Information", en Weizsäcker, C.F.v, 1984,16, pp. 342-366.

, "Kants Theorie der Naturwissenschaft nach P. Plaas", en Weizsäcker, C.F.v, 1984, 19, pp. 405-427.

, "Parmenides und die Graugans", en Weizsäcker; C.F.v, 1984, 21, pp. 441-465.

, "Parmenides und die Quantentheorie", en Weizsäcker, C.F.v, 1984, 22, pp. 466-491.

$\therefore$, "Das Weltbild der Physik und die Einheit der Natur. Ein

Gespräch mit Carl Friedrich von Weizsäcker", en Hackenesch, Christa (ed.), Bin so ausgeworfen aus dem Garten der Natur, Reinbek, Rowohlt, 1984a, pp. 275-313. Aufbau der Physik, München, Wien, Hanser, 1985.

, "Die Logik zeitlicher Aussagen und die Grundlagen der

Physik”, en Information Pbilosopbie 3, 1986, pp. 7-22.

...__ Bewusstseinswandel, München, Wien, Hanser, 1988.

, Die Tragweite der Wissenschaft, Stuttgart, Hirzel, 1990.

, DerMenscb in setner Gescbichte, München, Wien, Hanser, 1991.

Zeit und Wissen, München, Wien, Hanser, 1992a.

Weizsäcker, Christine von, Weizsäcker, Ernst Ulrich von, "Fehler-

$\because$ freundlichkeit als Evolutionsprinzip und Kriterium der Technikbewertung", en Universitas Jg. 41, 1986, pp. 791-799.

Weizsäcker, Ernst von, "Erstmaligkeit und Bestätigung als Komponenten der pragmatischen Information", en Weizsäcker, E.v. (ed.), 1974, pp. 82-113. (ed.), Offene Systeme, Bd. I, Stuttgart, 1974.

Weizsäcker, Viktor von, Gestalt und Zeit, Göttingen, Vandenhoeck \& Ruprecht, 1960.

, Der Gestaltkreis. Theorie derEinbeit von Wabrnebmen und Bewegen, Frankf. a.M.. Suhrkamp, 1973.

Wenzel, Harald, Hochmuth, Uwe, "Die Kontingenz von Kommunikation. Zur kritischen Theorie des kommunikativen Handelns von Jürgen Habermas", en KZfSS, Heft 2, 1989, pp. 241-269. 
, Die Ordnung des Handelns. Talcott Parsons' Theorie des allgemeinen Handlungssystems, Frankf. a.M., Suhrkamp, 1990. Whitehead, Alfred North, Prozess und Realitat. Entwurfeiner Kosmologie, Frankf. a.M., Suhrkamp; 1987. 1988.

Whorf, Benjamin Lee, Spracbe, Denken, Wirklichkeit, Reinbek b.H.. Rowohlt, 1963.

Wiel, Reiner, "Die Komplementarität von Selbstbewusstsein und Bewusstsein", en Cramer, Fulda, Horstmann, Pothast (ed.), 1987, pp. 44-75.

Wild, Christoph, Artikel "Problem", en Handbuch philosopbischer Grundbegriffe, H. Krings, H.M. Baumgartner, Chr. Wild (eds.), Bd. 4, München, Kösel, 1973, pp. 1139-1146.

Wilden, Anthony, System and Structure: Essays in Communication and Exchange, Londres, 1980a.

Willke, Helmut, Systemtheorie, Stuttgart, Nueva York, Gustav Fischer, 1982.

Willke, Helmut, "Three Types of Legal Structure: The Conditional, the Porpusive and the Relational Programm", en Teubner (ed.), 1986, pp. 280-297.

," "Differenzierung und Integration in Luhmanns Theorie sozialer Systeme", en Haferkamp, Schmid, 1987, pp. 247-274. Windelband, Wilhelm, "Geschichte und Naturwissenschaft", en Ders., Präludien. Aufsätze und Reden zur Einfübrung in die Pbilosopbie, Bd. 2, Tübingen, 1911, pp. 136-160.

Winograd, Terry, Flores, Fernando, Erkenntnis-Maschinen-Versteben.

Zur Neugestaltung von Computersystemen, Berlín, Rotbuch, 1989.

Wittgenstein, Ludwig, Tractatus logico-philosopbicus, Frankf. a.M., Suhrkamp, 1966. , Bemerkungen aber die Farben. Ober Gewissbeit. Zettel. Vermiscbte Bemerkungen, Bd. 8, Frankf. a.M., Suhrkamp, 1984.

Wuketits, Franz M., Biologische Erkenntnis: Grundlagen und Probleme, Stuttgart, Gustav Fischer, 1983.

Zaner, R.M., The Problem of Embodiment. Some Contributions to a Phenomenology of the Body, Den Haag, 1964.

Zeleny, Milan, “Autopoiesis: A Paradigm Lost?", en Zeleny (ed.) 1980, pp. $3-43$. 
(ed.), Autopoiesis, Dissipative Structures, and Spontaneous Social Orders, Colorado, Boulder, Westview Press, 1980a. (ed.), Autopoiesis. A Theory of Living Onganization, Nueva York, Oxford, North Holland, 1981a.

"What Is Autopoiesis?", en Zeleny (ed.), 1981a, 2, pp. 4-17. "Spontaneous Social Orders", en The Science and Praxis..., 1985, pp. 312-328. 
En el presente trabajo se definen de manera más estrecha conceptos ya conocidos. El glosario tiene la intención de mediar entre una comprensión general de los conceptos y el vocabulario específico de expresiones aquí utilizadas.

\section{Afectividad}

Con afectividad o sentimiento se hace referencia a una de las cuatro formas de comunicación, en las cuales se presenta la comunICACION. Ia afectividad se genera sobre la base de la diferenciación de afectado/no afectado y la $\rightarrow$ diferencia de simpatia/antipatía. Con la ayuda de los sentimientos se suele generar la "cercanía", misma que, sin embargo, no se refiere a lo espacial. De esta manera, tanto el "amor" como el "odio" son formas de apariencia de la cercanía. La $\rightarrow$ observación de la afectividad tienè lugar mediante los motivos, su $\rightarrow$ operación tiene lugar a travès de los afectos y los sentimientos, con lo cual los afectos se consideran como sucesos de corta duración, mientras que lós sentimientos se definen como estados de larga duración.

\section{Asimetria/simetria} It: $y$,

Una situación determinada simétricamente se debe entender como una circúnstancia en la cual no existe ningún peso dominante de ninguno de los lados. La simetría incluye a la igualdad. "Todos los hombres son iguales frente a Dios (religión) o frente a la ley (derecho)". En una situación determinada asimétricamente, existe un predominio de uno de los lados sobre el otro: "no cierto, sino falso", "no injusticia, sino justicia". En la situación simétrica, ambos lados soin equivalentes, la asimétrica es unt-valente debido a la preferencia por un lado. A pesar de ello, los respectivos compo- 
nentes pueden ser distinguidos. El resultado de la operación de distinción en la situación simétrica se llama $\rightarrow$ diferencia, el correspondiente resultado de la situación asimétrica se llama $\rightarrow d i$ ferenciación. Partimos del hecho de que ambas formas, es decir, la simétrica y la asimétrica, dependen una de la otra. No puede haber asimetría sin simetria, y viceversa. A ello se refieren los conceptos de diferencia y diferenciación.

\section{Asimetria/simetria y diferenciación/diferencia}

Una asimetría resulta de una diferenciación, y una simetría resulta de una diferencia. Sin embargo, se distinguen por el hecho de que las asimetrías y las simetrías están definidas como formas de operación, mientras que las diferenciaciones y las diferencias están definidas como formas de observación.

\section{Observación}

Con observación aludimos a una actividad (= operación) que es realizada no sólo por las personas (= individualidad o sistema personal), sino también por sistemas del sentido como la economía, arte, política, salud, religión, etc. De esta manera, la política puede observar a la economía, la economía a la religión, etc. Por lo tanto, el concepto de la observación se debe comprender muy generalmente para que sea aplicable a los diferentes sistemas del sentido. Por ello, en el nivel de la teoría de las distinciones definimos de manera general a una observación como el entrelazamiento de una diferencia simétrica con una diferenciactón asimétrica con la finalidad de generar información. Dependiendo de la forma de entrelazamiento puede haber distintas $\rightarrow$ modalidades de observación.

\section{Modalidades de observación}

De acuerdo con la teoría de las distinciones hay por lo menos seis formas distintas de observar el "mundo": frente a él, uno puede observar de manera fáctica, posible, alternativa, observante, - reflexiva y autorreflexiva. A las primeras tres formas las designamos como formas de observación de acción, las últimas tres como formas de observación.

\section{Código/programa :}

Los códigos y programas son principios de forma duraderos en el espacio de acción y comunicación de los sistemas del sentido, con 
lo cual su durabilidad es consecuencia de su apoyo mutuo. Con ello, el código designa un principio asimétrico (p. ej., para la cieni cia "cierto, no falso", para el derecho "justicia, no injusticia", etc.). El programa, por el contrario, designa un principio simétrico (p. ej. "analítico $y$ sintético" con referencia a la ciencia, "normativo $y$ cognoscitivo", con referencia al derecho, etcétera).

\section{Diferencia/diferenciación}

Llamamos diferencia (de dis-ferre: llevar separadamente, en dos partes) a una $\rightarrow$ distinción que exprese la equivalencia de sus dos lados y que, por lo tanto, es neutra de los lados, es decir, simétrica. Una diferenciación (diferenciación: elaboración de una relación jerárquica), por su parte, es una distinción que prefiere uno de los dos lados y que muestra, en este sentido, una forma asimétrica.

\section{Distinción}

La distinción es el resultado libre de firialidades de un proceso de separactón o división (dis-tineo: mantener separado). Es un concepto de más alta abstracción que los conceptos de separación: de la $\rightarrow$ diferencia (elementos equivalentes) y de la $\rightarrow$ diferenciación (elementos desiguales). El proceso de la separación (distinción) conduce a la producción de diferencias y diferenciaciones. Por medio de la operación de decisión se puede llegar a la $\rightarrow$ COMUNICACION y a la $\rightarrow$ ACCION y, con ello, a la sOCIEDAD. Por lo demás, las distinciones se pueden comprender generalmente como "estímulos" cognoscitivos y, en este sentido, como la condición para la posibilidad de la objetividad dimensional del sentido.

\section{Pragmática de las distinciones}

Comprende una posición teórica que utiliza in contextos del presente pragmático y del mundo vivencial- las distinciones "diferencia" y "diferenciación" para poder producir conocimientos teórico sociales. Con ello, la información es entendida como un suceso cognoscitivo, el cual puede generar un efecto dentro del mundo vivencial.

\section{Unidad}

$\therefore$.

La unidad se puede comprender como unidad solamente frente al trasfondo de una separación (= distinción). 


\section{DECaSIón/decisión}

.. Con DECISION nos referimos por lo habitual a una determinación que también tiene lugar sin intencionalidad o conciencia; mien- tras que con decisión nos referimos a una forma verbal y escrita de la determinación que tiene lugar sobre la base de la intencionalidad.

\section{Expectación/experiencia}

La experiencia es el resultado de la sedimentación de los hechos, es el aspecto perfectista de una $\rightarrow$ estructura social. Las experiencias tienen una forma asimétrica. Por el contrario, la expectación es el resultado de la sedimentación de las posibilidades, es el aspecto futurista de una estructura social. Las expectativas tienen una forma simétrica.

El entrelazamiento de la expectación y la experiencia (= las expectaciones seleccionan a las experiencias, las experiencias apoyan a las expectativas) representa la forma de cualquier estructura de la SOCIEDAD. Entre la experiencia y las expectativas se encuentra como mediadora la $\rightarrow$ inmediatez como la forma verdadera de la operación. En la forma elaborada aparece como el $\rightarrow$ presente.

\section{"Algo"}

Es la manera y el modo de una $\rightarrow$ esțuctura (social o de cualquier otra indole como sistema, expectación, información, etc.) que aún no se ha constituido. Expresa el estado de suspensión entre un suceso que aún no ha sucedido, y aquel suceso que ya ocurrio, mismo que puede conducir a la constitución de la forma cuando es efectuado.

\section{Hecho/posibilidad}

Un becho es una circunstancia que procesa en la forma de un pasado presente. Cada hecho tiene una forma que expresa el aspecto perfectista de la realidad cognoscitiva.

Por el otro lado, una posibilidad es un hecho que procesa en la forma de un futuro presente. Cualquier posibilidad expresa al aspecto futurista de la realidad cognoscitiva.

\section{Forma/autorreferencia}

.. Con forma nos referimos al aspecto perfectista de juego conjunto de las distinciones, mientra que la autorreferencia expresa al 
aspecto futurista del juego conjunto de las distinciones. La forma es la autorreferencia fáctica, la autorreferencia es la forma posible:

\section{Presente}

Se comprende como una categoría que coordina los modos del tiempo y del espacio. De esta manera, un "ahora" y un "aquí" es accesible tanto temporal como espacialmente. En la forma del presente, el "tiempo" se comprende de acuerdo con la tradición occidental-filosófica.

\section{SOCIEDAD/sociedad}

La sociedad se comprende como una unidad limitada políticamente, como sociedad nacional. La SOCIEDAD es la sociedad global, simboliza al área de la $\rightarrow$ COMUNCACIÓN posible en general (no a la comunicación en el sentido de la TkH). La sociedad en el sentido de Luhmann podría describirse a grandes rasgos $-\mathrm{y}$ esto no es suficientemente preciso- como la "socialidad".

\section{Acción/acción}

Tanto ACCION como "acción" designan formas del direccionamiento, de la adjudicación de la "responsabilidad", de la indicación de un 'causante', de la determinación de la selección. Su forma cognoscitiva es asimétrica en ambos casos.

$A C C I O N$ se refiere aquí a la forma general de la indicación de la "responsabilidad", "acción" a la determinación de la selección como operación espectal de decistón expresa. La unidad de la ACción consiste en la distinción entre aceptación/rechazo y finali$\mathrm{dad} /$ medios.

\section{Individualidad}

Con individualidad opersonalidad nos referimos a una de las cuatro formas de comunicación en las cuales se presenta la COMUNICACION. La individualidad ("no-dividibilidad") se forma sobre la base de las distinciones de consciente/inconsciente y particular/ general. Con la ayuda de la individualidad se comunican particularidades o singularidades y se producen “distancias" por medio de las ideas o la conciencia. Las operaciones de la conciencia individual tienen lugar por medio de las ideas o los pensamientos, su observación por medio de las manifestaciones de la voluntad. 


\section{Cognición}

La cognición representa aquel ámbito de la realidad que es accesible mediante las distinciones. La realidad accesible para nosotros está concebida exclusivamente de manera distinta, esto es que está dividida en unidades dispuestas a la acción y a la comunicación.

\section{COMUNICACrón/comunicación}

COMUNGACION se refiere a una oferta general de selección que se refiere a las formas de comunicación "corporalidad", "personalidad", "afectividad" y "socialidad".

Comunicación se refiere a una oferta especial de selección que se refiere exclusivamente a la forma de comunicación socialidad y que tiene lugar sobre todo de manera verbal o escrita. La forma cognoscitiva de la COMUNCACION y de la comunicación siempre es simétrica. La unidad de la COMUMCACIÓN consiste en la distinción entre entender bien/entender mal y de información/comunicación.

\section{Complejidad}

Reunir lo distinto es una obligación a la cual se debé someter cualquier circunstancia que quiere constituirse como complejo de unidad. Todos los componentes deben tener, por lo menos, un criterio común para poder pertenecer a la unidad superior. Con ello, los componentes particulares se simplifican (= reducción de la complejidad). La unidad de lo distinto formada de esta manera la designamos como complejidad.

\section{Corporalidad}

Con corporalidad nos referimos a una de las cuatro formas de comunicación en que se presenta la COMUNCACION. La corporabilidad se define como la forma reflexiva del cuerpo. La corporalidad se forma sobre la base de las distinciones de corporal/no corporal y deseos/indiferencia. Con la ayuda de la corporalidad se comunican "fácticidades", "necesidades" o "inmodificabilidades". Las operaciones de la corporalidad tienen lugar mediante la percepción de los sentidos y apariencias, y su observación mediante los gestos.

\section{Lógica, sistema de la lógica operacional}

Señala aquellas condiciones que se deben exigir de las operaciones para que éstas se puedan efectuar de acuerdo con el orden. 
Se trata de una lógica antes de la lógica, o sea, de una protológica.

Si se parte del hecho de que cualquier operación tiene solamente dos posibilidades, es decir, la de tener lugar o la de no tener lugar, entonces el principio de la identidad para las operaciones significa: sólo la segunda vez que se efectúe una operación se constituye la identidad. El principio de la contradicción para las operaciones dice: Si una operación puede tener lugar o no, entonces no pueden suceder ambas cosas a la vez. El principio del tercero excluido para operaciones dice: Si una operación o bien puede tener lugar o bien no tener lugar, entonces no se pueden excluir ambas cosas a la vez. Con esta protológica se trata del aspecto operacional de los hechos lógicos.

\section{Lógica, sistema de la lógica lingüistica}

El sistema de la lógica lingüística señala las condiciones que se deben exigir de las manifestaciones lingüísticas para que éstas puedan ser veraces: teoremas de la identidad, de la contradicción y del tercero excluido. Además, designa el aspecto de observación de las circunstancias lógicas.

\section{Negación}

La negación siempre presupone la distinción para poder constituirse. La negación se genera operacionalmente debido a las "grietas" discretas o "lugares vacíos" que se generan entre el final de una operación y el comienzo de la siguiente. Estas grietas ocasionan la distinción de "operar/no operar". Una sedimentación razonable de dichas "grietas" o "lugares vacíos" (= negación) forma aquello que llamamos una observacion, misma que, con ello, es la operación de una "no-operación".

\section{Objeto}

Un objeto es una relación de sucesos que consta de, por lo menos, cuatro sucesos distintos, los cuales se juntan en forma perfectista (- de manera de afirmación) y, con ello, asimétrica (- operativa) en dos distinciones. Los objetos son "objetos solamente para un observador". No existen los "objetos en sĩ". No obstante, la función de los objetos consiste precisamente en presentar "formasen-sî" objetivas y de posibilitar con ello una posición sin sujeto. 


\section{Operación}

Todo lo que sucede, si es que sucede, sucede en el momento. Por ello, una operación (como proceso de acción, p. ej.) tiene solamente dos posibilidades: o tiene lugar o no tiene lugar. Si tiene lugar, entonces se forman simultáneamente las dimensiones del sentido tiempo y objetividad. En el tener lugar/no tener lugar están contenidos simultáneamente el "tiempo" y la "distinción" como dimensión objetiva y como potencialidad de la observación. Con ello también está dicho que cualquier operación debe sincronizar su distinguibilidad - dada por la emergencia de la "distinción determinada temporalmente"- de alguna manera dentro del presente. Por ello, para cada "algo" que opera en la inmediatez surge el problema de la integración de la "no-simultaneidad simultánea".

\section{Paradoja}

Paradójico llamamos a aquel becho que es idéntico a su contrario. Las paradojas (y también las $\rightarrow$ Tautologías como paradojas "encubiertas") se pueden desparadojizar mostrando cómo se ban generado. Es decir que las paradojas se generan por lo habitual debido a la simultaneidad de las no-simultaneidades $y$, con ello, mediante el supuesto de los "comienzos extemporáneos". Cualquier forma de la identidad es paradójica en el sentido de que necesita una simultaneidad de igualdad y de distinción para poder mantenerse como "idéntica". De esta manera surgen las identidades - como la forma clásica del "comienzo extemporáneo"dentro de la dimensión del tiempo. Sin embargo, su representación tiene lugar dentro de un presente, mismo que considera lo distinto surgido de manera no simultánea como dado simultáneamente.

\section{Realidad}

Con realidad nos referimos a la realidad accesible cognoscitivamente mediante las operaciones distintas. Partimos de una distinción asimétrica de una realidad real y una cognoscitiva, con lo cual la realidad real representa al "punto ciego" de la realidad. Este punto ciego encuentra su expresión en el hecho de que consideramos la realidad compuesta cognoscitivamente como la "verdadera realidad real". 


\section{Autorreferencia}

Con autorreferencia nos referimos al aspecto del juego conjunto - de las distinciones; mismo que integra al tiempo futurista. Por lo contrario, la $\rightarrow$ forma expresa al aspecto perfectista de la combinación de las distinciones. La autorreferencia es la forma posible, la forma es la autorreferencia efectuada.

\section{Sentido}

Llamamos sentido a aquella operación de un contexto de referencias que relaciona, desde la posición del presente, lo fácticamente dado con lo potencialmente posible. Con ello, lo fáctico muestra una forma asimétrica, lo posible muestra una forma simétrica. Puesto que la operación de la referencia ocurre en el presente inmédiato, surge, debido a ello, el problema de la complejidad de la sincronización de la simultaneidad de bechos determinados y de posibilidades indeterminadas en una unidad del sentido, misma que se puede formar como unidad solamente mediante la reducción de su complejidad. Por lo tanto, el sentido es siempre un "sentido reducido".

\section{Dimensiones del sentido}

Este concepto se refiere a la forma de la $\rightarrow$ distinción. Si se añaden las dimensiones del sentido tiempo, espacio, objetividad y.socialidad, y se relacionan con los lados de la distinción simétrica, entonces se puede demostrar una simetría determinada de manera temporal, espacial, objetiva y social respectivamente: simetria "aún-no-designado/ya-designado" (= tiempo), simetría "completo/incompleto" (= espacio), simetria determinado/indeterminado (= objetividad) y simetría "seleccionable/no selecctonable" (= socialidad).;

\section{Socialidad}

Con socialidad nos referimos a una de las cuatro formas de comunicación en las cuales se presenta la COMUNCACION. La socialidad se genera sobre la base de las distinciones de público/no-puiblico y verbal/no-verbal. Con la ayuda de la socialidad se produce el consenso. Las operaciones de la socialidad tienen lugar por medio de temas y aportaciones, su observación tiene lugar mediante los roles. 


\section{Tipos de sistemas del sentido}

Este concepto designa las formas de comunicación de la COMUNCACION que forman cuatro sistemas del sentido: $\rightarrow$ socialidad $\rightarrow$ personalidad $\rightarrow$ afectividad $\mathrm{y} \rightarrow$ corporalidad.

\section{Estructura/proceso}

Las estructuras siempre son estructuras del tiempo de larga duración. Su función consiste en seleccionar las secuencias de procesos. Los procesos tienen a su vez una - visto temporalmenteduración más corta, con lo cual su función consiste en "apoyar" a las estructuras. Por lo tanto, los procesos y las estructuras se condicionan mutuamente. En el nivel de la teoría social, las estructuras son estructuras de expectación y los procesos sucesos de la experiencia, con lo cual, de acuerdo con la TgS, la teoría social se hace posible sólo sobre la base de estos dos conceptos.

\section{Simetria}

Las simetrias tienen la función de poner en marcha los procesos decidibles, presentando las indecidibilidades en forma de distinciones. Una simetría es la forma de operación de una diferencia, mientras que una asimetria es la forma de operación de una diferenciación.

\section{Tautología}

Tautológica es aquella circunstancia que es idéntica consigo misma. Una tautología es, en última instancia, una $\rightarrow$ paradoja encubierta. Niega la forma de dos partes de su afirmación de que "algo es", "lo que es", en el mismo momento que afirma su identidad.

\section{Inmediatez}

Con ello nos referimos al verdadero modo de operación de una $\rightarrow$ operación: siempre que tiene lugar una operación, tiene lugar en un "instante momentáneo". La forma elaborada de la inmediatez es el $\rightarrow$ presente, con lo cual se trata - con referencia a la forma de las afirmaciones- de la forma presentista de una afirmación. Desde la perspectiva de la religión, el presente es la "Epifanía del presente eterno", una circunstancia que tiene su origen en Platón y Parménides. Mediante la inmediatez se constituye la distinción entre momento/duración, misma que en su forma elaborada conduce precisamente a la distinción de $\rightarrow$ estructura/proceso. 


\section{Diferenciación}

Diferenciación se refiere a uno de los tres conceptos de separación en el contexto de este trabajo. Con una diferenciación se procesa la jerarquía de lo separado. Por ello, la diferenciación representa una $\rightarrow$ distinción partidaria de un lado. Por medio del acoplamiento de dos diferenciaciones se puede alcanzar la formación de una $\rightarrow$ diferencia; mediante la unilateralización de una diferencia se puede llegar a la formación de una diferenciación.

\section{Pasado/futuro}

Representan la forma elaborada de antes/después. El pasado y el futuro siempre tienen lugar solamente en el presente y, por lo tanto, son capaces de operación sólo en la forma de un "pasado presente" y de un "futuro presente".

\section{Verdad, pragmática}

Las operaciones ciertas son, desde la perspectiva de la pragmática de la verdad, operaciones cognoscitivas que se han adaptado a las circunstancias respectivas. Una teoria pragmática de la verdad siempre esta ligada a una teoría de la evolución socio-cultural, puesto que únicamente en el marco de dicha teoría se puede hablar razonablemente de una adaptación a las circunstancias respectivas. La teoría pragmática de la verdad integra la teoría de la concordancia de la verdad, en el sentido de que una "concordancia entre afirmación y circunstancia" se puede interpretar, desde la perspectiva de la pragmática de la verdad, como el "proceso de adaptación de la llave al candado". 
Metodologia de las distinciones. Forma, complejidad, autorreferencia, observación, construcción de teorias integrando lo macro y lo micro en las ciencias sociales, se terminó en agosto de 2002 en Imprenta de Juan Pablos, S.A., Mexicali 39, Colonia Hipódromo Condesa, México 06100, D.F.

Tiraje: 1000 ejemplares' 
na parte considerable de la innovación en las ciencias sociales se ocupa de la revisión y aplicación de aspectos teóricos y metodológicos. Respecto a estos últimos, el presente libro aborda lo que se ha denominado el "método de las distinciones". Dicha metodología lleva implícito el cuestionamiento sobre lo que se entiende por distinción (diferencia y diferenciación) como práctica cotidiana, para establecer criterios de análisis desde una lógica simple a la más compleja.

En este sentido, el conjunto finito o infinito de distinciones opera en el uso frecuente de manera gradual. De ahi que la practicidad de las distinciones derive imperceptiblemente a formas como la tautología, "yo soy yo", y/o distinciones que se distinguen en paradojas "yo no soy yo".

Rodrigo Jokisch, desde una perspectiva que recurre a la teoria sociológica, sugiere en este riguroso estudio que la práctica para construir distinciones puede ser consciente y, al nivel científico, representar una práctica metódica aún por determinarse en una metodología del uso de las distinciones, una "lógica de las distinciones". 